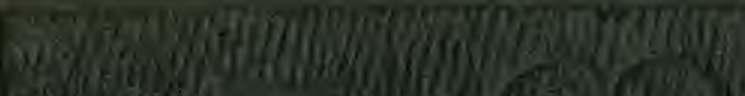

(E)

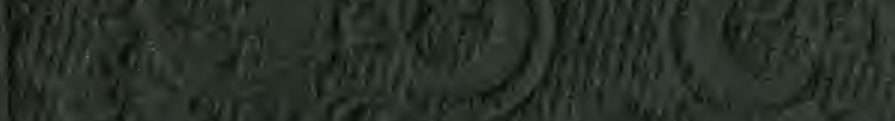

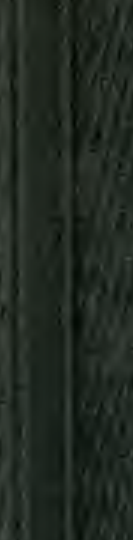

$\sqrt{3}$

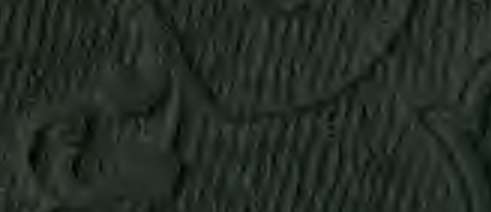

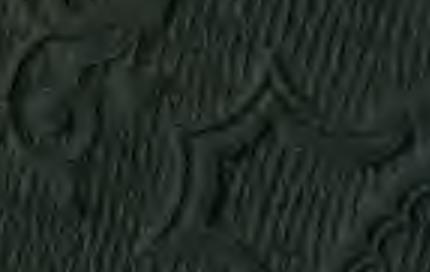

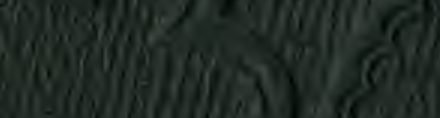
Afsily

18

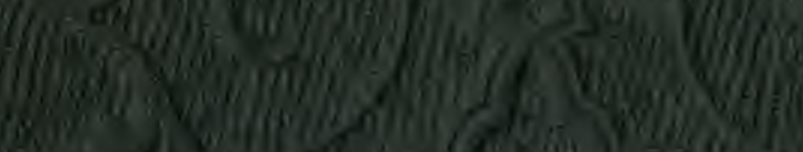
(19)

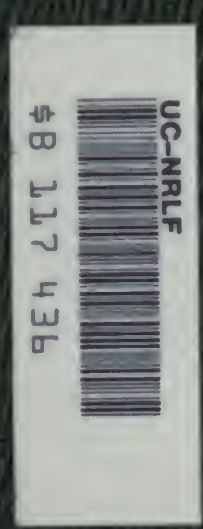

mas

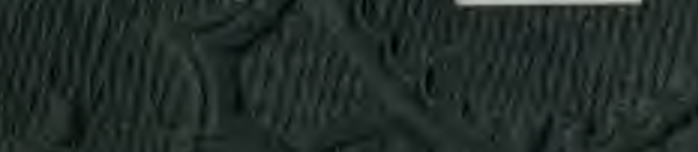



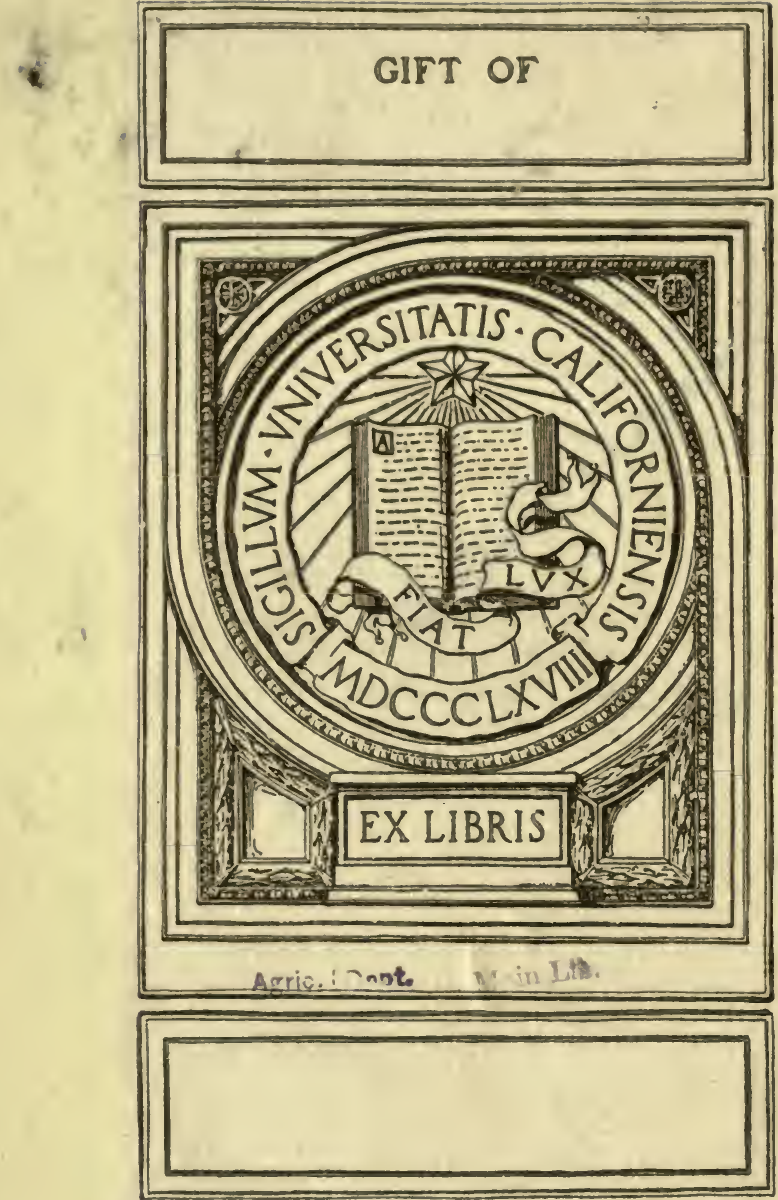
Eguidon 



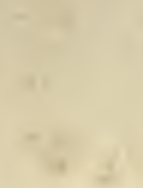

$-1$

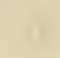

(1) 
Digitized by the Internet Archive in 2007 with funding from Microsoft Corporation 

$\because \because \because \quad \because \because \because \because \vdots \vdots$

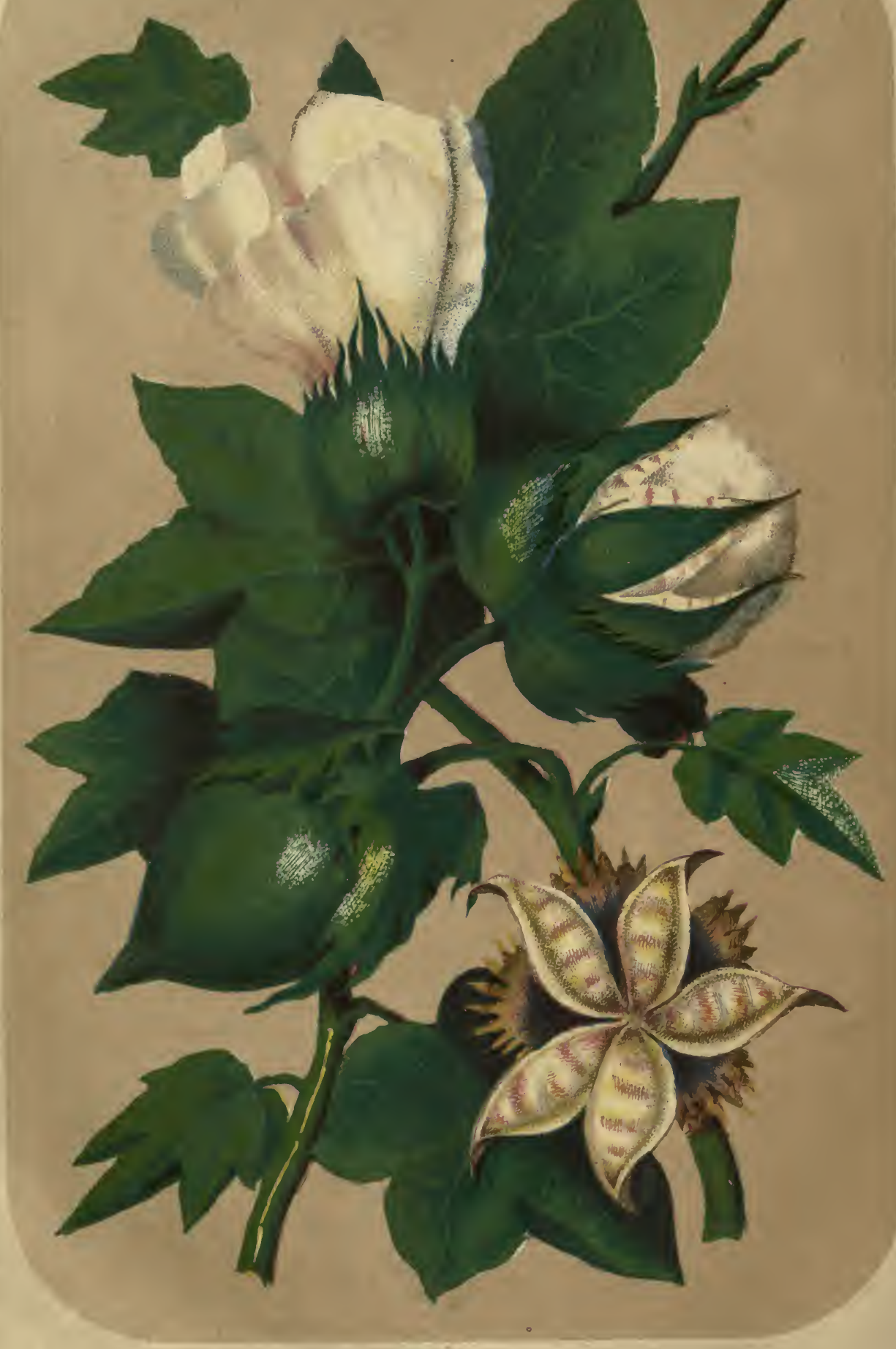




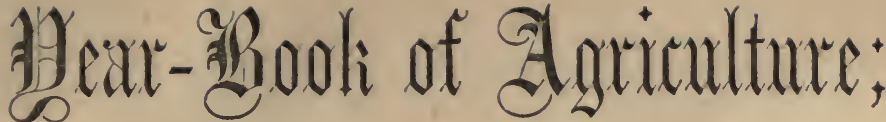

on $\mathrm{mm}$

\section{ANNUAL OF AGRICULTURAL PROGRESS AND DISCOVERY,}

\section{For 1855 and 1856.}

EXIIBITIXG THE

MOST IMPORTANT DISCOVERIES AND IMPROVEMENTS

Ix

AGRICULTURAL MECHANICS, AGRICULTURAL CHEMISTRY, AGRICULTURAL AND HORTICULTURAL BOTANY, AGRICULTURAL AND ECONOMIC GEOLOGY, AGRICULTURAL ZOOLOGY, METEOROLOGY, \&c.

TOGETHER WITH

STATISTICS OF AMERICAN GROWTI AND PRODUCTION - A LIST OF RECENT AGRICULTURAL PCBLICATIONS - CLASSIFIED TABLES OF AMERICAN AGRICULTURAL PATENTS FOR 1854-55 - A CATALOGUE OF FRUTTS ADAPTED TO THE DIFFERENT SECTIONS OR THE UNITED STATES, \&C.

WITH A COYPREHENSITE REVIEW, BY THE EDITOR, OF THE PROGRESS OF AMERICAN AND FOREIGN AGRICCLTCRE: FOR THE YEAR 1855.

ILIUSTRATED WITH NUMEROUS ENGRAVINGS.

BY

DAVID A. WELLS, A.M.

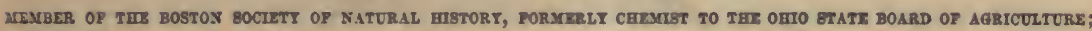
MESBER OP TEZ PENYSTLVANTA HISTORICAL 80CLTT, PENNSTLVANL gTATZ AGRICULTURAL 8OCIETT, EDITOR OF THS ANNUAL OF BCIENTIFIC DIBCOVERT, PAMTHAB SCIENCR, KNOWLEDGE IS POWRR, ETC. ETC.

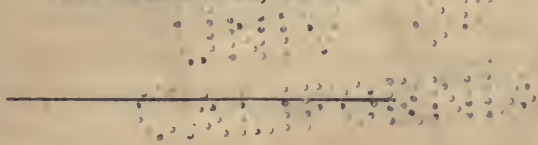

- PHILADELPHIA:

CHILDS \& PETERSON, 124 ARCH ST. 


\section{4}

\section{Entered according to Act of Congress, in the year 1855, by}

CHILDS \& PETERSON,

in the Clerk's Office of the District Court of the Cnited States for the Eastern District of Pennsylvania.

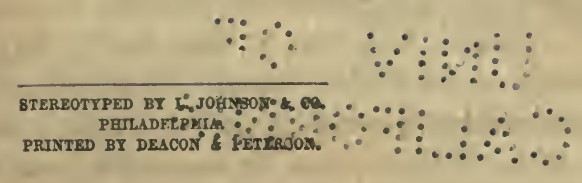




\section{PREFACE.}

The object contemplated in the publication of the YeAr-Book of AGriculture is to aid the progress and development of that science upon which the prosperity of our country so eminently depends. In its preparation, the editor bas carefully examined every important agricultural or scientific publication which has appeared in the United States during the years 1854-55, together with very many of the journals and publications of Great Britain, France, and Germany. He has not, however, confined himself to the mere examination of agricultural journals and reports, but has taken advantage of every opportunity and resource which could furnish any thing of interest or value.

The subjects embraced within the limits of a work, the object of which is to record the progress of agriculture in all its departments for a single year, are necessarily varied and extensire; since no branch of science or applied industry is dependent to a greater degree for its adrancement upon assistance imparted from beyond its legitimate boundaries, than agriculture. Hence the operations of the mechanic, the chemist, the naturalist, the engineer, and statician, are all allied more or less intimately with those of the farmer. It is not claimed that we have collected all that is new, or that all we have published is the result of the operations of a single year, but we do claim to have noticed all the recent improvements pertaining to agriculture which bave seemed to us of sufficient importance, or of which we have been able, after diligent effort, to obtain reliable and intelligible accounts. Every invention pertaining to agriculture patented in the United States during the year ending July, 1855, has been enumerated. All have not, however, been described, for the reason that no distinct descriptions of them have been published, and repeated applications addressed to the inventors themselves have failed of responses. Some of the topics treated of may also seem old and familiar, but a careful examination in such cases will show that they have found place in the record in virtue of presenting old facts in a new light or application, or because they contain, in addition to what was before familiar, new facts and suggestions. Norelty in arrangement and condensation may often render an old subject as interesting as a statement of novelties in fact. It has also been the aim of the editor to transfer to the pages of the Year-Book such reliable and standard articles on different agricultural topics as have appeared, from time to time, during the past year, in the leading journals of Europe or the United States. By pursuing this course, the Year-Book will be rendered eminently valuable, not only for the present but for the future, and a complete series of the volumes for successive years will thus form a most perfect and unique encyclopedia of every department of agricultural science.

The Year-Book of Agriculture will hereafter be issued early in September of each year, and no labor or expense on the part of both the editor and publishers 
will be spared to make it what it is designed to be-a complete and substantial summary of agricultural progress.

To the many friends who have aided us in the preparation of the present volume we would return our sincere thanks; our acknowledgments, however, are especially due, for favors rendered, to the Editors of the Scientific American and Philadelphia Horticulturist; to Mr. Nicol, Superintendent of the Model Farm of the Union Agricultural Society of Virginia and North Carolina; to Prof. B. L. C. Wailes, Geologist of Mississippi ; G. E. Waring, Esq., of New York; and C. L. Flint, Esq., Secretary of the Massachusetts State Board of Agriculture.

In the publication of the Year-Book of Agriculture one important fact is clearly and unmistakeably demonstrated-namely, that there is a constant progress and improvement in every department of theoretical and applied agriculture; that many strong hands and practical and comprehensive minds are enlisted in the work of experiment and investigation, giving us the right to expect from the future many great and valuable results.

Phimadelpeila, October, 1855.

Commonications for the Editor should be addressed "Year-Book of Agriculture ;" Care of Childs \& Peterson, or David A. Wells \& Co., 124 Arch Street, Philadelphia.

We would also take this opportunity to say, that while under no circumstances will the pages of the Year-Book of Agriculture be open to the publication of articles having any thing of the character of advertisements, the editor will be always ready to give place to a description of every new and useful improvement pertaining to agriculture, and also for engravings, if necessary. 


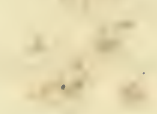

2.,

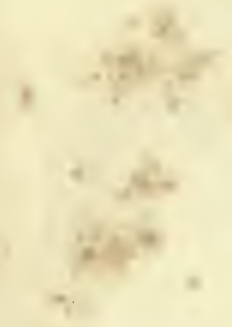




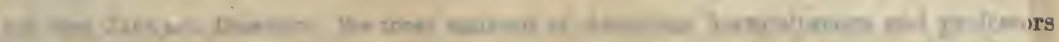

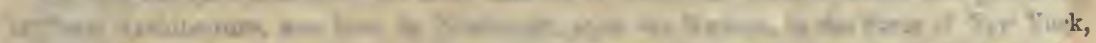

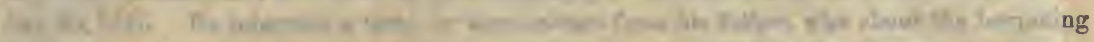

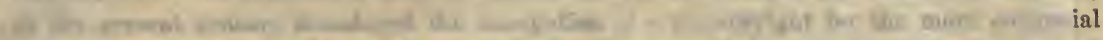

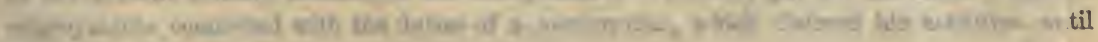
Hast ming?

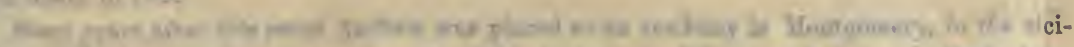

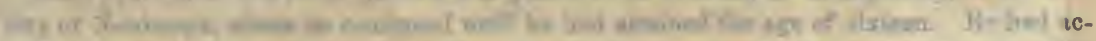

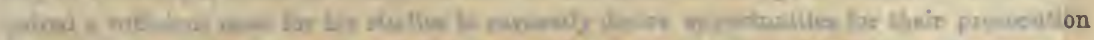

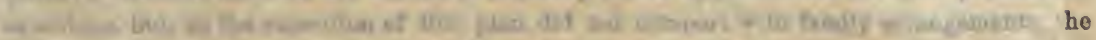

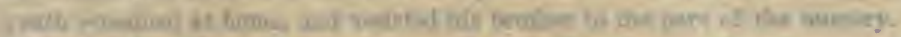

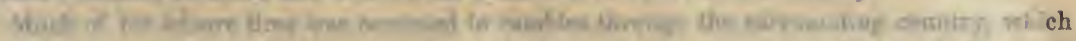

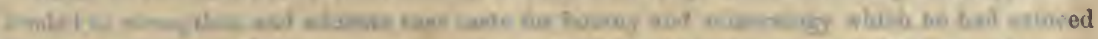

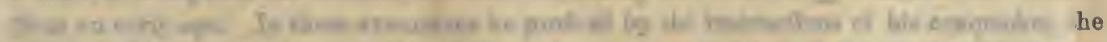

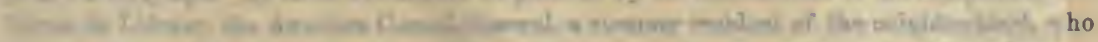

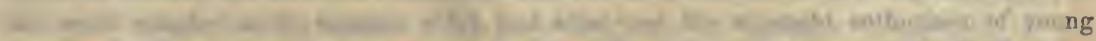
4.

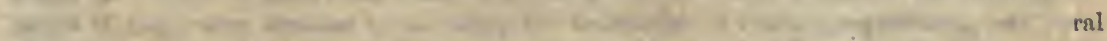

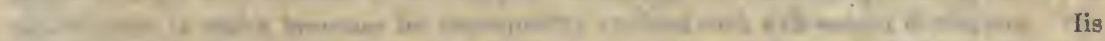

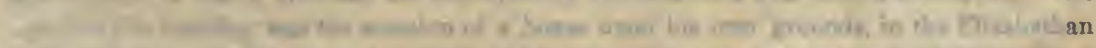

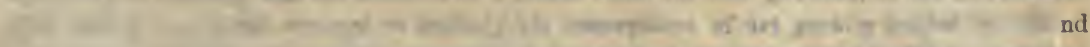
(20) whith at ang

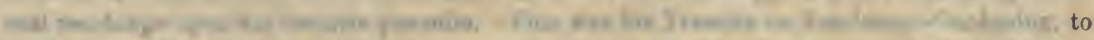

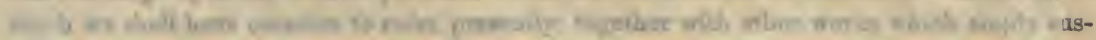

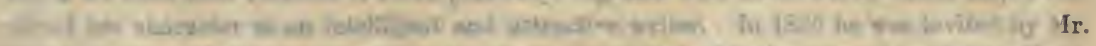

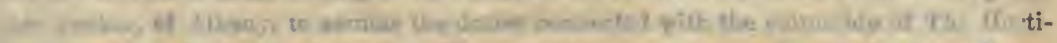

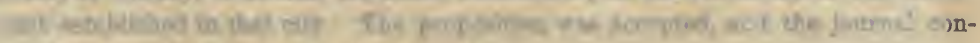
- Me niceligentere boit had ded.

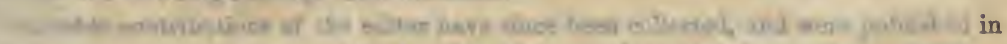

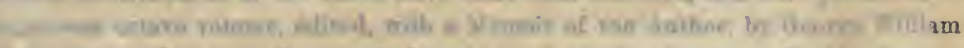

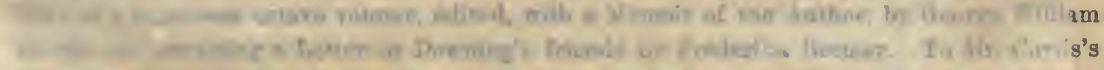

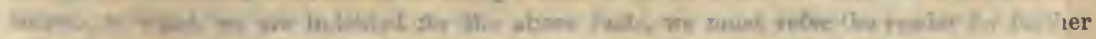

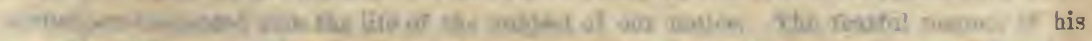

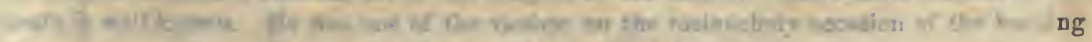

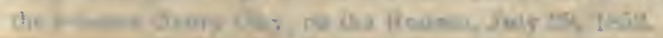

Mr. Downing may well be styled a national benefactor. If, as the poet tells us,

"A thing of beauty is a joy forever,"

what gratitude is due to that man who causes the land to smile with gardens, and ornaments every roadside with homesteads of architectural symmetry! This is a tempting subject, but our limits forbid indulgence. The works of this gifted artist, which we are now about to 


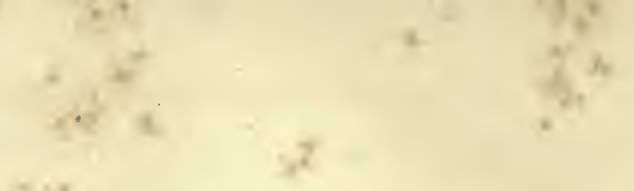

x

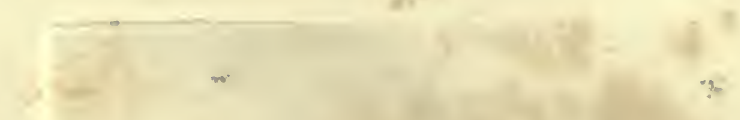

r

$\frac{1}{4}+5=$

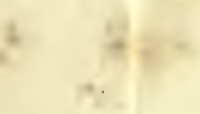

$\frac{1}{4+4}+4$

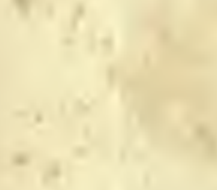

$=$

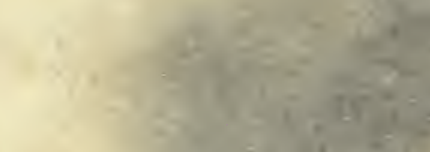

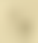

4

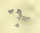

$+$

เ.
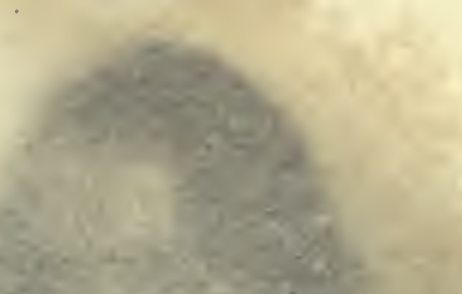<smiles>C1CCCCC1</smiles>

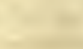

Wy
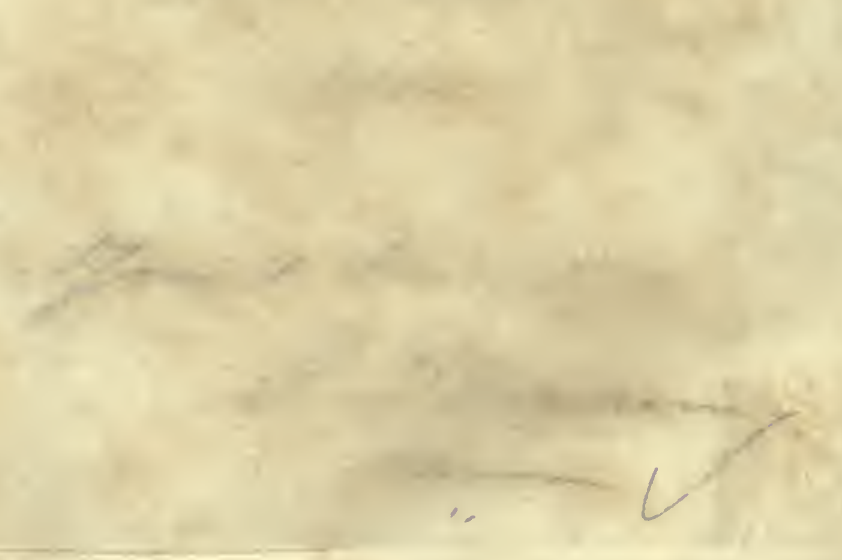

$-3$

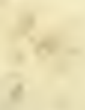

$1+x-1=$

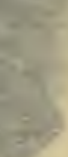

$-$

1

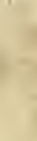

Wher uciren -..thy

F 


\section{A BIOGRAPHICAL NOTICE, AND AN ACCOUNT OF THE WORKS,}

\section{or

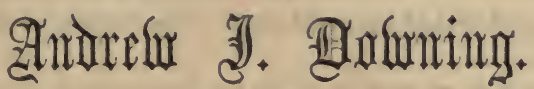

ANDREW JACKson Downisg, the most eminent of American horticulturists and professors of Rural Architecture, was born in Newburgh, upon the Hudson, in the State of New York, Oct. 30,1815 . He inherited a taste for horticulture from his father, who about the beginning of the present century abandoned the occupation of a wheelwright for the more congenial employments connected with the duties of a nurseryman, which claimed his attention until his death in 1822 .

Some years after this event Andrew was placed at an academy in Montgomery, in the vicinity of Newburgh, where he continued until he had attained the age of sixteen. He had acquired a sufficient taste for his studies to earnestly desire opportunities for their prosecution at college, but, as the execution of this plan did not comport with family arrangements, the youth remained at home, and assisted his brother in the care of the nursery.

Much of his leisure time was occupied in rambles through the surrounding country, which tended to strengthen and educate that taste for botany and mineralogy which he had evinced from an eurly age. In these excursions he profited by the instructions of his companion, the Baron de Liderer, the Austrian Consul-General, a summer resident of the neighborhood, who was much attached to the sciences which had awakened the untaught enthusiasm of young Downing. When wearied with wandering among the hills and valleys of the Iludson, his hours of study were devoted to maturing his knowledge of landscape-gardening and rural architecture, in which branches he subsequently attained such well-earned distinction. His first essay in building was the erection of a house upon his own grounds, in the Flizabethan style, which successful attempt to embody his conceptions of art greatly tended to extend that reputation which his known talents and energy had already gained in the surrounding country and among his more distant acquaintances. In 1811 he published a work, which at once made him known to many thousands who never had the opportunity of listening to his oral teachings upon his favorite pursuits. This was his Treatise on Landscape-Gardening, to which we shall have occasion to refer presently, together with other works which amply sustained his character as an intelligent and attractive writer. In 1836 he was invited by Mr. Luther Tucker, of Albany, to assume the duties connected with the editorship of The Horticulturist, just established in that city. The proposition was accepted, and the journal continued under Mr. Downing's charge until his death.

The admirable contributions of the editor have since been collected, and were published in 1853 in a handsome octavo volume, edited, with a Memoir of the Author, by George William Curtis, and including a Letter to Downing's friends by Frederika Bremer. To Mr. Curtis's volume, to which we are indebted for the above facts, we must refer the reader for further particulars connected with the life of the subject of our notice. The fearful manner of his death is well known. He was one of the victims on the melancholy occasion of the burning of the steamer Henry Clay, on the Hudson, July 28, 1852.

Mr. Downing may well be styled a national benefactor. If, as the poet tells us,

"A thing of beauty is a joy forever,"

what gratitude is due to that man who causes the land to smile with gardens, and ornaments every roadside with homesteads of architectural symmetry! This is a tempting subject, but our limits forbid indulgence. The works of this gifted artist, which we are now about to 
enumerate, with the citation of some opinions upon their merits, should be in the possession of all who love flowers, and can appreciate the pleasures connected with refined taste.

1. A Treatise on the Theory and Practice of Landscape-Gardening, adapted to North America, with a view to the Improvement of Country Residences. With Remarks on Rural Architecture, New York, 1841, 8vo. Sale in America to 1853, 9000 copies.

"Mr. Downing has here produced a very delightful work, and has convinced us that sound criticism and refined taste are not confined to this side of the Atlantic." - London Art Union Journal.

"A masterly work. * * * We have quoted largely from this work, because in so doing we think we shall give a just idea of the great merit of the author."-Loudon, editor of Repton's Landscape-Gardening.

"On the whole, we know of no work in which the fundamental principles of this profession are so well or so concisely expressed. * * * No English landscape-gardener has written so clearly or with so much real intensity." -Dr. Lindley, in the Gardeners' Chronicle.

"The standard work on this subject."-Silliman's Journal.

2. Cottage Residences, 1842,8 vo. Sale in America to 1853,6250 copies.

"It cannot fail to be of great service."-Loudon.

"We stretch our arm across the 'big water' to tender our Yankee coadjutor an English shake and a cordial recognition." - An English Horticultural Critic.

3. The Fruits and Fruit-Trees of America, 1845, 8vo. Sale in America to $1853,15,000$ copies.

"Downing's Fruits and Fruit-Trees of America deserves to be more generally known in Europe."-Trübner's Bibliographical Guide to American Literature, Lon., 1855, $12 \mathrm{mo.}$

4. Hints to Young Architects, by George Wightwick, Architect; with additional Notes and Hints to Persons about building in this country, by A. J. Downing, 1849, 8vo.

5. The Architecture of Country-Houses; including Designs for Colleges, Farm-Houses, and Villas, 1850, 8vo. Sale in America to 1853, 3500 copies.

6. Mrs. Loudon's Gardening for Ladies; edited by A. J. Downing, 1852, $12 \mathrm{mo.}$

7. Rural Essays, by the late A. J. Downing, edited by George Wm. Curtis, with a Memoir of the Author; and a Letter to his Friends, by Frederika Bremer, 1853, 8vo. This work contains, with one or two exceptions, all of Mr. Downing's editorial papers in the Horticulturist.

A few additional testimonies to the eminent services rendered by Downing to the beautiful pursuits in which he found such enthusiastic enjoyment may properly conclude this notice:

"Mr. Wilder says that a gentleman "who is eminently qualified to form an enlightened judgment' declared that much of the improvement that has taken place in this country during the last twelve years, in rural architecture and in ornamental gardening and planting, may be ascribed to him, [Downing.] Another gentleman, speaking of suburban cottages in the West, says- 'I asked the origin of so much taste, and was told it might principally be traced to Downing's Cottage Residences and the Horticulturist." "-Memoir, by G. W. Curtis.

"By these admirable works, [Fruits and Fruit-Trees of America, and Landscape-Gardening and Rural Architecture,] Mr. Downing has done much to promote the best and most judicious selection and culture of fruit-trees. It is one of the most common and earnest longings of the toiling residents of cities to be able one day to return to a snuggery in the country; and these admirable works will both minister to these longings, and teach how to realize them satisfactorily."-President King, of Columbia College, New York.

For the above carefully-prepared sketch of A. J. Downing, we are indebted to S. Austin Allibone, Esq., of Philadelphia, author of that very valuable work, the "Critical Dictionary of English Literature and British and American Authors."-Ed. Year-Book. 


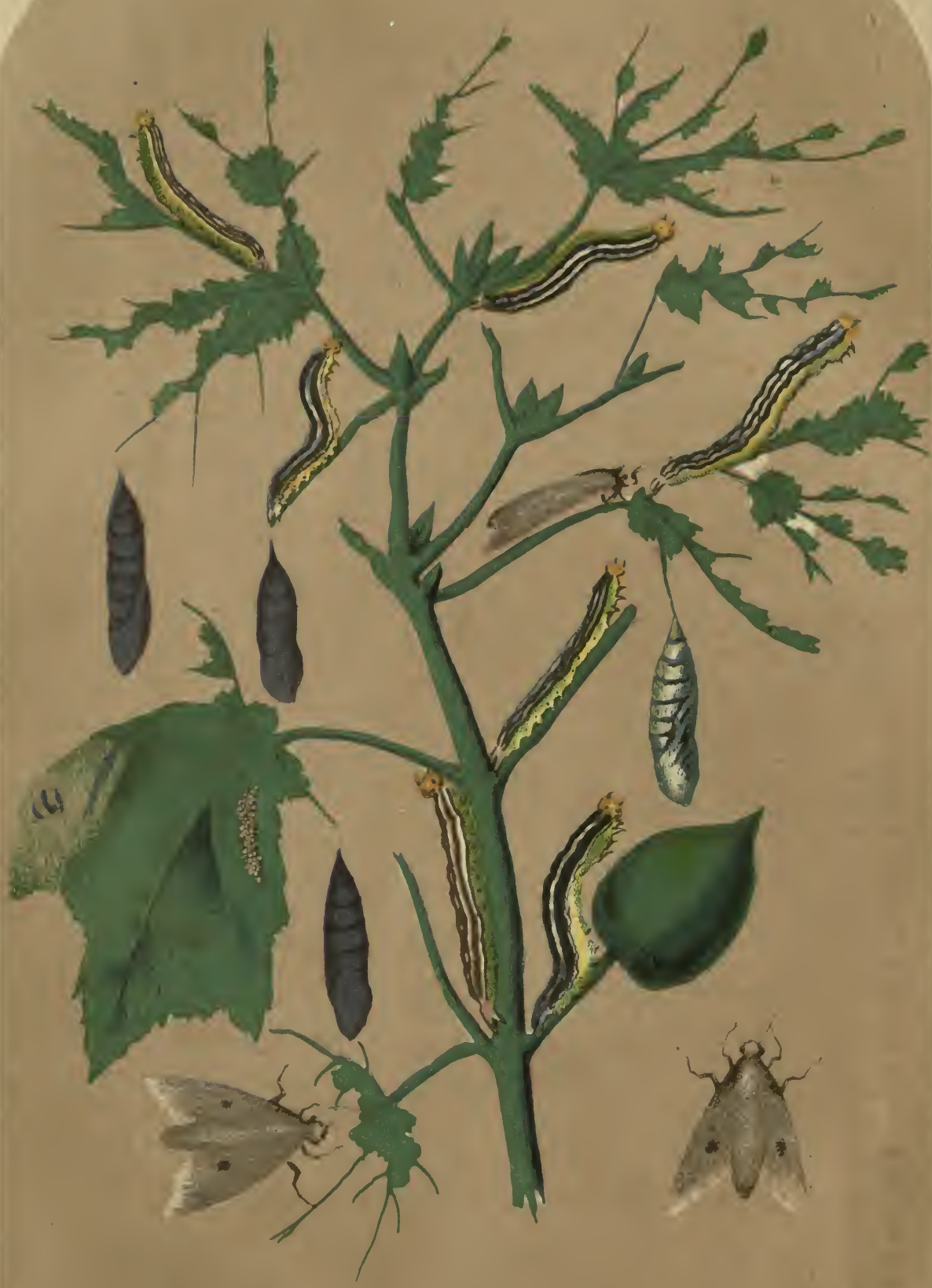

COTTON CATERPILLAR. 


\title{
Agricultural and ctommic gintam;
}

IXCLUDING

\author{
HORTICULTURE, ARBORICULTURE, THE CULTURE AND PRESERVATION OF SEEDS AND FRUITS, \\ THE INTRODUCTION AND PREPARATION OF VEGETABLE TEXTILE FIBRES;
}

OBSERVATIONS ON DISEASES OF PLANTS, ETC.

\section{The Cotton-Plant and its Varieties in the United States.}

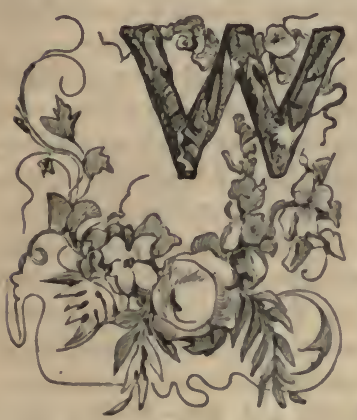

E present to the readers of the Agricultural Year-Book for $1855-6$, a series of the most beautiful and accurate eugravings ever published, illustrative of the growth and diseases of the great staple of American agricultural industry-Cotton. These engravings (which are also interesting from the fact that they are specimens of the new and beautiful process of Chromo-Lithography) were designed by Prof. B. C. L. Wailes, Geologist of the State of Mississippi, and first published during the past year by the authority of the Legislature, in the Geological Report of Mississippi.

Of the many varieties of the Cotton-plant known to naturalists, the annual herbaceous kinds are alone cultivated in the United States. The average height of the plant, in land of medium quality, is about five feet; in very fertile soil it attains to double that height, while in an exhausted and sterile soil it becomes quite a dwarf. Its appearance somewhat resembles that of the okra-plant, but is much more branched, and the leaves less in size and of more uniform shape. The branches are long and jointed, occasionally bifurcated, and bearing at each joint a bull or capsule containing the wool and seed. Each boll is accompanied by a broad indented leaf, springing from the same joint of the branch and resting upon a footstalk three or four inches in length. The woody fibre of the plant is white, spongy, and brittle, but is invested with a thick brown epidermis, which is very pliable and tenacious. The root is tuberous, penetrating deeply into the subsoil, and is thus less affected by drought than most other plants. The blossom is cup-shaped, two or three inches in length, never very widely. expanded; white in the first day until past noon, then changing gradually to a red-closing slowly for the next day or two, with a twist at the extremity over the germ of the young boll, by which it is speedily detached in its rapid growth, when it withers and is cast off, leaving the boll invested by a capacious, tripartite, dentate calyx, sufficiently large to enclose it until half grown.

The calyx containing the germ of the flower is of a triangular shape, and is technically known as the square or form. In this stage of growth these are liable to be disjointed and fall, from the long prevalence of drought, but more so when a rainy season suddenly succeeds, occasioning a second growth from the rapid elaboration of sap, which in its circulation seems not to enter into the footstalk as freely as into other parts of the plant.

The flower of the Sea-Island cotton is in its first stages of a bright sulphur color, the boll small, trilobate, and more elongated, while the other varieties produce bolls of a larger size, which open or divide into four, and occasionally into five, valves or cells. The cotton-plant commences flowering about the 1st of June, and ceases about the 1st of November, when the blant is killed by the frost. The bolls are egg-shaped, rather under the size of the egg of the 
that was drawn out; and as care was taken in the separation, most of the staple was uninjured. It is not pretended that every filament was unbroken-in fact, the delicate taper ends were sometimes wanting; but no one was neglected, in order that a fair representation might be made of the arailable length before ginning. Of course, the most perfect method of conducting that operation could do no more than leave the cotton of the same length.

"For the purpose of measurement, the filaments were gently extended upon a glass plate slightly greased or moistened, and the finger was pressed several times over the wwhole length to remove the curl. The measurement was made by dividers, and a diagonal scale to hundredths of an inch. The specimens examined were Georgia Sea-Island, three parcels-and one of short staple 'top-cotton,' or late cotton, not opened at the time of frost.

"The following is the result of the measurement obtained:-

"The length of the perfect filaments taken from the same boll is very uniform. The arerage length of the staple of mature Sea-Island cotton, of the kinds examined, as it goes to the gin, must be between an inch and a half and an inch and three-quarters. In extreme cases, the length may vary four-tenths of an inch from the average; but the larger proportion is within one-fourth of an inch abeve or below the average. The unripe cotton is not subject to greater variations than the ripe.

"There is a probability that the fibre taken from the base of the boll is the shortest, and that from the middle the longest, while that from the top is between the two; the variation, however, being very small.

"As far as can be seen from a single instance, the short staple seems to be remarkable for its uniformity in length, varying from $1 \cdot 27$ inch, to $1 \cdot 05$. The gentlementwo forwardecl the specimen supposed from its immaturity that it might show varied lengths of fibrein reality it exceeds all the other specimens in equality. A slight examination of these collons under the microscope shows that each has its distinctive character, and that the SeaIsland may differ in its varieties as much as some Sea-Island differs from some Upland.

"The adaptation of the different kinds of staple to different kinds of manufacture, is much more intimately connected with the minute characters of the fibre than is generally known; for instance, the peculiar character of the Sea-Island does not depend so much upon its greater length, nor upon its fineness, as upon its cord-like or 'spiral' structure.

"Again: the flat or ribbon-like varieties differ widely from each other, some of them showing, even in their flattened parts, an approach to the spiral structure.

"Such peculiarities can only be described and made available after the examination of a large number of specimens, and these should include every kind of cotton, from situations differing as much ás possible with respect to soil and climate."

\section{The Enemies of the Cotton-Plant.}

THE enemies of the cotton-plant are chiefly the caterpillar and the boll-worm.

The ravages of the chenille, or cotton-caterpillar (Depressario Gossypioides) have been long known in other countries. It prevailed destructively in South America and the West Indies, having been described previous to the present century, and is probably coeval with the cultivation of the cotton-plant. In 1788 and 1794, two-thirds of the crop in one of the Bahama Islands were destroyed by it. The remedy first resorted to was the burning of the cottonstalk in which the eggs of the insect were supposed to be deposited. This seems to have been ineffectual; it was certainly so as respects the insect that occasions the rot, as, during the whole period of its prevalence in this country, the burning of the stalks was universal, and no diminution of the disease was known to have resulted from the practice. "The most feasible remedy," says Mr. Wailes, in his report to the Legislature of Mississippi, on this subject, "is one I proposed more than ten years since; it is the destruction of the enemy by means of torches at night, immediately after the perfect imago or moth emerges from its puparium or chrysalis state, and flies abroad, it being very well known that fire-light will attract insects of this class. If the hands on a plantation were each provided with a lighted torch of pine wood, dried cane, or some similar material, and made to pass through the fields at intervals of five or ten rows apart, shortly after twilight had closed, myriads of moths would perish in 


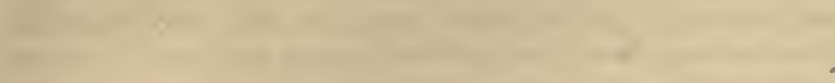

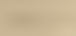

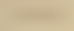

2.

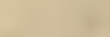

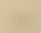

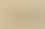

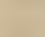

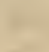

(n)

$\sqrt{2}$

$+$

19

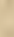

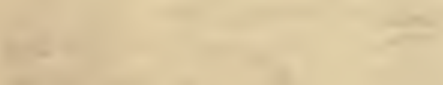

-

$$
\text { (1) }
$$$$
\text { 1 }
$$$$
\text { ? }
$$$$
\text { (n) }
$$$$
-=
$$$$
\text { x }
$$$$
\text { 1 }
$$$$
\text { . }
$$ 

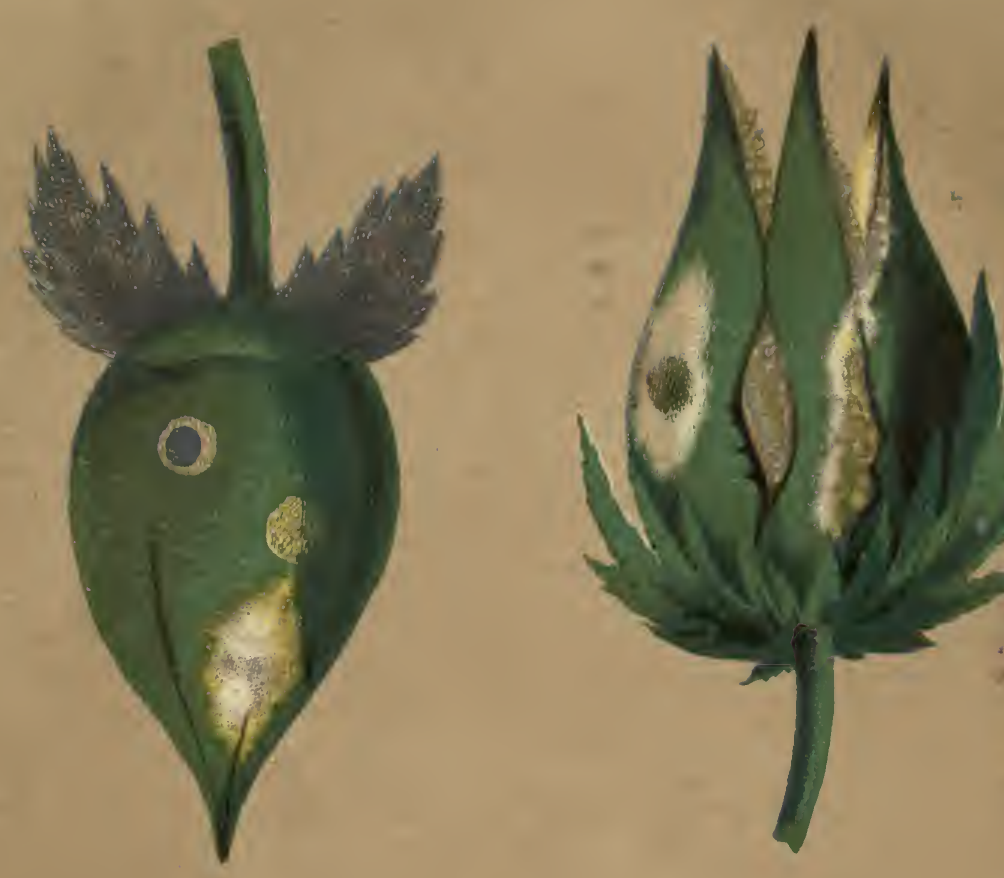

sर
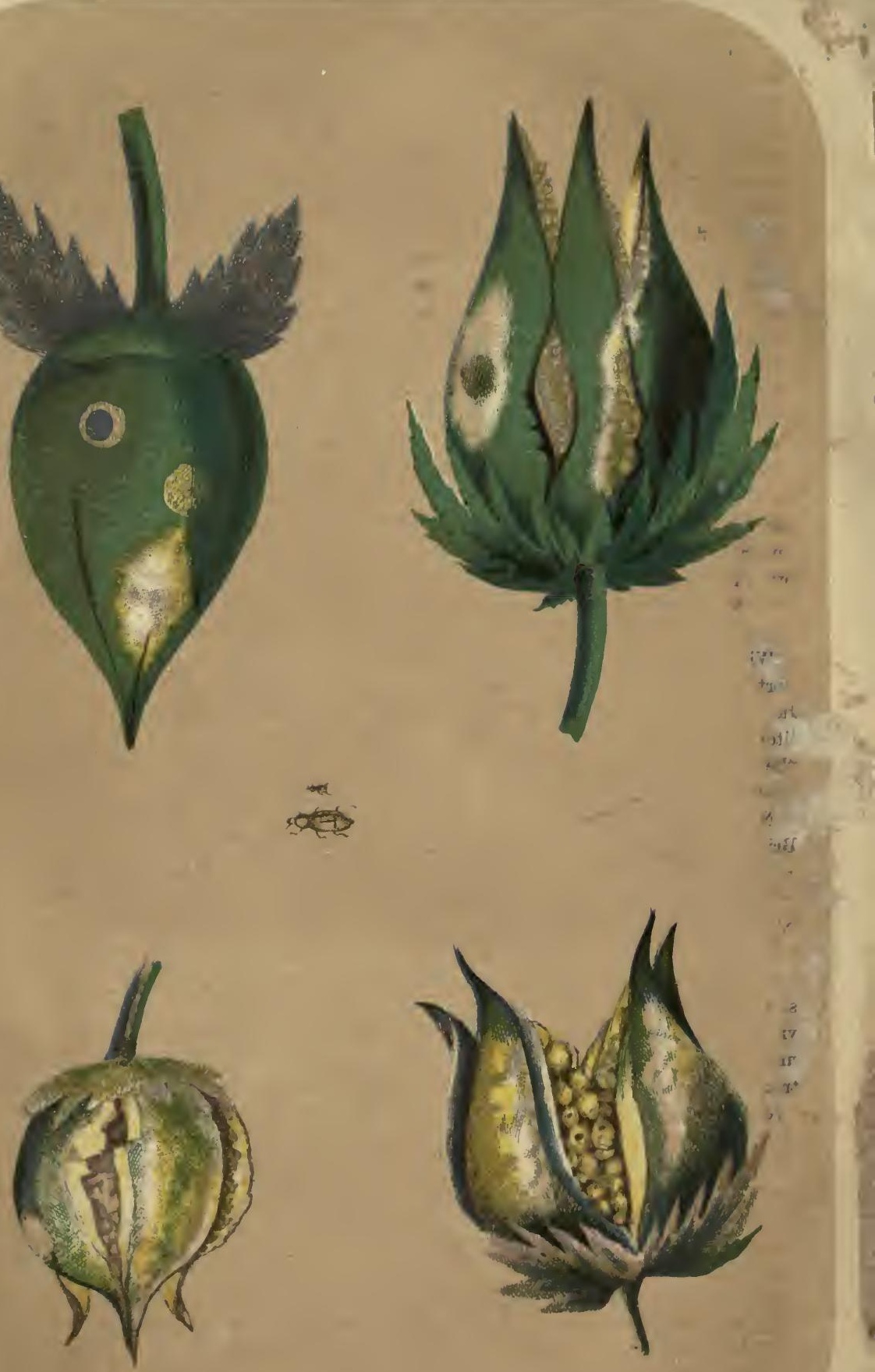

ROT IN EOTTAN 


\title{
A REVIEW BY THE EDITOR
}

\author{
OF THE
}

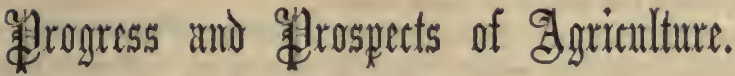

NEVER, in the history of our country, has Agriculture, in all its great and varied departments, presented so prosperous and promising a condition as at the close of the year 1855 . The season that has passed, in striking contrast with that which immediately preceded it, has proved fruitful to an extraordinary degree, and the careful estimates of the gathered crups almost exceed belief: Indian corn, ten hundred millions of bushels; wheat, from one hundied and sixty to one hundred and eighty millions; oats, four hundred millions; rye and cther grains, one hundred millions; and cotton, with a crop undoubtedly gmaller than that of some former years, not less than three million two hundred thousand bales, or, estimating four hundred pounds to the bale, one billion two hundred and eighty millions of pounds.

th this increase in material prosperity, a marked progress has also been made in all that I . iains to agriculture, considered as a science and an art-in the improvement and perfec- ion of tools, implements, and processes-in the increase and improvement of agricultural rrature-in the introduction and propagation of new and valuable animals and plants-in the increased patronage of the National and State governments-and in the more widely extended means and opportunities for elementary agricultural education.

Nor has this progress and improvement been confined to the United States. In Great دsitain, the examples and teachings of Mechi, Wilkins, Lawes, and Gilbert, the late Mr. Pusey, Prof. Way, of the Royal Agricultural Society, Prof. Anderson, of the Highland Agricultural Society of Scotland, and many other practical, far-seeing men, are producing most Leneficial results. Their efforts are also indirectly seconded by the manufacturers, as in the case of Mr. Salt, who has introduced the Alpaca sheep and Angora goats, and by others who utilize the refuse of their vast manufacturing establishments for fertilizers; or by their tatesmen, as in the case of Lord Clarendon, who, while Foreign Secretary, did much, in irtue of his position, to facilitate the introduction of foreign trees and fruit. In France, nder the direction of St. Hilaire and the patronage of government, the Society for the Inv:oduction and Acclimation of Useful Foreign Domestic Animals and Plants, are active and strenuous in their efforts. Under the direction also of government, aided by private individuals, the streams and lakes of the empire are becoming rapidly stocked with a profusion of fish, propagated by artificial means. American agricultural implements-partially through the results of the Great Exhibition of Paris, partially through an increased information-are finding a ready market in France, and in Vienna a warehouse for their exclusive sale has been established. Lastly, but not least, it must be recorded that Algeria, best known to American readers by its former piracy and white slavery, competed honorably with the United States at the Paris Exhibition in reaping machines; that the National Agricultural Society of the Sandwich Islands, during the past year, has issued its third annual report and a warded six hundred dollars in prizes, and that Liberia has established a model farm and plantation.

Let us, however, examine in detail some of the varied and interesting incidents that have been recorded during the years 1854-55:

As regards agricultural education, many important steps and prosperous beginnings have been made during the past year in the United States. In Georgia, through the munificence of the late Dr. William Terrell, the University of that State has been endowed with $\$ 20,000$ 
for the purpose of establishing a Professorship of Agriculture, and the trustees have elected to the chair Dr. Daniel Lee, former editor of the Genesee Farmer and Southern Cultivator.

In Massachusetts, arrangements have been made, in connection with Amherst College, for the instruction, in agriculture and its kindred sciences, of young men, not permanently members of the college, but who may resort to it, for longer ot shorter periods, at pleasure, for this specific purpose. This department is under the special direction of the well-known agriculturist, Prof. J. N. Nash, editor of the Valley Farmer, and the Rev. Dr. Hitchcock, formerly President of the College. The plan of instruction embraces a full course of lectures on the natural and physical sciences, and lectures and recitations on practical agriculture and the application of science to rural affairs.

The legislature of Michigan, at its last session, passed an act establishing an agricultural college in that State. This act provides that the site for an agricultural college shall be purchased within ten miles of the capital of the State, of not less than five hundred acres, nor to exceed one thousand; that twenty-two sections of Salt Spring lands shall be appropriated for the purchase of the land, erection of buildings, and all other necessary expenses to be incurred in the establishment and successful operation of said college; that the purpose of the school shall be to improve and teach the science and practice of agriculture; and that the course of instruction in said college shall include the following branches of educationviz., natural philosophy, chemistry, botany, animal and vegetable anatomy and physiology, geology, mineralogy, meteorology, entomology, veterinary art, mensuration, levelling, political economy, book-keeping, and the mechanic arts connected with agriculture. The tuition is to be forever free to pupils within the State.

During the summer scholastic term, or from the beginning of April to the end of October, the pupils are to be required to devote not less than three nor more than four hours to manual labor, no student to be exempt except in the case of sickness or other infirmity.

The legislature of Massachusetts, at the last session, passed an act incorporating the "Boston Veterinary Institute," which has since been organized in the city of Boston. The object of the institute is to afford ample instruction to persons desirous of qualifying themselves for the practice of reterinary medicine and surgery. The plan of instruction includes lectures on the anatomy and physiology of the horse, on the theory and practice of veterinary medicine and surgery, and on cattle pathology. Students will also be allowed to attend the lectures on chemistry and pathological anatomy in the medical department of Harvard University, and clinical lectures will be given by the faculty. The officers of the institute consist of the following gentlemen: D. D. Slade, M.D., President; George H. Dodd, Prof. of Anatomy and Physiology; Charles M. Wood, Prof. of Theory and Practice; Robert Wood, Prof. of Cattle Pathology. D. D. Slade, M.D., John W. Warren, M.D., George Bartlett, M.D., and Charles Gordon, M.D., Board of Examiners.

In 1852, a charter for an agricultural college was granted by the legislature of New York, chiefly by the agency of the late Hon. John Delafield, of Fayette, Seneca county, New York. It had been contemplated to build the college on Mr. Delafield's farm, and progress had been made to that effect by the procurement of some thousands of dollars, when the project was interrupted by Mr. D.'s sudden demise. Recently, the trustees of the institution have consented to its removal to the town of Ovid whenever the sum of $\$ 40,000$, required by their by-laws, shall have been secured to put it on an enduring basis. This site is central, beautiful, and healthy-one of the best, it is believed, that the State affords, and the people here have a mind to the work.

On the 1st of August, 1855, a meeting of persons interested was held in the town of Ovid, to confer together on the subject, and to assist in devising plans for the promotion of the institution. Addresses were delivered by various individuals, and resolutions were adopted in favor of raising the sum of $\$ 200,000$ for the purpose of carrying out the work; of this amount the town of Ovid was pledged for $\$ 10,000$, and Seneca county for $\$ 30,000$.

For the purpose of establishing an agricultural department of the academy at Westfield, Massachusetts, Stephen Harrison, of that place, bequeathed, during the past year, $\$ 5000$.

In 1844 , an agricultural department was established in connection with the college at Oberlin, Ohio, and a successful course of lectures given in connection with other instruction. 
At the last session of the Ohio legislature, an institution, bearing the name of the "Ohio Agricultural College," was incorporated and located at Cleveland. In order to unite the energies of all interested in agricultural education, it has since been determined to transfer the agricultural department of the college at Oberlin to the new institution at Cleveland, which, under favorable auspices, will commence its course of lectures and instruction on the 1st of December, 1855. The following board of officers and instructors have been elected: Harvey Rice, Esq., President; Professors,-J. P. Kirtland, S. St. John, N. S. Townshend, J. Dascomb, and J. H. Fairchild. The education course which has been proposed embraces the following subjects:-

1st. Those that relate to the land.-Geology, mineralogy, chemistry, \&c. 2d. Those that relate to plants.-Botany and vegetable physiology, field crops, orcharding, gardening, \&c. 3d. What relates to animals.-Comparative anatomy and physiology, natural history of domestic animals, veterinary medicine, insects, \&c. 4th. What relates to labor.-Rural architecture and landscape gardening, draining, use and construction of implements, surveying, farm book-keeping, \&c. \&c. A reading-room, supplied with agricultural papers and journals, are additional facilities offered to the student. The price of tuition for the entire course is $\$ 40$.

A "Farmers' High School," incorporated by the legislature of Pennsylvania in 1855, was organized at Harrisburg, Pennsylvania, in June last. The trustees are empowered to make choice of a suitable location, embracing not less than two hundred nor more than two thousand acres; and also'to choose a principal and other officers and assistants of suitable practical and scientific attainments, as well as make whatever arrangements the nature of the institute may require. The State Agricultural Society is authorized to appropriate any sum not exceeding $\$ 10,000$, whenever the school may require it, and also to make annual appropriations according to the extent of its resources.

The Gardeners' Educational School, established some years ago by the Belgian government, and located at Ghent, under the superintendence of the celebrated horticulturist, Van Houtte, is fulfilling the most sanguine expectations which have been formed concerning it. The young men, admitted between the age of fifteen and twenty, receive instruction, board, and lodging in the establishment. The expense is 500 francs per annum. The course of lectures and instruction lasts three years, and comprises all matters which, in every way, an accomplished gardener ought to know. The professors are appointed and paid by the Belgian government. The institution is equally open to foreigners as well as citizens of Belgium, and, although but recently established, has already pupils from many different nations. The arrangements of the school comprise spacious lecture-rooms, sitting-rooms, and dormitories for the pupils, a rich garden, museum, library, and herbarium, together with the immense horticultural establishment of Van Houtte, where every branch of the business is carried on on a great scale-itself the best practical school for young gardeners.

The Union Agricultural Society of Virginia and North Carolina, whose members reside partially in Virginia and partly in North Carolina, have recently raised the sum of $\$ 20,000$, and established a model and experimental farm, in the immediate vicinity of the city of Petersburg, Virginia. This society embraces within its organization the border counties of Virginia and North Carolina, i.e. what is called the south side of Virginia, (from James River south,) and all that portion of Carolina which finds a market at Petersburg. The limits of the farm are about one hundred acres, embracing a considerable variety of soil, a portion of which has been slightly improved by former applications of marl and lime; but, as a whole, its present condition affords an ample field for experiments in the improvement of worn-out land, by the judicious application of manures, deeper and more perfect tilth, subsoiling, under-draining, \&c.

Operations were commenced upon the farm, under the superintendence of $\mathrm{Mr}$. Nicol, one of the editors of the Southern Farmer, about the commencement of the present year. During the past season, the suitable buildings, offices, and fences have been erected, the farm laid out, trees planted, and some progress made in the course of practical experimentation. Thirty acres were seeded with various kinds of oats, and treated with different manures, and in varied quantities; (the results will be found in the present volume, department of Agricultural 
Chemistry.) Twenty-five acres were planted with different varieties of corn, and treated differently with various manures. The same course has also been followed with twenty acres of wheat.

Thus far, the greatest success has attended this novel enterprise, which may be regarded as one of the most important steps taken for the advancement of American agriculture during the past year. As its objects are by no means local or sectional, it has claims upon the interests of the whole country; and American agriculturists, in possession of choice seeds, fruits, \&c., will do no more than their simple duty in sending specimens to the superintendent, Mr. Nicol.

Under the auspices of the late Commissioner of Patents, Judge Mason, great activity has been displayed by the Agricultural Department of the Patent Office. A large number of foreign varieties of seeds and cuttings have been imported and distributed, and an agent for the collection of seeds has been recently sent to Europe. In addition, also, Mr. Townsend Glover has been employed for the purpose of investigating the habits of the insects injurious and beneficial to crops, and illustrating the same with the view of describing them, with the remedies for their diminution or destruction, and all other information on the subject, in the agricultural reports. Mr. Glover has been engaged during the year past in watching the operations of the rice and cotton insects in the Carolinas, Georgia, and Alabama, the corn and grain insects of the Middle and Northern States, and the insects attacking vines and fruit-trees in general, as well as numerous insects beneficial to the farmer.

The number of patents issued in the United States for improvements in agricultural machines, implements, and processes relating to agriculture, during the year ending July, 1855, was 302 ; of this number there were issued for plows and cultivators, 40 patents; for seedplanters, 45; grain and grass harvesters, 61 ; straw-cutters, 19; winnowers, corn-shellers, and threshers, 34 .

In no one department does American agriculture appear to such advantage as in respect to its implements and machines for facilitating or economizing labor. Since the establishment of the Patent Office, up to 1855, there have been granted for grain and grass harvesters, 111 patents; for plows, 372 ; for straw-cutters, 153; for smut machines, 140; for winnowers, 163; and for thrashing machines, 378. It must be also remembered that, for every patent granted, at least two applications have been refused. With the exception of stoves, more patents have been issued for agricultural machines and implements than for any other class of inventions. The great improvement in American agricultural implements has, however, been comparatively recent; and thirty years have not elapsed since " $a$ stalwart man could shoulder and carry to his work every item employed to aid or reduce manual labor, except the carts and an unwieldy, bungling harrow."

At the trial of agricultural machines exhibited at the Great Paris Exhibition, the competition for reapers, mowers, and thrashers was, in reality, confined to the American inventions, although some English and French machines were on the ground. The results of the French Exhibition, in common with that of the great English one, place our reaping and mowing machines, by general acknowledgment, far in advance of all others. The advantages of these machines during the past season, with our superabundant crops, have been very marked; and they are to be found, not merely in the saving of grain and the cost of labor, but in the fact of the prompt harvesting of every field as it successively ripens, without hurrying on the operation before the grain is matured, lest unfavorable weather or the scantiness of help, should oblige the postponement of the cutting till much of the grain is loosened from the ear and wasted in the field.

At the trial of thrashing machines at the Paris Exhibition, the best machine exhibited, was Pitt's American Thrasher. In the competition six men were set to thrashing with flails at the same moment that the different machines commenced operations, and the following were the results of half an hour's work:-

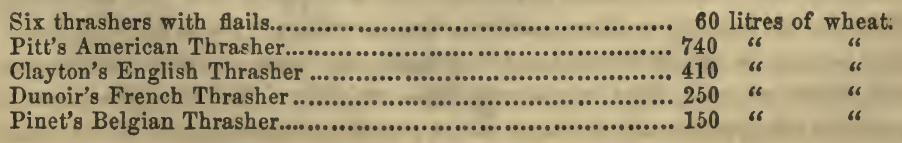


In regard to Pitt's machine, the Moniteur says-

"Pitt's machine has therefore gained the honors of the day. This machine literally devours the sheaves of wheat; the eye cannot follow the work which is effected between the entrance of the sheaves and the end of the operation. It is one of the greatest results which it is possible to obtain. The impression which this spectacle produced upon the Arab chiefs was profound."

One interesting feature attending the recent great improvement in the construction and operation of thrashers and winnowers has been pointed out by Mr. Allen, of the American Agriculturist - that since the introduction of these machines some of the choicest varieties of wheat have been extensively cultivated, which, previously, were so difficult of separation by hand-thrashing, as to be excluded from the best wheat-growing districts. Machines of this character are now in existence, which, when driven by a single horse, are capable of doing the work of fifteen men.

Among recent novel improvements in harvesters patented, are machines for cutting and collecting corn-stalks, harvesting corn, cutting and pulling cotton and cotton-stalks.

Numerous trials for the determination of the value of the various patent inventions for reapers and mowers have been made in various parts of the country during the past summer. The results, however, from the want of any fixed rules, have exhibited but little uniformity, and are of slight practical value. To obviate this difficulty, a "scale of points" has been prepared by Colonel Johnson, of New York, Dr. Elwyn, of Pennsylvania, and other eminent agriculturists. This scale will be found in full, in the pages of the Year-Book.

The trustees of the Massachusetts Society for Promoting Agriculture have offered a high reward for the best mowing machine that can be produced. The prize is $\$ 1000$ to the maker or exhibitor of the best mowing machine, to be awarded in 1856 .

To entitle any person to the premium, the machine, with full particulars of its principles of construction, weight, and selling price, must be entered for competition with the trustees on or before the first day of June, 1856. A general trial will be had of all the competing machines, due notice of which will be given, together with all needful particulars, at the commencement of the season of 1856. The trustees, in awarding the one thousand-dollar premium, will not confine themselves to the single trial which will be afforded to competitors to exhibit the powers of their machines, but they will also take into account the merits of each as displayed in competing for this year's premium and in its ordinary working, both for this and the coming year, whenerer and wherever an opportunity is afforded of seeing it in operation. All communications relative to the subject may be addressed to Thomas Motley, Jr., Jamaica Plains, or R. S. Fay, Boston, Massachusetts.

During the past year a company has been established at Newark, Ohio, for the purpose of manufacturing, principally, portable steam-engines, to be used for various agricultural purposes, such as thrashing, winnowing, shelling, and grinding corn, \&c. These portable engines, in time, must form an indispensable appurtenance of every large and well-regulated farm.

The whole number of reaping and mowing machines estimated to have been sold in the Cnited States during the past season is upwards of fifteen thousand, possessing a value of $\$ 2,000,000$.

The following conclusion of a report on reaping and mowing machines, presented by one of the county societies of Massachusetts, contains some suggestions relative to the introduction of machinery worthy of notice: "Substitute," it says, "machinery for human muscles as far as possible. Save the expenditure of exhausting labor and hot sweat whenever you can. 'In the doctrine of eternal hard work, your committee do not believe!' It has come almost to this : we must cultivate our fields by machinery, or not at all. Help is scarce and high, and, what is worse, is good for little or nothing when we get it. Irish help is next door to no help at all. The chief problem is not how much they cost, but how much they waste! Hence, if we must have them, (and who has any other?) let us have as little as we can. As fast as may be, let us introduce horse-rakes, and corn-planters, and mowing machines to our farms, or hold them as neighborhood property. Let us domesticate among cur farming tools a horse-power, a circular saw, a thrashing machine, and so on; and thus 
diminish the necessity for hand-help, instead of importing muscles from Ireland by the shipload. If Irishmen will come and demand their dollar a day and board, and codfish on Fridays, let them pass along to those who can afford to pay them and put up with their heedless waste. In a word, let us do what almost every manufacturer has long since been obliged to do to make his business profitable, and even to save himself from being crushed by his own machinery; that is, avail ourselves of all the helps which science and modern improvement suggest for our aid."

The State Agricultural Society of Illinois have recently introduced a new feature into their annual exhibitions, which is worthy of imitation. This is the exhibition of the natural productions of the State, of every kind and variety, derived from either the animal, vegetable, or mineral kingdoms. Such annual collections must obviously tend to promote, in a very great degree, the study and the taste for natural history and the diffusion of useful knowledge.

The third annual meeting of the United States Agricultural Society was held in Washington, at the Smithsonian Institute, February 21, 1855. Twenty-six States were represented by credited delegates from State and county societies, and there was also a large number of individual members of the Society present. The Hon. M. P. Wilder, of Massachusetts, President of the Society, on taking the chair, delivered a pertinent address, in which he recapitulated the operations of the Society during the past year. The following resolutions were adopted by the Society:-

Whereas, The prosperity of a country is in proportion to the improvement of its agriculture; therefore,

Resolved, That agriculture should be the first interest considered in legislating for the general welfare, and that such legislation should be had as will foster and protect this interest, which is paramount to all others.

Resolved, That the time has arrived for the agriculturists of the whole country to meet in convention, and determine for themselves what legislation is necessary for their protection.

Resolved, That such a convention, to be composed of delegates from each State of the Union, be earnestly recommended by this Society, in order that an agricultural platform may be established, which will meet the views of, and be sustained by, the whole body of agriculturists as a profession.

- The following officers were elected for the ensuing year: Hon. Marshall P. Wilder, of Massachusetts, President; W. S. King, of Boston, Secretary; B. B. French, Washington, District of Columbia, Treasurer; Executive Committee, John A. King, New York, C. B. Calvert, Maryland, A. L. Elwyn, Pennsylvania, J. Wentworth, Illinois, B. Perley Poor, Massachusetts, A. Watts, Ohio, and John Jones, Delaware.

The constitution was so amended as to have the payment of ten dollars constitute lifemembership, and to change the time for holding the annual meeting to the second Wednesday of January.

The third annual exhibition of the United States Agricultural Society was held at Boston, October, 1855. The sum of $\$ 20,000$ being desired for the payment of expenses and premiums, the entire amount was subscribed in one hour, through the efforts of the president, Marshall P. Wilder. $\$ 10,000$ were áwarded at the exhibition for premiums.

The great exhibition of the Royal Agricultural Society of England, for 1855, was held at Carlisle, in July. An unusual degree of interest was excited in respect to the exhibition of machines intended to illustrate the application of steam to agricultural purposes. For portable steam-engines adapted to farm-use, eight entries were made, of eight, seven, and sixhorse power. The prices ranged from $\$ 900$ to $\$ 1300$; the cheapest engine of eight-horse power being entered at a cost of $\$ 900$. In the trials, the getting up of steam involved a consumption of from 18 to 24 pounds of wood, and from 181 to 35 pounds of coal, in spaces varying from 39 to 66 minutes. The quantity of coal consumed (per pound) per horse, per hour, varied from $3 \frac{1}{2}$ to 10 pounds. The prize was awarded to an eight-horse portable engine, costing $\$ 1250$, consuming, in getting up steam, 24 pounds of wood, or 28 pounds of coal, in 66 minutes, or $3 \frac{6}{10}$ ths pounds of coal per horse-power, per hour, when in full operation.

For the prize of $£ 200$ offered by the Society for the best steam-plow, tractor, or cultivator, 
several machines were entered. The most remarkable machine of this kind was a steam "horse" or "tractor," of fourteen-horse power, exhibited by Mr. Boydell. In this, the machine forms its own railway as it goes over the land, thus overcoming one great difficulty in the way of steam locomotion upon the bare earth. It ran itself from the show-yard, over some difficult and steep road, to the trial-field, and there went through the operations of plowing, scarifying, and harrowing, with very fair success. Its performances seemed to stagger some of the old sticklers for things as they are, giving a pretty broad hint that steam was insensibly coming closer to the farmer. This invention, with some others, will be found described in another department of this volume.

In the trial of power chaff-cutters, the greatest quantity of chaff cut by one machine was 1485 pounds within the hour; the least, 600 pounds, showing a considerable variation. The minimum amount of power required for cutting 11 pounds of chaff, lifting one foot, was 1.267 pounds; the maximum, 2.868 pounds.

In the trial of hand-power chaff-cutters, the greatest amount of chaff cut within the hour was 210 pounds; the least, 90 pounds : the minimum power required for cutting one pound being $1 \cdot 284$ pounds; the maximum, $3 \cdot 310$ pounds.

The agricultural department of the Great Exhibition at Paris exhibited little of interest or novelty to American visitors. The plows, with the exception of the English, could not compare with the American varieties, either in design or workmanship. The chief anxiety of the contrivers would seem to be, says Mr. Greeley, in the Tribune correspondence, " that each shall be thoroughly guarded, at whatever cost, against ranning too deep into the ground, though to that excess they manifest not the slightest inclination."

"Many of the harrows exhibited were constructed with a respect for the truth that the pointed, wedge-shaped tooth is radically vicious, tending to compact the soil which it tries to pulverize and loosen. Harrow-teeth, based on the principle of the plow and the cultivator, cutting easily, lifting and turning orer all the soil that they disturb, are evidently coming into fashion."

A drain-tile, of somewhat novel construction, was exhibited. The novelty consists in an independent collar or broad ring (say three inches wide) which loosely covers each junction of the tile, not so much to prevent their filling up with earth as to keep one from sinking below or rising above the other, 80 as to stop the flow of water. The material is, of course, that of the tile.

"It is unsafe," says the writer above quoted, in commenting upon the agricultural department of this exhibition, " to condemn what you do not fully comprehend; but many of the European contrivances for mowing, reaping, \&c. by horse-power, seem absolutely puerilo compared with those known in our country. So the machines for thrashing and cleaning grain here exhibited seem generally such as we have for the last twenty or thirty years been superseding by better, and some of them clumsily made and in bad condition, as if they had been brought here from an old lumber-room, without cleaning."

The Floral Fête at the London Crystal Palace in June last was probably the greatest heretofore seen in Europe. Fire thousand dollars were distributed in prizes. Of course all the skilled gardeners of the kingdom rallied round the head of their order, Sir Joseph Paxton, each vying to excel. In the fruit department, owing to a cold spring, there was a disappointment. The show of rhododendrons was most magnificent.

The last meeting of the National Pomological Society was holden at Boston, September 13, 1854, Hon. Marshall P. Wilder in the chair. A most able and practical address was delivered by the president on the Raising of Fruits from the Seed, the Arts of Cultivation, and the Preservation and Ripening of Fruits. The following officers for the ensuing year were unanimously elected: Marshall P. Wilder, President; one vice-president from each State; H. W. S. Cleveland, Secretary; Thos. P. James, Treasurer. The Society adjourned to meet in Rochester, New York, in September, 1856.

The progress made from year to year in the cultivation of fruit is a marked feature in American agriculture and economic industry. It is stated that at least one thousand persons, in the vicinity of Rochester, New York, alone, are employed in the cultivation of fruit-trees, the sales of the products of whose labor amounted, in 1854, to half a million of dollars. 
More fruit-trees, it is also said, are raised in Monroe county, New York, than in all the United States besides, and these find a market in every district from Maine to the interior of California. Indeed, throughout the whole of Western New York, fruit is rapidly becoming one of the staple productions. Both climate and soil have proved highly favorable to its cultivation. Apples, pears, peaches, plums, quinces, and all the smaller fruits are produced in the highest perfection, and, if we except peaches, which of late have been somewhat uncertain, the crops very seldom fail. Besides, there exists the most ample facilities for marketing that could possibly be desired. One reason which has greatly contributed to extend the cultivation of fruit in Western New York is, that the wheat crop-the great staple of this region-is annually diminishing in value on accoint of the extensive ravages of the weevil. Hundreds of acres, which have formerly been devoted to wheat-culture, have, during the past season, in the Genesee Valley, been planted with rye. In addition, the rivalry and greater productiveness of the Western States, brought into close proximity by the increased facilities for intercommunication, have rendered the wheat crop of Western New York less profitable than in former years. On all these accounts, therefore, many of the New York agriculturists have latterly given their attention, with great profit and success, to fruit-growing; and in this respect the "Genesee country" has become already famous. For the purpose of extending knowledge and promoting the production of fruit, a society has been recently organized, under the title of "The Fruit-Growers' Society of Western New York," which announces its object to be "the advancement of the science of pomology and the art of fruit-culture." It embraces the twenty-three western counties of the State of New York, and in each county there is appointed a committee of three persons, selected from among the most intelligent, experienced, and zealous cultivators of fruit. These twenty-three county committees unitedly form one general committee, which has a chairman, who will receive all their reports and prepare them for publication at the end of the year. By way of suggesting a course of inquiry to the local committees, and also for the purpose of facilitating the work of making up reports, the chairman of the general committee has issued a circular in which the more important subjects for inquiry are brought forward in the form of questions, thus:

1. About how much land, in your county, is there occupied with fruit-trees? 2. About how many fruit-trees are there under cultivation in your county, exclusive of nurseries? and how many of these are apple, pear, peach, plum, cherry, \&c.? 3. What would you estimate the annual produce of fruit to be in your county, in bushels or other given quantities? and how does the culture of fruits compare with ordinary field crops, as to profit? 4. What quantity of fruits are sold annually from your county, and their value per bushel, barrel, \&c.? 5. How many nurseries of fruit-trees are there in your county? how many acres of land do they occupy? and about how many trees of the different fruits have they under cultivation?

It is also required, or recommended in the Society's by-laws, that each county committee shall report, as often as once a month, such information as may have been collected during that period. These monthly reports have been recommended on the ground that when the preparation of a report is postponed to the end of the year, it is either done hurriedly and loosely, or it is not done at all; whereas a few notes during a month can be written out in a few minutes, and, being fresh in the memory, will be much more likely to be correct. This plan strikes us favorably, and is at least worthy a trial. One thing it will do for those who put it in practice, and that is, it will give them, what is of great value, a habit of observing matters of interest closely, and of putting on record useful and interesting facts concerning their daily affairs. How negligent the mass of mankind are in this respect!

In addition to the minute practical investigations of this general committee, the Society intends to hold annual or semi-annual meetings, for the exhibition, examination, and comparison of fruits; to hear reports, and discuss such matters as may at the time be deemed of most importance. These meetings are to be held alternately in all the large towns, lying at accessible points, within the twenty-three counties.

At a recent meeting of this Society, M. P. Barry, chairman of the fruit committees in the several counties, stated it as his opinion, derived from the returns made him, that there are jour thousand acres of nursery embraced within the twenty-three counties corered by the 
Society. At 10,000 trees per acre, this would give 40,000,000 trees; one-fourth of which, yearly, would be $10,000,000$ trees annually set out.

On the Pacific slope of our country, considerable attention has been already given to the subject of horticulture and fruit-growing. A correspondent of the New York Country Gentleman states that the fruit crop of Oregon, for 1854 , sold for $\$ 200,000$. One grower, whose oldest trees were brought across the Plains in a wagon, imbedded in soil, about ten years since, and then no larger than pipestems, sold his crop in San. Francisco for the sum of $\$ 20,000$.

"No man," says the Horticulturist, "either in Europe or America, who has any knowledge of the fruit-growing capacities of the United States, entertains the slightest doubt but that we are to be the greatest fruit-growing and fruit-consuming people in the world. Even now, in the very morning of our national existence, with the stumps of the primeval forests yet standing thick around us in the oldest States, fruit-culture has acquired such an importance as it never has attained on the other side of the Atlantic. There, the few grow and consume fruits; here, the million. This is no empty boast-although something to boast of-but a simple truth. In this country there are few tenants; all, or nearly all, are proprietors, and have all the encouragement which belongs to the indisputable ownership of the soil. Added to this, is a vast territory, fertile soil, and a climate varied in such a manner that here we can succeed with one class of fruits, and there with another. Within the present boundaries of these United States, all, or nearly all, the fruits cultivated for the use of man can be grown successfully in the open air."

As a striking illustration of the rapid extension of civilization westward in the United States, and of the great attention paid to horticulture, even its most elegant departments, in our new settlements, we copy the following card from a letter received by us: "H. A. Terry \& Co., Seedsmen and Florists, Proprietors of Glenmary Garden, Dealers in Trees, Vines, Shrubs, Seeds, Books, gc., Coowcil Blurrs, Iowa." This place, until within a very recent period, was the extreme military post of the United States on our Western frontier. It is nearly eleven hundred miles distant from tide-water, and two hundred and fifty west of the capital of Iown, which last place, in 1839 , did not contain a single inhabitant. In 1845 , the county of which Council Bluffs is the shire-town, was included within the Indian Territory. The population of Council Bluffs at the present time is nearly ten thousand.

"One of the most gratifying indications, also, of the permanent prosperity of California, is the great and rapid increase of her agricultural resources. Two years ago, she was known only as a mining country, and the impression was, that, but for her mineral resources, the State would be valueless. This idea has been not only proved erroneous, but the fact has been fully established that this is one, or can be made one, of the best agricultural States in the Union. Nowhere can wheat, oats, barley, and most kinds of regetables be grown with less labor and expense than here. The soil is fertile and the climate unequalled."

It is now estimated that sufficient wheat will be grown in California to supply the entire demand until the next year's crop.

From a report made to the Liberian government, it appears that agriculture has not been neglected in this growing State. A model farm and plantation, some time since established, is progressing favorably. Coffee grows with great luxuriance, as well as the different varieties of grapes and the olive. The cinnamon-tree, introduced from the East Indies, is also multiplying rapidly.

The legislature of Tennessee, at its last session, appointed a committee to prepare and present a gold medal, with suitable devices and inscriptions, to Mark R. Cockrell, Esq., as a testimonial of esteem for his devotion to the advancement and development of the agricultural resources of that State, especially the wool-growing interests.

Upon the presentation of the medal, Mr. Cockrell, in reply to the remarks of the committee, said: "At the World's Fair at London, in 1851, the premium for the golden fleece was awarded to Tennessee. Germany, Spain, Saxony, and Silicia were there; the competition was strong, honorable, and fair. Nature gave me the advantage in climate, but the noble lords and wealthy princes of Europe did not know it, neither did my own countrymen know it, until we met in the Crystal Palace of London before a million of spectators. While their 
flocks were housed six months in the year, to shelter them from the snow of a high latitude, and were fed from the granaries and stock-yards, mine were roaming over the green pastures of Tennessee, warmed by the genial influence of a Southern sun-the fleece thus softened and rendered oily by the warmth and green food, producing a fine, even fibre."

A number of the leading English agriculturists, as a testimonial of their appreciation of the services rendered to the cause of agriculture by Mr. Lawes, (well known for his experimental investigations on the growth of wheat, mineral manures, \&c., in connection with Dr. Gilbert,) have recently erected and furnished a laboratory, which, together with an elegant silver candelabrum, has been presented to him. It may be expected that, with increased facilities, more new and valuable results will be attained.

The importations of English cattle into the United States have been very numerous during the past year. "A few years ago the taste ran in a different direction, and blood-horses were all the go. Priam, Glencoe, Monarch, and horses of that stamp were parchased in England at enormous prices-15,000 or 16,000 dollars being paid for a single animal; but a fondness for racing has diminished, not only in the Northern but also in Southern States, and the importation of well-bred cattle, sheep, and hogs has been pursued with more ardor."

In Kentucky, in Bourbon county especially, there are at present some of the finest cattle in the world, the descendants of foreign Shorthorn stock. As a proof of their superiority over the present English cattle, the Ohio Farmer states the following conclusive fact: "In the last three years about two hundred head of English Shorthorns have been imported into Kentucky, and not one in ten out of them have been able to take premiums over those bred in Kentucky, and, out of one hundred and fifty cows, but two have been successful competitors. The bulls have been more successful than the cows, for the reason that aged Kentucky bulls have been sold out of the State."

There is something in the climate and soil of Kentucky extremely favorable to the development of stock; and it is stated that, within a district of that State not exceeding forty miles square, there are now as many fine cattle bred as in all England.

The cattle interest of the Western States has also become one of great magnitude, especially in Ohio. The best evidence of this is the continued announcement of importations, intended for this section of the country, and the exhibitions of the various State fairs. Some of the finest of the recently-imported stock in the United States is now in the possession of the United Society of Shakers, of Union Village, Warren county, Ohio. The Ohio Farmer states that $\$ 2000$ were paid by this Society for a short-horned prize bull, imported during the past summer.

The Cashmere and Angora goats, and the Brahmin cattle, imported sometime since by Dr. Davis, of South Carolina, are multiplying both directly and by crossing with native stock. The results thus far attained exceed the most sanguine expectations.

A number of alpaca sheep have also been recently introduced into the United States from Peru, by Captain James Pedersen, of New Jersey.

The strange mania which has of late years manifested itself for importing and breeding foreign fowls, has nearly exhausted itself. The effect, so far from being beneficial, has undoubtedly produced a deterioration of some of the most valued varieties of our domestic fowls. Hybrid races have been produced, which are incapable, in a great degree, of propagating their species, are useless for supplying eggs, and worthless for the table. We would call attention to a paper in support of these views,* recently read before the Boston Society of Natural History by Dr. Kneeland.

Increased attention, attended with valuable practical results, has been recently given to the subject of the artificial propagation of fish in the United States. In Ohio, Drs. Garlick and Ackley, of Cleveland, have succeeded in propagating the speckled trout (Salmo fontanalis) of Lake Superior in great numbers, at small expense. A most interesting account of their experience has been published in the columns of the Ohio Farmer, and an abstract of the same will also be found in the present volume. The Natural History Society of New Jersey have proposed to stock the waters of the Hudson, the Delaware, the Susquehanna, and 
their tributaries, with the salmon and other raluable fish, on condition that the several States of New York, New Jersey, and Pennsylrania will defray the trifling expense of transporting the eggs and parent fish to the proper localities, and enact laws providing for the protection and preservation of the young fry. The estimated amount of expenditure required on the part of the States is only about two thousand dollars, and the end which can certainly bo thereby accomplished is the creation or regeneration of a great and important branch of national industry.

Joseph Remy, the poor fisherman of the Vosges, France, who discovered the art of artificially propagating fish, recently died at Bresse from a disease brought on by exposure to inclement weather in his researches. A pension of 1200 francs had been awarded him for his labors in this interesting branch of ichthyology. His son, Laurent Remy, is a zealous disciple of his father; and has exhibited so much skill in the art of pisciculture, as to have been intrusted by government with the duty of keeping the waters in the department of the Loire stocked with fish. This business has become a recognised feature in the list of alimentary productions in France.

In connection with the French Industrial Exhibition, there was held, during the past summer, a show of live-stock, at which specimens of the breeds of several different countries were presented. The English farmers were there with their Shorthorns, Herefords, Devons, and the most popular breeds of sheep and swine. The cattle brought from Switzerland, and known as the Fribourg breed, appear to hare been the objects of special interest. They are characterized by a surprising bulkiness of frame, being larger than any native breed of Great Britain. The color is brown or black, with large patches of white, and the face and back generally white. The prices asked for these cattle were fully equal to those demanded for choice English stock. As much as $£ 68$ was refused for an indifferent bull of the Fribourg breed, and he was again taken back to Geneva. Two cows from the same district were purchased by a small proprietor within six miles of Paris, for $£ 31$ each, and these were considered a bargain. Higher prices were refused for cows of the Schwitz breed, and many of these were taken back to Switzerland, a distance of six hundred miles; and this these cows had accomplished on foot, shod, of course, but active, and not apparently injured by the journey. They are structurally well adapted for travelling.

The exhibition of stock at the recent fair of the Royal Agricultural Society at Carlisle, England, is said to have been fully equal in numbers and quality to any of the previous fairs of the Society. The special correspondent of the Mark Lane Express says:

A more splendid show of Shorthorns we believe we never saw-so uniformly good, (with one or two exceptions only,) and denoting not only all that beauty of color, form, and feature which all so much admire and love to see, but those better and more substantial qualities-a large, rotund, proportionate frame, evidencing a tendency or capacity to produce plenty of good lean flesh, and of the primest quality, as well as to lay on, as they do, such enormous quantities of fat. This is as it should be : who can dine from off fat meat? We are glad to notice such a feature at this meeting. We think more attention is given to the breeding of animals of heavier frame, and denoting a tendency or propensity to produce good lean flesh, than heretofore. For the public good, we beg most earnestly still closer attention to this principle in breeding in every class.

The show of Devons was small, only 23 animals-whereas the average of the past nine years was 51, and that of Shorthorns, 98 .

In virtue of a recommendation from the War Department, Congress, at its last session, passed an appropriation for the purpose of importing camels from the East, to be used as beasts of burden on the vast sandy plains of the South-west which intersect the overland route to California. A national vessel, in charge of officers especially detailed for this purpose, has been sent to the Mediterranean, for the purpose of procuring the required number of these nnimals.

The production of regetable oils is a subject which imperatively demands the attention of our agriculturists. The price and the consumption of animal oils is increasing most rapidly, and the vegetable kingdom presents the only source from which we can expect to derive a cheap and adequate supply. An appeal has been made to the farmers of the United States 
on behalf of the Light-house Board, to engage in the cultivation of the rape and colzaplants extensively and most profitably grown in Europe.

It is a serious question whether our agriculturists, in importing foreign seeds and plants, are not neglecting valuable products and materials which are abundant at our very doors. The cotton-seed annually wasted at the South is capable of 'affording a large amount of superior oil. Recent experiments, made in Scotland, show that the cotton-seed cake, after pressing, is equal to linseed, rape, or bean cake for the feeding of stock. Indeed, its importation from New Orleans into Great Britain, for this purpose, has already commenced. Other facts, of a similar character, might also be adduced.

Many of our readers will remember the splerdid collection of woods, seeds, mineral and vegetable products sent from British Guiana for the New York Crystal Palace. This valuable and, at the same time, perfectly unique collection, made by the colonial government at great expense, has been secured, through the exertions of Dr. Gale, of Washington, and the aid of the British Minister, for the National Institute, and will, hereafter, form an important feature in the muserum of this Society.

In Russia, for some years past, a peculiar disease, called " rinder-pest," or cattle-plague, has beell committing fearful ravages among the flocks and herds of that country. During the past year it has exhibited some tendency to spread westward into Austria and Prussia. The authorities of the latter country have, therefore, just published a proclamation totally prohibiting the importation from Russia of horned cattle, sheep, goats, pigs, dogs, and poultry; fresh skins of oxen and other animals, horns, unmelted tallow, fresh beef, furs, manure, and stable implements that have been used. The following articles are prohibited if there is reason to believe they are the produce of infected or suspected districts: Raw wool, dried hides, and the hair of animals, with the exception of hogs' bristles. All persons who, from the nature of their avocations, may be fairly supposed to have had personal contact with infected cattle, such as cattle-dealers, butchers, graziers, drovers, tanners, leather-merchants, and poultry-dealers, will not be allowed to enter the Prussian territory; and should special reasons exist for making exceptions in particular cases, they must remain for some days before their admission under the surveillance of the authorities, submitting to such regulations as may be considered needful for the general security. In order the more effectually to maintain a control over travellers and goods arriving from Russia, they will only be allowed to cross the frontiers at specified points, all others for the present being closed.

The subject has also come before the Royal Agricultural Society of England, and the matter is also under serious consideration hoth on the part of the Society and of the Government. There is some reason to believe that the disease has made its appearance also in the Crimea among the animals intended for the allied armies, and the French government have especially instructed their veterinary surgeons in reference to its nature and propagation.

The potato disease appears to be diminishing in intensity, and but little complaint comparatively has been made of it during the past season. The British Meteorological Society, as the result of a long series of observations, have recently published the following summary of conclusions to which they have arrived:-

That the vital energy of the potato is unimpaired, and that it never becomes diseased until the stage of flowering, which is about one hundred days, or about three months, from the time of planting; that the causes are simultaneous in their action over a large tract of country, and at great distances, and are peculiar to the soil and air. That the object of the agriculturist ought to be the proper cultivation of the soil, and endeavor to economize the vital power of the plant at the time of flowering; and the removal of the flower before the formation of the seed would seem to contribute to this end.

Two interesting productions have been recently introduced into the Jardin des Plantes, at Paris, from Ecuador, by M. Bourcier, formerly consul-general of France in that country. One is the red and yellow ocas, which is of the form of a long potato, and has the taste of a chestnut; the other is the milloco, which has the taste and form of our best potatoes. These two roots, which are found in great abundance in the neighborhood of Quito, grow readily in the poorest land. The oca is cultivated in the fields of Mexico, but only succeeds in the warmer districts. 
In Great Britain the potato-rot has been much less this year than formerly. The European crop also has been generally large.

Attention has also been directed to the fact, that the sycamore-trees, which, for a number of years past, have been diseased, are now recovering. The malady appears to have commenced about the same time as that affecting the potato, and has never been explained or satisfactorily accounted for in any way.

In some parts of the South, especially in Louisiana, great trouble is experienced from the rapid extension and propagation of the so-called "coaco," or "nut-grass." The legislature of Louisiana have offered a premium of fifty thousand dollars for any practical plan of destroying it. A writer in the American Cotton-Planter states that some of the most valuable plantations in Louisiana have been rendered almost worthless by it, and that, unless great precautions are taken, it will spread over the whole of the Southern States.

One of the results of the Japan expedition, under Commodore Perry, was the procurement of a large number of Chinese and Japanese plants, which have been deposited in the National Conservatory at Washington. They were accompanied by a Chinese gardener, who is said to be well versed in the Eastern style of trimming shrubs and training flowers.

The foreign varieties thus procured embrace several new varieties of roses, including the China black rose, the guava, custard-apple, several varieties of oranges, persimmons, and dates, various species of China lilies, the lemon-grass, blue magnolia, and others.

During the past year a quantity of African corn has been imported into Boston from Winebabah, on the west coast. The corn resembles our Southern corn, but the kernels are somewhat smaller.

At the last session of the legislature of New York, an appropriation was granted to the State Agricultural Society to defray the expense of an investigation into the habits and character of the insects of that State injurious to regetation. The work has been, intrusted to Dr. Asa Fitch, well known as an entomologist. A collection already made by Dr. F. is understood to be the finest and most complete in the United States, and in some respects is unsurpassed by any in Europe.

As an encouragement for the growth of flax in Maine, the legislature of that State, at its last session, passed the following resolution :-

Resolved, That the sum of five hundred dollars is hereby placed in the hands of the Maine State Agricultaral Society for the encouragement of the raising of flax in this State, to be appropriated in such manner as in their judgment will best subserve such purpose.

The State Agricultural Society, on their part, voted to offer the whole in premiums, distributing $\$ 400$ among the county societies, and reserving $\$ 100$ to be offered in premiums by the State Society.

By the London Times, of August 9, 1855, it appears that the attempt to improve the cultivation of cotton in India, which, up to 1812 , had failed upon government farms under the care of government servants, has not been more successful in the hands of the natives. This is ascribed to the prejudices of the natives, coinciding with the belief of certain of the government agents, that "the introduction of the American varieties" would be of no benefit to India. By the sales by auction at Bombay it is, however, shown that the cotton grown from American seed for the last seven years has averaged from twenty-five to twenty-six per cent. higher than the native cotton. The Times, therefore, argues that further effort should be made. From this it appears that it is not likely that the United States will ever have a very formidable competitor in India.

Instigated by the high prices of breadstuffs during the past year in France, all the chemical and mechanical resources of that country have been applied in various directions for the discovery, development, and increase in quantity and quality of farinaceous edible matter. We have new inventions for corn-grinding, bread-making, and bread-baking. Agriculturists, more or less encouraged by government, are experimenting in the culture of roots and grains new to the soil of France. Amiong these a variety of upland rice may be particularly mentioned. A Mr. Callias seems in the way to-turn the fecula of horse-chestnuts to profitable account as a substitute for wheat and potatoes, if not on the table, at least in the industrial arts. The fecula of the horse-chestnut is extracted by grinding and sifting, with the same 
apparatus as is used for potatoes, the consumption of which, in the manufacture of starch, \&c., has hitherto been enormous. The process for extracting the bitter taste from these nuts is simply a series of washings in weak alkaline water.

Lieutenant Maury, of the National Observatory, who has done so much for the promotion of the interests of navigation, has recently proposed, in a communication to the American Farmer, that a national system of meteorological observations, for the exclusive benefit of the agricultural interest of the country, be established. He claims that, by an arrangement simple and inexpensive, results altogether as important to landsmen may be obtained, as have been yielded by the system of research pursued under his directions at sea. In his communication, Lieutenant M. says-

"The germination of the seed and the growth of the plant are but the display of a meteorological force, the expression of atmospherical laws, which, when rightly understood, cannot fail to confer upon agriculture and the well-being of States benefits as signal as the study of the movements of the same grand machine at sea has conferred upon commerce and navigation. I appeal, therefore, to the farmers, and all who are interested in the matter on shore, to follow the example of the sailors, and put their shoulders to the wheel, and help along the undertaking. Man by nature is a meteorologist, and everybody, whether ashore or afloat, has, even if he has not the intelligence to perceive it, an interest in it."

It is to be hoped that the vast amount of talk and "resolving" every year expended in favor of establishing a department of the General Government for the supervision and encouragement of the agricultural interests of the country, may ultimately find a termination in some plan as practical as that proposed by Lieutenant Maury. Thus far, government has done comparatively little or nothing for this leading branch of American industry. The two hundred and fifty or three hundred thousand dollars annually expended for printing and circulating the Patent Office reports would, if applied in a more practical manner, produce results of the greatest value. A portion of the Patent Office claims the dignity of an Agricultural Bureau, and under the last commissioner has done something to merit the title. In proportion, however, to its means, its results have been scanty; the reports are generally a mass of unsystematized matter, containing a few things good, some pernicious, and much that is worthless-the good being like a grain of wheat in a bushel of chaff. The Horticulturist states that many of the seeds "sent out year after year, as novelties, are bundles of perfect trash," and plants growing in the United States are said to have been imported at expense from foreign countries.

One of the most reliable methods of facilitating and insuring agricultural progress, is by the dissemination and circulation of good books and journals. In this respect, especial credit must be awarded to Messrs. C. M. Saxton \& Co., of New York, who have made agricultural literature a speciality. The number of books pertaining to agriculture and raral economy now published by this house is upwards of sixty, the majority of which are of a highly practical and scientific character.

We shall, also, do no more than justice, in taking advantage of our position as a reviewer, to award a large measure of praise to the Scientific American for its early and accurate reports of the progress of improvement in respect to agricultural machines and implements. This paper is the only journal in the country that describes in full American agricultural inventions.

The contributions made to agricultural literature during the past year have been numerous and important. An essay has been published by Baron Liebig, with the especial view of refuting the positions in respect to manures which Messrs. Lawes and Gilbert, of England, assert to have been established by their experiments. This, the friends of the great chemist claim, has been done most triumphantly.

A journal, devoted to veterinary science, the only publication of the kind in the United States, has recently been established in Boston, under the auspices of Dr. George H. Dadd.

We have thus briefly noted some of the memorable incidents and points of progress in the agricultural history of the year 1854-5. We think we err not in saying that marked improvement has been made, and that the promise for future years is most flattering. 


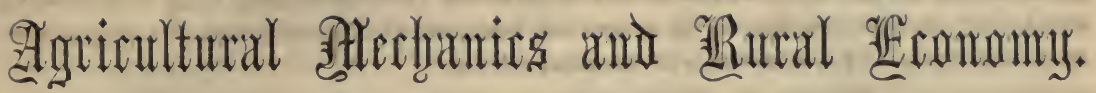

\section{Present State of Agriculture.}

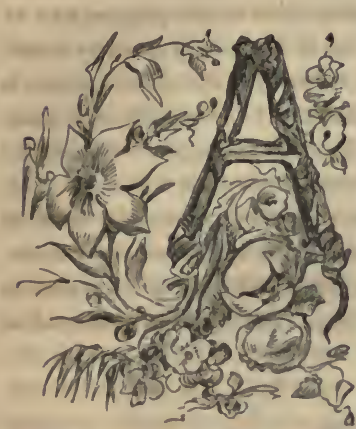

PERFECTED agriculture can result only from nice adjustments-a determination of the nature of the matter to be dealt with and its inherent forces, combined with a special knowledge of the individual organization and its functional wants. Defective products are mainly due to functional wants; there are no truly diseased products or disorganized organs. Graduate the supplies to the nutrient powers, satisfy the capacities of the plant at the proper time, and, all other things being aljusted, the husbandry is perfect; or give the plant its climate, temper the heats and moisture to its constitution, make its physical condition happy, and put within its reach the assimilating elements, and enough is done to insure productive returns. But to do this requires probably more knowledge of soils and of the cultivated regetables than we now possess. The object is to supply without waste, to cheapen the product by the expenditure of the least labor, and restrict the food to the kind and quantity, so that it shall not be lost by escaping into the air or by being washed to remote parts by rains. It is evident that adjustments require a complete insight into the physiology of vegetation, its incipient stage, its natural strength, the peculiar or special products to be found, the elements composing thom, and the best form in which these elements can be combined to meet all the wants of the being. As I have already said, functional endowments must be considered; hence, that course with a plant which will give it an early vigorous constitution and a full development of its organs in its first stages, must be pursued, and the foundation is then laid for the full amount of the products sought. $-D r$. Emmons's Nat. Hist. New York.

\section{Why the Farmer should give heed to the Man of Science.}

THE following judicious remarks form the conclusion of a recent lecture by Prof. Tuomey, of Alabama, upon science, as applied to agriculture :-

"In conclusion, allow me to say one word upon the apparent indifference with which agriculturists, as a body, listen to the teachings of science. Rural pursuits are far less farorable to speculative states of mind than those of the manufacturer; and hence, while the latter has pressed chemistry into his service, the cultivator of the soil is too often contented to pursue his own chance-directed processes, unaided by the light of science.

"This unnatural divorcement of science and agriculture has often arisen from not distinguishing between agriculture as a science and agriculture as an art. The man of science investigates one department, and the cultivator of the soil practises the other. Odium is often brought upon what is called scientific farming by the failure of men of science when they attempt the practice of agriculture. Now, I believe that, in general, it will be found that it was not the science, but the common sense, of such men that was at fault. The practice requires a different training, and, however sound his principles, the mere man of science fails for want of it when he attempts to try his own principles practically. Liebig, I apprehend, would make but a sorry plowman, yet the world has listened to his teachings. In all the arts 
of eivilization this division of labor is reeognised. The anatomist points out, from his knowledge of the hoof, the best mode of shoeing horses, but no one would think of employing him to put his own prineiples in practiee. The ehemist informs the tanner of those substances that contain the largest amount of tannin, and explains the rationale of all his proeesses, yet the ehemist is rarely expeeted to be able to produce leather from the raw hide, nor is the utility of his knowledge ealled in question on this aceount. Now, let this but be properly understood among us, and there will be an end to the sneers at 'book-farming,' nor shall there be any longer eause to complain of the proverbial tardiness with which praetical agrieulturists avail themselves of the discoveries of chemical seience."

\section{Machine for Cutting Cotton-Stalks.}

IN the States where eotton is grown, the removal of the stalks, prior to the preparation of the land for new planting, is a slow and laborious operation, for it is usually done by hand. The negro seizes hold of the stalk and bends it with one hand, while with the other he euts it off at the root by means of a heavy cleaver. An invention designed to effeet this operation meehanieally has been reeently patented by Mr. Bowerman, of Detroit, Michigan. It consists of a eart whieh is driven through the stalks in order to bend them down close to the ground. At the rear part of the vehiele a large horizontal knife is arranged to move vertieally between suitable slides. Motion is given to the knife by means of gearing on the wheels of the vehicle. As the eart advanees, the stalks bend, the knife is elevated, and then suddenly discharged, to fall upon the base of the bent stalks and clip them in a twinkling. Springs are employed to give additional force to the knife as it deseends.

\section{Improvement in Cotton Saw-Gins.}

A VALUABLE improvement in the eonstruetion of the saws of cotton gins has been reeently patented by Mr. A. D. Brown, of Columbus, Georgia. This invention eonsists in arranging the teeth of the saw in a series of curves eccentrie to their axis, or, what is equivalent, in a series of tangential lines. By this means, with a proper arrangement of the saws relatively to eaeh other, it is rendered impossible for any two saws to eateh the same fibre aeross a rib, and thereby eut or break it, while a peculiar degree of faeility is provided for the clearing of the saws by the brush. The expense of gins made aceording to this patent is no greater than those in ordinary use, while the eotton eomes out equally as well cleansed, and otherwise in a far superior state. The amount of work done is also the same as in other gins of like capaeity.

\section{Cleaning of Sea-Island Cotton.}

Sea-1stand cotron is nearly all ginned by hand, upon gins of the most primitive eonstruction possible to conceive. A writer in the New York Tribune furnishes the following deseription of the process and maehine in use, as witnessed on Edisto Island, South Carolina :-

"Let the reader faney a very roughly-made frame of two-inch square timber; the length of the frame is 2 feet 4 inehes; width, 2 feet 2 inehes; height, 3 feet 4 inches. Upon the front part of the frame there is a little box 8 by 12 inches, about 3 inehes deep, whieh holds the seed cotton. Upon each side of the box there is an iron fly-wheel, two feet across, of fifteen pounds weight. Upon the outside of the fly-wheels there are short bearings and little cranks. The inside bearing is formed by a wooden roller; about a foot long, driven into a soeket in the wheel. These rollers lie one upon the other over the back part of the box. From the eranks rods extend, like those of a small spinning-wheel or turning-lathe, to a treadle on the floor. Now, a man plaees a handful of cotton in the box, puts his foot on the treadle and starts the wheels, which make the two little rollers revolve toward each other; then he holds a loek of cotton up to the rollers, and the lint passes through and seeds fall back, if the cotton is in good order and the weather dry; if not, it eannot be separated without mashing now and then a seed, which injures the quality of a large lock. It is a day's work for a strong negro man or woman to gin twenty-five pounds. From the gin it is taken to the moter's 


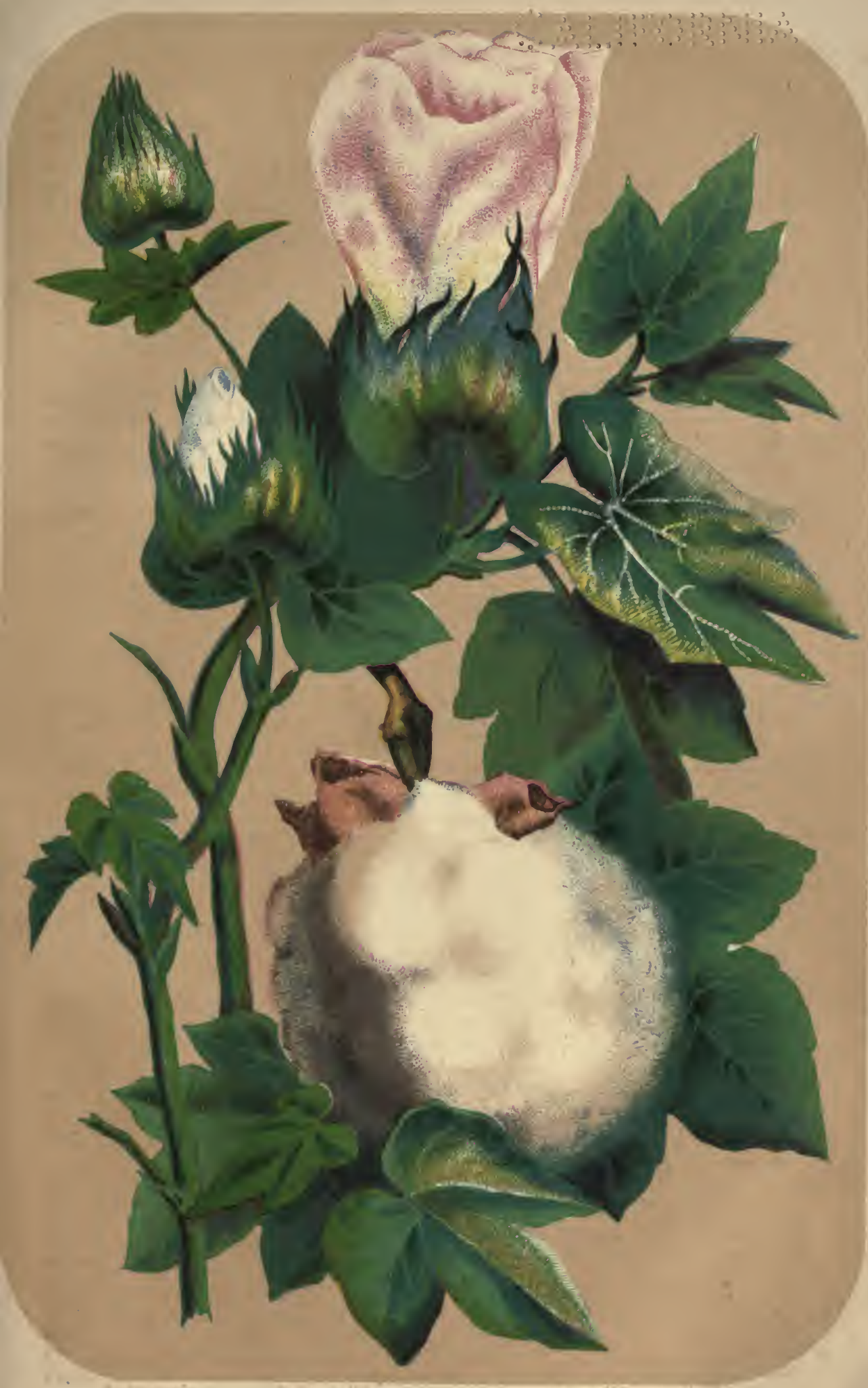




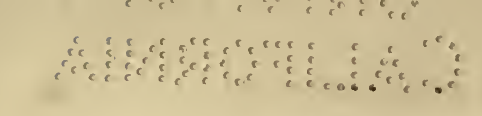


table, where one woman motes for two ginners. If a mashed seed is found, the ginner is called to pick it out. From the moter's table, the cotton goes to the overlooker's table, who sees that every mote is picked out. Then it goes to the packer's room, and thence in suitable weather into the bags. It packed by hand, three hundred and sixty pounds in a bag made of four and one-half yards of cloth. One bag is a day's work, the packer standing in the bag and beating down the cotton with a rammer, almost as solid as though pressed with a screw.

"Human ingenuity has been taxed heavily to furnish a cotton-gin that would clean SeaIsland cotton at a more rapid rate, without injuring the delicate, silky fibre of this variety, which is used for all the very finest threads, either for weaving or sewing.

"A great many sanguine inventors have satisfied themselves that they had accomplished this very desirable object, by inventing a gin that could be worked by other than human power, ginning faster than the roller-gin, without injuring the staple, but they have never been able to convince the Sea-Island planters. Governor Seabrook spent $\$ 5000$ in experi'ments, and others equally as much, to get a substitute, but have been compelled to go back to the little primitive machine we have described.

"We have often been assured by the cultivators of this description of cotton, that any man who could contrive an expeditious method of ginning their crops, could readily get assurances of $\$ 500,000$ for his invention, as soon as he could procure certificates from the spinners that cotton cleaned upon his machine was equal to that upon those now in use. Various attempts have been made with horse-power and steam-power to relieve the hard labor of propelling the roller-gins with the foot, but even this had to be abandoned on account of seeds being drawn through and broken with the lint. Even a substitute for the wooden rollers would be worth thousands of dollars. Those in use have to be made of wood not hard enough to glaze, or soft enough to broom; and, with all care in selecting the right quality, a pair of rollers wear out every day, and sometimes have to be renewed two or three times a day. These rollers must be split out and made smooth with the grain by a knife; the more rapid process of the turning-lathe will not answer.

"In conclusion, we put the pertinent question to American inventors: Have you or not ingenuity enough to make a Sea-Island cotton-gin? If you cannot produce the entire article, can you not find a substitute for the wooden rollers, which continually wear out?" -New York Tribune.

\section{Rafting Cotton.}

Mr. G. R. Griffiti, of Washington, District of Columbia, has recently perfected an invention by which cotton may be got to market and the seaboard in spite of low water in the Southern rivers. The plan is very simple, being merely the adoption of a kind of vulcanized Indiarubber bag, so constructed that any number of them may be connected together in the fashion of a raft, and either towed down the shallow streams by a steamer of light draught, or piloted by hands on the cotton, two men being able to manage one hundred bales. Twelve inches of water is amply sufficient for the transportation of cotton by means of these patent floaters; and if they can be suecessfully introduced, the condition of the streams hereafter will be no barrier to supplying the markets with the great Southern staple.

\section{Cotton Rigging for Ships.}

This article continues to increase in popular favor. The New Orleans Delta states, "that in April last there were thirteen large vessels in that port with a part or the whole of their running rigging and hawsers of cotton cordage. The officers of all these ships were unanimous in their testimony in favor of cotton cordage for running rigging, and many of them thought it would be adopted for standing also. A large new clipper vessel, recently built at Newburyport, Massachusetts, has all her rigging, both standing and running, of cotton cordage. An experienced sea-captain, in an article in the Delta, asserts that cotton rope is much stronger than Manilla, as by bending cotton and Manilla ropes together and heaving on it at the capstan the Manilla will always part first. In wet weather, likewise, it is more pliable, and in frosty weather it is not so stiff as Manilla. After it is used a few months it becomes smooth and glossy, and works through the blocks much better than any other rope. 


\section{Machine for Cutting Standing Cotton-stalks.}

THE accompanying figure is a perspective view of a machine for cutting standing cottonstalks, invented and patented August, 1855, by J. W. Bocage, Cypress Mills, Arkansas.

The nature of the invention consists in the employment of a series of circular saws placed upon a vertical shaft, and rotating between angular bars, which answer the purpose of fingers; the whole being placed and secured in a wheeled carriage, which is drawn through the cottonfield with mules or horses, and the saws rotated by gearing from the drawing-wheel, so as to act against the standing cotton-stalks and cut them down.

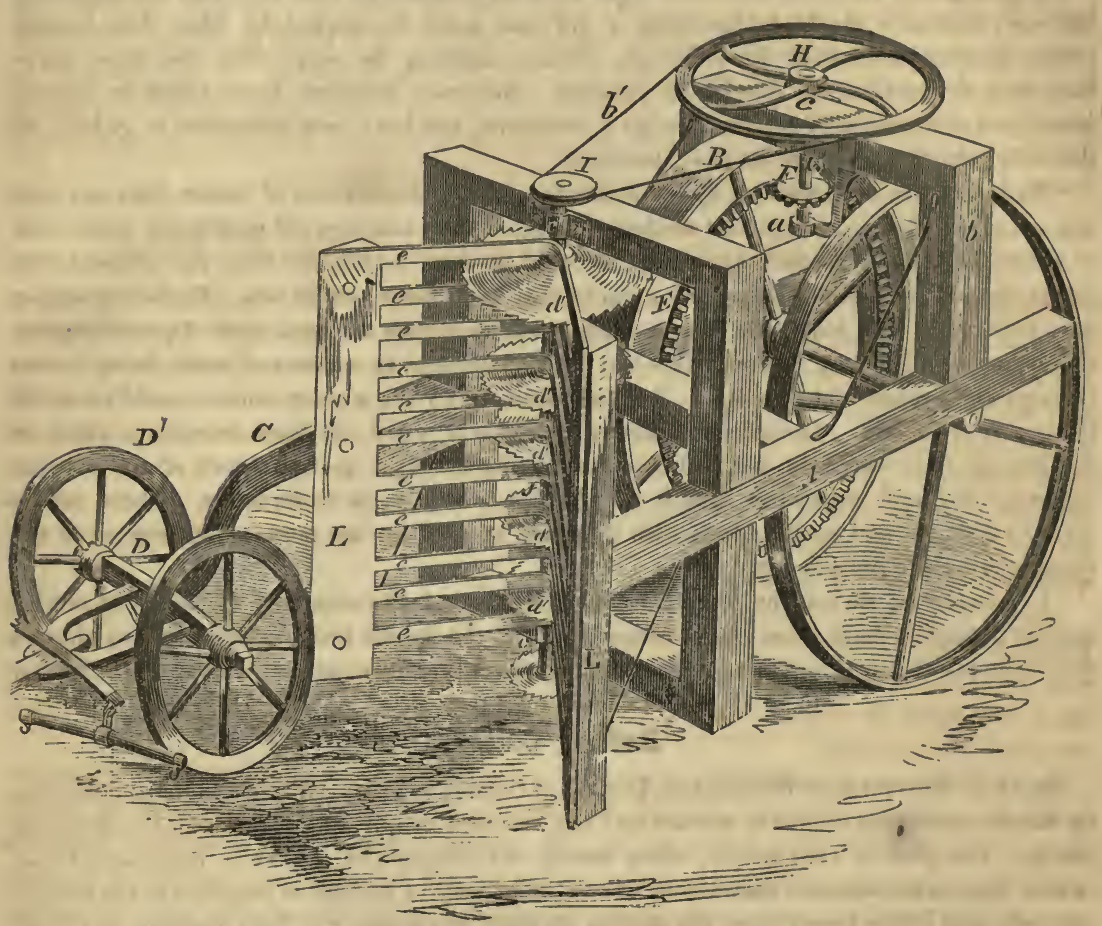

$A$ is a stout frame for supporting the machinery. It is sustained on the back and front wheels $B D^{\prime}$. The perch $C$ is connected to the front axle $D$ as in an ordinary wagon. A bevelled gear-rim $\mathrm{E}$ is secured to the spokes of one of the hind-wheels $\mathrm{B}$. A small pinion $\mathrm{F}$ on a vertical spindle $G$ gears into it. This spindle is secured in the cross piece $c^{\prime}$, and a pendant brace supported by standards $b$. $\quad H$ is a pulley on the upper end of spindle $G$. A belt $b^{\prime}$ passes around this pulley, and another small one $I$ on the top of the saw-spindle, which gives it a rotary motion-and consequently the saws $d^{\prime} d^{\prime}$-as the machine is drawn forward. The saw-spindle is secured in strap-bearings $c c^{\prime}$ on the top and bottom cross-pieces of the frame. The saws $d^{\prime}$ vary in size, the lower one being of the least diameter, and the size of them gradually increasing upwards-the top one being the largest. They are placed at suitable and equal distances apart. Six of these are represented in this machine, but more may be employed. L L is a metallic frame composed of horizontal bars $e^{\prime} e$ placed at equal distances apart, and bent nearly at right angles. The saw-shaft or spinaile is set just behind the inner angle formed by these bars, and the saws $d^{\prime}$ work through and between them; (about one-quarter of their discs project through the spaces.)

Operation.- The team is attached to the pole of the carriage in the common way, and as the machine is drawn along, the cotton-stalks are caught by the angular frame $L$, and forced towards the corner or angles of the bars or fingers $e^{\prime}$, holding them firm for the circular saws 
to act upon them and saw them down. As the saws decrease in diameter downwards, the upper part of the stalks will be cut down first; in other words, the stalks are cut successively from their upper to their lower ends.

Saws are superior to knives for cutting cotton-stalks by machinery in this manner, as they can be operated with less power, are more easily sharpened, and not so liable to get out of repair.-Scientific American.

\section{Cotton Cleaner.}

A NEW machine for cleaning cotton has recently been invented by Mr. J. B. Mell, of Riceboro', Georgia, which promises some advantages over the gins now in use. It consists in an ingenious relative and combined action of brushes and teeth, with which the rollers are armed. By the operation of these the pure cotton is rapidly taken from the mass of the feed, leaving the seed as well as the dirt behind. The eard or teeth, and brush rollers, revolve in opposite directions, so that, as the former raises the cleansed cotton, the latter sweeps it off, and it passes down the "discharge" and out of the box without interruption.

\section{Recent Improvements in the Preparation of Flax and Hemp.}

IIughes's IIemp and Flax-breaker.-An improvement in machinery for breaking and cleaning flax has recently been made by W. D. Hughes, of New London, Missouri. Three breakers, like heavy blunt knives, are attached to levers, and two of them are so arranged that they may be brought, while the machine is in operation, to the proper distance apart to suit the nature of the material to be operated upon. They may thus be eaused to approach each other or nearer to the line of operation to the corresponding breaker, so that the operator can adapt the machine to break any kind of hemp, whether it be well-rotted or not, and to act upon large and small bunches. In this way, perfect control of the breakers is obtained while the machinery is in operation.

Caryl's Flax-dressing Machine.-A valuable machine for the breaking and cleaning of flax, grown for seed, has been invented by Mr. A. H. Caryl, of Sandusky, Ohio. This machine is now in successful operation in various parts of the West, and is well worthy the attention of those interested in flax production. An explanation of its principles without engravings would be unintelligible.

Sugett's Improvement in Treating Hemp.-In a patent recently granted to Lewis C. Sugett, of Kentucky, for an improved process in treating hemp, the improvement consists in picking the hemp seven to ten days before ripening, its toughness being at its maximum about this time; the immersing thereof, after the usual mechanical treatment, in a solution of common salt at about $70^{\circ}$ Fahrenheit, during six lours, followed by a treatment with tar or an equivalent, previous to manufacturing it into twine or cordage; the whole for the alleged purpose of making it softer, stronger, more pliable, and more durable, and at the same time cheaper, than under any other treatment. The claims are as follows:

\footnotetext{
"The application of common salt, or other saline substance, to the steep-water, in order to effect the removal and separation of the gum at the most advantageous condition of the lint or harl. The saturation of the fibre and expulsion of its moisture, by immersion in boiling tar, pitch, or oil, for the purpose of more thorough and intimate application of the preserving substance to the fibres, preliminary to their conversion into twine or cordage."
}

Parker's Flax-breaking and Scutching Machine.-The peculiarities of this machine, recently invented by William Parker, of Belmont county, Ohio, are, that after breaking the flax it first presents the root-end of the fibre to the scutchers, retaining the seed-end, then withdraws the root-end and presents the seed-end, while the root-end is retained. The finished fibre is delivered on to an endless apron at the same time that the next tableful is received into the machine.

Jennings's Process for Improving the Quality of Flax Fibres.-This process consists in throwing down upon the flax a small quantity of oil, say about half an ounce to the pound of flax; this is done by boiling the flax in an alkaline soap-ley, washing with water, and then boiling it in water slightly acidulated with some acid; for which purpose acetic acid is, perhaps, the most suitable, from its exerting no injurious action upon vegetable fibre. The acid decomposes the soap, the fatty constituent of which is left in the fibre, or, perhaps, a mixture of an acid soap 
and a small portion of free oil. These enter into and through every part of the fibre. After this treatment, it is washed, and is then found to be soft and silky, its spinning quality being thereby much improved, and its value being very considerably increased; and, while the fibre is not weakened, this process gives to it what is known in the trade as "nature." The improvement in quality may be estimated at from $£ 8$ to $£ 10$ per ton, and is capable of being made with ease probably double.-Dublin Journal of Industrial Progress.

\section{New Method of Cleaning and Preparing the Plantain Fibre.}

VARrous attempts have been made at different times to construct a machine which would prove effectual for cleaning in a simple and economical manner the fibre of the plantain. Many expensive machines have been made and patented; but all have failed when brought into full operation, partly on account of the peculiar nature of the substance to be acted upon, and partly through iguorance respecting its composition and qualities. All inventors have acted on the principle of crushing the stem of the plant, and combing out the substance which fills up the interstices between the fibres, thus freeing them from native impurities. This appears to have been a false principle; and is the chief, if not the only, reason of all the failures which have resulted.

The Hon. Francis Burke, of Montserrat, West Indies, who has been experimenting on this subject for some time, has recently succeeded in completing a small machine which perfectly cleans the plantain fibre, leaving a beautiful white, silky substance, resembling flax, only three times as long. It is capable of being manufactured into any description of textile fabric, from the quality of the finest cambric to that of the coarsest sail-cloth.

This machine is said to combine simplicity of action with extreme chenpness. A piece of the stem of the plant is held by one end in the hand, passed into the machine through the "feeder," and, being still retained in the hand, is drawn out again perfectly clean and white. These machines are of different dimensions, and may be worked by the hand or any other motive-power according to its size.

A small machine worked by the hand costs but about fifteen dollars, and, with the assistance of a boy to feed it, will clean one hundred and fifty pounds per day; and is so portable that it can be taken to the spot where the plantains grow, when they may be prepared in one day ready for shipment. So small is the waste, that from 75 to 80 per cent. by weight of prepared fibre is procured from the plant, irrespective of its watery particles. The waste substance is a valuable pulp, which may readily be converted into the finest writing-paper. The pulp is estimated at a value equal to the cost of working, and the fibre is net profit.

\section{Transportation of Grain.}

Tue transportation of grain from all the great wheat and corn-fields of the West is a subject which now requires a careful investigation, from the immense amount of expenditure which it has been found to involve. The question is, simply, as to whether grain shall be transported in bags or barrels; and that a great saving is in favor of the latter it is our purpose to establish.

By the present system of moving grain there is a continual waste from the harrest-field to the mill, and until the flour is packed in tight, well-seasoned barrels. Western wheat is mostly thrashed from an out-door stack, and piled and winnowed on the ground; then bagged and brought to market, where it is emptied into elevators, and stored in bulk; the centre of the pile often heating until its value is destroyed. It is then shipped in bulk, and when it arrives at Buffalo, is transferred by elevators to a canal-boat, and thence to a storehouse in New York. If it is finally sold for exportation, it is put up in bags suitable for shipping, after haring undergone a dozen different handlings.

Now suppose the farmer had provided himself with barrels, and put up his grain on the farm, dry and in good order. 'Each common flour-barrel will hold about three and one-third bushels, for which the freight from Indianapolis to New York is about $\$ 1.40$ to $\$ 1.60$ per barrel; and, as a general rule, the charges on rolling freight on every line of railroad is from 
15 to 20 per cent. less than on other freight. And, independent of the evident economy of this system, there is another consideration which commends itself to the attention of farmers. It is well known that grain is even more liable to heat and spoil in bags than it is in bulk; while in barrels it is impossible to stow it in a position which will prevent the circulation of the air around it; and if the wood of which the barrel is made be well seasoned, it will absorb and dry out any moisture which may be in the grain. For in the transportation of grain from the warehouse to the cars, vessel, or storeroom, it is often necessary to do a part of the work in unfavorable weather; and thus, in winter-time, snow frequently drifts into the cars and moistens the bags, and in this or some way they are dampened; and then, if packed in bulk, there frequently ensues more injury from mould and other causes than the whole cost of barrelling would amount to, A friend who has had a great deal of experience in this matter estimates the saving to the farmer at at least six cents a bushel on every bushel of grain sent to this market in barrels; in fact, that by the present system of sending it in bulk or bags the farmer is losing six cents a bushel at the very lowest estimate.

There is another view of the matter, in the consideration that the manufacture of the barrels would add so much more to the productive interest of the country. What a vast amount of raw material, quite worthless in a wooded region, it would convert into cash! for each buyer of the grain would pay the value of the barrel at the point where it changed hands. When it reached France, it would be worth its original cost for fire-wood; for there fuel is sold by the pound at a high price. At any rate, there would be no loss, as in the case of bags, while in cost of freight, handling, storage, leakage, wetage, injury from mustiness, etc., there would be a considerable balance in faror of the barrels.

With Indian corn this saving would be more important than with wheat, because it is a grain 80 low in price that it will not bear costly transportation. When corn is only worth twenty-five cents a bushel at a point in the West whence it cost fifty cents to get it to New York, a difference of six cents a bushel in freight may entirely prevent it from being sent forward, as the uarket price would not allow a higher rate of freight, and any increase would take so much from the farnier's low price. But there is yet another fact regarding the transportation of grain in barrels that is worthy of consideration. The motion of the cars keeps the kernels of grain in the barrels in constant motion, and the natural tendency is to follow the circle round and round, instead of settling down to the bottom, as it does in bags or bulk. This has been proved by experiment. Besides this, the frequent rolling of the barrels gives motion to the grain, and helps to keep it sweet. If there should be any danger of dampness, it is suggested that a few dry corn-cobs or husks among the grain would be likely to prove a preventive. In conclusion, we are quite confident that if these hints should be followed by the majority of Western farmers, the amount of money saved in one year would be as much a source of surprise as self-congratulation. -New York Tribune.

\section{Improvements in the Construction of Granaries.}

A Mr. ADAMs, in a late number of The Journal of the London Society of Arts, has made a suggestion for a new kind of granary, by which he thinks that grain may be safely and effectually preserved for any number of years. The great difficulty now is the natural moisture contained in all grain, and which it is never entirely divested of by exposure to the atmosphere at the common temperature; this being the cause of much of the sour, musty flour found in market.

The following are Mr. Adams's observations upon the subject:-

"There does not seem to be any difficulty in the matter, if we divest ourselves of preconceived ideas, of the notion that a granary or grain receptacle must necessarily be a building with a floor or windows more or less multiplied in altitude. We may reason by analogy as to what is the cheapest and most effective means of securing perishable commodities from the action of the atmosphere and vermin. In England we put our flour in sacks. Brother Jonathan puts his in barrels, which does not thoroughly answer. *** If Brother Jonathan wishes really to preserve his flour or his 'crackers' undamaged, he makes them thoroughly 
dry and cool, and hermetically seals them in tin cans. This also is a common process to prevent goods from being damaged at sea.

"There can be no doubt that if we were to put dry wheat in an hermetically sealed tinned case, it might be kept as long as the famed 'mummy wheat' of Egypt. This will readily be admitted, but the expense would be queried. Let us examine into this. A canister is a metallic reservoir; so is a gasometer; so is an iron water-tank in a ship, at a railway station, or elsewhere; and a cubic foot of water-tank on a very large scale will be found tacost very much less than a cubic foot of canister on a small scale. And if a bushel of wheat be more valuable than a bushel of water, it will clearly pay to put wheat in huge canisters of iron. The wheat canister, in short, should be a wrouglt or cast metal tank of greater or less size, according to the wants of the owner, whether for the farmer's crop or the grain-merchant's stock.

"This tank should be constructed of small parts, connected by screw-bolts, and consequently easily transported from place to place. The internal parts should be galvanized, to prevent rust, and the external part also, if desired. It should be hermetically tight at all the points, and the only opening should be what is called a man-hole; that is to say, a canistertop, where the lid goes on, large enough to admit a man. When filled with grain, the top should be put on, the fitting of the edge forming an air-tight joint. Wheat put dry into such a vessel, and without any vermin, would remain wheat any number of years. But an additional advantage to such a reservoir would be an air-pump, by the application of which, for the purpose of exhaustion, any casual vermin would be killed. If the grain were moist, the same air-pump might be used to draw or force a current of warm air through it, to carry off the moisture. By this process, and subsequently keeping out the air, the grain might be preserved for any length of time. As the reservoir would be perfectly air-tight and water-tight, it might be buried in the ground with perfect safety; and thus cellars might be rendered available for granaries, economizing space of comparatively little value. The grain would be easily poured in from the surface; and to discharge it, an Archimedean screw should be used. The size of the reservoir should be proportioned to the locality, and it should hold a specified number of quarters, so as to serve as a measure of quantity, and prevent the expense of meterage. * * * If constructed above the ground, a stair or Yadder must communicate with the upper part, and the lower part must be formed like a hopper, for the purpose of discharge. For many farm localities this arrangement might be best, and wheat might be thrashed into grain direct from the field and stored. *** Granaries of this description would occupy less than one-third the cubic space of those of the ordinary description, and their cost would be less than one-fifth. *** With this security for storing safely, a farmer would have less hesitation in sowing great breadths of land. He would not be driven to market under an average value, and might choose his own time for selling. The fear of loss being dispelled, people would buy with less hesitation, and the great food stores of the community would, by a wholesome competition, insure the great mass of the community against a short supply. But as long as uncertainty shall prevail in the storage of grain, so long will it be a perilous trade to those engaged in it, and so long will the food of the community be subject to a very irregular fluctuation of prices. There is nothing difficult in this proposition. It is merely applying existing arrangements to unusual cases. There needs but the practical example to be set by influential people, and the great mass will travel in the same track. To the wealthy agriculturist it will be but the amplification of the principle of the tin-lined corn-bin, that keeps out the rat from the oats of the stable. *** Were this mode of preserving grain to become general, the facility of ascertaining stocks and crops after reaping would be very great. The granaries being measures of quantity, no hand-measuring would be needed, and the effects of wet harvest-weather might be obviated."

\section{Immense Grain Warehouse.}

THE Chicago Journal thus describes an immense grain warehouse recently erected in that city by Messrs. Gibbs, Griffith \& Co.:-

The structure extends from the dock to the railroad track, a distance of 190 feet. The 
river front is 60 feet wide, that on the railroad is 110 feet. The edifice is constructed as strong as wood and iron can make it, and is protected on the outside by a fire-proof roof and walls of brick, or sheathed with sheet iron. The height of the main building is 62 feet to the roof, or a little over 100 feet to the top of the cupolas, two in number, where is constructed the weighing apparatus. There are in the building above the lower floor, sixty-six bins of 5000 bushels capacity each, or of the dimensions of ten feet square by thirty-five feet in depth, all braced in the strongest manner to sustain lateral pressure. The two immense shipping bins hold 12,000 bushels each. The lower floor gives a clear space for rolling freight, and will easily accommodate 50,000 barrels. The uppermost story is designed to furnish conreniences for drying grain, and also for receiving and storing grain in bags. By way of recapitulation, it will be seen to be a moderate estimate that the warehouse can give storageroom to half a million of bushels of grain. The grain is received on the land side by four elevators, which can unload, in the aggregate, 10,000 bushels of grain per hour, or two hundred car loads. On the river-side a single elevator unloads the canal boats at the rate of 3000 bushels per hour, while in the same period, into the vessels, may be pouring at once, 8000 bushels of grain. The great heart of all, the seat of life in the establishment, is found very economically and snugly stowed in an interior angle of the building in shape of a splendid low-pressure engine of one hundred horse-power.

\section{Ford's Improved Granary.}

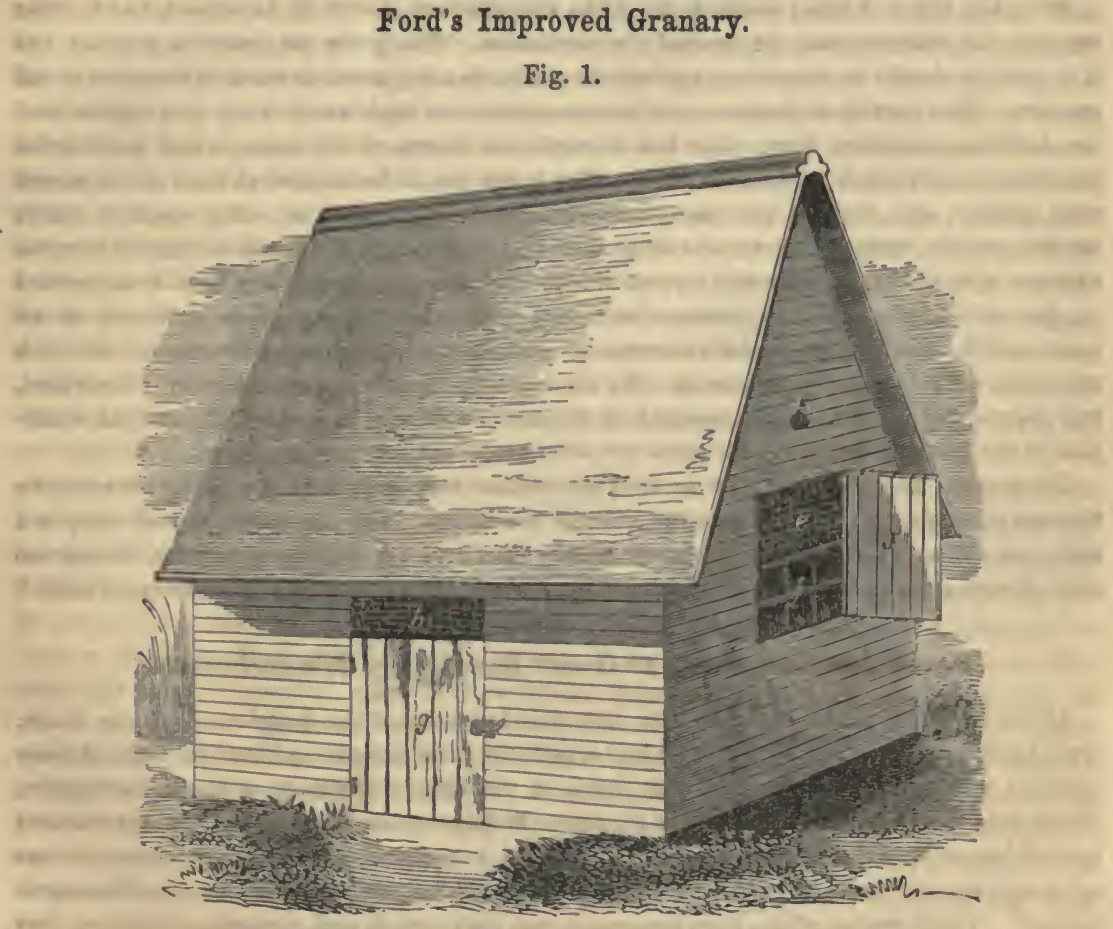

THE annexed engrarings are views of an improvement in granaries, for which a patent was granted to Ebenezer Ford, of Spring Cottage, Mississippi, October, 1854.

The nature of the improvement consists in erecting a building having double walls and double floors, furnishing the same with double partitions; the walls, floors, and partitions being filled in with salt, in order to prevent the attacks of insects.

Figure 1 is a perspective view of the granary, and figure 2 is a horizontal section of the same. 
Fig. 2.

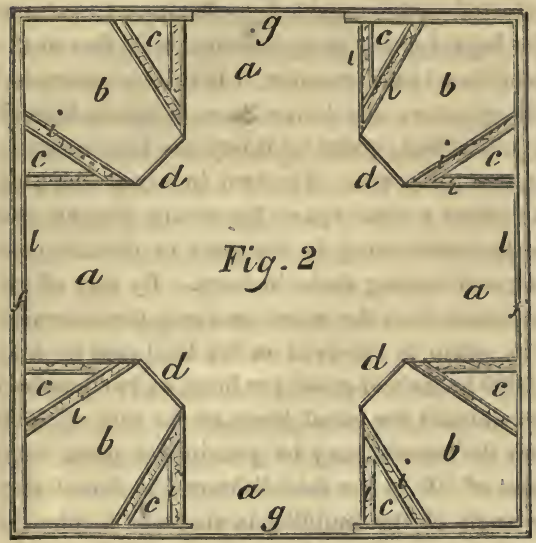

$a$ is the flooring; $b c$ are compartments; $d$ are doors; $e$ a wire gauze; $f$ are windows; $g$ is the door; $h$ is wire gauze on the same; $i$ are partitions; $k$ the smoke-hole; $l$ are the walls.

The building intended for a granary constructed on this plan is built in the usual manner, except that the walls $b$ are made double, one side of the other, the space between being fillea in with salt. The partitions $i$ are so constructed in the same manner, so that between the different compartments $a b c$ there are double partitions containing a filling of salt. When the granary is finished and ready for use, the floor should be saturated with salt brine. The house is now to be smoked by the introduction of a stove-pipe through the hole $k$, the pipe being connected outside with an ordinary stove-the smoke being carried through the hole $k$ directly into the interior of the building; sawdust, or any kind of wood used in smoking meat will answer.

When the house is being smoked, the doors and windows should all be closed, but in clear weather the windows may be opened for ventilation. The grain may now be put in; and if in bulk, it should be thrown up against the walls, slanting down towards the corners of the garners. The partitions between the compartments are high where they join the walls of the building, and slant down quite low towards the centre of the same, which permits the introduction of light in the various parts. The house should be smoked at least once a month with sulphur, and likewise with wood and sawdust during cloudy or sultry weather, which are the periods when the weevil and other insects generate. If no insects be carried into the granary with the grain, none will appear during the season; should any have been carried in, they will perish, and not generate any more. The object of the gauze at the top of the doors and the windows is to admit currents of cold air when an opportunity occurs. Salt is a substance very destructive to insects. By the employment of smoke in the manner described, any superabundant moisture occasioned by the use of salt will be carried off, and the condition of the granary may be at all times properly preserved.

The claim is as follows: " $\mathrm{I}$ am aware that salt has long been used as a filling between the timbers of ships, and also between the walls of ice-houses; and therefore to such devices I make no claim. But I claim the mode herein described for making granaries, having the walls, floors, and partitions filled in with common salt, in the manner substantially as set forth."

\section{David Leavitt's Barn at Great Barrington, Massachusetts.}

Aвоuт two years since, David Leavitt, Esq., late President of the American Exchange Bank, New York, purchased for his son, who had a taste for rural pursuits, a beautiful farm of three hundred acres, situated about one mile south of the delightful village of Great Barrington, Massachusetts. With the assistance of Professor Wilkinson, late Principal of the Agricultural Institution at Mount Airy, Mr. Leavitt commenced a series of improvements which, for the labor and expense attending them, are probably unequalled in the annals of American agriculture. The situation of the farm commands not only varied and picturesque scenery, but is admirably adapted for that system of improvements which its proprietor is so energetically and bountifully executing. Its outline is nearly quadrangular. On the south-east the farm is bounded by a high mountain, from which two streams run through a portion of the farm, forming a junction in a deep ravine a short distance from the house. A few rods below this junction, a dam is thrown across the ravine, and the arrested waters form a large and beautiful pond, if we recollect rightly, about twenty feet deep.

The barn is built in the ravine; in fact, one of its sides forms the dam to which we have alluded. It is a gigantic building, spanning the ravine, two hundred feet from side to side, 
and forty feet wide. The centre of the barn is a square; on each side, two wings with arched roofs, covered with tin, extend to the ravine on either side. The roof of the square centre is flat, and forms the base of a cupola twenty feet square, and about eighteen feet high. From this cupola rises a wooden spire of about thirty feet elevation. From the peculiar. situation of the barn, and by a great expenditure of labor and money in grading, easy drives are obtained into each story and basement of the building. The upper story is on a level with the surrounding table-land, and there is a magnificent driveway the entire length of the building, two hundred feet. On each side this driveway, there are bays for the storage of hay, a carriage-house, implement-room, and convenient apartments for the bailiff and farm laborers, coachmen, \&c. Above this, in the centre building, there are a granary, pigeonhouse, and rooms for the storage of cut-fodder and straw for litter. We should have said that the water of the brook, by being dammed up, furnishes a constant power, and is used for driving the machinery of the building. In the upper story, over the driveway, a shaft, with pulleys, runs the entire length of the building; and by it, and an ingenious contrivance, the hay is taken from the wagons, a load at a time, and deposited in the bays alongside. In this way a ton of hay can be unloaded each minute!

Descending to the next story, we find another splendid driveway, one hundred and sixty feet in length, and on each side stables and stalls for horses, cattle, \&c. By means of lead pipes, and conveniently situated stop-cocks, there is an abundant supply of hot and cold water for all purposes. The mangers for cows and horses are of iron, fixed on a swivel, so that they can be easily turned into the driveway, or feeding-room, away from the animals. This is very convenient, and might be generally adopted with advantage. The piggeries are on this floor, and are well arranged. In the pens for breeding sows, a framework of slats, about a foot high, is placed all around the inside of the pen, a foot or so from the outside boards. This is to prevent the sows, in lying down, from erushing the little pigs against the outside of the pen, the framework leaving a space into which they can escape, between the Blats, and be safe. Mr. Wilkinson thinks this arrangement has saved him many hundreds of dollars. The dairy is on a level with this floor. It is an arched room or cellar, eighty feet in length, extending into the bank of the river, under the driveway by which teams enter the third story above. The floor and roof, which is of stone, are cemented, and means are taken to secure good ventilation. At the end of the milk-room there is a large and convenient ice-house. The whole length of this floor, including ice-house, dairy, and stables, is two hundred and seventy-eight feet!

The basement, one hundred and sixty feet long and one hundred and forty feet wide, is used as a manure-cellar, and has an easy driveway to all parts of it. The arrangement for cleaning the stable is most complete. The trap-doors are placed on a slide, and by means of a lever at one end of the stable they can be all opened and shut at once, in a moment. All the straw for litter is cut, and this, too, greatly facilitates the cleaning of the stables.

The grain is threshed as it is drawn in from the field. The machine threshes ont the grain, separates it from the straw and chaff, and carries it, already cleaned for market or use, into the granary in the upper story ; it cuts the straw up fine for fodder or for litter, and conveys it up to the storeroom above. The grain or cut straw, by means of wellarranged tunnels, can be shot into any part of the feeding-rooms below. The root-cellar is in the eastern division of the second story, and there is an apparatus for sorting and cleaning the roots, by means of large riddles or wire sieves, as they are stored away. There are also machines for sawing lumber of all kinds, and one of Woodworth's largest and best planing and matching machines! The sawdust from these machines falls into a room below designed for its reception: it is used for litter. The manure is regularly dusted over with charcoal and sulphate of lime, in order to prevent the escape of ammonia. The advantage of cutting the straw for litter is most manifest in filling, hauling, and spreading the manure. It is all drawn out and spread upon the land in the winter. The conveniences of this method are quite sufficient to counterbalance any ordinary loss from leaching, evaporation, \&c. It is said that this barn has cost Mr. Leavitt some fifty thousand dollars!-New York Country Gentleman. 


\section{Ventilating Flour Barrel.}

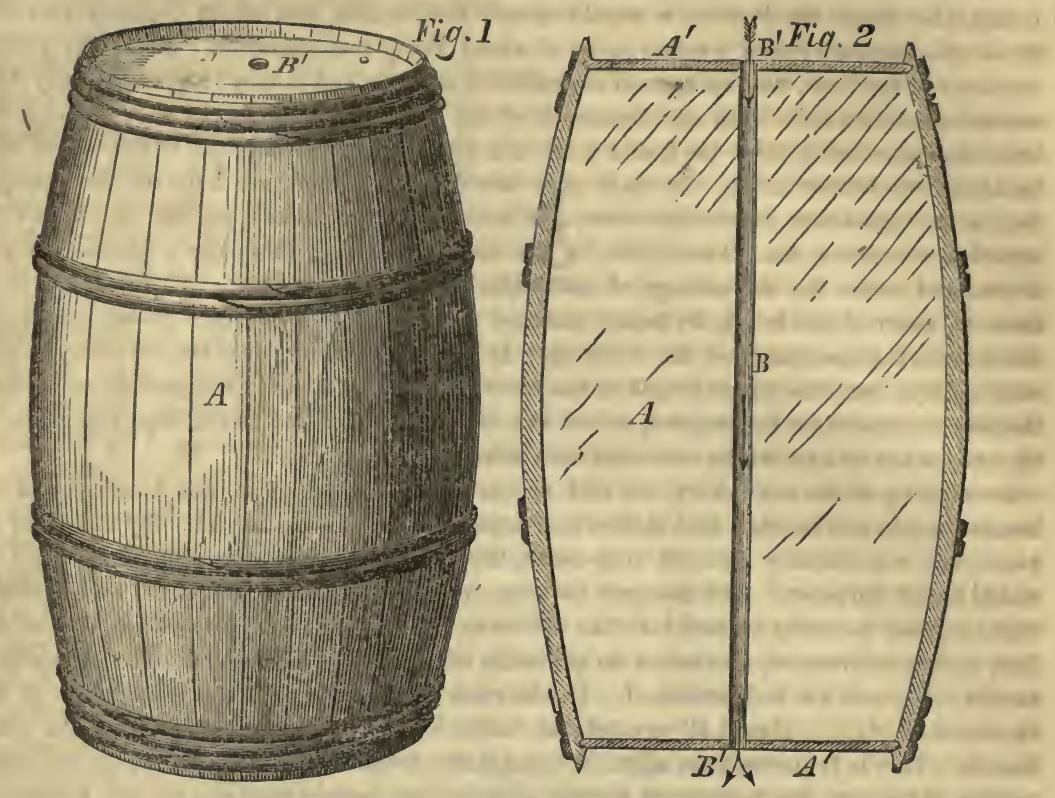

THE annexed engravings represent an improvement in flour barrels, recently patented by Thomas Pearsal, of Smithboro', New York. Fig. 2 represents a vertical section through the centre of the barrel, showing the ventilating tube.

It is well known that all commodities containing in themselves the constituents necessary to produce fermentation will, when closely packed in bulks of sufficient size to prevent the air from pentetrating them, sooner or later generate heat at the centre, which gradually diffuses itself through the mass; hence the enormous quantity of flour, meal, \&c. spoiled in transportation and storing. It is also well known that decomposition invariably commences at the centre of the bulk, owing to the increased pressure there, and to its being farther removed from the refrigerating influence of the atmosphere: it is a common occurrence on opening a barrel of flour to find it perfectly sweet and good at top, bottom, and around the outside of the bulk, while at the centre it will be both hot and sour. While this is common in bulks of the size of a flour barrel, it is rare in a half-barrel. On this theory the invention is based, and to remedy this evil there is inserted a tube or tubes longitudinally through the cask in which such commodity is to be packed, for the free circulation of air therethrough, so that the centre of the cask is no longer the centre of the mass; as in proportion as you increase the diameter of the pipe, you increase the number of centres in the bulk, thus mathematically dividing the mass into as many parts as required, which is equivalent to dividing the mass into as many smaller packages.

A represents a flour barrel with holes $B^{\prime}$ in each end in the centre of the heads $A^{\prime}$, to receive the tube $B$. In filling the cask, the head $A$ is taken out, and the tube $B$ inserted in the hole in the lower head of the cask; the desired quantity of flour or meal is then packed therein, and the upper head $A$ is put into the cask again, the tube $B$ protruding through the holes in each end of the cask, about half an inch, more or less, which is to be hammered down, forming a flange on the heads. Thus the air can circulate freely through the centre of the bulk, and its liability to heat is obviated, and at the same time the cask is materially strengthened. When larger casks are used, several tubes may be inserted in the same manner, if found necessary. These tubes may be made of iron, tin, wood, or any other suitable material-porous, perforated, or otherwise. 


\section{Machines for Dressing Flour.}

The following is an abstract of a paper recently read before the London Society of Arts, by Mr. T. Egan, on the above subject:-

"The mode of dressing meal after it is ground into flour is a subject that, no doubt, has engaged the attention of men in all ages, from the earliest dawn of civilization, when men first began to settle down from hunting and the chase, and to grow corn and cultivate land for human subsistence; but it must soon have occurred to them, even in a rude state, that the outer skin or bran made their cake dark in color, and was not nutritious or good for human food; so that they would soon try to devise means for separating this outer covering of the seed from the fine flour. Most probably the first invention for this purpose was the skins of sheep, or other animals, perforated with small holes, and fastened to a wooden frame. This frame being shaken, flour would pass through, while the bran would remain above. The second step, probably, was the invention of a sort of sieve, made with very thin slips of narrow wood, crossed upon, and worked down into each other, forming a kind of weft and warp, which was attached, as they best knew how, to hoops. To this sieve a semi-rotatory shaking was given, so that the fine part or flour was let through, while the larger particles were held in the sieve. This kind of siere is, to this day, used in many parts of Great Britain; but growing intelligence, however, has substituted wire sieves, which do the work both quicker and better. But, as population increased, and the wants of man became more numerous, the primitive mode of sifting by hand was too slow a process, and could not long supply the wants or gratify the tastes of the more enlightened people. Then it was that power was first applied to sifting meal and dressing it into flour, by means either of wind or water; and as soon as power became thus employed, the reel was introduced, very nearly as we have it at the present day. This reel consisted of a wooden hexagonal frame, some six or eight feet in length and two in breadth, with a wooden spindle or shaft through the centre; over and on the frame was drawn a kind of stocking or web material, sewn together in two or more parts, into which the meal was let from a hopper above. The shaft being connected with the mill, motion was communicated to the reel, and the meal was dressed into flour. The next thing to be considered is the kind of web or stocking put upon this reel. The most ancient kind was made of fine linen, probably in six pieces sewn together; and it is a curious fact, that in Austria, Prussia, Bavaria, England, America, and France, this ancient reel is the same in form and shape throughont, except that in some parts of France it is five or six times as long, and is driven much slower. The material used for the bolting-cloth was that which was most easily attainable in each country. In Germany and England, linen stretched and stitched with six seams was the first kind of cloth; and there is no question or doubt but in the process of time, and at a very early period, a mixture of linen and woollen cloth, called linsey, was used; but in France, where silk was easy to be obtained, they adopted it for bolting-cloth. It has been found, by experience, that a silk web cannot be driven at the same rate of speed as the German and English cloths; a fact which should be borne in mind by millers when they fancy they have discovered wonders in dressing with silk. The next improvement in order in the dressing of flour is the improvement of bolting-cloths, which was followed by the system of dressing flour through an iron wire-cloth. In this arrangement the reel was changed for circular wooden frames, three or four being used to each sheet or width of wire, as they were considered to afford support to the wire. Though the centre of the cylinder is a shaft, to which a series of brushes are attached, driven at the rate of 300 or 400 revolutions per minute, while the cylinder is stationary. This machine stands at an inclination of three or four inches to the foot. The meal is introduced at the upper end or head of the machine, and, in passing from one to the other, the flour is pushed through the wire by the revolution of the shaft, while the bran is retained in the cylinder until it reaches the lower end, where it falls into a hopper. This machine is apt to clog, and it becomes necessary for the miller to clear the outside of the wire cylinder from time to time with a hand brush. This mode of dressing obviously produces great pressure upon the wire, and the brushes force the finer particles of bran through the wire, along with the flour. Con- 
siderable breakage of wire takes place, but still the wire cylinders maintain the precedence over cloths, so far as regards the quantity of work performed.

"An improvement on this plan, known in England as the Yorkshire machine, resembles somewhat the foregoing, save that iron is used instead of wood for the ribs supporting the wire; and the cylinder, instead of being stationary, has a slow revolving motion given to it. A series of brushes revolves on the outside of the wire for the purpose of keeping it clean, thus doing away with the necessity of hand brushing. The interior brushes affixed to the shaft are capable of being adjusted by means of a screw, so as to stand at any recuired distance from the interior surface of the wire, whicb they are never allowed to come in contact with. The whole of these motions of the cylinder and the outside and inside brushes are obtained from gearing fixed at the head of the machine. These machines have been largely used, and are very efficient, but they are liable to continual breakage of the wire gauze, more particularly at the ribs which are used to support the wire, as in the machine before described. This machine is fixed at the same inclination as the one in which the cylinder was stationary. It is clear that the numerous ribs in all these machines form obstructions to the passage of the flour through the wire gauze. It occurred to Mr. Egan that if he could get rid of these ribs, the quantity of flour dressed per hour would be much increased, without in any way adding to the pressure on the wire; and that, at the same time, economy would result if, as was supposed, the breakage of the wire gauze was due to the ribs. In his machine, the only ribs used are those necessary to form the junctions between the sheets of wire; the distance between them thus being about eight or nine inches, instead of two and a half or three inches, as in the old machines. The inside brushes, instead of revolving with their surface parallel to the gauze, and being continuous throughout the length of the cylinder, as in the Yorkshire machine, are divided into separate portions, corresponding with each sheet of wire gauze, and are at an angle, so that one end of the brush is nearer to the cylinder than the other. The outside brush, instead of revolving, has a motion given to it similar to hand brushing. By these means the frequent breakage of the wire is obviated, besides dressing a larger quantity of flour per hour."

\section{Improvements in Flouring and Bolting.}

A Patent has been recently granted to Messrs. Stouffer, Brough, and Barr, of Chambersburg, Pennsylvania, for an important improvement in flouring and bolting.

The nature of the improvement consists in entirely separating the bran and the flouring particles previous to subjecting the stuffs to regrinding, by passing them through the superfine bolt, and then through a second one under it. The advantages of this improvement are set forth in the specification, as follows: "In the bolting process and apparatus an insignificant quantity of brown stuff is made, (which is only bran ground fine,) and avoiding entirely the production of middlings, at the same time increasing the production of superfine flour of uniform quality or brand; with good wheat, a barrel being produced from four bushels to four bushels and six pounds.

It is also stated in the specification, that all efforts heretofore made to produce a barrel of superfine flour from less than four bushels and twenty-five pounds of wheat, have failed to procure a regular run of quality, on account of the bran husk being reground with the farina, and imparting a red cast to the flour. The regrinding of all the offal, on account of gluten, has also a tendency to clog the bolts. The great quantity of bran also, in proportion to the flour, which is passed through the auxiliary mill, consumes a great deal of power.

A full description of this improvement, with a diagram, may be found in the Scientific American, vol. $\mathrm{x}$.

\section{Feeding Flour-Bolts.}

Samder Tagant, of Indianapolis, Indiana, has obtained a patent for an improvement in feeding flour-bolts, the essential feature of which consists in feeding the meal at all times uniformly to the bolts. The usual method of feeding the meal to bolts in making flour is by spouts having a drop-shoe under each. These drop-shoes receive a shaking motion by 
cams or wiper wheels, and the meal slides down their inclined bottoms, and is conducted to the bolts, often irregularly, by ordinary spouts. By the new plan, the "hopper-boy" which receives the meal for the bolts is fitted within an annular chamber, through which passes a vertical shaft, having arms upon it, with sweepers secured to their ends. Directly above the "hopper-boy," on the vertical shaft, an arm having oblique flights upon it is placed loosely, and is connected by cords to a rod passing horizontally through the central shaft. Spouts lead from the lower end of the annular chamber to the elevated ends of the bolts. The central vertical shaft passing through the centre of the "hopper-boy," rotates and gives motion to the flight-arm named, which also rotates and carries the meal towards the centre of the "hopper-boy," from whence it falls into the annular chamber and is cooled, while the sweepers take and force it into spouts, which convey it to the bolts, and thus feed it in more regularly than by the shaking of the shoes.

An improvement in dressing flour, patented during the past year, by Messrs. Nordyke and Hunt, Richmond, Indiana, consists in a peculiar device for expanding and contracting the rotating brushes, which act against the wire-cloth of the bolts and force the flour through. These brushes may be made to act against bolting-wires with a greater or less pressure, according to the will of the miller.

\section{Self-regulating Windmills.}

Mr. T. C. VICE, of Rochester, New York, has recently invented a self-regulating windmill, constructed as follows: The arms and frames are as usually constructed, but the canvas sails are fitted with rings at each end running loosely on an iron rod; also with rods and loops at suitable distances along its length, so that the sail is prevented from slatting, while at the same time it is at perfect liberty to be extended or contracted by suitable cords. The main shaft of the mill is hollow, and through it leads a light shaft, which carries on its end, and in front of the centre of the windmill, a bevel wheel. This wheel gears into power-wheels keyed on the end of light shafts, which extend the whole length of each arm, having bearings at proper intervals along its length. Revolving these shafts in one direction contracts the sail, by shortening a set of cords leading directly to the leech or edge of the sails, while revolving them in the other direction releases these cords and contracts another set, which are rove through sheaves or through staples on the opposite side, and serve to extend the sail. When all is right, the small shaft in the centre of the main driving-shaft is allowed to turn with it; but if the wind freshens and the mill moves too fast, the small shaft must be retarded, which will have the effect, by revolving the bevel wheels, to reef or contract the sails. As the weather moderates, and more sail becomes desirable, the surface may be extended by giving the regulating or central shaft a greater velocity.

This arrangenent is easily adapted to employment with a governor, so as to be literally self-adjusting; and in any event will, if successful in practice, save much of the disagreeable labor in attending windmills- that of reefing in cold and wet weather. A forty horse-power mill, or one the sails of which are each thirty-three feet long and six feet wide, would probably require considerable power to extend the sails thus simultaneously; but it may be recollected that this operation will usually be performed when the wind is light, the action in reefing being merely that of a brake to retard the wheel, and the action of the cords on the sails is in this case direct. Mr. Vice has provided means for making the mill itself supply the power for this purpose, and considers the whole susceptible of complete control by an ordinary governor.

An improvement in windmills has also been made by Daniel Halliday, of Ellington, Connecticut. This consists of the attachment of wings or sails to rotary movable spindles furnished with levers. These levers are also attached to a head which rotates with the sails upon the same shaft. Another lever is attached to the head; this is connected to a governor, which slides the head upon the shaft, so as to cause the levers to turn the wings or sails. The necessary resisting surface being thus presented to the wind, a uniformity of velocity is attained. The proper regulation of the obliquity of the sails, so as to adapt them to the varying motive force of the atmosphere, is represented by the inventor to be thus 
secured without difficulty, to a degree which renders his mill more constantly arailable than those hitherto employed. The mill built by him has five-feet wings; that is, the diameter of the wind-wheel is ten feet, and it has been in operation for six months, without a hand being touched to it to regulate the sails. It is so contrived that nothing but a squall of great severity falling upon it without a moment's warning can produce damage.

The mill mentioned has drawn water from a well twenty-eight feet deep, one hundred feet distant, and forced it into a small reservoir in the upper part of the barn, sufficient for all farm purposes, garden irrigation, and "lots to spare." The cost of such a mill will be $\$ 50$, and the pumps and pipes about $\$ 25$. It is elevited on a single oak post a foot square, the turn-circle being supported by iron braces. The wings are made of one longitudinal iron bar, through which run small rods; upon these rods, narrow boards half an inch thick are fitted, holes being bored through from edge to edge, and screwed together by nuts on the ends of the rods. This makes strong, light sails, but, as will be seen, are fixtures not to be furled or clewed up; but they are thrown up edge to the wind by a very ingenious and simple arrangement of the machinery, which obviates the great objection to windmills for farm use-the necessity of constant supervision of the sails to suit the strength of the wind.

A third plan for self-regulating windmills has also been invented during the past year by A. P. Brown, of Brattleborough, Vermont. It is somewhat on the plan of Halliday's, above described, and is regulated by a weight attached to a lever in such a manner that when at rest it keeps the sails flat, but as the breeze freshens, the wings open by the force of the wind and lift the weight, which falls back to its place when the wind lulls.

Wind is undoubtedly the cheapest power that a farmer can use; and, notwithstanding its inconstancy, if this improvement operates as well as it bids fair to in the mills already erected, it will be applied to many valuable uses.

\section{Horse-Shoeing Apparatus.}

A PATENT was recently granted to Noah Warlick, of Lafayette, Alabama, for the employment of a peculiar adjustable rest for the support of the horse's foot during the operation of shoeing. The arrangement consists in a standard, sustaining a support, hollowed out to . receive the horse's hoof. Attached to this support is an adjustable serrated slide, held by a screw, by which the slide may be maintained in any desired position; upon this, the horse's hoof rests during the operation of fitting the shoe, paring the hoof, and fastening the shoe to the hoof, the serrated edge of the slide preventing the slipping of the hoof from the headpiece. The use of this support is of importance to the operator, as, instead of holding the horse's hoof between his knees and supporting its entire weight, he is enabled to devote all his attention to the adjustment of the shoe and the keeping of the horse quiet.

\section{Improvements in the Construction of Horse-Shoes.}

Horse-Shoes without Nails.-Mr. Sewall Short, of New London, Conn., has recently introduced, with success, a new style of horse-shoe, invented by him, the object of which is to avoid the necessity of driving nails in the hoofs of the animal; a practice always more or less objectionable, and only submitted to from imperious necessity, and which frequently, from misplacing a nail, or splitting a hoof, renders a horse useless, at least for a time. Mr. Short is not the first who has attempted to clamp the shoe to the foot without nails, but is the first to do it in this simple and effective manner. He makes the whole in two pieces, employing, in addition, two small screws to aid in screwing the parts together. Both are made of malleable iron; the lower portion, or "sole," being very similar to the horse-shoe ordinarily employed, but with a groove around its exterior, and without nail-holes. The upper portion, or "vamp," is thin, and has a flange projecting inward from its lower edge to match the groove in the sole. These parts are so arranged as to secure a tight and firm connection; and the whole is made additionally secure by the aid of the set-screws before mentioned at the heel. A shoe of this kind once fitted, the vamp may be made to wear out a great number of soles. The exterior may be highly finished and plated with silver, which gives a very 
flashy appearance to a team of lively horses, or the shoes may be enamelled jet-black when intended for white or gray animals. One practical advantage to be derived from this style of shoes is the facility with which they may be removed or exchanged, so that a skilful hostler may exchange the shoes, or rather the soles, on every occasion when the presence of ice or the like renders it desirable, and it may even be expedient, in extreme cases of exhaustion, as with race-horses, to remove the shoes altogether for a time, and allow of a more refreshing rest.

Elastic Horse-Shoes.-Mr. J. O. Jones, of Boston, Mass., has invented and patented a new style of horse-shoe. It is not any way peculiar in its external appearance, but has a piece of India-rubber inserted between the two surfaces of steel or Swedish iron (the latter preferred on parements) from either side of the heel most of the way to the toe. These gire the shoe an elasticity elsewhere unknown; diminish the force and abruptness of each concussion when the shoe strikes on rock or other solid; induce the animal to put his foot down firmly and fearlessly; prevents bruises and consequent tenderness, resulting in lameness; and sometimes cures diseases of the foot already contracted. The rubber is never displaced, and the shoe is durable of itself, besides making the horse so.

Towers' Improved Horse-Shoe.-An invention has been patented, during the past year, by W. H. Towers, of Philadelphia, for an improved method of fastening horse-shoes. The invention consists in the construction of inclined flanges, or lips, rising from the front sides of the shoe corresponding in form with the parts of the hoof against which they are made to bear when fitted. One of the side-flanges is made separate, and fastened by sliding into a recess in the side of the shoe, and secured by means of a screw, thus entirely dispensing with the use of nails, and avoiding any liability to injury by pricking.

\section{Irresistible Bit for Refractory Horses.}

Mrssrs. Trues \& Fexwick, of Brooklyn, N. Y., have recently patented a contrivance for governing refractory horses, which seems to be a great and very desirable improvement in certain hard cases, while it will not be an expensive or cumbrous addition to an ordinary harness for general purposes. Stopping the breath has been sufficiently proved by experiment to be a sure and very rapid means of arresting the progress of an animal; but, instead of tightening a cord around the neck, as inveuted by somebody a few years ago, these gentlemen simply cover the nostrils with pads of leather. The bit itself is a little longer than usual, and carries at each side a slender metallic lever with a pad. Suitable coiled springs hold these levers away from the nose, in which position they are of no particular service, being, both for convenience and ornament, about on a par with the rings in the noses of pigs or in the ears of boarding-school misses. There are two methods proposed for operating these levers and pressing the pads upon the nostrils: one by employing a separate rein-the other, by attaching the ordinary reins to the lever in such manner that they will move them when pulled with great violence. The first method is undoubtedly the surest and least liable to derangement, in consequence of the weakening of the springs or the like; but the second is less troublesome to the driver, and will, we presume, be generally preferred. When arranged according to the second method, the springs must be sufficiently stiff to allow of the reins being held at the usual tension without affecting them, and the horse is guided without recognising their existence; but the moment the animal commences to be unmanageable, the pull is increased, and his breath and speed instantly stopped.

\section{Duplex Safety Rein.}

Turs invention, by Mr. W. A. Holwell, of Quebec, is designed to afford security against the running away of horses when under saddle or in harness. It is a very simple contrivance, and in this lies its merit. There have been a good many methods for controlling horses, or escaping from the dangers of runaway animals, such as the slipping off of the harness by a slide rein, and the disconnection of the traces by other means; in both cases the design being to let the horse out of and free from the vehicle, to go whither he will, while the carriage 
stops. But all the modes named are liable to the objections of eomplexity or uneertainty.

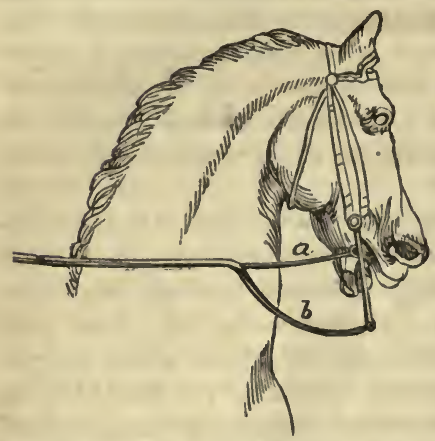
The mode adopted by Mr. Holwell is to furnish the bridle with a good curbing bit, the driving rein being attached at the lower part of the bit, as is seen at $b$ in the annexed figure; $a$ is a short piece of elastic material connected with the driving rein and the central eye of the bit. When the horse is passive, this elastie eonneetion is suffieient to drive him in the usual manner, and the porcion of the rein $b$ remains slack, so that the curb is not applied. But when the horse is spirited, or beeomes frightened, or attempts to run, all that is necessary is to pull tightly on the rein, as people always do in sueh cases, when the elastie pieee $a$ stretches and brings up $b$; so that the curb operates effeetually in the horse's mouth and brings him to a stand-still at once, provided that the bit is properly made.

\section{On the Uselessness of the Bearing Rein.}

Frox an article in a recent number of the Mark Lane Express, (England,) we make the following extracts relative to the uselessness of the bearing rein, as applied to horses. It says:-

On the Continent, the bearing rein is rarely used, and then only as a servile English imitation; but in horse-raeing, hunting, horse-loving England, it must be confessed, its use is all but universal. The folly of the praetice was, some years ago, very ably shown by Sir Franeis Head, in his Bubbles by an Old Man, where he eontrasted most unfavorably our English eustom of tying tightly up, with the German one of tying loosely down, and both with the French one of leaving the horse's head at liberty, (and a man of his shrewdness and observation, a distinguished soldier, who has galloped aeross the South American pampas, and saw there herds of untamed horses in all their native wildness and natural freedom, is no mean authority.) Now, he has pointed out most clearly that, when a horse 'has real work to do, whether slow work, as in our plows and carts, or quiek, as in a fast gallop, or in headlong flight aeross the plains of Ameriea, Nature tells him not to throw his head up and backwards towards his tail, but forwards and downwards, so as to throw his weight into what he is called upon to do. This is a faet within every one's observation. We have only to persuade the first wagoner we see (he is sure to have all his horses tightly borne up) to undo his bearing reins, when down will go every horse's head, so as to relieve the wearisome strain upon his museles, and gire the weight of his body its due natural power of overcoming resistanee; and thus each horse beeomes enabled to $\mathrm{d} g$ his work as comfortably and easily as nature intended he should do; for Nature never intended a heavy animal like a cart-horse to perform slow work only or ehiefly by strain of musele, but, on the contrary, by the power of weight as the rule, assisted by strength of musele as the exception, when extra resistance has to be overcome.

Thus, when we curb up a horse's head with our senseless bearing reins, and make him as ewe-neeked as we appear to do, we are inverting the rule and order of nature; we are evidently trying to prevent his using the full, unrestrained power of his weight, and are compelling him to overstrain and over-exert constantly those very muscles which should be kept in reserve for extra diffieulties-such as greater inequalities of the road, new-laid stones, \&e. It is a mistake to think it improves a horse's appearance; nothing contrary to nature can ever really do this. It is a mistake to think it ean ever prevent a horse's falling down, though it has been the means of preventing many an old one recovering from a stumble. But until our horse-owners be taught to look at this matter in its true light-the light of common sense-it is in vain to hope for any mitigation of this but too-universal cruelty. 


\section{Improved Harness Buckle.}

Mucr peril as well as painful annoyance has resulted from the old-fashioned harness buckles, by reason of their liability to break or draw out during accidents, which their own defects not unfrequently cause, and also from the difficulty of release to falling horses, occasioned by the tightening force of the animal's weight. C. and L. B. Oyster, of Chambersburg, Pennsylvania, have jointly claimed an improvement in buckles, which will completely revolutionize the principle of their action, if found applicable as designed by the inventors. It is proposed to dispense entirely with the tongue-holes in traces and other straps, and to rivet the tongue to the leather instead of the buckle. The bar of the buckle is furnished with a number of rachet-shaped teeth or stops, and corresponding cavities are cut in the tongue, but having reversed catches. The desired length of the trace is adjusted by bringing these teeth together at a given point, and securing them with a set screw. The screw puts the unhitching of the horse under the instantaneous control of the driver in cases of falls or other perilous entanglements.-Scientific American.

\section{Horse Muzzles.}

Tuz attention of Mr. Clowes, of England, has been directed to the removal of an unpleasant habit which some horses have of biting or sucking their crib or manger. This he professes to effect by means of a muzzle, which is represented in elevation in fig. 1 of our engravings, and in vertical section in fig. 2.

Fig. 1.

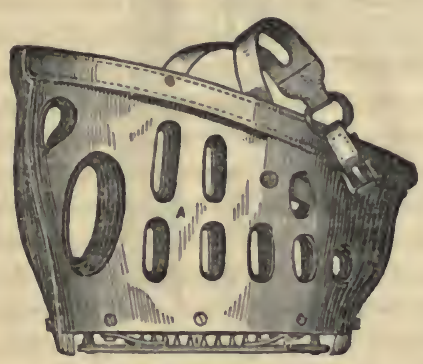

Fig. 2.

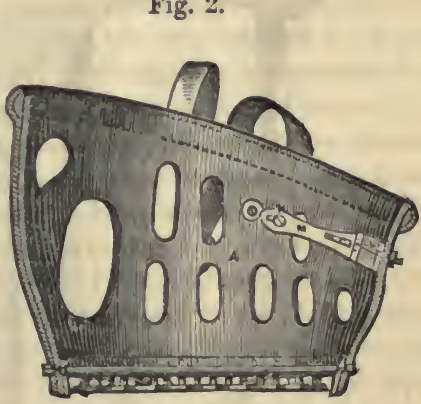

The body of the muzzle $A$ is composed of leather, or any other suitable material, and is formed with apertures in it, in order not to impede respiration. A light metal frame $B$ is fitted into the lower portion of the muzzle, and across this frame is fixed longitudinally the perforated bar C. Immediately beneath this fixed bar is placed a second bar $\mathrm{D}$, which is movable in a vertical direction, and is fitted with a number of prickers or sharp points $\mathbf{E}$. This movable bar is connected to the fixed bar by the two screws $F$, which allow of a slight vertical play between the two bars. Two blade springs $G$, secured to the under side of the fixed bar, are for the purpose of pushing down the bar $\mathrm{D}$, and shielding the prickers in the perforations of the fixed bar, when the movable bar is not acted upon by pressure from below. Two small projections $H$, formed on the frame $B$, and projecting beyond the bar $D$, serve to prevent this bar from being acted upon when the horse is eating off a flat or hollow surface of a greater width than the distance between the projections. But if the animal attempts to bite or suck his crib, or presses his mouth downwards upon any hard thing which is not wider than the distances between the projections $H$, the prickers will baforced upwards through the perforations in the bar $\mathrm{C}$, and as these pricking points will thereby be brought into contact with the animal's mouth, the objectionable habit will be effectually checked. The muzzle being open at the bottom, will not prevent the animal from feeding; but when it is desirable to stop him from feeding, a perforated plate may be inserted into the frame of the muzzle, being fastened therein temporarily by a fixed pin on one side and a small bolt on the other, so 
that it can be removed with the greatest facility. Another set of prickers are fitted into the back of the muzzle, and act upon the under jaw of the animal when attempting to suck his crib. The sharp points are fitted to the fixed curved bar $\mathrm{L}$, which is secured to the inside of the muzzle, and they are shielded or protected by the slotted or perforated bar M, which is connected to the bar L by screws at N, working in slots in the bar M, thus allowing it to be pressed downwards by the under jaw of the horse when sucking its crib, and thereby causing the prickers to protrude.

\section{Improvement in Ox-Yokes.}

THE annexed figures are representations of an improvement in ox-yokes, invented by Heman B. Hammon, of Bristolville, Ohio. The peculiarities of the invention consist in placing a ferrule or plate having branched slots upon the end of the ox-bow, and in fastening to the top of the yoke a movable washer having a projection caused to fit into the branched slots of the ferrule attached to the bow; by means of this combination the bow may be elevated or depressed as desired, and fastened in any position. The construction of the several parts will be understood by reference to the accompanying figures: $a$ (fig. 1$)$ represents onehalf of the yoke, with the bow-plate or ferrule and washer attached: $e g(f i g .2)$ and $c(f i g .3)$

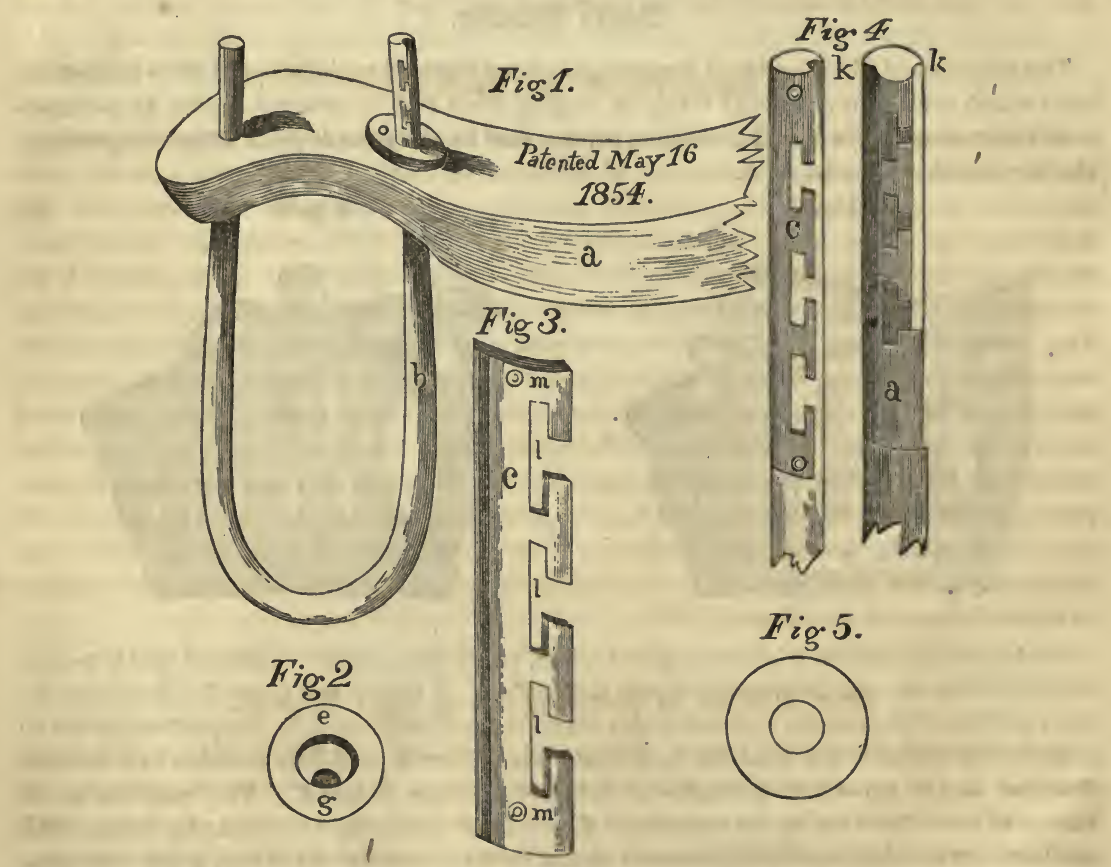

are prospective views of the washer and bow-plate, or notched ferrule. $a(f i g .4)$ is a section of the bow, showing the part cut away to receive the notched ferrule or plate, $c,(f i g .3$, ) in which $l l l$ are branched slots to receive and hold the projection on the washer e $g$. The plate $c(f i g .3)$ is fastened to the bow with two serews $m m$, and a groove $k k(f i g .4)$ is cut down in the side of the bow, close by the notched edge of the ferrule, which allows the projection of the washer to pass down and enter in either of the branched slots $l l l$. When the bow in the yoke hangs in a natural position, the washer is at the upper end of the branched slot, but if the bow should crowd up through the yoke-beam, the washer will fall down to the bottom of the slot, and is thus prevented from becoming disconnected with the bow. To release the bow from the yoke, it is only necessary to raise the bow up through the yoke, far enough to allow the washer to pass out of the upper end of the slot in the ferrule; then turn it into the groove $k$ in the bow, and raise it off. The opening in the washer eg is 
oblong, which allows it to adjust itself to the joke, whether the surface is straight or hollowed as in the old-fashioned kind.

Vose's Improved $0 x$-Yokes.-In these yokes, introduced and improved by Deering and Dickson of Albany, the neck blocks are separate from the beam, and attached to it by strong bolts passing from an iron thimble or socket in the block up through the centre of the beam. The advantages claimed for this improvement are as follows: First. By the neck block accommodating itself to whatever movement of the $0 x$, it is inipossible for his shoulders ever to become sore or broken. Second. It does away with the evil arising from one ox stepping in advance of the other, as by the moving of the blocks the weight must under all possible circumstances fall equally on both oxen, except (which is the third advantage) when desiring to favor one, you may move him one or more holes farther from the centre than his fellow. Fourth. By moving the neck blocks into either of the five holes, it can be changed at pleasure into a yoke of any width required for ploughing, carting, sleighing, or hauling, which advantage of itself makes its value equal to two or three of the common yokes. Fifth. Bows in this yoke will last much longer than in any other, because the tugging or jerking of the ox does not fall on the bow, but directly on the centre bolt. The bows are secured by keys passing through the bows and neck blocks, there being in each block two or more holes, so that the bow can be raised or lowered at pleasure.

\section{Improved Horse Neck-Yoke.}

A PATEXT for an improved horse neck-yoke was recently granted to John R. Pierce, of Castile, New York. The object of the invention is to furnish points for the attachment of the brenst straps, which shall be movable longitudinally on the yoke, to accommodate the side movement of one or both horses, the attachment being so connected that the movement of one will produce a similar movement of equal extent in the other, thereby causing the attachments to continue at all times at equal distances on each side of the carriage pole. The invention consists in forming the yoke with a cavity sufficiently large to contain the movable parts-namely, two racks and a pinion upon the main bolt, the racks carrying the attaching bolts. The attaching rings are fastened by eyes to the racks, which racks mesh into the opposite sides of the pinion. The horses being attached to the yoke in the usual manner, and driven forward, any movement of one of the attaching rings revolves the pinion, causing the rack carrying the other ring to move longitudinally the same distance in the opposite direction; thus enabling the horses to move either from or towards each other without deranging the position of the pole, the attaching rings being by this arrangement always at equal distances from the main bolt.

\section{New Method of Securing Tires upon Wheels.}

Tris invention, by John L. Irwin, of Franklin, Alabama, is designed to save time, labor, and fuel in the setting of tires, also to prevent accident in case of the loosening of the tire. All are familiar with the common mode of tire-setting, viz. by making the hoop a trifle smaller than the wheel, and then expanding the iron by heat until it will slip on; the subsequent cooling of the tire causes it to contract to its original dimensions, and consequently to bind tightly upon the wheel. Mr. Irwin dispenses with this process; instead of welding the ends of the tire together, he hooks them over, and connects them with a screw bolt; a recess is cut in the felloe for the bolt and hooked ends of the tire, which enables the operator to screw up the tire tightly after it has been applied to the wheel. If the tire becomes at any time a little loose, all he has to do is to apply a wrench to the bolt and tighten up. Under the old plan, the diameter of the tire would have to be reduced and reset.

\section{Goodman's Improved Axle-Box.}

Tris box resembles, in external appearance, that ordinarily employed for thispurpose, but the friction of the journal is received on vegetable rather than metallic substances. Mr. Goodman 
casts a box of iron provided with a number of ribs on its interior, between and upon which hemp, cotton-waste, leather, shavings, or other fibrous materials, previously well saturated with tallow and sulphur, are tightly driven with a caulking-iron. In short, while the use of hemp has been discontinued as packing for pistons in steam-cylinders, and its place supplied by metallic rings, Mr. Goodman has discovered that in other situations, where friction alone is to be encountered, without the existence of a high temperature, the reverse may obtain, and hemp may be substituted to advantage in place of metallic surfaces. Boxes of this character in use upon the New York and Erie Railroad have required oiling but twice in two months. There is a cavity on the top of the box of sufficient size to contain about threefourths of a pint of oil or tallow, protected from dirt by a suitable hinged cover, while the bottom of the box is filled with well-oiled waste, in the usual manner. The use of leathers at the ends of the bearings is entirely dispensed with, and thin slabs of cast iron are substituted, these slabs being made adjustable, to compensate for wear. The weight of the box, complete, is about sixty-three pounds, that of the ordinary box being usually about sixty; and the expense of fitting up being very nearly equal, it results that the hemp-packed box is cheaper than the ordinary brass-lined one, by nearly the whole cost of the brasses. The brass used in each box generally weighs about seven pounds, and is worth something like two dollars, \$hile the hemp to supply its place costs only about fourteen cents.

\section{Improvement in the Construction of Hogpens.}

THE accompanying figures represent in perspective and in section, an improvement in the construction and arrangement of hogpens, recently invented and patented by R. M. Abbe; of Thompsonville, Connecticut:-

The improvement relates to the construction of the trough guards. A pen is first built of the requisite size for a certain number of hogs, and on the front part of it the improvement is placed. The arrangements will be clearly understood by reference to the engravings.

Fig. 1.

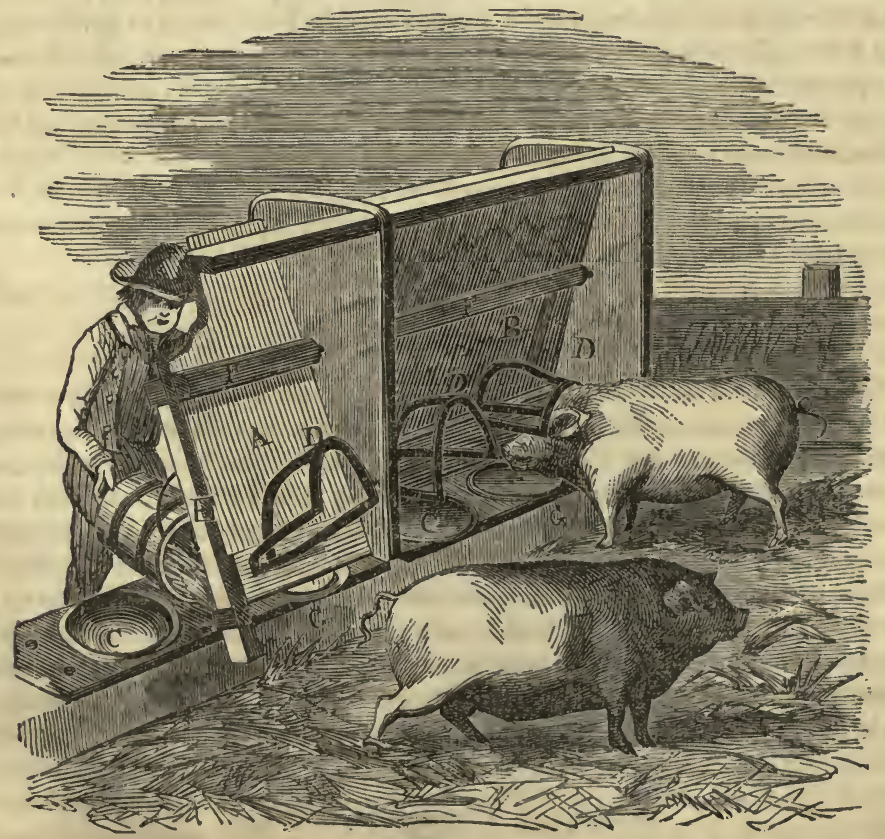

A B are swinging fronts intended to swing inwards on F F when cleaning out the troughs or feeding, (as shown with front $\mathrm{A}$ at $\mathrm{E}$,) and thus prevent the hogs interfering with any of 
these two operations. When the feed is placed in the trough, the swinging front is brought into place and made fast by a bar or button, (as shown by $\mathrm{B}$,) thus allowing the hogs free access to the troughs $\mathrm{C} C$. These troughs are made of cast iron-oral-formed basins-and firmly secured in a frame G. D D D are iron guards, one for each trough; these prevent the hogs from interfering with one another while feeding. They are fixed on the swinging-frame inside the pen, and being secured with screw-bolts, they can be raised or lowered to suit the size of the hogs. They are placed so as to allow each hog to pass his head in, but not his feet, and feed freely. The latter is a bad habit with hogs in common pens, by which they waste and foul their food.
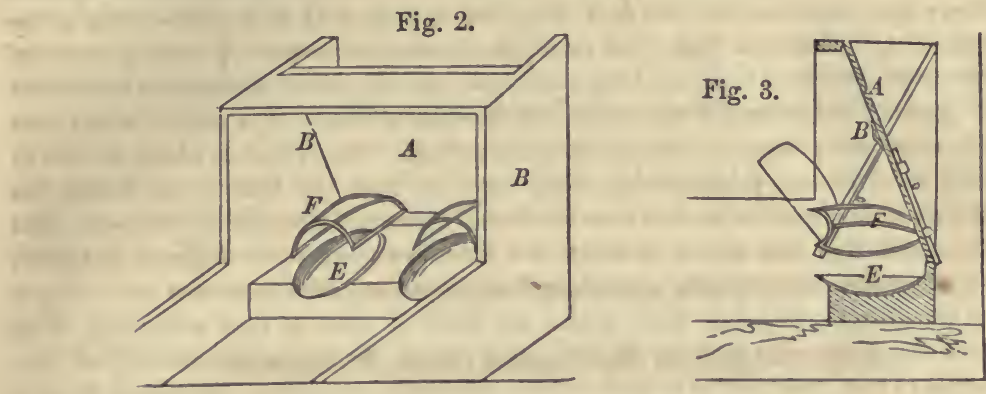

By this method of constructing hogpens, the troughs can be easily cleaned out, and thus kept in proper condition. The health and growth of hogs are both greatly promoted by keeping their troughs clean, for it is certainly injurious to them if fresh food is mixed with any surplus that has been left from a previous meal and suffered to ferment and become offensire. This method of constructing hogpens also saves food by preventing waste, as the hog by this arrangement cannot get his feet into or root out his food from the trough. The proprietor states that he guarantees a saving of thirty-seven per cent. in fattening hogs by the use of this pen. Another useful point is, that the front of the pen swinging on the bar F F may be used as a door for ingress or egress, thus doing away with the custom of tearing a pen to pieces whenever the occupants have to be removed. The person also in feeding does not come in contact with the filth that naturally accumulates in the pen, and the trough can be filled or emptied without getting into or reaching over the side of the pen.

\section{Hog-Killing in Cincinnati.}

THE following account of the process of killing and dressing hogs in one of the largest establishments of Cincinnati is taken from an Ohio paper:-

The building and its appurtenances are calculated for despatching two thousand hogs per day. The process is as follows: "The hogs, being confined in pens adjacent, are driven, about twenty at a time, up an inclined bridge or passage, opening, by a doorway at top, into a square room, just large enough to hold them; and as soon as the outside door is closed, a man enters from an inside door, and, with a hammer, of about two pounds weight and three feet length of handle, by a single blow, aimed between the eyes, knocks each hog down, so that scarce a squeal or grunt is uttered. In the mean time, a second apartment adjoining this is being filled; so the process continues. Next, a couple of men seize the stunned ones by the legs, and drag them through the inside doorway on to the bleeding platform, where each receives a thrust of a keen blade in the throat, and a torrent of blood runs through the lattice floor. After bleeding for a minute or two, they are slid off this platform directly into the scaldingvat, which is about twenty feet long, six wide, and three deep, kept full of water heated by steam, and 80 arranged that the temperature is easily regulated. The hogs being slid into one end of this vat, are pushed slowly along by men standing on each side with short poles, turning them over, so as to secure uniform scalding, and moving them onward, so that each one will reach the opposite end of the vat in about two minutes from the time it entered. About ten hogs are usually passing through the scalding process at one time. At the exit 
end of the vat is a contrivance for lifting them out of the scalding water, two at a time, unless quite large, by the power of one man operating a lever, which elevates them to the scrapingtable. This table is about fire feet wide and twenty-five long, and has eight or nine men arranged on each side, and usually has as many hogs on it at a time, each pair of men performing a separate part of the work of removing the bristles and hair. Thus, the first pair of men remove the bristles, only such as are worth saving for brush-makers, taking only a double-handful from the back of each hog, which are deposited in a barrel or box. ${ }_{\text {L }}$ The hog is then given a single turn onward to the next pair, who, with scrapers, remove the hair from one side, then turn it over to the next pair, who scrape the other side; the next scrape the head and legs; the next shave one side with sharp knives; the next do the same to the other side; and the next, the head and legs; and each pair of men have to perform their part of the work in only twelve seconds of time, or at the rate of five hogs in a minute for three or four hours at a time! Arrived at the end of this table with the hair all removed, a pair of men put in the gambril stick and swing the carcass off on the wheel. This wheel is about ten feet in diameter, and revolves on a perpendicular shaft reaching from the floor to the ceiling, the height of the wheel being about six feet from the floor. Around its periphery are placed eight large hooks, about four feet apart, on which the hogs are hung to be dressed; and here, again, we find remarkable despatch secured by the division of labor. As soon as the hog is swung from the table on to one of these hooks, the wheel is given a turn one-eighth of its circuit, which brings the next hook to the table, and carries the hog a distance of four feet, where a couple of men stand ready to dash on it a bucket of clean water, and scrape it down with knives, to remove the loose hair and dirt that may have come from the table. The next move of the wheel carries it four feet farther, where another man cuts open the hog almost in a single second of time, and removes the large intestines, or such as have no fat on them worth saving, and throws them out at an open doorway by his side; another move of four feet carries it to the next man, who lifts out the remainder of the intestines, the heart, liver, etc., and throws them on to a large table behind him, where four or five men are engaged in separating the fat and other parts of value; another move, and a man dashes a bucket of clean water inside, and washes off any filth or blood that may be seen. This completes the cleaning or dressing process; and each man at the wheel has to perform his part of the work in twelve seconds of time, as there are only five hogs at once hanging on the wheel, and this number are removed and as many added every minute. The number of men employed, besides drivers outside, is fifty; so that each man may be said to kill and dress one hog every ten minutes of working-time, or forty in a day. This presents a striking contrast with the manner that farmers commonly do their 'hog-killing.' At the last move of the wheel, a stout fellow shoulders the carcass, while another removes the gambril-stick, and backs it off to the other part of the house, where they are hung up for twenty-four hours to cool on hooks, placed in rows on each side of the beams just over a man's head. Here are space and hooks sufficient for $2000 \mathrm{hogs}$, or a full day's work at killing. The next day, or when cool, they are taken by teams to the packing-house, where the weighing, cutting, sorting, and packing, are all accomplished in the same rapid and systematic manner."

\section{The Milker's Protector.}

Mr. JoIIn M. WARE, of Seabrook, New Hampshire, has recently obtained a patent for holding cow's tails still during the operation of milking. The machine is fastened to one of the animal's ham-strings, and the tail is compressed. Mr. Ware styles his discovery the Milker's Protector. His claim is as follows: "I claim the Milker's Protector, constructed as specifiedviz. a combination of ham-strings and tail nippers applied together, and made to operate as described."

\section{Self-loading Cart.}

THE construction of a new self-loading cart, recently patented by S. W. Soule, of Oswego, New York, is as follows: In outward appearance this cart resembles the ordinary dirt-cart. An opening, however, is made in the middle of the cart body, through which a narrow frame 
or wheel somewhat like a steamboat paddle-wheel revolres. The ends of the spokes are furnished with scoops or shovels, and the wheel receires motion by a connection with the axle of the cart wheels. When the cart moves along, the scoops dig into the ground underneath the eart, and bring up the dirt, depositing the same into the body of the vehicle with great rapidity. As soon as the cart is loaded, the driver pulls a lever, which throws, the mechanism out of gear, and brings the scoopers away from the ground.

\section{Moss's Calve Suckler.}

THrs is merely a tin vessel, holding perhaps five or six quarts of milk, at the bottom of which is attached an exact counterpart of a cow's bag and teat of India-rubber. This teat has within it a valve, through which the fluid within is drawn out by a slight pressure similar to that of the calf's jaws, or of the hand in milking. All that is necessary in raising a calf is merely to hang the vessel on a hook in the stable or barnyard, fill it with the milk or hay-tea, etc., and let the calf go to it at pleasure. It will soon become accustomed to it, thus saring all trouble. The manner also of feeding by suction is more natural to the calf than drinking, and is more beneficial.

\section{Machine for Shearing Sheep.}

Trn accompanying figure is a top view of $\Omega$ machine for shearing sheep, for which a patent was recently granted to Palmer Lancaster, of Burr Oak, Michigan.

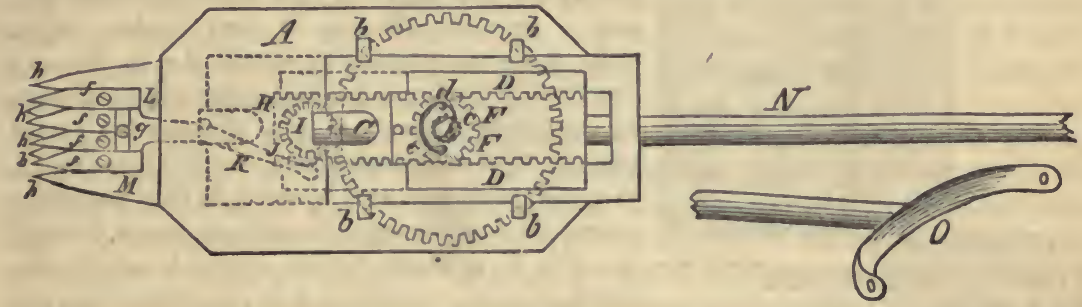

A A represent a top and bottom metallic plate secured a short distance apart by bolts or rods; (the bottom plate is hid.) These plates may be of rectangular or other proper form. On the upper surface of the upper plate $A$ there is a sliding frame, which works between suitable guides $b$. The sliding frame is provided with an upright handle C. At each side of this frame there is attached racks D D, one being somewhat higher or projecting farther up from the frame than the other. E represents a vertical shaft which works between the two plates A; the upper end of this shaft extends a short distance above the upper plate, and has two pinions F F placed loosely upon it, one pinion being directly over the other. There are also on the shaft $\mathbf{E}$ two ratehets $c$ e permanently attached to the shaft, the one being above the pinion $\mathrm{F}$, and the other below the other pinion $\mathrm{F}$. To each of the pinions $\mathrm{F}$ there is secured a pawl $d$, the ends of which are kept against the teeth of the ratchets by springs. The upper rack $\mathrm{D}$ gears into the upper pinion $\mathrm{F}$, and the rack $\mathrm{D}$ on the opposite side of the frame gears into the lower pinion $F$. On the shaft $E$, and between the two plates $A$, there is attached a spur wheel which gears into a pinion $\mathrm{I}$ having a crank pulley I above it on the same axis. To the crank pulley there is attached a connecting rod J, the outer end of which is secured to an arm $\mathbf{R}$ of a series of cutters $f$, which work on a pirot $g$, the cutters being of saw-teeth form, and attached to a common plate $\mathrm{L}$, through which the pivot $g$ passes. The cutters $f$ are directly over a series of stationary cutters $h$, which are formed at the end of a plate MI attached to the front end of the lower plate $A$. The cutters $h$ are of the same form as the cutters $f$, but are inclined a little upward. The cutters $f$ are very slightly inclined. To the back end of the lower plate $A$ there is attached a handle $\mathrm{N}$, having a bow $\mathrm{O}$ at its end. The bow 0 is placed under the shoulder of the operator, and may, if necessary, be secured thereto by straps. The implement is placed upon the body of the sheep, and the handle $\mathrm{C}$ is grasped by the right hand and moved back and forth, and a continuous rotary motion is given the 
spur wheel, in consequence of the pinions F F only being connected to the shaft $\mathrm{E}$ when turned in one direction-viz. from left to right. This is effected by the pawls $d d$. As the spur wheel gears into the pinion $H$, a vibratory motion is given the cutters $f$ by means of the connecting rod $\mathrm{K}$, and the cutters $f$ work over the cutters $h$, similar to the blades of shears, and will cut the wool from the animal in a perfect and expeditious manner; the implement, of course, as it cuts, being moved over the body of the animal.

The advantage of this invention, besides the rapidity with which it operates, is, that the implement will not mince or cut the wool twice, nor cut the animal, as is often done with the ordinary sheap-shears.—Scientific American.

\section{Drone-trap for Beehives.}

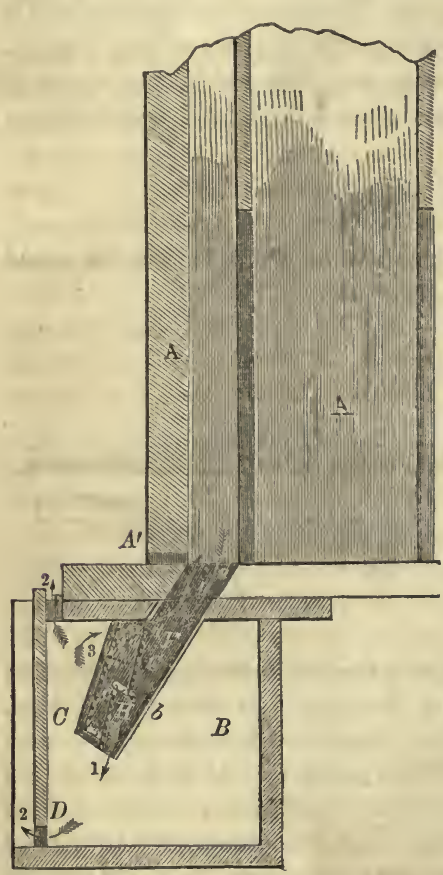

THE accompanying figure is a vertical section of an improved drone-trap for beehives, recently invented by Clark Wheeler, of Little Valley, New York.

A represents part of a beehive; $A^{\prime}$ is an ingress and egress passage of the working bees. $B$ is the drone trap-box; $\mathrm{C}$ is a sliding glass front for admitting light to decoy the drones into the box, \&c. $\mathrm{F}$ is the drone passage communicating with passage $a$ of the hive, and is set inclined; it consists of a tube having a reticulated front $b$ for admitting light, \&c., and is provided with one or more pendant valves $\mathrm{G} \mathrm{H}$; these valves swing on centres $d e$, as they are operated by the drones passing under them. As soon as the drones attempt to pass through the egress passage $A^{\prime}$ of the working bees, and find it too small, they will, being attracted by the light from the transparent front of the trap-box, seek an escape, through the tube $F$, as shown by the arrows 1 , causing the valves to swing outward as they pass, after which the valves assume their common position, and prevent their return to the hive. Working bees going into the trap pass out, as indicated by the arrows 23 , through the several passages E D $c$ provided for their escape, which passages are not large enough for the drones, their bodies being nearly twice as large as those of working bees. The movable glass front is taken out, when desired, to remove the dead or entrapped drones.

In parent or stock beehives, large numbers of drones are seen between the months of May and August, several thousands often existing in a single hive, consuming the surplus honey, and frequently depriving the working bees of their requisite food for winter. Few drones go off with young swarms, the greater number remain with the parent stock; hence it is both profitable and prudent to entrap a large portion of them from the stock hive or hives. The drone bees doing no labor, they should be always limited to the lowest number necessary. This simple and efficient drone-trap, for removing a superabundance of drones, can be applied to any hive in use.

\section{Fruit Preservatory.}

A Patent has been recently taken by Mr. William D. Parker, of New York City, for an improved fruit ice-house, which is reported to possess superior advantages. The object of this invention is principally the perfect preservation of fruit in all seasons, by keeping it at a low and equal temperature, free from moisture and injurious gases.

The house may be of any proper form. The sides of it are double, with a space of suitable width between them. The roof is also formed of two thicknesses. The spaces are 
filled or well packed with sawdust or other non-conducting substances. A short distance above the bottom of the icehouse there is a slatted floor. The slats rest upon proper supports, and the space between the slats and the bottom forms an ice-chamber. Just below the upper ends of the sides there is secured a double inclined flooring, the highest point of which is at the centre of the house, and inclining downwards towards each side; and directly underneath this flooring there is placed a wire-screen, a space being allowed between the screen and flooring. This space is filled with charcoal or other proper absorbent. Holes or traps are made through this flooring, which are provided with doors; and at one end of the house, at the upper part, above the inclined flooring, is the main entrance. The sides of the house are kept firm, or prevented from spreading under the thrust or pressare of the roof, by means of rods.

The space or ice-chamber between the slatted floor and the bottom of the icehouse is filled with ice, and ice is also placed on the inclined flooring.

The articles to be preserved or stored are lowered from the upper or inclined floor down into the lower chamber, and allowed to rest upon the slatted floor. By not allowing the vuter door of the house and the trap-doors of the inclined floor to be open at the same time, the lower chnmber is kept free from atmospheric influences and changes of temperature. The sawdust or other non-conducting filling, together with the ice, keeps the house at a low temperature, the filling keeping the interior of the house free from atmospheric influence. The charconl and other absorbents keep the house dry by absorbing moisture and vapors arising from the articles to be preserved.

The house is placed entirely above the ground, and may be constructed of any proper material-wood would probably be preferable. In case of the melting of the ice, proper pipes may be inserted to carry away the water, and the floors on which the ice is placed may be properly inclined for that purpose.

The construction of icehouses above ground, with double walls, filled between with straw, \&c., is not new, and is not claimed as such in this patent, but the general arrangement and combination of parts for the more perfect preservation of fruit, \&c., in all seasons, by keeping the temperature of the house low by the ice and non-conducting walls; also maintaining a dry and pure atmosphere inside, by the use of the absorbents described. The great feature of this invention is the prevention of incipient decomposition and decay of fruit, which can be accomplished in a low and dry atmosphere-the conditions fulfilled by this fruit preservatory.

\section{Artificial Egg-hatching.}

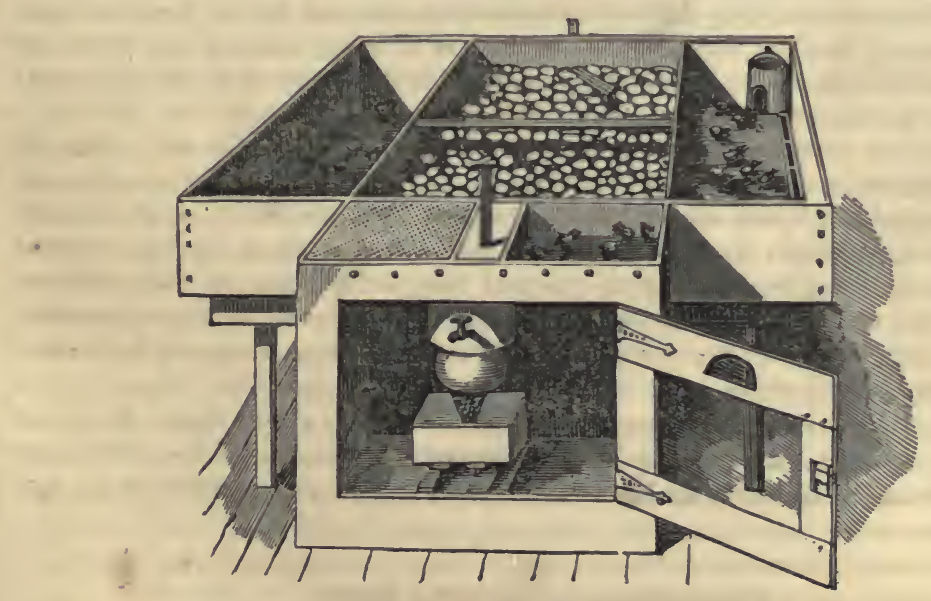

THE system of hatching eggs artificially has recently received a new impulse from the exertions of Signor Minasi, of London, who has labored to dispel the notion that top con- 
tact, as with the natural hen-mother, was absolutely essential for/successful hatching by artificial agents. It is this view which has so long retarded the progress of this curious art, as great complication of mechanical details was necessary under such a system, in addition to the constant attendance of a watcher, to keep the temperature to the right point. With this top contact, too, the eggs must be all of the same size; but, by Signor Minasi's plan, the eggs of ducks and pigeons may be hatched alongside each other. The heat he uses is derived from a simple spirit-lamp, by which he obtains the necessary uniform temperature. Our perspective sketch represents the hatcher complete. It consists of a water-tight platform or tray of metal, with a corrugated bottom, and filled with warm water at such a heat as will keep a layer of sand thereon up to a temperature of $104^{\circ} \mathrm{F}$. This sand-layer holds the eggs, which are screened by a glass-cover. The sand, which is of the "silver" kind, is a quarter of an inch deep, and the eggs, when deposited in it, are covered with a blanket, another blauket being employed to envelop the whole of the glass-frame. Under the tray is placed a mass of chopped hay, mixed with sand, this being changed daily. The heating lamp, which is itself on a novel principle, is placed with its flame about three inches from the bottom of the boiler or water-holder. When the proper heat has been obtained, the eggs, with their opposite sides numbered, are placed in the sand, and left for twenty-four hours, after which time they are reversed, to expose the other side. At the end of the sixth day that the eggs have been in the machine, it may be ascertained if the chicken is formed or not, by darkening the room, and holding them against a hole the size of a shilling, cut in the shutter for the purpose, when, if the egg be gently turned, the germ will be seen to float to the top. If no germ appears, the egg may be considered a bad one for hatching purposes. A bit of soft leather should be placed round the hole, against which the egg may be held without the fear of breaking. If the shell be a dark one, it will not be until the serenth or eighth day that this can be known. It requires a little practice before the eye becomes sufficiently experienced to detect this. The great advantage which science has over nature is here apparent, for if by the sixth day no chicken is visible, the egg may be at once remored as containing no germ, and its place filled by another. In eggs with lighter shell, such as Spanish, Poland, and Sultan fowls, the chicken is seen clearly after the fourth day. If, at the end of twenty-one days, any doubt should exist as to the vitality of the chickens then due, fill a basin nearly full of water, heated to about $104^{\circ}$ or $106^{\circ}$, and place some eggs gently in it. When the water is quite still, the eggs that contain live chickens will be seen to move about, and should be immediately replaced in the machine, and allowed another day or two more. When buying eggs for hatching, they must be placed in water, to find if they will lie flat at the bottom. If they do so, they are good for hatching; but if one end rises higher than the other, they will not answer the purpose; and should they float to the surface, or near it, they are rotten. Another method of telling new-laid eggs from stale ones is by examining them at the hole in the shutter. If there appears at the thick end a vacuum about the size of a fourpenny piece only, the egg may be considered new-laid, or only two or three days old; but if the vacuum be greater, the egg is a stale one. When the chicken commences to star the shell, it is better to remove it to a glass-box at the end, with a little flannel laid lightly underneath, and the same to cover over it, as, if allowed to remain in the sand, they sometimes injure their eyes. The chickens may be allowed to remain in the glass-box without food for the first twenty-four hours of their existence. They should then be removed to the artificial mother, where they will shift for themselves, and should remain for about five or six weeks. If a chicken appears weakly for the first two or three days, it is perhaps as well to put it in the glass-box, away from its more robust companions under the artificial mother, giving them, of course, a little food. In his experiments, Signor Minasi has been remarkably successful; and, having hatched sereral eggs of rare birds furnished him from the Zoological Gardens, is about to experiment on the eggs of the ostrich.

\section{Arrangement for Holding Eggs.}

A PATExT, for an improved arrangement for holding and conveying eggs, has been granted to Francis Arnold, of Haddam, Conn. It consists in having a suitable box, with a number 
of vertical curved springs attached by their lower ends to the bottom of the case. The eggs are slipped in between the springs, which hold them firm yet gently, preventing them from coming in contact or being broken by any ordinary concussion.

\section{Uncertainty of Preserving Records in Walls or Foundations of Buildings.}

IT is a common practice to place the coins of the time, newspapers, and other documents or records, in sealed vessels under the foundation-stones, or in some marked situation in the walls of new public or otherwise important buildings. At a meeting of the American Philosophical Society in April last, Dr. Boyé stated that, "On recently opening the corner-stone of the High School building of Philadelphia, erected fifteen and a half years ago, in order to deposit its contents in the new building about to be erected, the papers, coins, \&c., which had been deposited in a sealed glass jar, were found to be in a perfectly decayed and corroded condition, and saturated with water." Dr. Boyé states, that after a careful examination, he is satisfied that the water must have got in from the outside by infiltration-first through the mortar into the cavity, and afterwards from this through the sealing-wax with which the glass-stopper was secured. The corner-stone consisted of a block of blue marble, in which a rectangular excavation had been made, which was closed at the top by a marble slab sunk down into the stone, and secured by common mortar. The lime used appears to have acted upon and corroded the sealing-wax. The corrosion of the coins is ascribed to the sulphur in the glue or sizing in the paper.-Proceed. Amer. Phil. Soc.

\section{Improved Fancet.}

Asroxa the patents recently issued was one to Charles Cleveland, of Ashfield, Connecticut, for improvement in faucets, which will be of no small value to the public. They may be used in all cases to which an ordinary faucet is applicable, and also, by turning the spigot to a proper position, a ventiduct is opened; through which, in consequence of the peculiar formation of the aqueduct, air is admitted at the same time that the fluid passes through the aqueduct, thus adapting it to the drawing of fluids from vessels which are perfectly airtight; a matter of no little consequence in case of burning fluids, high wines, \&c.; while it will be found of still greater value for drawing fermented and effervescing fluids, such as beer, mineral waters, and the like.

\section{Frictionless Washing Machine.}

Is this invention of Mr. King, the inventor claims that it involves "no rubbing rollers, dashers, or pounders, to wear out the clothing, but a simple cylinder, constructed to apply steam beneath the suds and clothing, and out over them, whether the cylinder rotates or is stationary." The articles to be washed are put into the cylinder, the lower half of which contains suds, and the upper half steam, which latter has a constant escape at the top, raising the clothes under treatment into the upper half of the cylinder. As the cylinder is occasionally turned over, the articles have their position changed, being alternately in suds and steam. The steam accomplishes just what the washerwoman performs with her hands: it opens the fibres of the fabrics, and allows the alkaline matter of the suds to neutralize the oily or vegetable particles which hold the dirt to the goods; the dirt then rinses off without rubbing, and the continuous steam escape carries off all volatile matter.

\section{Improved Helve Fastener for Axes.}

A sIMPLE and ingenious contrivance for fastening helves to axes has been recently patented by H. A. and J. Bill, of Willimantic, Connecticut. The socket in the axe-head is made narrower in the central part, the side of the socket next the edge being convex. The opposite side of the socket is made straight, or nearly so, and the end of the helve is made to fit the socket on the side next the edge, space being left on the opposite side for a wedgekey. The extreme end of the helve is wider than the central part of the socket; but it can just be passed through when the wedge is out. After the helve is entered into the socket, the wedge is driven home, after which, unless the wedge is removed, the axe cannot be separated without absolutely tearing it off the end of the helve. 


\section{Correct Labels.}

IN the report of premiums awarded at a late exhibition at the Royal Botanic Gardens, London, we were gratified at seeing certificates awarded for "correct labels." This is a matter worthy the attention of our horticultural societies. Let certificates, or honorable mention, or a small premium, be given to the gardener or nurseryman whose labels are correctly spelled. There is great room for improvement in this respect; in catalogues also, as a general rule, the blunders are frequent and ridiculous.-Phil. Florist.

\section{Improved Joints for Gas and Water Pipes.}

THE great inconvenience to the public in all largely populated cities and towns, arising from the continual stoppage of the highways, by the laying or repairing of the gas and water mains, will, we are happy to observe, at no distant day, be greatly mitigated, and, indeed, to a great extent, removed. This important desideratum is effected by a valuable improvement in forming the joints of iron pipes, recently introduced and patented in England, and possessing numerous advantages over the common pocket-joint, secured with junk and lead. The plan consists in casting the pipes of equal diameter from end to end, in laying which they merely abut against each other. About an inch from each end, a bevelled flange or feather is cast round the outer circumference, forming an angular ring, and when two pipes are brought end to end, a piece of web, or gasket, woven for the purpose, is saturated with red or white lead, or other applicable unctuous matter, and drawn twice round the space formed by the two projecting rings. Over this an iron collar, cast in two pieces, and having grooves to admit the projecting rings, is fitted and screwed up by bolts and nuts through lugs, forming a perfectly air-tight joint. . At a glance it may be seen that numerous advantages must result from the application of this plan by all the gas and water companies; perhaps the greatest and most obvious of which to the public, from its general adoption, will be the saving of time in laying the mains and branches, and the avoidance of the greater part of the nuisance occasioned by such works under the present system, and inherently combining with it a great economy and saving of cost to the companies. This is effected, in the first place, by less excavation being required; man-holes will not be necessary to enable the men to get at the joints, and the operation is rapidly completed without the danger and nuisance of fires in the streets for melting lead, and by the employment of at most only one-third the labor required under the present system; while, instead of skilled workmen, any laborer who never before saw a joint may be taught in five minutes effectively to screw up the joints. The lead used under the present plan may be taken on an average at eighty-four pounds to a ton of main pipe, showing a saving in lead alone of from 15s. to 16s. per ton. A still further advantage and saving is effected by the superiority of the joint, forming almost an entire prevention of leakage and waste; for, while there is every facility secured for expansion and contraction, the perfection of the joint remains unimpaired. This manner of connecting pipes has equal applicability for the conveyance of steam for breweries, distilleries, dyehouses, conservatories, hothouses, and in all situations where the safe conveyance of fluids is a desideratum; and may safely call attention to its great simplicity and efficiency, its capability of supplying a great public good, and removing many public annoyances.

\section{On the Manufacture of Terra Cotta.}

THE manufacture of terra cotta, a comparatively new branch of business in the United States, is conducted in New York, at the principal establishment, that of Mr. Young's, as follows:-The material used by Mr. Young is one part Now Jersey clay, an article well known by all the potters in the Middle and New England States; and Long Island clay, one part, and sand from Rockaway Beach, one part; which are ground together in a common tub-mill, with one horse attached to a sweep, like the common brick-clay mill, or oldfashioned cider-mill. 
When the clay is worked to the right temper for use, it is packed away in the cellar, where it will keep just moist enough to mould well. When a new design is furnished, the first process is to mould the clay into the desired form, with a pedestal or back, if designed to set in the wall, or, if for the key of an arch, in the proper form, besides the ornamental part, for the position it is to fill. Now, the expense of this process would never allow of the article being used as a cheap building material. To obviate this, a plaster mould is taken, which is formed of as many pieces as may be necessary to allow the article, when cast, to be removed from the mould with facility. Sometimes these plaster casts are taken in fiveand-twenty different pieces to one mould. When thus formed, the whole is placed in a box of suitable size and shape, so that when liquid plaster is poured in, it forms a case of sufficient strength, the sides being two or three inches thick, to hold the various parts of the mould firmly in their place. The original laboriously-prepared model being removed, the workman has a perfect matrice in which he can duplicate his designs to any desired extent. The process of doing this is to have the matrice in its plaster case on a table before him, with his prepared clay, which he takes in his hands, and throws and presses it into every part, until his matrice is full, the plastic clay having taken every form, however minute, whether of a face, or leaf, or feather. The case is then rolled over, and lifted off of the mould, which is taken away, piece by piece, from the article formed, which is left to dry until firm enough to handle, when it is taken to the finishing-room and trimmed and repaired, if there are any imperfections, and then taken to the drying-room, until ready for the kiln; this is an oven nine by thirteen feet, and ten feet high. The articles are set in this, and heated by the consumption of a ton of bituminous coal a day for six days, bringing the clay to a white heat, and nearly to the melting-point. The same degree of heat applied to a kiln of brick would melt down all the arches. The articles in the drying-room are prepared for burning by the escape heat of the kiln. When well burnt, they are more like gray stone than any thing else, and may be used without paint, though that is generally applied to produce a uniform color.

The difference between terra cotta and stonework prices is the most apparent where the amount of carving is the largest. Window lintels of fancy patterns, with carved-work keys, corbels, and trusses complete, are from $\$ 12$ to $\$ 25$, or about one-third the price of stone.

\section{Cellar Floors.}

THE cheapest, best, and most durable cellar floor, which is also impervious to rats, may be made in the following manner:-Supposing the cellar wall already laid, with a sufficient drain to the cellar; then dig a trench all around the wall on the inner side, a foot wide and deep, connecting with the cellar drain. In the centre of this trench make a drain by standing two stones, bracing against each other, at an angle of about forty-five degrees; then fill up the trench with small stones, to within two or three inches of the top; cover these stones with a layer of pine shavings, and then with the earth thrown out of the trench, levelling off the same with the floor of the cellar. If the ground of the cellar should be gravel, nothing further will be required; but if clay, make it perfectly smooth, and strew over it a coating of clean gravel; one load of thirty bushels will be ample for a cellar of twelve hundred square feet. The cost of such a floor, estimating the gravel at $\$ 1$, will not exceed $\$ 8$; the cellar will be rat-proof, and the floor smooth, dry, and hard.-Rural Intelligencer.

\section{Alarm Bedstead,}

THE above name was given to a newly-invented bedstead recently exhibited at the Agricultural State Fair of Vermont. Its peculiarities are as follows:-At the head of the bed is placed a common alarm-clock, which can be so arranged as to give an alarm at any hour required; but should the votary of the sleepy god be unmindful of the summons, and roll himself over preparatory to another nap, in a moment, by an ingenious contrivance, one side of the bed is dropped upon the floor, leaving the surface of the bed at an angle of abont forty-five degrees, and rolling the occupant out upon the floor in a very unceremonious manner. 


\section{Patent Brick.}

THE annexed figures are views of an improved brick, for which a patent was recently granted to Levi Till, of Sandusky, Ohio. The nature of the improvement consists in forming each brick with channels or grooves upon the top, and with projecting conical spurs upon the bottom and upon one of its ends.

Fig. 1.

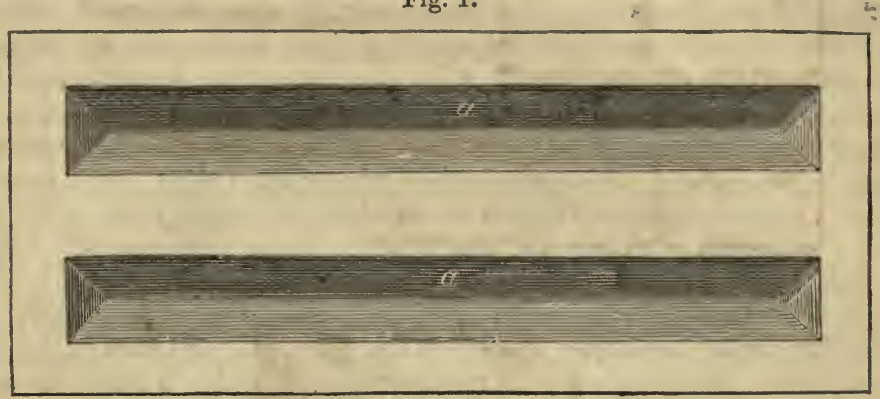

Fig. 2.

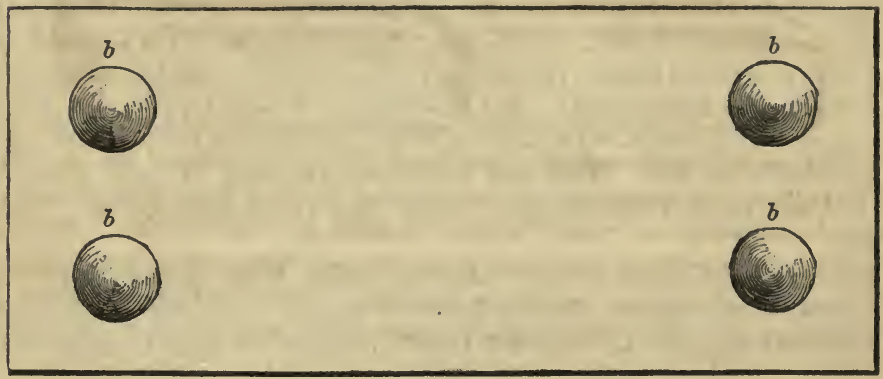

Fig. 3.

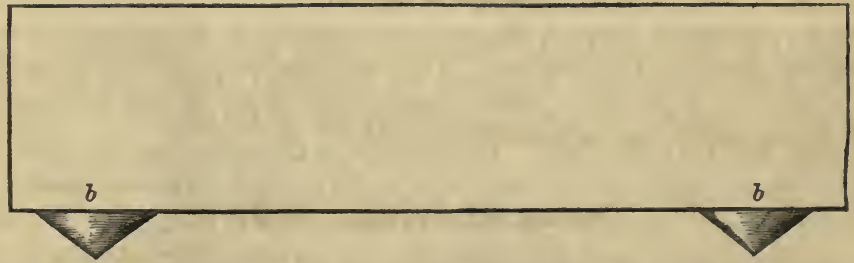

Fig. 1 shows the two channels or grooves $a$ a. Fig. 2 represents four projecting conical spurs intended to fit into the grooves $a a$-the spurs of one brick fitting into the grooves $a a$ of another, and vice versâ. Fig. 3 is a side view of a brick, showing the conical spurs $b b$

Fig. 4.

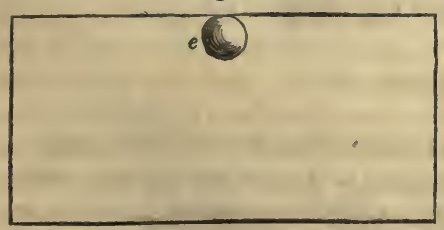

in elevation. Fig. 4 represents a small spur $e$, intended only to keep the bricks, as laid in the wall, at such an exact and uniform distance apart as shall leave the proper space for mortar. Fig. 5 shows a section of wall with the end of a joist $h$ laid upon it, which can be done by the carpenters on each story, as soon as the bricks are laid. $a a$ and $d d$ show the ends of brick, and $b$ is the half brick. A piece $e$ is nailed on the end of the joist to fit into the channel of brick, and which acts as a tie. Fig. 6 is a perspective view of three of these bricks. The following extract from the specification sets forth the advantages claimed for this brick:

"It will be perceived at once that in bricks made upon this plan the improvements will 
consist-1st. In the greater security and strength of the walls locked and bound together by this device; $2 \mathrm{~d}$. The bricklayer is enabled to lay several courses without the use of the line, and with much greater rapidity and accuracy than with common brick, it being scarcely possible to go wrong; and $3 \mathrm{~d}$. The spaces for mortar between the bricks are necessarily uniform, exact, and equal."

Fig. 5.

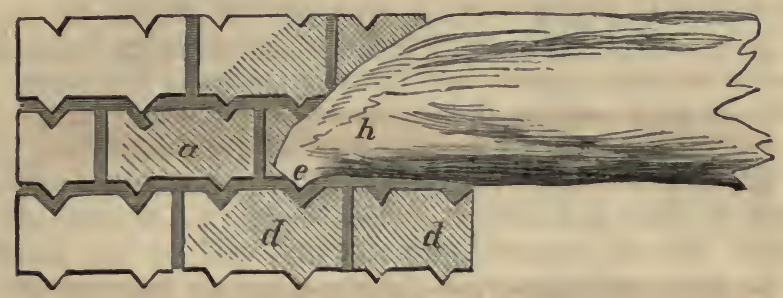

Fig. 6.

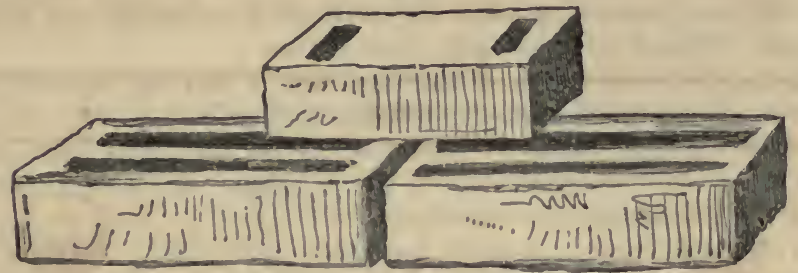

These bricks united together form a continuous chain, very suitable for the construction of domes and other such structures, as they are well adapted for resisting outward thrust, and they can be united by any "bend" which is possible for common brick. The wall cannot separate while there is sufficient weight on the top to keep the spurs in their channels. Such bricks will be good for building deep shafts in mines. They may be also used for drainage, the spaces between the courses affording a free passage for water.

\section{Papier-Mache Huts.}

A Papier-mache manufacturer in England has submitted to the authorities a model hut of that material, intended for camp use. The papier-mache pulp is mixed with rags, the result of which is a paper plank much stronger than wood, all but inflammable, a nonconductor of heat or cold, and impenetrable by wet.

\section{Boring for Artesian Wells.}

The following is a notice of some recent improvements in the machinery for boring Artesian wells, effected by Mr. Kind, of Saxony:

"The first improvement by Mr. Kind is what he terms the free-fall apparatus, the object being to release the chisel at any moment from the rods, and by allowing its free fall to do its work at the bottom of the bore-hole. This apparatus consists of a pair of tongs, capable of laying hold of a bar of iron in which the chisel is fixed; and these tongs open and shut by means of the action of the water in the hole on a disc of leather during the up-and-down motion of the rods. The operation proceeds as follows:-The rods, to the lower end of which the free-fall apparatus and chisel are attached, are lifted to the height requisite for the subsequent fall of the chisel; during this upward motion, the water in the bore-hole presses against the upper side of the leather disc by reason of the resistance it meets with by being drawn through the water; but the moment the motion of the rods is attempted to be reversed or lowered, the pressure of the water against this disc is also reversed, causing it to slide a little way on the rods. This motion of the disc is made to effect the opening of the tongs holding the end of the chisel, which is then disengaged, and free to fall without the rods and free-fall 
apparatus, which then follow at a more moderate rate of descent, and again take hold of the chisel in order to raise it for another blow. Nothing but actual experience can show the important effects accomplished by the free falling of the chisel. In the first place, it enables the great mass of iron rods to be replaced by others of a lighter construction, as they are much less severely handled in this than in the old process; wood is the material accordingly employed, which, by reason of its buoyancy in the water, is comparatively of little or no weight on the lever, even in the deepest boring, provided water be present; the labor or power is consequently greatly diminished, as by Mr. Kind's process the weight to be raised each time is merely that of the chisel, together with the small amount of counterpoise necessary to keep the rods down in the water, while the whole weight of the chisel becomes effective in its fall. A much more important advantage of the use of the free-fall apparatus, however, arises from the less liability it occasions to those serious accidents from the breakage of the rods in the hole always attending upon works of this nature under the old mode, when of any considerable extent. This will be readily understood from what has been stated of their not having to sustain those severe shocks and concussions, and also from their always being in a position of suspension from the point of support on the end of the lever, and never resting on their lower end in the bore-hole, whereby they are liable to be buckled up or broken from the superincumbent weight of the upper on the lower portion.

"The objection to the old system of continuous rods is thus very correctly stated by M. Degousee, in his treatise Guide du Sondeur-'When borings are very deep, the weight of the rods prevents the boring tool acting by percussion, and yet there are no other means of penetrating hard rocks. The instrument runs the risk of breaking frequently ; besides, to act by percussion, the instrument must be raised from 3 to 4 inches, and when then allowed to fall, is subject to a tremulous motion between each shock, which lashes it violently against the sides of the bore-hole. This tremulous motion, repeated from 12,000 to 15,000 times per day, and during many months, entails the deterioration of the retaining tubes; and, if the bore-hole is not tubed, makes the hole oval in soft places, giving rise to crumbling in; and the fragments occasionally press angularly against the tool in such a manner that the rods break by the efforts necessary to extract them.'

"We have here, accurately described, one of the principal causes which have hitherto prevented borings of very great depth becoming common, the breakage of the rods entailing such serious consequences that attempts have been frequently abandoned after a considerable expenditure of labor and money. Mr. Kind's free-fall apparatus remedies this objection by avoiding all those shocks and lashing of the rods; and, while it renders the operations more likely to be carried to a successful termination, removes one great cause of accident and failure.

"The core-boring is managed by having a sort of crown-tool, which cuts all round the periphery of the hole, leaving an annular space and solid central block or core, which core is broken off and brought to the surface by means of a particular form of clack. Instead of bringing up powder for examination, this apparatus then can produce a cylindrical block of the rock which is being bored through, as we have seen in the specimen cores, giving all the indications in the dips of the beds and their exact charaeter that could be obtained by the sinking of a shaft. This operation requires considerable care, in order to realize to the full extent the advantages to be derived from the exhibition of a perfect sample, by showing the direction and amount of the inclination of the bed or strata; that it is effectually accomplished is satisfactorily established by some cores brought up from depths exceeding 1000 feet, as well as by the public accounts of the numerous and very extensive works that have, during the last 10 years, been successfully completed under Mr. Kind's system and direction.

"Mr. Kind has also successfully applied his system of boring to the sinking of shafts of large diameter, and in certain localities, with economy. He aroids pumping during the operation; and if, as is most frequently the case, large feeders of water are confined to certain beds, he stops them back by means of wooden tubing. When a comparatively small power only is required to keep the works dry, the operation is carried on by means of two small engines, of from 10 to 12 horse-power each-one arranged for winding up the rods when the tool must be lifted, the other for boring.-Mining Journal. 


\section{Mosquito Window Screen.}

The annexed figures represent an improvement in window screens for excluding mosquitos and flies in summer, when a portion of the window is left open for proper ventilation. The inventor is B. B. Webster, of Boston.

Description. - Fig. 1 is an inside view of a window having the improved mosquito curtain attached, the lower sash being partly elevated in order to exhibit the curtain. B is a roller (moved by a spring in boxes A A) around which the gauze curtain is wound when the window is closed. The spring is indicated by the dotted lines in fig. 2 (a perspective sectional view) at A. C is a movable bar, that may be easily detached from the sash D, to allow the window to be easily opened when desired, without using the curtain. C C (fig. 2) shows this bar detached. When the window is partly open, the space between the glass and the bottom of the upper sash is effectually closed by some flexible material to prevent insects from entering the room in that way. A like insect curtain may be applied to the upper sash, if desired. The common mosquito curtains are fixed to a separate frame, made for the lower sash of windows, which has to be removed, and the curtain frame set in. This invention is certainly a neat and convenient improvement over the common kind. This curtain has only its small spring and roller-box B, secured to the. window sole by screws, and the bar $\mathrm{C}$, to which the upper end of the curtain is attached, clasped upon the lower part D of the sash, so that when the window is raised, as shown in fig. 1, the curtain is drawn up and covers the space, to prevent the ingress of insects. When the window is lowered, the springs in the roller-box wind the curtain by self-action on the roller $B$. The tension of the springs can be regulated in a minute to suit any window to which a curtain is attached.

Fig. 1.

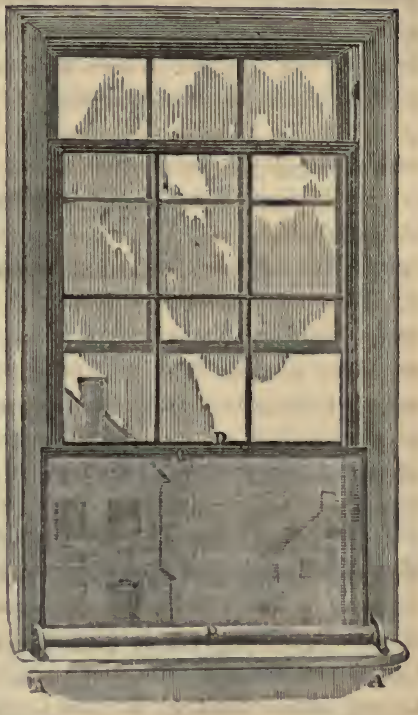

Fig. 2.

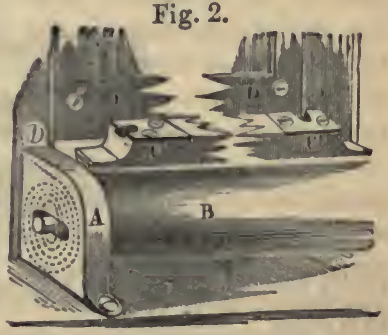

\section{The Way to Transport Logs.}

Mr. W. S. Boorr, of Connecticut, furnishes to the People's Journal the following information, the result of his experience in regard to the best method of transporting heavy timber from remote and difficult localities. In nearly all the easily-accessible localities on the Atlantic border, the forests have been cut down, and now the supply must be taken from those points where great difficulties in the way of transportation have to be overcome, such as mountains, ravines, \&c. The method at present in general use is to slide logs down by a hand-spike for one or two hundred yards, or pull them by team and dog-chain. But there is great danger both to team and driver by the latter mode, as the logs acquire increasing velocity in proportion to the steepness of the descent. Mr. Booth's plan is to provide a simple pole of any flexible wood, say five inches diameter and ten feet long, and attach it firmly as a tongue to the log. This tongue may be kept in place by means of a notch in the $\log$ and a couple of pins on the tongue, between which the chain is made to pass. The fixtures for hitching on the team are made in the usual manner.

In order to load the cart, the axle is placed on a slope, about five feet from the third part of the length of the log; remove the nearest wheel by pulling out the fastening, and let it lie in a horizontal position, with the end of the axle resting directly on the middle of the hub of the wheel, in the manner shown in fig. 1. Then, by means of a plank, placed on the axle and 
extending over the wheel to the under side of the log, roll on the log with a cant-hook or team and chain. Finally draw on the wheel with your team, which may be done by fastening a chain around and over the spokes, close to the hub of the wheel, as shown in fig. 1. The

Fig. 1.

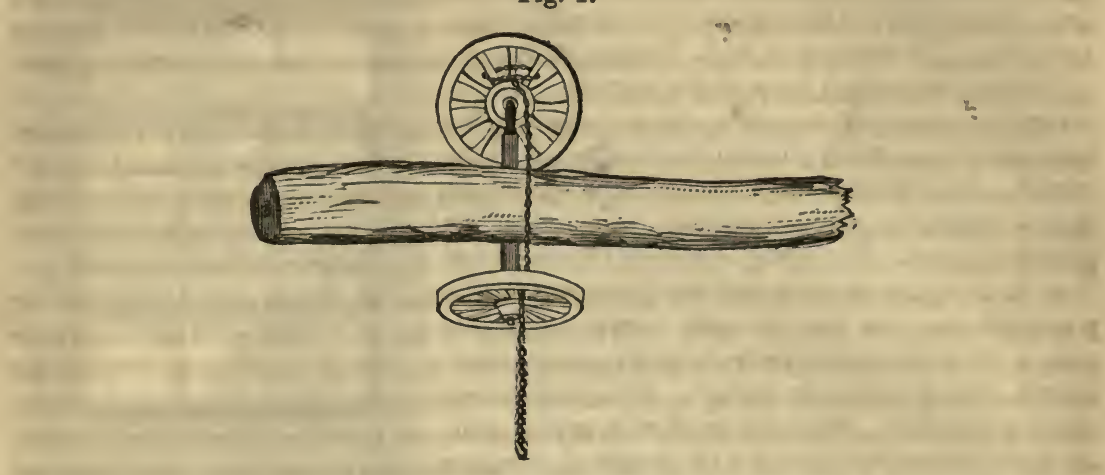

log should rest on the axle at one-third of the distance from the end. In drawing timber thus trailing on the ground, the greatest difficulty is, that the log does not follow the direct track of the wheels, but inclines to one side or the other of the track, thus lying obliquely along the road. To remedy this we use two chains-the one forming a noose under the log forward, and as close to the axle as can be fastened; the other forming a noose some eight or ten feet below, and connecting the two together in the manner shown in fig. 2. This plan will effec-

Fig. 2.

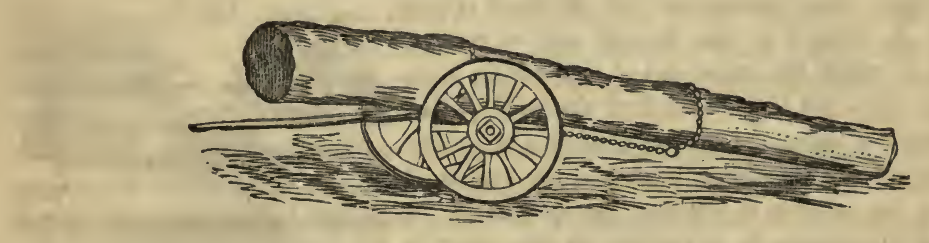

tually prevent the oblique trailing of the log; it will also answer where two logs are fastened at a time.

\section{Improved Stump-Extractors.}

THE Greenfield Gazette, Massachusetts, contains the following notice of the working of a new stump-extractor, owned and operated by W. W. Willis, of Orange, Massachusetts. The exhibition was public, notice having been given to the adjoining districts, and a considerable number of agriculturists were present. "At the appointed time," says the writer, "the hook of a stout chain was placed under the root of a moderately-sized stump, and it was turned out with as much apparent ease as though it had been a mere log, with no attachments to the ground. Other stumps, of still larger size and more extensive roots, were then taken out; and all with certainty, and without the slightest confusion; and the time occupied in removing each one, after the chain was applied, not exceeding ten minutes!"

An experiment on a somewhat larger scale was then tried with equal success. "An enormous stump, the growth, perhaps, of centuries, was selected, and a larger chain made fast, With a small half-circular spade, room was made under one of the roots, and a stout hook attached; the chain passing from the hook up over the end of the shears. Nearly the whole surface of the ground about the stump was covered with the stumps of a later growth of young pines, whose roots penetrated the soil, and mingled with those of their ancient progenitor. The stump itself was between two and three feet in diameter, and sound, as were its roots.

"A pair of stout oxen were then hitched to the lever and driven forward. When they had 
advanced some three or four rods, the chain was taken up, and they were turned back without any unhitching, the roots in the mean time cracking and making a noise like a pistol exploded under water. The ground gradually rose about the stump, and in five minutes its gnarly roots, which had securely laid there for ages, were brought to light. At the expiration of ten minutes, the old hero was fairly turned over, and the roots on the upper side pointing to the heavens. Upon actual measurement, we found the roots extending something more than sixteen feet from each side of the stump.

"The experiment was one of the most astonishing exhibitions of mechanical power that we have ever witnessed. The machine is exceedingly simple, and not liable to get out of repair."

The prices of these machines range from $\$ 125$ to $\$ 200$, including town-rights, which brings them within reach of moderate means, and cannot but be a good investment for the enterprising farmer.

An improvement in machinery for extracting stumps has also been recently invented by Edward Vaughn, of Alliance, Ohio. "The bearing of the screw employed in this stumpextractor is a half sphere fitted within a concave plate; the hub of the sweep for working the extractor has a projection resting upon anti-friction balls, and the screw passing through a recess is so arranged that the friction usually attendant on operating it in ordinary stumpextractors is greatly reduced, and at the same time the screw is allowed to oscillate and conform to the line of pressure when out of a rertical line. This machine is made with a frame to be drawn on wheels to the field where the stumps are to be extracted, and by a peculiar arrangement the wheels can be attached or removed at pleasure."

The Michigan Farmer's Companion thus describes a new stump-extractor recently introduced into that State:-

It is a very powerful, effective machine, turning out solid oak stumps three feet in diameter with as much ease as a dentist would extract a molar. Its lever power is the screw. The directions here given will enable any mechanic to make one: First, there are two bedpieces of best oak, 8 by 5 inches, 10 feet long, put together like a common crotch-drag, spreading 10 feet at the rear end; the cross-piece is inserted 2 feet from the forward end, and just behind this is inserted a strong bolt with a nut and screw, to prevent spreading. Three posts, 6 feet between joints, and 5 by 8 inches, oak, are mortised into the bed-pieces, forming a triangle; the hind posts are 8 feet apart at the foot, measuring across the frame: the top of these posts are let into a head-block, 10 inches thick, 18 inches wide, and $3 \frac{1}{2}$ feet long, made of the toughest oak; a knot would be better. A hole is made through this block, 3 inches in diameter at the top and 8 inches at the bottom; through this is passed a common cider-mill screw, $4 \frac{1}{2}$ feet long, with a clevis made of Swede's bar passing through the lever holes in the screw, to admit two holes for bolts an inch and a half thick; then a chain made of $\frac{3}{4}$-inch iron, $4 \frac{1}{2}$ feet long, with a ring on one end; a large hook on the other for hitching to roots; the nut in which the screw works is let firmly into the sweep, (like an old-fashioned cider-mill sweep,) to the end of which a horse is attached; the screw is lowered sufficient to hitch; the horse is then started, and the stump is raised out with great ease. Indeed, it was wonderful to see with what power and ease it drew into pieces a solid oak stump; it being so firm in the ground that it came into parts rather than yield entirely at one hitch. The whole cost of the machine is $\$ 24$.

\section{Patterson's Compound-action Clod-Crusher.}

A sILVER medal was awarded at the recent exhibition of agricultural implements at Carlisle, England, for an improved clod-crusher, the invention of Mr. Patterson. Its novelty consists in the employment of a straight axle, with a series of eccentrics upon it, for the purpose of placing each disc in a backward and forward position with regard to its neighbor. The eccentrics are so arranged upon the shaft, that their centres shall be in the same horizontal plane, or equidistant from the ground line. By this arrangement, a perfect selfcleansing action is obtained, owing to the peripheries of the dises continually crossing and recrossing each other. In this way a grinding action is exerted upon the clods, which reduces them to a fine mould. 


\section{Portable Steam-sawing Machine.}

ONE of the most novel and ingenious machines for sawing trees and timber has been recently invented by Mr. S. R. Wilmot, of New York City. It is nothing more nor less than a steam hand-saw. - The handle is made round and hollow, and has a steam piston fitted within, to which the saw is fastened. Steam is admitted at the back end of the handle, through a flexible pipe made of canvas or rubber. The rapidity with which the saw is made to move back and forth is astonishing. The principal object of this invention is to cut down trees in forests or swamps, or wherever the nature of the ground is such that it is desirable to have a very light but effective cutting apparatus. The operator takes up the saw by the handle, which is only two or three inches in diameter, holds it against the base of the tree, and lets on the steam. The next thing seen by the spectator is the tree in the act of falling, so quickly has it been cut through. Where the trees are very large, a light frame is employed, in which the steam-saw is held when at work. The extreme portability of this apparatus enables the operator to cut up a tree into logs, after it is felled, with the utmost facility. The boiler is of sheet iron, and, though amply strong, is easily carried about by one man. The flexible steam-pipe permits the saw to be taken from tree to tree, in any direction around the boiler; the only limit of the distance being the length of the hose. This apparatus, we are informed, has been thoroughly tested, and found to operate with the most practical success.-Scientific American.

In an invention of Pliny Young, of Milwaukie, Wisconsin, recently patented, the saw is made to cut while the carriage is moving either way. The whole apparatus or device is also self-acting, the log or timber being set to the saw, and the motion of the carriage reversed without any extraneous aid or power being applied. The log or timber may also be set at any required distance towards the saw, so as to saw stuff of any required thickness by merely altering the position of the slides.

\section{Improved Butter-worker.}

THE accompanying engraving represents a section of an improved butter-worker, recently invented and patented by Ezekiel Gore, of Bennington, Vermont.

The nature of this invention consists in the employment of an endless revolving sack or bag for containing and confining the butter, and conveying it to and between two fluted or working rollers, and through the water in the tub or box as fast as the rollers operate upon it, until it is thoroughly worked, washed, and seasoned.

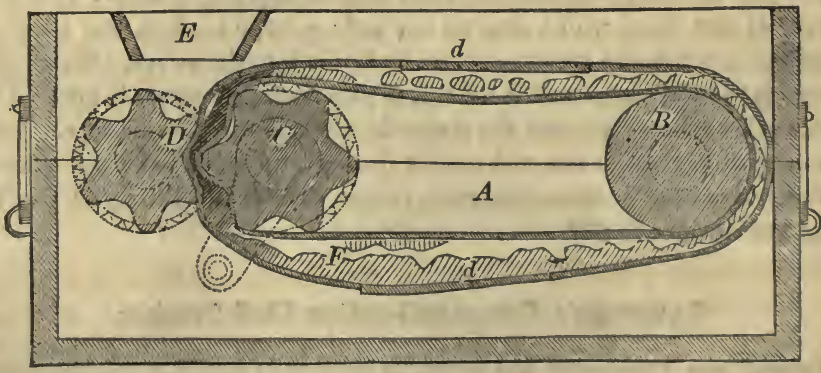

A represents the box or tub which contains the water for washing the butter, and also supports the bearings of the rollers B C D. The box A is made in two sections, so that its upper part may be removed, and also the rollers and sack, when it is desired to cleanse the lower part. The roller B is made perfectly smooth, and has its bearings at the back end of the machine, and the roller $\mathrm{C}$ is fluted, as shown, and has its bearings near the front end of the machine. On and around these rollers the sack $\mathrm{F}$ is arranged as represented. The roller $\mathrm{D}$ is fluted similar to $\mathrm{C}$, and operates in concert with it, but is prevented from touching it by the sack, which is placed and revolves between it, as illustrated. 
The sack carries the butter between the fluted rollers, said rollers, as the butter passes between them, effectually operating upon it, and working it to the state desired. E is a hopper arranged above the fluted rollers, as represented; through this hopper the salt is introduced between said rollers, which work it into the butter as the sack feeds it between them. The sack $\mathrm{F}$ has two openings $d d$ for the insertion and removal of the butter; the butter cannot escape out of said openings while the working and washing is being performed, as the cloth forming the bag is made to over and underlap at the places where the openings are formed. There is cog-gearing for turning the fluted rollers in opposite directions, and a crank for turning the same.

This invention has certainly the merit of novelty, and, we understand, gives good satisfaction when used practically.-Editor.

\section{Dickey's Patent Butter-mould.}

Turs is a small square form, resting upon a block, the face of which has the impression or print to be transferred to the butter. Into this form it is pressed, after being weighed, by a small square wooden spatula, made for the purpose. The doors of the butter-form are then opened by hinges, leaving the butter on the print block, which is then turned up, learing a good impression on its face. The square form is also a great improvement as regards convenience for packing for market.

\section{Method of Testing Butter.}

The method of examining butter here described is only for use in the determination of its commercial value. It is calculated to enable a comparison of several samples of butter to be effected at the same time. The following instruments are required:-

1. For measuring the butter, a cylindrical glass tube, about two and one-half inches long, and two lines (two-tenths of an inch) wide, open at both ends, is employed. It is ground in a conical form at one end, and flat at the other. Into this is passed a cork, attached to an iron wire, which closes the tube almost air-tight, but so that it can be readily pushed through it. When in use, the cork is drawn back to the flat end of the tube, which is then filled by sticking it into a mass of butter; care must be taken to prevent the intrusion of air between the portions of butter. A mark is made on the tube, to indicate the quantity of butter to be employed in the examination.

2. A graduated tube, five and one-half inches long, two and one-half lines wide, closed at one end, and ground off at the other, is divided at the lower portion into ten equal parts, in such a manner that these ten parts may represent exactly the volume of butter contained in the other tube to the mark. In order to find this volume, the butter-measure is to be filled with water, while the stopper is placed exactly at the mark; the water is then poured in to the tube to be graduated; and after waiting for half a minute, to make sure that all the water has collected, its level may be marked with a file, the height of water being taken to its lowest point in the middle of the tube. The space below this mark is then divided into ten equal parts, and marked with a file. Another file-mark is made three and one-half inches above the graduation.

To test butter by means of this instrument, the measure is to be filled, as above described, by inserting it to a little above the mark. This is effected with thin pieces of butter, by inserting the tube perpendicularly into the butter on a plate, until the edge of the tube comes in contact with the plate. The tube is then drawn back, and the stopper pushed down until the butter projects a little beyond the edge of the tube; and this operation is repeated until the tube gradually fills up. The mouth of the tube is then closed with the finger, and the cork pressed upon the butter until it is completely united; the cork is then pushed exactly to the mark, and the projecting portion of the butter scraped off. In this manner the presence of air is avoided. The butter-measure is then put over the open end of the graduated tube, and the butter pushed out of it by the stopper. The latter is then filled up to the mark with pure anhydrous ether, in which the butter is dissolved by shaking, the open end of the tube being closed by the finger. In about half a minute all the fat dissolves in the ether, 
while the impurities, such as buttermilk and water, are seen floating in the form of flakes or drops. If the tube be then left standing, all these impurities settle completely, in about twenty-four hours, to the bottom of the tube, forming a stratum, the thickness of which may be ascertained by the divisions of the tube. Each division, as may be ascertained by experiments conducted in other ways, corresponds pretty exactly with ten per cent. of impurities, whether there be water or other substances; and as half degrees may be easily marked, the quantity of butter may be determined to five per cent., or even more exactly.

Middling samples of butter deposit a stratum of two degrees; they consequently contain eighty per cent. of butter, and twenty per cenc. of impurities; in bad samples, which were still regarded as salable, the stratum was not more than two and one-half degrees, and one sample even showed four degrees, containing consequently only sixty per cent. of butter, and forty per cent. of impurities.-Polytechnic Jour. cxxx. p. 374.

\section{Estimation of Butter in Milk.}

Marchand has suggested a new process for the analysis of milk. He employs the lactobutyrometer-a straight glass tube closed at one end, and for nineteen-twentieths of its capacity divided into three equal parts. The third of these-the part next the opening-is graduated for the upper three-tenths into hundredths, which are continued to the number of ten above its line of termination. The lowest graduated third of the tube is filled with the milk to be tested, containing to each ten cubic centimetres one drop of caustic soda. The second third part is filled with ether, and, after careful mixture, the third with alcohol of $86^{\circ}-90^{\circ}$. The whole is again well mixed, closed with a cork, and placed in a water-bath heated to $109^{\circ} .4 \mathrm{~F}$. It is kept in an upright position until the thermometer falls to $86^{\circ} \mathrm{F}$., when the amount of fatty matter collected on the surface of the liquid is determined by reading the degrees or centesimal divisions which it occupies from below upwards to the lower level of the curve.

\section{Proportions of Cream in Milk.}

IN some careful experiments made by Dr. Anderson, of Scotland, the quantity of cream obtained from the first-drawn cup of milk was in every case much smaller than the last drawn; and those between afforded less or more as they were nearer the beginning or the end. The quantity of the cream obtained from the last-drawn cup from some cows exceeded that from the first in the proportion of sixteen to one. In others, the proportion was not so great. "Probably," says Dr. Anderson, "on an average of a great many cows, it might be found to run as ten or twelve to one." The difference in the quality of the cream was also much greater than the difference in quantity. From this it appears, that the person who, by bad milking of his cows, loses but half a pint of his milk, loses in fact about as much cream as would be afforded by six or eight pints at the beginning, and loses, besides, that "part of the cream which alone can give richness and high flavor to his butter."-Country Gentleman.

\section{On the Making of Butter.}

THE following statements respecting the manufacture of butter, were filed with the Secretary of the Worcester (Mass.) County Agricultural Fair, at their last exhibition by recipients of premiums:-

One farmer says: "My mode of making butter is to strain the milk in the pan about twothirds full, letting it stand thirty-six or forty-eight hours on a table or bench, in the coolest room in the house. The cream kept in tin and stirred daily, and churned once a week, the buttermilk thoroughly worked out, the butter is then salted to suit the taste, the next day worked out again and lumped for market. No cold water or artificial coloring or sweetening is used."

Another farmer says: "My manner of niaking butter is to set the milk in tin pans about half full, raised from the shelf on two narrow sticks the thickness of a board, and let it stand not over four meals. The cream should be taken from the milk while sweet, and stand not 
over three days, and stirred every day. After churning, the buttermilk should be worked out as much as possible before salting. No washing is required to make the butter keep well, for it will retain its flavor better without. One ounce of salt to a pound of butter is sufficient. It should be worked over the second or third day after churning."

One more statement: "Our mode of making butter is as follows: Strain the milk into tin pans, set it in a cool place to stand twenty-four to thirty-six hours, or until the milk is slightly changed. Then take off the cream, set it in a cool cellar from two to three days in rery warm weather; in cool weather, three to four days; then churn, work out all the buttermilk that can be, without softening the butter, before salting, then salt to suit the taste; let it remain for twenty-four hours, then work out all the remaining buttermilk, press it firmly into jars, or make it into lumps, as the season or the market may require."

\section{Improved Churns.}

ALthovgi a very large number of patents for improvements in.churns have been granted, yet, in the opinion of inventors, perfection has not been attained to. A patent, recently granted Ezekiel Gore, of Bennington, Vermont, affords some assurance for this assertion. In the process of churning, it is desirable to have some means of producing a ceaseless agitation among the oily butter-globules of the fluid ; also, of regulating at pleasure the resisting surface presented to the cream. When the cream to be churned is thin, the resisting surface within the churn should be greater than when it is of a thick consistency. Again, in gathering the butter together after it has been separated from the other milky matters, very little agitation is required. These results are obtained in the churn by making the dash-pins with their lower ends flat, and so arranged that they can be set feather-edged, to present the exact amount of resisting surface required.

Spain's Atmospheric Churns.-The peculiar feature of this churn consists in the constant admission of atmospheric air during the churning process, and the opening for the escape of fetid gas, which is always generated at such times, and in ordinary churns is retained to the great disadvantage of the butter, and loss of labor.

\section{Roe's Improved Cheese-Vat.}

Tre peculiarities of this improvement, by Mr. T. A. Roe, Ohio, are as follows :-

The outside or casing of the vat is composed of wood, inside of which is a metallic rat, of nearly the same shape; and between the vat and casing is a chamber to receive water, that surrounds the vat on all sides. Under the vat, and attached, is a heater, in the form of a cylinder, inside of which is another, so as to form an annular chamber between the two cylinders for water. The inside cylinder forms the fireplace, and is provided with a door and a pipe at the back end to carry off the smoke, \&c. This heater is connected with the water-chamber of the rat by three pipes, two of which pass from the top of the heater at each end, and one from the bottom of the heater, extending to one end of the chamber. By this direct connection, the heat from the heater is communicated to the water in the ratchamber. By this means, the milk or curd is subjected to a uniform temperature of any degree required, which is not the case when steam is used for heating as the curd, at the place where the steam issues into the chamber, becomes overheated, and other parts, by the condensation of the steam, are too cold to coagulate well, and thus the quality of the cheese is injured, and some part of the cheese wasted.

The vat is provided with gates to draw off the whey or water as may be required. There are several other devices connected with the rat, as facilities to its use.

\section{Improved Ice-Cream Freezer.}

As improvement in ice-cream freezers has been recently patented by Thomas M. Powell, of Baltimore, Md. The nature of the invention consists in constructing ice-cream freezers with three cylindrical chambers, two of which, the centre and outer ones, serve for the 
cream, and the intermediate one for the ice. By thus construicting the freezer, and surrounding it with ice, and filling the intermediate chamber with the same, the cream will be exposed to three freezing surfaces instead of two, as in other freezers, and will be more speedily and effectually frozen than by other freezers in use.

\section{Solidified Milk.}

A METHOD of making solidified milk, as adopted with success by Mr. Blatchford, of Armenia, Dutchess county; N. Y., is thus described in the New York Medical Journal by Dr. Doremus :

"To one hundred and twelve pounds of milk twenty-eight pounds of Stuart's white sugar were added, and a trivial portion of bicarbonate of soda-a teaspoonful-merely enough to insure the neutralizing of any acidity, which, in the summer season, is exhibited even a few minutes after milking, although inappreciable to the organs of taste. The sweet milk was poured into evaporating pans of enamelled iron, embedded in warm water heated by steam. A thermometer was immersed in each of these water-baths, that, by frequent inspection, the temperature might not rise above the point which years of experience have shown advisable. To facilitate the evaporation, by means of blowers and other ingenious apparatus a current of air is established between the covers of the pans and the solidifying milk. Connected with the steam-engine is an arrangement of stirrers, for agitating the milk slightly while evaporating, and so gently as not to churn it. In about three hours, the milk and sugar assumed a pasty consistency, and delighted the palates of all present. By constant manipulation and warming, it was reduced to a rich, creamy-looking powder, then exposed to the air to cool, weighed into parcels of a pound each, and by a press, with the force of a ton or two, made to assume the compact form of a tablet, (the size of a small brick,) in which shape, covered with tin-foil, it is presented to the public."

The doctor adds :

"Some of the solidified milk' which had been grated and dissolved in water the previous evening was found covered with a rich cream; this, skimmed off, was soon converted into excellent butter. Another solution was speedily converted into wine-whey, by a treatment precisely similar to that employed in using ordinary milk. It fully equalled the expectations of all; so that solidified milk will hereafter rank among the necessary appendages to the sick-room. In fine, this article makes paps, custards, puddings, and cakes equal to the best milk; and one may be sure it is an unadulterated article, obtained from well-pastured cattle, and not the produce of distillery slops; neither can it be watered. For our steamships, our packets, for those travelling by land or by 'sea, for hotel purposes or use in private families, for young or old, we recommend it cordially as a substitute for fresh milk."

The Committee on Public Health and Legal Medicine of the National Association, to whom this subject was referred, reported that they traced the manufacture of the article from the adder to its final conversion into the solid tablet, which consists of nothing but the solid constituents of pure milk, combined with nearly an equal part, by weight, of white sugar. It has a light yellow, slightly-mottled appearance, is of a very firm texture, and yields readily to the knife or grater. It is readily and perfectly soluble in water, and when so dissolved, in proper proportion, is, in fact, milk, with the addition of sugar, from which cream and butter can be obtained. The objections to the article are its containing sugar and a flavor somewhat similar to that of boiled milk. The latter inconvenience, it is thought, will be obviated by an improvement in the apparatus for manufacturing it. The price of the article is twenty-five cents a pound, which makes five pints of milk. The high cost, however, is, to some extent, more apparent than real, since the presence of sugar renders necessary a less amount of that substance in cooking, and the milk is of a much richer quality than that commonly sold in cities.

\section{On the Extraction of Tallow from the Tallow-Tree.}

THe seeds of the tallow-tree (stillingia sebifera) are picked in China at the commencement of the cold weather in November and December, when all the leaves have fallen. The seeds 
are, in the first place, taken to the building where the process of making the tallow is carried on, and picked and separated from the stalks. They are then put into a wooden cylinder, open at the top, but with a perforated bottom. This is placed over an iron vessel (about the same diameter, or rather larger than the wooden cylinder, and about six or eight inches deep) containing water, by which means the seeds are well steamed for the purpose of softening the tallow, and causing it more readily to separate. The furnace has four or five iron vessels in a row, about three feet high, four or five feet broad, and eight or ten feet long.

When the seeds have steamed ten minutes or a quarter of an hour, they are thrown into a large stone mortar, and are generally beaten by two men with stone mallets, for the purpose of detaching the tallow from the other parts of the seed. They are then thrown into a sieve, heated over the fire, and sifted, by which process the tallow is separated, or nearly so, although they generally undergo the process of steaming, \&c. a second time, that nothing may be lost. The other part of the seed is ground and pressed for oil.

The tallow now resembles coarse linseed-meal, but with more white spots in it, and derives its brown color from the thin covering over the seed, (between it and the tallow, which is separated by the pounding and sifting. In this state it is put between circles of twisted straw, five or six of which are laid upon each other, and thus forming a hollow cylinder for its reception. When this straw-cylinder has been filled, it is carried away and placed in the press. The tallow is pressed out by means of wedges, driven in very tightly with stone mallets, and passes through a hole in the bottom of the press inte a tub, which is sunk there to receive it. It is now freed from all impurities, and is a semi-fluid of beautiful white color, but soon gets solid, and in cold weather is very brittle. The inside of the tubs which collect the tallow is sprinkled or dusted over with a fine red earth, well-dried, which prevents the tallow from adhering to the sides. It is thus easily removed in a solid state from the tubs, and in this condition the cakes are exposed for sale in the market. As the candles made from this regetable tallow have a tendency to get soft and melt in hot weather, they are commonly dipped in wax of various colors, as red, green, and yellow. The cake or refuse which remains after the tallow has been pressed out of it, is used for fuel or to manure the land, and so also are the other parts of the seeds from which oil is extracted.

It may be remarked that this tree has been cultivated in South Carolinn for more than a hundred years, and appears well adapted to the climate.-Agricultural Department, Patent Office.

\section{On the Construction of Hot-beds.}

The following remarks, relative to the construction of hot-beds, were recently made at the Farmer's Club, New York City, by J. P. Lowe, Esq. :-

It is a useful practice, and indeed economical, to have the necessary amount of earth collected in a heap, say latter part of August, so that it may he ready for use when required in early spring at the time of making hot-beds. This heap, during the winter season, in consequence of frequent freezings and thawings, becomes finely pulverized, and not being trodden down, or in a compact state, the atmosphere can freely circulate through the mass, and in so doing deposits ammonia, \&c., which will prove conducive to its fertility.

Next in order, I shall speak of the proper covering for sashes, for the reason that this is generally provided during late winter as preparatory to the making of hot-beds. Moss, hay, and refuse material are frequently but injudiciously made use of, for, during the removal and replacement of such substances, nt times necessary to give air and light to plants, small portions by accident fall upon them, which soon undergo decomposition; and the plants, being too tender to withstand the produced effect, very often droop and die. Mats are, doubtless, much better as a covering to prevent the effects of frost than the materials already spoken of; for the objections in the one case are not applicable in the other, and the best kind as well as the most easy to construct are those made by almost every gardener. Two men accustomed to such work can make during a day from six to seven mats, six and a half feet long by five feet wide, and the mode of operation can readily be understood. A coarse frame of the required size is procured, and from four to five nails, according to the size of the mat required, and at equidistant points from each other, are driven in each of the 
end boards, about one and a half or two inches from the inner margin. The frame is then rested against a wall or other conrenient place, and a piece of strong twine is made fast to the first nail in order of those at the top board, and is then continued down to the opposite nail of the end board, and there made fast; the twine is then continued upwards, and brought down again, without being secured, for the purpose of measuring a length twice that of the mat intended to be made, and is then rolled upon a short piece of stick, with a slit in the end, in which the twine may be placed to prevent its unravelling when it shall have been wound up to within one and a half feet or two feet of the nail of the lower end board. A like arrangement of the twine is made with the other nails in succession. Then one man, each side of the frame, takes a small quantity of straw in his hand from a heap, necessarily near by, which had previously been arranged evenly for such purpose, and places it over the nails of the lower part of the frame, permitting the ends of the straw to project, say three or four inches, beyond the side line. His comrade upon the opposite does likewise, and these are looped in by means of the pieces of twine already spoken of, and the operation is so continued until the mat is made.

In due time the necessary amount of horse-dung should be saved; and it should be borne in mind that the richness and heating quality of this manure will depend much upon the food given the horses from which it is produced. If they have been highly groomed, a considerable part of their bedding, which generally accompanies the manure, should be mixed with it, so that the beds afterwards to be made may not be too hot.

The use of spent-tan is frequently desirable, and especially so where it can be procured cheaply. Professor Mapes, speaking of this material, says: "Gardeners often find that their hot-beds lose heat before the season is sufficiently advanced to part with their use. By mixing with the horse-droppings a quantity of spent-tan, they continue them in heat long after the horse-manure has ceased to be active; and, by such an arrangement, the slowly-decomposable tan is rendered an efficient manure for the next season's operations; for, when properly decomposed, no manure is more rich in the earthy salts than the decomposed bark of trees. The large quantity of carbonaceous matter resulting from its decomposition renders it retentive of ammonia, while its free, loose character causes soils, otherwise too compact, to be free and fertile."

In regard to the construction of the frames of hot-beds, it may be well to state that the double-board system for the sides, containing a space of confined air, which is one of the best non-conductors of heat, is now fast coming into use, for by its means there is a more evenness of temperature kept up. The mistake of cutting the glass for the sashes square is very frequent; I will quote Prof. Mapes on this point, as his explanation is very clear. He says:-

"Sashes should never be made with square ends to the glass; where they lap, the water will remain, sometimes in large drops or globules, forming lenses, the foci of which, from the heat of the sun, destroys plants; but if the ends of the glass be slightly curved, but one drop of water can remain, and thus the joints are always clean and free from the objection before named."

The best position for a hot-bed is that which will give it a south-eastern aspect, so that the plants may benefit by the morning sun. Decision being made as to the location, the frame is placed upon the ground, and a mark made around its inner sides; the earth is then generally dug out to a depth of some eighteen inches. The manure, having been previously well intermixed, is placed in this receiver, and continued to a height say of one and a half feet above the surrounding soil, or higher, as in the case of preparing a bed for egg-plants. Indeed the height will depend much upon the quality of the manure, its compactness in the bed, as well as the temperature required. The frame should then be placed on top of the bed, and more manure thrown in, but leaving a space between it and the glass of about eight inches. Before putting in the soil, the bed should be covered up by means of boards and mats, until it shall become sufficiently heated. The mats and boards are then removed, and about seven inches of soil placed on top, which should be made very even, and not in a slanting direction with the sashes; for in such case, at the time of watering or heary rains, if there be a leakage on the top, the streaming of the water would be hurtful to the 
plants. The sashes are now slid on, and the mats are placed on top, and a day or more suffered to elapse, as may be required, so that the soil may have its temperature increased sufficiently before sowing the seed, and become rather warm; this will have a tendency to destroy many of those insects that feed on young plants. After this, the covers may be taken off to permit the escape of steam, and drills are then made by means of the garden rake, over which the seed is scattered broadcast, and the rake is then used to cover it in. Some persons prefer not to make drills, but scatter the seed, and then sift some fine soil over it.

Young gardeners should make use of a thermometer to indicate temperature, which may be hung inside of the deeper of the two side-boards of the frame, so that when a person stands in front of the bed, it will be opposite to him.

From the time of the seed germinating until the plants arrive at maturity, much care is needed, for a very slight frost would be likely to prove injurious; but during mild days they should be permitted to have plenty of fresh air, and generally a slight opening to let out steam; for if the bed overheats during the early growth of the plants, they will grow too rapidly, and consequently be very tender.

The proper temperature of the inside air is considered to be from $45^{\circ}$ to $60^{\circ}$ Fahrenheit's thermometer, when positioned as described.

After the plants shall have somewhat grown, they will be likely to require watering, and care should be taken that the apertures of the rose of the watering-pot be very small, so that the water in passing through may fall gently upon the plants. If the weather happens to be very cold at the time they require water, it will sometimes be necessary to add a little hot water, to take the chill off that about to be made use of. Moreover, during cold weather, it will be necessary to water at noon, or soon after, but if mild, this may be done immediately before sunset. - Working Farmer.

\section{Employment of Cotton Waste in Hot-beds.}

At the Berlin Association for the Promotion of Horticulture, Prof. Cock made a communication about a substitute for horse-manure for generating heat in hot-beds, which, as a productive of caloric, is far superior to the latter. This substitute is the refuse of cottonspinning mills. A bed prepared on the previous day had, when examined in the afternoon, a temperature in its interior of not less than $113^{\circ}$ of Fahrenheit.

\section{Hay-caps.}

A Writer in the American Agriculturalist recommends to farmers the use of hay-caps, to be prepared in the following manner: Stout, unbleached sheeting should be taken, from thirty-six to forty-two inches wide; the latter is the best, which should be cut into lengths of forty to forty-five inches. To make forty of them (and no extensive farmer should have less than 100) would require a gallon of linseed-oil, which should be simmered with four pounds of beeswax, and a quart of japan added after it is taken from the fire. When cold, the mixture should be about the thickness of lard in summer; if not, more oil or more wax may be added. The cloths should then be payed over, to use a sea expression, with the hand or a small piece of shingle, on one side only, and then dried in the sun; when dry, the females of the family will cheerfully, and in a very short time, sew into each corner a stone of the weight of about seven or eight ounces, which completes the affair.

No hemming is required, as the wax and oil will keep the edges sufficiently firm.

In respect to their economy and usefulness, the writer says: I do not think I am extravagant in saying they will pay the cost in one season, and will last ten years if taken good care of. Within a few days we have had one entire rainy day, when my neighbor's hay was thoroughly soaked, while mine was as as safely covered as if it had been packed away in the barn. My manager thinks that one-third of the cost of some new covers just made were paid for on that day.

"Large covers, made in the same manner, to cover the whole of a load of hay, with heavier weights, of course, would also be an admirable protection against sudden showers." 


\section{Dederick's Improved Hay Presses.}

Fig. 1.

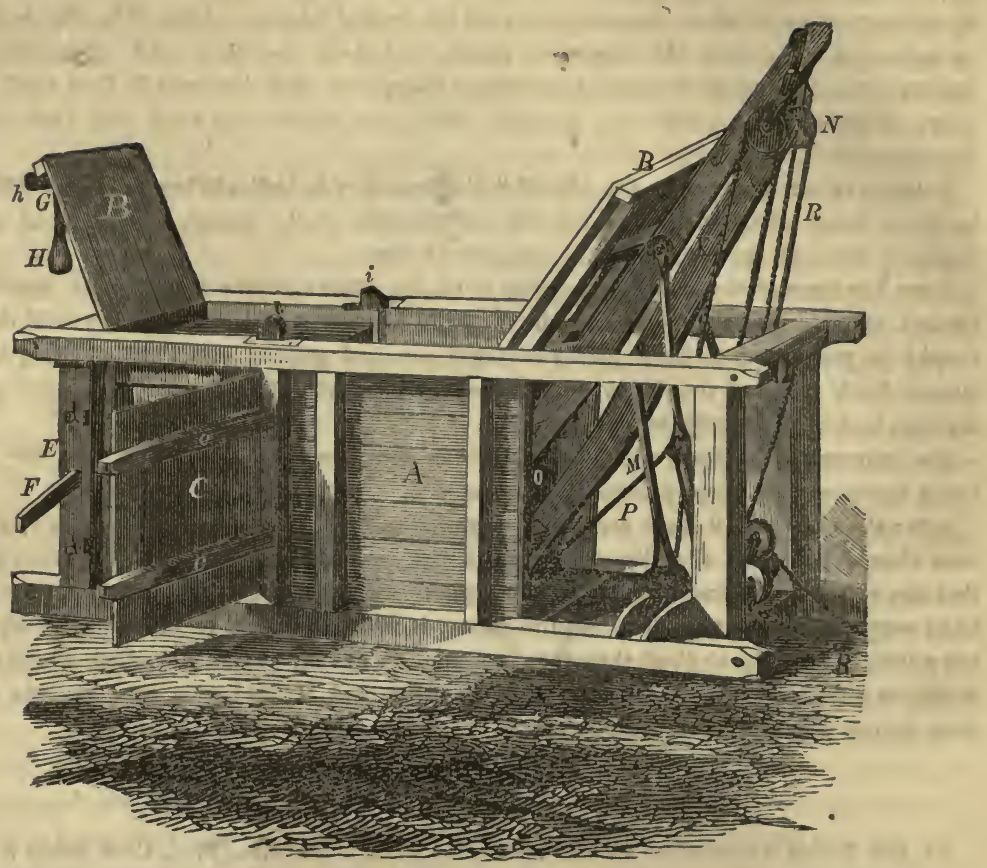

THE annexed engrarings represent the appearance and construction of an improved press adapted for packing hay, cotton, hops, hemp, \&c., for which two patents have been recently granted to Levi Dederick, of Albany, New York. One patent is for an improvement on the doors of the press, and the other is for an improvement in operating the follower, giving it a parallel motion, while pressing, by toggle-levers.

The Doors.-A is the case or box in which the cotton, hay, or other article to be pressed is placed. It has a trap-door B B, and a side-door C. The cotton or hay is placed in the case through the top-opening. The side door, especially, requires to be very securely fastened to resist the great pressure that comes upon it. This door is secured to a stile $\mathrm{D}$, having a small round tenon at each end. These fit loosely in recesses in the top and bottom pieces of the frame. To this stile, and also to the door C, are secured two arms or battens $c c$, the outer ends of which project a short distance beyond the edge of the door C. E is a stile attached to the top and bottom pieces, like the one at $\mathrm{D}$, but not to the door. This stile $\mathrm{E}$ has recesses $d d$, which, when the door is closed, fit over the end of the battens $c c$. F is an arm or lever attached to the stile $\mathrm{E}$ by a pirot when the door is closed; the outer end of this arm or lever is fitted in a recess in the stile. The door $\mathrm{C}$ is thus made perfectly secure; the outer ends of battens $c c$ fitting in the recesses $d d$, and the outer end of the bar lever fitting in the recess $f$. To unfasten the door, raise the outer end of $\mathrm{F}$ from the recess $f$, and turn the stile $\mathrm{E}$ around till the end of the battens clear the recesses $d d$. This door is for discharging the compressed material, hay, cotton, \&c. The top door, when closed, is secured by $a$ bar $G$, which is attached by a bridge to the front edge of the door. The bar is provided at each end with a flange $h$ to catch in the top side-pieces $i i$ of the frame, and this secures the top door on the hay or cotton when the case is full for pressing. By raising the lever $\mathrm{H}$ to a vertical position, the bar $G$ is turned so as to free the flanges $h h$ from the caps $i i$, and the door can be opened.

The Levers.-The follower presses horizontally in the case A; it is not seen, but suffice it 
to say that the inner ends of the levers $J \mathrm{~K}$ are secured to it, the one above the other. These levers are connected by rods $\mathrm{N}$ at their outer ends, and these have pivot-joints passing through the levers. L M are other levers secured by pivots to J K, and to lugs by like joints in the posts. There is a pulley attached to each side of the follower lever $\mathbf{K}$; below the ends of the connecting arms is a large roller 0 . A rope $R$ is secured at one end on the bottom of the frame, then passes over the outside pulley at $\mathrm{N}$, then down around the roller $\mathrm{O}$, then up and over the nigh pulley $\mathrm{N}$, then down and around the pulley on the bottom of the frame. By pulling on this rope, by winding it upon a windlass, \&c., the upper ends of the levers $\mathrm{J} K$ are drawn down, and the follower thrust forward, pressing the hay, cotton, or other material with great force. The levers have a quick motion and exert littlo power when they first commence to act, but hare a slow motion and exert the greatest power near the end of the stroke; this is the kind of motion required. The action of these levers is parallel, like that of the joints of a parallel ruler.

The rope $\mathrm{P}$ is connected at one end to the follower, then passes over a pulley on the topscantling of the frame, and down over another pulley. This cord is for drawing back the follower and elevating the levers, when the cotton or hay is pressed and secured in bale. This press may have a door on one or both sides. The foregoing engraving represents a bale in the press, bound ready for removal from the door $\mathrm{C}$, there being another such door on the other side, so that the bale can be removed from either side of the press at pleasure. B B

Fig. 2.

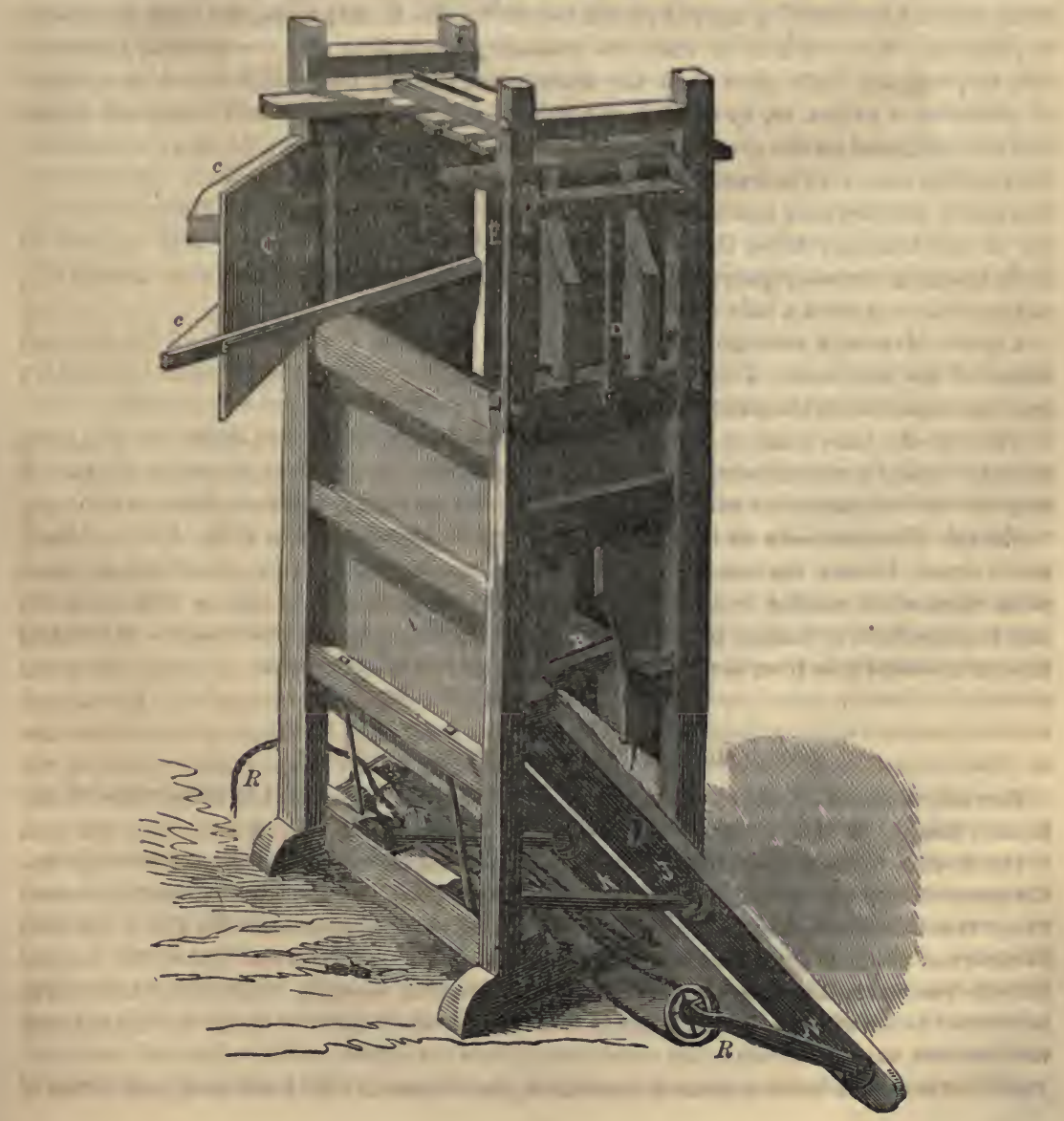


are the upper doors represented open, ready again for the reception of the hay. $J \mathrm{~K}$ are the levers, which, being drawn down by the system of ropes and pulleys $N R R$, press the follower 0 forward on the hay, with a power which is alike simple and tremendous. It is so constructed that, for transportation to any great distance, it is taken apart, (the levers, lever-connections, ropes, and pulleys being packed securely in a box,) making in all but seven conveniently handled pieces; and, by the printed directions for putting up and operating which accompany each press, it can be put together again in two or three hours by any two farmers, without the aid of a mechanic. It is so conveniently portable, that it can be moved from one field or farm to another by a pair of horses or oxch, drawing it, as they would a sleigh, upon its own shoes attached underneath. It is operated by a horse and capstan; the horse going round eight times to make a bale, and twice without changing his direction to draw back the follower. With two men and a boy it will bale, without any extra cxertion, from six to eight tons of hay per day, according to the number or size of the press.

Another form of this improved press is designated the upright or vertical press, (fig. 2, p. 67,) and differs but slightly from the horizontal already described. When the door $\mathrm{C}$, which, as in the cut of the other machine, is represented open, is closed, the head $\mathrm{U}$ is moved over to either side at pleasure; the hay is then thrown in, and when the box is full, the head is moved back again to the centre of the press; the power being then applied to the parallel levers J K, operated by the system of ropes and pulleys $N R R$, press the follower B up against the hay with the same simple power exercised in the horizontal. The door $\mathrm{C}$, and also a similar door on the other side, is then opened, the bale is bound, and the ends of it being relieved by releasing the end of the bar or handle $\mathrm{D}$, it is taken out from either side at pleasure. While this is an excellent stationary press, it is also a convenicntly portable one, as (weighing little more than the other press,) it can be readily shoved up a couple of planks on a wagon, or, by spiking on a pair of runners, it can be laid down and moved like the horizontal on the ground. The horizontal press is, of course, the more convenient, but requires some care in tramping in the hay in order to make a bale as nice in appearance as that under ordinary care coming from the vertical. As a cloth-press, one of these presses is in use at the Harmony Mills, Cohoes, New York, and it is easy to perceive that they can be made available for many purposes. One that can press 500 . pounds of hay costs about $\$ 175$, and one that can press a bale of 200 pounds, about $\$ 100$.

A great advantage attending this improvement has been the reduction of the size and weight of the hay-press. Presses of the old form required a separate and entire building for their accommodation, the posts supporting the framework being ten and twclve inches square. The size of the same posts in the improved press does not exceed five inches, all the other parts also being proportionate. Instead of being obliged to build as formerly, the farmer may now order a hay-press with as much facility as a mowing machine or horse-power.

Manny's Hay-press. - In an improved hay-press, recently patented by Pells Manny, of Waddam's Grove, Mlinois, the bales are pressed into a square form, and the levers act so as to press them when moving both forwards and backwards; that is, no time is lost, when one bale is pressed, in returning the followers to the point where they commenced, to press in the box a second bale from the point where they commenced to return.

\section{On the Manufacture of Cider.}

THE following article on the manufacture of cider is communicated to the Journal of the London Society of Arts, by Mr. T. W. Booker, M.P.:-

Mr. Booker states, in commencement, that in a recent conversation with a German baron, the proprietor of celebrated hock vineyards on the Rhine, an opinion was expressed, that many varieties of the common apple were capable of producing as valuable and desirable $a$ beverage as the hock grapes, if a different process of making the liquor were adopted. The process recommended by the baron for the manufacture of hock, and which he considers applicable to the manufacture of cider, is as follows:-The liquors, after the fruit is pressed, are straincd, so as to separate the coarse muss from the liquor, which is then put into large ressels, when shortly afterwards fermentation commences. This fermentation is watched 
with the utmost care and attention, as every thing connected with the future quality, richness, and value of the wine depends upon it; the finer muss, that remains in the liquor after it has passed through the straining apparatus, drops to the bottom in the course of a few days, and the wine becomes perfectly clear and transparent, retaining all its original saccharine matter, with all its strength, richness, and flavor. At this critical period, upon which we consider the quality of our wines depend, we adopt the process of racking. This racking must be effected in such a manner as to prevent any part of the liquor coming into contact with the atmospheric air; should it do so, fresh fermentation, in all probability, will take place; and by the same means, the like causes repeated will operate, and be followed by the same results-repeated fermentation-until the flavor and richness of the original liquor are destroyed, and the liquor, instead of becoming wine, would become as worthless as your inferior cider. The reason for this Rhenish caution in preventing the liquor from coming into contact with the atmospheric air during the process of racking, is this: The first fermentation is what is termed vinous fermentation, and results in the liquor subjected to it becoming wine; if repeated, or acetous fermentations are allowed to follow, the rinous and saccharine properties of the liquor are converted into acid, and the wine becomes vinegar. Now, the atmosphere is the laboratory from which the liquor absorbs the chemical agent which produces these distinct and separate fermentations. And now, practically to apply these observations: one fermentation is all that is wanted to convert the juice of the apple into wholesome cider. The plan to insure this is as follows:-First, grind the apples in the cider-mill, and squeeze the juice from the pulp, as is done at present. Second, run or pour the liquor, after being squeezed or strained, into a vat, capable of containing three or four, or even more, hogsheads. This vat must be placed in an elevated position, at least five or six feet above the floor, to admit the hogshead or cask in which the liquor is to be ultimately secured, to be placed under it. At the bottom of the large vat a tube is inserted, of from one and a half to two inches in diameter, for the purpose of discharging into a receptacle beneath it. While the process of fermentation is going on, the top of this tube should be corked or plugged up. When the liquor in the vat has settled or clarified, it is drawn off into the receptacle below, retaining all its original saccharine qualities. The operation is now completed, and the result will be found to be a liquor wholesome and palatable, full of spirit, richness, and flavor, and of value proportioned to the description or sort of apples which are cultivated. Our firm conviction is, that the difference in value of all the cider produced by these simple means, over and above that produced by our present careless and slovenly method, would amount to tens of thousands of dollars a year, and would be so much clear gain and profit to all those who make cider.

The production of good cider depends upon the description of fruit of which it is made, the season, and state of the apples when they are crushed, and the management of the juice while it is fermenting. It will therefore be proper to consider the subject under these three heads separately:

1. The kind of apple which makes the best cider. The acid which gives the peculiar quick and sharp feeling upon the palate, in good cider, having first been noticed in the apple, although it exists in many other fruits, has been termed the malic acid. It may not be amiss to say, that it is the due combination of this acid with saccharine matter-namely, the sugar of the apple, properly fermented-which is the object to be aimed at in the manufacture of cider. In the selection of the fruit will depend the proportion of malic acid contained in the liquor. The crab has a much greater quantity of this acid than the cultivated fruit; and, generally speaking, in proportion as we obtain sweetness by culture, we deprive the apple of its malic acid. Hence it follows, that some delicious table fruits will not make good cider; this rule, however, is not invariable, as the golden pippin and some other fine apples appear to contain the proper admixture of acid and sweetness which is desirable in the liquor. Mr. Knight recommends that the different sorts of fruit be kept separate, and considers that only those apples which are yellow, or mixed with red, make good cider; and that the fruit of which the flesh or rind is green, is very inferior. He recommends that the apples should be perfectly ripe-even mellow, but never decayed-before they are crushed. Mr. Booker is of opinion that the quality of cider has deteriorated since increased attention 
has been paid to orchards. This he believes to be owing to the want of a due proportion of the peculiar acid which is found in the greatest quantity in the wild fruit, and suggests that it may be expedient to mix a certain quantity of the crab-apples with the fruit before it is crushed.

2. The best time of the year for making cider. As Mr. Knight recommends the fruit to be perfectly ripe, even mellow, before it is crushed, the process of making cider, if this course is adopted, can only happen late in the autumn. As it is difficult, also, to manage the fermentation of the liquor in warm weather, it is better to defer the making of cider to as late a period as possible; if, however, the liquor can be put into a cold cellar after the first fermentation is over, the manufacture might commence earlier. It should be borne in mind that the juice of unripe fruits ferments more quickly than that of those which are ripe.

3. Fermentation of the juice. The researches of scientific men, although very elaborate, have done very little in throwing light upon the nature of fermentation : it appears to partake, in a measure, of the vital principle, of the phenomena attending which we know nothing. Many curious and interesting facts have been discovered during the investigation, but none of which appear to be of much use in the making of cider. There are three kinds of fermentation, or rather there are some products which pass regularly through three stages of fermentation-namely, the vinous, the acetous, and the putrescent. Other substances pass at once to one or other of the latter stages; gum and water turning to vinegar without forming any spirit, and meat at once putrefying. It is not desirable that the vinous fermentation should be complete in the manufacture of cider, in which case all the sugar of the apple would be converted into spirit; this never does happen without a portion of vinegar being also formed, the acetous fermentation going on conjointly with the vinous; as when cider frets a great deal, it may be very strong, but is comparatively of little value, having lost all its richness, and become sour. The vinous fermentation stops naturally before it has run its course, and it is the object of the maker to avail himself of this property in the liquor, and to endeavor to prevent any secondary fermentation taking place; the number of schemes which have been suggested to prevent this shows that it is the most important point to be attended to in the manufacture of good cider. Mr. Booker is of the opinion that a hundred-gallon cask is much better than one larger, and that the liquor is not only more easily managed, but more likely to be good; it may be that cider in large casks becomes stronger, but it is not so frequently rich as in small hogsheads. Although it may not be apparent, fermentation commences as soon as the juice is expressed from the fruit; and the sooner the cask is filled and allowed to remain quiet, the more regular and certain will be the process. What should we think of the brewer who, while his beer was working, brewed another quantity, and added the raw wort to the first? Yet this is constantly done in filling a large cask with cider; or even worse, for the apple-juice is added cold, whereas the wort might be mixed with the beer while warm. It would be greatly better to keep the liquor in open tubs, till enough be obtained to fill the cask, and then to put it together at once. The application of cold will check fermentation immediately. "I have seen liquor in a state of froth boiling out of a large jar, suddenly reduced to a state of quiescence, by pumping water upon the side. This fact induced me to cause an experiment to be tried during a very bad season for the cider-making, the weather being very warm : a cask of juice was rolled into a brook of cold water, and sunk by stones attached to it; it remained in that position till nearly Christmas, and was much better than any other made that year. Perfect stillness is very desirable, as motion is found to excite the acetous fermentation. A bottle of wine attached to the sail of a windmill in motion, was, after three days, converted into vinegar, although closely corked. When a second fermentation does take place in cider, there is very little hope of its being rich and good. In such case, I should recommend its being drawn out into tubs, exposed to the cold as much as possible, and, after being thus flattened, put back into the cask, at the same time well stirring up the whites of fifteen or twenty eggs, previously mixed up with a portion of the liquor; if this succeeds in fining it, which probably it will, it may then be racked into a clean cask, and closed as much as possible from the air. It is probable that a great deal of mischief is caused by some principle of fermentation remaining in the cask; this might be prevented by well scalding the casks 
before they are filled; or, what I think would be better, by washing out the casks with clear lime-water. One large piece of lime put into a hogshead of water, and allowed to settle, would answer the purpose. Some brimstone matches burned in the casks would have a tendency to prevent fermentation." - Journal of the Society of Arts.

\section{Krauser's Patent Portable Cider and Wine Mill.}

THE peculiar feature of this mill is an arrangement of reciprocating pistons, which, by their alternate action, will cause a quantity of apples or grapes continually to advance with irresistible force against the passing teeth of a rapidly-revolving cylinder, so that by the action of the latter the whole fruit is at once reduced to pulp, and discharged into the tub beneath the mill. The idea intended, and which is thus beautifully and effectively reduced to practice, is that of exactly imitating the action of the human hand in holding an apple against the teeth of a revolving cylinder until it is entirely reduced to pulp.

\section{On the Manufacture of Wine, and the Cultivation of the Grape for the Vintage in the United States.}

THE following article on the already important branch of American industry-the manufacture of wine and the cultivation of the grape for the vintage-has been prepared from three several articles, which have been recently published in the Philadelphia Horticulturalist, Putnam's Magazine, and Mansfield's Railroad Journal.

The cultivation of the vine, as an article yielding commercial products, has only recently commenced in the United States; but its extension is so rapid, that the day cannot be far distant when wine will be classed among the great staple productions of the country. In the valley of Ohio, taking Cincinnati for a centre, within a radius of twenty miles are planted fifteen hundred acres of vine-yards, two-thirds of which are in bearing. The average yield will not be estimated at less than two hundred and fifty gallons of wine per acre, which will give, as the present yield, two hundred and fifty thousand gallons of wine, worth from one dollar to one dollar and fifty cents per gallon. The rapidity with which this cultivation increases may be inferred from the statistics, which show that last year were sold in Cincinnati two millions of grape-cuttings, and four hundred thousand roots; a quantity sufficient to plant more than six hundred acres of vineyards. These were distributed to every part of the Union, from New York to Missouri, and as far south as Georgia and Texas. The average prices were, for cuttings, two dollars and a half per thousand, and for roots, forty dollars per thousand. It is interesting to know that while the increase has been so large in the quantity of wine manufactured, the demand increases in a still greater ratio. The first cultivators found considerable difficulty in obtaining a market for the produce of their vines; but now they have a ready market for their vintage at good prices. In addition to the amount under cultivation for grapes above stated, other parts of the South and West are extensively employed in the same manner. At Hermann, Missouri, there are five hundred acres, and in Indiana, Kentucky, Tennessee, North Carolina, and Georgia are probably as many acres more.

The quantity of wine made in the United States, according to the details of the two last census returns, is as follows :-

In 1840 , the whole amount returned was 124,733 gallons; in $1850,219,101$ gallons; increase, 80 per cent. An examination of the following table shows that the cultivation of the vine does not succeed in some States where it has been already attempted:

\begin{tabular}{|c|c|c|c|c|c|c|}
\hline " & & & & " & & \\
\hline 6 & Maryland & "6 & 7,805 & 6 & 6 & \\
\hline o6 & Now Jersey & "6 & $\begin{array}{r}9,416 \\
0\end{array}$ & "s & $"$ & 1,811 \\
\hline " & $\begin{array}{l}\text { North Carolina } \\
\text { Indiang. }\end{array}$ & 6 & 28,752 & "6 & “ & 11,958 \\
\hline 66 & Illinois & "6 & 10,200 & "6 & 46 & 14,055 \\
\hline “ & Kentucky & “6 & 2,209 & 6 & 6 & 7 \\
\hline " & Missouri & "6 & 22 & 6 & " & $\begin{array}{r}8, \\
10\end{array}$ \\
\hline 66 & Ohio & "6 & 11,524 & "6 & 66 & $\begin{array}{l}10, \\
48\end{array}$ \\
\hline " & Virginia & " & 13,911 & "6 & "6 & 5,408 \\
\hline
\end{tabular}


This table seems conclusively to show that the culture of the grape is losing ground in the several Atlantic States, and increasing with great rapidity in the valleys of the Ohio and Missouri. The census returns for 1840 and 1850 give the following aggregate of wine production in New Jersey, Pennsylvania, Maryland, Virginia, and North Carolina : in 1840, $\mathbf{7 4 , 2 6 4}$ gallons; in $1850,44,998$ gallons.

For the same period, however, we have the following as the aggregate production of the five States in the valleys of the Ohio and Missouri : in 1840, 25,194 gallons; in 1850, 83,935 gallons. A low estimate of the wine produce of the entire Ohio Valley for the year 1855 would be 600,000 gallons; and it may be safely predicted that the production of the same territory in 1860 will be counted by millions of gallons.

An attention to localities will show whereto American grape-culture is tending. Thus, in 1840, two-thirds the wine made in Ohio was made in Richmond county, but in 1850 four-fifths the whole was made in Hamilton, Butler, and Clermont counties, in the vicinity of Cincinnati. In Kentucky, most of the wine is made in the vicinity of Louisville and Covington. In Indiana, in the vicinity of Laurenceburg and Jeffersonville, (opposite Louisville.) These places are all in the space of 100 miles on the Ohio River.

It is an interesting question how this increased production of wine will affect our population, viewed in relation to the subject of intemperance.

By the census of 1850 , it appears that the imports of foreign wines into the United States for that year amounted to little over six millions of gallons, while our home manufactures of whisky, ale, and spirituous liquors reached the enormous sum of eighty-six millions of gallons; one quarter of a gallon for each person, and in value only ten cents per year; while France consumes nine hundred millions of gallons of wine, equal to $25 \frac{3}{4}$ gallons to every man, woman, and child (of either sex) in her population.

These facts are well worthy of consideration, especially when we reflect that France sustains the reputation of being a most temperate country. Indeed, if we compare the vinegrowing with the non-vine-growing countries of Europe, we find that drunkenness, with its carloads of evil, traverses the non-producing North only, while the South furnishes a prevailing example of sobriety.

In regard to the limits within which the culture of the grape for commercial purposes in Europe is restricted;-The cultivation of the vine is confined to the district within the parallels of Lisbon, $38^{\circ} 42^{\prime}$ (sea-board,) and Titiacum, (Caspian Sea,) $46^{\circ} 20^{\prime}$, making a range of $8^{\circ}$. But it must be observed that there are large districts within this range where the vine will not grow. These are the elevated and exposed plains of the interior. In Asia and Africa, the vine limit runs further south, to about $30^{\circ}$, but hardly as far north, making in all about $12^{\circ}$ of latitude.

In the United States, the vine limits are El Paso in New Mexico, latitude $32^{\circ}$, and Ann Arbor, (Michigan,) $42^{\circ}$, making a geographical zone of about $10^{\circ}$. But it must be remembered that there are large districts within these limits, which, on account either of the humidity of the climate or the height of the land, will not bear vines.

The grape, to make good wine, requires a temperature of at least $67^{\circ}$ Fahrenheit, in summer. Hence, the grape will not make wine to profit north of Cleveland; and as the northern half of Ohio, Indiana, and Illinois is a high plain, swept by lake-winds, it is not at all probable that wine can be made profitably north of the centre of these States. So also, the vine will not make good wine in a very hot or a humid climate. The cultivation of the vine for wine is, therefore, confined to a very small district; and in the United States that district will probably be found chiefly in the valleys of the Ohio and Missouri.

Notwithstanding the adaptation of this section of our country for the cultivation of the vine, few are aware how difficult a matter it was to introduce this branch of domestic industry. Many years were spent in unsuccessful attempts, and not a few instances of severe loss and disappointment to the early cultivators occurred, before success was attained. Although, from the earliest settlements of the West, various efforts were made to cultivate the vine, both by importing foreign varieties and by selecting the best productions of our native wilds, not one of these early vineyards is now in existence, and 
no one has, to this day, in any part of the United States, been successful in obtaining even a tolerable vineyard from any foreign grape.* Thousands of individuals have tried it, on a small scale, in various parts of the Union; and several persons-as, for example, Mr. Loubat, Mr. Longworth, \&c., of great experience abroad or knowledge at home, joined to abundant capital-have tried it on a large scale. The result, in every case, has been the same: a season or two of promise, then utter failure, and finally complete abandonment of the theory. The only vineyards ever successful in America are those of American grapes. We might add here that one foreign grape has been successfully acclimated here, and only one. The "Traminer," from the Rheingau, a small-berried vine, has been persuaded to thrive here, by Mr. Longworth. But this, for the manufacture of wine, is almost valueless. Nor has one of the hundreds of nurserymen and amateurs who have been, and still are, industriously striving to obtain new seedling varieties, yet produced one which has been sufficiently valuable in all respects to come into general cultivation.

While the attempt to introduce the culture of the grape was maintaining a doubtful conflict with apparently insurmountable obstacles, it received the timely aid of Mr. Longworth, of Cincinnati, who, after spending more than one small fortune in fruitless attempts to introduce the foreign vine and vine-dressers, obtained and proved the value of the Catawba Grape, which now constitutes nine-tenths of the vineyards cultivated in the West. This is a native grape, obtained from the mountains of North Carolina. In the manufacture of wine, Mr. Longworth has rendered to the country no less signal service; for, without any experience to guide him which was adapted to our new circumstances, a multitude of vexatious disappointments and losses were met and overcome. Even after years of successful manufacture, a year or two since, through some untoward circumstance, he lost by bursting, in a single season, thirty-six thousand bottles, valued at one dollar per bottle-enough to have ruined any ordinary fortune. No wonder then that all the vine-dressers of the country regard Mr. L. as the father of wine-culture in the United States; he having accomplished, by his own private fortune and untiring enterprise, that which must otherwise have failed or only succeeded by slow degrees. Mr. Longworth is still extending his arrangements for the manufacture of his "sparkling Catawba," by building yet other cellars, where the process peculiar to the manufacture of this wine may be perfected. His cellars furnish this year (1855) one hundred and twenty thousand bottles of the "sparkling," and next year he expects to increase the amount to two hundred thousand bottles.

The "still" or "dry" wines are the kind chiefly made by other cultivators; indeed no vineyard, however small the cellarage of its proprietor, seems to be without its casks of wine, but the manufacture of the "sparkling" requires a deep cellar with large tuns for its fermentation.

Great efforts are being made by the most enterprising cultivators to produce and introduce new varieties of the grape, but at present none have been sufficiently tested to entitle them to a very prominent place in general cultivation. Thus far the Catawba stands unrivalled. The Isabella in this climate ripens its berries unequally; and the "Cape" is even being dug up as not worth cultivation. Mr. Longworth, Mr. Buchanan, Dr. Mosher, and all who have tried it express great hopes of the "Herbemont," and it is forming a large share in the new plantations now being made. It is said to blossom about eight days later than the Catawba, and to mature its fruit several days sooner. It is a small, nearly black berry, growing very close on the cluster-very sweet, with tender pulp and thin skin, and not as liable as other varieties to be affected by the "rot."

- Of the various experiments made with regard to cultivating foreign grapes here, we will mention a few. Mr. Parmentier, of Long Island, established a vineyard of foreign grapes there, and was finally compelled to abandon it. M. Loubat planted forty acres at New Utrecht, L. I., with one hundred and fifty thourand imported vines, and they throve not, neither did they bear. Mr. N. Longworth, of Cincinnati, also tried a variety of grapes from Bordeaux and the vicinity of Paris. These he obtained from M. Loubat's vine-yard. They did not succeed. From Madeira he imported six thousand vines of their best wine grapes; these were rooted up, after trial, as worthless. Lastly, he procured seven thousand vines from the Jura, and, after trial of five years, these also were thrown away. The vine-dressers of Vevay, Ia., attempted the culture of vines from Switzerland, with no better suocess. The imported vines planted in the early vineyards of Pennsylvania, Alabama, and Kentucky all died after a few years. And yet there is not a grape of any reputation to be found in the United States (with the exception of the Catawba) that is not reputed to be of foreign origin. 
The most approved method of preparing the ground for a vineyard is by trenching with the spade two or three feet in depth during the fall and winter, previous to planting. Cuttings are mostly used, and are by many preferred to roots, even at the same price; the argument in their favor being that the roots which are produced from the foot of the cutting, when once disturbed, will not readily grow again, and these lowest ropts are for the grape admitted to be the most important. The cuttings are planted two in a hill in the place where they are intended to remain; and if both grow, one is cut off or removed to fill vacancies; the usual distance being about three by six feet apart. The cost of trenching a vineyard varies, with the nature of the soil, the amount of stone encomntered in the subsoil, and the amount of underdraining, from sixty to two hundred dollars per acre; and the planting, including the cost of cuttings, from fiftecn to twenty dollars more. The labor required during the first three years is very slight; thorough hoeing two or three times in a season, and spring and summer pruning, are all that is necessary. In the second year the vincyard is supplied with stakes, usually of good white-oak heart, costing about twelve to fifteen dollars per thousand. Locust stakes are better, and cost about double that sum. The common practice is to have only a single stake to each vine; although some very successful cultivators use two stakes with two "bows" to each vine. The "bow-and-spur" method of trimming is the most gencral method, although many prefer, instead of bending the branch in the shape of a "bow" or circle, to train each vine across to the next stake in the row.

The great enemy of the vintner is the rot. Of this there are two kinds; although some persons think there is but one, with a slight variation in its manifestations. The first makes its appcarance in the form of a spot of yellowish-brown upon the berry, and is called the "spot rot." This spot rapidly enlarges, so that in twenty-four hours from its first appearance in a vineyard, one-half of the crop is often blackened, and presents the appearance of having been for weeks affected with decay. The other variety of this disease first shows a slight discoloration under the skin of the berry, sometimes in veins or blotches, and has hence derived the name of "blue rot." All the searching and experimenting of the best vinegrowers have failed thus far to discover aught of its cause or remedy. Some have in despair given up the attempt to make any discoveries in this direction, and are in hopes to escape the difficulty by finding new varieties not subject to the disease.

The following statistics furnish some idea respecting the products and profits of the grapeculture in Europe and the United States. In 1828, the aggregate number of acres devoted to the culture of the vine in Europe was estimated at 72,537,500 acres, producing 1,574,680,000 gallons per annum. This gives an average per acre of 137 gallons. According to a careful French estimate, the profits of vine-culture, after deducting all charges, amounted only to five per cent. on the capital employed. The total amount of capital employed was estimated at $£ 200$ per acre; this includes the price of land, machinery, improvements, permanent labor, etc. In regard to the profits and products of the vine in the United States;-Mr. Robert Buchanan, one of the most experienced vine-growers in Ohio, has furnished reliable statistics, basing his estimates on the cost of getting a vineyard of six acres under thorough cultivation and bearing at Cincinnati, and upon its subsequent produce.

The price of land from fifteen to fifty miles from the city of Cincinnati is estimated at $\$ 50$ per acre:-

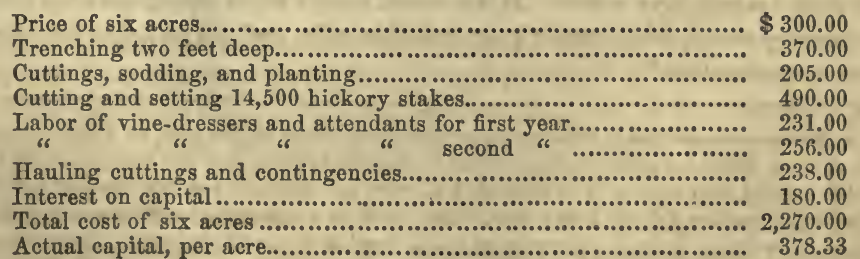

This estimate from experience, it is found, can be relied on by those wishing to plant vineyards for profit.

The products, according to a careful table prepared by Mr. Buchanan, average of six years, were about 490 gallons per acre. The results of other experiments correspond so nearly 
with this, that the cultivator may rely with much certainty on 400 gallons per acre, after two years, provided the vineyard is well cultivated and planted.

The following table gives the cost and profit of production:-

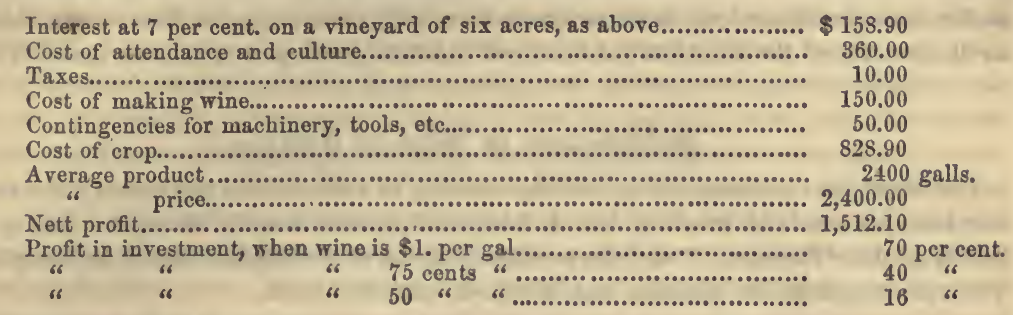

It thus appears that while the vine is unaffected by any great increase of insects, parasites, or other causes of blight, the grape may here be cultivated at a large profit, even when the wine is reduced to fifty cents per gallon. But such is the demand for pure Catawba wine, and such is the consumption of wine in this country, that it is safe to say that in full thirty years to come wine cannot be reduced to fifty cents a gallon. In all that time the good cultivators must realize heavy profits. It is true that now and then, as in the drought of 1854 , there will be a failure almost of the grape; but the heary crop of another year will more than bring up the average.

There must be five millions of acres planted in vines before the price can be reduced to a minimum in the Uniled States. This fact is enough to insure cultivators against any hazard of an overstocked market. There will probably be 600,000 gallons of Catawba wine raised in the Ohio Valley in 1855; but this is nothing to the demand. If it were doubled (which cannot be) every year for five years to come, the market would not be overstocked.

Au experienced cultivator of the vine in Kentucky writes as follows:-

Wine can be made as cheap in Kentucky as it is in France or Germany; it can be made as cheap as cider, and at fifteen cents per gallon it will pay better than any of our staple productions. And now for the proof; Say that an acre of vines will average 400 gallons. 400 gallons of wine, at fifteen cents, is $\$ 60$. An acre of our best land in hemp will average six hundredweight. 600 weight of hemp, at $\$ 5$, is $\$ 30$. Leaving a balance in favor of the rineyard, $\$ 30$, or 100 per cent. One acre of corn will average fifty bushels, worth thirty cents per bushel. 50 bushels, at thirty cents, is $\$ 15$. Leaving balance in favor of the vineyard, $\$ 45$. The expenses of establishing a vineyard will be balanced by the cost of seeds of hemp and corn sown annually, making all things equal in that respect. The tillage of the vineyard and making wine is not so laborious nor near so expensive per acre as the tillage and labor of securing the products of an acre of corn or hemp. If we could get one dollar perr gallon for wine when ready for market, or fifty cents per gallon from the press, what a source of wealth it would be! Set it down at half these figures, and the gold-mines of California would be poor in comparison. Only to think that 100 acres in vineyard, the products at fifty cents per gallon, amounts to $\$ 20,000$ per annum! A man having five acres, which he could manage himself, would find them more profitable than a Kentucky farm of two hundred acres, with three negroes to cultivate it.

Let us turn from these pleasing prospects for Kentucky, and look at the annual income France derives from the poorest and (for other purposes) the most worthless of her lands.

The actual returns from the departments of France show a grand total of about $924,000,000$ of gallons as the yearly produce, of which, in round numbers, about 24,000,000 of gallons are exported. It is impossible to estimate the value of these wines, so various are the qualities and prices; the vintage of a favorite year, in some districts, will command double and triple the price of those preceding or succeeding. Estimating the entire crop at fifteen cents the gallon, however, we find the net amount reaches the not inconsiderable total of $\$ 138,600,000$. One hundred and thirty-eight millions six hundred thousand dollars! And this from wine at five cents a bottle! A sum more than sufficient to pay off our national debt, or purchase Cuba, or buy a large piece of South America, perhaps enough to include the Amazon; and 
all in a single year. Here, in a country of such vast extent, embracing every climate, with hillsides and plains favorable for the cultivation of the grape, and native vines overspreading the forests and marshes in almost every State, we, professing to be a great agricultural people, so far have closed our eyes to these great facts, and, except in a few instances, neglected to avail ourselves of the most fruitful source of national wealth ever within the reach of man.

\section{Manufacture of Wine in Georgia.}

THE Southern Cultivator states that the att mpt to manufacture wine from a native grape has been successfully tried by Mr. A. Leary, of Munroe county, Georgia. The grape is known as the "Warrenton," and the produce is at the rate of eight hundred gallons per acre. The wine resembles the Madeira, and is high-flavored and mild.

\section{Improvements in the Manufacture of Sugar.}

C. Hustivgs Coliette, of London, has recently obtained a patent for improvements in the manufacture of sugar, the specification of which we give somewhat in full, knowing how. important a manufacture this is to a very large class of agriculturists.

This invention consists in an improved mode of treating cane-juice, molasses, beet-root juice, and other saccharine juices and syrups, for the purpose of obtaining sugar therefrom, freed or separated from the impurities and other substances with which it is mixed.

It has been for some time known that the yield of sugar from cane-juice, molasses, beetroot juice, and other saccharine juices, is smaller than it onght to be; and the cause of this small yield has been attributed to the use of a large quantity of charcoal to clarify the syrup, whereby a considerable proportion of sugar becomes absorbed, notwithstanding the most careful manipulation; the molasses produced by many of the ordinary processes often containing nearly as much as 50 per cent. of crystalline sugar.

For the purpose of avoiding these evils, the following process is employed: The juices, molasses, or syrups (obtained by any of the usual means from the sugar-cane, beet-root or other plants containing saccharine matters) are introduced into the defecation pan, together with the quantity of lime or lime-water necessary for defecation. About 30 or 40 per cent. of lime is sufficient for this purpose. As soon as the lime has produced the requisite effect upon the liquid, a sufficient quantity of superphosphate of lime is added to it for the purpose of neutralizing the lime, usually in the proportion of about 3 parts of the superphosphate of lime to 100 parts of the juice. The superphosphate of lime may be used at $4^{\circ}$ Beaume's hydrometer, or at any higher degree; and it is to be added as long as any reddish litmuspaper, dipped into the juice, is turned blue. Should too much superphosphate of lime happen to be added, this error can be rectified by the immediate addition of as much lime or lime-water as the superphosphate of lime in the solution will neutralize. The mixture will, by the above process, become thick and turgid, and must be filtered, which may be done in the ordinary manner through filtering-bags; and the filtered juice or syrup is then to be concentrated to $18^{\circ}$ Beaume, when it will again become turgid or thickened. For the purpose of separating any impurities which may still remain in the juice or syrup, superphosphate of lime is again added, so long as litmus-paper, dipped in the juice, is turned blue, after which the mixture is again passed through the filter; and the filtered fluid thus obtained must be concentrated, so as to produce the crystallization of as much sugar as can be separated in this manner, and the vacuum pan and crystallizing tubs may be used in the usual way for this purpose. Sugar refined or purified in this manner may be again dissolved or converted into syrup, and again submitted to the process, for the purpose of further purifying it.

The crystallized sugar thus formed is then to be separated in the usual way from the residual juice or syrup with which it is mixed.

From this residual juice or syrup a further quantity of sugar may be obtained by the following process: The juices or syrups are diluted to about $28^{\circ}$ Beaume with water or with some sweet juice, (the defecated juice of beet-root being preferred,) and lime or 
lime-water is added; and about half as much as was used for the first process will generally be sufficient to produce the requisite defecation. Heat is then applied, and before the syrup boils superphosphate of lime is added until the syrup ceases to produce any apparent alkaline action upon the test-paper; and by these means the phosphate of lime will be precipitated. The syrup must then be filtered as before, for the purpose of separating it from its impurities; after which the filtered juice or syrup is to be concentrated and crystallized as before, for the purpose of obtaining from it a further quantity of sugar. Centrifugal machines may be used for separating the crystallized sugar from juices or syrups.

The second residual syrup obtained by this last-mentioned process may also be subjected to the same process as that just described for treating the first residual syrup, in order to obtain, as results, a further quantity of crystallized sugar, to be separated from a third residual syrup as before.

In the same manner the process above described may be repeatedly applied to each residual syrup, which may remain after a previous process, until the syrup or juice operated upon shall be exhausted of sugar, or as much so as may be economically practicable.

\section{The Tile-laying Machine.}

Horace Greeley, in a recent correspondence with the New York Tribune, states "that the tile-laying machine of which only drawings and descriptions, so far as I am aware, hare reached our country, is commending itself to the judgment of British improvers. This machine, now worked with movable steam instead of horse-power, takes up its position at one side of the field to be drained, and commences the first drain at the point opposite on the other, slowly drawing thence to itself a chain, to which is attached an apparatus which cuts a mere crease from the surface downward to the required depth, at which it makes a hole barely larger than the tiles, which closely follow on a string, being firmly attached to the perforating apparatus, and paid out from the starting-point just as fast as required. Thus each foot of the drain is perfected the minute after it is begun, while the labor of throwing out and replacing several cubic feet of earth for every foot of drain is obviated. Obviously, this would not answer in a rocky nor in a miry soil, though in the latter this mode of cutting would tend to give firmness to the earth immediately surrounding the drain, at least for a time. .

\section{Machine for Thinning Turnips.}

At the recent Exhibition of the Royal Agricultural Society (England) at Carlisle, a machine for "thinning turnips" was exhibited by Messrs Garret \& Son.

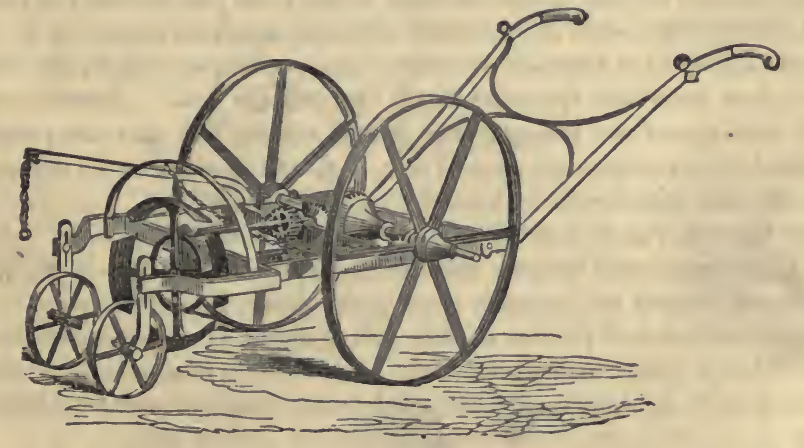

This invention, shown in the engraving, is designed for thinning out the plants in the drills, leaving only small bunches at regular intervals, varying from ten to eighteen inches apart. This is effected by means of a wheel which revolves at right angles to the axis of the machine when in motion, to the outer edge of which are attached a series of horizontal segmental knives revolving with considerable rapidity, describing, in consequence of the forward 
motion of the machine, a sort of spiral curve, as the knives travel over the ridges. By this means they sweep away all the plants in the intended interval, leaving nothing to do but to single the plants out by hand, which is done with great ease and rapidity by a boy. Five or six acres may be thus thinned out in a day.

\section{Steam for Agricultural Purposes.}

At the late Fair of the Royal Agricultural Society of England, a premium of $£ 200$ (one thousand dollars) was offered "for the steam-ultivator that shull in the most efficient manner turn the soil, and be an economical substitute for the plow or the spade."

In view of the great attention which this subject is exciting, the English Agricultural Gazette published the following article, addressed to the "Committee of Award," in which are set forth the alleged advantages of the steam-cultivator or digger over the plow or spade. We recommend the article to the attention of Amcrican inventors, as clearly setting forth the requisite ends which must be obtained to render any such invention practical and successful.-Editor.

"Turn the soil." Mark this expression; for the whole character and efficiency of the machine depends on this point. Break up, loosen and commingle the soil as much as you please, in preparing a seed-bed for any crop, but if weeds and grasses be left still green on the surface, if the seeds of our annual infesting enemies remain in favorable exposure to the vivifying sunshine and feeding dews, your tillage will be utterly abortive. On the other hand, if the ground be a stubble, bury every weed and withering stalk, and you promote its decomposition in the soil, making manure of what would otherwise injure as well as encumber; if it be a sward or a lea, still more urgently must you inter every blade and plant that might spring up among your intended crop. In the fundamental operation of tillage, the destruction of all remnants of old crops, and the loosening up of the staple for a succeeding one, you must "turn the soil." Was it not for this very purpose of burying obnoxious vegetation, and opening up a fresh surface of earth, that plows with mould-boards superseded the imperfect scratching instruments of yore? Is not the chief fault of the plow itself that it does not completely hide all surface vegetation, but too often (especially when the plowman is blamable) leaves grass or other living growth to shoot up among the seams of its furrows, and defy the weeder of the coming crop? For many tillage purposes, such as autumn cleansing or spring grubbing, no such inversion is needed; but in the first and foundation-work of breaking up after a crop, and to the full depth of the intended staple, you must "turn the soil." Perhaps an instrument able to stir and mix every portion of a deep staple might be made to bring up repeated instalments of earth long buried, and thrust down the long-exposed surface to take its place, at the same time forking out root-weeds and rubbish. As far as fertilization is concerned, perhaps a frequent commixing of soil and subsoil might suffice, instead of alternate exposure of each upon the surface; but the consideration of weeds alone inculcates the necessity of "turning the soil." Therefore we maintain that the first condition of the society's offer is well chosen, and that the premium will be misappropriated, in the opinion of practical men, if given to a machine (no matter how expert at comminution) that cannot entirely bury the surface.

Then it must be also "an economical substitute for the plow or the spade." . If there shall be an engine that turns over furrows effectively at less cost than the plow, (first expense included,) although it may be incapable of any other labor, give it the prize. And should there be a machine unable to plow at all, but able to dig in as perfect a manner as men can with spades, if it will perform this work alone more cheaply than men, it is entitled to the prize. Plowing ought to be accomplished for less money than by horses, and digging (though this of course is a more expensive operation) at less cost than by men.

The judges have not to determine whether or not digging $a$ la spade will be too expensive for the farmer, although indispensable to the market gardener; whether or not a cheaplydigging engine would not inaugurate miracles upon the clays; but, (useful or not,) according to the terms of the offer, they must award the premium either to an engine that digs more economically than the spade, or that plows more economically than our present horse-plow. 
Should a machine be produced of sufficient versatile powers to execute both shallow work like a plow and deep work like a spade, such a doubly-clever contrivance will of course merit the palm.

Before awarding the prize, and so pronouncing some invention to be an "economical substitute" for the implements with which to break up and invert whole ground, not merely for the grubbers and harrows with which we stir and pulverize soil already broken, let the judges well weigh this point of "economy." Besides the working expenses, they must calculate the wear and tear and the interest of the first outlay in purchasing the machine; and on the other side of the account they must be prepared with similar estimations of the charges for food, attendance, depreciations, Sc. attaching to horses and common implements. On the credit side they will have to compare the excellence or inferiority of the respective operations, and particularly they should fix a money value upon the time saved in the performance of the work, inasmuch as there is a great adrantage in having a breadth of land prepared for sowing in less time than usual, though the acreage expense may be the same; and any means (without incurring any neutralizing disadvantage) which gives the husbandman greater command over his soil, and more independence of the weather, is certainly to be valued as a pecuniary gain.

\section{Steam Machinery for Cultivating Land.}

THF annexed engraving represents an English invention, patented by Mr. John Bethel, of London, for adapting steam machinery for the cultivation or digging of land for agricultural purposes.

In this arrangement, as will be seen in the engraving, the digger is placed behind the apparatus, which is mounted on four wheels, and is intended to be drawn forward by horses: $a$ a represents the boiler and engine supplying the power; $b b$ the lever frames, at the outer end of which the digger $c c$ is located. Motion is communicated from the crank-shaft $d$, on which is a bandwheel $d$, from whence a band passes around another band-wheel $f$ on the axle of the lever arms $b$ b. Motion is by means of this

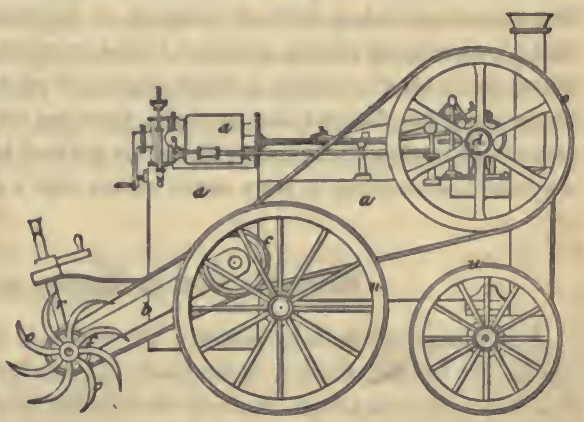
band communicated from the band-wheel $f$, at one end of the lever arms $b$, to a similar bandwheel $f$, on the axle of the digger-wheel $c$, at the opposite end. The depth to which the prongs of the digger enter the ground is regulated by raising or lowering the screw-shaft $r$ by means of a winch at its upper end.

\section{Fisker's Steam Plow.}

THE London Agricultural Gazette furnishes the following description of the construction and operation/of a new steam-plow, recently invented by Messrs. Fisker, of Stamfordsham, England, and exhibited at the agricultural fair at Carlisle, June, 1855 :-

"The whole apparatus is novel, and, we may say, uncommonly promising. Instead of a heavy wire rope to drag the plow frame by main force, a light endless hemp rope, only threeeighths of an inch thick, communicates power to the plow carriage, which we may call locomotive, as it propels itself in the following manner: a grooved wheel set in motion by proper spur-wheels from the rigger actuated by the hemp rope, winds, as it were, along a strong wire rope laid upon the ground; and the frame, being thus carried slowly forward, drags plows or other implements after it. The hemp cord does not touch the ground, but is held up at every forty yards' distance by a 'horse,' or small friction pulley-frame, about three and a half feet high. This cord travels at the rate of twenty miles per hour; but the speed being reduced by the wheel-work upon the plow carriage, the latter travels only two miles per hour. When 
two plows are in work at once, having the draught of four horses, the strain upon the rapidlyrunning cord will thus be less than half a horse's draught. We were informed by the exhibitor that a four-horse engine is sufficiently powerful to work two plows, and that with four hundred-weight of coal it will plow four acres in a day, the expense for labor being only that of two men and a boy. If this be strictly the fact, we have a camplete invention able to plow light land at a cost of say 3s. per acre. That it is not far from the truth we are sure, for we ourselves saw one plow drawn at the rate of at least two miles per hour when the engine had only seven pounds or eight pounds pressure upon the square inch, and this was an engine of sixhorse power at 40 pounds pressure. To be swe, the land had been previously plowed, pulverized, subjected to the trial of all sorts of drills, and been afterwards well trampled by hundreds of people, and consolidated with rain, so that the possible quantity and quality of the work could not well be ascertained. The plowing we saw was respectably though roughly done, but there was one point really performed-the furrows were well turned. If a steam cultivator can invert the soil thoroughly and cheaply, we may put up with a little imperfection in the straightness of cutting and evenness of laying. The method of anchoring the pulleys, and the arrangement of the pulleys and ropes, is very ingenious, and can hardly be explained with brevity. The anchorage consists of a plate or plow, a few feet in length, and eight inches only in depth; this can be easily drawn forward in the ground without the trouble of digging holes, taking up, setting down again, \&c., and yet it presents a sufficient resistance sideways to the pull of the ropes. A wheel, pinion, and crank, on each anchor is used to draw it by means of a rope towards a fixed post, when it is required to be shifted. The arrangement of the ropes about the anchored pulleys is like that of the chains in a travelling crane, the anchorage being shifted forwards at intervals without altering the length of the rope. The plows are not rigidly attached to the travelling frame, but are hung by short iron beams, which form levers, having a slight degree of play up and down. There are four plows-two before and two behind the carriage, pointing opposite ways, a neat lever movement lifting two out of work and dropping the other pair of plows in; so that the machine can plow both ways without having to turn round at the land's end."

\section{Boydell's Steam Horse, or "Traction Engine."}

A NEw carriage without a name, but which is described as a sort of portable railway machine, has been exhibited in London. It is a carriage that takes its own railway along with it-rails, plank-bearings, and all-and keeps putting down and taking up its track as it proceeds. This strikes one at first like the idea of getting into a basket and lifting yourself by the handles, but the editor of Chambers's Journal has seen the machine operate, and thus describes it:-

"It is evident that a flat deal-board will not, weight for weight, sink so far down into a bed of mud as will the narrow tire of a cart-wheel. It is evident, too, that cart-wheels may have a railway tire or edge, instead of an ordinary tire or edge : and that a line of rails admits of being laid down upon a wooden plank. A person, likewise, may readily conceive the idea of laying down one of these rail-planks under each wheel; and this, indeed, is very much like what is ordinarily done in the construction of a common railway. The problem, therefore, was this: to construct the wheels in such a manner, that by means of certain mysterious-looking levers, pins, screws, and iron arms, these railway-planks, when passed over by the wheels, should be taken up by the machinery, and laid down in a new spot; and this problem has actually been solved. Each wheel admits of being represented as consisting of a circle inscribed within a hexagonal frame of flat boards, each furnished with railway-trimmings. If the hexagonal frame be supposed cut or divided into six component planks, one of these planks laid down beneath each carriage-wheel, and the carriage itself pushed forward, there would be supplied for it a short railway, having a length equal to the length of each plank; and the carriage having run on to the extremity of the rail-planks, might easily be transferred to another pair, if they could be placed in due opposition with the last. In this manner, by means of two sets of alternating planks, the carriage might be made to run to any required distance. Now, this is just that which is accomplished by the rotation of the wheels them- 
selves in the carriage under consideration; only, instead of the alternation of two pair of planks merely, the changes are played on no less than six pair, one pair alone being in plane contact with the underlying ground at one time."

This machine was exhibited at the recent exhibition of the Royal Agricultural Society, Carlisle, England. Mr. S. W. Johnson, of the N. Y. Country Gentleman, who witnessed its operations, speaks of it as follows:-

"It seoms to involve a valuable principle, and excites vast interest. I did not see it in operation, but saw a one-horse cart with wheels rigged on the same plan, which was pretty heavily loaded with tiles, and driven about, backed, and turned short, over ridged and recentlyplowed land, and its action was very good. I doubt if the load would have been nearly so easily drawn with a common cart. In crossing the dead furrows, the shoes in a manner bridged the hollow, not allowing the wheels to run so low as they must have done otherwise. This cart is of course mainly intended for soft or plowed land, and doubtless it will not be long in becoming useful and used."

\section{Farm Steam-Engine.}

A correspondent of the Scientific American, writing from Chillicothe, Ohio, states that a portable steam-engine for driving a grain-separator and thrasher, has been constructed in that place and in operation since the 5th of last July, thrashing and cleaning from five to six hundred bushels per day. It is capable of doing more than this, but H. Wade-for whom it was built-says that this is excellent work. The boiler is tubular; the cylinder is of six inches bore and twelve inches stroke. It makes one hundred and seventy-five revolutions per minute, with steam at forty pounds pressure, and does more work than any common thrashing machine driven by eight horses. It is placed on broad tread-wheels, four feet in diameter, is easily drawn from place to place by two horses, with the boiler filled, and is very economical in the use of fuel. This engine is capable of driving various agricultural machines and sawing firewood for the family.

\section{Improvements in Rotary Spades and Diggers.}

Gibbs's and Mapes's Rotary Spade.-This machine, the invention of Mr. L. H. Gibbs, of Washington, and Professor Mapes, consists of two cast-iron circular plates, about two inches apart ; and working between them are eight stout, narrow, wrought-iron teeth, curved somewhat like the old-fashioned cultivator teeth. These teeth are hung, and have a trigger to throw them out as the machine revolves. A yoke of oxen are sufficient to draw the machine, and as it progresses each tooth in succession is pressed into the earth by the weight of the machine; and, when the weight falls upon the trigger, the tooth is thrown out with its load of earth, which is thus mixed and pulverized as thoroughly as if forked over. The two wheels cut $₫$ furrow about two feet wide and nine inches deep, which can be increased to any desired width and depth. It requires no holding, yet is provided with handles so fixed as to throw the machine out of the ground.

Gibson's Digging Machine.-This implement, an English invention, which has recently, to a considerable extent, come into use, consists of a number of cylinders, of about three and a half inches in diameter and six inches long, revolving on a fixed axle. On each of the cylinders is cast a disc, twelve inches in diameter, which is furnished with ten teeth or prongs of malleable iron or steel, of a curved or cat-claw form, springing from its periphery, and which, partly by the weight of the implement and partly by the strain of draught, is forced into the ground, and, as the implement advances, digs or forces up the soil; in fact, each prong performs precisely the office of a pick or hack in loosening the soil. This forking-up or loosening of the soil is not the only important office of the implement; but from the curved form of the teeth, it brings all roots and fibrous matter within the depth of its operation to the surface; thus producing a clean as well as a free tillage, or at once acting most effectively as a grubber in bringing up root-weeds, and at the same time performing the most important function of the plow in aerating the soil. The implement is mounted on a strong frame, 
partly of cast and partly of malleable iron, and furnished with a simple but most ingenious apparatus for regulating the depth of its working in the soil.

Samuelson's Rotary Digger.-This invention, by Mr. B. Samuelson, of Banbury, England, consists of a simple frame, running on two wheels, which, in their revolution, cause a series of forks or promgs to loosen and pulverize the earth to a depth of eight or ten inches, and over a width of three feet. Five or six horses, according to the state of the soil, attended by two men, are able to work over five or six acres a day. As the prongs come round, they bring up the soil and let it fall backward in a well-pulverized and mixed state; and to keep them free from earth, each circle of prongs wurks between a corresponding set of stationary clearing-teeth on the frame. This machine has been extensively introduced into Scotland; and the Royal Agricultural Society of England awarded it a silver medal after a thorough trial at Gloucester. The depth of entrance of the prongs is adjusted by a handle, geared to a pinion, working in a segmental tooth-rack on the framework. It will be readily apparent that this machine will pulverize the soil more effectually than the plow and the harrow. The only objection to it is the great amount of power necessary to operate it; but this may be obviated by reducing the width of the machine or simplifying the machinery. It will undoubtedly be many years before an implement of this sort will supersede the time-honored plow; but the principle of digging the soil and reducing it to a finer tilth than it is possible for the plow to do, is fully established.-Country Gentleman.

\section{The Plow.-An Improvement Wanted.}

IN the report of a lecture by the Professor of Agriculture in the University of Edinburgh, we find the following remarks, which contain a suggestion well deserving of consideration. To indicate and point attention to a want is, at all events, one of the most likely ways of obtaining a supply.

Although the necessities of man compel him to use the plow in preference to the spade, it is admitted by all that the work done by the two implements is of a very different characterthe plow leaving the soil in a condition far less suited to the purposes of regetation than the spade. This is more prominent on heavy soils than on light. By the operation of the spade the soil is left loose, the original surface with its weeds and exhausted mould being completely buried, and a fresh surface exposed. But the plow is a tool of a rougher nature. It is, in reality, a wedge forcibly dragged through the soil at a certain depth, lifting up that portion which is above it, at the expense of making that which is below it more compact, this latter receiving virtually all the force required for the separation. The consequence is, that more or less, according to the soil, this lower surface is compressed to such a degree as to leave a dense and compact surface, through which the roots of plants must find it difficult or impossible to penetrate. The furrow-slice, too, instead of being completely inverted, is not turned over to more than one-half or three-fourths of the way; the surface weeds are imperfectly buried, and the soil is not changed to the same extent as by the spade.

The great desideratum in practical agriculture is, therefore, to obtain an implement that shall have, like the plow, the capability of doing a large amount of work; and like the spade, of doing it in such a manner as to satisfy those conditions which we consider desirable for the purposes of successful cultivation. Many implements and machines have been constructed, and much skill and ingenuity from time to time expended in the endeavor to realize this great desideratum; hitherto, however, the results have not been very satisfactory. In no form of it does the plow cultivate thoroughly; it requires to be followed by roller, or harrow, or other tools, to complete the work, which, after all, is not so well done as by one operation of the spade.

What we want is not plowing so much as cultivation, or that process of disintegrating and fitting the soil which the farmer by necessity performs by three, four, or five separate operations, and then not so effectually as the gardener accomplishes in one.-Country Gentleman. 


\section{Plowing.-Amount of Travel.}

THE amount of work required on a given surface varies, of course, with the condition of the soil. Certain parts of the work may, however, be accurately calculated. In the Soil of the South, a table is given showing the space travelled in plowing an acre, with a given width for the furrow. These calculations are approximations to the truth, but not quite accurate. In plowing a field 500 feet square, more than 500 feet must be "travelled" in by the team, or even by the plowman. The team must travel at least 10 feet at each end beyond the termination of the furrow. Taking this estimate as accurate, and supposing the field to be square, (for with the shape of the field the number of furrows and the "space travelled" will be materially changed,) and the breadth of the furrow seven inches, the distance travelled by the team in plowing one acre will be about $15 \frac{3}{8}$ miles instead of $14 \frac{1}{8}$, as in the table. With a "furrow-slice 14 inches" the travel will not be, of course, "seven miles," as given in the table, but something more than $7 \frac{1}{2}$, and so on. The calculation, thus corrected, may be of some interest. The table, as given, is as follows:-

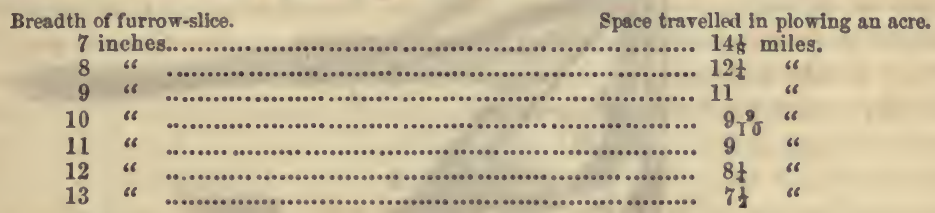

By this rate of calculation, a furrow once in

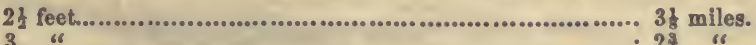

Hall's Side-Hill Plow.

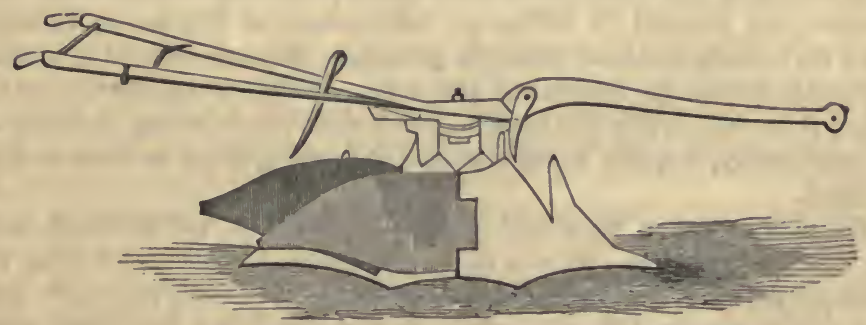

THE peculiarity of this side-hill plow is, that the beam and handles together turn round upon a pirot formed of the top of the standard. The share has a straight land-side, two feet ten inches long, with points at each end exactly alike. Suppose you are turning a righthand furrow, and wish to change to the left; you give a rod under the right handle a little jog, which unlooses a catch, and you walk round with the handle in your hand until the beam points directly the other way: now, pull the rod and close the catch, stoop over and give the mould-board a flap, and it turns back, bottom up, disclosing another under it exactly like the first, also bottom up, and pointing forward: turn this also, and you have before you a perfect plow - the reversed mould-board lying under the other, quite out of the way, and the reverse point forming the heel of the land-side. The length of beam in this description of plow is four feet; handles, four feet six inches; width of share, nine inches; length from point to upper angle of wing, two feet nine inches; length of wing from the joint to upper end, one foot seven inches; height of standard, one foot two inches; height of fin-cutter, nine inches. This plow was invented and patented by L. Hall, of Pittsburg, Pa., and is called the "Patent Hill-side, or Flat-land Swivel-beam and Double-flapped Mould-board Cast- 
iron Plow." This plow can be operated by a small boy, the share, which rolls under in changing from side to side, being easily shifted. We think it must prove to all interested a most acceptable improvement.

\section{Plow Cultivator. :}

THE accompanying engravings represent an improved plow cultivator, or horse-hoe, recently invented by W. S. Hyde, of Ohio, and H. Wright, of South Byron, New York.

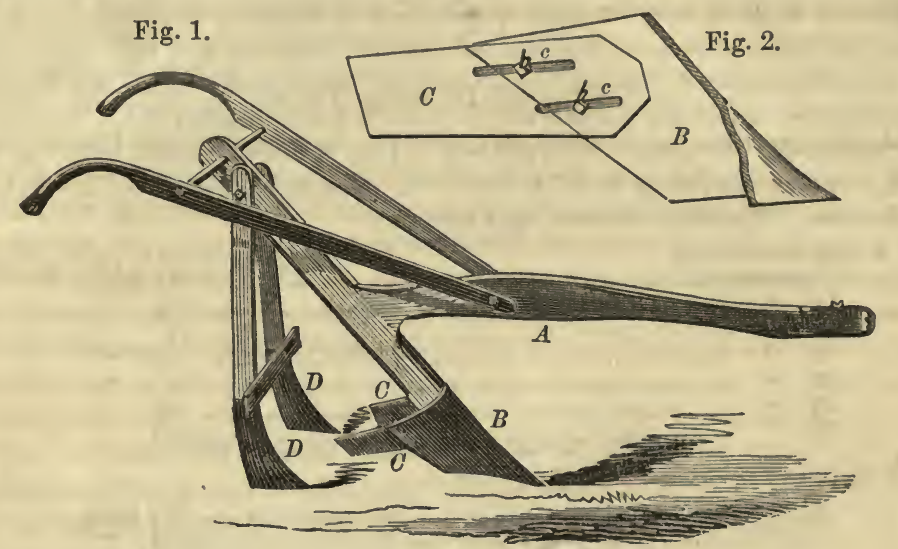

Fig. 1 is a perspective view, and fig. 2 is a section, showing one of the adjustable wings connected with the plow-shoe. A is the beam; B is the plow-shoe; D D are two adjustable cultivator teeth behind the shoe; and $\mathrm{C} \mathrm{C}$ are the adjustable wings. In fig. 2, $c c$ represents two slots in each wing, and $b b$ are screw-bolts to secure the wings in these slots. The wings $\mathrm{C} \mathrm{C}$ are flaring, and designed for hilling-up; consequently, as they can be adjusted by the slots $c c$ and the bolts further in or out on the plow-shoe, they are rendered fit to hill-up high or low, and made suitable for narrow and wide rows. The bar which connects the two cultivator teeth $\mathrm{D} D$ has bolts which also work in slots in their respective legs, and they swivel at the top; consequently, they can be set near and wide apart, to cut as close to the rows as may be desired.

To use this plow cultivator, the ground should be plowed deep, well harrowed, and marked both ways with a good marker. As soon as the rows can be seen, commence using the implement. Take off the wings from the shovel, and do not use them while the crop is small. Set the teeth to run as near the hills as possible; to work fast, have a man or boy follow while crossing, when the corn is small. As soon as the corn is a foot or more high, put on the wings, and set them level on the lower edge; and as the crop grows, set the hind teeth nearer together. To hill-up any crop, take off the woodwork to which the teeth are attached, and you have a most perfect implement for hilling. It is designed for corn, cotton, or any crop requiring to be hoed.

\section{Mapes's Lifting Subsoil Plow.}

ThIs new implement is so constructed as to elevate the soil for a short distance, but from a great depth, its whole force being upward and outward, like the action of a mole on its superincumbent soil ; and although the greatest width of the plow itself is but eight inches, still, when running at a depth of fifteen inches, it renders the soil finely divided to a width of four feet at the surface, and without elevating the subsoil or turning over the surface-soil. It may, therefore, be used to renew old meadows, where the grass-roots have become too compact for vigorous growth; for it will lift the sod one or two inches with a foot of soil attached; the cut through which the plow passes closing behind it in its course, and loosening the soil around every grass-root, thus giving free admission to atmosphere, rains, dews, etc. 
When used in corn-culture, it may be run through in striking out for the corn, learing the soil finely pulverized to a great depth immediately where the roots will form; and, after the corn is ready for the first hoeing or cultirating, this lifting plow may be run half-way between the rows, loosening the whole distance, and causing every corn-plant to wave as it passes along. When used strictly as a subsoil plow, it is moved by a separate team following the surface-plow, and entering twelve inches below the bottom of the surface-furrow, undercutting the land-side so that the next surface-cut will crack down to the subsoil track, and requiring less power for its accomplishment, while the turned furrow-slice on the other side of the plow, by its under-running, is slightly lifted and rendered pulverulent.

\section{Improved Ditching Plow.}

THE peculiarities of a new ditching plow, invented by John Lyon, of Farmington, Iowa, consist in a new and useful arrangement of mechanism, so as to constitute a machine for throwing up embankments in forming roads and foundations for fences, and for making open drains. Its construction is as follows: To a triangular-shaped frame a plow is attached, resembling in construction an ordinary plow, except the mould-board, which is so shaped that, instead of turning a furrow over, it merely passes under the soil, and raises it to a sufficient inclination to be deposited upon an endless conveyor as fast as it is cut up. The mouldboard has one of its side edges raised slightly higher than the other, so that the dirt will always clear the frame, and fall upon the endless conveyor, placed behind and at right angles to the land-side of the plow. This is composed of slats attached to two endless chains, and is thus made flexible. The connected slats are arranged upon revolving rollers, and move in a manner similar to an endless-chain horse-power. Guide-boards are also attached to the conveyor, for the purpose of confining the dirt. By the conveyor, the dirt is taken from the plow and deposited in the place desired, either for the purpose of forming a road or foundations for fences. By thus receiving the dirt, and depositing it at right angles to the plow, a road of any length can be formed with great ease and despatch. By raising and lowering a lever connected with the attachment of the plow to the frame, the plow can be adjusted so as to cut more or less deep.

The operation of the plow is as follows: As the machine advances, the plow enters the ground and raises the soil, which is forced, as the operation proceeds, upon the endless conreyor, and carried by the same as it revolves at right angles to the line of travel, and discharged at the end of the conveyor in a continuous stream, where it is laid either to form a road or foundation for fences.

\section{Planting Plow.}

TrE annexed engraving represents a planting plow, for which a patent was granted to $B$. M. Snell, on the 20th of March, 1855.

The nature of the improvement consists in constructing a planting plow, by combining a plow, resembling a subsoil one, with a seed-dropping apparatus, operated by the wheel of the plow, for the purpose of depositing the seed under the surface in the soft and prepared bed.

$A$ is the beam, from which descends the stock or coulter-post $B$; $c$ is the coulter; the share is secured on the post, $\mathrm{B} ; \mathrm{E}$ is a bar extending from the rear of the share and united to an upright $F$, whose upper end passes through the rear of the beam. This upright is furnished with holes and a pin, by which the plow is made to plant deep or shallow, as required.

The 'seeding-apparatus consists of a hopper $\mathrm{G}$ and dropping-tube $\mathrm{H}$, secured by a strap $I$ to the upright $\mathrm{F}$ and to the end of the beam. This hopper has a sliding bottom and hole therein, which when the slide is forced in, an opening is made for the passage of the seed into the tube. On the back of the hopper and dropping-tube is secured the axis of a pair of wheels, $k$, (one shown,) one of which is furnished with a cam or angular striker that forces in the slide of the hopper on each rotation of the wheel. 


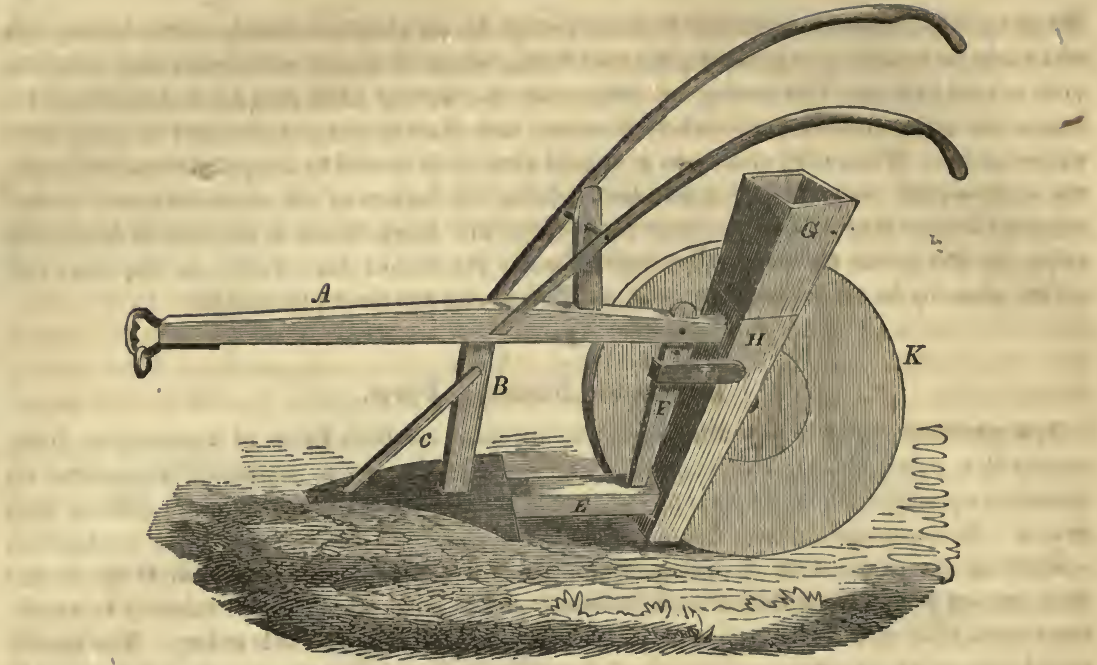

The object of this improvement is to create a soft bed for the reception of the seed in the earth, without the disadvantage attending the open furrow made when the soil is thrown out, and the frequent deposition of the seed on a hard soil or bed, and, of course, disadvantageously to its growth; also, to obviate a difficulty in planting corn on a hill-side, wherein the open furrow made is liable to create a wash of the land in heavy rains, occurring soon after planting, which frequently renders replanting necessary, besides the loss of soil where most needed. By this improvement, all the properties of a light bed and retention of the fertilizing property of the manure is obtained, particularly where such as guano or other volatile manure is used, as it is not thrown to the surface, as would be the case if the ordinary tine or small mould-board planter were used.

\section{Various Recent Improvements in the Construction of Plows.}

Williams's Lever Plow. - This improved plow, the invention of Mr. Williams, of England, is built on an open rectangular frame, supported by two fixed front wheels and a rear swivelling wheel; on each end of the frame are vertical guides to receive the ends of a set of leverbeams, which have attached to them whatever plows or cultivators may be desired. Provision is made for altering the depth of the plow's penetration, by means of chains attached to the lever-beams, and passing over bearing pulleys, and thence to a lever-handle at the stern of the plow. By turning this handle, the plowman can give any required depth of cut, or he can take the cultivating parts clear'out of the ground. A front frame-piece, to which the chain-pulleys are attached, has a cross transverse action, so as to give the cultivators a power of deviating from the straight line of working.

New Subsoil and Trench Plow.-At the recent exhibition of implements by the Royal Agricultural Society, at Carlisle, England, a silver medal was awarded for a new subsoil and trench plow, invented by Cotgreave. This implement combines the common plow, trench plow, and subsoil plow in one, and is capable of tilling the land to any required depth from ten to eighteen inches. To the beam of the plow is attached a foot for regulating the width and depth of the furrows, to which are affixed revolving discs, acting both as coulters and wheels; this is followed by the part resembling the common plow, to be again succeeded by the trench plow, which brings the soil up an inclined plane to the surface; lastly, the subsoiler comes into operation, pulverizing the subsoil the required depth. It is worked by four horses.

In connection with this plow, there was exhibited a new subsoiler, invented by Lord Beauclerc. The subsoil is stirred by means of a so-called Archimedean screw; it is a revolving iron shaft, of about a foot in length, on which are spirally arranged a number of stout spikes; 
the axis of this shaft runs lengthwise of the plow, and, as the implement is drawn along, it is set in motion by the spikes, which, it would seem, must pulverize the soil in the best manner.

Warlick's Improved Plow.-A plow improvement, patented April 4th, 1855, by Noah Warliek, of Lafayette, Alabama, has for its object the augmentation of the strength of plows without adding to their weight, so as to make them better adapted for operating in rough, stony, and rooty lands. It has a $\mathrm{Y}$-shaped brace, with its point to bear on the ground when required, and to give support to the plow, and enable it to be used as a crowbar or lever with safety, for prying up stones, stumps, roots, \&c.

Plow Standards.-A patent has been granted to George Easterly, of Heart Prairie, Wisconsin, for a peculiarly-constructed plow standard, so arranged that mould-boards of different sizes may be secured to it; likewise, shares of different thicknesses, to adapt it for plowing different soils. The improvement is, therefore, designed to make one plow more universal in its application to different kinds of work.

\section{Plows without Plowmen.}

UpOs the occasion of the recent presentation of a plow to Hon. H. L. Ellsworth, of Indiana, as an acknowledgment of services rendered to American agriculture, Mr. E. stated, that, in all his farming operations, he had dispensed with the plowman so far as it relates to holding the stilts. He said, "For yenrs no one has held my plow or dropped the corn. My plow-beam obtains its steadiness by being attached to an axle or two mole-wheels; and a wheel of eighteen inches diameter, made of one and a half-inch board, having an artificial finger fastened at one side, that dips into a measure of corn at each revolution, deposits the seed, which is covered by the next furrow."

\section{Gang Plow.}

TrE annexed engraving represents a gang plow, invented by G. W. Hildreth, of Lockport, New York. It is made entirely of iron, except the pole to draw by. The main frame is in

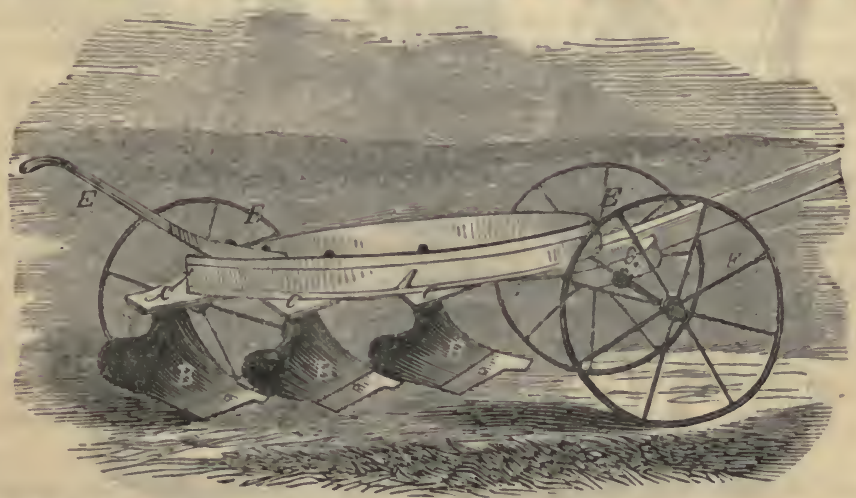

the form of a triangular ellipse $A$, for the purpose of shrinking on a wrought-iron band, to make it of any desired strength. The forward end of the said frame rides on an axletree, connected by a king-bolt and bolster-plates $\mathrm{D}$, allowing it to turn freely. The pole is attached by a device, which the driver can easily change, to make the gang run more or less to land, which pole guides the whole gang with precision, by the off-horse walking in the furrow, and it requires no holding. The wheels $\mathbf{E} \mathbf{E}$ are large, and can be easily changed so as to carry the plow clear of the ground, in moving from one field to another, and also to run the poles B B B any desired depth in the ground, from one to six inches, cutting and turning the whole surface clean. The gang will turn round without being touched by the hand, on a circle of three feet radius, and by lifting the rear end by the handle $F$, it will turn at right angles.

The plows are made strong, and ground smooth, and are made on a sharp angle; they 
draw light and score easy, and are locked to the frame by a hook tongue and groove $\mathrm{C} \mathrm{C} C$, and one carriage-bolt, which bolt is the weakest part of the fastening; and in case of running hard against any obstacle, where something must break, the bolt will break first, merely letting the plow drop off. A new bolt, costing less than five cents, repairs the break perfectly. The inventors say of it:

"This implement is designed for all kinds of crop-plowing or summer fallow; also for plowing corn, oats, and barley stubble, and fitting land for seed generally. It is a good implement for covering all kinds of seed sown broadcast; it has been used in almost every variety of soil, and has given universal satisfaction. It is well adapted to the soil in the Western. States and the plantations of the South. It works first-rate in muck, clay, and gravel. The material of which this plow is made, being iron, is strong and durable; the wheels are large, and having wrought-iron spokes and tire, are strong and light; it affords facility for changing the depth of the plows, and changing the quantity of land; it requires no holding, and is easily turned round; a boy that can drive the off-horse in the furrow can do as good work as a plowman; and it will work hard land that cannot be worked with a cultivator. The shears cut the whole surface of the ground, and turns it over; it is very convenient for carrying off loose stones from the field while plowing."

\section{Improved Rotary Cultivator.}

THE annexed engravings represent an improved rotary cultivator, the invention of $H . M$. Johnson, of Carlisle, Pennsylvania.

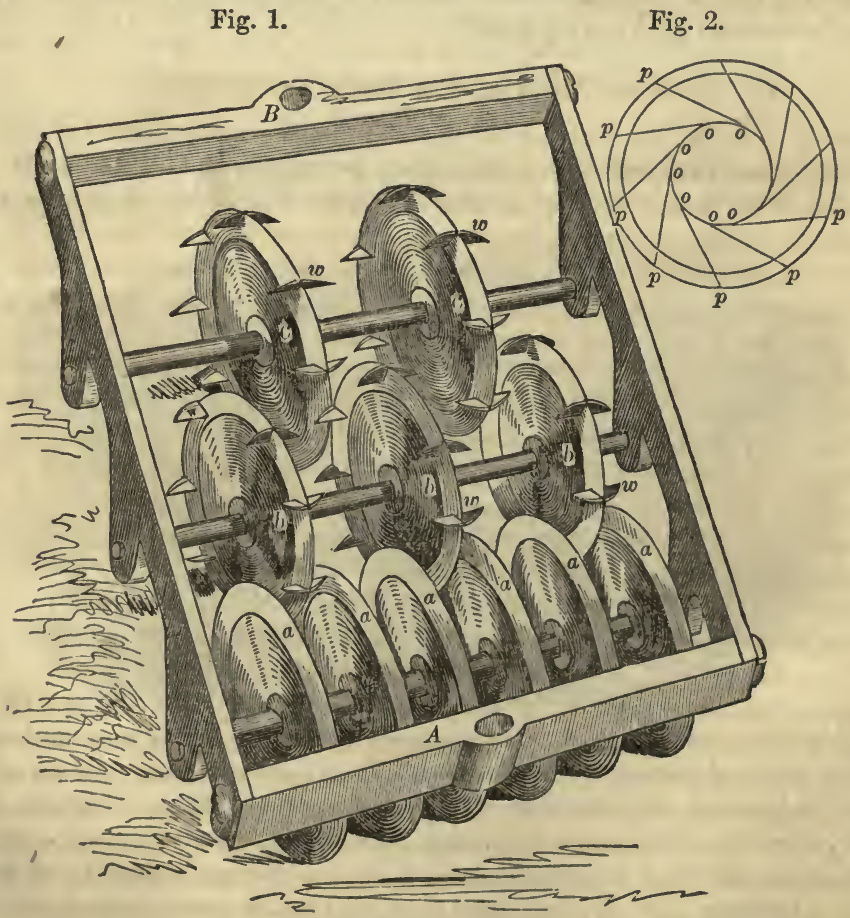

Fig. 1 represents the machine in perspective, and fig. 2 represents a section, the nature of which will be shown in the following description:-

It is only within the past three or four years that this class of agricultural implements has appeared to dispute the ground so long occupied by the ordinary cultivator in general use; and in England, where so much attention is bestowed upon this important branch of 
industry, we notice the very general introduction of the rotary cultivator. This improvement seems to present some advantages which are worthy of attention; and to render it more clear to the general reader, we will describe its construction:-

The frame A B supports three sets of coulter or toothed wheels; the first set, $a$ a, are merely circular rotary coulters, and are made of the usual plow steel, or, for general purposes, of cast iron, as thin as is consistent with due strength; they are bevelled to an edge, and at the height of the bevel are slightly thicker than in the interior part, to lessen friction. Their distance apart may vary to suit the soil intended to be cut through.

The second and third sets, $b b$ and $c c$, are so placed as to come alternately in the centre of the sections made by the first set, and consist of a coulter precisely like those of the first set $a a$; their edges are set with wings or knives $w w$, projecting laterally at such an angle, that, as the wheel revolves and advances, they descend edgewise with the least practical resistance, and come up flatwise, bringing up the earth fiom the bottom of the cut.

The inclination of these knives, and the effect of their position, is shown in fig. 2, in which the lines op show the direction of the plane of the knives, and their length is equal to the space between the coulter $a a$, so as to cut up all the earth as the machine passes over it.

The advantage of the circular form of knife is, that all hard substances, such as loose stones, are pressed one side, and they are made adjustable, so that if one breaks, it may be conveniently replaced. The patent provides for an increase of the coulters or wheels, and also for the attachment of the cultivator to a carriage, whereby it may be raised and lowered at pleasure when formidable obstacles are presented; and each coulter or wheel miay have a separate axle, and play up and down under the pressure of a weight or spring, thus readily adjusting itself to uneven surfaces.

\section{Trial of Plows at the Paris Exhibition.}

Durusc the progress of the National Exhibition at Paris, during the past summer, a trial of the various plows exhibited was made. The one found most effective was an English plow, contributed by Messrs. Howard, of Bedford, England. This plow, as carefully tested by the dynamometer, on clover sod, being drawn by two smartly-walking horses, turned a furrow ten inches wide and six and a half deep with a medium draught of only one hundred and eighty-two pounds, or a little more than half its own weight, (over three hundred pounds.) There are a good many men who could draw this plow at that gait, and almost any two men could easily do it. There were no plows entered from the United States, there being none on exhibition; but one from Canada was tried, and did good work. Most of the plows entered from the continent proved beneath contempt, as was to be expected. Some of them required over quadruple the power to propel them that was exacted by the winner; and one from Austria, that was confidently bragged on before the trial, actually twisted around, broke off, and gave up the ghost, in light clover soil, free from root or stone, and with but a single span of horses before it. -New York Tribune.

\section{Knox's Horse-Hoe.}

THe construction of this hoe may be understood by conceiving of the handles and beam of an ordinary plow, having two pieces of wood running backward from its sides, letter $\mathrm{A}$-fashion, at a point near the place where the horse is to be attached to the beam. At the point of the main beam in which these two sides meet is a cimetar-cutter or coulter, the office of which is merely to enter the ground and steady the machine during its action. At each of the other extremities of the two arms formed by the letter $A$ is a miniature plow. In the rear of the main beam, and directly under the handles, is placed a V-shaped share, point forward. Upon the rear of the wings of this share are teeth, each tooth being about three inches long, and projecting backward. A wheel and regulating clevis are placed upon the front of the beam, to which the horse or mule may be attached.

The action of this hoe is as follows:-The cimetar-cutter, as already stated, steadies it; the miniature plows throw the soil to the centre, and the comb again distributes it. Let it 
be borne in mind that in the planting of corn the rows should be straight, and the hprsehoe used before the weeds grow too large. This is also true of other crops. In hoeing corn, it should be passed down the side of one row, and then above that of the next in order, through the length of the field, and afterwards crosswise in the same manner. It is generally used with the mould-boards side in for other craps as well as corn, unless it be desired to throw the soil against the plants, flat cultivation being now rnore generally adopted. The amount of labor necessary for corn cultivation, when the common plow and hand-hoes only are used, deters many from giving this important crop the care it so justly deserves. By the use of this hoe, with a single horse cr mule, it is stated that a farmer may hoe as much corn in a single day, and do it as well, provided the rows are straight, as could be accomplished by twenty men by means of ordinary hand-hoes.

\section{Robinson's Improved Cultivator.}

THE accompanying engraving is a perspective view of an improved cultivator invented by J. A. Robinson, of Frémont, New Hampshire, patented February, 1855, which is designed for garden or field cultivation, and particularly adapted to drill-sown wheat and other small grains. The machine or implement consists of cutters attached to the two ends of a yoke of such height as to pass over the tops of the plants, the knives being adjusted to run as near the plants as may be desired, and the whole being made to travel on wheels.

$A$ is a yoke or bow, to the lower ends of which are secured the cutters B B, each being allowed to swivel around the point $a$, the nut $b$ serving to hold them secure when placed in the required position. By this method of adjusting the cutters, they are made to cut more or less distant from the rows of plants.

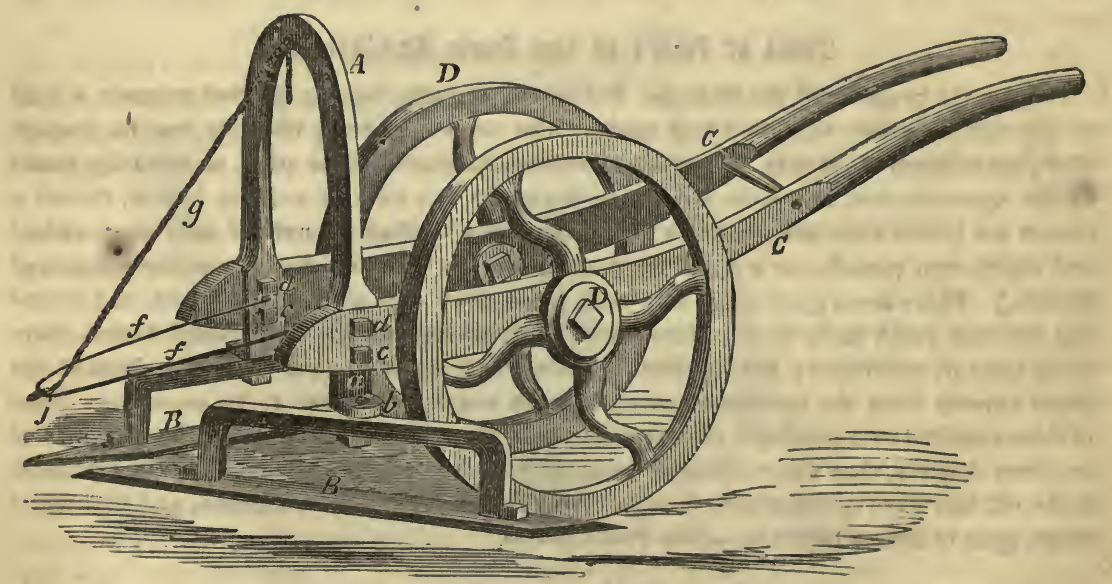

$\mathrm{C} \mathrm{C}$ are the handles for guiding the machine. They carry short shafts $\mathrm{D}$, on which are the wheels; $c c$ are square-headed pins which pass through the lower ends of the handles, and screw into the end of the yoke bow, which allows the bow a limited motion to make the cutters dip more or less beneath the surface; $a$ shows another square-headed pin which passes through a slot in the butt of the handle, (one for each handle,) and also screws into the yoke A the length of its slot. The yoke is by these pins set in position for the purpose of adjusting the dip of the cutters. By tightening this screw the cutters are held in place.

A device is employed to make each cutter move at an equal distance from the row of grain, or whatever it may be; $j$ is the guide point: it is held over the centre of the space between the points of the cutters by a bent wire $f f$, which is attached to each arm of the yoke, and is supported by a chain $g$ from the apex $i$ of the yoke A. The machine is used by wheeling it forward like a barrow, the guide-point $j$ being kept at the exact distance from the row. It will be observed that as the cutters can be set and adjusted to any distance to and from the plants, the weeds and grass can be cut up very near the rows. 
Mr. Robinson informs us that he has hoed small carrots with this machine, the points of the cutters being 11 inches apart, and he walked right along, hoeing them perfectly. As the cutters are adjusted to cut a little more than half-way to the adjoining row, the work is done thoroughly, no unhoed space being left between the rows. The cutters being set at an acute angle, they cut the weeds easily. They can also be adjusted to take the earth away from or carry it up to the rows.- Scientific American.

\section{Two-Horse Cultivator.}

A correspondent of the New York Country Gentleman recommends the use of a style of cultivator called the "two-horse" cultivator, and constructed as follows: You want nine cultivator teeth; or you may have less or more, as the strength of your team may be; you can have cast-iron or steel teeth, (the latter far preferable;) place one in front, the others opposite to each other; have the teeth about eighteen inches apart in the timbers, and a drag tooth in each hind end of the side pieces. This is to prevent a track being left by the two hind cultivator teeth. This must be rather longer than the old-fashion crotch drag, and flare at the ends, or else it will work rather bad. The side pieces should be three inches by five. The teeth must point exactly ahead. Have a hook on top of the forward end to hitch your team to, and not exactly at the end, as we usually do on harrows. This implement will do the work of three common harrows on land that has been plowed in the fall. I use the harrow once or twice in a place, then go on with the cultivator; and if your ground is dry enough to work good, you get well paid for your labor, for getting in wheat, barley, oats, or any kind of grain. This implement is far before the common harrow. We know how the corn cultivator works in our cornfields. In like manner does the two-horse cultivator work for sowed grain.

Peckham's Cullivator. - This does not differ materially from other cultivators, except in the form of the teeth. These are made in two pieces, a plate of cast steel being firmly bolted to a heary cast-iron shoulder or support. This steel plate is reversible, so that when one end is worn away, it may be turned, and the other end forms another tooth as complete as new.

Lapham's Patent Cultivator.-This invention of Seneca Lapham, of Champaign county, Ohio, is especially adapted for working among corn and other growing crops; also for preparing land for wheat.

By means of two long levers, one connected to the axle or shaft which supports the machine, and to which the wheels are hung, and the other to the tongue, to which the team is attached, the cultivating teeth can be raised or lowered, to suit the unevenness of the ground, and the machine directed independently of the team, by the person driving and walking behind. When a depression or elevation renders it necessary to change the depth of the teeth, by raising the lever which is attached to the axle, the teeth are lowered, or by lowering the lever, the teeth are raised; and when it is desirable to change quickly the direction of the machine to aroid an obstruction or a hill of corn or potatoes, by moving the lever connected with the tongue, the cultivator is readily turned, without the trouble and delay of guiding the team. When it is desirable to use this machine for cultivating young corn, the front tooth is removed and mould-boards affixed, which will prevent the earth from covering the corn, while the teeth break the soil and destroy the weeds; or, by placing the boards in a different position, earth may be thrown around the corn.

Suitable devices are provided for retaining the levers in place, and for rendering their motion easy.

Improved Rotary Cultivator.-An improved rotary cultivator, patented by G. B. Fields, of St. Louis, is formed in a cylindrical shape, with cutting plates or spades, between which are interposed clearing-boards for removing the earth adhering to the plates. Behind this cylinder is arranged a rotary harrow sustained above the ground and in the rear of the cultivating cylinder, for the purpose of breaking and pulverizing the earth after it has been loosened by the plow. 


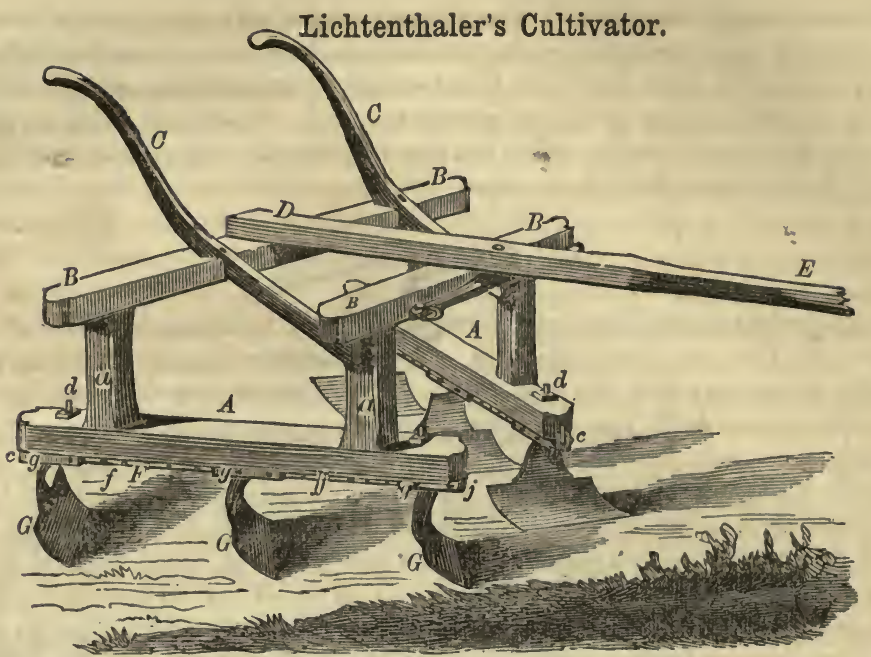

THE annexed engraving is a perspective view of a cultivator recently invented and patented by Griffith Lichtenthaler, of Limestoneville, $\mathrm{Pa}$.

The nature of the improvement in this cultivator consists in the peculiar manner of attaching the shares to the beams, whereby they (the shares) may be readily adjusted in position, and also allowed to yield to any obstructions with which they may come in contact.

There are two beams $A$, secured in an oblique position by cross-ties $B \mathrm{~B}$, which are attached to uprights $a$ on the beams. The oblique position of the beams gives the usual triangular or harrow-shape, the front ends of the beams being nearer together than the back ends. C C are the handles or stilts attached to the cross-ties, and D is a reach secured to the cross-ties, and having a swiveltree $\mathrm{E}$ attached to its outer end. In the under surface of each beam $\mathrm{A}$ there is a longitudinal groove or recess, in which a metallic strip $\mathbf{F}$ is fitted and secured therein by wedges or keys $c$ which pass through projections $d$. The projections pass upwards from the strips $\mathbf{F}$ through the beams $\mathbf{A}$, the wedges or keys being driven through eyes in the projections above the beams. . Each strip is perforated with holes $f$, as shown. The shares are represented by $\mathrm{G}$. Each share has a socket formed by two lips $g g$. The sockets are at the upper ends of the shares, and have holes through them. The shares $\mathrm{G}$ are secured to the beams $\mathrm{A}$ by placing the lips $g \mathrm{~g}$ in the recesses, the strip $\mathrm{F}$ fitting between the lips, and inserting a metal pivot or pin through the hindermost holes of the lips, and through a corresponding hole $f$ in the strip. Wooden pins $j$, are passed through the front holes of the lips, and through corresponding holes $f$ in the strips. The body of the shares are set nearly at right angles with the beams A A, and the dirt is thrown by the shares, as the machine is moved along, towards the centre of the machine. In case of the shares meeting with any obstruction, such as a root, stump, stone, etc., the pins being formed of wood, will break, and the shares $\mathrm{G}$ will turn backwards. By this arrangement the machine is prevented from being broken, or any of its parts wrenched by sudden stoppages arising from obstructions. The shares, by means of the sockets at their upper ends and the perforated strips F, may be readily adjusted to the beams. Shares of different forms may also be applied with the same facility, provided they have the sockets at their upper ends. The shares are cast iron, with a steel blade lying in the hollow part of the share extending about $1 \frac{1}{4}$ inch below; this steel plate is reversible, so that when one side is worn away, it may be turned and the upper edge put down, and is as complete as new. If desired, the whole machine may be reversed, so that the furrows may be thrown away from the corn, or cotton, or whaterer it may be. The advantage this cultivator has over others is, that the farmer is enabled to do more work in a given time and with less expense; inasmuch as it finishes the row as it passes orer it, and leaves the ground in a proper condition to receive the rain and retain the moisture a greater length of time, leaving no large furrows to conduct the water away. 


\section{Snedeker's Seed-Sower and Cuitivator.}

THE annexed engraving represents an improved seed-sower and cultivator recently invented by James H. Snedeker, of Bronson, Huron county, Ohio.

It is constructed on the principle of a common field-roller, in two sections, for facility in turning. The roller is covered with lancet-shaped cast iron teeth, of such a form as to penetrate the soil easily, and cut in pieces the lumps; these pulverize the earth thoroughly, and leare it in

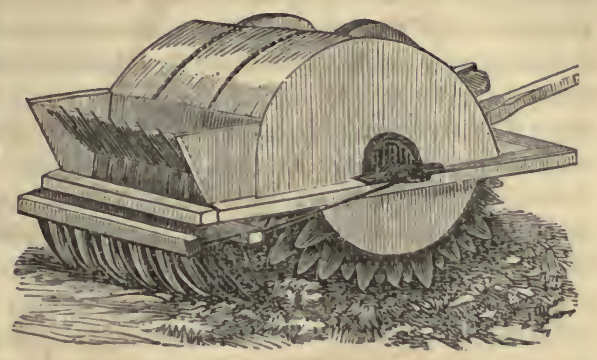
excellent condition for the seed. On a cross-piece of the frame, behind the rollers, is a set of teeth which pass between those on the roller, and keep them free from obstruction, which otherwise might break the teeth or stop the machine. Fastened by a hinge to the shaft of the roller is a piece of timber, into which are fastened cultivating teeth, which stir up and mellow the ground, and also act as drill teeth: this set of cultivating teeth is flexible, and readily adapts itself to the inequalities of the ground.

The seed-box is fastened to the frame immediately back of the cap, and from it pipes extend back and under the cultivating teeth. Back of the seed-pipes are another set of cultivating teeth, which penetrate the soil, serving to render it more mellow, and dragging in the seed.

The drill can be detached from the machine by simply unfastening a couple of hooks. The cultivator can also be detached at pleasure; and when desirable, the teeth can be taken from the roller, leaving a good farm roller, such as every farmer should have. If one of the teeth should become worn or broken, it can be taken out and replaced by a new one. In preparing corn ground, a sufficient number of teeth can be taken from the drill or first set of cultivating teeth, to leave those remaining in the proper places and at the right distances for dropping the corn as required. The cultivator can be raised free from any obstruction by the footlever attached to the driver's seat, and at the same time the seed shut off.

\section{Potato Digger.}

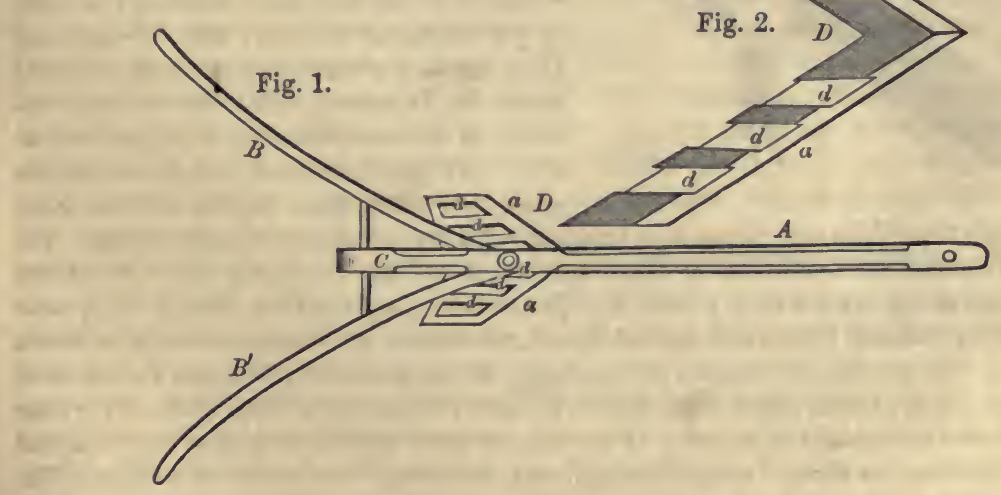

THE accompanying engravings represent an improvement in machines for digging potatoes, recently patented by Galusha A. Bundy, of Lyndon, Vt.,-fig 1 being a top view, and fig. 2 a transverse section, of the mould-board. The same letters of reference indicate like parts on 
both figures. This agricultural implement is in many respects like a common plow; it has a beam $A$ and handles B B, united to an inclined bar C, to which the scoop or plowshare D is attached. The scoop is formed with two angular mould-boards $a$, forming an angle. The improvement consists in providing these mould-boards with slots $d d d$, arranged in vertical directions, or nearly so; that is, standing upwards rather than horizontally. The planes of these slots are disposed parallel to each other and to the plane of the beam, and they are each made to extend from near the bottom of each mould-board to near the top of the same. Through these slots the dirt passes while the machine is used in plowing through or digging into a potato-field, the potatoes being thrown upon each side of the furrow and left in full sight. This mould-board works through the earth or soil, acting like a seive, raising and separating the potatoes from the earth, and leaving most of the earth or soil in its place.

There can be no question about the simplicity of this potato-digging plow : it raises the potatoes and leaves them only to be gathered up, which labor can be performed by boys. The claim is for the construction of the potato plow, with slots standing vertically or nearly so, and having their respective planes parallel to a vertical plane passing through the draught-beam. Digging potatoes is a severe and tedious operation; any machinery to obviate the manual labor in this department of agriculture should be welcomed by all those engaged in farming. We have been assured by Mr. Bundy that it will turn out several acres of potatoes in a day, and that it can be handled with as much facility as a common plow.-Scientific American.

This machine obviates the necessity of pulling up the tops, as they do not obstruct the operation of the digger, which may also be used as a cultivator for ordinary purposes.

\section{Ellis's and Gordon's Excavating Machine.}

This improvement of Messrs. Ellis and Gordon, of Rochester, N. Y., consists in the mode of operating the excavating machine by placing it within the circuit of an endless chain, which passes over a pulley anchored at one point, and over or around a capstan at another point, so that the machine shall form a part of the endless chain, and be operated forwards and backwards by it.

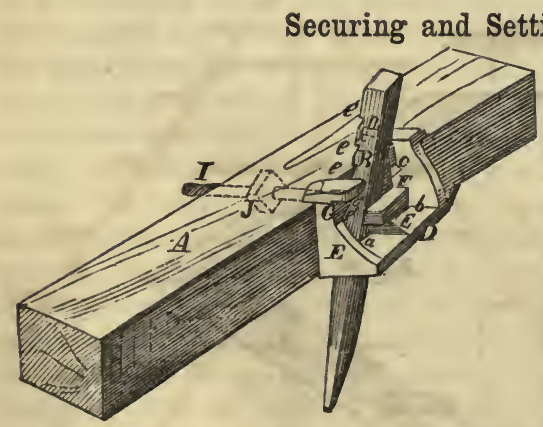

THE accompanying figure is a perspective view, representing an improved mode of securing and setting harrow teeth, for which a patent was recently granted to E. L. Hagar, of Frankfort, Herkimer co., N. Y. The improvement relates to a new method of securing the teeth in the frames of harrows; also in rendering them capables of being adjusted from a vertical to an oblique position, and set to any depth desired. A represents a section of a harrow-frame B E. D E is a metal casting set in an inclined recess, cut in the inner edge of the section $A$.

This casting is provided with two square holes $a b$ in its lower horizontal portion D-one running in a vertical and the other in an oblique direction. The projecting parts $\mathrm{B} E$ of the casting form two grooves $\mathrm{F} \mathrm{G}$, of a similar shape and size as the holes $a b$-one of which runs in an oblique direction in line with the hole $a$, and the other in a vertical direction in line with the hole $b$. On the plate $\mathrm{B}$, forming the back sides of the grooves $\mathrm{F} \mathrm{G}$, tongues $c d$ are cast. The tongue $c$ runs at right angles to the groove $\mathrm{F}$, and $d$ at right angles to the groove $\mathrm{G}$. These tongues enter notches cut in the sides of the harrow teeth, and aid in keeping said teeth in place. $\mathrm{H}$ is a harrow tooth. It is made square or many-sided. $e e e$ are the adjusting notches or traverse grooves which are cast in one of the sides of the tooth. These notches receive the tongues as represented. The tooth $\mathrm{H}$, when it is to be set obliquely, is passed through the hole $a$, and fitted as shown in the groove $G$, and when set in a vertical position, is passed through the hole $b$ and fitted in the groove F. I J is a clamp or elbow-shaped screw-bolt 
which passes through the plate $B$ of the casting, and also through the harrow-frame. This bolt, as it has a hook $\mathrm{J}$ on its inner end, serves for locking the harrow tooth in either of the grooves of the casting; and also as said screw passes entirely through the casting and frame $A$, it serves for locking the casting firmly to the frame A. There is a nut on the outer end of the screw-bolt. This nut, by being turned, causes the hook on the screw-bolt to bear against the tooth, and thereby causes the parts to be firmly clamped together. The screw-bolt I J is so arranged in relation to the two grooves, being between them, that its hook $J$ serves for locking the tooth $\mathrm{H}$ in both the positions described.

It is by providing the casting with two grooves-one oblique and the other straight-that the harrow tooth can be adjusted from a vertical to an oblique position, and vice versa ; and providing the tooth with a series of notches $e e e$, it can be set to any depth desired.

Making harrow teeth adjustable as described is an important idea, for in case their points are broken off, they can be sharpened, and the teeth lowered so as to stand even with the others. And also by securing the teeth to the frame, as described, they can, in case they are broken, be removed with ease and facility, and others secured in their places with like facility.

It is also an advantage, in connection with the adjusting arrangement, to have the teeth capable of being set straight or oblique, for in case it is desired to harrow shallow-plowed soil, then the teeth can be set straight, and in case it is desired to harrow soil which is plowed to a grenter depth, then the teeth can be set obliquely, and also lowered to the depth desired. By setting the teeth obliquely, they enter the soil more readily.

\section{Improvements in Harrows.}

THE accompanying engraving represents a form of harrow devised by Mr. W. B. Hanford, of Walton, N. Y., and described by him in The Country Gentleman. Mr. H. describes its construction as follows:

"It consists of two V-harrows, attached one behind the other, and about eighteen inches apart, as represented in the accompanying cut. The frame should be made of three-by-four white-oak scantling, but second-growth white ash, or very solid blue soft maple will answer, when it is desired to have them as light as possible. The forward harrow is made with a centre piece framed into a brace, and is two feet one inch from the forward tooth to the inside of the brace; the brace is framed into the side pieces or wings on either side, and forward of the three back teeth. The wings are five feet five inches, from the forward to the hind tooth, containing five teeth in each wing, and one forward in the centre piece, and six feet three inches across the hind teeth. The hind harrow is made in the same manner as the forward one, except that the brace must be placed farther back, and forward of only two hind teeth on each side, and the wings are four feet ten and a half inches from the centre of the middle piece to the hind tooth, with five teeth in each wing, but

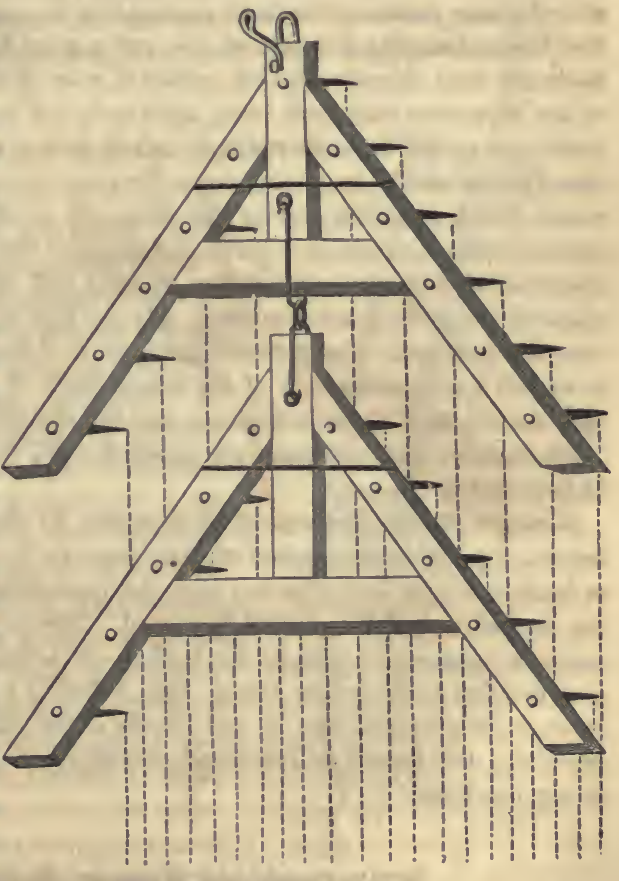
none in the middle, and set in such a manner as to exactly divide the space between the forward teeth, and mark three and three-fourths inches from centre to centre of the furrows of the teeth, the outside teeth of the hind harrow marking within the outside teeth of the for- 
ward one. The wings are united to the middle-piece, and secured by a band shrunk on far enough back to make it solid, and to receive a half-inch screw-bolt through the wings and middle piece forward of the band, and the nut turned up snug. The teeth should be made of three-fourths iron, unless the ground on which it is to be used is quite rough and stony; then perhaps seven-eighths iron should be used; they should be about eleven inches long, and the top end should be made dovetailing nearly the thickness of the frame down to a size to receive a burr, and a good screw cut on it, so that when drove the end of the tooth will come the thickness of the burr above the frame. The holes should be bored with a bit just the size of the screw on the top of the frame, and the under side beat out with a chisel, to exactly fit the tooth, but not too large, especially endwise of the wood. Put the tooth in its place; then place a bar of iron on the end of the tooth, with a small square hole near one end to receive the point, and drive it in firmly with a heavy hammer, striking on the iron bar by the side of the tooth, and occasionally striking the tooth sideways against the grains of the wood, to make it stand firmly in its socket. Then put on a good iron washer, and screw the burr on tight. The harrows are fastened together by two clevises and a link; the forward clevis clasps the brace and reaches forward, and is attached to the centre piece by the pin. To draw from the middle piece by a common clevis, inclines to lift the forward harrow too much, but it should be used with one similar to the one represented in the cut, placing the draft one and a half inches above the top of the harrow. This causes them ta draw flat, or swim fair, as it is sometimes termed, while they hold each other to the work. And by means of the clevis joint, in the middle, they adjust themselves very easily and quickly to an uneven surface of almost any kind, while a sod, or a stone, or an obstruction of almost any kind, can scarcely get more than one wing from the ground at a time.

It is light of draft, and easily handled or transported, weighing, as mine does, but one hundred and sixty pounds, or eighty each. I am satisfied from using it, that it will do more work in passing over the ground once, than any common single harrow that I have seen work, will, with the same number of teeth, in passing over the ground twice. I would not wish to disparage the Geddes harrow; it is a good one, and a great improvement on the old instruments; but there are some objections raised against it, some of which I think are obviated in mine. Some of the objections that have been made to it are these: If a sod, or any obstruction, passes under one of the forward wings, it raises both wings on one side till it has passed over; then again when the back wing meets the same obstruction, both wings on that side are again raised until it is passed over by that wing. In passing lengthways of a ridge, the joint in the middle allows it to adjust itself to the shape of the ground very handsomely, but in passing crosswise of ridges or over a hollow, it being stiff longitudinally, it cannot shape itself to the shape of the ground, and can touch only the tops of the ridges. Or if an obstruction passes from the nose under the centre of the harrow, it immediately raises up the middle, causing it to rest on the extreme ends of the wings, while it passes in this position, some five to nine feet, the length of the middle pieces and the obstruction."

Mr. Hanford does not claim any patent for this form of harrow, but wishes that all should be benefited by its use.

Ramsay's Flexible Harrow.-This invention, by the Messrs. Ramsay, of Strabane, Washington co., Pennsylvania, consists of three separate harrows or parts, united together by hinges or hooks and eyes in such a way that the implement is entirely flexible, and adapts itself to the inequalities of the ground traversed. The form of the several harrows when united is that of a right-angled triangle, the leading one being about two feet square, and the two hinder ones two feet three inches square, thus affording a sweep of about eight square feet. The teeth are so arranged that no one travels in the track of any preceding it. Among stumps, especially, this harrow will be found convenient, as but a small part of it needs to be lifted at at any one time.

\section{Hill's Combined Harrow, Roller, and Seed-Planter.}

A Patent has been recently granted to Daniel Hill, of Harrisville, Indiana, for a machino

which combines the harrow, seed-planter, and roller in one and the same construction. The 
mode in which the machine operates is as follows: If grain is to be sown, the seeds are distributed from a hopper placed above and in front of a harrow, which immediately passes over it; but if grass-seed is to be sown, the seed falls from a rotating cylinder fixed behind the harrow, on the ground freshly stirred by the harrow, and the roller, which is attached to the end of the frame or carriage supporting the harrow and seeding apparatus, passes over the seeds, and completes the operation of planting. Both seeders can be detached from the machine at pleasure, and the harrow and roller used separately, if desired. The roller and seeders may also be used in connection or separately for seeding grass-land, the distribution of grain from the seeders being regulated by an appropriate apparatus. The patentee states that the machine will work as much ground in a day as an ordinary harrow, and is no harder for the team; the harrow part being so constructed that the teeth of the harrow may be depressed or elevated at will. This combination of agricultural machinery is said to be simple and easy of construction, and may be kept in order without difficulty. It comes to us highly recommended by various county societies and private individuals.

M'Gaffey's Seed-planter.-A patented improvement, made by J. W. M'Gaffey, of Syracuse, New York, April, 1855, consists in the use of a tilt apron arranged in connection with a distributing roller, whereby the seed and manure are deposited in the furrow or hill at the same time.

\section{Hand Seed-Planters.}

Wakefield's Seed-Planter.-The accompanying engraving represents the construction and arrangement of a new hand seed-planter, the invention of C. A. Wakefield, of Plainfield, Massachusetts. The illustration represents a vertical section of the implement, with the plunger out, and the construction will be readily understood by reference to the following description:-

$A$ is the hopper or box containing the corn; it is fllled through the lid $a . \mathrm{A}^{\prime}$ is a gaide frame in front of the seed-box, to direct the up-and-down movement of the imbedding plunger $\mathrm{C}$, which, in its double movement by the groove $g$ and $\operatorname{pin} f$, alternately opens and closes a delivery slide, which works in a groove $e$ in the seed-box at its bottom. This slide has an aperture in it. As plunger $\mathrm{C}$ rises, a suitable number of grains of corn for a hill is conveyed through the passage $c$ into the receiving chamber $\mathrm{D}$. In the descent of the plunger $\mathrm{C}$ when planting, the delivery slide is drawn back to take in a fresh supply of grain from the hopper, and hold it ready for another delivery; at the same time the plunger, in its descent, ejects the charge of corn previously fed down into $\mathrm{D}$, and imbeds it at the proper depth in the soil. The plunger $\mathbf{C}$ opens the receiving chamber $\mathrm{D}$ by pressing against the back plate of it, which is acted upon by spring $E^{\prime}$, to allow the grain to pass out, and also to close said chamber again when the plunger is drawn back, so as to retain the seed fed into it for the next hill. $G$ is a flange projecting from the plunger $C$ at its bottom, on the rear side, for guiding and holding the grain, when being imbedded between it and the short front plate $\mathrm{H}$, which enters the ground and projects from the broad

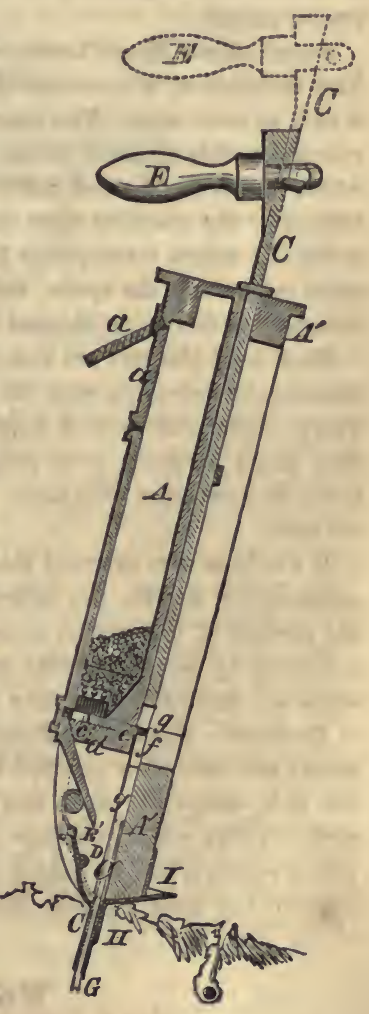
stop-plate I; this latter plate stops the further entrance of the implement into the soil. The side flanges project from the front plate $I$, and serve, in conjunction with the elastic back plate of the chamber $\mathrm{D}$ and bottom plate. $\mathrm{H}$, to scrape off the dirt adhering to the 
sides and edges of the plunger $\mathrm{C}$, when it is drawn out of the ground into the chamber $\mathrm{D}$. Any suitable derice may be used for guaging the stroke of the plunger to vary its depth of hole for the seed. $\mathrm{E}$ is the handle of the plunger $\mathrm{C}$; it is placed obliquely to the plunger, and is used by the operator to give the plunger an oblique direction into the soil. The implement is carried and used as shown, like a walking cane, requiring no delay, and is easily operated. The person using it steps from hill to hill, striking the implement into the ground, like a cane, causing the short front plate $H$ to enter the soil, the rstop plate $I$ to bear on the earth, and the plunger $\mathrm{C}$ to eject the corn or seed through the bottom of the receiving chamber $\mathrm{D}$, and force it to its required depth obliquely into the ground, after which, by raising the handle, the plunger $\mathrm{C}$ is elevated in the same oblique direction, the stop-plate I answering for a fulcrum during lateral strain upon the plunger in drawing it out, whereby the earth is shaken over the seed, and covers it; the scrapers and side flanges also scrape back all soil from the plunger, making it fall on the seed, so that the perfect covering of it is thus fully insured. It is thus more certain in its operation than if it made the hole for the seed perpendicular, and carried the soil up instead of covering each hill with the implement as it is rising out of the opening in the soil. The two simple motions of this implement or machine-only pressing down and lifting it up like a walking stick-by which the hole is made, the seed fed down and deposited, the seed-box closed, and the seed covered by the soil, makes it superior to those hand-planters which require a number of motions to accomplish the same objects. The weight of this implement is about seven pounds, and its cost five dollars. The editor of the Scientific American states that he was a witness to the planting of a quarter of an acre of corn with one of these planters in twelve minutes.

Dana's Hand Corn-Planter.-Another corn-planter, the invention of Charles H. Dana, of New Hampshire, is constructed in a manner similar to the above-described instrument, and is said to work well. The internal arrangements are such that when the planter strikes the ground, a slide attached to the handle is pressed down, which opens a cavity or charger, by which means the desired number of kernels of corn fall through a branching groove at the bottom of the machine upon an iron plate, which is closed upon a spade which pierces the earth and makes a receptacle for the corn. On lifting the machine by its handle, the iron plate opens from the spade, and the corn is left in the ground. Thus a man will plant with accuracy as fast as he chooses to walk across the field.

Hand seed-planters are but of recent date, but their convenience and superiority to handplanting and covering with the hoe have given them an extensive circulation in a very few years. One man, with a hand-planter like this, especially in well-plowed land, will plant four times as much corn, rice, beans, pease, \&c., as four men depositing the seed by the hand, and covering with hoes. The economy of such an implement for every farmer is selfevident.

It has been also asserted that the use of these hand-planters is advantageous in hastening germination, and for the following reasons: The seed is forced by pressure obliquely from the surface of the ground to the required depth, thus insuring the immediate absorption of moisture, by bringing it into perfect and hard contact with the soil under and around it, while the earth falling loosely over cannot obstruct the coming up and growth of the blade.

Barnhart's Hand Corn-Planter.-A patent, for an improved corn-planter (a hand implement) has also been granted to Andrew J. Barnhart, of Schoolcraft, Michigan. It makes the hole, drops the seed, and cover it by a simple operation. A small hollow cylinder or piston works within another containing the seed; by one stroke downwards this hollow piston makes a hole by taking up the earth, and then the seed drops down; the return stroke deposits the earth formerly lifted upon the top of the seed, and covers it.

\section{Wells's Patent Grass Seed-sower.}

TrE object of this invention, by Mr. Wells, of Virginia, is to facilitate the sowing of grass and clover-seeds, and, at the same time, prevent waste by unequal distribution.

The machine consists of a narrow box or trough ten feet in length, with a zinc bottom 
perforated with holes, through which the seed is shaken by means of a sliding rod, operated by hand with a small lever. The whole is made quite light, so as easily to be carried by a man with a belt across the shoulders.

\section{Andrews's Broadcast Seed-sower.}

A MeCHANical contrivance for imitating the hand in sowing has been recently invented by John Andrews, of Winchester, Massachusetts. This machine differs in some respects from any of the other sowers recently invented. In most of the machines peretofore contrived, the grain has been delivered from a vibrating tail-board, from which it was suffered to drop upon the land as the machine advanced. With these machines a very narrow strip only was sowed at a time, and their operation was consequently slow and defective. To obviate this inconvenience, and to produce a machine that shall imitate, as far as possible, the motion of the hand in sowing grain, is the object of this invention, which consists in delivering the grain in the requisite quantity to a hollow trough or scatterer, which is caused to swing back and forth round a fixed centre, by which means the grain is thrown to a considerable distance upon each side of the path travelled over, and the sowing is performed much more rapidly than the machines heretofore contrived have been capable of.

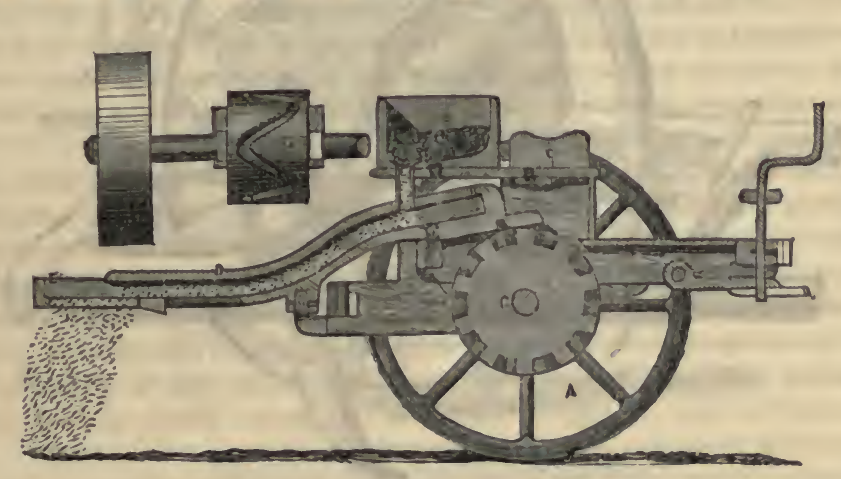

Our engraving represents the sower in sectional elevation, and with a separate detail of the scroll drum for swinging the distributor. The machine is carried upon a pair of wheels $A$, and it is drawn by shafts to the right. The grain-hopper is at $B$, near the seat $C$ of the driver. From this hopper the seed drops down through a tube opening at its lower end into the expanding trough-distributor $\mathrm{D}$, having a sieve at its extreme end for the seed to fall through. The distributor is carried upon a fixed stud centre $F$ as a swinging joint. The extreme forward end of the distributor carries a vertical pin, which enters a zigzag scroll groove cut in the periphery of the drum $G$ on the main axle. Thus, as the drum revolves, the zigzag action upon the forward end of the trough produces a widely-swinging traverse of the discharging end, where the grain falls to the earth; a rapid vertical shake is also given to the distributor by an undulating piece $H$ fast to the frame, and having a stud pulley of the distributor bearing upon it.

Brown's Broadcast Sower.-Mr. Brown, of Lawnridge, Illinois, has invented a machine for sowing seed broadcast. A series of oblique cups are placed upon a rotating cylinder underneath the hopper, in combination with a distributing plate, which convey the seed from the hopper in such a manner that it is sprinkled with perfect regularity and evenness over the whole ground traversed by the machine.

\section{Improvement in Corn-Planters.}

Tus annexed engravings are views of an improved corn-planter, recently invented and patented by William Redick, of Uniontown, Pa. Fig. 1 is a perspective view of the machine, 
and fig. 2 is a section of a side elevation. The same letters in the description refer to the same parts.

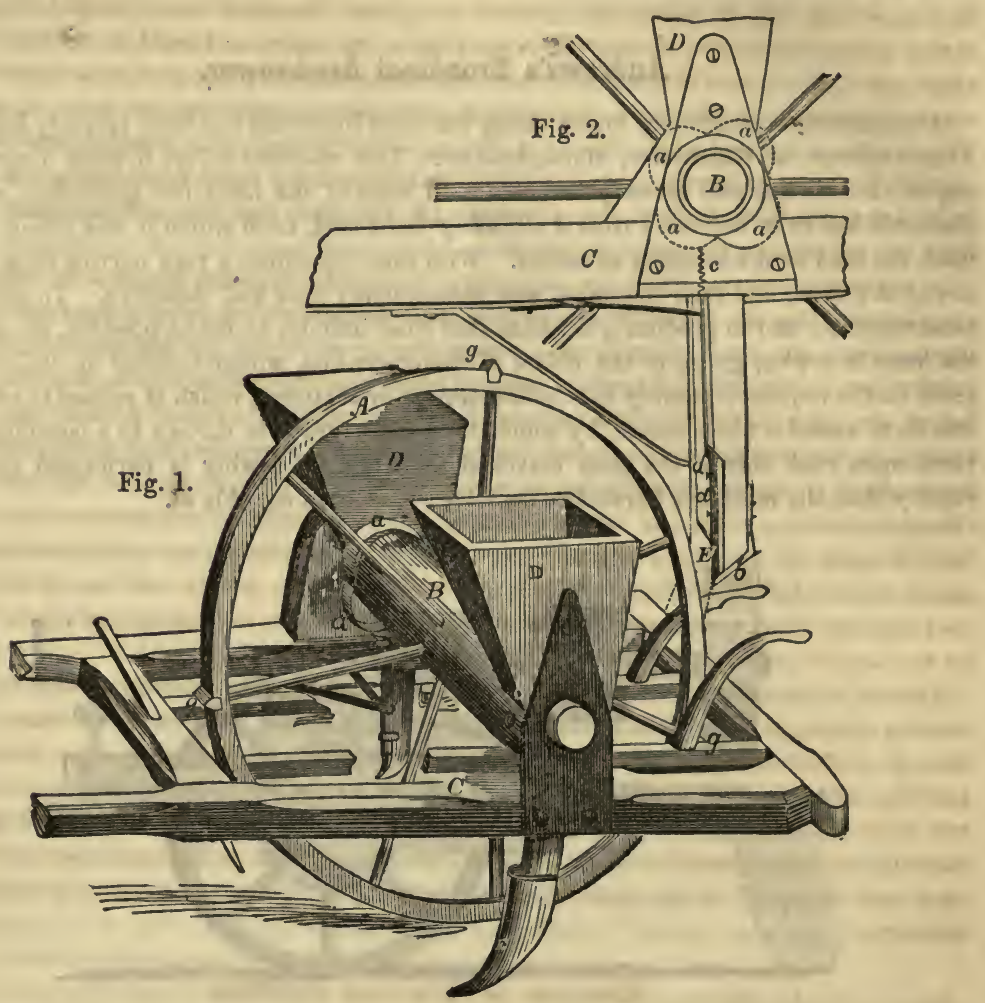

The cams are arranged on the axle, the markers on the periphery of the carrying-wheel, and the valves at or near the bottoms of the seeding-tubes, with their several operative parts, for the purpose of causing regularity in the marking and dropping of the seed, however irregularly the motion or speed of the machine may be.

$A$ is the carrying-wheel upon which the machine is supported and drawn over the ground to be planted; $B$ is the axle, fastened to the wheel, so as to move with it. The axle extends out each side of the wheel a suitable distance, and is provided with cells at regular intervals, which receive from the hopper and carry to the seeding-tubes the grains to be planted. These cells are provided with screws, the heads of which fit the cells, so that by running in or out of these the depth of the cell will be increased or diminished, so as to carry around only the regulated quantity of grains to be planted. In planting check-rows, each alternate screw is raised to the periphery of the axle, so as to pass through the hopper without receiving any grains therefrom. When drilling, all the screws are sunk, so that every cell shall carry out its quota; and in this case the valves in the tubes are hooked in the second or lower hole, so as to remain all the time open. C represents one of the shafts; they are curred near enough together at their points to suit the working of the horse, while at the axle, where the teeth or shoes are arranged, their width may conform to the distance between the rows of corn. $\mathrm{D}$ is the seed-box, there being one on each side of the wheel or on each end of the axle-said hoppers diminishing in width from top to bottom, where they are open to allow the grains to drop into the cells. $\mathbf{E}$ is a tooth or shovel-there being one in advance of each seeding-tube-for opening up a furrow into which the corn is dropped, the earth falling in over it when the machine passes, as in ordinary operations. The bottoms or lower 
ends of the tubes fit in behind these teeth, so as to prevent them from accident by striking against any obstructions, or from filling with dirt.

a $a$ a $a$ are four cams arranged around the axle B. $\quad b$ is a rod having its lower end attached to the valve $d$, and its upper end pressed up against the cams by a spring $c$, so that said spring and rod opens and closes said valve at every depression and swell of the four or quadruple cam. There is an inclined bottom on the tubes, made of spring steel, so as to yield should a grain be caught in the valve, and allow it to be thrown out when the valve again opens. The markers $g g g g$, of which there are four on the periphery of the wheel A, must bear such relative positions to the cams as that they shall arrive at the exact point where the seeds are to be deposited, after making due allowance for the time that the seed occupies in falling from the hopper or cylinder to the valve.

In relation to the construction and operation of this machine, Mr. Redick states, in his specification, that the devices which he uses have been employed before, separately, on seeding-machines, but not combined; and that it was by observing the defects of their separate results that he was enabled to unite them to produce a practical operative machine, that can lay off the ground, and drop the seeds at the marks previously made, without any variation caused by the unequal speed of the horse. In the old machines the variable speed of the horse caused irregular planting, becanse the markers had a variable and the seeds an unchanged velocity. "By my arrangement of the cams, valves, and markers," he says, "I have brought the machine practically to perfection in this particular, as the distance that the grains have to fall allows the markers to come to the precise point; and should the markers vary the least from the exact point, either in overreaching or falling short of it, the operator, by the handles, can raise up or draw back the machine to bring it right."

Fenwick's Corn-planter.-This invention, of R. W. Fenwick, of Brooklyn, Now York, is ex ceeding simple, and apparently effective. The nature of the improvement consists in having the seed-slide turn on a centre, and in connecting it with a conical valve at the bottom of the planting-tube, and with a sliding-tube which takes up dirt for covering the corn. When the end of the planting-tabe is struck into the ground the valve is operated, and with it the slide whereby a proper quantity of seed is taken from the seed-box in the upper part of the implement and dropped; at the same time the covering-tube is made to take up dirt and cover the corn.

\section{Machine for Planting Potatoes.}

Fig. 1

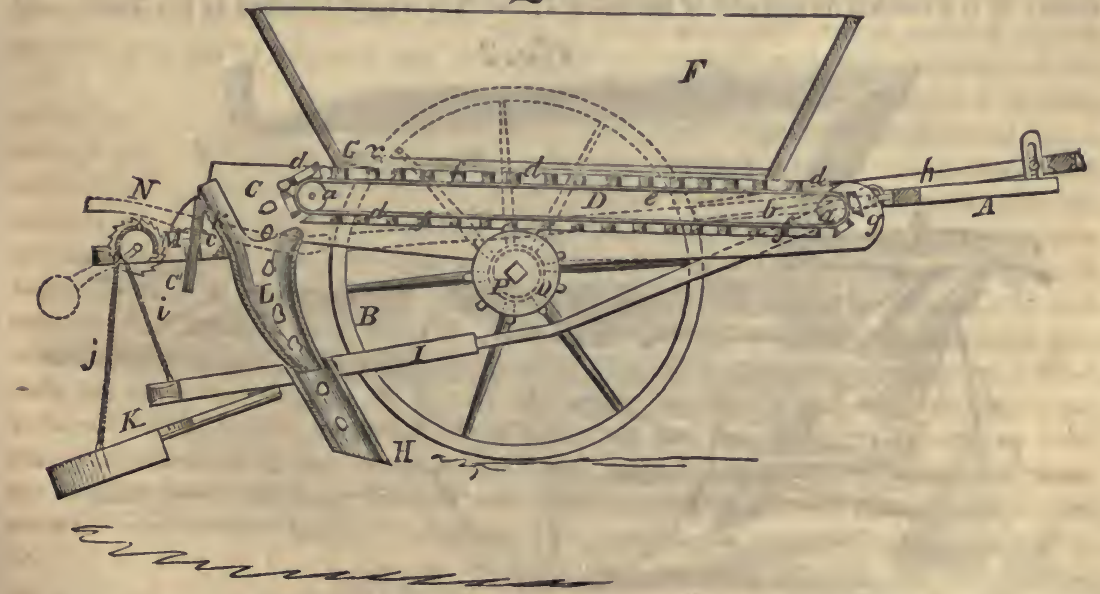

THE annexed engravings are views of a machine for planting potatoes, for which a patent was granted to Alexander Anderson, January, 1855. Fig. 1 is a vertical longitudinal section through the middle of the machine, and fig. 2 is a perspective view. Similar letters refer to 
like parts. This invention consists in the employment or use of an endless apron, placed underneath or at the bottom of a hopper, and provided with a series of apertures, which will be hereafter fully described; said apertures receiving the potatoes of a suitable size for seed and conveying them to the discharge-spout, through which they fall into the furrow at equal distances apart; said apertures also conveying potatoes that are too large for seed to a knife at the bottom of the hopper, by which they are cut of a suitable size for planting. The apertures in the under side of the apron receive the teeth of a wheel by which motion is communicated to the apron.

Description.-A represents a rectangular frame supported upon two wheels B B; and $\mathrm{C} \mathrm{C}$ are two cheek-pieces, between which an endless apron $\mathrm{D}$ is placed-said apron passing around rollers $a a$ at the front and back ends of the cheek-pieces. The front parts of the cheek-pieces rest upon a rod $b$, which passes transversely through the frame $A$ and cheekpieces, about midway between their upper and lower surfaces; said rod also attaching the shafts $\mathrm{E} E$ to the frame A. The lower surfaces of the back ends of the cheek-pieces rest upon a cross-piece $c$ of the frame, and the cheek-pieces and endless apron have an inclined position; $C^{\prime}$ is a rod, have a screw thread cut on its upper end. This rod fits in a plate $k$ on the ends of the cheek-pieces, and the rod projects downwards a suitable distance below the cross-piece $c$. The endless apron $\mathrm{D}$ is composed of a series of rectangular blocks $d$, the lower surfaces of which are attached in any proper manner to a belt $e$; the edges of the several blocks being in contact, except when passing around the rollers $a a$, between each two of the blocks a circular aperture $f$ is made, one-half of the aperture being in the edge of each block; consequently, each block of the apron has a semicircular recess in two of its edges, and these recesses, when the blocks are attached to the belt $e$, form the circular apertures $f$. F is a hopper secured to the upper surfaces of the cheek-pieces C C, and directly over the endless apron $D ; G$ is a knife placed at the bottom of the hopper, at its upper or elevated end; said knife passing across the hopper, and just above the endless apron D. H is the furrow-share, which is formed of a tube having its lower end cut obliquely, so as to form a point to enter the ground. The furrow-share is secured to a frame $I$, the front part of which is secured by eyes $g g$, which pass through the ends of the frame $I$, and into a cross-piece $h$ of the frame A. The back part of the frame $I$ is attached by a chain $I$ to a roller $J$, on the back part of the frame. $K$ is the covering-share, which is attached by a hinge or joint to the back end of the frame I; a chain $j$ connects the covering-share with the roller $\mathrm{I}$; $\mathrm{L}$ is a discharge-spout, the upper end of which is placed directly under the elevated and discharge end of the endless apron D. The spout $L$ conveys the potatoes into the tube of the furrowshare; $M$ is a ratchet on one end of the roller $J$, and $N$ is a pawl attached to the frame-said

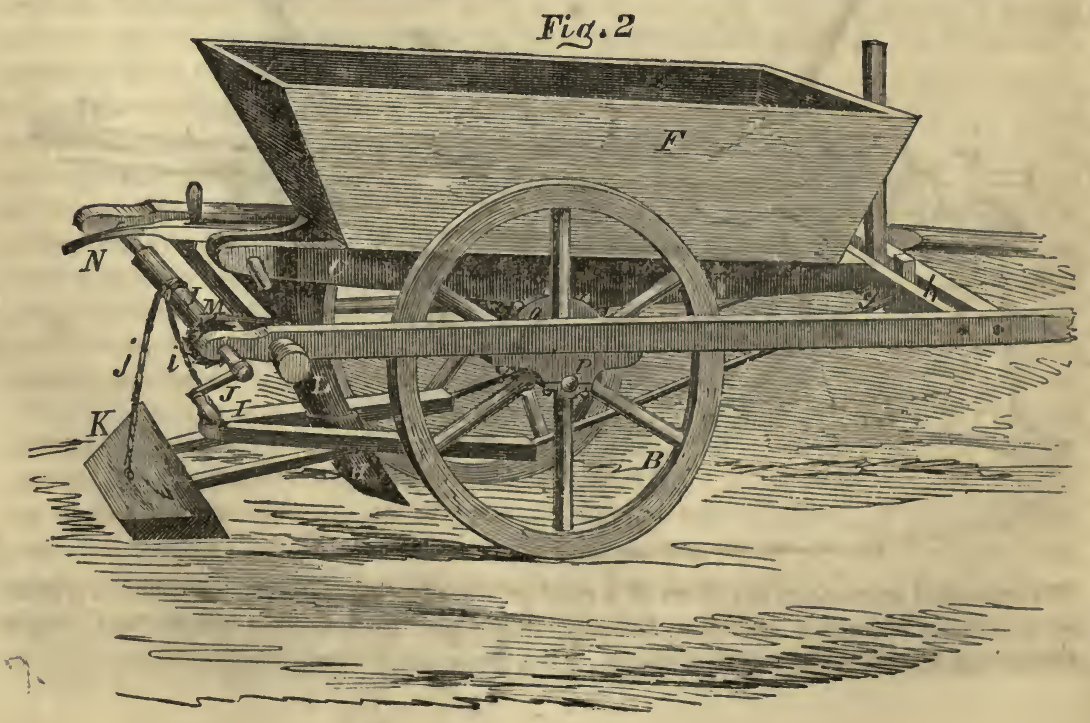


pawl catching into the teeth of the ratchet; 0 is a toothed wheel on the axle $\mathbf{P}$ of the wheels B B. The teeth of this wheel fit in the apertures $f$ in the endless apron $\mathrm{D}$.

Operation.-The hopper $\mathrm{F}$ is filled with potatoes; and as the machine is drawn along, motion is given the endless apron $\mathrm{D}$, by means of the toothed wheel 0 gearing in the apertures $f$, in the under side of the endless apron. Potatoes of a suitable size for planting will fall into the apertures $f$, and will pass under the knife $\mathrm{G}$, and be thrown into the discharge-spout $\mathrm{L}$ as the blocks $d$ pass around the roller $a$, at the upper or elevated end of the apron, the apertures being widened as the blocks pass around the roller in consequence of the edges of the blocks being forced apart. Potatoes that are too large for planting will project upwards above the surfaces of the blocks $d$, and will be cut by the knife $\mathrm{G}$; the top portion that is cut off will, if small enough, enter one of the apertures $f$, and be discharged into the spout $L$. If not made small enough at one cutting, it will be again cut when brought to the knife, the pieces of the potato remaining in the apertures are of course discharged as the blocks pass around the roller $a$. The potatoes drop into a furrow made by the share $\mathrm{H}$, and they will be dropped at equal distances apart, the distance between the potatoes being regulated by the size of the wheel 0 . The larger the wheel 0 , the nearer the potatoes will be planted; and one or more extra wheels of different sizes may be placed in the shaft $P$, and put in gear with the apron, as occasion may require. The furrow and covering-shares $\mathrm{H} \mathrm{K}$ are raised from the ground by turning the roller $J$. As the chain $i j$ is wound around the roller $J$, the frame $I$ is raised, and will act against the lower end of the rod C', and raise the cheek-pieces C C and endless apron D, and the endless apron will be thrown out of gear with the wheel 0 , the roller $\mathrm{J}$ being prevented from moving casually by means of the pawl $\mathrm{N}$ and ratchet $\mathrm{M}$. Thus by this machine the potatoes will be cut the required size, and planted at equal distances apart in the furrow. There is no uncertainty attending the operation. The machine is simple, not liable to get out of repair, and is economical to manufacture.

Nixon's Potato-planter and Seed-drill.-A potato-planter and seed-drill, recently patented by Mr. William Nixon, of Lincoln county, Canada West, is constructed as follows :-The hopper, or box for containing the potatoes, rests upon the axle passing through two wheels, with shafts attached to the axle in the same way that a cart or gig is constructed. A horse is then put before the planter, in like manner as a horse is placed before a cart, and the machine is drawn in the same way. The seed-hopper rests upon the axle and wheels, as above described, being keyed together, and fastened to a cog-wheel which drives a horizontal cog-wheel that is fastened to the underside of the cast-iron seed-wheels. When, therefore, the horse moves forward, the whole machinery is set in motion. There is a round bottom to the hopper that revolves correspondingly with the motion of the animal which draws the vehicle. In this bottom, or revolving platform, there are holes at given distances. For planting in hills, you open two holes, and leave all the others shut up; and in this case, four or five sets are dropped in one place, whatever distance you may think proper, the seed being cut by a sharp knife, placed immediately under the revolving platform. Some might prefer to cut the sets by hand, and in this case the knife may be removed, or the potatoes may be dropped without being cut. If drills are considered preferable to hills, the two large holes are plugged up with leather, sheeted with tin, and the plugs, made of the same material, taken out of the smaller holes. The seed is then poured into the hopper, the horse moves, the sets are cut, and dropped at regular distances. For planting corn, there is another set of smaller holes, by means of which corn may be planted in hills or drills upon the same principle as the potatoes are planted. For fine seeds, such as onion, turnip, carrot-seeds, etc., there are tin canisters with holes suitable for sowing such seeds. In connection with the other wheels, there is a seed-wheel, by which the whole is regulated.

Underneath the planter is a large tooth, like that of a cultivator. This tooth makes a suitable place for the seed to fall into, and is placed in front of a hollow sheet-iron tube, through which the seed falls to the ground; and behind the tube are two scrapers, so constructed as to cover up corn or potatoes, and two small brooms are used for the purpose of covering up the smaller seeds which drop from the tin canisters. To this part of the planter there is a set in the rear of the hopper, by means of which the drills can be made deep or shallow, as the farmer thinks proper. 


\section{McFarlane's Corn-Planter.}

THE accompanying engraving is a perspective view of an improved corn-planter, the invention of Mr. J. G. McFarlane, of Newville, Cumberland county, Pa. The object of the invention is to make the furrow deposit the seed with manure or plaster, if desired, and cover the seed with earth-all at one and the same operation.

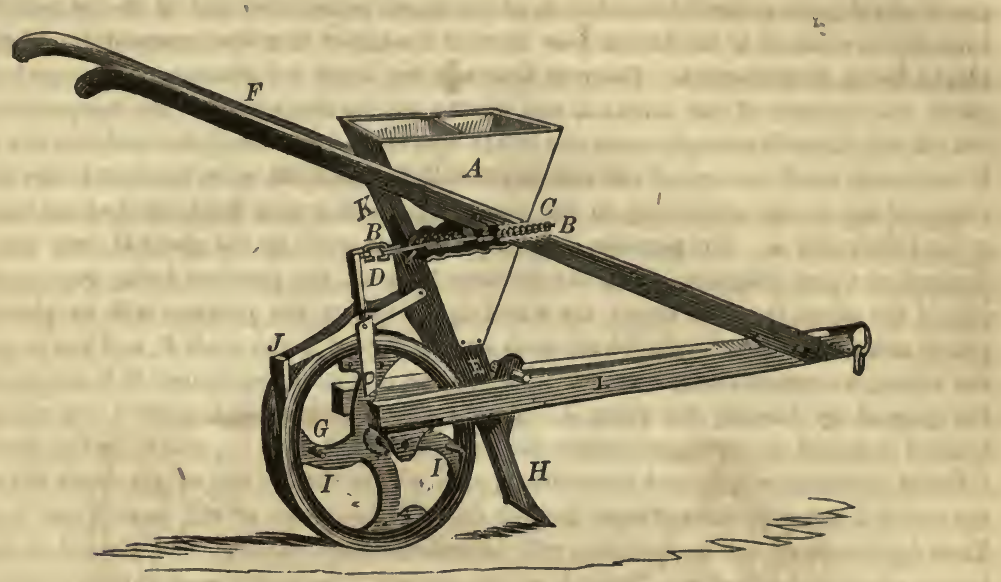

The nature of the invention consists in the employment of a self-acting scraper, working over the feeding apertures for regulating the proper number of grains to be fed into the hill; it also consists in the use of a hanging scraper, by which the groove of the wheel is always kept clear, so as to be in a condition for facilitating the operation of the wheel. $A$ is the hopper; it has a division for corn and another for plaster or guano. B is the slide; it is operated by a spiral spring $\mathrm{C}$ and a crank $\mathrm{D}$. It has a small, round aperture 1 , which receives and discharges the grains of corn from the hopper; at the other end is an oblong slot 2, through which the guano or plaster passes, and is discharged through the tunnel $\mathrm{E}$ along with the grain. $F$ are the handles; $G$ the operating wheel, which is behind the depositing tube H. The wheel has a grooved periphery and flanges at each side; these cover the seed after it is deposited. II are projecting pins on the wheel for striking on the dropshoulder of the crank, as the wheel revolves, to operate the slide at certain intervals, making the hills. Two or more of such pins may be used, so as to increase or diminish the number of hills in a row. The drill-tube $H$ is arranged so that a wooden pin can break to relieve it from breaking when it meets with a sudden resistance from some obstruction. $J$ is the scraper; it acts by its own weight, and rests in the groove of the wheel, to keep it free from dirt. $\mathrm{K}$ is a self-acting scraper, which rests by its own weight on the slide $\mathrm{B}$, for the purpose of preventing more than the proper number of grains from passing over the aperture 1 at once. $\mathrm{L}$ is the beam.

This corn-planter, according to recent improvements, is constructed entirely of iron, and is simple and effective in its arrangements. At the Agricultural State Fair of Pennsylvania, 1855 , the machine received the first premium, and may, without doubt, be classed among the very best of recent agricultural improvements.

\section{Improved Hay-Knife.}

Is an improved hay-knife, patented May, 1855, by Seth Whalen, of West Milton, Saratoga county, New York, the knife has a cross-head handle, and the blade is formed with a bend near the handle, so that it stands out from it at a suitable distance without a shank, the blade heing simply screwed to the centre of the handle. This method of constructing hay-knives divides the applied power between the two handles, with the knife in the centre, economizes 
labor, and enables the operator to cut with greater ease and more facility than with the oldfashioned hay-knife, which has not a cross-head handle. The knife also cuts in two directions, both vertically and horizontally.

The claim of this patent sets forth the nature of the invention clearly; it is as follows: "I claim attaching a blade made of sheet-steel, and bent at its upper extremity, so as to stand out from the handle and between the arms, whereby a great saving in time, labor, and expense in making hay-knives can be effected, and an equal distribution of the power of the operator exerted in a perfect manner upon the edge of the knife, causing it to act more effectually upon the hay than the ordinary knife."

\section{Hand Thrashing-Machine.}

Axovg the agricultural machines recently introduced into England, a hand thrashingmachine, invented by the Rev. Mr. Wilson, of Ayrshire, is worthy of note. We present two engravings of this improvement. Fig. 1 being a perspective elevation of a machine intended to be worked by human power, and fig. 2 a corresponding view of the same in section.

Fig. 1.

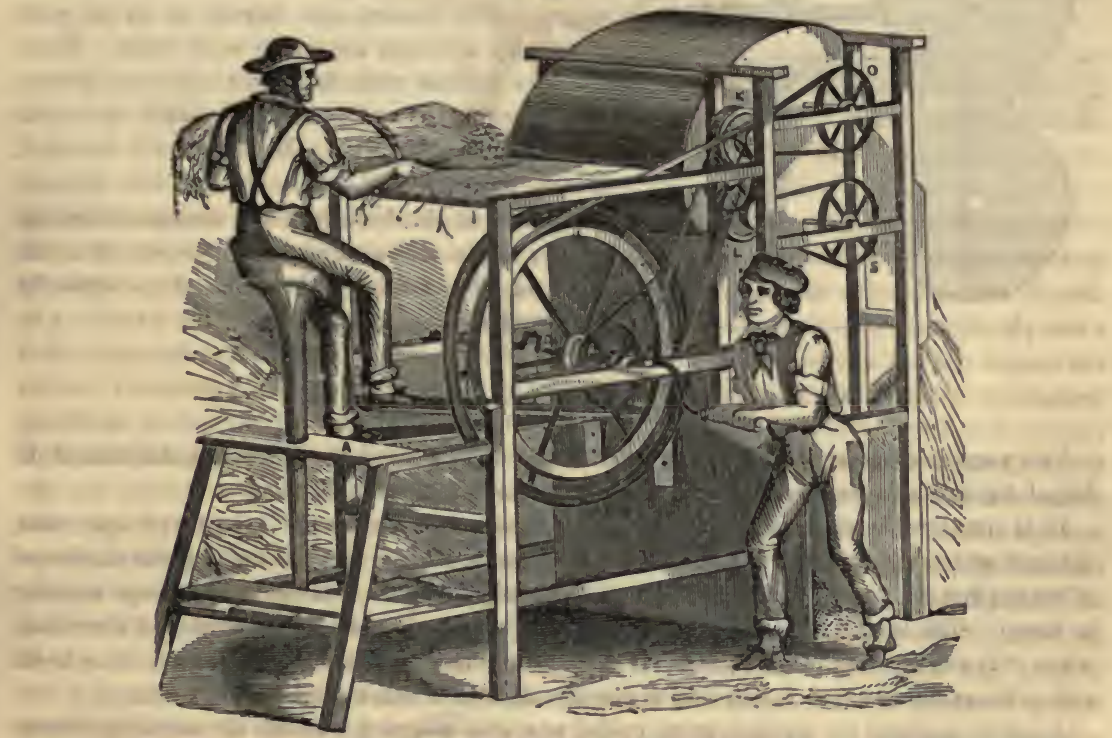

In the common thrashing-machine, the essential feature of the separating apparatus consists of a cylinder known as the "drum," fitted with projecting beaters, placed longitudinally upon the cylinder. Such a revolving drum is contrived so that its projecting arms shall strike the grain as it passes between the rollers. Mr. Wilson substitutes for the drum a species of flattened beater, revolving on a shaft, and giving the grain two distinct thrashing blows at each revolution. This beater is made of a flat, rectangular board, attached to a shaft, as delineated in fig. 2.

This thrashing-machine possesses the advantage of being worked by hand as well as by horse or steam power. A single attendant can accomplish the whole process of thrashing. The separation of the grain from the straw is effected more economically, and with a less expenditure of power than hitherto, by reason of the unthrashed grain being struck on both sides alternately.

The framing of the machine is an ordinary rectangular erection, having a platform $A$ at one end, with an adjustable seat $B$ for an attendant, who feeds the unthrashed grain into the machine, and at the same time aids the thrashing action with his feet. He accomplishes the 
latter by working the two treadles $c$, which are linked to a pair of cranks on the winch-shaft $\mathrm{D}$, which is mainly turned by a separate attendant. This shaft carries a pulley $\mathrm{E}$, from which a cross-band $\mathbf{F}$ passes to a pulley on the end of the lower fluted feed-roller $G$. The same shaft also carries a large pulley $\mathrm{H}$, from which a band passes to a pulley on the end of the shaft of the upper beater $\mathbf{J}$; this shaft having upon it a spur-wheel gearing with a similar wheel on the shaft of the lower beater M. In this way the two beaters simultaneously revolve at the same rate, but in reverse directions. The shaft of the upper beater has also a pulley, with a band passing from it to the pulley 0 on the end of the shaft of the large upper straw-clearing cylinder $I$. The lower roller $Q$ is similarly driven by a pulley on the bottom beater-shaft, by a band passing to the pulley on the roller-shaft.

Thus, as the grain is fed in, it is drawn forward by the grooved rollers $G$ and carried into contact with the pair of beaters $J \mathbf{M}$; and, as these beaters revolve at a high rate, they alternately strike the grain upwards and downwards. Each edge of the beaters crosses the Fig. 2. horizontal line of traverse of the straw to a short extent, (variable at pleasure,) so that, as the unthrashed straw passes along, the grain is most effectually separated or struck off by the alternate and opposed actions of the beater edges. The beaters are keyed, so as to work constantly at right angles to each other. Hence the two beaters work into each other, as it were, like wheel-teeth, and subject the grain to a most severe thrashing action. As the grain is detached, it falls down clear of the machinery, into a proper receptacle at the bottom of the casing of the machine; while the cleared straw passes off to the back of the machine, between the constantlyrevolving rollers, fig. 2.

\section{New Turnip and Root-Cutter.}

THE vegetable cutter for which the prize medal was awarded at the recent exhibition of the Royal Agricultural Society, Carlisle, England, is constructed as follows:-

It is fitted with an improved cutting-plate, leaving a number of ledges and open slits, through which the dirt, as it separates from the roots, falls in front of the implement, instead of among the cut pieces, which latter is a serious objection, as it tends to encourage scouring in sheep. The ledges retard the last flat piece of turnip till the next revolution of the wheel, when it is cut into the proper sizes. It has thirty sheep and four cattle knives, so as to cut either for cattle or sheep, according to the direction in which the fly-wheel is turned.

Another machine for which a prize medal was also awarded was one for reducing turnips and other roots to pulp preparatory to feeding.

The object of this machine is to introduce a more profitable method of feeding animals, by giving them minced roots mixed with straw chaff (cut straw) or other chaff, or meal-bran, or linseed or rape-cake, instead of the old method of feeding them sometimes with roots only, and sometimes with dry food only. Animals by this mode of feeding, improve faster and at considerably less expense than by the old system. The same inventors exhibited a model of a steaming apparatus for cooking cut straw and chaff.

\section{Improvements in Straw-Cutters.}

Gale's Improved Straw-Cutter.-In an improved straw-cutter, invented and patented by Warren Gale, of Auburn, New York, the nature of the invention relates to an arrangement of the knife (or knives) of the cutting cylinder, so that it shall cut against a flange (or flanges) on the opposite cylinder; also, in combination with the cutting cylinders, the method of arranging the mouth or throat through which the straw is fed so that it shall govern the feed 
of the straw to the cutters. A strong straight knife is attached to the lower cylinder, and a strip of hide to the upper; the two are geared together, and as they rotate, grasp the feed, draw it forward and cut it off, cutting through from three to five inches of feed at each revolution.

Wick's and Simonton's Straw-Cutter.-The nature of the improvement consists in the employment of a knife-cylinder operating in connection with a vibratory bed, whereby economy of power and superior cutting action are obtained.

The straw to be cut is placed in the feed-box, and a rotatory motion given by means of a crank to the knife-cylinder. The knives, as they rotate, cut the straw which passes between their edges and the under surface of a bed, which vibrates or moves forward by the pressure of the knives as they bear against it while cutting through the straw-the bed returning backwards as the knires pass it by the action of a spiral spring - the knives and bed, by their operation, giving the proper feed-motion to the straw.

The straw-cutter for which a premium was awarded at the recent exhibition of agricultural implements by the Royal (English) Agricultural Society was possessed of the following peculiarities: It feeds itself by means of tooth-rollers. The straw is kept compact by a lever and weight underneath, which act on the mouth-piece and roller. Two convexly-curved knives, attached to the arms of a fly-wheel that revolves perpendicularly to the feeding trough, perform the cutting, and it is adjustable to cut any needed length.

Clinton's improved Straw-Cutter.-The following are the peculiarities of a new straw-cutter recently patented by Lyman Clinton, of North Haven, Connecticut. One of the most common arrangements for straw-cutters is the combination of a cylinder or arbor carrying lateral knives, with another cylinder covered with hide, the straw being clipped by passing between the knives and roller. Mr. Clinton has aroided the disadvantages of this mothod by a very ingenious arrangement, which dispenses with the hide-roller altogether, and substitutes in its place a second knife-cylinder. The knives are straight and mounted on narrow shoulders or wings, and on the periphery of each wing, just behind each knife, there is a groove or rebate. The arbors are so geared that the knife edges come together in the act of revolving, like . pair of shears, and cut off the straw in the most perfect manner, as fast as it is fed in between them. The edge of the rebate, behind each knife, serves as a fulcrum on which the ends of the straw rest during the act of cutting.

Squire's Straw-Cutter.-The peculiarities of this straw-cutter patented during the past year by G. L. Squire, of Chicopee, Massachusetts, are as follows:-It has two shafts, one of which receives a more rapid motion than the other; upon one is placed circular or disc cutters, but upon the other both circular cutters and finger-plates. These finger-plates act as follows: The shafts of the knives have to be made long, so as to lay in the straw longitudinally with the shafts, and the fingers whipping round draw down the straw to the action of the rotating knives, which thus cut like circular shears; the cutters can be set by nuts at any distance apart, so as to cut fine and coarse, as may be desired. It cuts straw, cornstalks, \&c., with great rapidity, and the cutters can be sharpened with great facility.

Bennet's Straw-Cutter.-A patent granted during the past year to J. H. Bennet, of Bennington, Vermont, relates to the kind of straw-cutters employing a straight knife set in a lever, and moving in the arc of a circle. The knife-stock is set in a vertical, oblong slot cut through the main timber of the frame, and working on a pivot in the slot. By this arrangement the knife is guided and kept steady while operating. There is a flat spring arranged over the front part of the oblong slot, and the knife is so bevelled, that when its lever is lowered, it (the knife) bears upon the upper side of the flat spring, while the under side of the lever bears upon its top, thereby keeping the cutting-knife close up to the steel guard, thus making it cut in a superior manner. The said spring, in case of clogging, yields slightly, and its reaction after a cut assists the operator in raising the lever which operates the knife.

\section{Teddying Machines.}

EvERY farmer should own a teddying machine. This contrivance is arranged with a pair of wheels like a sulky, and with long teeth extending from a false axle to within an inch of 
the surface of the ground, and is propelled by a horse. Three or four hours after mowing, the teddy is run over the mown grass, and by its action every blade is thrown up into the air and falls loosely in a reversed position, suffering free circulation of air, with new surfaces exposed to the sun. Six acres may be thus teddied in a single hour.-Working Farmer.

\section{Grain and Grass-seed Headers and Harvesters.}

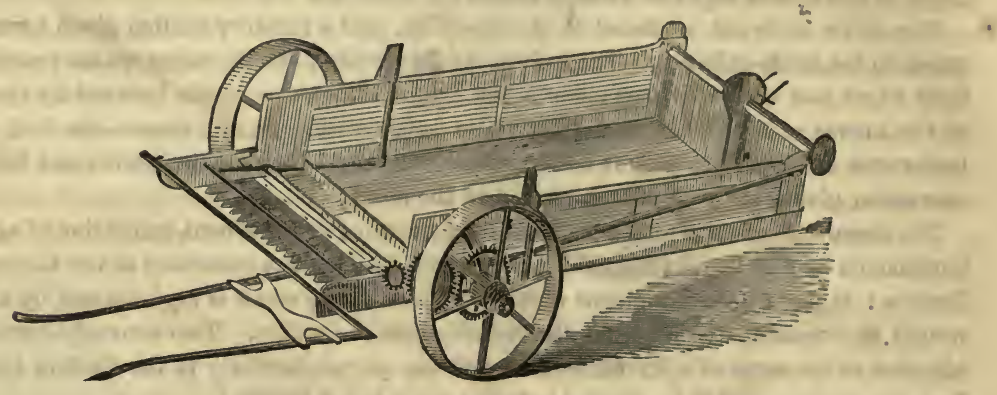

Steadman's Clover-seed Header.-The above engraving illustrates a new and improved clover, timothy, and other grass or grain-seed header and harvester, the invention of Mr. T. S. Steadman, Orleans county, New York. As will be seen by the cut, it is drawn by one horse, which walks outside of the part of the field intended to be harvested. Turning continually to the right, it cuts equally as well as when turning a corner, as when going straight ahead. The seed-heads are gathered by the comb, cut off by the revolving knives, and by a self-raking apparatus attached, thrown to the rear end of the box. By detaching the intermediate gearing-wheel, it is immediately converted into a three-wheeled wagon, and can be driven wherever wished. By pressing down one or both of the levers shown on the rear end of the box, one or both sides of the comb and cutter may be lowered or elevated at pleasure. The peculiarity of the machine is, that it cuts and saves only the heads of the grain or seed, and by an extra pair of wheels it can be applied to the gathering and harvesting of any kind of grain or grass-seed. It will cut from eight to twelve acres per day with ease. All the bolts in the machine are in sight, with but one exception.

Gage's Clover Gatherer. -The peculiarities of a machine recently invented by J. S. Gage, of Dowagiac, Michigan, consists of a cylinder provided with a series of toothed bars, so arranged that as the cylinder rotates the teeth are projected forward in front, and the seed is combed from the standing stalks and conveyed into the interior of the cylinder. This machine is well adapted to secure the seed of clover-fields, which are intended to be plowed in for fertilizing.

\section{Mowing Machines vs. Scythes.}

LET us compare, a little, the two modes of cutting grass. Day laborers hired at $\$ 1$ per day will probably mow in medium grass $1 \frac{1}{2}$ acres to the hand; that is, it will cost $\$ 5$ or $\$ 6$ to mow 8 acres, and 25 cents each hand for boarding will be $\$ 1.50$ more, which, added to $\$ 5.50$, makes $\$ 7$ for mowing 8 acres. Now hire a man with a span of horses and a machine to cut the 8 acres, at 50 cents per acre, and he will cut it in a day, $\$ 4.00$, and $\$ 1.00$ more will pay their boarding, making in all $\$ 5.00$, and the grass will be spread better for curing than a man will spread it after the 5 hands, which, in the estimate, will make $\$ 3.00$ advantage to the mower. At that rate the machine will pay for itself in 40 days' mowing, besides saving so much hard labor.-Ohio Farmer.

\section{Improvements in Reapers, Mowers, and Harvesters.}

Russel's Mowing Machine. - This machine, invented by Fisk Russel, of Boston, consists of a square frame mounted on two wheels, one of them being a heavy cast-iron wheel, from 
which the motive power is derived; the other, a secondary wheel, placed in the opposite side of the frame, and forward of the main wheel, for the purpose of supporting that side of the frame, preventing the heavy drag of the knife-bar on the ground, and effectually obviating the side draft of the machine. In connection with the secondary wheel is an apparatus for elevating or depressing the knife-bar. By means of a lever, the driver, while sitting on the machine, may in an instant raise the knife-bar to the height of fifteen inches. It is thus

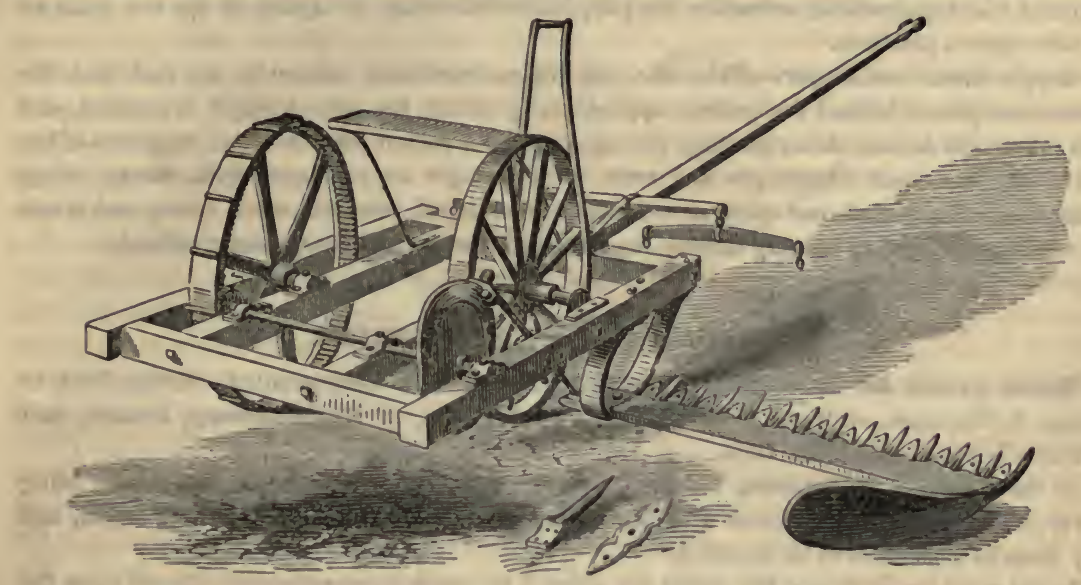

passed over stones or other obstacles without changing the course of the team, and at the proper moment is lowered to its former position. The same apparatus admits of the knifebar being firmly fixed at any desired point, so that the knives may cut at different heights, leaving the stubble at such lengths as the peculiar surface of the ground or other circumstances may render expedient. Motion is given to the knives by means of a cam-wheel placed on the same shaft with the pinion connected with the main-wheel, requiring only one set of gear to obtain any desired number of vibrations of the knives, from 35 to 48 , to one revolution of the main-wheel, thereby making it very easy to graduato the speed of the knives to the natural walk of any horse. Each knife is placed upon the knife-bar independent in itself, moving on a centre pivot by means of an iron rod passing under and attached to the back end of the knives, giving them an oscillating motion, and effecting a drawing, circular cut. The knives are double; that is, they have a cutting edge at each end, and by removing the eap which secures them in place while at work, any one can be removed and nnother substituted in its place, or the ends can be reversed when one edge becomes dull. This machine is made both for one or two horses.

Dietz and Dunham's Improved Reaper and Mover.-At the recent State Agricultural Fair of New Jersey, Messrs. Dietz and Dunham exhibited an improved mowing and reaping machine, in which by a peculiar construction, motion is transferred to the cutters directly from the driving or ground-wheel of the machine, by means of a simple lever, and without gearing of cogs, shafts, \&c.

Manning's Reaper and Morcer.-In this invention the knives have a rotary motion, and are operated by small cog-wheels and rope-pulleys. The horse walks behind the knives, pushing the machine before him.

Lupton's Improvement in Harvesters.-A patent for improved grain and grass harvesters was granted to T. W. Lupton, of Virginia, in June, 1855. The arrangement combines rotary cutters with wire fingers, reel, and endless receiving aprons. The fingers bend the grain at an angle at which it is swept and cut by the cutters, conveyed away by the aprons, and deposited on the ground. The aprons are dispensed with in cutting grass.

Kroger's Improved Harvester.-This invention, by A. E. Kroger, of Norwalk, Connecticut, is intended to obviate all the difficulties which have hitherto attended the use of these machines on rough and rocky ground. The invention accomplishes this as follows:-In the first place, 
he curves up the fingers a little in front, so that, on meeting an obstruction, they will be likely to rise up and slide over the same; secondly, in the attachment of the finger-bar to the frame, he employs springs in such a manner that when one end of the finger-bar strikes a stone, the bar yields, and easily glides over the obstacle, without raising the whole machine.

Burgess's Improved Reaper.-An English reaper has been recently patented in the United States, (August, 1855,) the peculiar improvement of which consists in employing the principle of the Archimedean screw for the purpose of delivering or laying off the cut grain as it falls upon a platform.

Rugg's Mower and Reaper.-This machine ciffers from most others in the fact that the horses are placed behind the cutting apparatus, by which the side draught is avoided, and the driver sits behind them, guiding the machine by a sort of rudder-wheel underneath his seat. It has some advantages and some disadvantages as compared with others, being somewhat complicated, has much more weight of material, occupies more space, and is not so readily managed in turning about; it performs its work, however, most creditably.

\section{Improvements in Maize Harvesters.}

Three patents for machines for harvesting Indian corn were granted, during 1854, to James S. Burnham, of West Jefferson, Ohio; G. A. Bruce, of Mechanicsburg, Illinois; and William Lapham, of Salem, Ohio.

In the invention of Burnham, the machine is mounted on a truck frame, the cutters being arranged in front, in connection with horizontal reels, which receive the falling stalks, and lay them in a position to be bundled.

In the machine of Bruce, the stalks are severed by oblique rotary cutters, placed upon the side of a truck, and revolving through motion communicated from the wheels of the carriage. As the stalks fall down, they are caught by revolving arms, and by an ingenious arrangement deposited in bundles upon the ground.

The invention of Lapham was for an improved reel for collecting the stalks.

An intelligible description of these machines cannot be given without engravings; they all, however, appear to answer the end for which they were intended.

\section{Experimental Trials of Mowing and Reaping Machines.}

Durnat the past season, numerous experimental trials of the various popular mowing and reaping machines have been instituted by various agricultural societies in different sections of the country. The following is a summary of the reported results of the principal experimental trials:-

The first trial we have to notice was instituted by the State Agricultural Society of Illinois, in the summer of 1854, to test the respective merits of Manny's reaper, and Atkins's selfraking reaper, $\$ 1500$ being proposed as the premium. The last-named reaper is distinguished in the report as Wright's, the name of the manufacturer. The trial lasted several days, and the report of the umpires gives the following as some of the results:

Wright cut $20 \frac{22}{100}$ acres in 12 hours and 55 minutes; Manny cut $20_{1}^{22}$ acres in 10 hours and 3 minutes. Time consumed in reaping, binding, and shocking: Wright's first field, $3 \frac{37}{100}$ acres, bound in 18 hours and 25 minutes; Wright's second field, $4 \frac{31}{100}$ acres, bound in 25 hours and 30 minutes; shocked in 4 hours and $38 \frac{1}{2}$ minutes. Manny's first field, $3 \frac{89}{100}$ acres, raked and bound in 25 hours and 47 minutes, (this included the time of the raker, who stands on the machine;) shocked in 4 hours and 40 minutes.

The umpires refused to decide between the two reapers, declaring the contest so close as to render it impossible to say which was the best.

Under the auspices of the Westchester (New York) Agricultural Society, a trial of mowing machines took place at Bedford, New York, June 15, 1855. The following machines were entered for trial :-

Ketchum's machine, manufactured by Howard \& Co., of Buffalo, New York.

Russel's machine, manufactured by R. H. Pease, of Albany, New York. 
Forbush's machine, sold by Griffing \& Brothers, New York City.

Manny's mower, with Adriance's improvement, manufactured at Worcester, Massachusetts.

Manny's mower, sold by L. C. Ball, of Hoosick Falls, New York.

Hallenbeck's machine, manufactured at Albany, New York.

Allen's machine, of New York City.

Ketchum's machine, manufactured by T. and S. Hull, of Poughkeepsie, New York.

Ketchum's one-horse mower, manufactured by Ruggles, Nourse \& Mason, Massachusetts; sold by R. L. Allen, of New York City.

The following is the official report of the judges. From the exhibition of the machines enumerated, they confidently say that any one of them will give good satisfaction to the farmers of the country; but as each and all possess peculiar excellencies, we will specify them under the following heads:-

1. Operation of the machines on fair ground, driven at first by the same driver and team, and afterwards by the exhibitors themselves or under their direction.

On this point, your committee find that the machines of Ketchum, Hallenbeck, Manny, and Allen are of equal excellence.

2. The lowest and smoothest cut of each machine.

Your committee are of opinion that upon this point there is no marked difference in the four machines just mentioned.

3. Trial on rough, uncleared bottom.

Your committee, on this point, give the preference to Allen's and Russel's machines.

4. Evenness of grass as left by the machine for curing.

We find that the machines with the iron cutter bar have the preference in this respect.

5. Freedom of knives from clogging.

We are of opinion that the machines of Ketchum, Manny, Hallenbeck, and Russel, on account of the finger-caps not reaching back to the finger-board, are least likely to clog.

6. Amount of power required to perform a given amount of work.

Your committee think there is but little difference in this respect between the machines of Hallenbeck, Manny, and Allen.

7. Facilities of transportation from one field to another, and for escaping obstructions in the field.

We believe that Manny's machine has advantages over any other in this respect.

8. Durability and simplicity of construction.

We believe Ketchum's and Allen's the most durable, and Hallenbeck's the most simply constructed machines exhibited.

9. Cost of machines :-

Manny's, made by Adriance.................. \$120|Ketchum's, made by Hull.................... \$120

Manny's, made by Ball........................ 115 Hallenbeck's................................ 106

Russel's.......................................... 125 Forbush's .................................... 120

Allen's........................................... 120 Ketchum's on $\theta$-horse machines............... 95

Ketchum's ....................................... 120

Your committee, in this report, have included, under the term of Ketchum's machine, that of Hull and the one-horse mower manufactured by Ruggles, Nourse \& Mason; and also where Manny's is spoken of, they mean to include the machine manufactured by Adriance, of Worcester, Massachusetts, and by Ball, of Hoosick Falls, New York.

The committee of the Munroe County (New York) Agricultural Society, appointed to report on the trial of mowing machines, instituted at Rochester, June 27, were united in the opinion that, of the eight machines exhibited, the Ketchum machine, and the Manny with Wood's improvement, were the best on the ground, but were divided in opinion as to which of these two was the best; but a majority finally decided in favor of the former, believing that that machine cut the elosest in the ground, while the latter was the easiest for the team and for adjustment over uneven and stony surfaces. The side draught was also light, while in the former machine it was quite heavy.

The first premium the committee award to the Ketchum machine, and the second premium to Manny's machine with Wood's improvement.

The third premium is awarded to Wheeler's machine, of Cayuga county. This machine 
cut with shears, and performed good work, having an adjustable beam, and so arranged as to have little or no side draught.

At the trial instituted by the State Agricultural Society of New Jersey, at Newark, July, 1855, Ketchum's, Allen's, Whitenack's, Manny's, Forbush's, and Deitz \& Dunham's machines were used, and all worked well, though each had their farorites.

The machine called Whitenack's seemed to be the favorite with the largest number. Mr. Dunn, a large farmer of Hunterdon county, says he used one of these machings all last summer without grinding the knives; that it will cut from six to eight acres a day of grass, without worrying man or horse; that it runs light and is easily handled, and does not get out of repair. He cut ten acres of oats a day, quitting at five o'clock. The cost of this machine was $\$ 130$ as a mower, and $\$ 150$ as a reaper.

The lightest machine is that of Dietz \& Dunham, weighing five hundred and seventy-five pounds, complete. This is a new machine, and runs with a different motion from the others, the movement of the knives being operated by a cam-wheel instead of a crank.

At the trial of mowing machines in competition for the premium of $\$ 600$ offered by the State Agricultural Board of Massachusetts, the result seemed to be in favor of Manny's machine, in competition with Ketchum's, Russel's, and Allen's. The horses of both the latter appeared to labor much harder than with the other machines, and the report says-

"There was a necessity for an additional heavy man to assist in managing Allen's machine, which was looked upon as a great drawback. The second mode of trial was by allowing each competitor to cut a single swath through the field and back again, and then examining the ground, after the hay was removed by a horse-rake. In this trial, the machine of Manny showed a closer-cut swath, and evidently was considered by the spectators generally as the best machine."

At a trial of mowing machines, instituted by the Hampden (Massachusetts) County Agricultural Society, June 29th, 1865, four different machines were entered-Hovey's, Russel's, Manny's, and Ketchum's.

In the trial, Hovey's machine failed, after a short time, from an accident, and was withdrawn. Russel's machine finished its work in good time, but in an unsatisfactory manner. In relation to its performance, the committee state: "It is not requisite for us ' to point out' the reasons of the failure; but several farmers expressed the opinion that raking after such mowing would 'extract teeth' too fast to be either easy or profitable. The fault may have been in an inexperienced team or in inexperienced driving, and not at all in the machine. We can only say that the opinion of most seemed to be that if we must have such mowing by horse-power, farmers would better put their fist to the 'thole,' and drive the 'heel wedges' a little longer."

The comparison, then, was narrowed down to two machines-Manny's and Ketchum's. Of these the committee report as follows: "It would, perhaps, be difficult to say which did its work best. If difference there were, most of the committee thought it in favor of Ketchum's mower. The work done by the latter certainly had a most elegant appearance; but it should be remarked that the lot that fell to this machine was the more feasible, as Manny's lot was marred by a fence and also by a random swath of its rival; the horses, also, attached to Ketchum's patent were said to be more accustomed to the work, a consideration of no small importance. Whether, after these considerations are duly weighed, a verdict of better work should be given in favor of this machine, is perhaps a matter of doubt. But distinctions without a difference are needless. They both did well. If all our meadows could be shorn of their velvet covering as handsomely as either of these lots, the age of 'whetstones' might, without regret, be suffered to pass away; they would have 'shown their grit' long enough.

"Thus much upon the work of the two; but there are other considerations of importance. Ketchum's machine seems much more simple; Manny's invention seems complex, at least to one whose knowledge of mechanics extends not much beyond the hoe-handle and flail. Some of the committee expressed a doubt whether they were deep enough in gudgeons and screws to put such an apparatus in working order, even if it were sent to them. It is an obvious remark that the greater the complexity, the greater the danger of getting out of repair, and 
the greater the expense-important items for farmers who must use these machines. Each machine is represented to have its peculiar merits. Manny's patent is accompanied by a reel, designed to give an inclination to the grass favorable to easy cutting; it has also a side wheel, which would seem to aid in diminishing the side draft. On the other hand, Ketchum's mower boasts of some features which are claimed to be equally valuable. It has a curve or arch under the main beam which is said greatly to facilitate the escape of the previous swath (if of swath we may speak) under the machine. It was remarked by many during the trial that owing to this or other reason this one of the four competitors seemed to clog less than the others. The adrocates of this machine also plead that placing, as this patent does, the knife-finger in a line with the axle of the carrying-wheel, gives it an advantage in reaching the bottom of furrows and other depressions across which it passes; as when the wheel sinks the knives must sink also, and there seems to be some reason in the claim.

"With regard to the weight of the several machines, we cannot accurately speak. That is a consideration of far less importance than the requisite power of draft; with regard to this we had no opportunity of judging, except from the appearance of the horses employed. They seem to give in every case an involuntary testimony to the fact that mowing has not yet ceased to be hard work. In behalf, therefore, of the animals on which we propose henceforth to throw the labor of mowing, we send in to the manufacturers a most respectful ahd earnest petition that mowing machines may in some way be mado of easier draft; that in saving the men we may not murder the horses. There seemed to be no great difference between Manny and Ketchum in this respect. The expense was also understood to be about the same. If, then, the question were narrowed down simply to this: Which of the two would you purchase, if either? probably most or all of the committee, from what they saw this day, would incline in favor of Ketchum's improved mowers of 1855, but not Ketchum's mower of 1854 , which is said, like some crops, to have been a failure."

The committee further suggest that a very desirable improvement in mowing machines would be an arrangement whereby two horses or one may be employed upon them at pleasure. "We are satisfied, from what we have seen, that two horses, sach as live with most farmers in this vicinity, would find ample employment with a single cutter."

Trial of Reapers and Mowers at the Freneh Industrial Exhibition of 1855. -The final trial of all the reaping and mowing machines of the Exhibition came off on the $2 \mathrm{~d}$ of August, and is thus reported in the Paris Constitutionnel:-

There were ten machines in the Exposition; nine of them were sent out by the Imperinl Commissioners to the place of trial, about forty miles distant from Paris; this was a field of oats, of about fifteen acres, standing up well, and divided into lots or pieces of about an acre each, by swaths being cut through at a given distance parallel with each other, each piece being numbered, and one machine allotted to each piece. At the beat of the drum, three machines started off together. J. S. Wright, of Chicago, Illinois, managed by his agent, Mr. Jewell; Patrick Bell's machine, by Mr. Fourent; and a machine from Algiers. These machines were calculated to do their own raking by machinery. Wright's machine cut his piece in twenty-four minutes, Bell's in sixty-six minutes, and the Algiers machine in seventy-two minutes. The raking or discharging of the grain from all of the three machines was badly done, the grain being much scattered in its delivery upon the ground, Wright's doing much the best. The cutting, however, was well done. The mechanical movement of the automaton raker of Wright's machine was truly wonderful. The operation of the machine was highly successful. Bell's machine, by Fourent, did the cutting and gathering of the grain in a very neat manner; the grain was delivered freely to one side of the machine for the binders. After the jurors had carefully noted the trial thus far, the signal again was giren, and off started three other machines, J. H. Manny's, of Rockford, Illinois, managed by Mr. Mabie; Bell's, by Croskill; and a French one-horse reaper. Manny's cut its piece in twenty-two minutes; Bell's, by Croskill, and the one-horse French reaper, both failed to cut their pieces; while Manny's did its work in the most exquisite manner, not leaving a single stalk ungathered, and it discharged the grain in the most perfect shape, as if placed by hand, for the binders. It finished its piece most gloriously. Again, after the jury had taken further notes of the trial, the signal was given, and three other machines 
started off on the contest, Hussey's reaper, by Dray; M'Cormick's, by M'Kenzie; and Bell's, by Perry. Hussey's machine cut its piece in thirty minutes, M'Cormick's in twenty minutes, and Bell's failed to finish its piece. Hussey's machine did its work remarkably well, cutting clean and smoothly, and leaving the grain in the track of the machine in good condition for the binders. This machine was conceded to be too heary and laborious for the team, and leaving the grain in the track of the machine was found to be an objection, as it necessarily needed to be bound and removed as fast as the machine did its work, in order that the machine could pass around a succeeding time; yet this machine is unquestionably a good one, and it may be used to great advantage, as it would likely prove durable, being very strongly made. M'Cormick's machine performed its task well, cutting a close and even swath; but the raker or attendant, who performed the labor of discharging the grain, seemed to be very much strained, being obliged to ride backward upon the machine at one end of the reel, having to reach fully across the entire width of the machine with a long handled rake to gather the grain and lay it off of the machine. The horses on this machine were much troubled by a strong lateral pressure against their shoulders, occasioned by the tongue of the machine. This reaper, on the whole, is much too cumbersone and heavy for two horses. However, it has proved itself vastly superior to any of the inventions of the Old World; and from the fact of its success heretofore, particularly at the London Exhibition in 1851, it elicited a good deal of admiration and curiosity. The contest was now fairly narrowed down to three machines, Manny's, Wright's, and M'Cormick's. But, on starting, Wright's again broke down, and left the struggle exclusively to the two machines-Manny's and M'Cormick's.

The two machines were then to be changed, in presence of the jurors, from the capacity of reaping to that of mowing. Manny's made the change in one minute; M'Cormick's in twenty minutes, with three men. Each machine made one cut through the field and backManny's machine doing the best of two. Then the change was made again for reaping, and in the same time respectively as before. Then both machines were taken into a wheat-field. Manny's machine cut three swaths, and with an ease of action and perfection of work which fairly placed it far beyond any further competition, though M'Cormick's reaper cut two swaths, and in a workmanlike manner. Even if the two machines were equal as to the quality of work, yet it was observed Manny's would have the advantage of being the most compact, less cumbersome, and of much less weight than M'Cormick's; and in Manny's there is no lateral pressure against the horses, as by M'Cormick's; also of being much the lightest draft, and more easily adjustable to different heights of cutting, and more easily convertible for the two purposes of reaping and mowing. This seemed to be the only machine against which there could be no objection urged.

Although the decision and report of the jury was not published, yet it is understood that large offers were made for the patent-right of Manny's machine for France.

\section{Scale for Estimating the Relative Value of Different Mowing and Reaping Machines.}

Sove years since, the Agricultural Society of New York, after considerable deliberation with many prominent breeders, adopted a scale of points for the estimation of live stock. This scale, in its practical application, has given great satisfaction, and has been an important aid to committees. It is now proposed by Colonel Johnson, of New York, Dr. Elwyn, of Philadelphia, and other prominent agriculturists, to establish a scale of points for reapers and mowers, and by settling first what is wanted to make a perfect machine, to afford thus some guide to committees at exhibitions for awarding premiums according to their approximation to a recognised and established scale.

A circular, setting forth the desiderata deemed necessary for forming a correct judgment respecting various machines, has been issued, from which we derive the following:-

$A$ Scale of Points is necessary in trials of reapers and mowers for three reasons: 1 . That a correct decision may be obtained; 2. That the grounds of the awards may be understood 
by those who wish to buy machines; and, 3 . That the awards of different committees may be understandingly compared.

It is idle for any committee, no matter how capable of judging clearly and correctly, to jump at a decision in the aggregate between the claims of rival reapers, so many of which are established as good machines; some of them, perhaps, nearly equal in all important respects, and no one of which is best on every point. A comparison must be instituted between them, and a careful decision had upon each specific point. Having a scale of these various points, with their relative value fairly apportioned, even an inferior committee could hardly fail to arrive at a pretty correct award.

'Such has been the character of most of the trials, that the decisions have little weight. The premiums at one trial are given to certain machines, and in the adjoining county or state the verdict is reversed, and other machines declared best. None of the details upon which judgment was formed being known, it is impossible for a farmer not at the trials to get any aid from them in selecting a reaper. Indeed the variety of verdicts given in this blind manner tends to confuse him; whereas, had the decisions been given upon each specific point, he could, by comparison of the reports, decide which reaper was best suited to his circumstances.

It is important for farmers to have such machines used in trials as are ordinarily built and sold to them. They do not want to be misled by a machine of extra cost and finish taking the highest prize. They want to see the machines tried that they have got to buy. Therefore, let all societies introduce a rule to this effect; and if any manufacturer is found trying to work underhandedly or unfairly on this or other points, he should be excluded from the trial and the award at the judgment of the committee.

The following scale is not offered to the public as being perfect, but as being an improvement upon any plan as yet proposed. It has received the careful consideration of farmers well acquainted with machines and with public trials, and has been altered so that it meets the united approval of leading persons in the agricultural societies of five different States.

\section{Scale of Points in Trials of Reapers.}

No. Perfect at

1 Cost of machine.

28 Simplicity of construction to do its work.

$310 \quad$ Facility of management, including time and room required for turning.

430 Durability and reliability.

516 Adaptation to varied and uneven surfaces, and to cutting at different heights.

630 Freedom of the knife from clogging by fibrous or gummy matter.

79 Motive power, or power required for a given amount of work.

845 Manual labor in raking.

926 Rapidity, or amount of harvesting in a given time.

1045 The manner of leaving the grain for binding.

1172 Saving of grain in cutting, binding, and handling, and in the stack.

$\overline{300 *}$

To determine the relative value of points correctly, they should, as far as practicable, be estimated by dollars and cents, though several cannot be arrived at in that manner. As a matter of convenience, those are put into the scale that can be estimated by money, at a unit for each dollar.

1st Point, "Cost."-This I get at by supposing a machine good for five years' wear, which the higher-priced ones certainly are; the difference in price between the cheapest and the highest-priced is $\$ 35$. This amount, divided among the fire years, gives $\$ 7$; and the interest on $\$ 35$ is $\$ 2.10$, making $\$ 9.10$. This, therefore, is put at 9 in the scale, being a unit for each dollar.

The $2 \mathrm{~d}$ Point should read, "simplicity of construction to do its work. The more a machine does, the more machinery may there be to do it. A self-raker, and even a binder, may be

- Judgment being formed by the committee relative to each machine on each specific point according to the following scales, the machine whose aggregate resches the highest number is the victor; three hundred being the sum total of a perfect reaper, two hundred and twelve of a perfect mower, and five hundred and fifty of a perfect comblned machine. 
just as simple in its structure as some hand-raker, considering what it does; and, to make judgment fair and equitable between them, the object and work must be fairly considered, as well as construction.

This point is not of great importance; those following should control. For if a machine is easily managed, durable, \&c., it is little matter about a piece or two more of gearing or frame.

The 3d Point- "Facility of management, including time and room required for turning"is so similar to the ninth point-rapidity of operation-thát one of these must be set low, or too much weight will be given them.

The 4th Point- "Durability and reliability"-is of much more importance. Any machine, however good in other respects, is an immense evil to the farmer if it fails in time of need. Having relied upon it to save his grain, and it proving worthless, and having made no other provisions, he is obliged to hire harvesters at largely-increased cost, if, indeed, he can get them at all, or perhaps submit to the loss of a valuable crop, wholly or in part. Opinions would vary greatly as to the number this should be set at.

The 5th Point-"Adaptation to varied and uneven surfaces, and to cutting at different heights"-should be set much lower than the previous one.

The 6th Point- "Freedom of the knife from clogging"- seems to merit much consideration; though not so important in reaping as in mowing. Some machines, it is known, choke or clog by fibres being drawn in the opening of the fingers in cutting damp or wet grain. This is particularly the case where there is much undergrowth. It is important to be able to cut when the dew is on, because it is cooler, and the grain shatters less. But if the knife constantly clogs, little progress can be made.*

The 7th Point-" Motive power, or power required for a given amount of work." The difference in team required to work any two reapers is never more than one pair of horses, the value of which for a harvest will vary considerably in different sections. Large farmers who have plenty of horses would only consider the cost of an extra pair as the worth of the extra grain they had to feed during the reaping. Probably putting this at the same as the 1st point, "cost," will be fair and certainly high enough, particularly as the inconvenience of using an extra pair has its weight in the estimate of $3 \mathrm{~d}$ point.

The 8th Point- "Manual labor in raking." To establish the value of this point, it is first to be considered that there is considerable difference between hand-raking reapers in the ease with which grain can be raked from them. It would not be too much to allow ten to estimate the difference between them.

Then a self-raker saves a hand, and that, too, at the very hardest of work, over the best hand-raker. As wages were last year, and will be the present, this hand in harrest, with his board, costs at least $\$ 2$ a day. If a little less than that in some sections, it will be enough more in others to make it equal this and more too. The wheat-harvest will last from eight to twelve days-say ten-and oats, rye, barley, \&c.-say five days. The latter is, perhaps, a day or two longer than Southern farmers would generally have grain for; but it is too little by five days for the North, so that fifteen days' work would be a moderate allowance, making the saving $\$ 30$. Something more should be added to this, because of the excessive labor that is saved, one hand being hardly sufficient to work all day long, and day after day in raking off. For this five is added. Add the previous ten, giving forty-five for this point.

The 9th Point-"Rapidity, or amount of harresting in a given time." Suppose reapers cost on an average with transportation $\$ 140$, and are worn out in five years; that is, $\$ 28$ a year; the interest is $\$ 8.40$. The team, two pair, $\$ 18$. The rake $\$ 30$, and driver $\$ 20$. The latter not having as hard work and a cheaper hand answering, his labor is estimated a little less than the raker. The total is $\$ 104.40$. The narrowest reaper cuts four and a half feet, and the widest six feet, (with a very few exceptions not necessary to be allowed for, making

\footnotetext{
* Thus far it has been impossible to find data by which to estimate the relative value of the points, and opinions will perhaps vary very much concerning them. But in the others, we can get sound data to base them upon, and though in carrying out the estimates some come to high figures, they are not, therefore, to be rejected or considered wild.
} 
a difference of one quarter. Then one quarter of the above figures would give the value of this point at twenty-six.

The 10th Point- "Manner of leaving the grain for binding." More difference than one hand can be made in binding by the gavels being well or badly laid. Between the best and worst machine to rake from there is in the manner of depositing the grain at least a difference of a hand and a half, costing for the fifteen days $\$ 45$, making this point, therefore, forty-five.

The 11th Point-"Saving of grain in cutting, binding, and handling, and in the stack." Those who have compared the working of different reapers, know that some will save largely as compared with others, and it is very easy to make a difference of several bushels in each day's work of ten to fifteen acres, even to the amount of a bushel or more an acre, particularly if the grain is over ripe.

There is, first, the loss in not cutting clean; second, shattering by the reel and in cutting; third, shattering in raking off; fourth, loss from scattered grain being badly raked off ; fifth, loss in handling the sheaves, the grain not having been raked straight, and consequently being imperfectly secured in the sheaf; and sixth, liability to injury in the stack by the weather, if the heads are not all laid one way in the raking.

These losses, though depending much upon the hand, will all be found to exist, and greatly to vary between different machines with good hands. Some of them are trifling; yet in the aggregate they make a point of much more value than any other.

Suppose the difference of loss in extreme cases is only half a bushel to the acre-that one hundred and twenty acres of wheat and sixty acres of other grains are cut-which would be twelve acres per day for the season of fifteen days. Thus there is saved sixty bushels of wheat, worth say \$1 per bushel, and thirty bushels of oats, barley, rye, \&c., worth say forty cents, making the saving $\$ 72$. Though seventy-two seems at first to be large for this point, it ought to be set higher rather than lower.

If this scale is at all correct, there is, of course, great difference in machines. If the forty or fifty varieties invented, and of which some thirty are more or less in use, could all be brought together, some would run very low in the scale, while others would go high. Of the points in the scale, two hundred and six (less ten in the 8th point of raking) equal one hundred and ninety-six, are estimated in money value of say only $\$ 14$ a season, making $\$ 210$. Some of the reapers would not in thorough trials reach sixty on these points, while others would reach one hundred and sixty and over, thus showing there may be a difference in reapers of over $\$ 100$ in a single season's use.

With so large a difference in reapers, and the demand so rapidly increasing, and it being difficult-almost impossible-for farmers to compare them themselves, it is not strange that so many attempts should be made to test them by farmers, united in their State and county societies. Yet how few of the numerous trials have as yet resulted in any permanent good! Wherefore this abortive result in efforts which have cost so much in time, labor, and money to societies, committees, reaper-builders, and the public generally? Is not the failure chiefly owing to the want of a systematic plan to insure thoroughness and guard against mistakes? If so, a good scale of this kind will correct the evils, and it is useless to go into trials without something of the sort.

\section{Scale of Points in Trials of Mowers.}

$\begin{array}{rrl}\text { No. } & \text { Perfect at } \\ 1 & 9 & \text { Cost of machine. } \\ 2 & 8 & \text { Simplicity of construction to do its work. } \\ 3 & 10 & \text { Facility of management, including time and room required for turning. } \\ 4 & 30 & \text { Durability and reliability. } \\ 5 & 10 & \text { Adaptation to varied and uneven surfaces. } \\ 6 & 16 & \text { Adaptation to cutting close to the ground. } \\ 7 & 70 & \text { Freedom of the knifo from clogging by fibrous and gummy matter. } \\ 8 & 9 & \text { Motive power, or power required for a given amount of work. } \\ 9 & 20 & \text { Rapidity, or amount of cutting in a giren time. } \\ 10 & 30 & \text { The manner of leaving the grass for curing. } \\ & \mathbf{2 1 2} & \end{array}$


Remarks upon the Mowing Soale.-After the full remarks upon the reaping scale, it is unnecessary to add much here. The plan is easily understood. The first four points are unaltered. The 5th in reaping is divided, making the 5th and 6th, and increasing the aggregate ten. The 7 th is largely increased, because of the difficulty and importance of getting machines that will cut without choking. The 8 th is not altered, though it might, perhaps, be reduced. The 9 th is reduced six, because of reduction in expenses of working the mower as compared with the reaper. The 10th is also reduced, for though an important point, there is not the differenee in mowers in the manner of leaving the grass, to make a higher amount necessary to fairly compare them. Nearly all leave the grass spread perfectly.

\section{Scale for combined Reapers and Mowers.

$\begin{aligned} 300 & \text { The reaper scale. } \\ 212 & \text { The mower scale. } \\ \frac{38}{550} & \text { Ease of convertibility. }\end{aligned}$

Were all machines alike easily converted from reaper into mower, and vice versa , the best combined machine would be that which reaches the highest aggregate in the two scales; but, in consequence of varying in this respect, this other point must be added, making the points in a perfect combined machine reach five hundred and fifty.

\section{Bowen's Thrasher and Grain-Separator.}

THE annexed figure represents a longitudinal section of a grain-separator, for which a patent was recently granted to Archibald Bowen, of Wadesville, Clark county, Virginia. The nature of this improvement consists in combining two reciprocating beds-the upper perforated and inclined towards the foot of the machine, and the lower inclined in an opposite direction, so that the grain and straw shall be received from the thrashing cylinder upon the upper bed, which, while it causes it to traverse its entire length and leave the machine at its foot, permits the grain to fall through its perforations upon the lower bed, which by its inclination and reciprocating motion, carries the grain to the chaff-separating portion of the machine, where by blast and screens the grain is thoroughly cleaned.

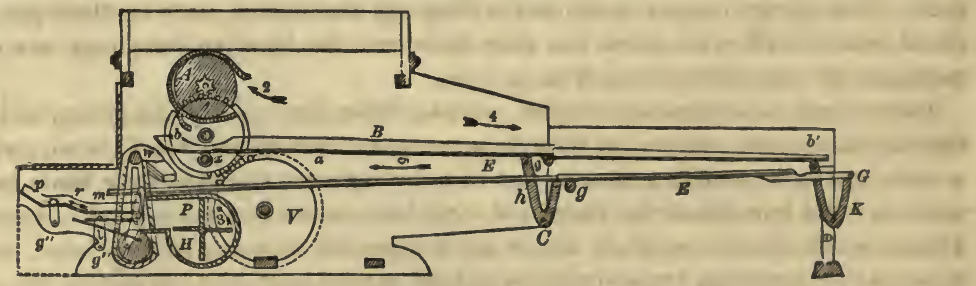

In the engraving, $A$ is the thrashing cylinder, rotating as shown by arrow 1 , and acting on the over-thrashing principle, the grain and straw entering as indicated by arrow 2; but this separator is equally well adapted to the ordinary under-thrashing machine. $B$ is the upper bed, composed of sheet metal, having the perforations a punched in it from the top; these perforations diminish in size from $b$ to $b^{\prime}$. The upper extremity of this bed is supported by the bar $c$, which by reason of two cranks $d$, or eccentrics, one at each end of the bar, revolves around the shaft $e$, causing the end of the bed to rise and fall, and reciprocate longitudinally, two straps $i$ keeping the bed upon the bar $c$ as the bar revolves. This bed is jointed at $g$, and is supported near that joint by the long arms $h$ of two bent levers $C$, placed one on each side of the bed. The extremity $b^{\prime}$ is supported by the arms $k$ of two bent levers D. The lower bed $\mathrm{E}$, which is a plain sheet of metal, inclines towards the head of the machine, and is supported by the arms $k$ of levers $\mathrm{D}$, arms $h$ of levers $C$, and at the head by two levers $b$, one on each side of the bed. The arms $\mathbf{F}$ of the bed $\mathbf{E}$ are jointed with the rods $\mathrm{G}$ connecting the hed $\mathrm{E}$ with the levers $\mathrm{D}$, and through which motion is communicated to the bed $\mathrm{E}$ from the bed B. The levers $b$, besides sustaining the head of the bed $E$, also support one extremity 
of the screens $m$ and $n$, the other ends of these screens being supported by the levers $b$ and $b$; these levers have their fulcra at $g g^{\prime} g^{\prime \prime}$. The termination of the screen $m$ is an inclined plane $p$, connected with the screen by the steeper plane $r$. $\mathbf{P}$ is the fan revolving, as shown by the arrow 3 , within the chamber $H$. S are the elevators which receive the cleaned grain and convey it up the spout $W$, where it is discharged into bags. The beds $\mathbf{B}$ and $\mathbf{E}$ are so constructed as to be capable of separation at $g \cdot g^{\prime}$, for facility of transportation. V is the drivingwheel which gives motion to the wheel $X$, and through it the pinion $Y$, for driving the thrashing cylinder and rotating the shaft.

The simplicity of the construction and operation of this machine renders it a valuable improvement in grain-separators, as the grain, being received on the upper bed, is thoroughly separated from the straw during its passage over the bed, and by the action of the bed $\mathrm{E}$ descends in the opposite direction to the mill, while the straw passes over the tail of the machine, thus effectually making the first separation. The second separation is no less thorough, as the grain receives the blast under the best possible circumstances to insure the blowing off of the chaff, while from the confining of the blast above the screen $m$, and the arrangement of the inclined planes $r$ and $p$, the liability of the grain to be blown off is greatly diminished.

In relation to this invention, the Winchester (Va.) Republican says-By this machine the wheat is thrashed and bagged, the straw is completely separated and delivered by itself, while the chaff is completely separated from the wheat and thrown by itself, without the least conflict of one with the other; in fact, a place for each, and each in its own place, seems to have been the great object of the inventor.

\section{Improvements in Grain and Seed-Cleaners and Winnowers.}

Beech's Improved Grain and Seed-Fan.-In this fan, patented August, 1854, the improvements consist mainly in dispensing with the shoe, which, as commonly used, is loaded with riddles and directing-boards, and swings in the blast, very much obstructing its force. The air is used as it comes direct from the drum, unobstructed by any fixture whatever. The current is upwards and forwards, through the descending column of grain; and with the arrangement of inclined planes, between which the air passes, the grain is suspended in the upward current, falling according to its specific gravity from the drum to the tail of the fan; thus the full force of the blast is used, taking out the lighter impurities without wasting a sound kernel. After the grain has passed through the blast, it falls on the sieve, and the heads, sticks, \&c. are separated from it.

There is sufficient power in the blast to separate the cheat, cockle, \&c., for preparing wheat for market, thereby dispensing with the screen, and saving the small sound grains which must be lost in separating with a screen. In cleaning wheat for seed, advantage is taken of the above-described arrangement, whereby the grain falls according to its weight. By taking out a board which directs the grain, the sound and perfect kernels, falling through the strongest current of air, are caught on a screen below and carried over it to the front of the fan, while the lighter grains and all the impurities fall under the fan or are carried over the tail-board.

Leach's Grain-Cleaner.-A patent was granted in March, 1855, to George Leach, of Owego, New York, for an improved machine for cleaning grain. The device consists in the furrowing of the rubbing-stones in a peculiar manner; also a peculiar device for maintaining the parallelism of the stones. The face of the bed-stone has four grooves cut in it, tangential with the spindle orifice, and they extend about half-way between the spindle and the periphery. At the edge of the face of the stone there are four furrows, slightly curved, that extend inwards nearly half-way to the spindle. The runner-stone has four furrows in its face, which also curve and extend from the edge about half-way to the eye. Between these furrows are others which are curved from the edge to points near the eye, and from these points to the eye they are tangential with it, (the eye.)

Keech's and Stillwell's Combination Fanning Mill.-This mill is constructed upon strictly philosophical principles, and is said to answer most perfectly the end desired. The blast generated by this fan is so proportioned as to overcome the weight or gravitating power of all the impurities possessing less weight than the grain; which impurities are forced out of the 
mouth of a vertical trunk, while the grain falls into a receptacle by its own weight, clean and free from chaff, dust, \&c. The machine can also be arranged as to act with equal facility in cleaning grass or any kind of seeds possessing different specific weights from wheat.

Grain and Smut Machines.-The nature of an improvement, patented February 6, 1855, by Messrs. Bean and Wright, of Hudson, Michigan, consists in combining the grain-separator with the smut apparatus in such a manner that the air, in passing to the fan of the separator, goes through the smut screen, and materially assists in cleansing the grain more perfectly than by other machines.

Indian Meal Sizing.-A patent has recently been issued in England for the employment of finely-ground and bolted Indian meal for sizing, stiffening, and finishing textile fabrics, such as cotton and linen goods; that is, for the use of corn flour as a substitute for wheat flour for stiffening goods.

Horne's Improved Corn-Sheller and Winnower.-In this improved corn-sheller, patented by J. V. Horne, of Magnolia, Illinois, the ear passes between a toothed cylinder and a concave plate, whereby the grain is instantly stripped off ; the corn and cob then fall into a revolving screen, which conveys the cob away out of the machine, while the corn falls through the meshes of the wire on to a concave receiving-pan. The winnowing is done by a fan which sends a blast of air lengthwise through the screen. The grain is elevated high enough for bagging by means of miniature elevators.

This improvement combines all the conveniences that could possibly be desired in a cornsheller-viz. it shells, separates the cob, cleans and bags the grain, all by the turning of one crank.

\section{Improvements in Grinding Mills.}

Felton's Improved Mill.-An improvement in mills for grinding feed has been made by Amory Felton, of Troy, New York, which consists in the employment or use of a corrugated cylinder and a concave and cap having spiral flanges and reciprocating teeth. The grain to be ground is placed in a hopper above the corrugated cylinder, and is made to rotate when the grain passes between the concave described and the cylinder, and is crushed between the spiral flanges of the concave and the corrugations on the cylinders, and is then discharged, ground, by an opening in the end of the concave. This mill is now in use, and grinds four bushels per hour by one-horse power.-Scientific American.

The following figures represent an improved hominy mill, recently invented and patented by B. Bridendolph, of Clearspring, Md. Fig. 1 is perspective view of the mill. A is the hopperbox; $B$ is a metal cylinder with projections on its inner surface; $C$ is the hulling-shaft, working in cylinder B. It is of a compound spiral shape; it has a spiral face and spiral edges on its threads. This shaft revolves in the cylinder $\mathrm{B}$ by the bevel-gearing $u \mathrm{P}$. The shaft of the bevel-wheel $u$ is rotated by hand by a crank lever, or it may be driven by any other power. $f$ is a fan which is rotated by a band from pulley $w$ passing around pulley $d$, on the shaft of the fan. The corn is put into the inside $h$ of the hopper-box, and the shaft $C$ being rotated, the corn passes gradually from the hopper down through the cylinder $\mathrm{B}$. The spiral threads of the shaft $\mathrm{C}$ beats the corn against the rough interior surface of the cylinder, carries it down, and at the same time packs it in a mass at the bottom, while the spiral edges (which run reverse to the spiral of the threads) act $s 0$ as to strip the hull from the grain, and break and take the eyes out of it.

The outlet of the hollow grinding cylinder is regulated by a small vent-gate at the one side at the bottom, which allows it to escape just as fast as the mill hulls it. It then falls upon a sieve s, ( fig. 1,) and the hulls, eyes, and other impurities are there separated from it by the blast from the fan $f$, when it passes down and out in a clear state from a shute under the fan.

This mill can be made of any size, from a hand up to a horse-power. A hand-power mill, the patentee informs us, hulls one bushel per hour; a horse-power from 50 to 80 bushels per day. Several thousands of them have already come into use. It can be made on a large scale, so as to convert it into a corn and cob mill. Fig. 2 represents a vertical section of a cylinder and shaft, when used as such a mill. It is made like fig. 1 in every respect, excepting 
the addition of the conical nut $n$ and corresponding seat at the lower end of the shaft. This nut is secured to the shaft $\mathrm{C}$, and a key passes through the shaft under it. The shell or concavity in which this nut works is separate from that of $B$, the cylinder, and it can be taken off and attached to the framing, so as to renew those parts when they get dull, which can be done at a very small cost. The nut $n$ grinds the hominy into meal: it can be enlarged as a corn and cob mill to grind fifteen bushels per hour.

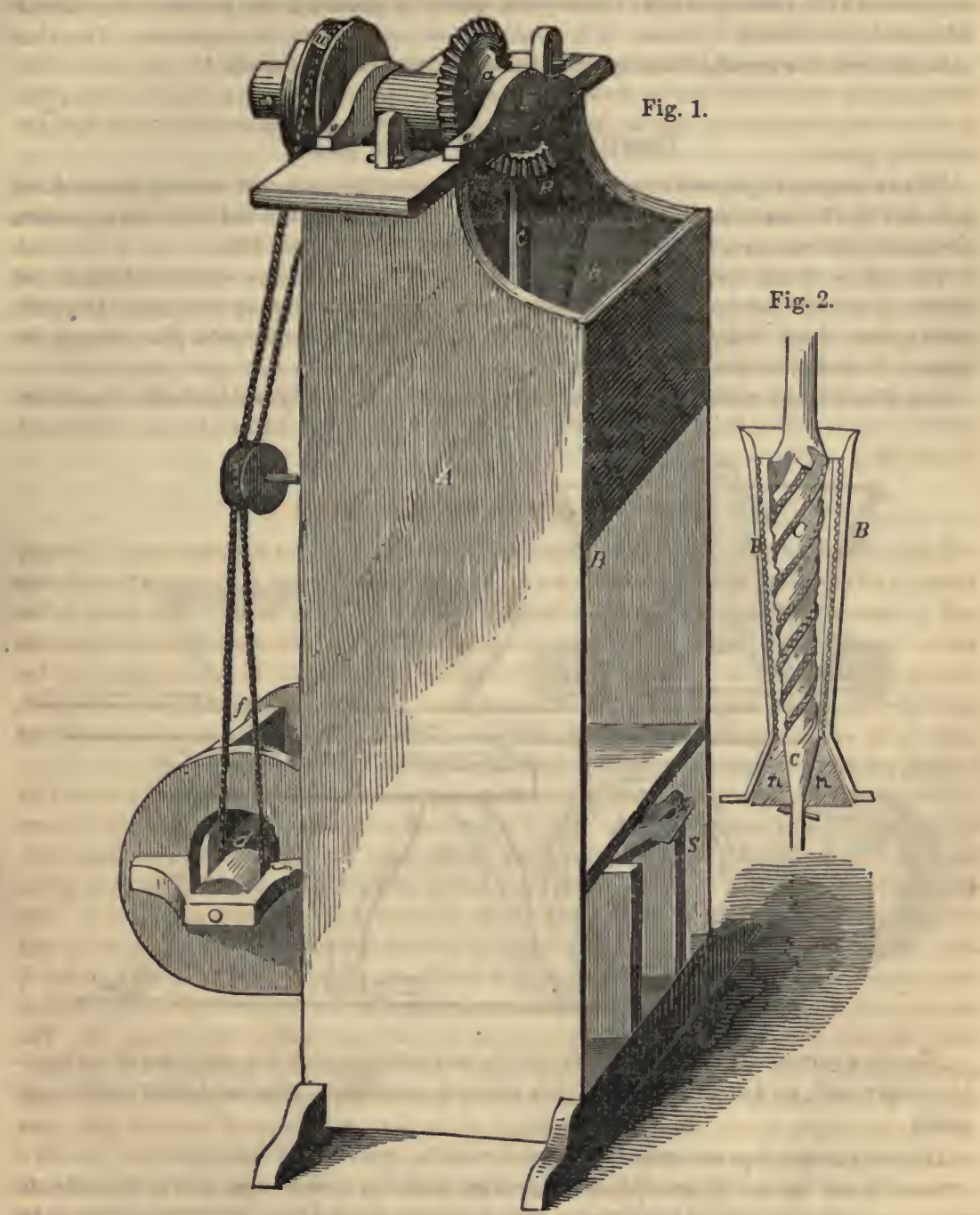

Wilson's Corn-grinder and Crusher.-In a corn-grinder and crusher recently patented by W. D. Wilson, of Richmond, Indiana, the grinding roller of the mill has a V-shaped groove on its periphery, and the concave in which it runs has a similar shaped tongue, so that a great amount of grinding surface is obtained in a small space.

Crushing and Grinding Mill.-A patent for an improved machine for grinding corn and cobs was granted to Jacob Weigle, of Erie county, Pennsylvania, and described with diagrams in the Scientific American, March 31, 1855. The nature of the invention consists in forming a crushing and grinding apparatus by uniting with each other, upon the same shaft, the smaller 
ends of two corrugated segments of cones, and combining with them corrugated, enclosing casings supplied with two feeding apertures, and arranged in such a manner that corn and cobs can be fed into one opening, and ground-shelled corn be fed into the other aperture, and both be converted into meal.

Shearman's Method of Feeding Grain to Millstones.-An 'Improvement recently patented by Simeon Shearman, of Goshen, Indiana, consists in an arrangement placed between the ordinary hopper and the grinding stones, whereby the grain, in passing from the one to the other, is winnowed and dusted by means of a fan-blast and appropriate arrangements. The blast also acts upon the spindle, keeping both it and the grain cool and clean.

\section{Leavitt's Portable Grain Mill.}

THE accompanying figures represent an improved portable grain mill recently invented and patented by Charles Leavitt, of the city of Quincy, Illinois, and for which the first premium for grain mills was awarded at the State Agricultural Fair of Ohio, 1855.

The nature of the invention consists in applying to a portable corn mill (in which the external portion or concave revolves upon a fixed cone) the following improvements: First, the combination of the bed-plate, legs or supports, the breaker, and the main pirot, cast in one piece. Secondly, in combination with the foregoing, a lever in two parts, attached to an external revolving concave, constructed and arranged substantially as hereinafter described.

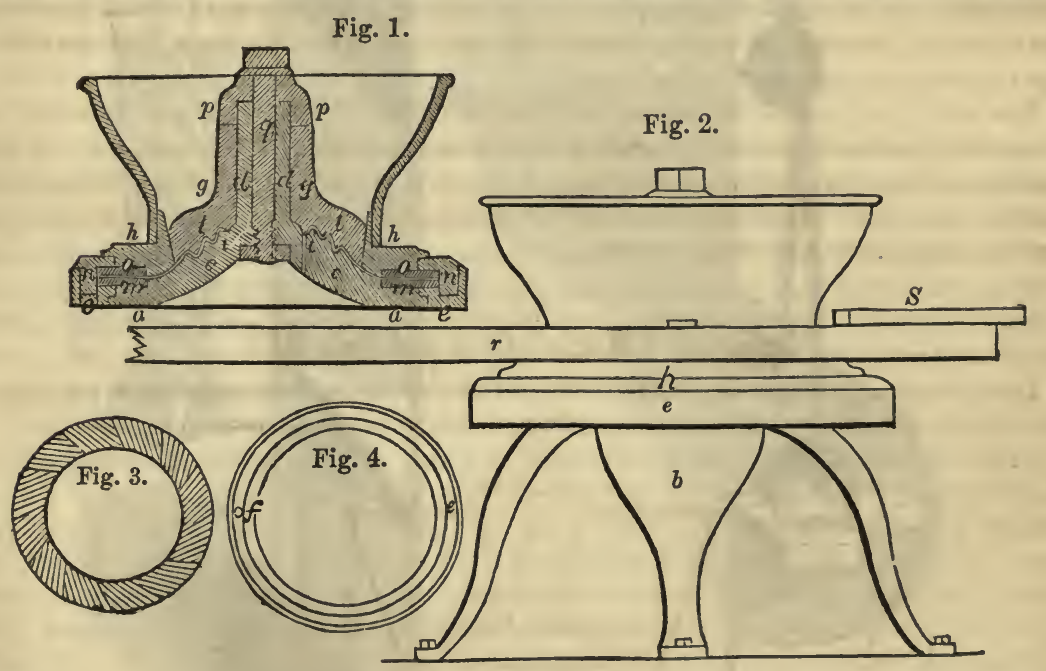

Fig. 1 is a vertical section of the mill; fig. 2 is an elevation; fig. 3 is a plan view of the movable rings; and fig. 4 is a plan view of the annular conductor. Similar letters refer to like parts.

The bed-plate $a$, legs or supports $b$, ogee-breaker $c$, and vertical main pivot or journal $d$, are cast in one piece. Upon a flange projecting from the lower edge of the bed-plate $a$ is placed an annular grooved conductor $e$, which has an outlet at $f$. Between the top of the breaker $c$, and the base of the pirot, is an annular groove $i$, with an outlet at the bottom thereof, for the purpose of collecting and discharging the oil from the pivot $d$, and preventing it from mixing with the meal. A sleeve $g$ fits upon the pirot $d$ and revolves thereon, its lower edge resting upon the bottom of the groove $i$. A top plate or cover $h$, having a circular opening in its centre a little less than the base of the breaker $c$, is joined to the sleeve $g$ by four strong arms $l$. The plate $h$ extends to the outer edge of the conductor $e$, and carries on its under side square projecting scrapers $n$, which fit in the conductor and revolve therein. The arms $l$ are toothed on their under sides to correspond with the teeth in the breaker $c$. 
forming together an effective crusher for the corn and cob when ground together. In the space between the base of the breaker $c$, and the inner edge of the conductor $e$, are secured by bolts (in such a manner as to be readily removed when required) a flat ring of steel or hardened iron $m$, with grinding teeth on its upper side, of any convenient form; but it is preferable for crushing or coarse grinding to use teeth the transverse section of which presents one side inclined and the other vertical. The mill is run in such a direction that the vertical sides of the upper and lower grinding surfaces shall meet each other. In a groove in the upper plate $h$ is placed another ring $o$ of the same size, material, and form as $m$, with the teeth of the same form, and arranged as before described: this is also removed when required. Between the ring $o$ and the central opening is a circle of large teeth inclined to the rear, and vertical to the front, and bevelled upwards on their inner edges for the purpose of forcing or crowding the grain on to the rings. It is preferable in grinding fine meal to run the grinding surfaces in such a direction as to oppose the inclined sides of the teeth in one ring to the inclined sides of the teeth of the other; and with that view another pair of rings are made to fit in the same places as the others, with the inclined sides of the teeth reversed. Upon the top of the pirot $d$ is a cap $p$ which rests on the sleeve $g$. Through the oap, pirot, and bed-plate a screw $q$ passes, having its nut at the bottom; the object of this screw is to regulate the mill by pressing the grinding surfaces together. Upon a flange on the edge of the central opening is a suitable hopper. Upon each side of the hopper, resting upon the top plate $h$, and secured thereto by bolts, is placed a piece of scantling extending to about twelve feet from the centre of the mill; they there meet at a very acute angle, forming a lever secured to a bolt, by which the horses are attached. A board s extends from one of the ends of the scantling to the other, upon which a man can stand to feed the mill.

This mill is best adapted for crushing and grinding corn and cob together, or by using the rings which present the inclined sides of their teeth to one another for fine meal, etc. If the teeth should wear out or break, fresh rings can be put in at a trifling expense. The annular conductor is a good improvement upon mills of this description, which allow the meal to fall from all parts of the base of the concave.

\section{Granger's "Magic" Corn and Cob Mill.}

THIs invention, patented September, 1855 , and which received the first premium for grind-

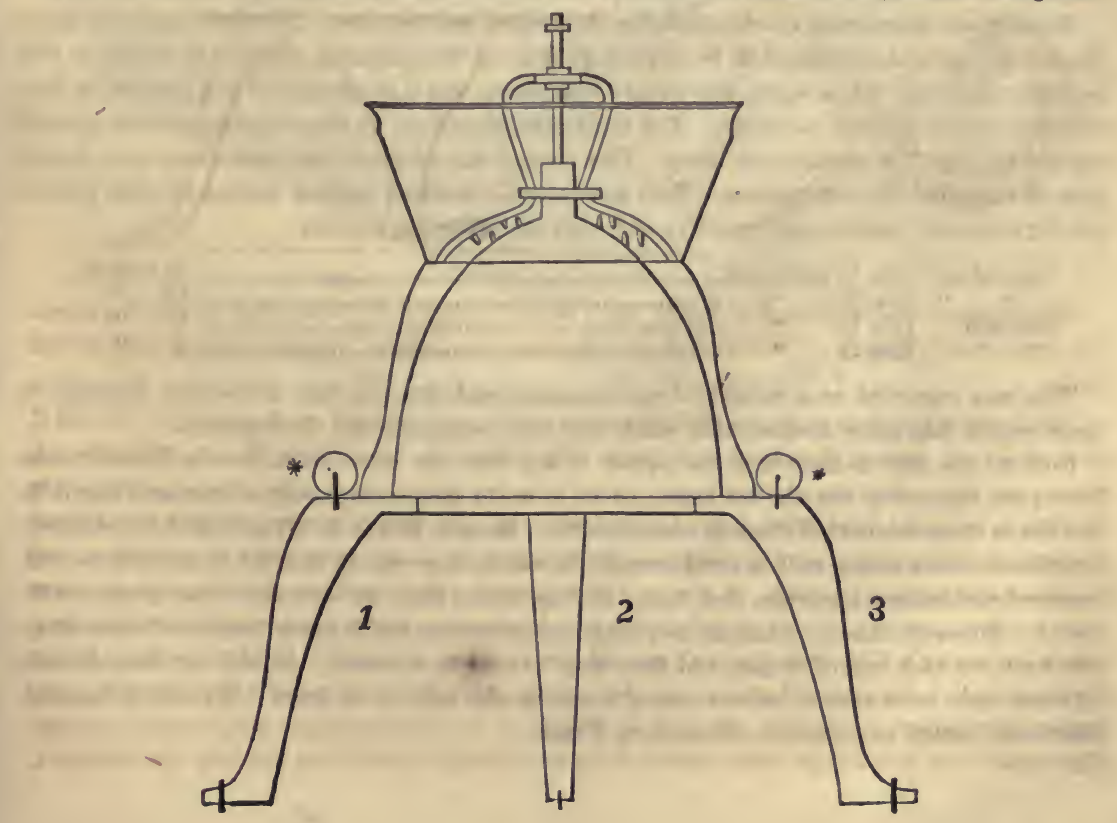


ing mills at the Pennsylvania State Agricultural Fair for 1855, is claimed to possess some advantages over all other similar inventions both in respect to the small amount of power required to operate it, and in the quality of the work performed. The striking peculiarity about this mill is found in the fact that the centre or core is stationary, while the outer casing revolves, the power being thus applied most advantageously at the point of greatest resistance. A disadvantage is thus obviated which pertains to some other mills-namely, that the weight of the driving arms applied to the movable centre bears unequally, causing it to grind fine upon one side and coarse upon the other.

The movable casing of Granger's mill has an attachment of small rollers at its base, on the outside, which renders the motion and consequent grinding action of the mill uniform, and prevents the rotary casing from changing its position. The mill may be made to grind coarse or fine, as may be desired, by elevating or lowering the outside casing by means of a screw. This external casing revolves on a case-hardened pirot attached to the top of the stationary core or centre-a point easily accessible for the purpose of oiling the bearings. The centre is firmly supported upon three triangular legs.

A great advantage claimed by the manufacturers of this mill, Messrs. Cresson, Stuart, and Peterson, of Philadelphia, is, that in imparting the motion to the outer casing, instead of the centre, the corn and cobs by the outer revolution are caused to descend and adhere to the inside, while in the opposite case, the same materials, by the centrifugal force imparted from the revolving centre, have a tendency to work upwards and away from the points where the grinding action takes place.

The construction of this mill will be easily understood by reference to the engraving, which represents it as seen in section.

\section{Great Flouring Mills.}

Вотн in England and the United States, great exertions have been made in the last fifteen years to improve flouring mills and make them produce the largest amount of flour in a given time. At the Great London Exhibition, a conical mill was exhibited, which was afterwards examined by a committee of Parliament and a number of scientific gentlemen, and pronounced to be a wonder of its kind. Two of these conical mills were put up in an establishment alongside of two old-fashioned flat mills, and the following is given in an English paper as a result of the trials:

There were three trials as regarded the old system and the new. The first experiment on the old mill gave a discharge of 16 pounds of flour in five minutes, which was equal to 192 pounds per hour; while upon the patent mill there was a discharge of $38 \frac{1}{2}$ pounds in five minutes, or 462 pounds per hour. The difference, therefore, on that experiment was against the old system 270 pounds per hour. The second experiment tried was even more favorable as regarded the new system. Two conical mills worked against two on the flat principle for one hour, ascertained exactly, and with the following results:

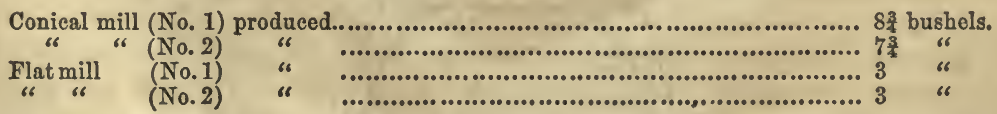

This was regarded as a wonderful achievement, and the scientific committee declared in their report that these conical mills must very soon supersede the old flat mills.

Now we are glad to have it in our power to say that our scientific millers in Pennsylvania have been improving the old flat burrs, so as to make them completely eclipse and throw in the shade these celebrated English conical mills. Messrs. Wilson \& $M^{\prime}$ Cullough have recently completed a new steam mill in our borough, in which they run $4 \frac{1}{2}$ feet flat French burrs, two hundred revolutions a minute, that turn out flour faster than we ever saw it run from a millspout. These gentlemen calculate to grind regularly from six to seven barrels of extra flour per hour, on each run of stones, and they may be able to do more. As high as thirty bushels of wheat have been ground on one run of stones in this mill in an hour! We ask if this has ever been beaten anywhere?-Harrisburg Union. 


\section{Manure Excavators.}

A patent has been recently granted to A. R. Hurst, of Harrisburg, Pennsylvania, for the improvement in manure excavators represented by the annexed figure, which is a perspectire view. The object of the implement is to loosen the manure, to allow of its being easily shovelled.

The nature of the invention consists in attaching a strong durable implement, very similar in construction to an ordinary pitch-fork, to the hindmost part of a sled, having suitable attachments to render the implement effective in its operation, by hinge-joints, in such manner that its teeth can be adjusted so as to be caused to take a strong hold on the manure as the sled is drawn forward; and consequently to loosen and separate its particles in the most effectual and speedy manner, and when not excarating, can be adjusted so as not to come in contact with the surface of the ground.

A represents the sled, strongly braced by the iron straps B B, each of which terminates at its front end in a hook $a$, to which the power is attached; $\mathrm{C}$ is the swinging cross-bar, which has the excavating or separating teeth $\mathrm{D}$ secured in it. This bar is hinged to the sled by

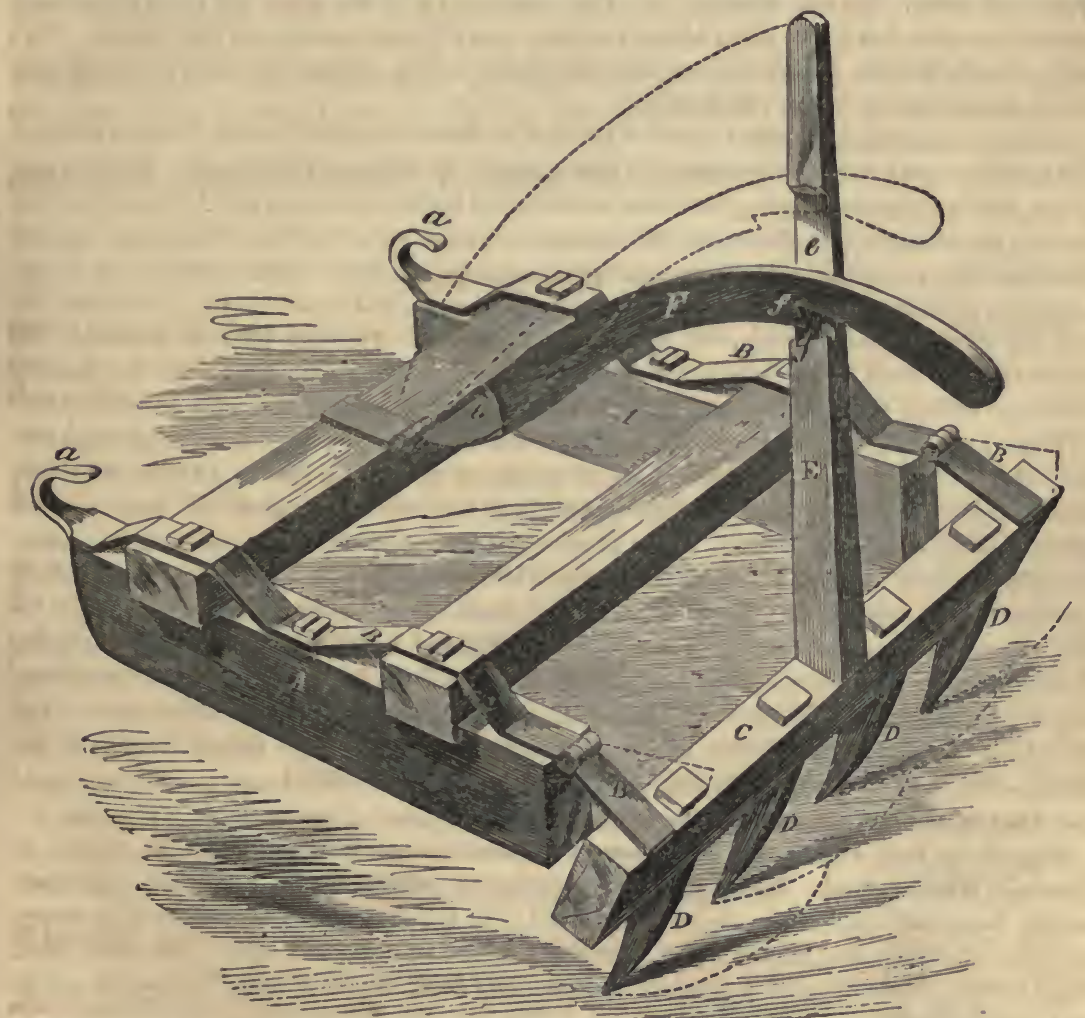

joints $c c$, and is capable of swinging on said joints when necessary. The teeth $\mathrm{D}$ may be placed at any suitable distance apart, and may extend from one side of the sled to the other. $\mathbf{E}$ is an upright lever for throwing the teeth in operation; it is attached to the swinging cross-bar $c$. $e$ is a slot cut through said lever. $\quad F$ is a curved swinging stop-bar for keeping the lever $\mathrm{E}$ in place, while the excavating operation is being carried on. The bar $\mathrm{F}$ moves in the slot $e$ of the lever $\mathrm{E}$, and holds the said lever in the position shown in full lines, by means of the stop $f$, which fits in the recess $g$ in the lever. By means of this lever, it may be seen that when the resistance is greatest on the teeth, the operation of the bar as a stop 
is the most effective. The lever $\mathrm{E}$ can be depressed and the teeth thrown out of operation by moving the end of the bar $F$ to the position shown in dotted lines; this operation drawing the stop $f$ out of the recess $g$. The position of the teeth when elevated, or out of operation, will be seen in the lower dotted lines, and their position, when in operation, in full lines. The lever $\mathbf{E}$ rests on the shoulders $i i$ of the $\operatorname{bar} f$, when the teeth are not in operation. The teeth of the implement are forced into the manure, and the sled is drawn over the same by hand or horse-power, the former, as the latter is drawn forward, taking a firm hold upon a large portion of the manure, and loosens and separates its particles ready for shovelling.

\section{What it Costs to Fence the Country.}

THe amount of capital employed in the construction and repair of fences in the United States would be deemed fabulous, were not the estimates founded on statistical facts which admit of no dispute. Burknap, a well-known agricultural writer, says: "Strange as it may seem, the greatest investment in this country, the most costly productions of human industry, are the common fences, which divide the fields from the highways, and separate them from each other. No man dreams that, when compared with the outlay for those unpretending monuments of art, our cities and our towns, with all their wealth, are left behind. You will scarcely believe me when I say that the fences of this country cost more than twenty times the amount of specie that is in it."

In Germany, and many other parts of Europe, no fences are seen for miles, either between the highlands and fields, or between the lots occupied by different individuals. In some districts, the boundaries of each proprietor are required by law to be marked by trees, and the owners are compelled to plant fruit and ornamental trees upon the line of highways against their land, at prescribed distances, and kept constantly growing. Public officers, at stated intervals, examine and survey the streets and public ways, and report to the public authorities any failure of compliance with these legal provisions. In some parts of Germany, the highways are lined for miles with rows of fruit-trees, bending with fruit over the passing traveller, adding grace and beauty to the landscape, and refreshing him with grateful shade.

There seems to be in this country a mania for fences. Not only are our fields and pastures enclosed, but divisions and subdivisions of our farms are made, and in addition to these, small yards and gardens close about our buildings are often multiplied till they mar the whole beauty of the homestead. This is particularly noticeable about old establishments. The first occupant enclosed a small garden, and after it had grown up to trees, he fenced off another for his vegetables. Then, from time to time, a small yard for poultry, another for the calves, and another for the house, a barn-yard, and so on, not omitting a front-yard, follow, until an acre or two of the best part of the farm is cut up like a chequer-board, having neither utility nor beauty to commend it. By-and-by the old farm changes hands, and the old rubbish is cleared away, and a sudden and almost magical change occurs in the scene. We see at once that system has taken the place of accident and caprice, and good taste has triumphed over conformity to old-fashioned notions of convenience.

We believe that, as a matter of economy, a great change is required in the matter of fences in Now England. Fences are for two purposes, protection from cattle and sometimes unruly boys, and shelter from the wind and cold. In the first place, we believe that nearly all fences between the highways and our fields might be dispensed with. But what, then, shall protect us from cattle wandering at large, and from droves passing to market, and to and from pasture?

As to droves of cattle, they are soon to cease. The railroads convey them nearly all, and if they are still to travel by means of their own locomotives, how much more reasonable would it be to compel their owners to drive them in yokes, or secured by ropes, or otherwise, than to insist that the owners of land shall fence them out a road from the place where they are raised to the market-towns. As the cows and oxen kept for use on our farms, they might easily be conducted in the same way to and from their pastures. Our pastures must still be enclosed. There is much rough land that can profitably be used for no other purpose. But the saving in dispensing with the fences about fields would be immense. No 
amendment of the law of the New England States generally, we apprehend, is necessary. Owners are not now obliged to fence against cattle in the highways, but persons driving or suffering their cattle to run loose in the road are bound to see that they do no injury. All that is needed is, that public opinion, which rules every thing else in our country, should be set right on this subject. As to shelter from the wind and cold, we apprehend that a rail fence or a stone wall round a field affords but very little. For gardens and fields, even in exposed positions, shelter is often necessary, and fences may sometimes be profitably constructed with this view. Generally, however, a judicious planting of belts of pine or hemlock-trees, on the northerly and westerly sides of our lots, will be found far more effectual and economical than any thing else, except for very small enclosures.

We see many subdivisions of farms which seem to us worse than useless. Fields are often divided into two, three, five or ten-acre lots, which had much better remain in one. This is often done for convenience in fall feeding, so that cattle may be turned into the fields before the crops are off in the fall. Our answer to this is, that this whole system of fall feeding on fields is an error. We believe that it is a fair estimate that a good mowing field will, without being fed at all, keep in grass better for ten years than it will five, if annually fod closely late in autumn. Soft lands are almost ruined by the treading of cattle, and the short bulbous roots of the herds-grass are pulled up and destroyed by the feeding of neat cattle that are not provided by nature with teeth enough to cut the grass evenly. It is better economy to feed our cattle at the barn in the autumn, than to allow them thus to injure the crops of future years. We would advise farmers, therefore, rather to remove the division fence which they already have in their fields, to escape the temptation to do what they know to be wrong, than to construct others for convenience in feeding their cattle in their mowing fields. If a fair estimate could be made of the actual cost of maintaining our unnecessary fences, and of the waste of valuable wood and timber used about them, so that each farmer should know the amount of his tax annually for this object, we think a great change for the better would soon occur.-New England Farmer.

\section{Improved Wire Fences.}

JoHn Nesmyti, of Lowell, Mass., has recently invented and patented a machine for the manufacture of wire fencing, adapted for farm or ornamental purposes.

This fence consists of a strong netting, woven by the machine, varnished with asphaltum blacking, coated with coal-tar, painted or galvanized, rolled up in portable rolls, from thirty to sixty rods in length, and sold to consumers at from sixty cents to $\$ 1.50$ per rod-the price varying according to the height of the fence, the size of the mesh, (or squares,) and the number of the wire. It can be readily set up by any ordinary farmer, and no nails are necessary, but the netting is fastened by wire or staples to posts of wood, iron, or stone, placed from eight to fifteen feet apart, and the edge of the netting is to be kept on a level from one terminus to another. When properly set, it is strong enough to "hold" an ox, and too close to be penetrated by a chicken. It offers so little resistance to wind and tide, that no gale can blow it down, or flood wash it away. If fastened to posts, set upon feet instead of being set in the ground, this fence may be laid flat on the land, or entirely removed on the approach of the flood-season in districts subject to floods, and set up again as good as ever when the flood has subsided. It excludes none of the rays of the sun; it harbors no weeds or vermin; it covers none of the soil, like hedges and walls, and the peculiar mode of its texture enables it to undergo, without the slightest injury, that alternate expansion and contraction to which all metallic substances are subjected by the changes of temperature incident to the atmosphere.

Mr. R. S. Fay, of Massachusetts, in a communication to The New England Farmer, states that he has used this fence for folding sheep at night on land that he wished to manure, shifting once or more every week, and has found it answer the purpose perfectly.

Mr. F. further says: "I have had some iron rods made with a double foot, which I drive into the ground and attach the fence to it either by copper wire or stout twine. A man and a boy will enclose a quarter of an acre in less than an hour, having these posts, which should be set not more than a rod apart. When I change the fence to a new spot, I unfasten it from the posts, throw it down, begin at one end, and roll it up as you would a carpet. And so in re- 
setting, reverse the process, rolling it out where it is to be set; drive down the posts, and then raise it and attach it to them. My fence cost $\$ 1.50$ per rod, and it is a cheap mode of handling or enclosing at that price."

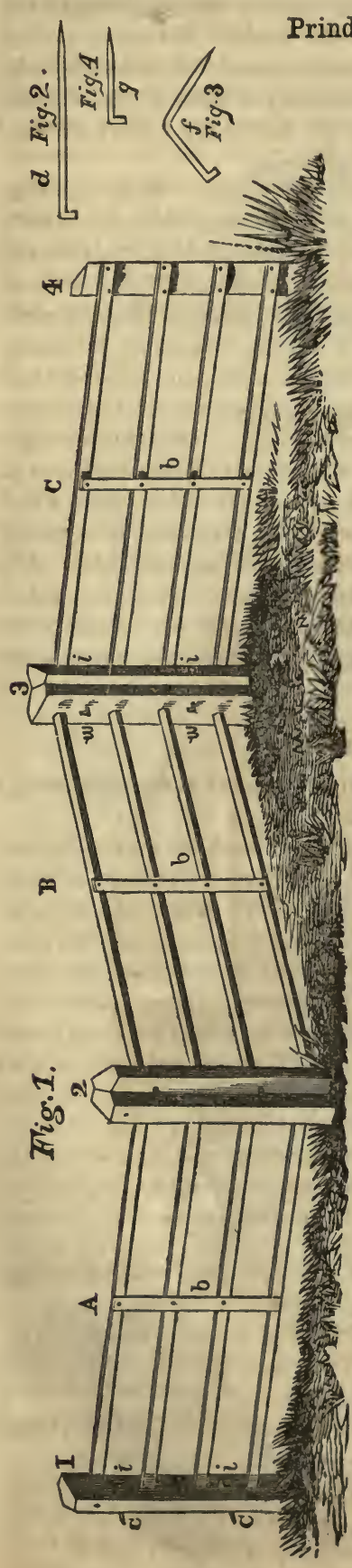

Prindle's Improved Field Fence.

THE accompanying figures represent an improvement in the construction of field fences, recently intrented and patented by N. R. Prindle, of East Bethany, Genesee co., N. Y.

Fig. 1 is a perspective view of the fence embracing three panels and posts, from 1 to 4 inclusive. Fig. 2 is a view of one of the metal spikes which unite the panels. Fig. 3 is a view of fig. 2, embracing the form it assumes when the panels have been united and set in position; and fig. 4 is a view of the wedge which is employed to secure the metal connection.

The nature of the invention consists in the mode of fastening together the adjacent posts or standards of a field fence, by passing a piece of metal having a head on one end through two adjacent posts, and securing the same by a wedge or its equivalent at the other end, the posts being so bevelled as to cause any desired angle to be made by the separate panels.

Fig. 1 is a perspective view of three panels of this fence, embracing three different kinds combined, as at $\mathrm{A} \mathrm{B} \mathrm{C}$, and posts or standards, 1 to 4 inclusive; $A$ is narrow board, (five inches wide,) one inch thick, connected to posts 1 and 2 by mortising; $\mathrm{B}$ a square rail (two and a half inches) or pole, inserted into posts by boring only; $\mathrm{C}$ a panel mado by nailing, as at posts 3 and 4, nailed upon reversed sides, the posts being differently sawed; $c c$ are small metal connections one-fourth to five-sixteenths of an inch in diamoter, and passing through the adjacent posts 123 , and connecting the different panels $\mathrm{A} \mathrm{B} \mathrm{C}$, firmly supporting the same; $w w$ are small wedges or keys two and a half inches long, driven into the posts to secure the whole, firmly locking each pair of posts alternately, and forming a lever upon each side; $i$ i are holes in the posts for the above metal connections, and also represent the heads of the same; $b \quad b \quad b$ are narrow boards nailed firmly to the middle of each panel or length. To take down or remove this fence, withdraw the wedges $w w$.

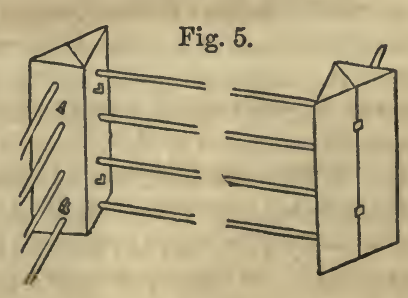

This fence is designed to be set up a little crooked or at any desired angle, as is shown by fig. 5 . It can also be used straight by staking, etc., or in a continuous circle, for 
stack-yards or other small enclosures. In exposed situations, the posts or standards may rest upon stones, and be connected therewith by metal pins, inserted in the stone and bottoms of the posts. The metal connection readily bends, accommodating itself to any desired angle, as at posts 2 and 3, fig. 1. The posts may be made of split logs, the convex surfaces being placed in contact, the panels united, and the required angle given, as above described.

The great advantage of this invention consists in the peculiar-shaped standard or post, so connected with the metallic fastening, that the fence will sustain itself without having its posts set in the ground. These posts will enable the builder to make almost any kind of a fence, from almost any variety or form of timber-whether boards, bars, rails, poles, \&c., or mostly of wire or pickets, if desired, rendering the same a portable or hurdle fence, easily and quickly transferred from place to place. The work of construction, very conveniently for the farmer, can be performed mostly in winter, as it is formed of separate panels or lengths, ready for setting up in the field. By adding a different connection, any panel will serve as a gate- $a$ fact of much importance to the farmer. To make small enclosures, such as stack, sheep, and poultry-yards, is but a few moments' labor with this fence.

\section{Thompson's Circular Self-Acting Gate.}

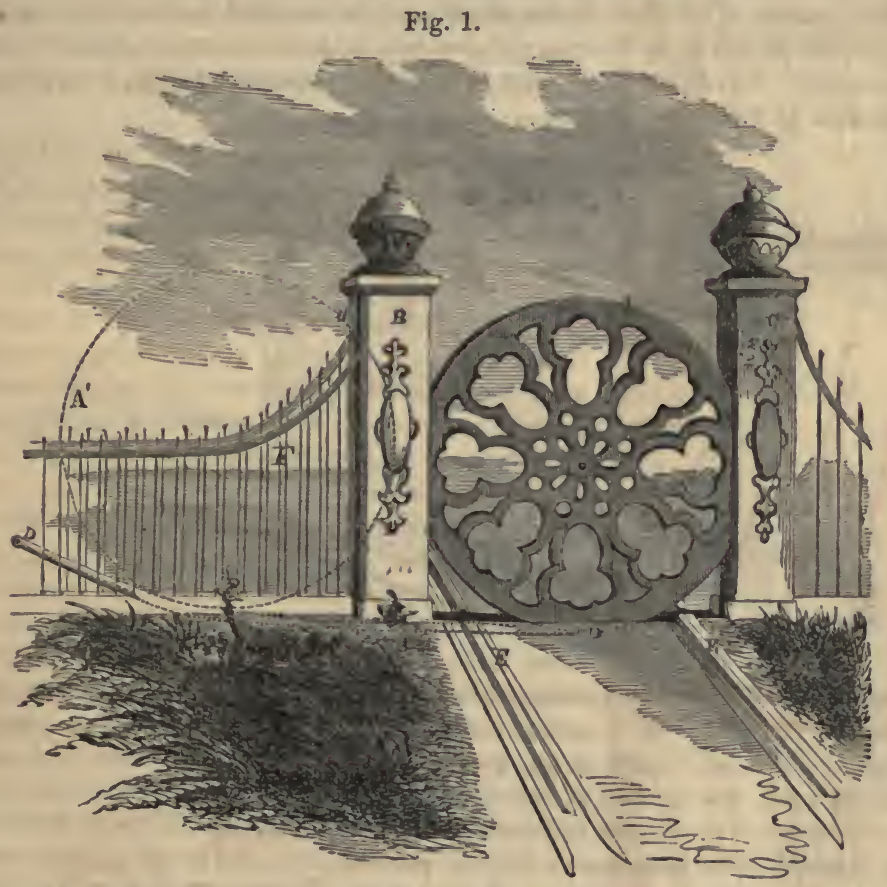

THE accompanying engraving is a perspective view of an improved peculiarly self-acting gate, recently invented and patented by William Thompson, of Nashville, Tenn.

The invention relates to gates for farms, parks, andenclosures of any kind, and consists in constructing the gate $\mathrm{A}$ of a circular form like a wheel, as shown, and allowing it to rest, when closed, on a vibrating rail $\mathrm{D}$, which is operated by a person, wagon, or carriage on the track, to make the gate roll to the one side and open when approaching it, and then roll back when the carriage or wagon has passed through to close it.

A A is the gate; $\mathrm{B}$ is a post formed in two separate pieces to leave a channel $d$ between them from the bottom to the cap-piece. $\mathrm{F}$ is a double fence at one side, to allow wheel $\mathrm{A}$ to roll through the channel of the post $B$ to the left-hand side, as shown by the dotted lines $A$ when the gate is open. C is the right-hand post, with a channel in it, but not through it, to receive 
a part of one side of gate $A$, and retain it when the gate is closed. The gate rests on a vibratory lever D, sunk a little below the roadway at the middle of the track, but elevated at the one side. This lever railway is hung upon a pivot, with its long end towards the opening of the gate, so as by its weight at that end to tilt down the gate into its place, self-acting, when the lighter end is relieved from the weight or pressure of a carriage, \&c. on the roadway, after it has passed through. E is the platform; it is secured to the short end of the rail $\mathrm{D}$ at the left-hand side, and extends both in front and back of the gate. Supposing a person or carriage to be approaching the gate, his weight or that of the carriage on the platform will depress the now elevated end of the lever $\mathrm{D}$ at the left, and the gate will roll into the position shown in dotted lines $\mathrm{A}$, until the person or carriage has passed off the platform $\mathrm{E}$ on the other side; the lever $\mathrm{D}$ will then rise to the position as shown in the figure, and tilt the gate into its place and close it. The vibrating rail $\mathrm{D}$ may be so hung that its long end will be to the left of the pivot or vibrating point, as by a weight on the platform it can be so adjusted to open and close the gate independent of the point at which it is hung on its pivot. Different methods of securing the platform to the tilting-rail may be employed. The platform, also, may be provided with any suitable fastening, such as a spring switch with a vertical lever at one side, which will set free a catch on the platform, and allow it to act so as to prevent animals opening the gate by merely getting on the platform.

The inside corners of the posts at the ground may be extended as close to the gate as possible, so as to fill up the space between the gate and the posts, to prevent hogs, \&c. from thus passing through. The filling up of these spaces may be executed neatly, to accord with the general contour of the gate.

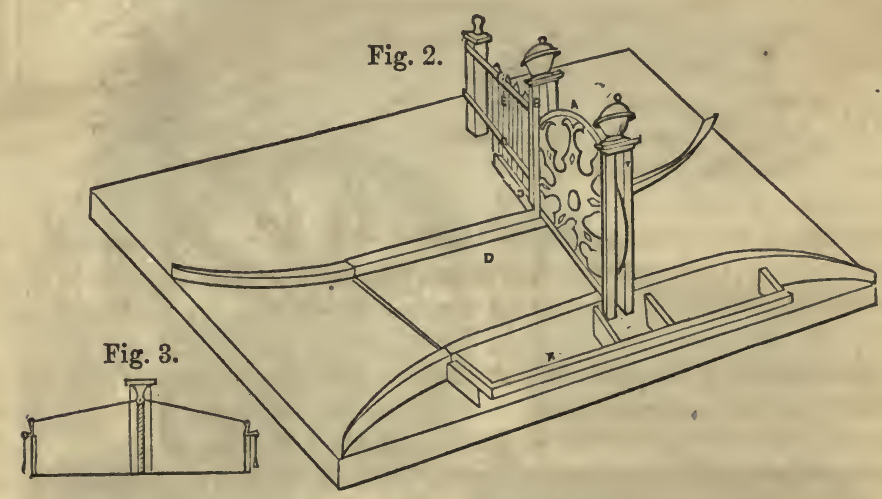

Various modifications of this gate may be adopted, embracing the same general principles of construction and operation, according to the taste of those who put them up. In fig. 2 the gate $\mathrm{A}$ rests upon a rail $\mathrm{C}$ sunk in the lever platform $\mathrm{D}$ a little below the road-way in the middle of the track, but elevated at one side and extending some distance to the left. This platform $\mathrm{D}$ extends both in front and back of the gate. The rail $\mathrm{C}$ is firmly fastened to the platform $D$, which itself rests upon a fulcrum next the short end of the rail upon which the gate rolls, and the platform has a weight $F$ at its edge sufficiently heavy to keep the short end of the rail upon the ground, and the long end in an inclined position, thus shutting the gate. By the pressure of a carriage or person upon the platform, the position of the rail is reversed and the gate rolls open. The platform D may be provided with any proper catch or fastening, so that the gate cannot be casually opened by animals, a plan of which is shown at fig. 3 .

There is claimed for this gate great simplicity of construction; and when its cheapness, utility, and beauty (if desired) shall be remembered, and it is likewise borne in mind what little skill is required to make it, and how little its liability to get out of repair, it is believed that it will be regarded as preferable to the common gate swinging on hinges; and may possibly be esteemed superior to any form of gate among the various inventions of more modern date. 


\section{Improvements in Gates.}

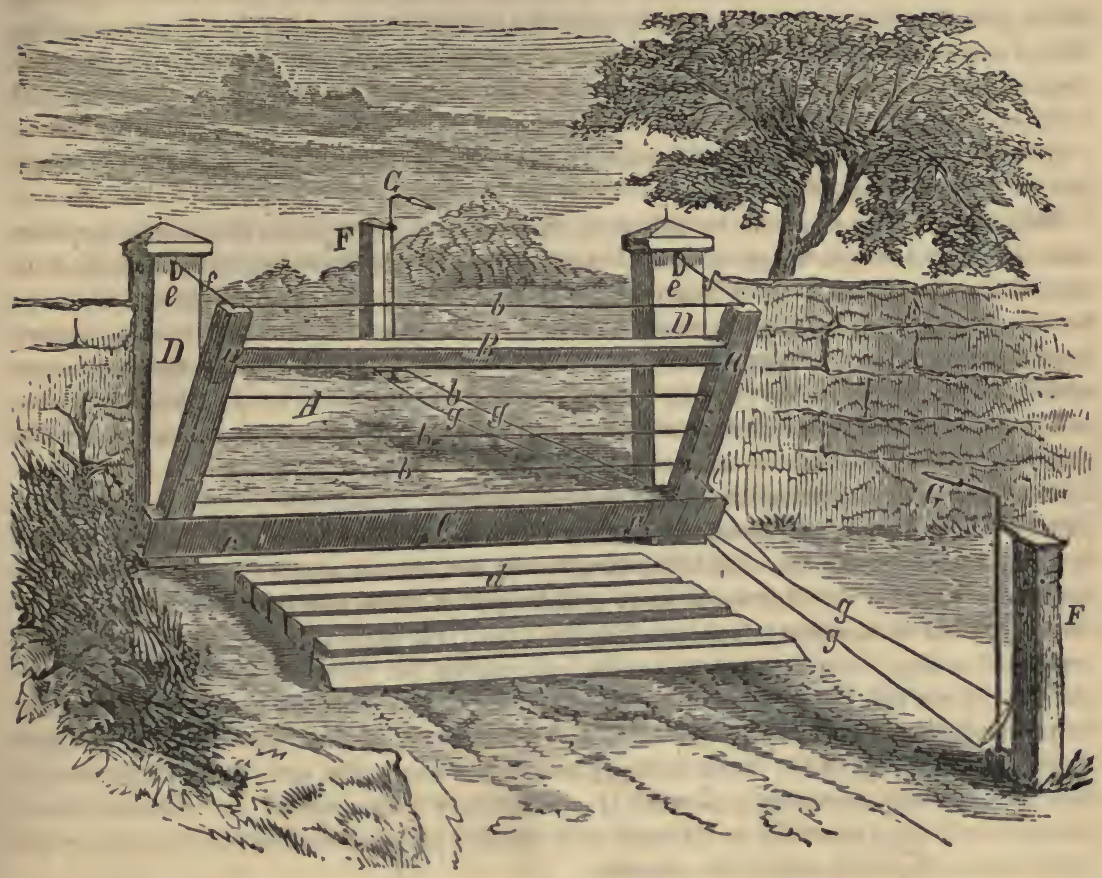

THE accompanying engraving is a perspective view of an improved farm-gate, for which a patent was recently granted to Henry B. Lumm, of Sandusky, Ohio. This gate is so constructed and arranged, that it may be opened or closed by a person in a carriage or on horseback.

D D are the two posts of the gate; they are hollow, and have an opening near the cap, in each, in which is secured a grooved pulley $e$ e; $f f$ are cords or chains secured to the top of the side bars $a a$, and passing over the pulleys $e e$ into the hollow posts. To the inner ends of these cords are secured balance-weights, so that when the gate is up or closed, these hold it plumb in position, keeping the gate $\mathrm{A}$ closed. This gate has a lower bar $\mathrm{C}$, which is hinged at $c c$ to the sill between the two posts. It therefore folds upwards when closed, and downwards when open. The gate is formed with the side bars $a a$, the lower bar $\mathrm{C}$, and top bar $B$, and strong smaller bars $b b b$. When folded down, these bars are received in the openings made for them in the road-way $d$. When the gate is open, therefore, it lies flat between the road-way sleepers $b$, which act as fenders, and the carriage drives over it. $\mathbf{F} \mathbf{F}$ are posts a little distance from the gate on each side; $G G$ are handles to upright levers, which are connected at the middle to two strong crossing wires or iron rods $g g$, which are secured at one side to a lug $i$ on the lower bar C. The levers turn or vibrate in their sockets; and by turning the handles $\mathrm{G} G$ to the one side or the other, the gate is opened and closed, folded up and let down.

Operation.-Allowing the gate to be in the position shown, (closed,) and a carriage going forwards from the nigh side to pass through, the driver has but to take hold of the lever $G$ and push it forwards, when the then off wire $g$ will be thrown further back, and draw the gate down flat between the sleepers of the road-way $d$, and the carriage is allowed to proceed through the gate. When it arrives at the other side, the driver takes hold of the other handle $\mathrm{G}$ and draws it to the one side, and thus changes the wires $g$ and raises up the gate, closing it after him. 
A patent for an improved gate was also granted to W. G. Phillips, of Newport, Delarrare, in March, 1855.

The nature of the invention consists in providing the gate-post or pivot and the platform with springs, so arranged that a rehicle passing on to the platform will press upon a spring, and so operate the gate as to allow the vehicle to pass through, and in going from the platform on the opposite side, another spring is pressed by the carriage, which causes the gate to close.

¿

An automaton gate, which is highly recommended, has recently been invented by Mr. C. Winegar, of Union Springs, New York.

This contrivance, not unlike a clock, consists of two principal parts, the running and regulating parts. A weight which opens and shuts the gate is contained in a tall box fixed at the side of the gate, resembling in external appearance a large post. The weight in descending turns a crank. A rod placed between this crank and the gate, and connected to each, receives by this means a reciprocating motion, and would open and shut the gate in rapid succession until the weight reaches the ground, were its motion not controlled by a latch which fastens it shut when it strikes the post, or which fastens it open, as soon as it reaches a smaller post placed at the proper point for this purpose.

The opening and shutting is effected from the carriage or saddle by simply giving a slight pull or jerk to a loop suspended from the arm of a tall post a short distance from the gate. A wire, extending from this loop to the hinge-post, and thence across the top of the gate to the latch, instantly sets it free whenever a slight pull is given, and the crank and rod immediately draw it open, where it is retained by the latch. On passing through, the loop is pulled on the other side, loosening the latch again, and causing the gate immediately to close. By placing the two tall posts with the loops sufficiently distant from the gate, the opening may be accomplished at any desired time before arriving there, an increased length of the wire being all that is required. As an ordinary weight will move the gate about fifty times, all that is commonly necessary is to wind it up regularly once a week. In extreme cases, a workman who goes regularly to his work each morning may be employed to raise the weight as he passes, requiring only a few seconds.

\section{Improved Method of Building Stone Houses.}

Mr. L. P. BALL, of Worcester, Massachusetts, in a communication to the New England Farmer, calls attention to a new method of constructing houses, recently introduced into New England. He says-

Last year (1854) a stone machine shop, 400 feet long, 40 feet wide, and two stories high, with walls 21 inches thick, was built in Worcester of a kind of slate in the following manner: The entire mass of stone blasted from the ledge was carried to the building, the nature of the ledge being such that a very large portion of the stone obtained by blasting was in small pieces; into the mortar, which was made of lime and coarse sand, were put, and intimately mixed with it, all the small chips and fragments. All the larger stones were reserved for the process of filling in. The walls were made by filling the mortar into boxes, made by placing planks outside and inside of the wall, a distance apart of the desired thickness of the wall. These planks are kept in their places by plumb straight-edges of sufficient strength, placed and fastened upon the outside of the planks. When the planks have been thus properly disposed in their places to a height of three or four feet above the foundation, the mortar, in a very plastie state is brought from the mortar-bed in hods, and poured into the space between the planks. Into this soft, yielding mass were disposed all the larger stones in such a manner as to make the wall one solid mass of mortar and stone. These processes of alternately filling with mortar and larger stones are repeated until the mould is full.

The mould or planks forming the wall are allowed to remain upon the walls until the mortar has set, say twenty-four hours or more, according to the quality of the mortar; and are then removed and reset, and all the foregoing operations repeated until the walls of the building are completed. The windows and door-frames are made and set in the same manner as they are for brick buildings; over the doors and windows is put a wood or stone lintel to hold 
the pressure of the wall until it is dry. Care is to be taken in placing all of the stone around the windows and doors to have them permanently fixed in their places, so as to form a solid jam. The flooring timbers are placed and anchored into the walls in the same manner as they are in brick buildings. As this kind of wall is somewhat uneven for the reception of the flooring timber, a piece of scantling, say 24 by 6 inches, should be placed and levelled upon the walls, and be firmly bedded with mortar to receive the joists and other flooring timber.

The exterior of buildings constructed as above can be finished, if desired, with either "stucco" or mastic, and the expense of the whole stated to be not far from the cost of common wood dwellings, or from $\$ 1.25$ to $\$ 1.50$ per square yard of the wall all finished. This price, however, must vary some with the price of lime in particular vicinities, and with the facility with which the sand and other materials could be obtained.

\section{On the Drying of Fruit.}

"WE recently noticed," says the American Agriculturist, "a simple apparatus for drying fruit at the residence of a farmer in Dutchess county, a description of which may furnish a hint to others. Upon the south side of his kitchen is a 'stoop' some ten feet high. Just below the roof is arranged a shelf or platform, the full size of the stoop, and resting on small rollers upon each side; a sort of railway is formed, each rail consisting of two narrow slats or boards nailed together, but kept separated about an inch from each other by short bits of board placed between them at short intervals; these railways are nailed up against the two sides of the stoop, and project out eight feet from the roof. Upon these the drying platform is supported by a number of wheels or pulleys, formed by sawing off sections of a round stick after a three-quarter inch auger-hole has been bored through its centre; these are arranged in the opening between the two slats forming each side rail, and are held in place by wooden pins put through the side pieces. The wheels or pulleys stand a little above the surface of the rails, and over them the platform moves easily. Plums, cherries, apples, and other fruits are spread upon the platform, and during drying days it is rolled out upon the projecting supports, exposing the fruit to the sun. At evening, or upon the approach of rain, the platform is ensily shoved back under the roof. Such an apparatus can be constructed in a single day; it will last for years, and be amply sufficient to dry a large quantity of different kinds of fruit annually.

"A similar apparatus might be arranged upon a garret floor, to be shoved out through a temporary opening under the eaves trough. In this case the inner portion of the platform should be held by pulleys over it to prevent the outer end from tipping downwards. If this is done there will be no necessity for projecting supports."-American Agriculturist.

At a recent meeting of the New York Farmers' Club, the following remarks respecting the drying of fruit were made by Solon Robinson, Esq.: At the West, where apples and peaches grow in such luxuriant abundance as to be utterly valueless in a grain State, a very rude kiln is in common use. They are built in this way: parallel walls of stone are built about a foot high, and covered with flat stones, the joints plastered with clay, and the flues between the walls connected at one end with a short chimney to carry off the smoke of fires built at the other end. Upon these flat stones, when heated, the fruit is spread until dry. I have known these kilns built, where there were no stones, all of clay. A smooth log is laid down as a mould for the flue, and the clay built over it, and then it is withdrawn, and so on a succession of flues, which are all covered and smoothed off on the top, and thereon the fruit is placed to dry. It is sometimes badly burnt. There is another rude kind of drying kiln at the West. A wooden house, say six feet square, has such a flue as I have described, or a store with the mouth open on one side of the house, for convenience of firing, with the pipe or flue carried out on the opposite side. This heats the air inside of the house very hot. Then one side of the house is filled with drawers that pull out like a bureau. These are made only two inches deep, with basket-work bottoms to hold the fruit and let the air pass through. This plan is better than the kilns I described, but not perfect. The North American Phalanx in New Jersey had a drying kiln built in the form of a large brick chimney, with drawers in three stories of the building, that operated very well in drying fruit, green corn, beans, okre, 
and other vegetables, but the mistake in its formation was that it was not open at the top, to create a draught and carry off the moisture. If such a chimney were very tall, with the heat in an oven at the bottom to heat the air drawn in from outside, I think fruit would dry very rapidly. Any and every farmer can have one of these drying flues; and where fuel is cheap and fruit plenty, I have no doubt that the profit would be very large. It is worth trying. There is another plan of building a drying chimney that may be more effectual than one with an open top, and that is the plan adopted in some foundries to dry the wet claywork of cores used in casting. There the current of heated air is introduced at the top and draws downwards, and escapes at the bottom. But, after all, I do not think that we have arrived at the true way of drying fruit. I have full faith to believe that the time will come when fruit will be made into a pulp, and freed from skins and cores and seeds by machinery, and the water evaporated by heat, somewhat upon the same plan it is now from pulp of rags to make paper. What we want is an invention to facilitate this purpose. That it can be done I know, for it is done in a rude way at the West in an article called "peach leather," or, as the chairman suggests as a better name, we will call it peach marmalade. Peaches are pulped and spread upon plates or tin platters, and dried in the sun or a slow oven.

Pumpkin meal is an article made by the Shakers, and sold in this market to a limited extent. The process ought to be better known, and more widely applied. And if so juicy a fruit as pumpkins can be dried and ground into meal, I want to know why apples cannot be treated in the same way.

\section{Adaptation of Trees to Economic Purposes.}

As in the case of metals, timber is provided in manageable masses. The size of trees is adapted for human, not Cyclopean artisans. Had they generally approached the Gigantic Sequoia, what could have been done with them-with logs, one of which, laid along the pavement of some streets, would fill them to the roofs of three-story houses! The difficulty of felling, transporting, handling, and slitting such into beams or into boards, would have been seriously embarrassing, whereas the most useful trees are never too large for easy control, rarely exceeding four feet in diameter, and a fair average would give from fifteen to eighteen inches nearly. The mahogany-tree is remarkable for its magnitude, and yet the largest recorded log was only seventeen feet long by fifty-four and sixty-four inches. Another feature of the world's timber is, the heaviest woods are not found in the largest bolls, but generally in the smallest-a provision that vastly facilitates man's control over them. Fir is only as heavy as oak, while ebony, lignum-vitæ, and box are rather shrubs than trees. Hickory is rarely seen a foot in diameter, and exceedingly few sticks of rosewood are met with as large. Thus the largest trees are light and easily worked. Had they been light and porous as the cork-tree, or heavy and dense as lignum-viti, they had been of comparatively little use to man. But we are ordained to be elaborators in wood as well as in the metals; and hence the facilities for its acquisition, its varieties of masses, properties, and adaptations.Ewbank,-The World a Workshop. 


\section{Amricultural êromistry and Eralumy.}

On the Utilization of Sewerage Products for Agricultural Purposes.

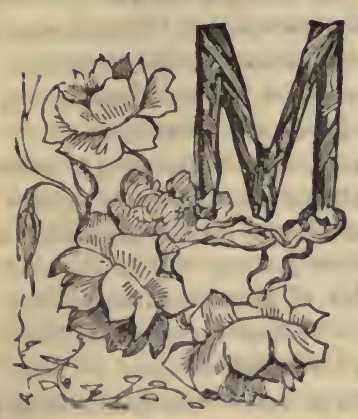

R. MECHI, the well-known English agriculturist, at a late meeting of the London Farmer's Club, delivered the following lecture on the utilization of sewerage products, especially those of London, for agricultural purposes:-

One hundred years hence, which is not long in the history of a country, our successors will scarcely believe that a nation, wanting annually many millions of quarters of grain to fill up its own inadequate production of food, should waste the only means by which such deficiency might be made good. I mean the productions of the land when they have fulfilled their office of nutrition to man and beast. Every one now at all conversant with the theory of modern agricultural chemistry must know that our agricultural produce loses little by such a process, and that the bulk of its elements are returned to us in the shape of excretre, if we take the trouble to collect them. I am aware that the practicability of doing so has been questioned; but I purpose this evening to show that there is no difficulty in the matter, except what exists in the brain of man. The same power that brings your water into London will take it out again; for, according to Professor Way and other chemists, 2,500,000 inhabitants will only add three thousand seven hundred and sixty tons in solids and fluids to the quantity of water.

If agriculturists studied attentively Professor Way's able paper on Town-sewage, (see Royal Agricultural Society's Journal, vol. xv. part 1, p. 135, ) it would teach them a great and profitable lesson. They would learn that of all the manure made by human beings (and I have no doubt by animals) twelve parts out of thirteen in weight escape as urine, only one-thirteenth part being solid! Well may farmers love the sheep-fold, and well may they deplore yard-feeding, where the rains from the untroughed roofs may, in too many instahces, thus take away nearly all their manure. Mr. Way has found that, taking the averago of men, women, and children, each individual of the population will, in the course of twenty-four hours, contribute to the sewage of a town one-quarter of a pound of solid and three pounds of liquid excrement. A knowledge of these facts shows us how trivial is the question of solid manure; for, at a quarter of a pound each, daily, the total solid manure of 2,500,000 people will only weigh two hundred and seventy-nine tons. According to Mr. Way, the excrement of each person is diluted with or distributed through twenty gallons, or fourteen hundred times its own weight, of water. It must appear singular to a disinterested observer that, while farmers seek eagerly after every new manure, and are subjected to much imposition in such purchases, they appear to be apathetic on the question of town-sewage. Omitting the sanitary consideration, there can be no class so deeply interested in the question of town-sewage as the farmer. Those sewers carry away to our rivers all the products which he has at so much care and cost produced for the food of the people. To repair the exhaustions caused by these supplies, he rushes to Peru for birds' dung, at an expense of some millions, while the very graveyards of foreign nations are taxed to supply bones for his turnips. The rapid increase of water-closets and new sewers, with a more abundant water supply, are daily lessening the supply of human excretæ in a solid form, diminishing, in fact, pro tanto, the ordinary channel of supply, so that shortly we may expect that only the stable-manure and ashes of London will be available for agricultural 
purposes, while the weekly supply of 6000 or 7000 bullocks, 40,000 sheep, and all the other rast solid and fluid consumables of the metropolis, from tea to turtle, will be floating down the sewers unheeded and unsolicited.

This cruel neglect can only arise from a disbelief of the value of such manure, or from a doubt of the possibility of applying it economically. I purpose, therefore, this evening, to go into statistical details with a view to ventilate the question, and to prove how easily such an operation may be successfully carried out with individual and general benefits. Water alone is manure; who can doubt this? Look to the costly water-meadows in various parts of the kingdom; and what farmer who has a water-meadow does not appreciate its great value to him as producing early, late, and most abundant vegetation? My own experience, with two miles of pipes on my farm of one hundred and seventy acres, has proved that fluid applications of manure are far the most profitable, and that their influence is quite as important and advantageous to cereal as to other crops. In proof of this I have threshed some fields of wheat, producing six quarters per imperial acre;* oats, thirteen quarters, and barley, eight quarters, which latter is one quarter more than I estimated in my balance-sheet. Now, such productions as these on a naturally wretched soil prove more than volumes of argument, and I have no hesitation in saying that, had my neighbors to pay $£ 2$ per acre annually in interest for improvements over and above their present rent to obtain similar results, they would be considerable gainers. If it answers my purpose to lay down pipes, erect an engine, make tanks, erect pumps, and so on, for the mere purpose of applying the manure made on my farm in a fluid state, with a large supply of water from my spring, surely it must equally and more certainly pay a farmer to receive back his corn, bullocks, sheep, and other productions, after they are done with, at a very much smaller cost; for their very essence will return to him, accompanied by all the good things that metropolitan luxury can command from every foreign part. If we go into a statistical inquiry of the weekly supply of London in tea, coffee, and sugar; wine, spirits, and beer; fish, flesh, and fowl, (foreign and British;) the tons of soap, and the thousand-and-one refuses of our manufactories, gasworks, \&c., one becomes amazed at the fructifying power involved in such a consideration. The alkaline and granited solutions of our pavements by trituration and abrasion, the smuts from our smoke, have all a considerable value.

The mere wear and tear of shoe-leather has its value, as it grinds down the pavement into hollows. I apprehend that the daily cost of feeding each individual in this metropolis, taking the average of rich and poor, young and old, would not be less than ten-pence per day, or thirty-seven and a half millions sterling per annum. Now, in parts of Lincolnshire it is the custom to value the manure at half the cost of the oil-cake consumed. On this principle, which appears to be a sound one, the agricultural value of the manure from this thirty-seven and a hals millions of food ought to be something very considerable, to say nothing food consumed by the animals of the metropolis. The rubbing, washing, and agitating which the solid excrement receives in passing through miles of tortuous sewers, cause it to be dissolved and pass away in a fluid state, which we may any day prove by an examination of the sewers' mouths at low-water. I think farmers cannot be aware that all the solid and liquid manure of men and animals is liquifiable by solution or suspension, and can be applied in a shower, sinking deeply into the subsoil of drained land. Perhaps I may be here permitted to explain why I consider this mode of application far superior to the solid form. If you make a transverse cut or opening in the soil, you will find that the British agricultural piecrust is only five to eight inches thick. The slips and railway cuttings plainly reveal this humiliating fact. Below this thin crust we see a primitive soil, bearing most unmistakable evidence of antiquity and unalterability. The dark shades of the cultivated and manured surface have not been communicated to the pale subsoil; and we have evident proof that solid manure plowed in, in the ordinary way, exercises little influence on the subsoil. Nor can this be wondered at, when the plow sole has been polishing and solidifying the floor at the same depth for the last few centuries. Now, when I apply liquified manure, (which

* The "quarter" of Fnglish agriculturists is eight bushels; so that the yield of wheat was forty-eight bushels per imperial acre of four rods, each forty-six perches or rods. 
means all the solid and liquid excrements of the farm animals mixed with water,) it soaks deeply into the subsoil to the depth of the drains, which I have seen, on the very strongest clays, discharging the liquefied manure at a depth of four and five feet. Here, then, is the secret of my great crops on a miserable soil. The manure ritalizes, warms, and chemically changes the miserable subsoil; the roots of the growing crops know this, and send down their fibres or mouths to appropriate and elaborate the subterranean treasures now for the first time placed at their disposal in an available condition. I could show you twenty loads of rich oil-cake bullock pudding, or manure; I would mix it with water, apply it in a shower, and you should search the surface in vain for any proof of its whereabout. It has gone down to do its work. I will not drag you through all the details of the modus operandi of this method of manuring; you may see it all any day you choose on my farm, or on any of those of other's who are practising the same process. What I want you to believe is, that townsewage is liquid guano, applicable to every soil and every crop, and worthy of your utmost attention. It is true that undrained land, requiring drainage, such as heavy clays and spring soil, must undergo that operation before they can derive the benefit of such an application; but there are extensive tracts of chalks, sands, and hot gravels, almost praying to be fertilized by the sewage of our towns.

Although I apply my liquefied manure on the surface, I am quite convinced that, during the summer season and among the growing crops, it would be far more advantageous to apply it subterraneously, as effected by Mr. Wilkins. By this means, the openness and tillage of the surface is undisturbed; the rays of heat and light are employed in warming the earth, and eraporating from the leaves the subterranean supply of fluids which the plants absorb by their roots, and which arise to them by capillarity. The question is a large one, involving cousiderations of cost; but most certainly production is rastly increased and stimulated by the new method.

One important reason for the superiority of liquefied over solid manures, is, that water is the great arrester and conveyance of ammonia-that invisible and truant spirit which is ever escaping unseen from reeking dung-heaps. It is this ammonia which dissolves the silica of the soil, and makes the kernel of our wheat and the lean of our flesh; and it is for this ammonia that we so affectionately prize unwashed Peruvian guano or birds' dung. When you have learned to apply fluid manure to the soil, you will find your crops yield as much as they do after the sheepfold, and you will get corn as well as straw; that is, if you do not sow too much seed.

You must give up all hopes of obtaining town-sewage in a solid form, for Professor Way's paper, (which every agriculturist should read,) in the Royal Agricultural Society's Journal, and other evidences, are conclusive on that point.

Now, in railroad undertakings we find landed proprietors and other interested parties joining with town capitalists, and affording them every inducement and opportunity to open up a country with general benefit. Let the same be done with sewage. Depend upon it, without this co-operation no town capitalists will be so miscalculating as to place their capital at the mercy of local prejudice or neglect. It therefore remains with agriculture itself to determine whether this interesting question shall receive its proper solution. But supposing that the new company has laid down its main line of pipes for the country distribution, where will you find the $£ 3$ per acre for the network of iron pipes, \&c. requisite on every farm? It appears to me that, where the capital is required, it may be readily obtained from the Lands Improvement Company or Land Drainage Company, and that the annual charge which would liquidate principal and interest in a few years would leave a large margin of advantage for both landlord and tenant. To those who desire to see the mode of applying town-sewage may be quoted the instance of G. H. Walker, Esq., who takes the town of Rugby, \&c.; W. Worsley, Esq., near Manchester, who uses the sewage of a neighboring district. In both these cases steam-power is applied.

Of course, if the London sewage is used, I apprehend it would be pumped to elevated district reservoirs, whence it would flow from main pipes connected with smaller ones on the various farms, so that they would be always charged with a sufficient pressure to cause a jet; this would render unnecessary any steam-engine or tank on the farm. A register of quantity, 
like a gas-meter, would enable the conıpany to make their periodical charge. I annex the following statistical account, with which I have been favored by Edwin Chadwick, our greatest authority in such matters:-

The gross daily quantity of water pumped into the metropolis was, in the year 1850, fortyfour million gallons. The actual quantity consumed for domestic purposes, or that you could estimate for sewage as containing house refuse, or house-manure in suspension or solution, at times when there is no rain applicable as manure, would not be more than trenty million gallons per diem. I say house-manure, because rain and storm waters bring, as surface washings, dung from the streets, and soot and birds' dung from the roofs of houses. You may judge of the daily quantity visibly by the fact, that forty-five million gallons would be delivered in twenty-four hours by a brook nine feet wide and three feet deep, running at the rate of three feet per,second, or a little more than two miles per hour; and three sewers, of three feet diameter and of a proper fall, will suffice for the removal (for distribation) of the same volume of refuse or soil water. The total weight of this annual supply of water is nearly seventy-two millions of tons. The daily cost of raising the whole supply by engine-power one hundred feet high (for distribution) would be about $£ 25$, or $£ 9000$ per annum. Supposing the supply were equally distributed, $i$. e. the forty-four millions, it would be about fifty pailsful for each house, and would weigh about thirteen hundredweight.

Those who doubt the cheapness at which water can be raised may be assured by visiting the Croydon Water-works, where six hundred and fifty thousand gallons are forced to a mile distant, and elevated one hundred and fifty feet, at a cost of thirteen and a half hundredweight of dust-coal per diem of twenty-four hours. With regard to the mode of conveyance, it appears to me that our railway lines might be availed of to lay down lines of pipes; but, of course, all such questions would be easily arranged by competent engineering authorities. Perhaps it will be as well to state, that fifteen yards of three-inch iron pipe per acre will be all that is required, or about five and a half hundredweight of iron per acre. This is the quantity on my farm; I have one hundred and seventy acres piped. The value of London sewage has been variously estimated; but Professor Way has calculated it by its ammonia at two millions sterling. He has made no valuation of the water alone; I apprehend that fifty millions of gallons daily, or two hundred and twenty-four thousand tons, would have, even when unmixed with manure, a considerable irrigating value.

In order to ascertain whether this application of sewage will pay the farmer a profit, and leave a sufficient interest for the capital invested by a company, let us calculate seventy-two million tons of sewage, at one penny per ton, would be $£ 300,000$. Now, take the pumping or raising this quantity at the exaggerated sum of $£ 50,000$ annually, there would remain $£ 250,000$ as interest on the capital invested, which, at six per cent., would be also the exaggerated sum of $£ 4,000,000$ sterling.

I have assumed the sum of one penny per ton as representing that which would leave the farmer and landlord a very large profit on their pipe investment. I can confirm this by my own practical experience. But it must be obvious to any one who reasons, that, as one hundred tons of water per acre represents a rain fall of twenty-four hours, this alone, without the saturation of manure, must be worth one penny per ton, or $3 s .6 d$. per acre, and, indeed, in dry weather, for grass crops very much more. As to the quantity required per acre, Mr. Telfer, of Ayr, tells me that he applies five hundred tons of water per Scotch acre at five dressings to his Italian rye-grass, with five hundredweight of guano at each dressing, making a total annual application of twenty-five hundredweight of guano per Scotch acre, (onefourth larger than the English acre.) This is in a naturally moist climate: therefore, we may estimate the water-absorbing power of the barren sandy wastes in the neighborhood of the metropolis far more considerable. That those wastes would be rendered highly productive after the application of town-sewage cannot be doubted.

The experiments of Mr. Wilkins, who grew two crops of hemp and flax in one season, last year, settle the question. Now, if you apply five hundred tons per acre, you will only require one hundred and fifty-two thousand acres to absorb your seventy-six millions of tons. As six hundred and forty acres are a square mile, you would at that rate require two hundred and thirty-seven square miles, or a square area whose diameter would be about fifteen miles. 
I have a strong conviction that a very much larger quantity of sewage, say one thousand tons per acre, at least, may be profitably applied to our sandy, gravelly, and chalky wastes. This would afford a great economy in distance and expense. On the Edinburgh meadows as much as six thousand tons per Scotch acre are applied; but that appears to me hardly a necessary quantity. Still, if such large quantities could be applied to so limited an area, it is clear that, instead of one penny per ton, the cost need not much exceed one farthing. Six thousand tons, at one farthing per ton, would be $£ 6,5 s$. per acre. This would pay; for the average letting of the Edinburgh meadows to the cow-keepers was, I am informed, last year, £21 per acre-a pretty good evidence of the beneficial effects of town-sewage on waste lands that were, a few years since, worthless and barren.

I apprehend that no one will doubt the economy of transmission of fluids by tubes, seeing that by road-carriage the charge of carting near the metropolis would be, at least, eight-pence per ton, per mile. There is no fear of our being overwhelmed with cheap hay or superabundant milk by this process, for our wants become annually more and more gigantic. In conclusion, I do hope that this club of practical agriculturists will, by their resolution this evening, stamp their opinion of the necessity for this great national ecoumy.

\section{Subterranean Application of Liquid Manure.}

A Mr. Wrukiss has patented in England an ingenious plan for applying liquid manure directly to the bottom of the roots of plants, in the subsoil, instead of using it upon the surface of the ground in the usual way. There is but one serious objection to it-and that is its expensiveness, which is likely to prevent its general adoption. The liquid nanure is conveyed under the surface-soil and growing crops in tubes, not unlike draining tile, allowing a line of pipes to each row of turnips, corn, potatoes, or other agricultural plants. To avoid the loss of manure by its infiltration into the subsoil and deep earth, the whole area operated upon has the surface-soil removed to the depth of twenty or more inches, and the denuded surface is covered with water-lime, cement, or pounded clay, to render it impervious to water, when the surface-soil is restored to its former place. In all cases where the subsoil is naturally retentive, it would appear to be a needless expense to pave or cement it to prevent the loss of manure, however liberally it may be used; but, on all pervious land, something shonld be done to aroid the washing away of the liquid food of agricultural plants, where one manures highly.

Mr. Wilkins has pipes leading from liquid manure tanks that convey the fertilizer to the underground conduits, through which it is brought into contact with the rootlets of every plant under cultivation. The manure rises up to the surface of the tilled soil by capillary attraction. Care, of course, is taken not to have the liquid so strong as to injure any crop, and not to give the soil, which in truth lies in a tight basin, too much water for the healthy growth of plants. Mr. W. selected last season a piece of ground one hundred feet square, which he had prepared on his principle, and by the side of it he had one hundred feet square of the same kind of soil, which was treated on the old system. Both pieces were planted and sown alike, and he had advertised the day when the roots on both would be taken up, and invited the publio to come and see and judge for themselves. The results were, as reported in the London Agricultural Gazette, that on the prepared land the mangel-wurtzel grown was at the rate of sixty-nine tons two quarters and twenty-two pounds to the acre; the Indian corn grown on it ripened and came to perfection, but not on the unprepared piece; the potatoes were taken up in eleven weeks, and when weighed were found to be more than double the weight of those grown on the unprepared land; and one of the cabbages weighed sixteen pounds, although its stem remained in the ground, and had at the time of the examination fifteen young cabbages upon it. Mr. Wilkins exhibited some lucerne, which he said was the third cut, and contrasted it with the first of some grown on the old system. Remarkably fine specimens of flax and hemp were exhibited, grown by this new process. Only four inches of liquid was allowed to stand at any time at the bottom; and the soil above must be from twelve to eighteen inches. 
The leading idea is not to permit any element of fertility to escape, either by solar cvaporation or leaching and washing, but compel growing plants to absorb and assimilate the maximum of their appropriate food.

\section{Chinese Economy of Manure.}

A CORRESPONDENT of the London Literary Gazette gives the following memorandà respecting the economy of manures, as noticed in China:-

My first cxcursion was to a place called Gading, thirteen miles from Malacca, where I had permission to reside in a house occupied by some Chinese Christians, who are cultivating a gambir and pepper plantation. The house was a mere huge shed. I lived in it a fortnight, as, strange to relate, the Chinese (I trust because they were Christians) kept it clean. No people in the tropics really cultivate the soil as these do. They do not merely plant and reap; they dig and trench and levcl; they eradicate weeds and stumps; they keep the ground clean, and they manure. The process of manuring, indced, was the only thing I objected to, as the tank was a large bucket kept standing for conrenience in a corner of the house. The rage for liquid manure is such, that, in the Chinese villages, a bucket often stands near the door for public use. The pigs, for the same reason, are far better lodged than with us, having a floor of poles with a tank beneath, in which all the manure is collected.

\section{Mr. Mechi and Tiptree Hall.}

ALu have heard of Mr. Mechi, the celebrated English agriculturist, and of Tiptree Hall, where his experiments in farming have been carried on; but few are acquainted with the history and details of this gentleman's experiences. We derive the following abstract from the correspondence of the New York Tribune:-

Americans, who may have known London twenty or five-and-twenty years ago will rcmember a constant affix to the dead walls of the metropolis- "Mechi's Magic Paste."

This, in time, was succeeded by "Mechi's Magic Strop" and "Mechi's Magic Razor," until at last these articles, by constant puffing and advertising, bccame of almost universal use throughout Great Britain. As the result of his enterprise and tact, Mr. Mechi became possessed of no inconsiderable wealth, a portion of which he resolved to devote to agricultural experiments, still retaining his shop in town.

Although the advertising of Mechi's articles had, in a great measure, ceased, it was impossible that a keen and enterprising man of this sort could be entirely forgotten. It was not his character to allow himself to sink into oblivion together with his paste. After the decline of that commodity, some time elapsed before Mr. Mcchi again turned up; but when he did turn up, he turned up with a vcngeance! It was during that exciting period when "free-trade" was agitating the minds of Englishmen and threatening to produce a revolution in the nation, that Mr. Mechi again came before the public. The scene was the House of Commons ; the hour, twelve at night. Ministerial and Opposition benches were thronged; the gallcries secmed rcady to sink under the mass of "strangers" crowding into them. "Ilear! hear!" was most vocifcrous; "Oh! oh!" unusually sarcastic. Amid a volley of both, some "honorable member" had just sat down, when, amid a silence as profound as death, up rose Sir Robert Peel. That great statesman commenced, of course, in his blandest tones. He touched lightly on the theme by the last speaker; he treated tenderly two or three salient points which had occurred in the debate; and, after eliciting a cheer or two from those who sat around him, came at once to the topic of his speech.

He wanted that night, he said, to address himself to the agriculturists of England. He desired to tell the landlords to their faccs that the science of agriculture in this country was most imperfectly understood. England, he wanted to impress upon them, was at least a quarter of a century behind the age in agriculture, and would be outstripped even by Russia, if we did not speedily adopt new methods. It was his opinion that, in many respects, the English farmer had the very A B C of cultivation yet to learn. [At such an assurance as 
this, I need not tell you how great was the astonishment. It became greater as Sir Robert Peel continued.] Within a very few days past he had visited, at no great distance from the metropolis, a model farm. [A sareastic cry of $\mathrm{Oh}$ !] Yes, a model farm, from which the agricultural member who cried "Oh!" might take many a useful lesson. It was the farm of $\Omega$ well-known citizen of London-of a tradesman of great enterprise and of considerable property; but of one, be it observed, who had not been used or accustomed to farming, and who was yet able to teach English agriculturists a lesson in agriculture. Upon a barren heath Mr. Mechi had planted a model farm; and such were his improved methods of cultivation, of draining, of manuring, and of subsoil plowing, that upon that barren heath there stood at that moment the rery finest crops throughout the length and breadth of Britain. He admonished country gentlemen that new methods of cultivation had been too long neglected. He warned them that, instead of being before the rest of the world, they wern lamentably bchind it. He cautioned them to take care lest they were outstripped as farmers by peoplc of whom they appeared to entertain much too light opinions. And the text from which he preached throughout was this same farm of Mr. Mechi, of which nobody, before that day, had ever heard; but which, from that day and long after, became the battle-field on which protectionists and frec-traders, corn-law men and anti-corn-law men, fought many a heavy fight of words, both bcfore Parliament and the people. "The Modcl Mechi" and "Mechi's Model Farm" bccame the watchwords of one party, while by the other the dictionary of the English language was dissected for every defamatory and disparaging dissyllable the dialect afforded to designate Mechi as disgracefully as they desired us to decm that he descrved.

Since all this occurred, eight or ten years hare run their course. Free-trade has become the law of the land; the averments of Sir Robert Peel as to the backwardness of English agriculturists have been recognised as partly, if not wholly, true; and Mr. Mechi, who held his course complacently while the tempest howled around him, now enjoys the favoring gales and gladdening sunshine of a prosperous carcer. I need searcely tell you that ho is what he always was. It is the world that has changed-not the man. But Mr. Mechi knows (no one better) how to turn the changes and chances of the world to account, and I will proceed to tell you how he now applies his knowledge.

Once every year, just at the close of the London senson, when every one in town is sighing for a brcath of country air, just before the commencement of the harvest, Mr. Mechi has an "agricultural gathering" at Tiptree Hall. To this gathering are invited all the notabilities of the day. Farmers, imitators, and admirers, all turn out to see "Mechi's Model Farm." To these, collected at his hospitable hall, Mr. Mechi proceeds to show his improvements. He walks them over his fields and through his stock-yard; he expatiates upon his difficulties and explains his improvements; he discourses on his crops, exhibits his machincs, lectures learnedly on his manures, shows how he distributes them, and when the party have acquired sufficient information and astounding appetites, he concludes the day by setting them down to a banquet, such as a Londoner alone knows how to manage.

As a place of country-resort, Tiptree Hall has few attractions. Situated on an elcvated, bleak, and barren heath, without a tree within a mile of it larger than a laurel, it boasts not a single rural bcauty, such as we regard rural beauty in this country. Mr. Mechi has made a great effort to compensate for this by artificial gardening; but though every thing has been done that a cultivated taste and a lavish expenditure could effect, yet the result, as a whole, is eminently unsatisfactory. Terraces and embankments have been thrown up to relieve the flat monotony of the landscape; a bog has been converted into a series of little lakes; walks of every possible variety have been wound around plantations; tender shrubs have been planted and effectually reared on spots where Nature never intended that a shrub should grow; flower-beds have been laid out with all the elaboration of which the Italian style of gardening is susceptible; color has been properly introduced where nothing was to bc seen but drab-colored heather; but still the result is unsatisfactory. The place, in fact, as a retreat, has no capabilities. Nature has predetermined that there shall be about it none of the specialities of an English farm, and Nature has yet, in this respect, becn too strong for man.

But what of Tiptree as a "model farm?" Is it what it professes to be? Is it what Sir 
Robert Peel described it? Is it an example which the farmers of the world may advan. tageously consult and imitate? Now, as to this point, I must frankly say that my notions are poised so very equally in my mental scales that I am unable to give a distinct or satisfactory reply. I have seen better things in farming than Tiptree Hall, many better things; but while I declare this, I must also acknowledge that I never satw so remarkable an example of what industry and enterprise may accomplish under the most unfavorable circumstances. Certainly no one but a man accustomed to get sharp edges from the collision of steel and stone ever would have thought of trying to cultivate such a place at all. One would fancy that Mr. Mechi had taken up an idea from his shop that you could get a good crop out of stones as well as a keen edge. You should have heard his own account of what Tiptree Farm was when he came there! "Vainly," said he, "did I try by solid manures to render this vile, plastic clay a useful pasture. It was like bird-lime in winter, and like cast-iron in summer. Poor, indigenous, and drab-colored grasses choked and eradicated the finer kinds I bad sown, and the animals wandered about hollow and dissatisfied. Now, fine and fattening grasses clothe the fields with perpetual verdure, the land keeps three times as many animals, and the close and shaven pasture indicates their affection for it." And this description of Mr. Mechi's pasture is a fine description of his whole farm. Where the drab-colored grasses were alone seen ten years ago, crops of the finest wheat, barley, and oats now clothe the wold and greet the sunshine as it merrily glances from the heavens. Every one admits that there can be no finer crops. They are grown from very small quantities of well-selected seeds; but these small quantities, under Mechi's system, seem to be more productive than large quantities anywhere else.

How, then, have these results been produced? The answer is simple. By deep drainage and liquid manures, regardless of expense. Mr. Mechi's knowledge of chemistry taught him that the worst soil might become better by allowiag their pores to be fermented by the sweet rains of heaven. Every clod in the hard clay at Tiptree was choked by stagnant water. He drew it off by deep drainage. Then the plow let in life and light upon heaps of earth which had never felt the influence of either. Still, though the land was broken upthough from a hard, cold clod of clay it had been converted into a dry mould-still it was poor and needy. Mr. Mechi's next application to it was, accordingly, intended to give it strength and heat. By means of pipes carried all over the estate, liquid manure was laid on freely wherever it seemed to be required, and the ground soon showed how much it was strengthened, and how much it was disposed to give a grateful and hearty acknowledgment of the favor conferred upon it.

In bygone times, it used to be a great joke with the farmers to ask Mr. Mechi where was his "balance-sheet?" You may grow a crop upon one of your own razors, was the argument, but what will it cost you? For many years, while the price of wheat was low, Mr. Mechi was compelled to acknowledge that he had invested more in the soil than the soil returned him. But things have now changed, and Mr. Mechi retorts the joke upon the farmers. "It is not," says he, "the man who farms with the least expense who makes the most money. When prices were low, and labor was low, I invested large sums of money in the land; now that prices are high, I invest no longer, but I reap the benefit of my investment at low prices. My fields produce more than yours; my returns are, consequently, greater than yours. And it is the result of investment in improvements at periods when improvements can be made at low rates of wages." Such are the arguments of Mr. Mechi. They are, to a great extent, of world-wide application.

Mr. Mechi held his annual gathering in July of the present year, 1855, as usual-some three hundred farmers, savans, and statesmen being present. Mr. M. stated that he realized $\$ 3500$ from Tiptree last year, and that his balance-sheet can no longer be considered unsatisfactory. Stock, which is at present unprofitable to feed, is not kept by him in any great quantity. Several of his largest sheds are empty-pigs and bullocks in diminished numbers, and the sheep in the fields.

Mr. Mechi does not like looking behind him. He seems afraid of the fate of Lot's wife, if he did so; and therefore, once a principle is conceded and successfully illustrated at Tiptree and other model farms, he leaves contentedly to time its full realization over the face of 
the country. While the bulk of English agriculture still struggles to arrive at deep draining and deep disintegration of the soil, at clean fields, liberal manuring, and the clearing away of useless hedgerows and trees; while it is still miles away from such elaborate applications as that of liquid manure by underground pipes; and while the use of steam in any form is still very exceptional,-Mr. Mechi and his coadjutors are looking forward confidently to steam drainage and steam cultivation. A machine, invented by Lord Dundonald, was exhibited for the accomplishment of the former object; and, though the trial was not carried to a sufficient extent to enable a very confident opinion to be formed on its merits, its ingenuity and simplicity of construction were readily acknowledged by some of the most practical men present. To bring about steam cultivation, a very pretty little working model was shown. This model went up a steep embankment, along a rough road, turned in different directions with great ease, and dug away with its spades in soft garden mould. It appears to be rather complex in its parts, and otherwise open to objection; but, taken in connection with other recent improvements, it must be admitted that Mr. Mechi has fair grounds for his conviction that we are brought close to the application of steam-power to the cultivation of the soil. Toward this result the mechanical treatment of the land, in the best-farmed districts of England, has been long tending, and the Royal Agricultural Society has at length acknowledged the want by inviting the attention of inventors to it in their prize-list.

\section{Draining of Lake Fucino, in Italy.}

ONE of the most gigantic operations, involving drainage, is now in progress at the Lake Fucino, or Celano, in Sonthern Italy. This lake is about eighty miles east of Rome and one hundred and ten north of Naples; and, being surrounded by the highest $A$ pennines, is, as it were, the reservoir into which fall all the rain and melted snows which flow down from its gigantic neighbors. From the effectual manner in which it is enclosed on all sides, there is no natural outlet for its waters, and thus it happens that an immense space of land is submerged; a yet larger space is continually threatened by the possible rising of the body of the lake; much land and eapital have been lost; and the inevitable consequence would be, that capital would be completely withdrawn, and what might be made a garden would become a desert. Yet, notwithstanding these uncertainties and dangers, such is the fertility of the soil, that a population always springs up in its immediate neighborhood, just as it does on the ashes of Vesurius. The object of the present undertaking is not merely to drain the lake, but to form a channel of communication with the Liris, whereby all future accumulations of water may be carried off.

The attempt to drain this lake is not altogether a new one. Julius Cæsar intended to have it drained, and might have done so, had it not been for his death. Claudius was the next emperor who undertook the work, and that, too, in good earnest; "not merely for profit," says Suetonius, "but for glory." It is interesting to observe that the mode of completing the enterprise was similar to that now adopted. Certain persons offered to drain it at their own expense, provided the land redeemed was conceded to them. Partly by tunnelling, and partly by cutting the mountain, he, with difficulty, completed a canal, after working eleven years incessantly with thirty thousand men. Pliny, speaking of it, says-"Among the great works of Claudius especially deserving of notice, though destroyed by the jealousy of his successor, was the tunnelling of a mountain to carry off the Lake Fucinum; * * and all was done in the midst of inner darkness-facts beyond the conception of all, except of such as have seen them, and incapable of being described by him in language." The praise is not too great, when we consider the low state of science which marked that age, and the want of powder. All the details of the outlet were not completed, however, by Clandius; and Nero, so far from finishing them, suffered it to fall into ruins. Adrian repaired it. From that time, or from the fall of the Roman empire, up to the thirteenth century, this grand public work experienced the same fate with all other public monuments in Italy. Frederic the Second, in 1240, Alphonse the First of Arragon, and Prince Colonna, at the beginning of the seventeenth contury, made several efforts either to drain the lake or to limit its ravages; all of which, from various reasons, failed. . Under the reign of Charles th 3 
Third, the waters of the lake became so low that the remains of Marruvio, one of three submerged cities, were discovered, and all sense of danger passed away; but, from 1783 to 1787 , the floods returned yet stronger than ever, and wholly destroyed the fertile lands in the neighborhood. From that time till now, various plans have been presented, adopted, and begun, though for several reasons suspended. The work is now, however, it is to be hoped, in a fair way of being completed, having been undertaken by a French company. The commencement of the operations will be upon the old tunnel of Claudius, which is incomplete, and is sixteen feet below the lowest part of the bed of the lake. Its actual height is from seven to fourteen feet; but it is now proposed to enlarge it to the height of twenty feet, and sixteen feet in breadth. When completed, a dain is to be erected at the mouth of the tunnel, with a number of sluices at different levels. The highest sluice will be opened, which will carry off the first few feet of the surface water. While these works are in course of execution, dredging machines are to be used, with the view of clearing a canal for the sluices to the deepest part of the lake. The sluices will afterwards be removed, one after another-one only remaining in permanence to regulate the flow of the water into the tunnel. To this must be added, that the formation of a reservoir, as a temporary recipient for rain or river water, enters also into the plan of the company. In this way modern science and enterprise will triumph over obstacles which Nature has ever interposed to the cultivation of a vast tract of land, and will complete a work which was designed so far back as the time of Julius Cæsar. There is this difference, however, that, whereas the ancient plan contemplated only the limiting of the inundations of the lake, the actual plan attempts the complete drainage of it. Of enterprises of this character, it is said to be the grandest that has ever been undertaken. Lake Haarlem, in Holland, extended, indeed, over a larger area; but it was not so completely drained as the lake of Fucino will be. A few words now as to the benefits arising from this mighty operation. Thirty-three thousand acres of the richest soil will be reclaimed, which become the perquisite of the company. This is not all, however; for an end will be put to the uncertainty and insecurity which arise from the periodical rising of the lake, and which forbid the employment of capital on land which may be submerged the next season. This probability, or possibility, depends on a curious feature in the natural history of the lake. This is the sudden rises in the water-level to which the lake is subject, the causes of which have never been explained, though speculation has been busy. The variation in its level, within twenty years, has amounted to so much as forty feet, it having been, in 1816, higher, by forty feet, than it was in 1835. Since that year, it has again been gradually rising, until it has now risen twenty feet higher than it was in 1835 . These are no slight variations, and prove how much danger attends the cultivation of the land bordering the lake for a considerable space. Strabo, in a note which I quote from Suetonius, alludes to the yet greater height to which the waters attained in his days, and suggests an explanation of the cause similar to one which has been adopted in the present day. It is a most curious question. One favorite theory of the present day, though without any facts to support it, is as follows:- There is a certain drainage area belonging to the lake; but a considerable belt of high ground above it has no drainage at all. It is suggested that, in the winter-time, with a prevailing wind from one direction, the streams are carried toward the lake, increasing its bulk and its height. With a contrary wind, these streams are carried off, and a corresponding diminution ensues. Another theory is, that there are fissures in the rock whereby the water escapes; that by some causes these fissures are closed; that during other years these fissures are again opened, and the water flows. The drainage of the water, it is supposed, leaves sand and earth, which choke up these fissures; that the water consequently rises, and, when high, bursts through and finds for itself a channel. Whichever theory be right, or whether either, it is clear that an immense benefit will be conferred by the drainage of the lake, not merely by the restoration of much land that is constantly submerged, but by giving security to the proprietors in the neighborhood. Nor is this vast undertaking without great interest to the antiquary. Three cities and a large number of country-houses, have, at various periods, been swallowed up by the waters of the lake. History preserves the names of these three cities-Valeria or Marruvium, Penna, and Archippus - which contain a treasure of antiquities perhaps not less precious than that of Pompeii. In 
the reign of Charles the Third, about the latter end of the fourteenth century, the waters of the lake fell so low that the ruins of the ancient Valeria were exposed to view. The statues of Claudius, of Agrippinn, and of Nero, were found there, and now adorn the Palace of Caserta. Among other objects, have recently been discovered the ruins of a house on the borders of the lake, and a large stone bearing an inscription, on which is recorded the name of a freedman of Tiberius Cæesar. The curiosity of the antiquary will, therefore, be now especially directed to the lake of Fucino.

\section{On the Collection and Preservation of Liquid Manure.}

A CORREspondext of the Journal of the Royal Agricultural Society, England, describes the following method adopted by him for the collection, preservation, and distribution of liquid manure. He says-

Knowing something of the value of urine, and the profit to be derived from it, I am the more anxious to induce others to try it, and will, therefore, take this opportunity of saying something about the mode $I$ have adopted to collect it, and the expense of the tanks to retain it, which may be useful to those who have not yet set about so important an operation in agricultural pursuits.

My land is clay, two hundred and fifty deep; in this soil only have I had experience, so for this only do I prescribe. Having well considered where the liquid is to be used, as well as where it is to be made, and resolved upon the most convenient situation, I have a hole dug full seven feet in diameter and twelve feet deep, the bottom being shaped like a basin, and well rammed, with a little water, into a good puddle. The construction of the tank is commenced by the bricklayer forming a circle with bricks (four-inch work) round an opening of five feet, leaving a space behind the brick-work to be filled and rammed well in with claypuddle by the laborers as the building is worked up, no mortar being used with the bricks, or any thing else till the dome is to be formed; mortar or cement is then required, the roof is then arched in, a man-hole left in the centre of each tank, and covered with a three-inch yellow deal cover, (two-inch oak would be better.) One of these tanks, containing one thousand gallons, cost £2 17. 6d., (about \$14.)

Several of these tanks should be made adjoining each other; they then form a most excellent filter to keep back any hay or straw that would prevent the egress of the liquid from the water-cart, receiving it into the first from the stables, and pumping it out from any other one of them. It must be observed, also, the tanks being formed, the drainage into them is the next feature to be considered. I have adopted a mode economical and effectual, by laying down in the parement what is called at the iron-works an angle-iron gutter of very small size, and covering the surface of it with a flat iron bar, just to lie within the surface of the gutter, wherein all the urine is received and conveyed away immediately, and all the straw, dung, and dirt is kept out. This is highly advantageons, as the urine is conveyed away immediately, without escape of ammonia, and the little gutter may be uncovered as often as you please, and swept out with a broom. There is no under-drain to get stopped; all can be seen and kept in order by a commonly useful person, without the aid of what is called a tradesman. I should like to see three of these little gutters down a stall, whereby all the urine would be canght; three gallons per day from each moderately-sized horse, more from cart-horses that drink freely, considerably more from cows, and a much larger quantity from pigs than is usually calculated. If all the water is caught from farm-horses, cows, pigs, farm-servants, and household-people, the tanks would be filled very quickly; and, whenever the tank containing one thousand gallons of urine is filled the second time, and properly applied to Italian rye-grass, the result will show it is not too high an estimate to calculate the tanks and drains paid for. The first application will convince the grower of ten acres of this grass, that his present stock is insufficient to eat it. He must add to it, and thereby increase the quantity of urine considerably, and so go on to keep a much larger farming stock altogether. The often-asked question, "How shall I obtain urine enough ?" will cease to be asked, and the amount of solid fæces so much increased as to obviate the necessity for a constant outlay of capital to procure it." 


\section{Liquid Manure for Plants.}

FEw things, in the management of plants, are more overlooked than that of applying liquid manure. When the roots of plants are confined within a garden-pot, the soil soon becomes exhausted; and, if it be desirable to grow the plant rapilly, it must be turned out of the pot, and the exhausted soil shaken from the roots, and replaced with fresh earth, or recourse must be had to liquid manures. Floriculturists cannot be aware of the advantages of applying manure in a liquid state, or it would be more frequently used. I have found that all free-flowering plants, such as petunias, geraniums, some of the calceolarias, balsams, and cockscombs, are improved; and, indeed, I have not found any flowering plant whatever that has not been benefited by a greater or less quantity of this element. In watering plants with liquid manure, it will be observed that the soil, after having been watered a few times, does not dry so soon as when watered with clear water, and this independent of the extra nutritious qualities left in the soil by the application of manure-water; it is, then, a great point gained, by whatever means effected, when plants, whether in pots or in the natural soil, can be cultivated without the necessity of frequent waterings. As there is no more labor required in using manure-water than in applying the same quantity of water without any mixture of manure, considering, too, that its advantages must be obvious to all who give it a fair trial, it does seem somewhat unaccountable to see persons exerting a great amount of labor to accomplish very small results. It must be regarded as so much labor misapplied, when, had half the same labor and attention been bestowed, using at the same time liquid manure, far more satisfactory results would have been obtained.-Floricultural Cabinet.

\section{Manuring Fruit-Trees.}

THE Dutch, who are admirable gardeners, had, in the great London Exhibition, an instrustrument called "Earth-Borer," for manuring fruit-trees without digging the ground. A circle of holes is bored around the tree at two feet distance from the tree, and a foot from each other. Taking the tree at a foot diameter at the surface of the soil, the circle will be five feet in diameter and fifteen feet in circumference; and, if the holes are three inches diameter and a foot apart-fifteen inches-there will be about twelve holes, more or less, according to the diameter of the tree. They are eighteen inches deep, (where there is enough depth of soil,) and slanting towards the centre; are filled with liquid manure, diluted more or less in dry weather, and stronger as the weather is damper. For the time of application, Dr. Lindley tells us-" For fruit, the proper time for using liquid manure is when the fruit is beginning to swell, and has acquired, by means of its own surface; a power of suction capable of opposing that of the leaves. At that time, liquid manure may be applied freely, and continued from time to time as long as the fruit is growing. But, at the first sign of ripening, or even earlier, it should be wholly withheld. If liquid manure is applied to a plant when the flowers are growing, the vigor which it communicates to them must also be communicated to the leaves; but when leaves are growing unusually fast, there is sometimes a danger that they may rob the branches of the sap required for the nutrition of the fruit; and, if that happens, the latter falls off. And we all know that, when ripening has once begun, even water spoils the quality of the fruit, although it augments the size, as is sufficiently shown by the strawberries prepared for the London market by irrigation; great additional size is obtained, but it is at the expense of flavor; and any injury which mere water may produce will certainly not be diminished by water holding ammoniacal and saline substances in solution."

\section{Covered and Uncovered Manures.}

THE following is an abstract of the result of some experiments on the comparative value of covered and uncovered manures, recently made by Lord Kinnaird, of England, and reported in the Journal of the Royal Agricultural Society of England for 1854 :-

In 1851, a field of twenty acres, of very equal quantity, being a rich loam naturally dry 
and in good heart, with an exposure to the south, was selected for the experiment, and divided into two equal portions. The manure was applied at the rate of twenty cart-loads per acre.

The whole field was planted with potatoes; the seed all of one kind, and planted the first and second week in April. All braided well and showed no difference in growth till the first week in July, when a decided superiority began to manifest itself in the half of the covered yards. The vines on the portion of the field manured from the exposed yards began to decay by the latter end of July, while the other portion of the field still retained its dark-green. The crops were taken up on the 1 st to the 4 th of October, and, after careful measurement, and weighing of two separate portions in each division, the result was as follows:

\begin{tabular}{ccccc}
\multicolumn{5}{c}{ With Uncovered Manure. } \\
Measurement. & \multicolumn{2}{c}{ Tons. } & Cwt. & lbs. \\
One acre produced & 7 & 7 & 6 & 8 of potatoes. \\
do. do. & 7 & 18 & 99 do. \\
\multicolumn{5}{c}{ With Covered Manure. } \\
Measurement. & \multicolumn{2}{c}{ Tons. } & Cwt. & lbs. \\
One acre produced & 11 & 17 & 56 of potatoes. \\
do. do. & 11 & 12 & $20 \quad$ do.
\end{tabular}

As soon as possible after the potatoes were harvested, the field was plowed and wheat drilled in, at the rate of three bushels per acre. As soon as the weather was suitable in the spring, the whole field got a dressing of three hundredsweight of Peruvian guano per acre. During the winter, very little difference was apparent; but, shortly after the application of the guano, the wheat on that portion manured by the covered dung took a decided lead, which it retained all summer. The whole field was cut on the 26th of August, 1851; the portion manured by the uncovered dung being at least four days earlier than the other. As before, the two separate portions in each half of the field were measured, cut, and stacked separately. On the 4th of September, each portion was thrashed, the grain carefully measured, and the straw. On account of a wet season, the grain was lighter, weight than usual, in Great Britain, per bushel. The result of the experiment was as follows:

\begin{tabular}{lcc}
\multicolumn{3}{c}{ Product in Grain. } \\
Acre. & Bushel. & lbs. \\
1st & 41 & 19 \\
2d & 42 & 38
\end{tabular}

\begin{tabular}{ccr}
\multicolumn{3}{c}{ Product in Grain. } \\
Acre. & Bushel. & 1bs. \\
1st & 55 & 5 \\
2d & 53 & 47
\end{tabular}

With Uncovered Manure.

Weight per bushel.
lbs.
$61 \frac{1}{2}$
$61 \frac{1}{2}$

With Covered Manure.

Welght per bushel.

lhs.

71
Product in straw.
Stones. lbs.
152 of 22
160 of 22

These and similar experiments have satisfied Lord Kinnaird of the advantages to be derived from having farm-yard manures put under cover.

\section{On the value of Gas-lime for Agricultural purposes.}

GAS-Line differs from ordinary lime only in consequence of having imbibed, during the purification of the gas, sulphuretted hydrogen and more or less ammoniacal salts. In numberless instances it has been used with great advantage in compost heaps. In the neighborhood of Edinburgh it has been extensively employed by some of the most spirited farmers. Formerly it used to be given for the carting away; but now it is sold at $3 d_{.}$a ton, and the demand is greater than can well be supplied. Some farmers, who have applied liberal dressings, state that the succeeding crops have been better than after the ordinary applications of farm-yard manure; others affirm that, compared with newly-burned lime, it is, in every respect, superior. In Glasgow, the refuse lime is sold at from 1s.6d. to $2 s .6 d$. a ton. Some have applied it to red land, like caustic lime; but it will be found much more profitable to compound it with earth, peat, couch-grass, or other vegetable matters. The ammoniacal water of gas-works, in large cities, is generally used in chemical manufactories for the preparation of commercial ammonia; but in small works, in country villages, it is often 
thrown out with the tar. It is a most valuable fertilizer, containing, in some cases, as much as one and a half pounds of sal-ammoniac in the gallon. It may be used to promote the fermentation of peat or couch-heaps, or may be mixed with any earthy or carbonaceous composts. In England, it has been used, in some cases, in conjunction with saw-dust, and gave very beneficial results. If applied to grass-land in too large quantities, it is liable to scorch the surface; but, diluted, it produces fine, dark-coloured herbage. The lime-water of gas-works is also a potent fertilizer; but hitherto it has been little used. The lime employed to purify the gas is, to a certain extent, liouified ; and, after considerable evaporation, a quantity of fluid, somewhat viscid, and smelling strongly of hydro-sulphuret of ammonia, is run off to an underground tank. This lime-water, about five hundred tons of which are annually produced at the Edinburgh Gas-Works, has hitherto been given for the carting away. One or two farmers have used a. good deal of it; but very large quantities are still allowed to run to waste. If mixed with bibulous substances, more especially if they are capable of being fermented, an excellent compost for use, along with other manure, will be produced. Gas-tar may also be employed in a similar manner with advantage, only it is necessary to use it rather cautiously and along with other substances, or it may injure the crops to which it is applied.-Transactions of the Highland Agricultural Society, Scotland.

In regard to the value of gas-lime, great difference of opinion exists among American agriculturists. Much of the gas-lime, as it comes from the purifiers, is in the state of hyposulphite of lime, most of which, by exposure to air, moisture, and vegetation, passes into sulphate of lime, (gypsum.) Some carbonate is also undoubtedly formed. So long as the lime remains a hyposulphite, its value for agricultural purposes cannot be very great. The hyposulphites, as is well known, are all depilatories or hair-removers. The depilatory powders sold by druggists are compounds of this character. We have heard of an instance where a gentleman farmer added fresh gas-lime to his hog-pen, with the intent that the swine should incorporate it with the compost-heap. This was effectually accomplished; but at the expense of the bristles and hair of the hogs, which was, in a great measure, removed during the operation. The editor of the Horticulturist, who has a poor opinion of it, says: Some years ago we were informed, by a very intelligent gentleman near Toronto, that it was not worth hauling two miles; that they had tried it to their entire satisfaction; yet it might be valuable elsewhere or under other circumstances. We have seen an analysis by Professor Johnson, in which he found in one hundred and twelve pounds fifty-six pounds of water, twenty pounds of carbonic acid, and thirtysix pounds of lime and sulphur. This thirty-six pounds is about the same as gypsum, and is all we should consider of any particular value.

Dr. Ure, the celebrated chemist, has described it as "vile refuse, which should be buried many fathoms deep in some barren region; for, when spread on the farmer's field, after discharging sulphuretted hydrogen with vapor of prussic and other malignant gases, its sulphur gets oxygenated into sulphurous acid-two volatile products alike detrimental to plants."

The following is a paper on the use of gas lime, by J. F. W. Johnston, of England:-

Refuse Lime of the Gas Works.-This refuse lime consists of a mixture of carbonate of lime with a variable quantity of gypsum and other salts of lime containing sulphur, and a little coal-tar and free sulphur, the whole colored usually by a little Prussian blue. The following table exhibits the composition of two gas-limes which have been analyzed in my laboratory from Edinburgh and London. The first two columns show what they were when sent to me; the second two, what they will become after long exposure to the air, after being made into compost, or after being, thoroughly and for a length of time incorporated with the soil.

This table shows that these gas-limes differ much in composition, especially in the proportions of sulphur or of the acids of sulphur they contain. This arises chiefly from the kind of coal which is employed in the manufacture of gas in different works.

The most marked difference between the two samples here analyzed is in the compounds called sulphite and hyposulphite of lime. The latter of these substances dissolves readily in water, and its presence in such very different proportions satisfactorily accounts for the very different effects which have followed from the application of gas-lime to the land in different districts. The rains dissolve the hyposulphite and the sulphuret, and carry them down in 
Composition of Gas Limes.

\begin{tabular}{|c|c|c|c|c|}
\hline t & \multicolumn{2}{|c|}{ As they are. } & \multicolumn{2}{|c|}{$\begin{array}{l}\text { As they will } \\
\text { become. }\end{array}$} \\
\hline & Edinb. & Lon. & Edinb. & Lon. \\
\hline Water and coal-tar ... & $12 \cdot 92$ & $9 \cdot 59$ & $12 \cdot 91$ & $9 \cdot 59$ \\
\hline Carbonate of lime............. & 69.04 & $58 \cdot 88$ & $67 \cdot 39$ & $56 \cdot 41$ \\
\hline Hydrate of lime...................... & $2 \cdot 49$ & $5 \cdot 92$ & $\ldots \ldots$ & .......... \\
\hline te of lime (gypsum)............... & $7 \cdot 33$ & $2 \cdot 77$ & $16 \cdot 35$ & $29 \cdot 32$ \\
\hline d hyposulphite of lime...... & $2 \cdot 28$ & $14 \cdot 89$ & ............. & ............ \\
\hline Sulphuret of calcium .................... & $0 \cdot 20$ & $0 \cdot 36$ & (......... & (.......... \\
\hline Sulphur ..................................... & $1 \cdot 10$ & 0.92 & .......... & $\ldots \ldots \ldots$ \\
\hline Prussian blue ... & $2 \cdot 70$ & $1 \cdot 80$ & $2 \cdot 70$ & $1 \cdot 80$ \\
\hline $\begin{array}{l}\text { Alumina and oxyd of iron................. } \\
\text { Insoluble matter, (sand, \&c.)........... }\end{array}$ & 0.64 & $\begin{array}{l}3 \cdot 40 \\
1 \cdot 29\end{array}$ & 0.64 & $\begin{array}{l}3 \cdot 40 \\
1 \cdot 29\end{array}$ \\
\hline & $98 \cdot 69$ & $99 \cdot \$ 2$ & $100^{\circ} 09$ & $101 \cdot 81$ \\
\hline
\end{tabular}

too great quantity to the roots of the young corn, and hence the complaints of some that the gas-lime has killed their wheat, while others have found, when applied as a top-dressing in a similar way, that it greatly improved their crops of corn. Unless its composition be satisfactorily ascertained, therefore, - unless, for example, it be found that water dissolves very little of it,- - there will always be a degree of risk in applying it directly to the land while any corn crop is growing. There may not be the same danger in putting it between the turnip or potato drills, and afterwards riaging up the land in the way that quick-lime is applied in many districts. To fallow land, howrerer, to laud which it is intended to reclaim, and especially to mossy land, the Scotch varieties at least may be applied directly with safety aud with great benefit. In the neighborhood of Paisley it is in constant demand for the improved moss land, and sells at about 18. $6 \mathrm{~d}$. a cart-load.

But those varieties which contain the largest quantity of the soluble hyposulphite of lime also form at last the largest quantity of gypsum. Thus the Edinburgh lime analyzed would never come to contain more than seventeen per cent., but the London lime might eventually contain as much as thirty per cent. of gypsum. This suggests the propriety, therefore, of laying it on and harrowing it slightly in some months before any crop is sown, -in the spring, for instance, before the turnip sowing, - or of making it into composts, perhaps the best and safest method of all.

This lime ought in no case, if possible, to be wasted; and from what has been above stated, it appears that it may always be safely used-

Directly upon mossy land, upon naked fallows, and in spring when preparing for the turnips.

In composts, in which, by the action of the air, the whole of the soluble salts of lime will have a tendency to be converted into gypsum, and consequently the benefits which result from a large application of gypsum will be obtained by laying such composts upon the land. As it appears usually to contain only a small proportion of caustic lime, it may be with safety mixed at once with the manure, though not in too large quantity. It may also prove a valuable admixture with guano, on which its action will ultimately be to fix rather than to expel the ammonia.

Strewed sparingly over the young braid, it is said to prevent the attacks of the turnip-fly, and harrowed in in considerable quantity, when the ground is naked, slugs and vire-worm disappear before it. The action upon this last pest of the farmer will probably be greatest when the soluble hyposulphite is largest in quantity. If as dry as the specimens of which I have given the analysis above, the gas-lime is worth to the farmer, at least, one-half as much as an equal weight of quick-lime.

If applied in too large quantity in this way, however, it is sometimes injurious to the young corn crop, which has not time to recover from its effects till much of the season of early growth is past. But grass land, though at first browned by the application, soon recovers, and repays the cost of application by a greener and earlier bite in spring. 


\section{Nascent Manures.}

THe following article on the above subject has been published by Dr. David Stewart, Chemist of the Maryland State Agricultural Society:-

Reasoning from analogy, all manures must be presented to the plant in the nascent state, in order to their assimilation; but a safer proposition, perhaps, would be, that many elements of plants, while they exist in their normal or natural condition, are as perfectly unassimilable, or as incapable of affording nourishraent to them, as they are to animals. A hundred illustrations of the law will at once occur to every intelligent mind; and the facility with which even inorganic compounds unite while in the nascent form is familiar to all. Every molecule of matter, whether composed of compound or simple atoms, seems to have a form of its own, and until it has assumed this form, or state of aggregation, it is in the nascent state, or in an allotropic condition. While in this nascent state, its tendency to unite with other bodies which have an affinity for it is wonderfully increased; indeed, it is often the only condition in which two substances will combine. Lime and magnesia, when recently slaked, are capable of uniting more freely with other substances; if, however, the slaked lime or magnesia is kept for a long time, even although perfectly excluded from the air, it will gradually assume the form of granules, and subsequently these molecules will form crystals, or the lowest order of organism; and these organisms seem to possess a degree of resistance to external force analogous to the resistance of the higher organisms; indeed, the more perfect crystals, of the same substance and in the same solution, will grow and become more perfect at the expense of those which are irregular. Upon this principle, the perfect crystals may be said to be approximating to the allotropic condition or nascent state, while the perfect crystal is in the normal condition.

It may be said that extent of surface is one of the causes of this, and a better illustration is sand or quartz, which is perfectly insoluble in its natural or normal condition, however fine the powder, even in some of the strongest acids. But sand or silica is frequently found in the nascent condition, and then it dissolves readily in water; moreover, it can be kept in this condition for years; but if heated to the temperature of $260^{\circ}$, it assumes the normal condition, and becomes perfectly insoluble even in acids; whereas, before, it would dissolve in acids, alkalies, or pure water.

Lime and magnesia, while in the caustic state, are capable of converting sand into soluble silica; and this is perhaps one of the good effects of liming, especially when we consider the remarkable influence that soluble silica exerts in absorbing ammoniacal manures. We may also account thus for the crumbling of stable walls, the moist condition of old walls, and especially those that are exposed to ammoniacal exhalations. Moreover, we have a plausible mode of accounting for nitre-beds, and the remarkable value of old plaster; also the purifying influence of whitewashing, if it is done with caustic lime, and not with whiting or carbonate of lime. Lime, while caustic and moist, in contact with sand, converts a small part of the surface of the grains of sand from the insoluble to the soluble silica; and this is the reason why caustic lime is necessary to the formation of good mortar, as it is not (as is almost universally supposed) a mere mechanical mixture of lime and sand, neither is it grains of sand cemented together by the induration of lime; but the actual solution of the surface of the grains of sand produces a still more intimate union.

Well, this soluble silica gradually absorbs from the atmosphere the ammonia, for which it has a remarkable affinity; and as ammonia is the vehicle of poisonous exhalations of disease, as well as the perfume of flowers, these exhalations are so concentrated upon the walls of hospitals, that it sometimes becomes necessary to remove the plastering, in order to get rid of erysipelas and other diseases. Nearly or quite all of the nitric acid of commerce was no doubt originally derived from ammonia in the order above referred to ; for if my theory, as above stated, is admitted, then every authority will sustain me in saying that old plaster contains ammonia, and this ammonia is converted into nitric acid on the wall. Salts of nitric acid can be seen by any one on the surface of old walls. Moreover, the leachings of old walls have frequently been used in the manufacture of gunpowder, and old plaster always enters into the composition of artificial nitre-beds. It will be readily admitted that 
silica can never enter the rootlet of a plant, however fine the powder, unless it is in solution; and that the finest powder of sand or silica differs as much in solubility from nascent silica as sand differs from sugar. The importance, then, of soluble silica to grasses and wheat, and especially in corn, and, indeed, its value as manure, has long been recognised. (See Liebig's Chemistry, American edition, 1841, p. 200.) It was first supposed that potash was the vehicle for its conveyance to every part of the plants; but the modern idea is, that ammonia is the main instrument of its conveyance. Certain it is, that it loses its base at the instant of its deposition on the stem; and if potash were the base, then it would be necessary that the potash be carried back again to the earth, and the plant would be constantly embarrassed by excrementitious matter; whereas, the ammonia being volatile, evaporates, and leaves the glassy coating, or element of strength, on the surface of the stem. Thus, it is found that more ammonia is actually exhaled from plants than we ever give them in the form of manure; and it is strongly suspected that soluble silica is really the manure, while ammonia is merely the vehicle for the conveyance of soluble silica through the plant. When the carcass of an animal falls in the field, the luxuriant grass or grain "falls," on account of the absence of the relative amount of soluble silica, or the excess of ammonia uses up at once all of this necessary element that is available.

Two years since, I manured two lands in the centre of my oatfield, the one with Peruvian guano, the other with soluble silica, leaving a land unmanured between. The proportion of straw on the guanoed land was very much increased; but last summer the same field was in wheat, and a corresponding diminution in the proportion of straw was noticed on the land that had been guanoed two years since; and what is more remarkable, the land on each side of the guanoed land averaged seven hundred and forty-six pounds more of wheatstraw per acre, although no manure of any kind had been applied to either since it was in oats; whereas the silicated land not only produced more straw than either of its unmanured neighbors, but also excelled the guanoed land in wheat nearly three bushels per acre, and ripened earlier than any other part of the field.

The difference between the silicated land and the unmanured averaged nineteen hundred and sixty-six pounds, while it also produced nine and one-tenth bushels of wheat more than the adjoining unmanured lands. A part of my oatfield of last summer exhibited the same increase in the weight of the straw, although no silicates have been applied since it was in corn two years since. But the most remarkable result was obtained in my cornfield of this year, where the corn on the silicated portion averaged ninety-three pounds per shock, while one part unmanured only weighed forty-two pounds per shock; each shock represented sixty-four hills of corn, and the average of thirty-one shocks was taken. This manure was applied in my presence, and I personally gathered and weighed the produce of each separate shock in the field with my own hands; therefore I can vouch for the correctness of the results. And now, can we not account for the well-known and remarkable efficacy of dissolved bones on this principle, when compared with normal phosphate of lime, whether it be in the form of bone-ash, ground bones, or phosphate guano?

"Bones have been used with profit at the rate of from $\$ 20$ to $\$ 60$ per acre ;" and it has been repeatedly demonstrated that one bushel of dissolved bones, for immediate effect, is equal to five times as much ground bones; in other words, that one pound of nascent or soluble phosphate of lime is worth more than five pounds of normal or natural phosphate of lime, or bone-earth. It will be admitted that every acre of land on the face of the earth contains from one-tenth of 1 , to 4 per cent. of lime and magnesia; and if only one-tenth of 1 per cent. at the depth of cultivation, even then each acre must contain from fifteen hundred to two thousand pounds of lime and magnesia. Now, it is manifest if ten or even thirty bushels of dissolved bones were applied to an acre, the first rain would convert all of the free phosphoric acid or biphosphates that they contain into neutral nascent subphosphates; and it is therefore nascent subphosphate of lime that is taken up and assimilated by the plant. Thus we are enabled to account for the wonderful effects of what are called in commerce biphosphates, which really contain very little free phosphoric acid, but all of the phosphoric acid exists as neutral nascent phosphate of lime. The fact is, that dissolved bones are unmanageable as a manure in this country, (in England biphosphates are applied 
in solution,) until reduced from a fluid to the form of a powder, by the means of ivory-black, guano, or some less valuable diluent; and the universal distribution of carbonates of lime, \&c. in these, converts nearly all of the biphosphates into neutral nascent phosphate or subphosphates. - During the past summer, I have been experimenting on two separate fields with four of these compounds-two of which were made in New York, and two in Baltimore; the most remarkable results were obtained from experiments made upon a few hills of corn. But I will confine my statement to two series, where whole rows of shocks were compared with contiguous unmanured rows; the average of twenty-three shocks, each shock representing sixty-four hills, exhibited a difference of about 25 per cent. ; or the manured weighed forty-two pounds per shock, while the unmanured weighed forty-two pounds; and these manures were applied in my presence, at the rate of ten bushels per acre broadcast, and I gathered and weighed the corn in the field myself. Now, it is most probable that no atom of free phosphoric acid, or phosphate of lime, ever enters the rootlet of a plant without destroying it; and, having proved that a solution of bones would necessarily become precipitated in contact with any soil, we are driven to the conclusion that this precipitate or nascent subphosphate is the valuable manure, and we take it for granted that it will preserve the nascent form for some time in moist situations, as we know that moist oxide of iron will continue to preserve this form, as the antidote for arsenic, for weeks together. Ultimately, however, it also loses the nascent and assumes the normal form, and becomes so insoluble, that five times the dose is required, in order to afford the soluble material for the same proportion of arsenic. Thus it is with phosphatic guanos and bone-dust; none of them are absolutely insoluble in pure water, and when thus dissolved as subphosphates, they are converted in the nascent form, and more readily redissolved than before their solution. The contact of a piece of wood or string has been known to hasten the solubility of the most insoluble substances; for instance, the inner part of the metallic worm of a still, opposite a wooden support, has been known to dissolve in the distilled waters passing through it; and the same remark is made with regard to hydrant pipes: the normal condition of insoluble bodies is then disturbed, and the allotropic or nascent condition produced, by contact with regetable substances in a state of change; this, then, may account for the influence of organic manures, and indicates the philosophy of the modern plan of manuring in Europe, which is by hauling out the manure on the field, load by load, as it is generated, instead of permitting it to ferment in heaps in the stableyard. Now, query, would it not be still better to stratify it with powder of feldspar, phosphorite, or phosphatic guano, and concentrate this disturbing force of fermentation upon the elements, which, when reduced to the nascent state, are worth more than the 1 or 2 per cent. of alkalies, \&c. in the manure itself?

It is still the question with physiologists whether nitrogen is ever assimilated by plants, much less by animals, in its normal condition; and it is a curious fact that both the plant and animal may starve when fed on carbonaceous food exclusively, although both are bathed in an atmosphere containing four-fifths of nitrogen, which is perfectly useless to both, because not presented in the nascent form.-American Farmer.

\section{Methods of Preparing Muck for use as Manure.}

The Annual Report of the Massachusetts State Board of Agriculture, for 1855, furnishes the following statements relative to the preparations of muck for use as manure, each being the results of the writers' (practical farmers) observations:

A Middlesex farmer says:- "I use swamp muck most successfully composted with stable manure, on different varieties of soils, but think it does best on high land of a loamy soil. I notice it is used very extensively by farmers, with satisfactory results, when composted with other manures thoroughly." A farmer of Worcester county says:- "I use it extensively on my hard, clay soils; it works well on dry lands to keep them moist, and on clay soils to keep them light." Another writer, from Dukes county, follows:- "It should be hauled out in the fall, and exposed to the frost during winter, and mixed with stable manure in the proportion of two parts muck to one of manure; it should also be used in the hog-pen, barnyard, and barn-cellar. I have found it a good manure on loamy, gravelly, and sandy land, 
especially for top dressing for grass when composted as above." A Norfolk county farmer, who has met with great success, says :- "The best way of using swamp muck is to dig it and expose it to the sun, air, and rains one year; and then, when in a dry state, place it in a barncellar, where it will take the droppings of the cattle above until it is thoroughly saturated; then mix it well, and it is ready for use. It is good for all high lands." He estimates it at about three dollars by the cord of one hundred and two bushels. A Middlesex farmer, of great experience, states that "swamp muck is of different qualities, and varies as much as wood when used for fuel. Peat mud, the older the better, consists principally of regetable matter. It has most effect on high and dry ground. Wood-ashes are the best article to correct its acidity." .

Similar accounts come from every section of the State. From Hampshire county we have the following:- "The best method of using swamp muck, judging from experiments of my neighbors and my own, is to cart it out in the autumn, expose it to the frost and snows, then spread and plow it in in the spring on sandy, dry soils; or in other words, on soils of an opposite nature to its own. I plowed in twenty-five loads on one quarter of an acre last spring, and planted it to early potatoes, corn, peas, cucumbers, squashes, and melons. It was a great preventive against drouth. That ground has been sown to rye, and it looks first rate." And from Plymouth county - "Swamp muck, as also upland soils, are valuable to mix with various kinds of manure to retain and absorb the salts. For upwards of two years I have adopted a different course with my swamp land from any I know of. I employ men with long-bitted hoes, sward-hooks, etc., to dig up the hummocks and bushes, in bodies large and small, as is convenient, and pile them in bunches for a few days to dry; after which I select a central bunch, in which I form a cavity or hole near the bottom or surface of the ground. Then I set fire to some of the dryest and most combustible, and as it burns I replenish it from the other bunches, smothering in the coal-pit form, though more combustible, till it is burned down to a perfect body of ashes and sand. I have not carried the experiment into full effect, as I designed to ; but so far as I have used the ashes, they have given me entire satisfaction. Their nature is to improve exhausted lands; and my belief is that they may be spread upon the same land upon which the ashes were made, and increase the growth of English grass. Much has been said upon the subject of reclaiming wet, swampy lands; but after all that has been done, as I understand it, a coat of manure is required to produce a good crop of English grass. Now, if our worthless swamp lands possess the very article required to produce such grass by the simple process as above named, I think it would be an improvement in one point of agriculture."

A farmer of Barnstable county says - "The best compost manure is made in our barn and hog-yards, of swamp muck, sea-weed, and animal manure. Swamp muck and sea-weed are accessible to all who will take the trouble to procure them. My barn and hog-yards are so excavated and dug as to absorb the liquids passed into them. Every spring and summer, after my barn-yard is emptied, I replenish it from time to time with swamp muck, peat, sea-weed, and other materials from the farm, which, with the animal manure produced by yarding my cattle, furnish me in the autumn with 200 loads of good compost, which I either stack in the yard or cart on to the land $I$ intend to plant in the spring. I again replenish the yard, giving me, with the proceeds of my hog-yard, from 100 to 150 loads more in the following spring. In addition, I have for two years past composted in the field adjoining my peat-bog from 75 to 100 loads of peat, (thrown from the pit in summer or autumn,) with sea and rock-weed, or ashes and animal manure, which I esteem of equal value to barnyard manure. I estimate the value of a cord, or four ox-cart loads, of barn-yard manure composted as above at from $\$ 4$ to $\$ 5$. We esteem the value of this for a corn crop and the improvement of land higher than pure animal manure."

I give one more extract, from a farmer of Berkshire county. He says- "I have used swamp muck for a number of years past with good results, by mixing it with yard and stable manures in the proportion of one-third to one-half muck, and consider it worth $\$ 1$ per load to use for agricultural purposes on soils that are a mixture of loam and gravel."

The testimony is uniformly in favor of composting muck with other manures. Its power of absorbing valuable liquid and gaseous substances is very considerable; and this makes it 
an excellent substance to mix with guano, when the latter is to be used as a top dressing. The importance of a free use of dry swamp muck as an absorbent of the liquid manures of the barn and stable can hardly be overestimated. The loss throughout the State from the neglect and consequent waste of these rich manures, which with a little care might all be saved, is almost incredible. The attention of farmers was but lately called to this subject; but the value of these substances is acknowledged by some, and efforts are now made to save them by means of the use of muck and loam, either properly composted in the barn-cellar, or supplied daily to the stalls of cattle. No judicious farmer should neglect to save all such substances as tend to increase the value and productiveness of his lands. It is poor economy and bad calculation to buy concentrated manures, or to buy any manures abroad, till every thing of the kind is saved at home.

From what has been said, we may infer that good dry swamp muck is worth on an average from $\$ 1.25$ to $\$ 1.50$ per cord; that it is best on light, loamy, sandy, or gravelly soils; and that it is valuable as a compost with barn-yard manures or with guano.

\section{Top Dressings.}

Aт a recent meeting of the Highland Agricultural Society of Scotland, results of a series of trials of various substances for top dressings were detailed. The manures employed were nitrate of soda, sulphate of ammonia, Peruvian guano, and common salt-sometimes simple, sometimes mixed together. These were applied to wheat, to grass, and to potatoes with results, however, not so similar as is desirable. In the trials with wheat, the results per acre of I., those of Mr. Finnie, and II., of Mr. Hope, will be found in the subjoined table. In the trials of Mr. Finnie, the gross produce per acre is given in quarters and bushels; in those of Mr. Hope, the increase in bushels per acre, compared with an unmanured portion of the same field:

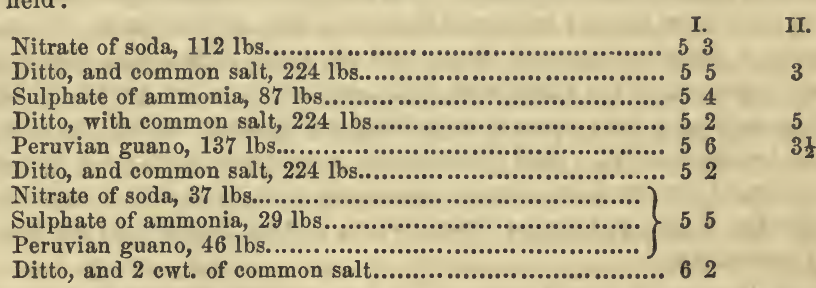

In considering the results of these and other valuable experiments upon saline top dressings, our readers will not omit to remember how great and varying is the influence of wet or dry seasons upon such applications. The greater number of these are indeed most beneficial in wet seasons: they seem to act with very diminished power in dry springs and summers.

The good effects produced by a mixture of various fertilizers has never, we think, obtained that careful consideration which this branch of the inquiry deserves; and yet many facts should surely lead us towards such a path ; the very great advantage, for instance, of using common salt mixed with soot, rather than by itself, for carrots and potatoes, is well known; and, some time since, Professor Johnston illustrated the advantage of this inquiry by a series of valuable experiments. The Professor found that in a field of 40 acres of potatoes, which had been manured throughout with 40 tons of farm-yard dung per acre, a top dressing of various salts gave the subjoined increased of bulbs:

\begin{tabular}{|c|}
\hline 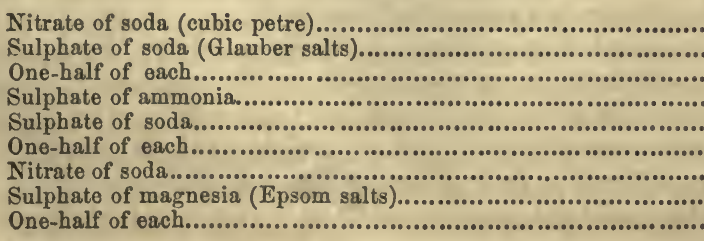 \\
\hline
\end{tabular}


In the more extensive trials of Mr. Fleming, planted on the first of June, and top dressed on the first of July, the produce from these various saline applications was as follows:

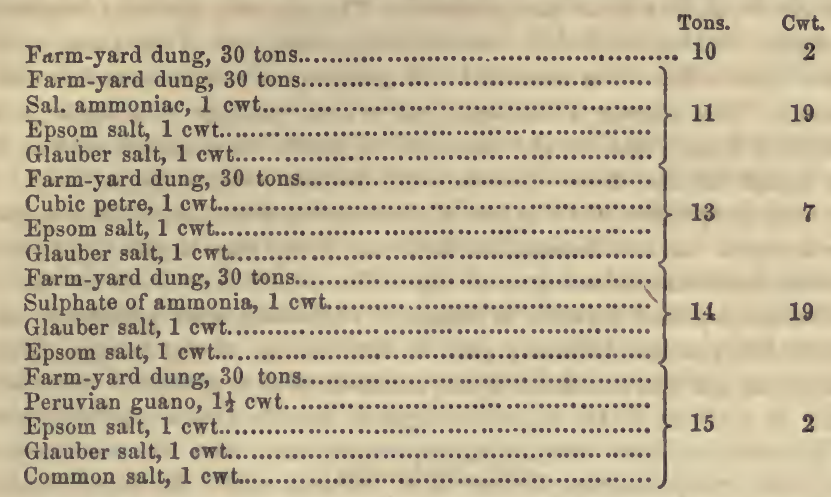

Our readers may derive, we think, considerable benefit from carefully attending to these points when they are about to employ top dressings. - Mark Lane Express.

\section{Fish Manures.}

Tue following is an abstract of a lecture recently delivered by Prof. Way, of England, on the applicability of fish as a substance for fertilizing:-

Prof. F. commenced by adverting to the importance of the subject. The employment of artificial manures, however much it might have extended, was yet in its infancy, and in the course of ten years it was probable that one hundred acres would be artificially manured for every acre that was so treated now: but this could only happen with the aid of fresh sources of supply of the raw material for the manufacture of such manures. There was the greatest difficulty in obtaining the material to supply the manure market. In the case of phosphate of lime, the demand had so increased that the price had nearly doubled in the last two or three years. It was, however, fortunate that phosphate of lime, occurring very largely as a mineral deposit, had been searched for and found in several localities, and other supplies of it were opening up, which promised eventually to meet any demand. No less important than phosphate of lime, as an element of manure, was some form of nitrogen, of which the value was so abundantly proved. Now, it could not be doubted, as he hoped to show, that such a source of nitrogen, in the highest degree available for the wants of vegetation, existed in fish. This source of nitrogen was practically unlimited, and he could not think that the obstacles in the way of obtaining it in sufficient abundance and at moderate price were by any means formidable.

Of the value of fish and fish-refuse as manure there could be little dispute. The use of fish, however, in its natural state was necessarily confined to a comparatively short distance from the place where it was caught; so valued, however, was this manure, that he had seen hop and wheat-fields covered in the winter with sprats at a distance of twenty-five miles from the sea, and that before the days of railways, and when the farmer had to send his teams to fetch them home. The question, however, of importance was, To what standards is the value of fish as a manure to be referred? In respect to this, Prof. Way remarked that the quantity of vater in fish was not nearly so great as was usually thought. It was a vulgar error to suppose that fish was less solid than flesh; on the contrary, while the flesh of the ox contained as much as 77 per cent. of water, different kinds of fish varied from 60 to 65 , and some contained much less than this, even. The quantity of nitrogenous matter in fish varied considerably; to this ingredient no doubt a great portion of the manuring property of the fish was due. We had experience of the value of dried blood, woollen rags, of horses' hair, and other animal substances, all of which were powerful manures; and the nitrogenous parts of flesh being of the same composition, could not fail to have the same 
effect upon regetation. The next ingredient in fish was the oil. The proportion of this differs very much in different fish. In the flesh of the herring, 12 per cent. had been found. In the mackerel, Prof. Way had found as much as $24 \frac{1}{2}$ per cent. of oil, or one-fourth part of its entire weight. In this fish the oil seemed to substitute part of the water found in other varieties; for it did not contain more than 44 per cent. of moisture, or two-thirds of that usually present. The quantity of nitrogen and of ash was also very large; both of them very considerably larger than in any other fish of which the comparison tras known. If available in quantities, therefore, this fish would be very valuable for manure. Now, considering the large proportion of oil in fish, it became important to consider of what value it might be in manure. It had become the fashion of late years to give too exclusive a consideration to the importance of nitrogen in regetation; not that we could too much value this important element, but that we were in danger of neglecting those substances which took a less prominent, but a no less necessary part, in the economy of vegetation. That carbonaceous matter in the soil was beneficial, if not indispensable, to profitable cultivation, did not seem to admit of a doubt; and if so, there might be clearly a choice between carbonaceous substances, according to their rate of decomposition, \&c. Now oils were very susceptible of oxidation, with the production, of course, of carbonic acid. He might only mention in illustration, the spontaneous combustion often occurring when oily rags used for machinery, \&c. had been thrown into a heap, and by the absorption of oxygen and heat consequent thereupon, it had, in many cases, caused great destruction of property.

Then again, the manufacture of "drying oils," as they were called, by boiling linseed and other oils in contact with the air, the experiments of Saussure, who placed different oils under receivers of air, and found at the end of the experiments that all the oxygen had become carbonic acid at the expense of the oil, were also to the purpose. Now it was easy to see that oil distributed through a porous soil would, on account of the great surface exposed, suffer rapid oxidation, and give off a ready supply of carbonic acid, which at particular periods of their growth might be most important to some plants.

Mr. Way quoted passages from the work of Dr. Home, printed in 1762, and the "Georgical Essays" of Dr. Hunter, a few years later, to show that a very high opinion of the value of oil as manure was held by early writers. He also referred to the experiments of Earl Spencer with oil, to the use of whale-blubber, which, however, no doubt owed much of its value to the flesh. He showed also that many of the substances known as powerful manures, and containing nitrogenous matter, also contained oil. Thus woollen rags, rape-cakę, \&c. might owe part of their efficacy to this cause. Rape-cake contained about 4 per cent. of nitrogen, while its oil varied from 12 to 15 per cent.

On the whole, this subject of oil, as manure, was well worth looking into; not that oil would be likely to be used directly as a manure, (its value for other purposes being opposed to such a use of it,) but that we might be able to value more correctly substances in which occurred, and could not profitably be extracted, as suitable for manure. The other main ingredient of fish was the ash or mineral matter, which, although of less importance than the others, (on account of the smallness of its proportion,) was not to be overlooked. Mr. Way here referred to the analyses of different fish, showing that in the lobster the quantity of phosphate of lime was as much as 5 per cent. of the fish in its dried state, and about the same in the mackerel: this phosphate of lime could not be without its use.

Mr. Way next directed attention to the various methods of preserving fish that had been proposed, including those of Mr. Petit, by sulphuric acid; of Mr. Elliott, by the use of alkali; of Mr. Bethell, hy the employment of tar-oils; and of M. de Molons, by treatment with highpressure steam. He also mentionod the plan which was adopted by a manufacturer of manure, (Mr. Stevens,) who had a contract for the refuse fish of Billingsgate market, of incorporating the fish in super-phosphate of lime, the quantity of water in the fish serving to dilute the acid, and being dried up by the natural heat of the process. He remarked, however, that there would be no difficulty in preserving the fish, if it could be obtained. It was not so much a question of this or that process, but of the supply of raw material. He could not help believing that this was not an insuperable difficulty, if systematic measures were taken to effect the purpose. Was it affirmed that our system of taking fish was incapable of 
improvement? Were the nets and other appliances of the fisherman, which were the same in kind as we read of 1800 years ago, although possibly improved in detail,-were they the last and supreme effort of ingenuity and invention? Was nothing to be accomplished in the way of extracting from the waters of the sea a greater supply of its teeming population? Surely it was open to improvement. But it seemed to him that the calculations and arguments on this question were not usually quite to the point. Everybody talked of "refuse" fish, that is to say, the offal of edible fish, and the fish accidentally caught which were unfit for the food market; and it was said by those who certainly well understood the subject, " 3 boat with so many men will take in the day such-and-such a quantity of fish, of which the uneatable fish will amount to so-and-so, and that quantity will not keep a factory in work or create a manufacture of any national importance." But he said that fishing for manure must be the primary, and the capture of edible fish the secondary, consideration, if they desired to raise this into a great national question. And we had jet to learn what would be the result of a day's labor of a given number of men, when their attention was directed, not as now, to the comparatively rare and valuable fish, but to those which hitherto they had despised and aroided. In his opinion, the statistics hitherto put forward were worth nothing, because they were not derived from this point of view. In the search after fish for the manufacture of manure, the proverb that "All is fish that comes to the net" ought to be varied to "All is fish that the net can reach."

Prof. Way concluded his lecture, as he had begun it, by urging the necessity of encouraging every attempt to obtain new sources of raw material for the manufacture of manure. Without this, a term would be reached when the competition for manufactured manures, with an insufficient supply, would raise the price up to the extreme limits at which their use would be remunerative; for a time the deficiency would be met by adulteration and inferiority of the article; and this, together with the scramble to get manure, would soon wean farmers from their partiality to artificial manures. Then, indeed, the progress of agriculture in this country, at all events in the use of artificial manures, would receive a serious check. He did not wish to draw a gloomy picture, but such a state of things must ineritably result, if the increasing demand for manures were not met with some new and abundant supply of the raw material._Furmer's Magazine.

\section{Sewage Manure.}

Thovas Wrckstexd, of Leicester, England, has secured a patent for making sewage manure, by mixing charcoal reduced to fine powder with milk of lime, of the thickness of cream, and then causing this mixture to flow ihto a stream of the sewage water by means of pumps.

\section{A Fact in Manuring.}

A PERsov carrying some orange-trees from China to the Prince of Wales' Island, when they had many hundred fruit on them, expected a good crop the next year, but was utterly disappointed; they produced but few. A Chinese, settled in the island, told him if he would have his trees bear, he must treat them as they were accustomed to in China; and he described the following process for providing manure:- "A cistern, so lined and covered as to be air-tight, is half-filled with animal matter; and to prevent bursting from the generation of air, a valve is fixed which gives way with some difficulty, and lets no more gas escape than is necessary: the longer the manure is kept the better, till four years, when it is in perfection; it is taken out in the consistence nearly of jelly, and a small portion buried at the root of every orange-tree, the result being an uncommonly great yield." A person hearing of the above fact, and wishing to abridge the term of the preparation, thought that boiling animals to a jelly might have a similar if not so strong an effect.' Accordingly, he boiled several puppies, and applied the jelly to the roots of a sterile fig-tree: the benefit was very great, the tree from that time for several years bearing in profusion. Hints of this kind are well worth preserving, for though a farmer may neither have the apparatus of the Chinese, 
nor puppies enough to become an object of attention, yet the reduction of manure to a mucilaginous state ought perhaps to be carried further than it is.-Horticulturist.

\section{How to Use Guano.}

Tre London Mark Lane Express, gives the following directions respecting the use of guano.

First.-Never mix it with any thing; all lime, compost, ashes, and similar ingredients, too often contain enough caustic alkali to drive off the ammoniacal parts before the soil can surround and absorb them. A vast amount of mischief and loss often follows this sad mistake. If applied alone, the soil will best adapt it for plants.

Second.-Mix as much as possible with the soil, not too deeply, but plow it in after sowing it broadcast, unless it be for beans or drilled and ridged crops, when it may be sown on tho surface before the ridges are made.

Third.-If applied as a top dressing, always apply it, if possible, before rain, or when snow is on the ground; and if on arable land, harrow, hoe, or scuftle, if possible, immediately after the operation.

Fourth.-The best mode to apply it is by water. A slight solution of it is by far the most powerful and speedy application.

Fifth.-If sowed with drilled grain, or indeed any seed whatever, it should never come in contact. It is not a bad plan to sow broadeast, after the corn-drill, and then harrow, as it is kept in the nearest proximity to the seed, without coming in contact with it.

Lastly.-Be sure to get, if possible, the genuine article; cheap guano there is none.

The quantity of genuine guano per acre used is from two to three hundred pounds. The latter quantity, when the land is deficient and requires speedy renovation.

\section{Guano Deposits of the Atlantic.}

IT is now well known that the guano of the Chincha Islands and other sources, under rainless skies, is a product of a peculiar fermentation, in which ammoniacal salts and nitrogenous products are formed from a variety of animal matter. Not only the dung, bodies, and eggs of several varieties of birds, but a large amount of flesh and bones of seals, make up the substance of the decomposing mass.

On the islands of the Atlantic, the dung, bodies, and eggs of birds are found; but the frequency of rain modifies the decomposition, so that the resulting matter differs essentially from that of the Peruvian shores. It possesses, however, a high value in special applications, and presents some interesting scientific points.

Dr. A. A. Hayes, of Boston, has fully investigated the composition of the guanos of different islands, including ancient as well as recent deposits. On some of these, two species of birds are still found in countless numbers, which make daily additions to the accumulated remains of former years.

The substance of this kind of guano is matter derived from the fish-food of birds. Its color is light, yellowish brown, becoming, when air-dried, nearly white. It has no ammo-. niacal odor, but smells strongly of freshly-disturbed earth. It is never so finely divided as the Peruvian, its particles being sometimes as coarse as mustard-seed, resembling closely the sand from oolite limestone. There is, however, always some finely-divided organic matter, in the state of humus, either between the particles or making part of the substance of them. An average composition is the following:

Moisture after being $\operatorname{air}-d$ ried........................................................ $4 \cdot 40$

Organic matter, crenates, humates, oleates and stearates, magnesia and lime............ $6 \cdot 40$

Bone phosphate of lime...................................................................46 60

Carbonate of lime............................................................................ $39 \cdot 80$

Phosphate magnesia.................................................................................. $1 \cdot 20$

Sulphate lime.............................................................................. $\quad 80$

Sand.......................................................................................... $\cdot 21$

Traces of chloride and sulphate of soda. 
The carbonate of lime here given is an essential part of each particle of the bone remains, and does not exist, except occasionally as mixture to the amount of one or two per cents., independently. The humic acid is often in union with ammonia and magnesia, the whole percentage of ammonia, or rather nitrogen, not exceeding in the ancient deposits more than two per cent. A more solid aggregate of grains afforded-

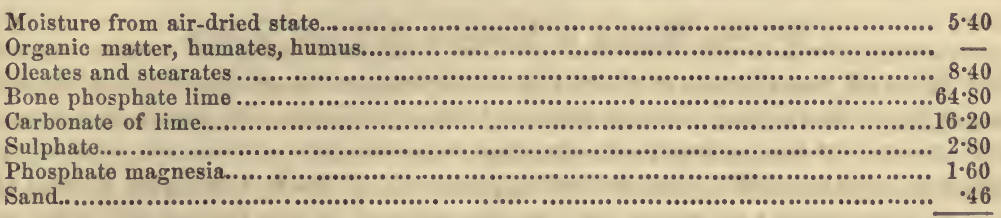

$\overline{99 \cdot 66}$

The grains adhered slightly; the dry mass was of a pale, nankin color, and exhibited the first step in a change which results in a consolidation of the arenaceous remains into a solid rock.

It will be observed that, if we admit the moisture and organic matter, there are seventyfive parts of bone phosphate of lime in one hundred of the dry guano, constituting a source of this prime requisite in the constitution of fertile soils highly important. From the nature of the decomposition, this bone phosphate is soluble to some extent in water, and thus adapted to application when the immediate effects are desired.

Comparing the composition here given with that of fish-bones, we observe an increased amount of phosphate of lime, and are led to the consideration of the cause of this anomalous composition.

Another variety of this guano appears as a solid compact rock, banded in lines by darkbrown colors. Although the irregular forms of the masses mark it as an aggregate, its hardness, next to that of feldspar and greater than that of fluorspar, removes it from the class of ordinary calcareous aggregates. But the chemical composition is more remarkable.

One hundred parts afford-

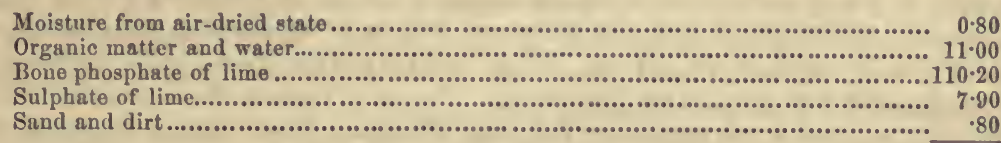

130.70

The 50.47 parts of phosphoric acid are, for convenience of comparison, supposed to be united with lime to constitute bone phosphate of lime. For economical purposes; it is necessary to grind the masses to a fine powder; it then dissolves slowly in water.

This compound generally forms a covering of ten to twenty-four inches thick over the guano on those islands not frequented by birds. Some rough masses are found in the mass of the arenaceous guano; but they appear to have been once a surface-covering.

Dr. Hayes explains the singular composition of this aggregate and the guanos more rich in bone phosphate than the bones of birds by referring to the kind of fermentation which organic animal matter undergoes in presence of excess of humidity. Briefly, it is the reverse of that which produces ammonia salts in the Perurian guano, acids being the result here. The whole series of acids, the products of humus decomposition, carbonic acid, and probably acetic acid, being generated in the mass, have dissolved the carbonate of lime of the deposit, while the resulting salts have been washed away by the rains, leaving the phosphate of lime in excess. Where daily depositions are taking place, this effect does not follow, as the first decomposition produces ammonia; but, under other conditions, the carbonate of lime of the bony structure is removed, and the phosphate is left in excess.

The occurrence of rocky masses at the surface is explained by the well-known fact that the solutions of salts formed tend to the surface; and, as the water evaporates under the sun's rays, the earthy salts dissolved by the acid fluids below are left in the interstices existing in the sand-like deposits of food-remains until they are filled, and every trace of granules obliterated. The increased amount of sulphate of lime, the uniform acid state of these guanos 
and cavities lined with crystals, are all according facts in favor of the conclusion adopted. The experiments, in their extended application to other aggregates, are proving that many compact rocks may be formed at common temperatures by a similar action, not always inrolving a chemical solution of the materials.

\section{On the Mixing of Common Salt and Guano.}

THE following experiments, performed by Mr. Barral, editor of the Journal d'Agriculture Pratique, prove the value of common. salt as a fixer of ammonia. M. Barral took two samples of guano: the one he kept pure-the other he mixed with a refuse salt obtained in the manufacture of gunpowder, (and consisting principally of common salt with a small quantity of saltpetre, nitrate of potassa,) in the proportion of 50 per cent. of this salt. "The sample of pure guano which we analyzed," says M. Barral, "contained 12.56 per cent. of nitrogen; the sample mixed with salt contained only 6.23 per cent. We do not take into account the nitrogen in the state of nitrate mixed with the salt. We subjected equal weights of the two samples to heat for three hours in the same stove, in a current of air, maintained at $100^{\circ}$. They were spread out so as to have the same thickness, and occupy an equal surface, and they had been equally pulverized. At the end of the three hours, on examining the two samples, we found that the pure guano had lost $5 \cdot 7$ per cent. of its nitrogen, while the mixture had lost only 1.9 per cent. of its nitrogen.

"Though this experiment appeared to us to be in favor of the preservative power of salt, we repeated it under another form. We left in the open air, in plates, during fifteen days, equal weights of the pure and the mixed guano. At the end of that time we examined anew the amount of nitrogen, and found that the pure guano had lost 11.6 per cent. of its nitrogen; while that mixed with salt had lost only 5 per cent. Thus we see salt can be usefully employed for mixing with guano."

This property of salt, as a fixer of ammonia, has not been sufficiently attended to in agriculture. While chemists recommend gypsum, nitrate of lead, chloride of zinc, sulphate of iron, and chloride of manganese for this purpose, common salt is but rarely alluded to. It has been used extensively of late, with nitrate of soda as a top dressing, with the view of strengthening the straw of the cereals. It has been alleged that guano tends very much to increase the growth of vines in the potato crop. We are of opinion, from numerous experiments before us, that, when applied to this crop, the guano should always be mixed with some fixer of the ammonia, such as gypsum, salt, or charcoal: at present prices, the most expensive of these, at the rate of one hundredweight per acre, will not cost more than $2 s$. per acre. Another important fact, independent of the value of the salt, brought out by M. Barral's experiment, is the great waste of ammonia which takes place on exposing guano to the air. It will be remarked that, in the case before us, upwards of one-tenth of the nitrogen was lost in the course of fifteen days. This shows the necessity of farmers husbanding as much as possible this important ingredient of their manure. Instead of throwing their guano in exposed sheds, as is too often done, it should be carefully covered up, and mixed, immediately on their receiving it, with some preserver of its ammonia.

\section{Superphosphate of Lime for Root Crops.}

SUPERfHosphate of lime is used to a great extent in England as a manure for turnips, ruta bagas, mangel-wurzels, and other root crops. When sown broadcast, it has very little influence on the crop; but when drilled with the seed its effects are oftentimes astonishing. Philip Pusey and some others have shown, too, that, when the superphosphate is dissolved in water and applied in the seed-drills in a liquid form, the effect is still more beneticial. Alfred $\mathbf{S}$. Ruston, in the London Farmer's Magazine, gives the results of some carefully-conducted experiments on the subject. There were seven separate experiments made; but; as the results agree pretty closely, we select one as a sample of the whole.

Three plots were dressed with eleven loads of barn-yard manure per acre, thrown into ridges, and sown with mangel-wurzels, April 17 th. The first plot receired no artificial 
manure. The second, one hundred and twelve pounds of Lawes's superphosphate of lime per acre, drilled in $d r y$, and the third plot, one hundred and twelve pounds of Lawes's superphosphate of lime drilled in a liquid state. The crops were weighed October 4th. The first plot yielded per acre eight tons and fifteen hundredsweight; the second, thirteen tons and fifteen hundredsweight; and the third, seventeen tons and seven hundredsweight. In other words, one hundred and twelve pounds of superphosphate per acre, drilled in dry, gave an increase of five tons, and the same quantity applied in a liquid state, an increase of eight tons and twelve hundredsweight per acre. The cost of the superphosphate was $\$ 1.80$ per acre. This is a good result, although it is usually found that superphosphate has a more marked effect on turnips than on ruta bagas, and even still more than on mangel-wurzel.

The above yield will appear small to those who are frequently reading of crops of one thousand five hundred to two thousand bushels per acre. The great drought of last year, doubtless, materially injured the crop, especially where no superphosphate was applied. But, as the weather in England last summer approximated more closely to what it usually is in this country, the experiment may be looked upon as pretty correctly indicating what would be the effect of an application of good superphosphate of lime, in a dry and in a liquid state, to mangel-wurzels in this climate.-Albany Cultivator.

\section{Amount of Manure applied per Acre.}

THE following, from the Rural New Yorker, displays the minute quantity of concentrated manure which falls upon a square yard of surface-soil when applied at ordinary rates:-

An acre of land contains forty-three thousand five hundred and sixty square feet, four thousand eight hundred and forty square yards, or one hundred and sixty square rods. By those who have used guano, it is said three hundred pounds is sufficient to manure an acre; two hundred and two pounds would give just one ounce aroirdupois to the square yard. One cubic yard would give a trifle over one cubic inch to the square foot. A cubio yard of highlyconcentrated manure, like night-soil, would, if even and properly spread, manure an acre very well. A cubic yard of long manure will weigh about one thousand four hundred pounds; a cubic foot not far from fifty pounds. A cord contains one hundred and twentyeight cubic feet; a cord and a quarter would give about a cubic foot to the square rod. If liquid manure be used, it would take one hundred and seventy barrels to give one gill to a square foot upon an acre, which would be equal to about fifty pipes or large hogsheads. It would be quite useful if farmers would be a little more specific as to the amount of manure applied.

\section{Natural Supply of Ammonia in Ordinary Soils.}

Aт a recent meeting of the Royal Agricultural Society, Professor Way, in the course of some remarks on the atmospheric supply of manuring or fertilizing matter, called attention to the large amount of ammonia constantly taken up by the soil, and washing into the land by rain, and to the great importance, consequently, of exposing the soil in such a manner to atmospheric influences as may best tend to this ammoniacal absorption. Fallowing of land, he remarked, had given way to rotation of crops; but that there was no such thing as such a simple resting as fallowing was supposed to imply in this case, for an alteration of the soil under the influence of oxygen was constantly going on. Every interval, even, between one crop and another, was in reality a fallow. Land should be laid up as lightly as possible, for the purpose of its aeration. The working of the land, with a view to this abundant aeration, was one important means of improvement. He regarded it as indispensable, to the full development of the powers of soil, that steam-power should be brought to bear effectively upon its cultivation. The amazing bulk of ammonia locked up in the land itself could not be taken up by plants, and would therefore remain in a form unavailable for vegetation, unless the management of soil tended to release such manuring matter, and bring it within reach of the roots. He had calculated, from data furnished by some rich loamy land of tertiary drift, that the soil within arailable depths contained ammonia at the rate of one ton (equal 
to six tons of guano) per acre. This was a stock of wealth which would repay the most active measures being taken for its release and distribution.-British Farmer.

In a lecture before the Massachusetts Legislative Agricultural Society, in the spring of the present year, by Dr.A.A.Hayes, of Boston, substantially the same views were expressed. Dr. Hayes has found, by experiment, that the quantity of ammonia contained in the majority of the soils of New England is very great, far beyond what is generally supposed. In the state in which it exists, however, it is unavailable for fertilizing purposes, being combined with vegetable and organic acids, and forming neutral and insoluble salts. In applying manures, therefore, to lands in this state, the object sought for it is to produce a fermentation, or a chemical action, which will break up the ammonia compounds in the soil, and render them available for the support of regetation.

The type of manures best calculated to effect this is dried blood or animal matter, which, under nearly all circumstances, when exposed to ordinary temperatures and moisture, ferments most powerfully.-Editor of Agricultural Year-Book.

\section{Use of Nitrate of Soda as a Fertilizer.}

The Royal (English) Agricultural Society having offered a prize for a manure equal to guano, at a cost of $£ 5$ a ton, Mr. Pusey has shown that the conditions are satisfied by nitrate of soda, and at a charge less than that specified. He says, in illustration, that forty-six acres of land, if cropped with barley, and dressed with seventeen hundredsweight of nitrate, would yield an increase of eighty sacks beyond the quantity usually obtained. A cargo of this fertilizer was brought to England in 1820, but for want of a purchaser, was thrown overboard. A second importation took place in 1830; and from that date up to 1850 , the quantity brought from Peru, where the supply is inexhaustible, was two hundred and thirtynine thousand eight hundred and sixty tons; value, $£ 5,000,000$. With the price reduced to $£ 8$ a ton, Mr. Pusey observes-" "Our farmers might obtain from their own farms the whole foreign supply of wheat, without labor, and with but a few months' outlay of capital. I do not mean to say that no failures will yet occur before we obtain a complete mastery over this powerful substance; but I am confident that, as California has been explored in our day, so vast a reservoir of nitrogen-the main desideratum for the worn-out fields of Europe-cannot be left within a few miles of the sea, passed almost in sight by our steamers, yet still nearly inaccessible, at the foot of the Andes."

\section{Experimints with Manures.}

From the Report of the Superintendent of the Model Farm of the Virginia and North Carolina Union Agricultural Society, published in the "Southern Farmer," we extract the following results of some experiments on oats with various manures:-

200 pounds of Peruvian guano gave 2240 pounds of oats per acre, say 70 bushels.

250 pounds of De Burg's superphosphate of lime gave 1712 pounds, say $53 \frac{1}{2}$ bushels.

227 pounds bone-dust gave 1676 pounds, say $52 \frac{1}{4}$ bushels.

An acre without any manure gave 1140 pounds, say $35 \frac{1}{2}$ bushels.

On another portion of the field, which contained 30 acres, where the soil was of " a slightly lighter texture," 100 pounds of Peruvian guano gave 1672 pounds per acre, say 52 bushels.

183 pounds of Chilian guano gave 800 pounds, say 25 bushels.

100 jounds of Mexican guano gave 1225 pounds, say $38 \frac{1}{2}$ bushels.

Experiments made last season with artificial manures on carrots, on the State Farm of Massachusetts, gave the following results. The manure was apportioned according to its cost, each acre being dressed with twelve dollars' worth :-

Barn-yard manure.

Guano.

Potash

De Burg's superphosphate of lime

Mapes's improved ditto.

Reservoir manure

\section{3 pounds per acre.}

660

628

586

572

540

66 60 68 60




\section{Experiment with Nitrate of Soda and Guano on a Peat-Bog.}

THE land on which the following experiment was made, was a peat-bog, reclaimed in 1850 , thoroughly drained, and six inches of clay applied over the whole surface; the only crops raised upon it had been oats, turnips, and again oats sown out with grass. In March last, I sowed on one portion of the new grass two hundred and twenty-four pounds of nitrate of soda, with one hundred and twelre pounds of salt; on another portion, four hundred and forty-eight pounds of guano; and on the remainder of the field no manure was applied.

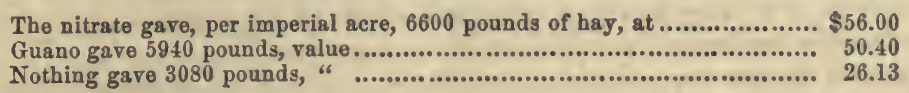

Independently of the increase of weight of hay from nitrate, I prefer that manure for either new or old grass, às it appears to require little moisture to put it down to the roots of the plants. A strong dew in the course of one night appeared sufficient for that purpose, and in about thirty-six hours after its application the grass turned to a luxuriant dark-green color; whereas the guano requires a good shower of rain to put it down: unless it gets such fall of rain, it does little good.

My trial of nitrate on oats and barley last year leads me to prefer guano for these crops. I applied one hundred and sixty-eight pounds of nitrate on one portion, and three hundred and thirty-six pounds of guano on another; but the oats, top dressed with nitrate, kept a blueish sort of color throughout the season, did not ripen equally, and left the ear soft; while those which had guano ripened equally, had a harder, crisper ear, and weighed better. The land upon which that experiment was made, had not been previously cropped, and was of a mossy loam, with a mixture of clay.-Jasiss Drce Nicor, in Journal of Royal Agricultural Society.

\section{Experience in Land Drainage.}

The London Agricultural Gazette gives the following results of the experience in draining on several of the largest estates in Great Britain :-

Mr. G. Guthrie states: During the last thirty years I have drained many thousand acres; the result in all cases was highly satisfactory, the tenants being generally willing to pay $6 \frac{1}{2}$ or 7 per cent. on the expense, and the advantage to them, I am aware, greatly exceeds that interest. The drainage I have adopted is the parallel system. For some years I have allowed no drainage under $3 \frac{1}{2}$ feet deep in hard land, and in moss or bog, $4 \frac{1}{2}$ or 5 feet. At one time (twenty years ago) our.drains were only 27 or 30 inches; but experience has shown us the grent advantage of deeper drains. Our present drains are $3 \frac{1}{2}$ feet deep, at 24 feet distance. The direction of our minor drains is with the fall. We do not regard the furrows, the land in this district being sown out flat. I have used 2-inch and 21 -inch pipes for minor drains, and 4-inch to 6-inch tiles with soles for leaders. Collars or socket-pipes have not been used in this district, although I believe they ought to be. We have generally stones thrown out of drains, with which we fix the joints of pipes very firmly. I have not tried the practice of giving air at places to drains, and do not consider it at all necessary. The average number of acres to one outlet I cannot accurately say; perhaps 8,10 , or 12 acres, according to circumstances. In conclusion, I believe there is no expenditure of capital more profitable than that of drainage.

The agent of the estates of Lord Yarborough states, that until within the last four years the drains were put in from 16 to 24 inches from the surface; but during the last four years a great part of these have been taken up, and put in not less than 3 feet. No difference is made between arable and grass land. The soil generally is clay, with the subsoil of the same character; where the latter has sand veins, or is at all gravelly, a greater depth is adopted-in some few cases they are 5, 6 , and even 8 feet deep, the object being to go wherever the water is. On the strong soils, 3 feet draining is found so far to be effectual ; the system is to drain down each furrow, the lands being generally about 8 yards wide. Egg-shaped pipes, $2 \frac{3}{4}$ inches by $1 \frac{1}{2}$, without collars, have been partially used; but open tiles (with sides 
where necessary) have been more generally used, and are preferred. The average depth of rain-fall in the neighborhood is a little over 20 inches.

Mr. G. T. Bosanquet gives the following as the result of his experience in draining; he says : The result of our drainage operations on all descriptions of land has been most satisfactory. I believe nothing pays better than draining land. The drainage adopted has been generally on the parallel system; but that must depend a good deal upon the nature of the ground and the fall. The prevailing depth of the drain is about 3 feet. I have not laid drains quite so near each other on grass land as on arable. The direction of the minor drains has been generally with the fall. I have found 2-inch pipes answer best for the minor drains; I would not advise that smaller should be used on any ground. I have never used collars, as I think they would have a tendency to displace the pipes and destroy the regularity of the channel. I have not sufficient experience to say if there is any benefit by giving air at places to either main or minor drains. The average number of acres discharging at the several outlets is about 3 acres, sometimes more. I am quite convinced, from experience, that nothing pays better than draining, if well done, and the drains are not placed at too great a distance. I have one field on my estate which was utterly worthless until drained: it would not grow the poorest grass; it now produces good crops of corn and roots. But I strongly advise that whatever is done in draining should be well and effectually done, and that the pipes should never be less than 2 inches. I am of opinion, also, that although the water will find its way down to very deep drains, say 4 or 5 feet, this does not obviate the necessity of close draining. We are also less careful than we ought to be in forming the outlets.

\section{Clay-Ball Draining,}

A PLAN for draining, entitled "Clay-Ball Draining," has been recently patented in England by Capt. Norton, R. A., which consists in using hard spherical balls of clay as the draining medium. The clay of which the balls are made is moulded by any convenient machinery, preserving the spherical form as accurately as possible. When dried, the balls are burned to a crystalline hardness, so that when deposited in the earth they will literally endure for ages. The size or diameter of these drainage balls must be varied to suit different circumstances; but a diameter of four or five inches is the average size preferred. Such balls, when laid in drain cuts in the soil, allow the surface water to descend and pass freely through or between them, and thus get clear off the land. Spherical stones would obviously perform just as effectively as the clay balls, but the latter are preferred, for the reason that in them absolute sphericity may be secured, while that would be impossible even with the use of the smoothest and roundest pebbles.

Fig. 1. is a longitudinal section of a portion of a field drain of this kind, and fig. 2 is a corresponding transverse section. A rectangular cut $\mathbf{A}$ is first made in the soil $\mathrm{B}$ in any convenient manner; and when a sufficient depth has been attained, the bottom of the recess is levelled off, and made hard and substantial as a base, by laying thereon lengths of slate or other

Fig. 1.

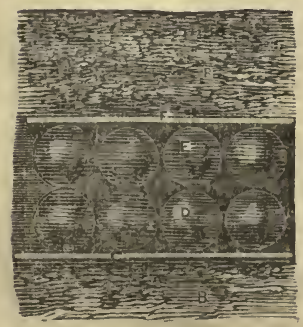

Fig. 2.

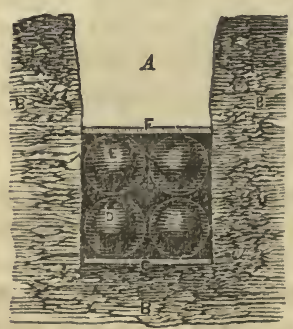
conveniently and economically available material C, filling up the entire width of the drain cut. In this condition of the work, a bottom row or layer of spherical clay balls $\mathrm{D}$ is laid into the drain, the two diameters of each transverse pair of balls being in the same transverse line of the drain as indicated in fig. 2. This drain is supposed to be eight inches in width, so that two clay balls, each four inches in diameter, suffice to fill it. When the entire base of the drain is thus filled in, a second layer of balls $\mathrm{E}$ is set above the lower layer, the diametrical lines of the balls coinciding vertically in the manner shown in fig. 2 . This completes the draining medium, and the two layers of balls are then covered over with a cover layer of slates F, to carry the 
earth thrown in above in levelling and making fair the field. It is preferred that the sod-side of the superincumbent earth should be downwards. This relation of the balls gives a clear thoroughfare for the drainage water through the central space enclosed by each set of four balls, as in fig. 2 ; at the same time there are three half passages or thoroughfares for the water at the bottom and top of the ball layer, and one half passage on each side. Hence there is always a free passage for the water to drain down, and percolate through the enclosed spaces due to the contour of the balls, getting clear away along the slate base of the drain channel to the main outfall.

Captain Norton illustrates his contrivance under several forms, the balls being variously disposed in the drain cuts, while, in one instance, three several sizes of balls are used in combination. Drains made in this way always present a full, free passage for the descent of the water, as the spaces between the balls can never be diminished except by the introduction of other solid bodies; and the roundness of the balls is itself a point in faror of the aroidance of such foreign deposits; like the links of a chain, the balls will always conform to the actual surface of the ground, and no sinking can effect any serious dislocation, or prevent the drainage from being full and free.

\section{Analysis of the Ashes of Oak and Pine Leaves, and their Comparison with those of Cotton and Corn.}

At the request of the Black Oak Agricultural Society, of South Carolina, Prof. C. U. Shepherd has recently analyzed the ashes of the oak and pine leaves, together with those of the cotton and corn plants, with a view of ascertnining the value of the former as a manure for the latter, so far as the mineral ingredients of the oak and pine leaves are concerned. From the published report of Prof. S. we derive the following particulars:-

"The agreement retween the ashes of the pine and of the oak leaves, in regard to soluble and insoluble substances, is striking; the ratio being as one to twelve in pine-leaf litter, and as one to thirteen in that of the oak; while a very remarkable contrast subsists between their contents of carbonate of lime and magnesia and of silica. The carbonate of lime and of magnesia in one hundred pounds of oak-leaves is six times greater than in the same weight of pine-leaf, while the silica of the latter surpasses that of the former by two and a half times. In all other respects the difference between the two species of ash are inconspicuous.

"Prof. Shepherd states that one hundred pounds of pine or oak leaves contrin but onethird the quantity of the highly-important alkaline carbonate requisite for one hundred pounds either of cotton or corn; but as this ingredient is afforded to some extent by all clayey soils, through the gradual decomposition of the feldspar and mica they contain, it seems probable that this amount of leaf-litter would be adequate to maintain the soil in fertility for both of these crops.*

Table, showing (in pounds and decimals of pounds) the Mineral Constituents in 60 pounds Indian Corn, in 60 pounds Pine-Leaves, and in 60 pounds Oak-Lectves.

\begin{tabular}{|c|c|c|c|}
\hline 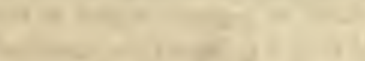 & Corn. & $\begin{array}{l}\text { Pine } \\
\text { leaves. }\end{array}$ & $\begin{array}{c}\text { Oak- } \\
\text { leaves. }\end{array}$ \\
\hline Potash................................ & $\begin{array}{c}\text { lbs. } \\
0.1111\end{array}$ & $\begin{array}{c}\text { 1bs. } \\
0.0596\end{array}$ & $\begin{array}{l}\text { lbs. } \\
0.800\end{array}$ \\
\hline Phosphate lime and magnesia.... & 0.1766 & 0.1566 & 0.223 \\
\hline Carbonate lime and magnesia.... & 1.0265 & $0 \cdot 1987$ & $1 \cdot 172$ \\
\hline Silica ..................................... & 0.2192 & 0.5647 & 0.267 \\
\hline Sulphate potash........................ & 0.0127 & 0.0082 & 0.042 \\
\hline
\end{tabular}

“One hundred pounds (or rather one hundred and ten pounds, making allowance for hygrometric moisture in the atmospherically dry leaf) of either of these kinds of leaf-litter will fully supply the phosphates indispensable for the same weight of cotton and corn; while of the less important carbonates of lime and magnesia, it will (except in the case of the pineleaf for cotton) generally give a large surplus. In the one hundred pounds of pine-leares,

* Still it might be useful to add, along with this quantity, all the wood-ashes at command upon the plantation. These usually contain about fifteen per cent. carbonate potash. 
there are three times too much of organized silica for corn, and forty for that of cotton. In the one hundred pounds of oak-leaves, there is only a sufficiency of the same element for the corn, but eleven times more than is needed for the cotton. Of sulphate of potash and the chlorides, the one hundred pounds of leaves of either kind will supply all that is demanded by either crop, in like quantity.

\section{On the Absorption of Nitrogen by Plants.}

A DEBATE of great interest has been entered into in the French Academy between the celebrated agricultural chemist, M. Boussingault, and M. Ville, respecting the absorption of nitrogen by plants, which has been conducted with unusual interest and some acrimony.

The question discussed by these gentlemen was this: May we ascertain whether or not vegetables possess the faculty of directly absorbing to their advantage a portion of this gaseous azote which forms the greatest part of the atmosphere? The importance of the question is evident: if the free and gaseous azote may directly enter into vegetable organisms without passing through some intermediate combination, the veritable source of agricultural wealth is in the atmosphere; if, on the contrary, before the azote commingles with the plant, it must unite itself to some other element, the agricultural chemist must turn his attention to the search of some new and better method of favoring the slow and difficult formation of combinations of azote. In both of the hypotheses the importance of manure remains incontestable, but their functions will not be so important. If azote gas is not capable of assimilation, if it is simply destined to temper the action of the oxygen with which it is mixed in the air, it is evident how important organic matters are in manures, bringing as they do the elements of the azotic principles elaborated by the plants. If, on the contrary, the azote of air is absorbed during the act of vegetation, if it becomes in this way an integral part of the regetable, then the mineral substances of manures contain the greatest part of their fertilizing properties; for the azote element would have been abundantly furnished by the atmospheric air. Why, then, has the chemist not yet determined this important point, whether gaseous azote is or is not directly assimilated by plants. The great obstacle lies in the difficulties of making the experiment, which should resolve the question. When the chemist would place a plant under a definitive regimen, to ascertain what it obtains from the mineral kingdom, whence it extracts a portion of its aliment, it is indispensable to measure, to weigh, to analyze every thing-the air it respires, the water which moistens it, the soil which upholds. M. Boussingault and M. Ville use different methods, of which they are tenacious. It cannot be denied that M. Boussingault exhibits a great deal of art in the process he used in his experiments. He first abandoned the ridiculous pretension-commonly entertained before him-of measuring by default the azote a plant would have absorbed while it lived during a certain time in a limited quantity of air. He substituted in its stead, raising the plants in a completely sterile soil, and comparing the composition of the seed and the composition of the small crops so obtained at the expense of air and water alone. A handful of earth previously calcined, and watered with distilled water, evidently can furnish no organic matter to the plant which is developed there; and consequently, if, after the crop is gathered, the chemical analysis shows it contains more azote than the grains sown contained, it is manifest that this azote came by the air: this result M. Boussingault obtained by experimenting with the seed of clover and of peas.

But in communicating this result to the world, M. Boussingault did not pretend to do more than to exhibit the bare fact. He made no deduction to demonstrate that it came by the air in its normal state, or by the rare ammoniacal vapors from which the atmosphere is never exempt. M. Ville did not imitate his silence. He studied the question, and found the azote of the crops was ten, twenty, thirty times greater than the azote of the seed. However, M. Boussingault, pursuing his researches, (using a different method,) attained diametrically opposite results, or results which are completely negative. To aroid any objection which might be urged on the ground of the permanent communication of the apparatus with the external air, he planted the objects of his experiments in a completely closed vase, and furnished them in the beginning with the quantity of carbonic acid and of water necessary to their alimenta- 
tion during the whole course of their development. The apparatus was thus made extremely simple, being nothing but a large glass globe, capable of holding some sixty or eighty quarts; he placed in the bottom of the globe (after having made it sufficiently humid) a certain quantity of pumice-stone, pounded, which had been washed, heated red hot, and, after it had cooled, mixed with the ashes of barn-yard manure and of seed similar to those about to be planted. The opening of the globe was immediately covered with a cork, which was itself covered with a caoutchouc cap. Forty-eight hours after this had been done the cork was again removed, and enough pare water added to bathe the base of the pumice-stone, which had been disposed in a heap. Then the seeds were planted-they being inserted in a glass tube, which guided them to the place where they should lie. After the seeds were introduced, the tube was again closed, and, when the seed had germinated sufficiently, the confined atmosphere was charged with carbonic acid gas, by substituting in the place of the cork a second globe superposed on the first, having about one-tenth of the capacity of the first, and containing the acid gas prepared beforehand; the juncture between them was then filled with sealing-wax, and half of the apparatus was buried in the ground. The experiment was now abandoned to itself, and the experimenter had little more to do besides to observe the plants' progress, to take advantage of the opportune moment to transfer them to his laboratory. The result of M. Boussingault's experiments is, that there is no azote fixed in an appreciable quantity during the course of the vegetation: the azote of the seed passed into the plant, the azote of the air remained fixed in the air. M. Ville urges that a positive result is of more importance than a mere negative result; that he has, to sustain his position, the gramme of azote which he discovered in the plants he reared on a perfectly sterile soil; besides that, during his experiments, he ascertained the circumstances in which M. Boussingault placed his plants are peculiarly unfarorable to the health of the plant, and to the exercise of the function of assimilating: they pervert the function whose office they both are studying.

This discussion, although no positive results were attained, will nevertheless be read with interest.

The following is an abstract of a communication previously presented to the French Academy by M. Ville, on the absorption of nitrogen:-

After stating that it has often been asked if air, and especially nitrogen, contributes to the nutrition of plants, and, as regards the latter, that this question has always been answered negatively, the author remarks that it is, however, known that plants do not draw all their nitrogen from the soil, the crops produced every year in manured land giving a greater proportion of nitrogen than is contained in the soil itself. The question which he has proposed to himself for solution is, Whence, then, comes the excess of nitrogen which the crops contain, and, in a more general manner, the nitrogen of plants, which the soil has not furnished? Ile divides his inquiry into the three following parts :-

First. Inquiry into and determination of the proportion of the ammonia contained in the air of the atmosphere.

Second. Is the nitrogen of the air absorbed by plants?

Third. Influence on vegetation of ammonia added to the air.

1. The author remarks, that since the observation of M. Theodore de Saussure, that the air is mixed with anmoniacal vapors, three attempts have been made to determine the proportion of ammonia in the air; a million of kilogrammes of the air, according to M. Gräyer, contain 0.333 kil. ammonia ; according to Mr. Kemp, 3.880 kil. ; according to M. Frésenius, of the air of the day, $0.098 \mathrm{kil}$; and of night air, 0.169 kil. He states that he has shown the cause of these discrepancies, and proved that the quantity of ammonia contained in the air is 22.417 grms. for a million of kilogrammes of the air, and that the quantity oscillates between $17 \cdot 14$ grms. and $29 \cdot 43$ grms.

2. The author states that, though the nitrogen of the air is absorbed by plants, the ammonia of the air contributes nothing to this absorption. Not that ammonia is not an auxiliary of regetation, but the air contains scarcely 0.0000000224 , and in this proportion its effects are inappreciable. These conclusions are founded upon a great number of experiments in which the plants lived at the expense of the air, without deriving any thing from the soil. For the present, he confines himself to laying down these two conclusions: 1 . The nitrogen of the air 
is absorbed by plants, by the cereals, as by all others. 2. The ammonia of the atmosphere performs no appreciable part in the life of plants when vegetation takes place in a limited atmosphere. After describing the apparatus by means of which he carried on his experiments on the vegetation of plants placed in a soil deprived of organic matter, and the manner in which the experiments were conducted, he adduces the results of these experiments in proof of the above conclusions.

3. With reference to the influence of ammonia on regetation, the author states that, if ammonia be added to the air, vegetation becomes remarkably active. In the proportion of four ten-thousandths, the influence of this gas shows itself at the end of eight or ten days, and from this time it manifests itself with continually increasing intensity. The leaves, which at first were of a pale-green, assume a deeper and deeper tint, and for a time become almost black; their petals are long and upright, and their surface wide and shining. In short, when vegetation has arrived at its proper period, the crop is found far beyond that of the same plants growing in pure air, and, weight for weight, they contain twice as much nitrogen. Besides these general effects, there are others which are more variable, which depend upon particular conditions, but which are equally worthy of interest. In fact, by means of ammonia we can not only stimulate vegetation, but, further, we can modify its course, delay the action of certain functions, or enlarge the development and the modification of certain organs. The author further remarks, that, if its use be ill directed, it may cause accidents. Those which have occurred in the course of his experiments appear to him to throw an unexpected light upon the mechanism of the nutrition of plants. They have at least taught him at the expense of what care ammonia may become an auxiliary of vegetation. These experiments, which were made under the same conditions as those upon the absorption of nitrogen, are then described, and their numerical results given.

To the conclusions already stated, the author adds that there are periods to be selected for the employment of ammonia during which this gas produces different effects. If we conmence its use when several months intervene before the flowering season of the plants, it produces no disturbance; they follow the ordinary course of vegetation. If its use be commenced at the time of flowering, this function is stopped or delayed. The plant covers itself with leaves; and if the flowering takes place, all the flowers are barren.

\section{Chemical Investigation of the Phenomena of Vegetation.}

THe following are the details of experiments recently presented to the French Academy by M. Boussingault, on the phenomena of vegetation, the researches described being mainly undertaken for the purpose of settling the question, whether plants obtain their supplies of nitrogen from the atmosphere directly, by absorption:-

On the 17th of May, 1854, the author sowed three seeds of the garden-cress (Cresson alenoisa) in a flower-pot containing three kilogrammes of earth; and at the same time three similar seeds were placed in the same quantity of earth, enclosed in a glass vessel capable of containing 68 litres, which was then closed so as to exclude all air. On the 16th of June, the plants in the closed space were twice as large as those in the flower-pot, which had remained in the open air. On the 15th of August, the plants were collected: the enclosed plants had flowered normally, and bore the usual quantity of ripe fruit.

In the second series of experiments, the seeds were placed in a soil which had previously been calcined. To this the ashes of various plants were added. The plants vegetated in an air-tight case of plate glass, capable of containing about 104 litres. Air was then constantly drawn in by an aspirator, after passing over pumice-stone moistened with sulphuric acid. By a simple arrangement of the apparatus, carbonic acid was allowed to enter the receiver in such quantity, that the air carried with it from 2 to 3 per cent. of this gas. The pumicestone in which the seeds were placed was contained in pots containing 4 decilitres; the pots being previously heated to redness. The ashes were prepared with particular care, in order that no carbon should be mixed with them. The carbon, which is of no consequence in itself, would possess an influence if nitrogenous bodies were contained in the ashes. The amount 
of nitrogen in the ashes was carefully determined: they contain cyanides. The author found in one gramme of the ashes of

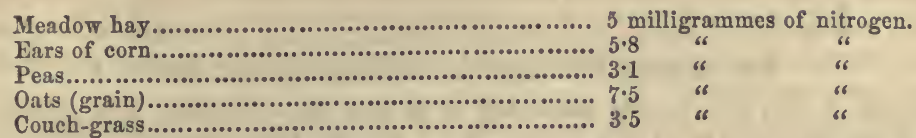

The mixed ashes mentioned in the following experiments were those obtained by the combustion of the stems and leares of beans and lupines: $1 \mathrm{grm}$. of these ashes contained $0 \cdot 1$ milligrm. of nitrogen. Besides this, the washed ashes of stable manure were frequently added. The seeds of beans and lupines employed in the experiment contained the following quantities of nitrogen: dwarf beans, 4.475 ; lupines, 5.820 per cent. The experiment lasted two months and a week. A seed weighing 0.337 grms., and consequently containing the amount of nitrogen stated below, was sown on May 12, 1854. The soil consisted of pumicestone, to which $0.05 \mathrm{grm}$. of mixed ashes were added. On July 19 th, the plant had eleven leares, and the cotyledons were withered. In this experiment, 37,000 litres of air were passed through the apparatus in which the plant was enclosed. The result of the first experiment was as follows: In this, as in all the other experiments, A represents the amount of nitrogen found in the plant and in the soil at the conclusion of the experiment, and $B$ the nitrogen contained in the seed from which the plant was raised. In this case no uitrogen was taken up by the plant:-

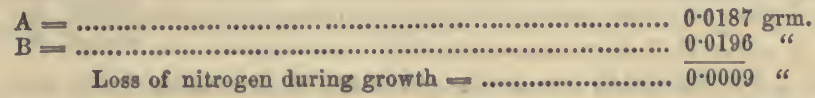

Vegetation of a Bean in two months and ten days. - The seed weighed $0.720 \mathrm{grm}$. It was sown May 14, 1854: $0.01 \mathrm{grm}$. of mixed, and 5 grms. of washed ashes, were added to the soil. On June 22d, the plant had six normal dark-green leaves. The seed-lobes were strong and very fleshy; they had withered on July $2 d$. The plant began to bloom on July 20th, when these leares had fallen from the stem. On July 25 th the plant bore four open flowers, twelve fully-developed leaves, of a pale-green color, and three young dark-green leaves: the stem was 23 centims. in height. The plant, dried on the water-bath, weighed 2 grms. During its growth, 41,500 litres of air had passed through the apparatus. No nitrogen was absorbed.

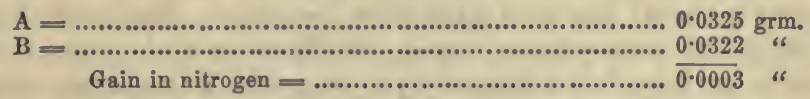

Two Beans vegetated for three months and a week. -The two seeds weighed $1.510 \mathrm{grm}$. They were sown on May 12th. The soil had added to it 0.3 of mixed, and 3 grms. of washed ashes. On July 17 th, the plants had twenty-six leaves and thirteen flowers. On the 25th, there wore four small, dark-green pods, and the leares were very pale. On the 10th of August, two of the pods were fully developed; they contained three well-formed seeds, nearly as large as those from which the plants were grown; they weighed 7 centigrms. The dried plants weighed 5.15 grms. During the experiment, 55,500 litres of air passed through the apparatus. Result:-

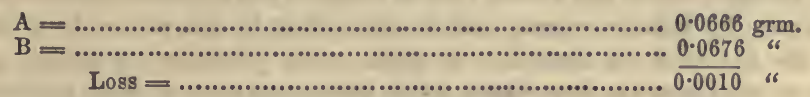

In this case, also, there was no absorption of nitrogen.

In the following experiments, all the preceding arrangements, as regards the soil, the addition of ashes and water, were retained; but the pots in which the plants were grown were placed so that the wind could not move their leaves, while the plants were sheltered from rain by a glass apparatus. They stood upon a balcony, 10 metres from the ground.

$A$ Bean vegetated for three and a half months in the open air.-The seed, which weighed 0.78 
grms., was sown on June 27th. Manure ashes were added to the soil. On October 12th, the plant bore one pod, containing a single imperfect seed. Result:-

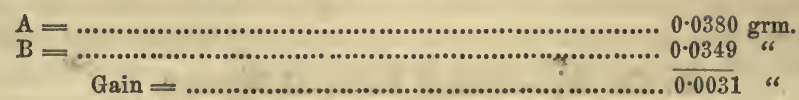

Vegetation of Oats three months and a half in the open air.-The stalk bore grains. Four grains of oats, weighing $0 \cdot 151 \mathrm{grm}$., were sown on May 20, 1852. Manure ashes were added to the soil. On September 1st, the plants had from six to nine leaves, and each of them a lateral shoot. The straws were very straight, end each bore a ripe, well-formed, but very small seed. The five seeds together weighed two centigrms. The dry plants weighed 0.67 grm. Result:-

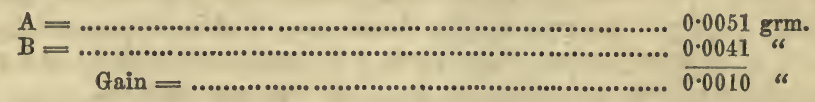

Vegetation of a dwarf Bean in two and a half months.-The plant was watered with water saturated with carbonic acid. The seed weighed $0.655 \mathrm{grm}$; sown May 17, 1853; manure ashes added to the soil. On July 9 th the plant had seven expanded flowers. On August 20 th the flowers had produced no fruit. The stalk was 33 centims. in height, and bore 15 leaves: the cotyledons and seed-lobes had withered, but still adhered. The plant was strong, and weighed $2 \cdot 72$ grms. Result:-

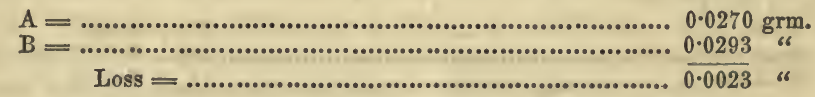

Vegetation of two Lupines in two months.-The two seeds weighed $0.630 \mathrm{grm}$.: they wero planted June 30, 1854. 2 grms. of washed ashes were added to the soil. On September 5th, each lupine bore eight leaves: the cotyledons were withered: the plants 11 centims. high:-

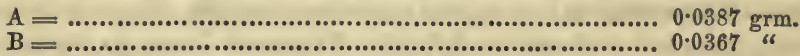

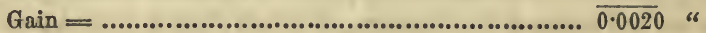

Vegetation of Cress in two months.-Seeds were produced. The seed weighed $0.50 \mathrm{grm}$., and was sown on July 15, 1854. The soil had an addition of $0.1 \mathrm{grm}$. of mixed, and $1 \mathrm{grm}$. of washed ashes. The water given to it was saturated with carbonic acid. The seed-leares were evolved on July 24th, and normal leaves appeared on the 30th. On August 6th, the seed-leaves were withered: they were taken off and preserved. The plants began to flower on August 18th. The leaves were very small. The flowering went on from the 18th to the 28th of August: the flower-leaves became dry in proportion as the upper ones flourished. On September 15th, each stalk bore a very small seed, although the fruit differed but little in size from that of garden-cress:-

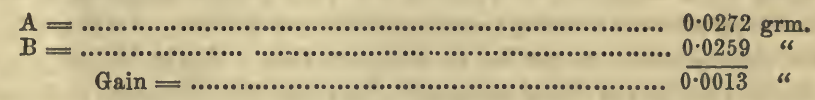

These last results of the vegetation of plants in the open air show that the quantity of nitrogen which may be absorbed from the atmosphere by plants is not greater than may be accounted for by errors of determination. It certainly appears that a little nitrogen was taken up. In his memoir, the author further refers to the question, whether this nitrogen is derived from the minute organic bodies which float in the air, or from carbonate of ammonia. He observed the formation of green spots, produced by minute green cryptogamia, on the outside of the flower-pots, which were never seen on those excluded from the air. He also saw those green filaments produced in rain water, which had been collected at the beginning of a shower, and kept in a flask. Bineau has observed that these filaments consume all the ammonia of rain water. The author concludes with some observations on the part played in regetation by the nitrogenous body pre-existing in the seed, or that formed by the aid of the manure. He describes the regetation of a plant from seeds which weighed only $\frac{1}{6}$ milligrm., and which must therefore have contained a scarcely ponderable quantity 
of nitrogen, and finds in the vegetation of this plant a convincing proof that the gaseous nitrogen of the atmosphere is not assimilated by plants.-Comptes Rendus, Oct. 2, 1854, p. 601.

\section{On the Agricultural Value of Gypsum.}

BY SAMUEL W. JOHNSON.

IT is nearly one hundred years since gypsum (plaster of Paris, sulphate of lime) began to acquire its agricultural significance. Since that time it has become celebrated on account of the successes that have attended its use; while the ill results, and want of results, that have followed its application, have not failed to make it many enemies. Franklin, in the United States, and Schubert Von Kleefeld,* in Germany, towards the close of the last century, simultaneously gave a great impulse to the use of gypsum. Within the last seventy years, an immense number of observations and experiments have been made with it; and yet to this day the method and condition of its action are very imperfectly understood.

Before we attempt to learn that which is now unknown, we must first of all carefully examine our existing stores of knowledge; we must have in mind all that has been done and learned relating to the subject: we thus acquire points of departure, discover the trails which may guide us through the maze, and save ourselves the trouble of repeating what has been already either well or vainly done.

What is gypsum? When pure and unburned, 100 pounds contain-

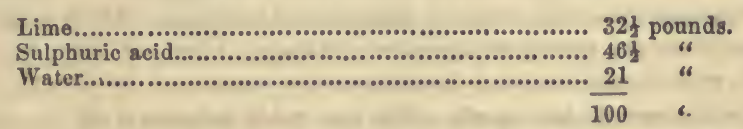

The water is in chemical combination with the sulphate of lime. By leating the compound, the 21 per cent. of water is driven off; and what remains, called burned or boiled plaster, consists in 100 parts of-

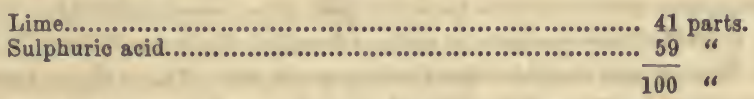

The agricultural effect of burned and unburned plaster, so far as we know, is precisely alike; for when the former is exposed to dews or rains, it immediately recovers its water, unless it has been too strongly heated, in which case it attracts water slowly or not at all. This attraction of water is in itself no advantage, for the water attracted combines chemically with the plaster, and can never be of avail to the plant any more than the water already contained in unburned gypsum. When the plaster has thus satisfied its chemical thirst for water, it has no more absorbent power for that substance than so much ordinary soil; and hence the notion that plaster helps vegetation to water, and is thus of agricultural value, is not supported by a particle of evidence. The advantages of burned plaster are, that it is more easily reduced to a fine powder, which facilitates its solution in water and its distribution throughout the soil. Besides, by its use the transportation of 21 per cent. of water is saved. On the other hand, unburned plaster is cheaper by so much as the burning costs; and burned plaster, if too strongly heated, may become a little less readily soluble in water. This latter consideration is not probably of much weight, so that it is reasonable to suppose that on the soil 79 pounds of plaster $=100$ pounds of unburned plaster. Actual experiments have failed to establish any superiority in the agricultural effect of one form over the other, in case both were equally pulrerized.

The above statements refer to pure sulphate of lime; but plaster, as quarried for agricultural purposes, often contains several per cent. of admixture, as clay, carbonate of lime, \&c. These are of little consequence unless their quantity be quite considerable. The presence of quick-lime in calcined may perhaps account for the ill success of some in fixing ammonia

* Schubert of Clover-field, so knighted by Joseph I, on account of his merit in extending the cultivation of clover. 
with help of gypsum; for, as is well known, caustic lime expels ammonia from all substances that contain it.

What crops are benefited by plaster?-It were not difficult to find authentic cases of plaster having proved useful on almost every field crop, and there is no lack of instances in which it has failed on every one. But the loose way in which the statements of farmers are often given to the public makes many of them of little or no value. It is a well-recognised fact that circumstances alter cases; when we know the circumstances, we can understand the difference in the cases. Usually, in the records of experience and experiment which we find in the papers, so few circumstances are taken into the account that we are actually no better enlightened at the end of the story than before; there is no making out the case. This is especially true of the statements with regard to plaster; and hence we find contradiction upon contradiction, and contradiction contradicted. It is not that statements do not contain the truth; they may contain nothing but the truth, but they rarely include the whole truth. This is not at present to be entirely helped, but there is vast room for improvement. In attempting, therefore, to give a summary of the results of practice in the use of gypsum, it is only possible to assume as facts those statements which have been confirmed by the according voices of many observers.

It is the result of all experience that plaster is especially advantageous to the cultivated leguminous plants - viz. clover, lucerne, esparsette, vetches, peas, and beans. Its effects upon clover in particular have been remarkable. European writers assert that to gypsum is largely due the introduction of clover into agriculture, and the many improvements that have followed its cultivation. On other crops it seems to be beneficial only by way of exception, and jet the exceptions are numerous and often striking. After the above-specified plants, tobacco, cabbage, rape, hemp, flax, and buckwheat are mentioned by Girardin as benefited by plaster. All writers agree that grain crops are rarely influenced by it. In the United States, gypsum has been reported useful on almost all crops. It is a favorite application to meadows. Professor Norton used to mention the case of meadows near Springfield, Massachusetts, on which the mere application of a few bushels of gypsum (two to three bushels, if I remember rightly) per acre ensured a good yield of grass, where otherwise the growth was very inferior. It is also very common to apply a handful of plaster to each hill of corn and potatoes at the time of planting, or when the plants are some inches high; how often profitably, we have no means of knowing. It has indeed been found useful on wheat.

There is obviously need of new trials on every kind of crop. We reasonably hope one day to learn under what circumstances plaster can be useful, even to those crops for which it is not usually recommended. Undoubtedly, those conditions which cause the occasional failure of plaster to benefit the leguminous plants, are closely related to those which make it more generally unreliable when applied to other crops; and the conditions that make it generally useful to the former, make it sometimes valuable for the latter.

What part of the plant is most developed by plaster?-With regard to this question, experience answers that the increased development of a plant consequent on the use of gypsum is disproportionately great in the stem and foliage: the production of seed is not greatly increased. This observation stands naturally connected with the fact that plaster is most efficacious on those plants used for fodder which yield a large mass of vegetation, and least valuable on the grains which are cultivated mostly for their seed. Tobacco and maize, which have much foliage and stem, potatoes, which develope much foliage under cultivation, and produce fleshy tubers and little seed, are further examples. A few experiments are on record in which plaster applied to peas produced a decided increase of straw, but hardly affected the amount of seed. Stockhardt, however, says that the seed-production is usually increased, though not proportionately to the straw.

The effect of gypsum on the quality of the plant.-Whether crops, which have attained a larger growth in consequence of the use of gypsum, contain a larger proportion of sulphuric acid and lime than similar crops produced by the same without plaster, is not yet fully ascertained, since experiments made to determine this point have not agreed in their results. New investigations would easily settle this matter-one very important for the theory of the action of plaster. 
It is well known that peas often refuse to cook soft, even after hours of boiling. The reason of this is not at all understood. It has been asserted that manuring the crop with plaster gives the peas this quality; but the contrary is also asserted. This is a point to bo studied.

Influence of the soil on the action of plaster.-The character of the soil must necessarily greatly affect the operation of this fertilizer. A soil already rich in sulphate of lime of course cannot be greatly benefited by addition of more. A poor, light, or exhausted soil, deficient in mineral plant-food, as phosphoric acid, potash, \&c., cannot be expected to become fertile by treatment with plaster; for this substance cannot supply those matters which are wanting, and without which no plant can flourish. Cold, wet, heary, and impenetrable soils are usually almost unaffected by plaster; sometimes, its use has been apparently disadvantageous on them. Porous soils, either sandy or loamy, which readily dry after rains, and which are well dunged, experience the most benefit from plastering. Excess of moisture and poverty of the soil are the chief hinderances to the action of gypsum. On lime and chalk soils it is no less effectual than on others. In general, it may be stated that unless the other conditions of good culture be observed and provided for, the farmer who uses gypsum will "lose his money and his trouble." It is undoubtedly a fact, that the circumstances which insure the best effect from gypsum are nearly identical with those which are otherwise most favorable to vegetable growth.

Effect of climate and weather.-Countries, like South England, the greater part of France, Bohemia, \&c., where, on account of the vicinity of the sea, or the existence of forest and hill ranges, the climate is uniform; and where, during the growing season, the rain-falls are frequent, but moderate; where, in other words, it is neither too wet nor too dry, -there gypsum stands in greatest favor. It is doubtless the fact that the frequent wetting of the soil assists the action of plaster by bringing it into solution; yet the weather probably exerts more influence on the plant itself directly than on the action of the plaster with which it is manured. Climate modifies the conditions of vegetable growth to a wonderful degree. In the more northern part of our temperate zone, a stiff clay soil is very intractable and unproductive; while in Egypt, where it never rains, a similar soil yields the most profitable returns. We should, therefore, expect to hear from a Canadian farmer that plaster has little good effect on clay soils; while in the warmer South, they might be benefited most of all.

Quantity and time of application.- In England and Germany, it has been found that 250 to 400 pounds per acre is the best quantity to apply. The advantage of larger applications is usually very inconsiderable. Gypsum is usually applied in the spring, and in case of clover, \&c., when the vegetation is 3 to 4 inches high. In the United States, it is applied to corn and potatoes in the hill at planting, but more frequently when they have attained the abovementioned height.

Many farmers are of opinion that plaster acts best when it remains adhering to the leaves for some time. Accordingly, it is highly recommended to sow plaster just before or after $a$ gentle rain, or when the dew is on the plants. Warm, moist weather insures the full action of plaster. If the weather be cold at the time of sowing, its effect is stated to be very insignificant. This is, however, doubtful. In Germany, the first of May is generally considered the best season for plastering; and experiments made in Saxony, especially to ascertain the most favorable time, have confirmed the opinion. Not a few, however, deem it indifferent whether the plaster adhere to the plant or fall directly upon the soil.

Dombasle employed the following method: He plastered his meadows at the time of seeding, and repeated the dose in the following spring. Clover treated in this way grew very luxuriantly, sometimes even to the detriment of the grain with which it was sown. It is reported that clover thus plastered is less injured by frosts, and is ready to cut a week or two earlier than when gypsum is not applied.

Duration of effect.-According to Girardin, "experience has established that plastering (of clover?) should not be repeated oftener than once in five or six years, if any action is to be expected from it." Other writers agree in admitting that its benefit continues nearly or quite as long. Its effect has often been observed to be greater the second than the first year after application, and is often unabated the third season. The duration of its action is doubtless 
somewhat dependent on the quantity applied, and must be materially influenced by the weather in the second, third, and following seasons, as well as in the first.

I have thus given a condensed statement of the results and opinions of practical men relative to the use of plaster. The conclusion adopted are those which are sustained by the majority of facts. It is apparent what uncertainty prevails". in our knowledge of this subject. It remains, by means of new and more careful observations and by more rigid experiments, to determine the actual value of these statements, and to acquire additional information.

Hundreds of single results that have been published are of no value whatever in deducing general rules, because the ragueness of many agricultural terms makes it impossible to know what degree of truth a statement possesses. A soil is a very complex thing, and may include many conditions which effect the action of a fertilizer; yet in a report of a trial of plaster we find nothing written of the soil except the prefix clayey, or sandy, or loamy. The important characteristics upon which the whole result of the experiment hinges may never be recognised nor mentioned; and hence, while the fact is true that the crop was benefited or not, we have no logical ground to assume that any of the mentioned causes or circumstances had any thing to do with the effect, more than a number of other unnoticed causes which must have been present and operative.

Admitting that much remains to be learned, still it is evident that for practical purposes so much may be accepted-viz. :

1. Leguminous plants are especially benefited by plaster, while-

2. All other plants of large foliage, whose agricultural value does not consist in the production of seed, are usually aided by it in growth, upon-

3. Soils not already containing sulphate of lime, but-

4. In which all other parts of mineral plant-food are present in available form, and in sufficient quantity; which are, in practical language, well dunged, if not rich without manure; and which, further,

5. Present no physical obstacles to vegetable growth-which are dry, sufficiently porous, and well tilled, when-

6. The climate and weather are favorable to vegetation, when the temperature is mild, and rains are frequent but moderate.

Does plaster exhaust the soil.-This frequently-asked question is easily answered, and by the word no. A soil is never exhausted by what is added to it, but always by what is removed. But a little explanation is needed, for although plaster cannot exhaust the soil, plastering is usually followed by exhaustion; and for the simple reason, that by its use nothing but sulphate of lime (ammonia indirectly?) is added, while phosphoric acid, potash, silica, \&c. are removed. A purse soon gets empty if eagles are constantly taken out, though cents be now and then put in. The crops which plaster enables the farmer to remove from the soil exhausts it. Suppose that a few bushels of plaster raise the yield of clover upon a field ten per cent.; then, ten per cent. more of phosphoric acid, potash, \&c. pass from the soil into the crop than would have passed had no plaster been used. If plaster only be added, then the field will be exhausted in one-tenth less time than if nothing at all had been applied. In both cases, the total amount of vegetation produced until exhaustion supervenes will be the same, and the amount of exhaustion the same. In the one instance, the final result might be reached in ten years; in the other, in nine years. The difference is merely one of time. If benefit is to be derived from the use of plaster, it must be accompanied with other manure, or its action, however good at first, will ultimately cease. Manuring a poor soil with nothing but plaster is attempting to sustain vegetation on plaster alone; and this, like feeding children on little else than arrow-root, is a stupendous folly. It is trying to build brick houses without brick. Plants cannot be made of sulphate of lime any more than men can be made out of starch. "Out of nothing, nothing comes." The healthy plant is the result of the co-operation of many causes - the coincidence of many conditions. One cause, one condition can only act favorably when all the others but this are present. There is, there can be, no agricultural panacea. 


\section{New Method of Determining Nitrogen.}

DR. Srmpson, of Dublin, has presented to the Chemical Society a communication respecting a new process for estimating nitrogen. There are two modifications of his method. The first served for determining the comparative amount of nitrogen and carbonic acid formed during the combustion of an azotized organic substance. It did not differ widely from Liebig's process now in use, except that oxide of mercury, diluted with oxide of copper, was employed for burning the substance, and chlorate of potash was placed at the end of the tube to yield a supply of oxygen. The absolute method resembled Dumas's in principle; carbonate of manganese, however, being the substance employed for the production of carbonic acid, and some peculiar arrangements being introduced, especially in the receiver over the mercury trough. These processes had been worked out in Bunsen's laborntory; and were equally applicable to the determination of nitrogen in such substances as the vegeto-alkaloids, in nitrates, or in salts of ammonia.

\section{Phosphate of Lime-A New Test.}

THF action of boracic acid upon the phosphate of lime, as described by C. Tissier in the Comptes Rendus, (Paris,) is exceedingly interesting to agricultural chemists: If to an acid solution, either nitric or muriatic, containing phosphate of lime (or a soluble phosphate and chloride of lime) and an excess of boracic acid, there be added borate of soda in sufficient. quantity to saturate the acid which holds the phosphate in solution, no borate of lime is precipitated, but all the phosphoric acid is thrown down in the form of phosphate of lime. This precipitate has not a variable composition, like that formed by being saturated with ammonia, but has a constant composition and a well-defined formula. It corresponds with that for which Berzelius gives the formula, $8 \mathrm{Ca} .0,3 \mathrm{P} \mathrm{O}^{5}$, and which contains phosphoric acid, 49.09 ; lime, 50.91. This method of precipitating phosphoric acid from its solution will greatly facilitate the determination of the quantity of phosphates contained in soils and manures.

\section{Value of Soil-Analyses.}

At a late meeting of the Farmers' Club in New York, Prof. Mapes adduced the following circumstances, as showing the value of soil-analyses:-At the meeting of the National Agricultural Society in Washington, Mr. G. W. Custis stated that he was owner of the Arlington Estate, containing $80 \mathrm{me} 5000$ acres of land and several hundred negroes. For several years he had found it necessary, in order to pay his own expenses and those of his family, (including the negroes,) to mortgage the estate. He had an analysis made of his soil, with a view to ascertain its deficiencies for a wheat crop, and, under proper instructions, he had those deficiencies supplied; and "Now," said he, "gentlemen, I can say, instead of mortgaging my estate, I am continually lessening the mortgages I had previously obtained, and this year $\mathrm{I}$ have ten thousand bushels of wheat for the miller, while until the analysis was made I never was able to sell a single bushel of wheat above what was used for the hands." Mr. John Jones, of Delaware, the largest wheat-grower within two hundred miles of Washington, said he bought a farm for $\$ 10$ an acre, which he agreed to pay in small instalments and on a very long mortgage; the owner being glad to sell at that low price and on those easy terms. When he commenced operations, his first crop of wheat was some seven or eight bushels to the acre, on the plan of cultivation usual in the neighborhood. He sent his soil North to have it analyzed. On the basis of the analysis he planned his operations; and, "Gentlemen," said he, "I raised a larger crop of wheat than any other man within the same distance of Washington. The assessors this year valued my land at $\$ 70$ an acre, calculating from the value of the crop of wheat." These cases had come under his (Prof. M.'s) supervision, and the preparation which he recommended, after analyzing the soils, was a mixture of guano with bones dissolved by sulphuric acid. They had added sulphate of ammonia, which had cost them only as much as the carting of barn-yard manure had usually 
cost. The soils of those gentlemen contained rather more potash than usual. But he had yet to find the first soil which is not capable of being benefited by the addition of the superphosphate of lime.

\section{Phosphates in Turnips.}

LIEBIG, in his recent work, appends the following note on the amount of phosphates found in turnips. The note occurs in connection with the following sentence, and: has special reference to some experiments of Messrs. Lawes and Gilbert, of England, which are in opposition to the views of Liebig:-

"The small percentage of phosphates contained in the turnip is the reason why, in Germany and France, there is often obtained after grain a stubble crop of this root in the same year."

- The note is as follows:-

"If we calculate from the results of ash-analyses the quantities of phosphoric acid which are required respectively by a wheat crop, including grain and straw, and by a turnip crop, including roots and leaves, we find that wheat removes less of this substance from the soil than turnips. This result is apparently in contradiction to the fact so well established by practical experience, that wheat requires more abundant supplies of phosphoric acid in the soil than the turnip. The two facts become reconciled when we take into account the longer time that the latter has in which to accumulate this mineral ingredient.

"The turnip requires phosphoric acid to be supplied through the whole of its long period of growth, four or five months, but uniformly and always in small quantity only in a given time. Wheat needs the greater share of its phosphoric acid during the growth of the seed. This is the period in which, as practical men believe, the soil suffers the greatest-is most exhausted. If the wheat-plant finds a sufficient quantity of phosphoric acid within reach of its roots during the few weeks in which its seed is formed, then each kernel attains a full and normal development; if there be a slight deficiency of phosphoric acid, then the seeds are less numerous or less large; if the deficiency be very considerable, then nothing but straw is produced.

"The quantity of phosphoric acid which a wheat soil should contain does not therefore stand in relation to the sum total which the plant needs, but to the quantity which the kernels require during the period of their development.

"When we compare the quantity of phosphoric acid which the soil must yield to a wheat crop during the month in which its seeds are forming, with that needed by a turnip-crop in any equal space of time, it is plain that wheat requires the presence of a far larger amount of this indispensable body in the soil than the turnip. This is a fact not to be disregarded in manuring the soil for these crops.

"The produce of a field stands related to the amount of that mineral ingredient which its soil contains in smallest quantity.

"As a general rule, the manuring of a field should not be calculated from the sum total of mineral ingredients which the plant takes from the soil, but must be proportioned to that maximum of these substances which is required by the plant in a certain period of its growth."

In respect to the above, Mr. S. W. Johnson, of England, in a letter published in the Working Farmer, says:-

"The above makes evident how necessary it is that not only the kind and quantity of substances removed by a plant from the soil be considered, but also the time and cireumstances in which the supply should be made. The latter are of equal moment with the former. Plants differ physiologically and structurally. These differences must be investigated, and taken into account. The chemist has hitherto too much neglected them. He has attempted in many cases to deduce the whole list of the plant's chemical needs from its chemical analysis. Nothing could be more fallacious. He has found that an average crop of wheat and tarnips contain nearly the same amount of phosphoric acid. He cannot, therefore, conclude that, so far as this ingredient is concerned, they will both flourish equally in the same soil." 
Messrs. Lawes and Gilbert deduced from their experiments that turnips require more phosphoric acid in the soil than wheat, because that, on what they considered an exhausted soil, the addition of superphosphate of lime enabled them to raise turnips. Prof. Liebig, in his new work, has objected to this that the soil was not exhausted, as is proved by the fact that it yielded tolerable crops of wheat; and expresses his belief that the yield of turnips was not due to the supply of phosphoric acid, but to the solrent action exercised on the silicates of the soil by the free sulphuric acid of the agricultural superphosphate which was applied in large quantities. The considerations contained in the above note explain why wheat requires a soil richer in phosphoric acid than the turnip does.

It is an interesting fact that a soil does exist which produces wheat, but refuses entirely to grow turnips, as the experimental soil of Messrs. Lawes and Gilbert. In the majority of cases we should expect the reverse. This shows the danger of too hasty generalization, and the importance of having a thorough knowledge of all the circumstances which act in any particular case.

\section{On the Amounts of Ammonia and Nitric Acid in Rain Water.}

Ar the British Association, Dr. Gilbert and Mr. Lawes communicated the results of their investigations on the amounts of ammonia and nitric acid in rain water. Their results during many months of the last two years were tabulated and compared with those of Boussingault; the great result being that rain water contains not quite one part of nitrogen to the million in the form of ammonia, and about five parts to the million in that of nitric acid. The ammonia is found in largest quantity in mists and dews, as might naturally be expected from its being evolved at the surface of the earth, and being absorbed by any moisture. In answer to questions put to him afterwards, Dr. Gilbert stated that the nitric acid was found most abundantly after storms, and varied very greatly at different periods of the year. The amount of ammonia which descended in a month's rain was more constant. The doctor expressed his opinion, but with hesitation, that nitric acid and ammonia were about equally efficient in supplying nitrogen for plants; and therefore, as nitric acid is the more abundant in the atmosphere, he conceived that it afforded actually the larger quantity of azote to the vegetable world.

Boussingault has recently published some additional researches on the above subject, from which it appears that the rain of the country contains less ammonia than that of the city, and that the ammonia is more abundant at the beginning than at the end of a shower. He has also examined the dew, and always found it to contain ammonia. The proportions by several trials were six milligrammes to the litre; but the amount is reduced to 1.02 after a rainy day. On the 14 th to the 16 th of November, a thick mist prevailed so rich in ammonia that the water had an alkaline reaction; a litre of the water contained about two decigrammes of carbonate of ammonia. Seventy-five rains, including the dew and mist examined, contained as a mean half a milligramme of ammonia. The great quantity of ammonia contained in the mist appears interesting in its bearing on vegetable pathology; in fact, although ammonia in small quantity is favorable to regetation, a large proportion would be injurious, and would show its effects, especially on the leaves of flowers. Moreover, such a storm might have a deleterious influence upon respiration, and especially on the lungs of persons with pulmonary affections.

\section{New Theories in Agricultural Science.}

M. BAdDrimont, professor of chemistry at the Faculty of Sciences at Bordeaux, has published a work "On the Existence of Interstitial Currents in Arable Soil, and the influence which they exert on Agriculture," in which, after a long study of the subject, he states that there is a natural process at work by which liquid currents rise to the surface from a certain depth in the ground, and thus bring up materials that help either to maintain its fertility or to modify its character. Many phenomena of agriculture and of vegetation have at different times been observed, which, hitherto inexplicable, are readily explained on this theory. Such, for example, the improvements which take place in fallows; and there is reason to believe that these currents materially influence the rotation of crops. 
In Germany, Schleiden is attracting much attention by his masterly views on the phe nomena of vegetation; and it will surprise many to hear that he admits of no relation between the fertility of a soil and the quantity of fertilizing matters expended upon it. "The goodness of the soil," he says, "depends upon its inorganic constituents, so far, at least, as they are soluble in water, or through continued action of carbonic acid; and the more abundant and various these solutions, the more fruitful is the ground." Arguing from this riew, it is not richness of soil or humus that produces the multiplied varieties of Alpine plants in Germany, or the absence of it that produces but few. "Soluble mineral constituents" are shown to be the characteristic of our cultivated field; and "an agricultural plant" is defined as one "distinguished from wild individuals of the same species by peculiar qualities which constitute its fitness for culture, and which depend upon a modification of chemical action." The amazing yield of Indian corn in Mexico-from two hundred to six hundred-fold-is something which, with all our skill, we cannot accomplish, and is a fact in favor of the argument "that in no case do the organic substances contained in the ground perform any direct part of the nutrition of lants." The annual destruction of organic matter all over the earth is estimated at one hundred and forty-five billions of pounds, equal to two and one-fourth billions of cubic feet; and if all vegetation depends on organic matter for nutrition, to satisfy this consumption "there must have been, five thousand years back, ten feet deep of pure organic substance on its surface." Another illustration is furnished by taking the number of cattle and other animals in France in a given year, (1844,) and observing the amount of food they consume. The process of nutrition would require $76,789,000,000$ pounds of organic matter; six times more than the whole number contribute of organic matter towards reproduction, and in one hundred years "the whole organic material of the country would be consumed."

Again: look at a farm. How much more is carried off from it than is given back again! Generally the amount of its yield is three times greater than that of the organic matter it receives; while of the manure applied, the greater part is not taken up, but imperceptibly decomposed. Carbon is the most important of the constituents of plants: an acre of sugar plantation produces 7500 pounds of canes, of which 1200 pounds are carbon, and yet sugar plantations are rarely manured, and then only with the ashes of the burnt canes. With bananas the result is still more striking: the yield is 98,000 pounds of fruit in a year from a single acre, and of this 17,000 pounds-more than a fifth-is carbon; and the same acre will give the same return year after year for twenty or thirty years; and the ground at the end of that time will be richer than at the commencement, from nothing more than the decay of the large leaves of the plant. Here in Europe, too, the difference in weight and in carbon between the seed and the produce has often been noted: in wheat, 89 per cent; in red clover, 158 per cent.; and in peas, 361 per cent. These facts afford evidence of a supply of carbon derived from other sources than those commonly supposed to exist; and while we know that seeds will germinate and become vigorous plants in pure quartzose sand, or in cotton-wool, or on a board, we seem to have proof that the chief source of supply is the atmosphere. This is an interesting point, which further research will verify: Schleiden shows the process to be eminently simple. He says, in his work, of which a translation has been published by the Horticultural Society-"According to Link, Schwartz, and others, an acre of water-meadow contains 4400 pounds of hay, which, when dry, contains $45 \cdot 8$ per cent. of carbon. The hay then yields 2000 pounds of carbon, to which 1000 pounds may be added for the portion of the year in which the grass is not cut, and the roots. To produce these 3000 pounds of carbon, 10,980 pounds of carbonic acid is requisite, which may be raised to 12,000 pounds, to compensate for the nightly expiration. Now, Schubler has shown that an acre of so wretched a grass as Poa annua exhales in 120 days (too low a computation) of active vegetation, $6,000,000$ pounds of water. To supply the exigencies of the plants, therefore, it is only necessary for the meadow to imbibe $3 \frac{1}{2}$ grains of carbonic acid with every pound of water.

Mr. Lawes has found, also, that in a plant of any one of our ordinary crops, more than 200 grains of water must pass through it for a single grain of solid substance to accumulate within it. He states the evaporation from an acre of wheat during the period of its growth to be 114,860 gallons, or $73,510,000$ gallons per square mile. With clover, it is rather more; with peas and barley, less. When we apply these calculations to a county or a kingdom, we 
are lost in the magnitude of the processes by which nature works; but we see the more clearly that, on such a scale, the quantity of material supplied by the air, though minute to the individual, becomes vast in the aggregate. We see, moreover, the necessity for understanding the relations between evaporation and rate of growth, and the laws and effects of absorption in soils. A thousand pounds of dry calcareous sand will gain two pounds in weight in twelve hours when the air is moist, while pure agricultural clay will gain thirtyseven pounds.

The source of nitrogen comes next to be considered; and this also is seen to be independent of manures. Hereupon, it is observed that "our domestic plants do not require a greater supply than in a state of nature. A water-meadow which has never received any dung, yields yearly from forty to fifty pounds of nitrogen, while the best plowed land yields only about thirty-one pounds. The plants for which most dung is used, as potatoes and turnips, are in fact proportionally the poorest in nitrogen." That there is a supply independent of the soil, is further seen in the millions of hides furnished every year by the cattle of the Pampas, without any diminution of produce; and in the great quantities of nitrogenous matters, hay, butter, and cheese, carried off from pasture-land; far more than is returned by the animals fed thereon. Experiments with various kinds of plants on various soils have satisfactorily demonstrated that increase of nitrogen in the land and in the crop does take place, quite irrespective of supplies of manure.

With respect to ammonia, "it appears that one-thirteenth of a grain in every pound of water is sufficient for the exigencies of vegetation, and there is perhaps no spring-water in the universe which contains so little." Then as to sulphur and phosphorus, which are also among the constituents of plants, the quantity needed in proportion to the time of regetation is so small, that 540,000 th of a grain of sulphuretted hydrogen per cubic foot, diffused through the atmosphere to a height of 3000 feet, is all that is required.

The consideration that cereals would soon disappear from the north of Europe, if not cultivated, and perhaps from nearly the whole of this quarter of the globe, adds weight to the arguments in favor of enlightened attention to the inorganic constituents of plants. The point is to bring the soil into harmony with the conditions by which growth may best be promoted. Much depends on the nature of the soil; the darkest-colored lands are generally the highest in temperature; hence the advantage of vegetable mould; while deep, light sands, and clay, which turns almost to stone in dry weather, weary and vex the cultivator by their unprofitableness. It is to be remembered, however, that soils which have the highest temperature of their own, may not be those most susceptible of receiving heat-that is, from the sun, because some lands are warmed by the springs that irrigate them. Here we have an explanation of the phenomena of certain soils which are warm in winter and cool in summer. The application of humus evolves heat by the process of combustion; and sand, lime, clay, and humus are the combinations needed, the clay being in a proportion of from 40 to 50 per cent.; if less than 10 per cent., the land will be too light and poor.

Although Schleiden's views apply chiefly to the practice of German agriculturists, they will be found to bear on the whole science of cultivation. In summing up, he insists strongly on the necessity for selecting good seed; that from a barren soil, he observes, is likely to be more true to its kind than from well-manured land. Also, that the time of sowing should be adapted to the requirements of the plant; rye and barley, for instance, should be sown in drier weather than oats. And it will surprise many to read that he advocates a less frequent use of the plow. He holds plowing to be a "necessary evil, one to be employed only so far as necessity requires;" because, by the too frequent loosening of the soil, the decomposition of humus is so rapid as to overbalance the benefit supposed to arise from exposure to the atmosphere. He shows, too, that covered fallows are in most cases preferable to naked fallows, as the latter tend to waste the valuable qualities of the soil; while, in a field sown with clover, the quantity of humus and carbonic acid is increased by the leaves preventing evaporation. Naked fallowing is to be adopted only when the soil cannot be loosened in any other way; but there is to be no stand-still; "the notion of rest, so prevalent among cultivators, is clearly wrong, except it be rest from the destructive influence of the plow:" and always must it be borne in mind "that manures do not act immediately on regetation by 
means of their organic contents, but by reason of the inorganic substances which they involve."

Such is a brief outline of some of the views of one who holds a high position among men of science; and though in some particulars they may seem to be at variance with practice in this country, there is much in them worthy the attention of intelligent cultivators. It is remarkable how different branches of science help in advancing the question, and facts arise in support of the philosopher's theories. By a recent inquiry into the amount and nature of the rain-fall at the observatory, Paris, it has been proved, that from the 1st of July, 1851, to the end of 1852 , the quantity of azote combined therewith was-omitting fractions-22 kilogrammes per acre, being 12 kilogrammes in the form of azotic acid, and 10 kilogrammes of ammonia. The quantity of uncombined ammonia in the same time was 13 kilogrammes per acre; and of uncombined azotic acid, 46 kilogrammes. In the months when azotic acid was most abundant, there was least ammonia; the former always increases with stormy weather. Besides these elements, the quantity of chlorine present was equivalent to 18 kilogrammes of marine salt, leaving out the insoluble matters held in susponsion.

In all this we seem to get a glimpse of the law of supply and demand in the great vegetative operations of nature; and we see that those who advocate a more sparing employment of manures are not without good reason for their arguments. In the middle of Russia, corn is grown year after year on the same land, with no other fertilizer than the burnt straw; and in parts of Spain, wheat and barley succeed each other without any manure at all. And, without going so far for facts, we have them close at hand, in one of our midland counties. A few years ago, the Rev. S. Smith, in the neighborhood of Banbury, England, instituted a course of experiments on this very point, and with results which are singularly interesting. He took a field of four acres, having a gravelly soil, with clay, marl, and gravel as the subsoil. It had been hard worked for a hundred years; but except a thorough plowing, no other means were taken to improve it: not a particle of manure was supplied. Wheat was then sown in single grains, three inches apart, and in rows a foot apart, a space of three feet being left quite bare between each three rows, and this was continued in alternate stripes all across the field. The sowing took place at the begining of autumn; and in November, when the planted rows began to show, all the intervening three-feet spaces were trenched by the spade, and six inches of the subsoil made to change places with the surface. "In the spring," says the reverend agriculturist, "I well hoed and hand-weeded the rows of wheat, and stirred the intervals with a one-horse scarifier three or four times, up to the very period of flowering in June." The crop looked thin and miserable until after April, when it began "to mat and tiller;" it did not turn yellow in May, and the stalk grew so stout and strong as to bear up well against the storms. When harvested, the result was highly gratifying, for the yield amounted to from thirty-six to forty bushels per acre, or rather per half-acre, seeing that as the alternate stripes were left bare, only onehalf of the field was really planted. The quantity of seed used per half acre was a little more than a peck.

Adjoining the field in which these experiments were carried on was another which had four plowings, ten tons of manure, six or seven times as much seed, and yet it gave a quarter less to the acre. This might be looked on as an accident, were it not that Mr. Smith has repeated his experiment year after year, and always with greater success. He believes that if all the conditions be literally fulfilled, the same favorable result may invariably be obtained. No manure whatever is to be used; and in the second year, the stripe is to be sown which was left bare in the first; and so on, changing from one to the other, year after year.

Here arises the question as to cost, and in contrasting the expense of plowing with that of spade-labor, he finds that he takes up only so much of the subsoil as the atmosphere will readily decompose in the year-four, five, or six inches, descending gradually to two spits. He employs six men at $2 s$. a day, and they dig an acre in five days, making an outlay of $60 s$. for the whole; but as only one-half is to be dug for the year's crop, the time and cost are reduced by one-half, and thus brought down to the cheapest rate of plowing. The cost per acre, in the instance above mentioned, was $£ 314 \mathrm{~s}$; the return from the four quarters and two bushels of wheat and the straw, $£ 11$ 14s., leaving a profit of $£ 8$. It should be under- 
stood that the cost includes rates, taxes, interest, scarifying, reaping-in short, all the operations from digging to harvest.

The parish in which Mr. Smith resides contains two hundred wheat-growing acres; he calculates that fifty laborers would have dug these in two months and eight days, so that, beginning the last week in September, all would be finished by the first week in December, leaving five months for the occurrence of casualties and their reparation before the crop has grown. His system, after the first plowing, it will be seen, is based entirely on spadehusbandry; he is of opinion, that it is applicable to thousands of acres "of hitherto impracticable and unremunerating clay." •

Schleiden and Smith agree in their faith in nature's unassisted fertilizing powers, if not in their mode of clearing the way for the exercise of those powers. The system of the latter combines fallow without loss, for the yield is double; nature is left to drop the ammonia, and the time is given for its combination with mineral matters in the soil. The atmosphere contains all the organic elements of wheat, and if the ground be kept stirred, uncrusted, and loosened to a suitable depth, they will find their way in; and nitrogen even, as late experiments demonstrate, will be absorbed. As for inorganic constituents, Mr. Smith believes that they always exist in sufficient abundance, if sought for by frequent digging.

\section{Capillary Attraction of the Soil.}

From numerous observations which have been made at different times on the peculiar appearance of the surface of soils, clays, \&c., during the warm summer months, and the fact that they, when covered with boards, stones, or other materials, so as to prevent them from supporting vegetation, become, in a comparatively short time, much more productive than the adjacent uncovered soil, led to the belief that the soil possessed some power within itself, aside from the roots of plants, of elevating soluble materials from deep sources to the surface.

To throw some light upon the subject, in May, 1852, I sunk three boxes into the soilone, forty inches deep; another, twenty-eight inches deep; and a third, fourteen inches deep. All three of the boxes were sixteen inches square. I then placed in the bottom of each box three pounds of sulphate of magnesia. The soil to be placed in the boxes above the sulphate of magnesia, was then thoroughly mixed,"so as to be uniform throughout; the boxes were then filled with it. This was done on the 25th of May, 1852. After the boxes were filled, a sample of soil was taken from each box, and the percentage of magnesia which it contained accurately determined. On the 28th of June, another sample of surface soil was taken from each box, and the percentage of magnesia carefully obtained as before. The result in each case pointed out clearly a marked increase of magnesia.

On the 17th of July, a sample of the surface soil was taken for a third time from each box, and carefully examined for the magnesia. Its percentage was found to be very perceptibly greater than on the 28th of the preceding month. On the 15th of the months of August and September following, similar examinations severally were made, with the same evident gradual increase of the magnesia in the surface soil.

The following are the results as obtained :-

\begin{tabular}{|c|c|c|c|}
\hline & $\begin{array}{c}\text { Box } \\
40 \text { inches } \\
\text { high. }\end{array}$ & $\begin{array}{c}\text { Box } \\
28 \text { inches } \\
\text { high. }\end{array}$ & $\begin{array}{l}\text { Box } \\
16 \text { inches } \\
\text { high. }\end{array}$ \\
\hline 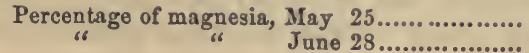 & $\begin{array}{l}0.18 \\
0.25\end{array}$ & $\begin{array}{l}0.18 \\
0.30\end{array}$ & $\begin{array}{l}0.18 \\
0.32\end{array}$ \\
\hline July $17 \ldots . . . . . . . . . . . .$. & 0.42 & 0.46 & 0.47 \\
\hline Aug. $15 \ldots . . . . . . . . . . . .$. & $0 \cdot 47$ & 0.53 & 0.54 \\
\hline Sept. $15 . . . . . . . . . . . . . .$. & 0.51 & 0.58 & 0.61 \\
\hline
\end{tabular}

Before the middle of October, when it was intended to make another observation, the fall rains and frosts had commenced; on this account the observations were discontinued. The elevation of the magnesia, as shown in the above experiments, depends upon capillary attrac- 
tion, or the property which most liquids have to rise in tubes, or between plane and curved surfaces.

The minute interstices between the particles composing the soil are, to all intents and purposes, small tubes, and act as such in elevating moisture from below to the surface. The particles held in solution by the water are likewise elevated with it, and are left, on the evaporation of the water, distributed throughout the surface soil. This explains the reason why manures, when applied for a short or longer time upon the surface of soils, penetrate to so slight a depth. Every agriculturist is acquainted with the fact that the soil directly under his barn-yard, two feet below the surface, (that is, any soil of any ordinary fineness,) is quite as poor as that covered with boards or otherwise, two feet below the surface, in his meadow; the former having been for years directly under a manure-heap, while the latter, perhaps, has never had barn-yard manure within many rods of it. The former has really been sending its soluble materials to the surface soil, the latter to the surface soil and the vegetation grown near, or upon it, if uncovered.

The capillary attraction must vary very much in different soils; that is, some have the power of elevating soluble materials to the surface from much deeper sources than others. The pores or interstices in the soil correspond to capillary tubes. The less the diameter of the pores or tubes, the higher the materials are elevated; hence, one very important consideration to the agriculturist, when he wishes nature to aid him in keeping his soil fertile, is to secure soil in a fine state of mechanical division and of a high retentive nature. Nothing is more common than to see certain soils retain their fertility with the annual addition of much less manure than certain others. In fact, a given quantity of manure on the former will seem to maintain their fertility for several years; while a similar addition to the latter quite loses its good effects in a single season. The former soils have invariably the rocks, minerals, \&c. which compose them in a fine state of division; while the latter have their particles more or less sandy and coarse.-S. M. Salisbury, M.D., in Prairie Farmer.

\section{Benefit of Droughts.}

Ir may be a consolation to those who have felt the influence of long and protracted dry weather, to know that droughts are one of the natural causes to restore the constituents of crops and renovate cultivated soils. The diminution of the mineral matter of cultivated soils takes place from two causes :

1. The quantity of mineral matter carried off in crops, and not returned to the soil in manure.

2. The mineral matter carried off by rain water to the sea by means of fresh-water streams.

These two causes, always in operation, and counteracted by nothing, would in time render the earth a barren waste, in which no verdure would quicken and no solitary plant take root. A rational system of agriculture would obliterate the first cause of sterility, by always restoring to the soil an equivalent for that which is taken off by the crops; but as this is not done in all cases, Providence has provided a way of its own to counteract the thriftlessness of man, by instituting droughts at proper periods, to bring up from the deep parts of the earth food on which plants might feed when rains should again fall. The manner in which droughts exercise their beneficial influence is as follows:-During dry weather, a continual evaporation of water takes place from the surface of the earth, which is not supplied by any from the clouds. The evaporation from the surface creates a vacuum, (so far as the water is concerned,) which is at once filled by the water rising up from the subsoil of the land; the water from the subsoil is replaced from the next below, and in this manner the circulation of water in the earth is the reverse to that which takes place in wet weather. This progress to the surface of the water in the earth manifests itself strikingly in the drying up of springs and of rivers and streams which are supported by springs. It is not, however, only the water which is brought to the surface of the earth, but also all that which the water holds in solution. These substances are salts of lime, and magnesia of potash and soda, and, indeed, whatever the subsoil or deep strata of the earth may contain. The water, on reaching the surface of the soil, is evaporated, and leaves behind the mineral salts, which 
I will here enumerate-namely, lime, as air-slaked line; magnesia, as air-slaked magnesia ; phosphate of lime, or bone-earth; sulphate of lime, or plaster of Paris; carbonate of potash and soda, with silicate of potash and soda, and also chloride of sodium or common salt, -all indispensable to the growth and production of plants which are used for food. Pure rain water, as it falls, would dissolve but a very small proportion of some of these substances; but when it becomes soaked into the earth, it there becomes strongly imbued with carbonic acid from the decomposition of vegetable matter in the soil, and thus acquires the property of readily dissolving minerals on which it before could have very little influence.

I was first led to the consideration of the above subjects by finding, on the re-examination of a soil which I analyzed three or four years ago, a larger quantity of a particular mineral substance than I at first found, as none had been applied in the mean time. The thing was difficult of explication until I remembered the late long and protracted drought. I then also remembered that in Zacatecas and in several provinces in South America, soda was obtained from the bottom of ponds, which were dried in the dry, and again filled up in the rainy, season. As the above explanation depended on the principles of natural philosophy, I at once instituted several experiments to prove its truth.

Into a glass cylinder was placed a small quantity of chloride of barium in solution; this was then filled with a dry soil, and for a long time exposed to the direct rays of the sun on the surface. The soil on the surface of the cylinder was now treated with sulphuric acid, and gave a copious precipitate of sulphate of baryta.

The experiment was varied by substituting chloride of lime, sulphate of soda, and carbonate of potash, for the chloride of barium; and on the proper reagents being applied, in every instance the presence of those substances were detected in large quantities on the surface of the soil in the cylinder. Here, then, was proof positive and direct, by plain experiments in chemistry and natural philosophy, of the agency, the ultimate beneficial agency of droughts.

We see, therefore, in this, that even those things which we look upon as evils by Providence, are blessings in disguise, and that we should not murmur even when dry seasons afllict us, for they, too, are for our good. The early and the later rain may produce at once abundant crops; but dry weather is also a beneficial dispensation of Providence, in bringing to the surface food for future crops, which otherwise would be forever useless. Seascnable weather is good for the present; but droughts renew the storehouses of plants in the soil, and furnish an abundant supply of nutriment for future crops.-JAmes Hiagins, Maryland State Chemist.

\section{New Method of Using and Dissolving Bones.}

Aт a recent meeting of the Hillsborough Agricultural Society, at Manchester, New Hampshire, General Riddle being called upon by the president to relate his experience in the use of guano and other special manures, made some statements in regard to the way of dissolving and using bones, of which the following is a condensed summary :-

General Riddle took sixty gallons of ley from oyster-shell lime to two hundred pounds of bones, and boiled them together a few hours, and the bones were all dissolved or reduced to a powder. A bushel of lime, he says, will make six gallons of ley; and further, that bones dissolved or reduced in this ley make a dry powder, which may be applied like ashes. $\mathrm{He}$ put a gill of this powder to a hill, on twenty rows of corn, and omitted it on five rows through the field. There was an astonishing difference in the appearance of these different portions of the field. The corn where the bone-dust was applied was much the largest, and of a far deeper green in color.-Nash's Valley Farmer.

\section{Liebig's Fifty Propositions.}

TuE following fifty propositions are copied from the recent work of Liebig on Agricultural Chemistry, or his reply to the statements and experiments of Messrs. Lawes and Gilbert. These fifty propositions are claimed by him to be distinct truths, established by the researches of chemistry as applied to agriculture. 
The growth of a plant presupposes a germ, a seed; the land-plant requires a soil; without the atmosphere, without moisture, the plant does not grow. The words soil, atmosphere, and moisture are not of themselves conditions; these are lime, clay, sand-soils, soils originating from granite, from gneiss, from mica-slate, from clay-slate, all entirely different in their compositions and qualities. The word soil is a collêctive word for a large number of conditions. In a fruitful soil these conditions are combined in proportions adapted to regetable growth; in an unproductive soil some of them are wanting. In the same manner, the words manure and atmosphere include a plurality of terms or conditions. The chemist, with the means at his command, analyzes all kinds of soil; he analyzes manures, the air, and the water; he resolves the collective words which express the sum of the conditions of vegetable growth into their single factors, and, in his explanations, substitutes the individual for the combined values. In this process, it is evident there is nothing hypothetical. If it pass for a perfectly-established truth that the soil, the atmosphere, water, and manures exercise a influence upon the growth of the plant, it is no less beyond doubt that this influence is entirely due to the constituents of the soil, \&c.; and the province of the chemist is to set these ingredients before the eyes of those occupied with vegetable cultivation, and to illustrate their qualities and relations.

1. Plants in general derive their carbon and nitrogen from the atmosphere; carbon in the form of carbonic acid, nitrogen in the form of ammonia. From water (and ammonia) they receive hydrogen. Their sulphur comes from sulphuric acid.

2. Cultivated in soils, situations, and climates the most various, plants contain a certain number of mineral substances, and, in fact, always the same substances, whose nature is learned from the composition of the ash. These ingredients of the ash were ingredients of the soil. All fruitful soils contain a certain quantity of them. They are absent from no soil in which plants flourish.

3. In the produce of a field is carried off and removed from the soil the entire quantity of those soil-ingredients which have become constituents of the plant. The soil is richer at seed-time than at harvest. The composition of the soil is changed after the harvest.

4. After a series of years, and after a corresponding number of harvests, the productiveness of a field diminishes. When all other conditions remain unchanged, the soil alone becomes different from what it was previously; the change in its composition is the probable cause of its becoming unproductive.

5. By means of manures, as stable-dung and animal excrements, the lost fertility may be restored.

6. Manures consist of decayed vegetable and animal matters, which contain a certain quantity of soil-ingredients. The excrements of animals and of man represent the ashes of food burned in the animal or human body; i.e. the ashes of plants which have been gathered from the soil. In the urine are found those ingredients of the plant, derived from the soil, which are soluble in water; the solid excrements contain those which are insoluble. Manures contain the materials which the consumed crops have removed from the soil. It is plain that by incorporating manures with the soil the latter receives again the withdrawn ingredients. The restoration of its original composition is accompanied with the recovery of its original fertility. It is certain that one of the conditions of fertility is the presence of certain mineral ingredients in the soil. A rich soil contains more of them than a poor one.

7. The functions of the roots of plants, in reference to the absorption of atmospheric food, are similar to those of the leaves; i.e. the former, like the latter, possess the property of taking up and assimilating carbonic acid and ammonia.

8. Ammonia, which is contained in or added to the soil, comports itself as a soil-constituent. The same is equally true of carbonic acid. '

9. Animal and regetable bodies and animal excrements enter into putrefaction and decay. The nitrogen of the nitrogenous matters is thereby converted into ammonia, a small portion of the ammonia decays (oxydizes) further into nitric acid.

10. We have every reason to believe that nitric acid may replace ammonia in the processes of vegetable nutrition; i.e. that its nitrogen may be applied by the plant to the same purposes as that of ammonia. Animal manures accordingly furnish the plant not only with 
those mineral substances which it is the function of the soil to furnish, but also with those forms of food which it naturally derives from the atmosphere. This supply is an addition to that quantity which the atmosphere contains.

11. Those forms of vegetable food contained in the soil which are not gaseous or volatile enter the plant through its roots. The vehicle of their transmission is water, by the agency of which they become soluble and transportable. Many of these kinds of food dissolve in pure water, others only in water which contains carbonic acid or a salt of ammonia.

12. All those substances which exert a solvent action on such ingredients of the soil as are themselves insoluble, cause, by their presence, a given volume of rain water to take up a larger quantity of vegetable food than it otherwise could.

13. From the progressive decay of the organic matters of manure originate carbonic acid and ammonia salts; they constitute an active source of carbonic acid in the soil, whereby the air and water present in the soil are made richer in carbonic acid than they could be in their absence.

14. Animal manures not only offer to the plant a certain amount of soil and atmospheric food, but in their decay is supplied, in the form of carbonic acid and ammonia, an indispensable means of rendering soluble and a vailable to the plant the insoluble ingredients of the soil in greater quantity and in shorter time than could occur in the absence of decaying organic matter.

15. Other things being equal, regetation receives less water through the soil in warm, dry seasons than in wet years; the harvests in different years stand in relation thereto. A field of giren quality yields smaller crops in dry seasons; by the same average temperature the yield increases to a certain limit with the increase of the quantity of rain.

16. Of two fields-one richer, one poorer in plant-food-the richer yields in dry seasons more produce than the poorer, other things being equal.

17. Of two fields alike in character, and containing an equal amount of soil-ingredients, one of which, however, has besides a source of carbonic acid-viz. decomposable regetable or animal matter-the latter yields more in dry seasons than the former.

18. The cause of this difference in yield lies in the unequal supply of matters, both as concerns quality and quantity, which the plant receives from the soil in a given time.

19. All obstacles present in the soil, which hinder the solution and absorbability of the plant-food, proportionally destroy its ability to serve as food; they make the plant-food ineffective. A certain physical state of the soil is a needful preliminary condition to the efficacy of the food therein contained. The soil must allow the access of air and moisture, and permit the roots of plants to extend themselves in all directions, and seek out their nutriment. The expression, telluric conditions, comprises every thing necessary to vegetable growth that depends upon the physical qualities and composition of the soil.

20. All plants need as nourishment phosphoric acid, sulphuric acid, the alkalies, lime, magnesia, and iron. Certain families of plants require silica; those that grow on the sea-shore and in the sea itself require common salt, soda, and iodine. In some families of plants the alkalies may be in part replaced by lime and magnesia, and vice versâ. All these bodies are collectively designated as mineral food. The atmospheric food of plants is carbonic acid and ammonia. Water serves itself as food and also as a general medium of nutrition.

21. The bodies that are necessary as food for the plant have an equal value in this respect; i.e. if any one of the entire number be wanting, the plant cannot flourish.

22. Fields which are adapted to the cultivation of all species of plants contain all the soilingredients that are necessary for these plants; the words poor or unfruitful, and rich or fruitful, express the relations of these soil-ingredients in quantity or quality.

Among qualitative differences are understood differences in the solubility of the mineral ingredients, or in their capability of entering the vegetable structure through the agency of water.

Of two soils which contain equal quantities of mineral food, one may be fruitful, (considered as rich,) the other unfruitful, (considered as poor,) when in the latter these nutritive substances are not free, but exist in the state of chemical compound. A body in chemical combination opposes, by its attraction for the bodies it is combined with, an obstacle to 
another body that tends to unite with it. This opposition must be overcome before the two will unite.

23. All soils adapted for cultivation contain the mineral nutritive matters in both these forms. Taken together they represent the capital of the soil; the freely soluble parts are the movable or available capital.

24. The improvement—enriching, making fruitful—of a soil by proper means, but without addition of mineral plant-food, implies a conversion of a part of the inactive, unavailable capital into a form available for the plant.

25. The mechanical operations of tillage have the object to overcome chemical obstacles, to set free and render directly useful the plant-food that is in insoluble chemical combination. This object is accomplished through the co-operation of the atmosphere, of carbonic acid, oxygen, and water. This action is called weathering. The presence of standing water in the soil, which cuts off the access of the atmosphere to the chemical compounds in the soil, hinders the process of weathering.

26. Fallow is the period of weathering. During fallow, by means of air and rain, carbonic acid and ammonia are added to the soil. The latter remains there when substances are present capable of fixing it, i.e. depriving it of volatility.

27. A soil is fruitful for a given species of plant when it contains the mineral substances needed by that plant in proper quantity and proportion, and in a form adapted for entering it.

28. When this soil has become unfruitful by continued use, by the removal of a series of crops without replacing the mineral ingredients carried off, it will recover its productiveness for this kind of plant by lying one or more seasons in fallow, if, in addition to the soluble and removed ingredients, it had contained a certain store of the same substances in an insoluble form, which, during the fallow, by mechanical division and weathering, are capable of becoming soluble. By the so-called green manuring this result is effected in a shorter time.

29. A field which does not contain these mineral forms of plant-food cannot become fruitful by lying in fallow.

30. The increase of the productiveness of a field by fallow and tillage, and the removal of soil-ingredients in the crops, without a return of the latter, brings about, in shorter or longer time, a state of permanent unfruitfulness.

31. In order that the fertility of a soil be permanent, the removed substances must be replaced at certain intervals; i.e. its original composition must be re-established.

32. Various species of plants require the same kinds of mineral food to their development, but in unlike quantities, or at different times. Some cultivated plants need that silica be present in soluble form in the soil.

33. When a given field contains a certain amount of all kinds of mineral plant-food in equal proportion, and in suitable form, it will become unproductive of a single species of plant so soon as, in consequence of continuous cropping, any single kind of plant-food-e.g. soluble silica-is so far exhausted that its quantity is insufficient for a new crop.

34. A second plant which does not require this ingredient (silica, e.g.) will yield one or more crops on the same soil, because the other, for it necessary, ingredients, although in changed proportions, (i.e. not in equal quantities,) are yet present in quantity sufficient for its perfect development.

After the second, a third kind of plant will flourish in the same field, if the remaining soil-ingredients be enough for its wants; and if, during the growth of these kinds of plants, a new supply of the wanting plant-food (soluble silica) has been made available by weathering, then, the other conditions being as before, the first plant will again flourish.

35. On the unequal quantity and quality of the mineral ingredients of the soil, and on the differing proportions in which they serve as food for the different kinds of plants, is based the alternation or rotation of crops in general, as well as the peculiar method according to which it is carried out.

36. Other things being equal, the growth of a plant, its increase in bulk, and its perfect development in a given time, stand in relation to the surface of the organs whose function is to take up the food of the plant. The quantity of plant-food that is derived from the 
atmosphere depends upon the number and surface of the leaves; that which is taken from the soil, upon the number and surface of the roots.

37. If to two plants of the same species, during the formation of leaves and roots, an unequal amount of nourishment be offered in the same space of time, their increase of mass is unequal in this time. That plant which has received more food increases more, its development is facilitated. The same difference in growth is manifest when two plants receive the same amount of food, but in unlike forms as to solubility.

The rapidity of the development of a plant is facilitated by furnishing it with, all the necessary atmospheric and telluric nutritive matters in proper form and at the right time. The conditions that shorten the time of development are the same as those that contribute to its amount.

38. Two plants, whose roots have an equal length and extension, do not flourish so well near or after each other as two plants whose roots, being of unequal length, acquire their nourishment at different depths in the soil.

39. The nutritive substances needed by the plant must act together in a given time, in order that the plant attain full development in this time. The more rapidly a plant develops itself in a given period, the more food does it need in that time. Annuals require more rapid supplies than perennials.

40. If one of the co-operating ingredients of the soil or of the atmosphere be partly or entirely deficient, or want those qualities that adapt it to absorption, the plant does not develop itself in all its parts, or only imperfectly. The deficiency of one ingredient renders those present ineffectual, or diminishes their effect.

41. If the absent or deficient substance be added to the soil, or, if present, but insoluble, be rendered soluble, the other constituents are thereby rendered efficient.

By the deficiency or absence of one necessary constituent, all the others being present, the soil is rendered barren for all those crops to the life of which that one constituent is indispensable. The soil yields rich crops if that substance be added in due quantity and in an available form. In the case of soils of unknown composition, experiments with individual mineral manures enable us to acquire a knowledge of the quality of the land and the presence of the different mineral constituents. If, for example, phosphate of lime, given alone, is found efficacious-that is, if it increases the produce of the land-this is a sign that that substance was absent, or present in too small proportion, whereas there was no want of the others. Had any of these other necessary substances been also wanting, the phosphate of lime would have had no effect.

42. The efficacy of all the mineral constituents of the soil taken together, in a given time, depends on the co-operation of the atmospheric constituents in the same time.

43. The efficacy of the atmospheric constituents in a given time depends on the co-operation of the mineral constituents in the same time; if the latter be present in due proportion and in arailable forms, the development of the plants is in proportion to the supply and assimilation of their atmospheric food. The quantity and quality (available form) of the mineral constituents in the soil, and the absence or presence of the obstacles to their efficacy, (physical qualities of the soil,) increase or diminish the number and bulk of the plants which may be grown on a given surface. The fertile soil takes up from the air, in the plants grown on it, more carbonic acid and ammonia than the barren one; this absorption is in proportion to its fertility, and is only limited by the limited amount of carbonic acid and ammonia in the atmosphere.

44. With equal supplies of the atmospheric conditions of the growth of plants, the crops are in direct proportion to the amount of mineral constituents supplied in the manure.

45. With equal telluric conditions, the crops are in proportion to the amount of atmospheric constituents supplied by the air and the soil, (including manure.) If, to the available mineral constituents in the soil, ammonia and carbonic acid be added in the manure, the fertility of the soil is exalted.

The union of the telluric and atmospheric conditions and their co-operation in due quantity, time, and quality, determine the maximum of produce.

46. The supply of more atmospheric food (carbonic acid and ammonia, by means of ammoniacal salts and humus) than the air can furnish, increases the efficacy of the mineral 
constituents present in the soil, in a given time. From the same surface there is thus obtained, in that time, a heavier produce-perhaps in one year as much as in two without this excess of atmospheric food.

47. In a soil rich in the mineral food of plants, the produce cannot be increased by adding more of the same substances.

48. In a soil rich in the atmospheric food of plants, (rendered so by manuring,) the produce cannot be increased by adding more of the same substances.

49. From land rich in the mineral constituents, we may obtain in one year, or for a series of years, by the addition of ammonia alone, (in its salts,) or of humus and ammonia, rich crops, without in any way restoring the mineral substances removed in these crops. The duration of this fertility then depends on the supply; that is, the quantity and quality of the mineral constituents existing in the soil. The continued use of these manures produces, sooner or later, an exhaustion of the soil.

50. If, after a time, the soil is to recover its original fertility, the mineral substances extracted from it in a series of years must be again restored to it. If the land, in the course of ten years, has yielded ten crops, without restoration of the mineral substances removed in those crops, then we must restore these in the eleventh year, in a quantity tenfold that of the annually-removed amount, if the land is again to acquire the power of yielding a second time a similar series of crops.

\section{Weeds in Walks.}

THE following modes of preventing the growth of weeds in gravel-walks, are copied from the correspondence of the London Gardener's Chronicle:-

In order to prevent weeds from growing on walks, put a layer of gas-lime under the last inch of gravel. This also helps to bind the gravel.

The following is the way in which I managed walks when I was a gentleman's gardener. In one situation I held I had three miles of gravel-walks to keep in order. In winter, when there was sufficient frost to freeze the gravel in the mornings, I employed the laborers in cleaning the walks with a half-worn out birch-broom, sweeping backwards and forwards, and then removing with a new broom what the old ones took off the surface. When the walks were covered with moss, it was scraped off with a hoe before the broom was used. After having pursued this practice for six years, my walks looked as fresh and clean as if they had been newly gravelled. Last season very few weeds made their appearance during the summer; by performing the operation when frost is on the ground, you not only remove all small weeds, but you sweep off most of the seeds deposited there to vegetate the following summer. If docks, thistles, or dandelions appear, cut out their crowns and put a little salt on them; you will not have to repeat the salting twice in one place.

\section{On the Composition of the Salt best Adapted for Dairy Purposes.}

THE nature of the salt best adapted for the dairy has long formed a subject of discussion among dairy farmers, and many opinions, and not a few fanciful prejudices, exist regarding it. It is well known that, for a long time, very decided opinions existed as to the superiority of bay-salt, and at one time the imports of that variety of salt were considerable. Bay-salt is produced in Spain by the spontaneous evaporation of sea-water, which at high-water is allowed to run into shallow ponds, in which it is gradually concentrated by the heat of the sun's rays. The salt so deposited is always in crystals of considerable size, and generally of a brownish color. In spite of the color, it is a very pure salt, and contains but little of the magnesian compounds present in the sea-water, which are entirely left in the mother-liquor from which the crystals have been separated.

Lime and magnesia-especially the chloride of magnesia existing in salt-have a very powerful affinity for water, and retain it in considerable quantity. The chloride is even a deliquescent substance-that is to say, it absorbs moisture from the air; so that a sample of salt containing it, even if artificially dried, will again become moist, if kept for some time. 
For this reason the dryness of a salt is an excellent criterion of its purity, and, in the absence of an analysis, may serve to guide the purchaser.

As far as the use of salt for the dairy is concerned, it seems obvious that we must mainly depend on its purity; and it was, doubtless, for this reason that bay-salt was formerly preferred.

It is necessary to be remarked, however, that the form of the salt is not immaterial; and that when in fine powder it is clearly preferable to large grains or crystals, and that because it admits of more thorough incorporation with the butter, and its antiseptic effects will be secured by the use of a smaller quantity than would be necessary if in large crystals.

As a general rule, the salt now met with in commerce is rery fine; but instances are sometimes met with in which the magnesia salts are present in considerable quantity. I have seen specimens containing as much as 3 per cent. of chloride of magnesium and sulphate of magnesia, and such samples contain much water; so that the amount of pure salt does not exceed from 89 to 90 per cent.

Such salt should be carefully avoided for dairy purposes; and all care should be taken to obtain it as pure as possible.-Prof. Anderson, Mighland Ag. Soc.

\section{Qualities of Pasturage.}

THE following remarks on the qualities of pasturage are taken from the Transactions of the Croyden Farmers' Club, England:-

What is the cause that some pasture will readily fatten stock fit for the butcher, while others. with an abundance of grass, will only keep stock merely in a growing or thriving condition?

That such is the fact, all farmers are and have been aware of for ages past, but as to the causes of these differences no good or sufficient reason has been assigned. I will, however, state what I consider an explanation why the one does fatten so readily, and why the other does not, and also give reasons and authorities for such opinions. First, the fattening qualities of what are termed rich grazing lands may probably be owing to all the several elements of nutrition being present in such quantities in relation to each other, and in states of combination, that are well adaptẹd for being assimilated and deposited as fat and muscle, thereby requiring no unnecessary expenditure of the vital power or principle to produce such effect.

Dr. Thomson, in his "Experimental Researches on the Food of Animals," says- "Besides the necessity for the presence of the same materials in the food which exist in the blood, it is requisite that each should bear a certain relation to the whole." Now it is reasonable to think that it is so, and also that where one or more elements in the food are in excess, that there must be an expenditure of vital power to get rid of such excess.

Prof. Johnston also says - "It has been ascertained by physiologists that all the parts of the body undergo a slow and sensible process of renewal, the place of that which is removed being supplied by new portions of matter derived from the food, and that this renewal goes on so rapidly, that in the space of time the whole body of the animal is renewed. I may observe that we know by experience when a rich pasture is broken up, it takes many years when again laid down to pasture before it at all approaches to its former fattening powers, and also before it again produces all those numerous grasses (if ever it does again) which grew upon it before it was broken up. There may be another cause which aids in the fattening qualities of such pastures; and that is the presence of some plant or plants containing one or more of those classes of compounds which have the property of changing one compound into another, thereby saving an expenditure of the vital power in digestion."

Why is it, that the majority, I may say, of meadows which produce an ample crop of herbage to satisfy the appetite of animals grazing thereon, will not fatten them fit for the butcher without the aid of some artificial food? Here again, as in the former case, we can only conjecture. We are certain that all the elements requisite to form the animal are present in the herbage and hay grown thereon, from the fact that animals bred on, and fed upon, the produce of such pastures or meadows come to full maturity in health and strength; still, it does not follow that the several quantities of these elements are in such a relation to each other, and in such combinations of forms, as not to require considerably more expendi- 
ture of the vital powers to convert them into the various compounds to be assimilated and appropriated by the different organs and parts of the body, than would be required in the former case upon the good grazing land; added to which, another, and I think, perhaps the principal, disturbing cause may probably be owing to the presence of some plant or plants among the herbage which exercise an unfavorable action upon the fat-producing powers, and which, from the soil being peculiarly adapted for their flourishing growth, may be produced in bulk, as compared with the aggregate herbage grown, sufficient to bring about the marked difference noticed. To make myself and meaning here more clearly comprehended, I will suppose a case:-We know that some piants excite the kidneys to increased action. Supposing, therefore, that in any pasture (however abundant it might be in quantity) there were growing some plant or plants which exercise an exciting influence upon the kidneys, provided that influence was not energetic enough in the first instance to produce disease of those organs, the secretion from them would be much, as well as permanently, increased under the daily stimulant taken with food. Now, as that secretion is wholly derived from the blood, we can readily form an idea that there must be a much larger quantity of blood required to furnish the increased quantity of urine secreted, with all its salts and other organic compounds, whether immediately derived from the food, or from the disintegration and breaking up of the already formed parts of the body. Such being the case, it would be natural to conclude that the animal would not become what we call fat under the increased consumption of the blood in that direction. This may seem to be putting an extreme case; but we should reflect that there is no organ or part of the body, varying, of course, in the different species of animals, on which there is not some vegetable production that exercises a certain specific influence, more or less, according to the constitution, the breed, and susceptibility of the individual animal. The same effects are also true as regards the inorganic elements of nature; and it is upon those facts, the results of observation, that the art of medicine is founded. I say again, if we consider this, there may be some reason for supposing that the accumulation of any superfluous quantity of fat and muscle, to the extent that we consider an animal to be fatted, may be retarded by the presence of any such plant or plants, in an undue proportion to the requirements of nutrition.

"The next consideration is, What can be done to improve those pastures? All agree that where drainage is required it benefits their feeding qualities in most instances; draining is more often required in pasture lands and meadows than is generally supposed. It increases the number of the finer sort of grasses, as well as increases the bulk of those already growing; it also gets rid of, or greatly weakens, those plants which delight and flourish in most soils, which, though they may not be called wet ones, still generally retain water to a considerable extent in the subsoil; and among those plants which flourish in moist soils are many not favorable to animals. These pastures will also be greatly improved by high manuring, more especially where draining was required and has been done; for supposing all the injurious plants to remain which are natural to the soil, their bulk and produce, as compared with the more nutritious grasses, will be greatly lessened by the soil being made more rich and congenial for the growth of the finer sorts, which will, by their greater numbers and more vigorous growth, check and weaken the others; consequently there would be in a given weight of herbage a much larger proportion of the really nutritious grasses to the injurious ones, than when the pasture was in its natural state, therefore with a less disturbance of the natural functions of the organs of the animals grazing upon it. Much benefit, I think, would arise if botanists, and those who make plants their study, were to direct their attention specially to the qualities and properties of those plants and grasses which grow in our meadows and pastures. Farmers have not time for such details; nor, ihdeed, is it necessary that we should enter into them. All we can do is to observe for ourselves, and bring our reasoning faculties to bear upon the experiments and facts which are and may have been brought to light by the chemist, the botanist, the physiologist, the entomologist.

Our endeavor should be to think and reflect whether any or what relation a new discovery or fact already known bears upon any department of farming. The improvement which has taken place in our ureeds of cattle, sheep, and pigs, and which, I have no doubt, has quite doubled our supplies of animal food in fifty years, has not been brought about by scien- 
tific men, but by men of close observation and deep reflection, which qualities are generally the parents of sound judgment. It has been accomplished by practical farmers in every sense of the word, who by observation of a few of the laws of organic life, as manifested in animals living under different conditions as to food and climate, and availing themselves of those laws, have gradually brought about this vast improvement in our breeds of stock.London Farmers' Magazine.

\section{Hay Making.}

THE following article from the Irish Economist, with extracts from Morton's Cyclopedia of Agriculture, (English, ) although referring in part to methods and grasses foreign to this country, still contains truths worthy of consideration by every farmer :-

Chemistry informs us that of the various ingredients which compose grass, those portions which are immediately soluble in water are the most fitted for purposes of nutrition; and, therefore, it should be cut at that period when the largest amount of gluten, sugar, and other matter soluble in water is contained in it. And that period is not, generally speaking, when the plants have shot into secd; for the principal substance is then woody fibre, which is totally insoluble in water, and therefore unfitted for being assimilated in the stomach. It has been shown that "when the grass first springs above the surface of the carth, the chief constituent of its early blades is water, the amount of solid matter comparatively trifling; as its growth advances, the deposition of a more indurated form of carbon gradually becomes more considerable, the sugar and soluble matter at first incrcasing, then gradually diminishing, to give way to the deposition of woody substance," the saccharine juices being in the greatcst abundance when the grass is in full flower, but before the seed is formed. During all the latter part of the process of fructification, the formation of the seed, \&c., the sugar rnpidly dccreases in quantity, and when the seeds have arrived at maturity, the stem and leaves begin to decay; 80 that, if the grass is not cut when in flower, a great amount of nutriment will be wasted. Many of the natural pasture grasses, however, are exceptions to this rule, some possessing a grcater nutritive value when the seed is ripe, than at the time of flowcring. In the cock'sfoot grass, (Dactylis glomerata,) for instance, the proportional value at the time the secd is ripe to that at the time of flowering, is as seven to five; the value of the grass of the sweet-scented soft grass, (Holcus odoratus) when seeding, excecds that at the time of flowering in the porportion of twenty-one to seventeen; and with the meadow cat's-tail, or timothy grass, (Phleum pratense) the culms are found to contain more nutritive matter when the secd is ripe, than those of any other species of grass that have been submitted to experiment-the value of the culms simply exceeds that of the grass when in flower in the proportion of fourteen to nine. But though there is more nutriment contained in the seed crop of these grasses than in the flowering crop, nevertheless the loss of lattcrmath, (later mowing,) which would have been produced in the time the seed was ripening, would more than outweigh the superior quantity of nutritive matter contained in the seed crop ; and by aiming at the greatcr amount of nutriment contained in these grasses at seeding, a loss is sustained not only in the lattermath, but in the bulk of the hay itself; for although the crested dog's-tail grass (Cynosurus cristatus) yields just twicc as much grass when the seed is ripe as at the time of flowering, the majority of the grasses possess a much greatcr quantity of produce when flowering than at any other time. The grass of the Welsh fescue is of equal value in nutriment at ench stage of its growth; and the nerved meadow grass (Poa nervata) is equal, both in nutriment, quality, and quantity of produce, at flowering and seeding; but nearly all the other varieties combine the properties we have bcen describing-namcly, of producing the greatest weight of grass, and also the largest amount of nutritive matter, when in flower. The meadow fescue (Festuca pratensis) is of more value when flowering than when the seed is ripe, proportionally as three to one; the crested dog's-tail, although yiclding much less grass at that time, contains nearly twice the quantity of nutritive matter when flowering as when the seed is ripe; and the tall, oat-like soft grass, (Holcus avenaceus, ) at the time of flowering, exceeds its value when the seed is ripe, in the proportion of five to two. But without multiplying examples, it is obvious, from the foregoing remarks, that nearly every species of grass-no matter whether it contains most nutriment when flowering or when seeding-yields the most profit in hay and lattermath if it 
be cut when in flower. "It has, indeed, been proved that plants of nearly all sorts, if cut when in full vigor, and afterwards carefully dried, without any waste of their nutritive juices, contain nearly double the quantity of nutritive matter which they do when allowed to attain their full growth, and make some progress towards decay."

Now, the different kinds of grasses begin to flower at"yery different periods; and as it is evident that the best time to mow is when the greatest number of the most valuable grasses are simultaneously in flower, we may, perhaps, say that the herbage "should be in that state of forwardness which indicates the full blossoming of all the earlier pasture grasses, and the ripeness of seed of the earliest; or, in other words, the seeds of the sweet-scented vernal grass, (Anthoxanthum odoratum,) sweet-scented soft grass, meadow fox-tail, (Alopecurus pratenses,) sheep's fescue, (Festuca ovina,) soft broom grass, (Bromus mollis,) etc., may be completely ripe ; and the smooth-stalked meadow grass, (Poa pratensis,) hard and smooth fescues, (Festuca duriuscula and Festuca glabra,) common quaking grass, (Briza media,) and crested dog's-tail, may all be in full blow. This will generally be about the middle of June. If the cutting of the crop be much protracted, the plants become withered at the bottom of their stems : thus the roots are injured, the future growth of the blades is weakened, and the eddish or aftermath materially lessened in quantity and deteriorated in quality, while the ripening of the seeds greatly exhausts the land. On the other hand, if cut too soon, there will be a loss in the quantity of hay; the lower or shorter portion, one inch in the height of which will weigh as much as two inches of the top, will not have sufficient time to grow to a profitable length, and a loss will be thereby incurred by the grass withering too much when being made. It is much better to be too early than too late.

The proper season for mowing the grass, so as to secure the largest amount of nutrient properties within it, being thus determined, the next consideration is-the preservation of these useful qualities in the hay.

Experiments show that, out of the various constituents of which grass is composed, the mucilage, starch, gluten, and sugar, which are soluble in water, are alone retained in the body of an animal for the purpose of life, the bitter extractive and saline matters being considered as assisting or modifying the functions of digestion, rather than as being truly nutritive parts of the compound, and being voided with the woody fibre. The woody fibre serves only to give bulk to the food, and therefore distension to the stomach, which, when moderately filled, brings those muscles into active exercise which tend so much to promote healthy digestion, by keeping the food in constant motion.

The principal object, then, which is to be aimed at in hay-making, is, to retain the soluble portion of the grass in perfect integrity.

This cannot be completely accomplished because of the imperfection in our present mode of hay-making, and the many casualties attending it. From various experiments made by Dr. Thomson, it has been found that $387 \frac{1}{2}$ parts (by weight) of grass form only 100 when made into hay. This amount of grass, under favorable circumstances, contains of matter soluble in hot water 28.13 parts, and in cold water 8.21 parts ; but instead of this amount, the equivalent quantity of hay, or 100 parts, contains only 16 instead of 28 parts soluble in hot water, and 5.06 instead of 81 parts soluble in cold water. A very large proportion of the soluble or nutritive matter of the grass has obviously disappeared in its conversion into hay. The result of the process has therefore been to approximate the soft, juicy, and tender grass to woody fibre, by washing out or decomposing its sugar and other soluble constituents. "These facts enable us to explain the reason why cattle consume a larger amount of hay than is equivalent to the relative quantity of grass. Thus, animals which can subsist upon one hundred pounds of grass, should be able to retain the same condition by the use of twenty-five pounds of hay, if the latter suffered no deterioration in drying; but experiments have shown that a cow, for instance, thriving on one hundred pounds to one hundred and twenty pounds of grass, requires twenty-five pounds of hay and nine pounds of barley or malt." The great cause of this deterioration is the water which may be present, either from the incomplete removal of the natural amount of water in the grass by drying, or by the absorption of this fluid from the atmosphere. "Water, then, existing in hay from either of these sources, will induce fermentation, a process by which one of the most important constituents of the grass-namely, 
sugar-will be destroyed. The action necessary for the decomposition of the sugar is induced by the presence of the albuminous matter of the grass; and the result is that the sugar is converted into alcohol and carbonic acid; and that alcohol is produced in a heated haystack, in many cases, may be detected by the similarity of the odor disengaged to that perceptible in a brewery."

The process of hay-making, then, is the removal of this moisture from the grass; and Dr. Thomson has found that the only method which succeeds in preserving grass perfectly entire is by means of artificial heat.

The quantity of water or volatile matter capable of being removed from hay at the temperature of boiling water varies considerably; the amount of variation during his experiments being from twenty to fourteen per cent. If the lower percentage could be attained at once by simply drying in the sun, the process of hay-making would probably admit of little improvement; but the best new-made hay that he has examined contained more than this amount of water, the numbers obtained verging towards twenty per cent. When it contains as much as this, it is very liable to ferment, especially if it should happen to be moistened by any accidental approach of water. Rye-grass contains, at an early period of its growth, as much as eighty-one per cent. of water, the whole of which may be removed by subjecting the grass to a temperature considerably under that of boiling water; but even with a heat of $120^{\circ}$, the greater portion of the water is removed, and the grass still retains its green colora character which appears to add greatly to the relish with which cattle consume this kind of provender. The advantages attained by this method of making hay are sufficiently obvious. By this means all the constituents of the grass are retained in a state of integrity; the sugar, by the absence of the water, is protected from undergoing decomposition; the coloring matter of the grass is comparatively little affected, while the soluble salts are not exposed to the risk of being washed out by the rains, as in the common process of hay-making.

From the above chemical obserrations, made by Dr. Thomson, in his recent researches upon the food of animals, we learn the theory of hay-making; the inquiry now is-How, in practice, can we best approximate to the correct principles laid down?

It is an essential point that the mowers should be good workmen, and perform their work neatly and evenly, making the scythe cut as near the ground as possible, in order to insure the greatest bulk of hay, and facilitate the springing up of the young shoots of the eddish or aftermath. They generally begin to work before sunrise, and remain until after sunset; from one acre to an acre and a half, according to the bulk of the crop, being a fair day's work for a man. As soon as the dew is off, the mowmen should be followed by men and women with forks, who shake and spread the swaths evenly over the whole surface of the meadow; or this may be most economically and expeditiously done by means of a "tedding machine," drawn by a horse, which will do the work of twelve or fifteen hay-makers, and distribute the grass more thinly and evenly as it crosses the field.

And this must not be allowed to lie long beneath the scorching heat of the sun without being turned; for by thus doing; the upper part becomes brown and withered, whereas it is desirable to keep it as green as possible. All the grass which has been tedded and turned during the day ought to be thrown together the same evening in "windrows ;" that is, long rows throughout the field, gathered together by the hay-makers working in opposite directions, the two outside women or boys using rakes, the others forks, the hay gradually accumulating, while thus being sent on from one to another towards the place of the intended row, until it forms, from a party on each side, a double row, and two men follow, putting these two into one compact " windrow," about five feet wide and three high ; or the hay mny be put together into small heaps or "footcocks," the former method being preferable for expedition, and affording sufficient protection from heavy dews, the latter more secure from the injury of rain, and may be adopted if the weather prove cloudy or adverse. The following morning-or on the return of suitable weather-the whole must again be thrown out, so as to secure the greatest possible benefit from the sun's rays and drying winds : and the grass mown on the preceding night and early that morning may be tedded when the dew is off, and afterwards turned; and, provided it be fine drying weather, the first day's hay will now be sufficiently "made;" that is, it will have lost most of its moisture-the chief part of its natural juices will remain; and as 
it has been well scattered about and frequently turned, this will have been effected without some portions of the grass being too much withered and others still too succulent. It still retains its fine light-green color, and the farmer's aim now is to secure it with the greatest possible haste. For this purpose, the hay is gathered together into rows and the rows divided and collected into "haycocks," which may be done by torking; but if the sky is overcast and threatens rain, the windrows should be drawn up into large cocks by horses, two horses walking, one on each side the row, dragging a rope after them, which passes round the end of the row ; two men ride upon this rope, and as the horses proceed, the hay rises up between them, forming a heap; and this, having slid far enough to accumulate a sufficient quantity, the rope is lifted up, the hinder portion of the mass pulled up on to the top, and another cock commenced. Care should be taken that the cocks are "made up" neatly and well, to keep out the rain, and the horses or hand-rakes must be kept going during the whole time. All the hay must, in due course, be made and cocked after the same manner. Unless the aspect of the sky betokens approaching showers, the smaller kind of haycocks, made by rolling up the windrows with forks into proper-sized heaps, will be best.

The next morning, or soon as the weather permits, they may be well thrown out in "staddles" of a few yards in width, to insure the hay being sufficiently well dried, and it will then be ready for loading.

Of course the farmer must not be implicitly guided by any given rules for hay making; in this operation he has to depend upon a very fickle and changeable power-namely, the influence of the weather, and he must vary and modify them to suit circumstances. The object to be aimed at can alone be exhibited to his view, and a model method pointed out for him to imitate as closely as he can. The description given of the chemical nature of this process explains to the haymaker what he has to do; and, perhaps, the following truths will assist him in discovering the most eligible way of doing it:

1. He must remember that the chief point is to preserve the hay from dew and rain; water washes away the soluble salts and other matters, and when in the stack will cause fermentation, and that injures the hay by destroying some of its most valuable properties; therefore, bring it into windrows or make it into footcocks at nightfall, and never open it in the morning until the dew has evaporated.

2. Bear in mind that if the weather is unfavorable, the less it is disturbed the better, and the longer will it retain its native powers. Hay has been found to preserve a great amount of its nutritive qualities for many days-nay, even weeks-when mown wet, or when saturated with the rains while lying in the swath; if, therefore, the weather be unfavorable, it will be better not to tedd the hay at all, nor even turn over the swath. If repeatedly dried and wetted again, it soon becomes valueless; this error of meddling with hay amid frequent हhowers must, if possible, be avoided; for it is far better to have it somewhat tainted in the haycock than thus exhausted of its nutriment, and spoilt by repeatedly being spread.

3. Take care not to allow it to remain long under the hot beams of the sun without being turned; this will preserve the color and fragrance of the grass, so that without baking it too much, (thus destroying its virtues,) it may be so dry that as little heating or fermentation as possible shall occur in the stack, remembering also that coarse grass does not require so much "making" as fine succulent herbage.

In leading to the stack, all the force of the farm must be brought into requisition if necessary, as much depends upon the speedy and proper securing of the hay. The shape of the rick is not a very important consideration, but an oblong form is perhaps the best-small in size if the farmer has been unable properly to make his hay; but if it be in good order, the larger the better, as less surface in proportion to the quantity will thus be exposed to the atmosphere to imbibe moisture or have its goodness washed and dried out. Stacks, both of meadow hay and the artificial grasses, are sometimes ventilated by męans of funnels up the interior, either consisting of rough wooden framework, or made by keeping open a hole with a skep or similar appliance, drawing it up and treading the hay round it as the stacking proceeds, for the purpose of preventing the hay from becoming mow-burnt by thus letting off the superabundance of hot vapor. This may be regarded as an advantageous practice, although the hay around the chimney generally becomes mouldy unless the funnels be covered 
up before all the heat has passed off. A desirable, and probably much better and safer plan, when the hay harvest has been accompanied by wet weather, is to place a few layers of straw in the stack at intervals. This will absorb the moisture from the heating hay, and prevent the risk of fire. In clover and sainfoin stacks, mixed layers of straw are particularly useful, (especially when the straw has been stacked very green,) as the straw not only absorbs the superabundant moisture occasioned by the peculiar succulence of the herbage, but becomes itself almost as good as the hay; and the whole together cuts up into most admirable fodder.

Every grower should possess a rick cloth, either that kind supported by poles and ropes over the stack during the time it is being built, or a common cloth sufficiently large to throw over the stack to protect it from wet. They prove also exceedingly useful, both in the corn and hay harvests, in covering down stacks.

The sides of the stack should lean well outwards, so as to miss the drip from the eaves; and after its subsidence or settling, it should be well trimmed-that is, the bent, \&c. pulled out by hand, and the corners neatly.tucked in, the trimmings being employed to top up the stack. It is then securely thatched; and care ought to be taken that in all future cuttings for fodder, the interior should not be unduly or needlessly exposed.

\section{Grape Mildew.}

M. River states that in 1847 he was invited by Dr. Loze to examine a sort of wine to which extraordinary properties were attributed. Another invitation to the same effect was received, in 1849, from M. Souleyet, who spoke highly of the efficacy of this wine in curing some diseases. M. Rivet found iodine in the wine; and he learned that the vines which produced it were not attacked by the oidium, and that M. Mouries had effected remarkable cures among vines by manure containing iodine. Having made some experiments, the following facts were elicited :-

1. Manure produced by the fermentation of marine plants has been employed in some parts of Spain since 1835. The soil which has received this manure contains, on the average, 1-600000 part of iodine. The vines which grow in it have never, up to the present time, been attacked by the oidium.

2. The wine made from these vines has some peculiar qualities. In commerce, where it is rare, it bears the name of Malaga Rives de Mer. It is of all vegetable productions the richest in iodine, containing on the average 1-50000 part of that principle.

3. Iodine found naturally in plants or animals possesses an action which, by its nature and intensity, cannot be produced by its chemical preparations. M. Didot pointed out the absence of oidium on vines, the wood of which had been smeared over with coal tar.

M. Lapierre-Beaupre stated that according to his observations the mildew does not attack the stem; the vines which were diseased in 1852 even appeared to have for the most part escaped in 1853. It was stated by M. Pascal that acetate of lead prevents the development of oidium and other cryptogams. M. Sourdette proposes a simple and inexpensive preservative, which has proved successful in some experiments made during two years in the neighborhood of Bordeaux. In order to prevent and arrest the development of the oidium, it is sufficient, three weeks after pruning the vine, to smear the stem and shoots with pure liquid tar, applied with a large brush. This operation costs very little, and has proved very successful on all the plants on which it has been performed, even although they were in the midst of infected vines.-Comptes Rendus.

\section{When Should Grain be Cut?}

A Most important question for the farmer. Careful observation, and some little experience during twenty years' residence in a great wheat-growing country, has convinced the writer that it is fully ten per cent. profit on the crop to the farmer to cut his wheat before the grain is fully ripe. Our rule is to commence cutting as soon as the earliest part of the crop has passed from the milky into the dough state.

There is no occasion to let it lay to cure when cut while the straw is still partially green. 
Bind it up as fast as cut, and set the bandles in stooks, "Dutch fashion"; that is, two and and two leaning together, in dozens, or twenties, or any given number, so as to give an even count. Set in this way, the most unripe grain will cure and perfect itself.

The advantages are, the grain is heavier, sweeter, and whiter: there is less loss of shattered grain; the straw, where that is an object, is so much better feed as make it worth while to cut early, even if there were a loss on the grain, which is not the case.

For seed, the best portion of the field should be set apart and left to mature until fully ripe, and then carefully cut by hand, and very carefully handled, because the very grains which should be saved for seed are the ones most easily shattered. Give these bundles a slight thrashing, and give the grain a thorough winnowing; screen out all but the most plump kernels, and sow those for your next crop, and you will succeed in improving both quality and product.

This question, of "When should grain be cut?" has been agitated for many years, both in this country and Europe.

In the second volume of British Husbandry, it is said-

"The question has been for some time agitated regarding the state of ripeness on which grain should be reaped, and it has been recommended, as a general rule of practice, to cut down the crop before the uppermost grain can be shaken out. Taking all things into consideration, it seems to be the most prudent plan to have the grain cut before it is fully ripe; but in this, a medium course should be adopted; for although grain, if allowed to become too ripe, assumes a dull, husky hue in the sample, yet, if not ripened enough, it shrivels in the drying."

Cadet de Vaux asserts that "grain reaped eight days before the usual time has the berries larger, fuller, and finer, and better calculated to resist the attacks of the weevil. An equal quantity of the corn thus reaped with corn reaped at maturity gave more bread, and of better quality. The proper time for reaping is that when the grain, on being pressed between the fingers, has a doughy appearance, like a crumb of bread just hot from the oven."

Mr. C. Howard, in the Report on Select Farms, says-

"Wheat ought never to be allowed to remain uncut till it is fully ripe. Experiments, easily made, will prove to every cultivator of it that by permitting it to stand until the straw has lost its succulency, he gains nothing in plumpness or bulk of grain, but loses much in its color and fineness of skin; besides which, he incurs the risk of shelling by the high wind, or by its being cut under the influence of a burning sun.

"When fully ripened by standing in the shocks, no dry hour should be lost in getting it well secured."

Loudon observes that "in harvesting wheat the best farmers, both in England and on the Continent, agree that it ought to be cut before it becomes dead ripe. When this is the case, the loss is considerable, both in the field and the stack-yard, and the grain produces an inferior flour."

An experienced Pennsylvania farmer of our acquaintance always cuts his oats while the straw is green. This he learned to do, contrary to all old practice, by accident. His hay crop was short one year, and he determined to cut his oats green-losing, as he thought, the grain for the sake of the straw. For seed, he left a strip through the middle of the field, where the oats were best. When he came to thrash, he was surprised to find the early-cut straw yielding as much and as plump grain as that which stood till it was dead ripe, while the straw was incomparably better; in fact, the stock ate it as rapidly as they would timothy hay._Louisville Journal.

\section{On the Proximate Principles of the Bran of Wheat.}

Some years since, M. Millon, as a result of long labor, arrived at the conclusion that bran is an alimentary substance; that bran bread and pilot bread was more healthy and more nutritious than white bread. This opinion has been contested, and Millon has been ironically attacked for not conforming to the regimen he recommends. But the opinion is now sustained by Cherreul, who declared his views on the occasion of a memoir of M. Mouries on 
this subject. It is known, too, that according to Magendie's experiment dogs could live on bran bread, while they died when fed on wheat bread. This fact, which appears singular, is explained through the researches in question.

The inner surface of bran is covered with azotized principles, which, like diastase, will dissolve starch, changing it into dextrine and sugar. These principles differ somewhat from diastase. Still it is demonstrated that bran acts as a ferment in fermentation, and consequently in a similar manner in digestion.-Silliman's Journal, Paris Correspondence.

\section{On the Value of Cotton-seed Cake as Food for Cattle.}

A writer in the Scotch Journal of Agriculture gives the following results of a series of experiments in respect to the value of the cotton-seed cake as food for cattle and other stock. The cake used was obtained from a quantity of cotton-seeds which had been pressed in a mill near Edinburgh, for the purpose of extracting the oil contained in them.

Before giving the details of the experiments, which seem to prove that the cotton-seed cake is as valuable in some respects as oil meal, linseed cake, or bean meal, we would call attention to the analysis of the cotton-seed cake, made by Dr. Anderson, as compared with other feeding substances:

\begin{tabular}{|c|c|c|c|c|c|c|}
\hline 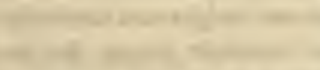 & $\begin{array}{l}\text { Linseed } \\
\text { cake. }\end{array}$ & $\begin{array}{l}\text { Rape } \\
\text { cake. }\end{array}$ & $\begin{array}{l}\text { Cotton- } \\
\text { seodd } \\
\text { cake. }\end{array}$ & Beans. & Oats. & Barley. \\
\hline Water... & $12 \cdot 44$ & 10.68 & $11 \cdot 19$ & $15 \cdot 84$ & $12 \cdot 66$ & $15 \cdot 97$ \\
\hline Oil.. & $12 \cdot 79$ & $11 \cdot 10$ & $9 \cdot 08$ & $1 \cdot 59$ & $6 \cdot 12$ & 1.88 \\
\hline Albuminous compounds...... & $27 \cdot 69$ & 29.53 & $25 \cdot 16$ & $4 \cdot 70$ & $10 \cdot 16$ & $7 \cdot 74$ \\
\hline 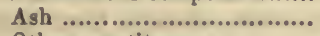 & $6 \cdot 13$ & $7 \cdot 79$ & $5 \cdot 64$ & $3 \cdot 36$ & $2 \cdot 66$ & $2 \cdot 14$ \\
\hline \multirow[t]{2}{*}{ Other constituents.............. } & $40 \cdot 95$ & $40 \cdot 90$ & $48 \cdot 93$ & $54 \cdot 51$ & $68 \cdot 40$ & $72 \cdot 27$ \\
\hline & $100 \cdot 00$ & $100 \cdot 00$ & $100 \cdot 00$ & $100 \cdot 00$ & $100 \cdot 00$ & $100 \cdot 00$ \\
\hline Nitr & $4:$ & $4: 38$ & $3 \cdot 95$ & $3 \cdot 89$ & $1 \cdot 60$ & 1.22 \\
\hline Silie & $1 \cdot 0$ & $1 \cdot 18$ & $1 \cdot 32$ & & & \\
\hline Phos & $2 \cdot 73$ & $3 \cdot 87$ & $2 \cdot 19$ & 0.49 & 0.65 & 0.56 \\
\hline Phosphoric acid................. & 0.55 & 0.39 & $0 \cdot 15$ & $0 \cdot 46$ & 0.01 & 0.35 \\
\hline
\end{tabular}

It will be seen from this table that cotton-seed cake holds a respectable place as an article of food for cattle; while oats and barley, which are considered by some intelligent and experienced feeders as equal, weight for weight, to linseed cake, are very deficient in oil and albuminous compounds, the two most important constituents in any feeding-stuffs. It is as well to mention, however, that this opinion has been disputed by many eminent feeders.

The parcel of cotton-seed cake used was of a yellowish-brown appearance, very brittle, of an agreeable nutty flavor. We first tested, says the writer, its palatableness: pieces were laid before cattle, sheep, and pigs, which deroured them with an avidity and relish seldom manifested towards kinds of food to which they had not been accustomed. We next instituted an experiment with it: eight cattle, that had been fed on turnips and straw all winter, were selected in the beginning of March; four were fed on cotton-seed cake at the rate of 6 pounds per day to each, and the other four on a mixture composed of $2 \frac{1}{2}$ pounds linseed cake, $2 \frac{1}{2}$ pounds of bean meal, and 1 pound of treacle, with chaff, and a little salt; both lots got, besides, as many Swedish turnips and as much straw as they could eat. This feed was continued for six weeks, at the end of which time, the quantity of cotton-seed cake being nearly exhausted, the cattle were sold fat to a butcher, after the best two in the whole lot, which were chosen from those fed on the cotton-seed cake, had obtained the premium for the best fat at a district agricultural show. We considered this experiment favorable for the cotton-seed cake, and, though somewhat vague and by no means rigidly conducted, it was quite sufficient to warrant a more extended experiment. A new supply of seed having been obtained, six cattle were selected which had been fed on turnips and straw up to the 10 th of January, when the experiment commenced; two of them got, in addition to their turnips, 4 pounds of linseed cake; two, 4 pounds of cotton-seed cake; and two, 4 pounds of bean 
meal, till the 10th of April, when they were slaughtered. They were measured on the 10th of January and 10th of April, (when the cotton-seed cake was finished,) and weighed after they were slaughtered. The results are as follows:-

\begin{tabular}{|c|c|c|c|c|c|}
\hline \multirow{3}{*}{ 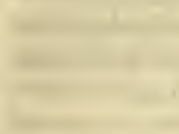 } & \multirow{2}{*}{ 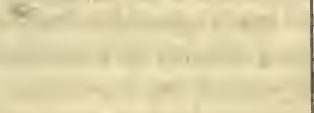 } & \multirow{2}{*}{$\begin{array}{c}\text { Weight } \\
\text { by mea- } \\
\text { surement, } \\
\text { Jan. } 10 .\end{array}$} & \multirow{2}{*}{$\begin{array}{c}\text { Weight } \\
\text { by mea- } \\
\text { surement, } \\
\text { April 10. }\end{array}$} & \multicolumn{2}{|c|}{$\begin{array}{l}\text { Weight after } \\
\text { being slaughtered. }\end{array}$} \\
\hline & & & & Beef. & Tallow. \\
\hline & & Pounds. & Pounds. & Pounds. & Pounds. \\
\hline & 1. Linseed cake .............. & 894 & 977 & 903 & \\
\hline & 2. Linseed cake ............... & 888 & 966 & 911 & 59 \\
\hline & 3. Cotton-seed cake.......... & 861 & 950 & 955 & 49 \\
\hline & 4. Cotton-seed cake.......... & 830 & 912 & 875 & 63 \\
\hline & 5. Bean meal ................... & 888 & 945 & 882 & 58 \\
\hline & 6. Bean meal .................. & 860 & 961 & 920 & 52 \\
\hline
\end{tabular}

They consumed each daily during the experiment about 150 pounds of Swedish turnips, besides straw. The cattle, when slaughtered, were not as fat as we would have wished; but we thought it better to send them to the butcher, as the cotton-seed cake at our disposal was finished. This will account for the actual weight being less than the weight by measurement, as cattle not in a ripe condition never weigh out to the measurement, a fortiori. The difference between the real weight and the weight by measurement, on the 10th of January, will be greater than the difference between the real weight and the weight by measurement on the 10th of April ; so that the real increase in weight during the three months of experiment is not indicated by the figures above. All that we wish to prove is, that cattle fed on cotton-seed cake made as much progress as those fed on linseed cake and bean meala fact which was abundantly manifest both from the appearance and touch of the animals.

Subsequent experiments were made with cotton-seed cake obtained from New Orleans, with nearly the same results. In some instances the cattle refused to eat it, unless previously mixed with other food. This dislike was attributed to the cake having been injured by sea water or other causes. Several other persons who used the New Orleans cake expressed their satisfaction with it, and esteem it valuable. In some cases the cattle did not seem disposed to eat it at first, but eventually did so, when they became very fond of it, and greatly improved.

Two methods are adopted in New Orleans for the extraction of the oil from the cottonseed. They are as follows:-

Plan I.-1. Break up the cake as fine as can be in a cast-iron or other mill; 2. crush it as fine as can be through rollers; 3. put it into large casks, and put a jet of steam into it; then the oil, the stearine, and the oleine will rise to the top, and the seed below is prepared for the feeding of cattle. Plan II.-Crush and run it between rollers; apply a jet of steam into it till it is properly cooked; then put it into the presses. It will give 5 quarts of oil to each 100 pounds of cake.

In addition to the oil contained in the cotton-seed, there is also an exceedingly bitter principle, which has never been examined chemically. This principle would undoubtedly act medicinally. When the fresh cotton-seed is examined under the microscope, it may' be noticed in the form of minute red spots or vesicles, distributed uniformly throughout the white part of the kernel. In the mealed or crushed seed the action of this principle is not so strikingly noticed; it still, however, exists, and is undoubtedly the cause of the repugnance which cattle sometimes manifest towards it.-Editor of the Year-Book.

\section{Farinaceous Aliment Obtained from Straw.}

THE attention of agriculturists in France has been recently directed to the discovery of a method of converting straw into a kind of bran. This discovery has been claimed by two individuals. The first is a miller near Dijon, who, it is said, on trying the mill-stone of a new mill, discovered the possibility of converting straw into a nourishing food. The second, M. Jos. Maitre, of Vilotte, near Chatillon.

This distinguished agriculturist, known for the purity and perfection of his breeds of 
sheep, conceived the idea of converting into farina not only the straw of wheat and other grains, but of hay, trefoil, lucern, sainfoin, etc. His efforts are said to have been perfectly successful, and his discovery arrived at, not by chance, but by long experiment and research. The aliment which he has produced is said to be a complete substitute for bran. It is given to sheep and lambs, who consume it with a vidity, and may be given to all other graminivorous animals as a grateful and substantial food. We know in this country that the mere chopping of straw adds greatly to its powers by facilitating mastication and digestion. We may believe that a more perfect comminution of its parts will produce a corresponding effect, and extend very widely the uses of straw and other fodder as a means of feeding our domestic animals.Quarterly Journal of Agriculture.

\section{On the Relative Value of different kinds of Meat for Food.}

M. Marchat, of France, took twenty grammes of the muscle of the pig, ox, sheep, calf, and hare, which contained neither sinews nor muscular tissue, nor adhering fat, except whàt naturally exists between the muscular fibres, and dried them in a water-bath for several days, and thus ascertained the loss which each sustained by desiccation:-

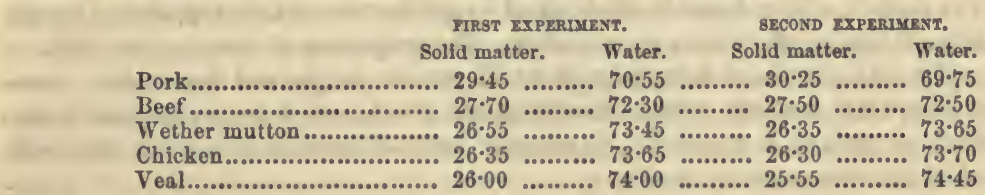

According to these numbers, we should arrange the meats in the following order of their relative nutritive powers: pork, beef, mutton, chicken, veal. This order is, however, not the true one; becadse the leanest meat contains a certain amount of fat; and because this substance is not so important an article of food as the pure muscles, it is necessary to ascertain how much a certain quantity of meat contains before we can judge properly of its relative nutritive value. M. Marchal accordingly treated the dried flesh with ether to dissolve out the fat, and obtained the following results :-

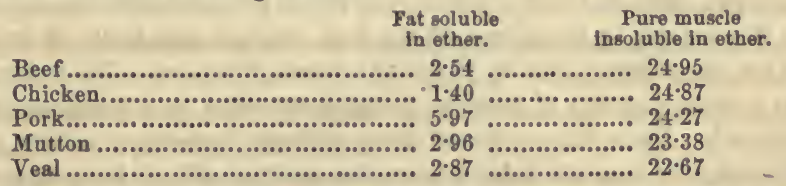

The last table shows that the true order should be beef, chicken, pork, mutton, and veal; a result which experience confirms. It may, however, be remarked, that there is considerable difference between the same kind of meat derived from different animals, and that the same amount of two different kinds of beef-broth, both containing the same amount of water, may have different nutritive values.-Comptes Rendus de l'Académie.

\section{Liebig on the Improved Manufacture of Bread.}

IT is known that the vegetable gluten of the various kinds of grain undergoes a change when moist; in a fresh condition it is soft, elastic, and insoluble in water, but in contact with water it loses these properties. If kept a few days under water, its volume is gradually increased until it dissolves, forming a thick mucilaginous fluid, which will no longer form a dough with starch. The ability of flour to form a dough is essentially lessened by the property of regetable gluten to hold water, and its change to the state, for example, in which it is contained in animal tissues, in meat and in coagulated white of egg, in which the absorbed water does not moisten dry bodies. The gluten of grain, in flour not recently ground, undergoes a change similar to that which it suffers when in a wet state, for the flour absorbs moisture from the air, being in a very high degree a water-absorbing substance; gradually the property of the flour of forming dough is lessened, and the quality of the bread made there- 
from injured. It is only by artificial drying and keeping from the air that this deterioration is prevented. In rye flour, this change occurs as soon, perhaps sooner, than in wheat flour.

About twenty-four years ago, the Belgian bakers commenced the use of a remedy by means of which bread equal to that made from the freshest, best flour, was manufactured from flour which, by itself, would give only damp, heavy bread. This remedy consisted of an addition of alum, or of sulphate of copper, to the flour. The effect of both these substances in the preparation of bread rests upon the fact that when warm they form a chemical combination with the gluten, (previously made soluble in water, and changed thereby,) which restores to it all its lost properties; it is again insoluble, and capable of holding water. The relations of vegetable gluten to caseine, with which it has so many properties in common, induced me to make some experiments, whose object was to replace both of the substances (sulphate of copper and alum) so deleterious to health and to the nutritious properties of bread, by some substance having the same effect, (as regards the gluten,) but devoid of injurious qualities. This substance is pure cold-saturated lime-water. If the lime-water be mixed with the flour intended for dough, and then the yeast or leaven added thereto, fermentation progresses in the same manner as in the absence of lime-water. If at proper time more flour be added to the "risen" or fermented dough, and the whole formed into loaves, and baked as usual, a sweet, beautiful, fine-grained, elastic bread is obtained, of exquisite taste, which is preferred by all who have eaten it any length of time to any other. The proportion of flour to lime-water is as follows:-for 100 pounds of flour, take 26 to 27 pounds or pints of lime-water. This quantity of lime-water does not suffice for mixing the bread, and of course common water must be added, as much as is requisite. As the sour taste of bread is lost, much more salt may be used to give it a palatable quality.

As to the amount of lime in the bread, 1 pound of lime is sufficient for 600 pounds of lime-water. In bread prepared as above there is nearly the same amount of lime as is found in an equal weight of leguminous seeds, (peas and beans.) It may yet, be established as a physiological truth, by investigation and experiment, that the flour of the cereal grain is wanting in the property of complete nutrition; and from what we know thereof, the cause would seem to lie in its deficiency in the lime necessary for the formation of the bones. The cereal grains contain phosphoric acid in abundance, but they contain far less lime than the leguminous seeds. This fact may explain many of the phenomena of diseases observed among children in the country or in prisons, if the food consists principally of bread; and in this connection the use of lime-water by physicians merits attention. The amount of bread produced from a given quantity of flour is probably increased in consequence of an increased water-compound. From 19 pounds of flour, without lime-water, seldom more than $24 \frac{1}{2}$ pounds of bread were obtained in my house; the same quantity of flour, baked with 5 pounds of lime-water, gave 26 pounds 6 ounces to 26 pounds 10 ounces of good, well-baked bread. Now, since, according to Heeren's determinations, the same quantity of flour gives only 25 pounds 18 ounces, the increase of weight, in consequence of the use of lime-water, appears to me indubitable.

\section{The Preservation of Cheese.}

THE following article on the preservation of cheese is translated from the Maison Rustique, Paris, for the Working Farmer, by H. S. Olcott, Esq.:-

The preservation of cheeses is a most important point to those engaged in their manufacture, especially when they are intended for export. Their consistence and their state of fermentation more or less advanced in the storehouses or cheese-rooms should serve as a guide. The method of manufacture also affects largely their preservation. Those cheeses which have received pressure in a too fresh state, and from which the whey is not entirely separated, are liable to rise, and have in their centres holes or reservoirs of air, which give to the paste a spongy and disagreeable look. When this accident arises during the manufacture, and if the fermentation is considerable, place the cheese in a cool and dry place, and pierce it with skewers of iron in the places where it rises the most; the air or the gases escape by these openings, the cheese subsides, and the interior presents fewer cavities. To prevent this 
accident, the English make use of a powder, which is sold under the name of cheese-powder; it is composed of a pound of nitre and one ounce of powdered Armenian bole intimately mixed. Before salting the cheese, and while it is about being placed in the press, they rub it with an ounce of this mixture; a stronger dose would produce a bad effect.

The part that the salt plays is very important. We know, indeed, that the caseine in the dry state exists in an indefinite condition; but then it possesses only a weak flavor, and not agreeable. The addition of the salt on the one hand, and the preparation or perfection in the storehouse on the other-operations which require the greatest care and vigilance-succeed in procuring a gentle fermentation, or a gradual reaction between the elementary substances of the cheese. This reaction proceeds so much the more rapidly as the cheese is softer and as the place is warmer and more moist. In proportion as the fermentation has been gentle, so much the more is the flavor of the cheese sweet and agreeable. It is at this precise moment, when the reaction between the elements has produced combinations agreeable to the taste, that it is necessary to perfect the cheese: sooner than this it is not finished; later, it is in a state of decomposition more or less advanced. When the cheese is in the right condition, it is put in a place cool and not too moist, in a good cellar which does not contain any liquor in fermentation; those where wine will keep well are equally good for cheese, but the two together in the same cellar will mutually exercise a bad influence.

Some cheeses with soft and fine paste are put in boxes of fir or beech. By closing these boxes tightly, and giving them a coat or two of paint, the cheeses will be preserved for a longer time and in a better condition. Chaptal and others claim that cheese after transportation is never so good as when it is just taken from the cellars. The fact is, it decomposes during its transportation, and it is for this reason that in a tight varnished box the cheese will retain those qualities which constitute its excellence.

The cheeses of Holland are usually covered with a coating of linseed-oil varnish: this preparation is doubtless one of the principal causes of their preservation on long royages; their small bulk may also be adduced as a reason.

The insects which attack cheeses are-1. The fleshworm or cheese-mite, (acarus siro,) which devours them when partly dried. These animals are so much the more dangerous, because they hatch beneath the crust, whence they spread throughout the interior, causing great injury. When one is careful to brush the cheeses frequently, to wipe them with a cloth, to wash with boiling water the shelves on which they lie, one can protect himself against these mites. But the most certain way is, after having rubbed the cheeses with a brine, to let them dry, and smear them over with sweet oil. It is in this way that they treat Gruyere cheese when it is attacked by this destructive insect.

2. The larvæ of the gilded green fly, (musca cesar,) of the common fly, (musca domestica,) and above all of the fly of putrefaction, (musca putris.) These larvæ introduce themselves into the cheese and make ravages. The presence of these vermicular insects, which denotes an advanced state of putrefaction, excites much repugnance with the great number of consumers; some persons, on the contrary, prefer the cheese in this state, because it is then stronger and of a more pungent flavor.

We can destroy all these animals by vinegar, the rapor of burning sulphur, or by washes of chloride of lime. When the storehouse contains these insects in abundance, take up the cheeses, and scrape and wash the shelves with water holding in solution chloride of lime; then scrub at the same time the floor, and apply to the walls a coating of whitewash. When the cheese-room is dry, replace the cheeses, which have been previously washed with a weak solution of chloride of lime, dried, wiped with a cloth or scraped, if they need it, and finally rubbed, as has been said, with a cloth soaked in oil.

If the cheeses have arrived at an advanced state of decomposition, they are put in powdered charcoal, mixed with a small quantity of chloride of soda, which destroys their offensive odor, and haste must be made to finish their manufacture before they become entirely putrid. As to mould, this can be prevented by scraping the cheese, by brushing it, and by rubbing it with the oil.

To give to new Gloucester cheese the taste and appearance of old cheese, with a probe we take from the two sides and centre-penetrating as far as the middle in each case-cylinders 
of the paste, which are replaced by similar ones from an old and fine cheese. After keeping the cheeses thus prepared for a fow days, they will have acquired all the agreeable qualities of old Gloucester.

\section{Preserving Timber.}

Antoine Le Gross, of Paris, has recently obtained a patent, the object of which is to preserve all kinds of timber by a cheap chemical solution, which does not injure its fibre. For this purpose he employs a solution of hydrochlorate of manganese, saturated with chalk and the oxide of zinc. The logs or pieces of timber are steeped in this solution about twenty-four hours. The vessel to hold the timber is placed vertically, so that the timber can be placed on end to allow the liquid to flow through the pores by capillary attraction. If placed horizontally, the liquid will not flow through the fibres of the timber. Some creosote may be added to the liquid, and with a good effect.

\section{On the Preservation of Vegetables.}

THE following extracts on the preservation of vegetables are taken from the work of a French author, M. Appert, entitled "The Art of Preserving all kinds of Animal and Vegetable Substances for several years. Published by order of the French Minister for the Interior, in the Report of the Board of Arts and Manufactures." The author states that "this method is not a vain theory. It is the fruit of reflection, investigation, long attention, and numerous experiments, the results of which, for more than ten years, have been so surprising, that notwithstanding the proof acquired by repeated practice, that provenders may be preserved two, three, and six years, there are many persons who still refuse to credit the fact."

After stating the experience he has had in the cellars of champagne, in shops, manufactories, and warehouses of confectioners and grocers for forty-five years, he proceeds to say"I owe to my extensive practice, and more especially to my long perseverance, the conviction-1. That fire has the peculiar property not only of changing the combination of the constituent parts of vegetable and animal productions, but also of retarding, for many years at least, if not of destroying, that natural tendency of those same productions to decomposition.

" 2 . That the application of fire in a manner variously adapted to various substances, after having, with the utmost care; and as completely as possible, deprived them of all contact with the air, effects a perfect preservation of those same productions with all their natural qualities.

"The details of the process consist principally-1. In closing in bottles the substances to be preserved; 2 . In corking the bottles with the utmost care, for it is chiefly on the corking that the success of the process depends; 3 . In submitting these enclosed substances to the action of boiling water in a water-bath for a greater or less length of time, according to their nature, and in the manner pointed out with respect to each several kind of substance; 4 . In withdrawing the bottles from the water-bath at the period described." As an example of his practice, we give his method of preserving dwarf kidney-beans:- "I cause the beans to be gathered as for ordinary use. I string them and put them in bottles, taking care to shake them on the stool, to fill the vacancies in the bottles. I then cork the bottles and put them in the water-bath, which is to boil an hour and a half. When the beans are rather large, I cut them lengthways into two or three pieces, and then they do not require being in the water-bath longer than one hour." When they are to be used, he gives the following instructions:- "Scald the French beans as if they were fresh, in water, with a little salt, when not sufficiently dressed by the preserving process. This often happens to them as well as to artichokes, asparagus, and cauliflowers. If sufficiently boiled, on being taken out of the bottles I have only to wash them in hot water in order to prepare them afterwards for vegetable or meat soup."

This author furnishes several recipes for other vegetables, all of which are on the bottling principle; but there is another process, which consists in evaporating the watery parts of vegetables, and preserving them dry. We recollect some years ago receiving from Holland a few packages of sugar-peas, kidney-beans, and other vegetables, in this dried state, which, when cooked, were as well flavored as they would have been in the green state. 
These we believe are obtained by drying in chambers, through which currents of heated air were introduced : they were completely dried and shrivelled up, and had the appearance of strips of thick parchment or leather until they were boiled, and then they swelled out to their usual dimensions. We have also seen kidney-beans preserved by first boiling them tender, and afterwards drying them in a warm, airy place, when they may be kept for any length of time in bags or boxes, till ready for use. This drying process may be applied to peas, beans, kidney-beans, cabbages, cauliflowers, spinach, beets, parsnips, carrots, potatoes, \&c., the latter being cut in slices. There is no subject in domestic economy of which so little is known generally as the preservation of vegetables and vegetable cookery. We know, for instance, that some potatoes require steaming, and others boiling, to have them in perfection; some require to be boiled in their skins, and some without; and we are informed by M. Soyer, that the soil in which the varieties of potatoes are cultivated has a great deal to do with the mode in which they ought to be cooked.-London Gentleman's Companion.

\section{On the Results of Experiments on the Preservation of Fresh Meat.}

THIs inquiry, presented to the British Association by Mr. G. Hamilton, was undertaken with a view of discovering a method by which beef could be brought in a fresh state from South America. The experiments were made by enclosing pieces of beef in bottles containing one, or a mixture of two or more, of the following gases:-Chlorine, hydrogen, nitrogen, ammonia, carbonic acid, carbonic oxide, and binoxide of nitrogen. Of these the last two only possessed the power of retarding putrefaction. Beef that had been in contact with carbonic oxide for the space of three weeks was found to be perfectly fresh, and of a fine red color. Binoxide of nitrogen is capable of preserving beef from putrefaction for at least five months, during which time the beef retains its natural color and consistence. When meat that had been preserved by the last process was cooked by roasting, it was found to possess a disagreeable flavor. If cooked by boiling, the ebullition must be continued for a much greater length of time than is necessary for fresh meat.

Dr. Calvert remarked, that he had opportunities of observing the well-known valuable antiputrid properties carbonic acid, and instanced the case of the carcass of a horse that was at present in a fresh state, although four years had elapsed since it had been soaked in liquor containing the acid. He recommended the use of this acid for preserving bodies intended for dissection, as it neither affects the tissues nor discolors the organs.

New French Method of Preserving Meat and Fruit.-The French have been experimenting upon this subject, and it is reported that a mode of preserving meat and fruit has been discovered by which they are not altered in size or appearance, so that at the end of six or eight months, when placed on the table, they would be taken to be perfectly fresh. MM. Delabarre and Bonnet have submitted to the French Minister of War some samples of meat preserved by their method. This consists in drying it by natural means, and then preparing it with materials furnished by the animal. When the water which composes a large part of fresh meat is driven off, the osmazome supplied by the animal is applied as a varnish, to the increase of the nutritious properties of the meat. By desiccation the meat is reduced in size and weight one-half, and this is done without the application of artificial heat. It may be eaten in this state, and is not disagreeable. When cooked, half an hour's immersion in hot water is sufficient to increase its bulk to what it was originally, and to render it as palatable is if fresh meat had been cooked.-Practical Mechanics' Magazine.

In addition to the above, a kindred process has been devised by a Hungarian for preserving the potato, which, valuable as it is, especially in view of its cheapness, is nevertheless rendered far less widely available than it should be, by reason of its bulk and its perishable nature. But both these qualities are due to the great proportion of water it contains-about seven-eighths of its entire weight. The Hungarian's process divests the potatoes of their water, and reduces them to a dry powder like Indian meal, which may be cheaply transported any distance, and will keep in any climate; a ton of potatoes being reduced to less than three hundredsweight of the potato meal, which can at once be restored to the state of mashed potatoes, by simply boiling in fresh water. 


\section{On the Influence of Water in Cooking Vegetables.}

Mr. S. W. Johnson communicates to the New York Country Gentleman the following recent memoranda of Professor Boethger, of Frankfort, "On the influence of water in cooking regetables" :- -

na

"If one portion of vegetables be boiled in pure (distilled or rain) water, and another in water to which a little salt has been added, a decided difference is perceptible in the taste and odor, and especially in the tenderness of the two portions. Vegetables boiled in pure water are vastly inferior in flavor. This inferiority may go so far, in case of onions, that they are almost entirely destitute of odor or taste, though, when cooked in salted water, they possess, in addition to the pleasant salt taste, a peculiar sweetness and a strong aroma. They also contain more soluble matter than when cooked in pure water. Water which contains 1-420th of its weight of common salt is far better for cooking vegetables than pure water, because the salt hinders the solution and evaporation of the soluble and flavoring principles of the vegetables. This explains the advantage of the general use of salt in cooking, and the impessibility of correcting, by subsequent additions of salt, the want of flavor in vegetables that have been boiled without it."

\section{Use of Coffee among the Natives of Sumatra.}

A correspondent of Hooker's Journal of Botany gives the following account of the manner of using coffee among the natives of Sumatra ; he says:-

In going up the river Chenaku, I saw everywhere coffee planted about the houses, and in every case the fruit dropping and decaying on the ground. Upon inquiring, I found these people drank an infusion of the leaves and entirely neglected the berries. I was anxious to taste this and see it prepared, and had an opportunity of doing so. A number of young twigs of the plant were gathered, with their leaves, and, after being cut to about a foot in length, were placed closely together between two strips of bamboo, tied at the ends, so as to form a dense dise of green leaves about eighteen or twenty inches in diameter. This was then held over a clear, blazing fire (the ends of the bamboo serving for a handle) until the leaves were of a rich, brownish-green color, and perfectly crisp and brittle. The latter part of this process requires some care, as, when nearly dry, the leaves are almost as inflammable as gunpowder, and if once they catch the flame the whole is consumed in a moment. When dry, the leaves are pounded by crushing in the hand. The powder of the leaves is infused in boiling water, exactly like tea, though in much larger quantities; it produces a dark-brown liquid, looking like coffee, smelling like green tea, and tasting like a mixture of the two. It is very pleasant, however, and refreshing, and I can understand how these people are passionately fond of it. The curious part of it is, that, while theine, caffeine, and theobromine have been found (nearly identical as they are in composition and properties) in use in three distinct parts of the world, and valued for the same exhilarating qualities, here is a people, little raised above savages, using in an independent manner one of these very plants, being evidently uninstructed, as otherwise they would have used the berry.

\section{Chinese Method of Scenting Tea.}

A Chisa correspondent of the London Athenoum furnishes the follawing information respecting the methods of scenting tea, as practised by the Chinese. He says: "I have been making inquiries for some time past about the curious process of scenting teas for the foreign markets; but the answers I received to my questions were so unsatisfactory, that I gave up all hopes of understanding the business until I had an opportunity of seeing and judging for myself. During a late visit to Canton, I was informed that the process might be seen in operation in a tea-factory on the island of Honan; and accordingly embraced an opportunity to visit the place with an eminent Chinese merchant. When we entered the tea-factory, a strange scene was presented to our view. The place was crowded with'women and children, all busily engaged in picking the stalks and yellow or brown leaves out of the black tea. For 
this labor each was paid at the rate of six cash a catty, and earned, on an average, about sixty cash a day - a sum equal to about threepence of our money. Men were employed giving out the tea in its rough state, and in receiving it again when picked. With each portion of tea a wooden ticket was also given, which ticket had to be returned along with the tea. Besides the men who were thus employed, there were many others busily at work, passing the tea through various-sized sieves, in order to get out the caper, and to separate the various kinds. This was also partly done by a winnowing machine, similar in construction to that used by farmers in England. Having taken a passing glance at all these objects on entering the building, I next directed my attention to the scenting process, which had been the main object of my visit, and which I shall now endeavor to describe.

"In a corner of the building, there lay a large heap of orange-flowers, which filled the air with the most delicious perfume. A man was engaged in sifting them, to get out the stamens and other smaller portions of the flower. This process was necessary, in order that the flowers might be readily sifted out of the tea after the scenting had been accomplished. The orange-flowers being fully expanded, the large petals were easily separated from the stamens and smaller ones. In 100 parts, 70 per cent. were used and 30 thrown away. When the orange is used, its flowers must be fully expanded, in order to bring out the scent; but flowers of jasmine may be used in the bud, as they will expand and emit their fragrance during the time they are mixed with the tea. When the flowers had been sifted over in the manner described, they were ready for use. In the mean time, the tea to be scented had been carefully manipulated, and appeared perfectly dried and finished. At this stage of the process, it is worthy of observing that, while the tea was perfectly dry, the orange-flowers were just as they had been gathered from the trees. Large quantities of the tea were now mixed up with the flowers, in the proportion of forty pounds of flowers to one hundred pounds of tea. This dry tea and the undried flowers were allowed to lie mixed together for the space of twenty-four hours. At the end of this time, the flowers were sifted out of the tea, and by the repeated sifting and winnowing processes which the tea had afterwards to undergo, they were nearly all got rid of. Sometimes a few stray ones are left in the tea, and may be detected even after it arrives in England.- A small portion of tea adheres to the moist flowers when they are sifted out, and this is generally given away to the poor, who pick it out with the hand.

"The flowers at this part of the process had impregnated the tea-leaves with a large portion of their peculiar odors, but they had also left behind them a certain portion of moisture, which it was necessary to expel. This was done by placing the tea once more over slow charconl fires in baskets and sieves prepared for the purpose of drying. The scent communicated by the powers is very slight for some time, but, like the fragrance peculiar to the tealeaf itself, comes out after being packed for a week or two. Sometimes this scenting process is repeated when the odor is not considered sufficiently strong; and the head man in the factory informed me he sometimes scented twice with orange-flowers, and once with the 'Mo-le, (Jasminum sambac.)

"The flowers of various plants are used in scenting by the Chinese, some of which are considered better than others, and some can be had at seasons when others are not procurable. The different flowers are not all used in the same proportions. Thus of orange-flowers there are forty pounds to one hundred pounds of tea ; and of the aglaia there are one hundred pounds to one hundred pounds. The quantity of flowers used seemed to me very large, and I'made particular inquiries as to whether the teas that are scented were mixed up with large quantities of unscented kinds. The Chinese unhesitatingly affirmed that such was not the case ; but I have some doubt on this point. The length of time which teas thus scented retain their flavor is most remarkable. It varies however, with the different sorts. Teas scented with orange-blossoms will keep well for two or three years. Other flower-perfumes, it is said, may be retained as long as six years.

\section{On the Use of the Red Camomile (Pyrethrum roseum) for the Destruction of Insects.}

For some years a vague report has reached us of a Caucasian plant having astonishing and eminently useful properties-that of destroying fleas and bugs; it was also known that 
this marvellous plant belonged to the genùs Pyrethrum, but the specific character was uncertain. This plant has been recently introduced into Brussels in the rich collections of the botanical garden. We hope that in some years the red camomile shall have freed our people from one of the most abominable plagues which afflict sensitive humanity. Some details of a plant of so certain a future as that of the red camomile will be, without doubt, acceptable to our readers. In Transcaucasia, its country, this plant bears also the name of the Persian Camomile, the flea-killer, and flea-wort; it forms a little shrub with perennial roots, branched twelve to fifteen inches high, bearing many flowers at first of a deep red, afterwards a clear or rosy red, and an inch and a half in diameter, (the size of the flowers will also cause this plant to be cultivated as an ornament in our gardens;) the stalks dry up after the ripening of the seeds, but the roots are perennial, and for some years may be multiplied by division. Freshly gathered, the flowers are not very odorous, but dried they acquire an odor so strong and penetrating that it kills all the insects and all the vermin, of which until now no certain agent of destruction has been found. The red camomile can bear $20^{\circ}$ Centigrade of frost, a temperature to which it is often submitted on the Caucasian mountains and on the plains, elevated from 4500 to 6500 feet above the sea level. Although it inhabits virgin soil, it is easily brought into cultivation in gardens, and, since its energetic properties have been recognised, it is cultivated in a large way in different parts of Southern Russia. One very remarkable fact is, that the knowledge of the secret of the manufacture of the red camomile powder for the destruction of fleas, \&c. only dates, even in Caucasia, back about ten years, while the employment of this strong powder was known in regions far distant from Circassia. It seems that an Armenian merchant, named Sumbitoff, travelling in the south of Asia, observed that the inhabitants sprinkled themselves with a powder to prevent the stings of insects. This powder was nothing else than that made of the flowers of the red camomile. Returned to his country, our Armenian told his son of the discovery, and taught him to recognise the plant. This son became poor by reverses of fortune, but bethought himself of his father's secret; he set himself then to make this powder, and retired with very large profits from this trade. In 1818, he sold a pood (about twenty kilogrammes) of camomile powder at twenty-five roubles, (near one hundred francs;) and although the secret had been published, and every one knew the preparation of this powder, more than twenty villages in the district of Alexandropol were actually given up to the cultivation of the red camomile. The flowering of the Pyrethrum roseum commences in June, and continues more than a month. The flowers are gathered in dry weather. In one day a good harvester can collect from thirty to eighty pounds of these wild flowers. They generally dry them in the sun; but it is remarked that those dried in the shade have more virtue. The bed of flowers is stirred from time to time to help the drying; three or four days is sufficient to drive off every trace of moisture. To obtain one pound of dried flowers it requires about one hundred pounds of fresh ones! They are then reduced to a eoarse powder with the hand, and by means of a little millstone, or a little brass mill, a very fine powder fit for use is obtained. We see by this that the process is very simple; the most difficult question is how to operate upon a sufficiently large number of flowering plants. To give an idea of the importance of the manufacture of this powder, we must state that in Transcaucasia alone there are made each year for consumption in the Russian Empire more than 40,000 kilogrammes. Baron Folkersahm has recently published a valuable paper on the cultivation of the red camomile. His memoir terminates with the following remarks: That this powder preserves you from fleas and bugs; it kills flies, gnats, maggots, lice, and even the worms which are produced in the wounds of our domestic animals. To kill insects provided with wings, they mix a little of this with a substance which will attract them; for instance, to destroy flies, it is mixed with sugar. M. Folkersahm desires that the effects of this powder should be tried on other insects and worms hurtful to man or to his horticultural plantations. He adds, that if experiments demonstrate the efficacy of this powder, each person could cultivate in the corner of his garden a certain number of plants of red camomile to kill the insects, caterpillars, \&c. which ravage his field. From an approximative calculation, it is found that a space of eighteen square versts furnishes a quintal of powder. Mr. B. Roezl, who lived a long time in Russia, states that the Insecten pulver (powder of the 
Pyrethrum) is imported every year from Persia and the Caucasian provinces into all parts of the Russian Empire; and that used fresh, sprinkled over the window-sills, it makes all the flies fall instantly, asphyxiating them; but that at the end of a year it loses its energy. He also states that it is the Pyrethrum carneum and roseum which produce this powder.Journal d' Horticulture de Belgique.

\section{Alcohol from the Tubercles of the Asphodelus ramosus.}

THE tubercles of Asphodelus ramosus have been employed for some years in Algeria for the manufacture of alcohol. It has been asserted that they contain neither starch nor sugar, and the experiments of M. Clerget fully confirm this opinion. When grated and pressed, they yield 81 per cent. of juice, of specific gravity 1.082. When treated with iodine, not the slightest indication of starch can be obtained. The juice has no action on polarized light, but if it be heated with hydrocbloric acid at the boiling temperature, it rotates the plane of polarization to the left very powerfully. When mixed with two per cent. of yeast, it enters rapidly into fermentation, and yields eight per cent. of alcohol, being about twice as much as can be obtained from the juice of sugar-beet. The dried tubercles of the plant do not yield more than three per cent. of alcohol. M. Clerget is engaged in the investigation of the principle which undergoes fermentation.

\section{Odors of Flowers.}

SCHUBLER and Köhler have made many interesting observations on odors as well as colors. They found that, of the various colors of flowers, some are more commonly odoriferous than others, and that some colors are more commonly agreeable than others.

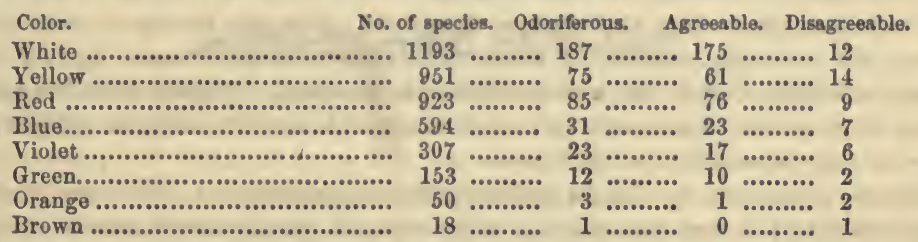

The white most odoriferous and agreeable-the yellow and brown most disagreeable.Prof. Darby.

\section{On the Aroma of American Wines.}

AT a recent meeting of the American Wine-Growers' Association at Cincinnati, the following was read from N. W. Thatcher, of Chillicothe:-

* * * * "The great desideratum in wine-growing is, doubtless, to procure a grape possessing at once sugar in abundance and an agreeable aroma; probably the Catawba (there are some spurious varieties of this grape) possesses these qualities to a more profitable degree than any grape we now cultivate, inasmuch as it is perfectly hardy; but this grape should not be regarded as the type of American grapes, for we shall yet surpass it; and to those whose palates do not accord too much with the foxy aroma of the Catawba, the Herbemont is the most acceptable grape, but the latter is not sufficiently hardy for extensive and profitable cultivation; but as we have several varieties of that class of grapes, we may look for the production of seedlings from them that will surpass any of the Fox family. Doubtless a cross of the Herbemont and Catawba would produce a valuable grape as to flavor and juiciness. It is, doubtless, a desideratum to obtain a grape possessing all the requisites for good wine; that is, it should be productive, hardy, juicy, sweet, and well-flavored. Until we can get one grape possessing in a sufficient degree all these, we can cultivate several varieties and attain our object by mixing the berries in the mash-tub. This is desirable, at least, to afford variety in our wines, as well as to give flavor to strong-bodied wines which are without it. The taste of the juice of the grape, as well as for various kinds of food, becomes fixed to some particular sorts by custom, and finally to the exclusion of any thing 
new; and hence I infer it will be difficult, after a few years, to eradicate the predilection of Ohio wine growers, even for the foxy aroma of their Catawba wines. If we look forward to the exportation of wines to foreign countries, we must look for their production in grapes of the Herbemont type. I am a wine-grower to a very limited extent, and only as an amateur; but still my experiments are, so far as they are successful, as valuable in their results as if I crushed the grapes of a township. I shall make no wine this season. I am satisfied that we can make as good wines in this country as in any other, and at equal price. I would prefer the best Cincinnati wine to any foreign I have ever seen, except, perhaps, the pure Xeres, Sherry, and Mangannelta, which we rarely see."

\section{New Use for Buckwheat Straw.}

Ir has been recently stated that the straw of the buckwheat has been applied with success in Russia as a substitute for quercitron, or yellow-oak bark, in dyeing.

\section{The Effect of Colored Light on Germination.}

To determine the commercial value of any seeds, one hundred of them are placed in a pot in a stove, made for the purpose of quickening the process of germination. If all the seeds germinate, the seed obtains the highest value in the market. If only eighty germinate, the seed loses 20 per cent. in value. This process ordinarily occupies from twelve to fifteen days; but Mr. Lawson found that by using blue glass they are enabled to determine the value of seed in two or three days: and this is a matter of such commercial importance to them, that it is quite equal to a gift of $£ 500$ a year.-Proceedings of the Royal Polytechnic Society.

\section{Plants Under Different Conditions.}

Dr. Gladstone, F.R.S., has communicated to the London Chemist some interesting facts in relation to certain experiments made by him upon plants under different colored glass, and under different atmospheric conditions:-

Darkness promotes a rapid and abundant growth of thin rootlets; it prevents the formation of chlorophylle, but does not interfere much with the general healthiness of the plant, nor with the production of the coloring matter of the flowers. Partial obscurity produces the same effects in a modified manner, but greatly facilitates the absorption of water; and the cutting off " of the chemical or blue ray under such circumstances seems to make very little difference. The withdrawal of all but the caloric rays interferes with the length of the roots, and produces a badly-developed plant. The pure luminous ray causes the rootlets to be few and straggling, and diminishes the absorption of water. Hyacinths were well developed under the pure chemical influence.

Experiments were made on the germination, under like influences, of wheat and peas, as samples of the two great orders of plants. The first series was made in common air, the plants being placed on damp bricks, twelve seeds of each kind being employed in each separate instance. The periods of germination, and all the circumstances that marked the growth of the plants, were carefully noted; drawings were made, and at the close of the experiment the height of the plants, the length of their roots, their weight, and the number of seeds that had germinated, were recorded. The effect of the same solar radiations on the two plants was extremely different. In respect to the wheat, it was found that, under the given circumstances, the absence of the chemical rays favors the first growth, and the presence of the luminous rays does not impede it. Afterwards the opposite effect takes place; the roots are retarded in their development by the yellow ray much more than by all the rays of the spectrum in combination. The calorific ray is, on the whole, the most favorable to their growth-eren more so than the complete absence of all solar radiations. The shooting forth of the plume is favored also by the withdrawal of the chemical rays, especially just at first; but the full and healthy development of leaves requires all the rays of the spectrum, the luminous being particularly necessary. In respect to peas under the given circum- 
stances, it was found that the cutting off of the chemical rays favors the first germination of the seed; and this appears to be the principal, if not the only, advantage of the darkness obtained by burying the seeds in the soil.

The development of roots requires also the absence of the chemical ray, but is rather favored than otherwise by heat and luminosity. The first development of the plumule also proceeds best under the same circumstances. Yet these are not the conditions which produce a healthy plant; they cause too rapid and succulent a growth. When the plant is fairly established, those radiations which are, comparatively speaking, devoid of light, but replete with chemical power, seem the most suited to it. The points in common between the different actions of the solar radiations on wheat and on peas are, that in both cases the cutting off of the chemical ray facilitates the process of early germination; and that both in reference to the protrusion of the radicles and the evolution of the plume, obscurity causes an unnaturally tall growth and poor development of leaves, and the yellow ray exerts a repellant influence upon the roots, giving the wheat a downward and the pea-roots a lateral impulse. A comparison of the results obtained by means of the yellow, of the obscured colorless, and the obscured yellow glasses, showed that the yellow ray has a specific action in many respects, but not of the character which has sometimes been ascribed to it. The diversity of effect of the same ray upon the two plants was well exhibited by what took place under the colorless and red glasses. Under the former there grew a tall and vigorous crop of wheat-plants, with a mere matting of stunted roots from the peas, while under the latter a thick crop of green and spreading plants arose from the germinating peas, but the wheat were few and straggling, and unhealthy in appearance. Seeds of the wheat and the pea were placed in jars, containing respectively carbonic acid gas, hydrogen from which every trace of oxygen was removed by pyrogallate of potash, common air from which carbonic acid was removed by caustic alkali, and normal atmospheric air. These merely corroborated the opinion generally entertained, that oxygen is absolutely requisite for instituting the first change in the cotyledons of the seed. Peas and wheat were also grown in oxygen gas, under the colorless and colored bell-jars. They grew and appeared to flourish best under the chemical influences of the blue glass.

\section{The Grittiness of Pears.}

The grittiness of pears greatly diminishes their value as a dessert. The proximate cause is known to be the deposit of hard matter in the pulpy cells, analagous to that which gives the bony texture to the stone of plums, cherries, \&c. In stone fruits the gritty matter is collected, and forms the pit or stone; but in the pear there is no part exclusively appropriated for the grit, which is found sometimes in large or small masses throughout the pulp.

The cause of this grittiness is unknown, but the accumulation of it may be arrested or diminished by sheltering the fruit from the cold rain which may fall during its growth, and arrest the free circulation of the sap. This hypothesis was suggested by M. Delaville, a French gardener, who remarks that the sorts which are most subject to spotting and grittiness are those which have the finest skin.

The manner in which M. Delaville protects his pears is as follows: As soon as the fruit is completely set, he encloses each cluster in a cornet of paper, fixed to the top of the stalk by a piece of rush, (bast.) This cornet must be sufficiently large to guard the fruit from all exterior injuries. The cornet should be very wide, and the small end placed upwards, so as to leave nothing uncovered except the bottom of the fruit-stalk. But this protection is unnecessary where the fruit is trained against a wall. About a fortnight before gathering, the cornet should be removed, in order to give the fruit color and to complete the ripening.

At the exhibition of the Imperial Horticultural Society of Paris, some St. Germain pears were exhibited, part of which were full of spots and grittiness, while others were fine and pulpy. Both samples were from one tree, but the fine ones were protected in the manner above described.-Phil. Florist. 


\section{Report on the Gases Evolved in Steeping Flax, and on the Composition of the Dressed Flax Fibre.}

By John F. Hodgrs, M.D., F.C.S., Prof. of Agriculture, \&c. Queen's College, Belfast.

THIs report contains the results of investigations which were undertaken in connection with the technical processes employed in the preparation of the flax-plant for textile purposes. The attention of the author was chiefly directed to.the examination of the method of steeping in water heated by steam, introduced by Schenck, and usually termed the hot-water system. In this process, which was fully described in a report made to the British Association for the Advancement of Science, at the Belfast meeting, it was found that the chemical changes produced by the fermentation of the flax straw in water maintained at a temperature of $90^{\circ} \mathrm{F}$., did not materially differ from those which accompany the ordinary method of steeping in pools in the open air; and that, in fact, Schenck's method might be regarded as merely the common process of the Irish farmer, accelerated and subjected to scientific control; the peculiar fermentation by which the adhesive matters of the straw are softened and dissolved being attended in both cases by the production of a considerable amount of butyric acid.

Examinations of the gaseous products of the fermentation were made at steeping-works in the neighborhood of Belfast, and also in experimental works in Queen's College; the water contained in the experimental vats being maintained at the requisite temperature by pipes conveying steam from the boiler of an engine connected with the college heating apparatus. The gases evolved from the fermenting liquid were analyzed in accordance with the processes proposed by Bunsen, and were found to consist of carbonic acid, hydrogen, and nitrogen. No traces of carbonic oxide, carburetted hydrogen, nor of sulphuretted hydrogen were detected. The following was the corrected composition of the mixture of gases collected in a trial of Schenck's process, in the steeping-vats in Queen's College. The carbonic acid was removed by the introduction of balls of caustic potash, and the residue examined by explosion with oxygen, \&c.

Composition in 100 vols.

Carbonic acid................................................................ 22 29

Hydrogen.......................................................................... $44 \cdot 30$

Nitrogen....................................................................... $33 \cdot 41$

Composition of dressed flax.-It was usually assumed, formerly, that by the process employed in the preparation of flax for spinning purposes, the fibre was deprived of all the constituents which the plant, during its growth, had extracted from the soil, and that it might be regarded as possessing the same composition as the cellulose of the chemist. This opinion was, several years ago, proved to be erroneous; and the results of the following analyses of samples of flax fibre show that not merely does the dressed flax of commerce contain a portion of the inorganic matters of the plant, but that there remains locked up in the cells of the fibre a considerable amount of the nitrogenized and other proximate compounds of the unsteeped straw. The following were the methods adopted in the examination of the flax fibre:-The fibre, cut into small pieces, was repeatedly treated with cold water so long as any thing dissolved. The solution obtained was strained through linen, and afterwards filtered. On boiling the filtered liquid, only a slight troubling was observed; but on the addition of a few drops of acetic acid, a precipitate of caseine was obtained, which, after twelve hours subsidence, was collected, washed, dried, and weighed. In the liquid from which the caseine was separated, when evaporated almost to a syrupy consistence, alcohol produced a bulky grayish precipitate, which was collected, washed, and dried. The alcoholic liquids, on concentration, afforded a rich orange solution, and gave, on evaporation, a reddish brown residue, which when heated, evolved a strong caramel-like odor, and its solution had a sweetish taste, and afforded the usual reactions of grape-sugar. The several precipitates, after being weighed, were carefully incinerated, and the weight of ash obtained in each case deducted. The determinations of the amount of nitrogen in the samples were made according to the method of Will, and included first, the estimation of the total amount of nitrogen in the dried flax, and secondly, of the amount which was retained in the form of insoluble 
azotized compounds, in a portion of the fibre exhausted by treatment with water. The amount of wax and oil present, was obtained by treating a portion of the fibre, dried in a peculiar apparatus at $212^{\circ}$, in which the substance is exposed to the vapor of ether, which, when condensed in a separate cooling apparatus, is occasionally forced through it by atmospheric pressure. The residue of the flax, after exhaustion with water, and the subtraction of the amount of insoluble salts which it was found to contain, and of the wax and insoluble nitrogenized bodies, as calculated from the amount of nitrogen in the washed fibre, was regarded as cellular fibre. The following is a statement of the results obtained in the examination of two samples of dressed flax, of arerage quality. The samples dried at $212^{\circ}$ contained respectively, No. I. $9 \cdot 10$, and No. II. $8 \cdot 61$ per cent. of water:-

\begin{tabular}{|c|c|c|c|}
\hline Wax, volatile oil and acid, resinous matter.. & $2 \cdot 200$ & & $2 \cdot 620$ \\
\hline Sugar, and coloring matters soluble in alcohol.. & $1 \cdot 541$ & .... & $0 \cdot 624$ \\
\hline Inorganic matters soluble in alcohol............... & 0.281 & & $0 \cdot 116$ \\
\hline Gum and pectine............................. & $0 \cdot 698$ & . & $0 \cdot 280$ \\
\hline Salts, insoluble in aleobol.......................................... & 0.076 & ...... & $0 \cdot 044$ \\
\hline Nitrogenized compounds soluble in water, caseine, \&c....... & 32560 & ............... & $1 \cdot 386$ \\
\hline Nitrogenized compounds insoluble in water..................... & $2 \cdot 940$ & ............ & $4 \cdot 310$ \\
\hline organic matters united with the fibre.............. & 0.238 & & $1 \cdot 490$ \\
\hline 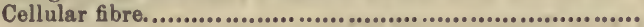 & & & \\
\hline
\end{tabular}

The total amount of inorganic matters present in the samples was obtained by the careful incineration of the dressed flax in platinum dishes. No. I. dried at $212^{\circ}$, left 1.40 per cent., and No. II. 1.54 per cent. The ash of No. I. was white, while that of No. II. had a brickred color. Each had respectively the following composition:-

Ash of sample No. I.

Ash of sample No. II.

\begin{tabular}{|c|c|c|}
\hline . & $2 \cdot 19$ & \\
\hline de or sod & $2 \cdot 75$ & \\
\hline ......... & $29 \cdot 24$ & \\
\hline gir.................................................. & $4 \cdot 64$ & ... \\
\hline de of iron ................................................. & $3 \cdot 72$ & n......................... \\
\hline ric acid................................................ & $5 \cdot 23$ & n.......................... \\
\hline d..................................................... & $6 \cdot 00$ & ............ \\
\hline ic acid.................................................... & $28 \cdot 17$ & \\
\hline a..................................... & & \\
\hline
\end{tabular}

In addition to the above analyses of fibre prepared by the hot-water system, a sample of Courtrai flax was examined. The amount of pure fibre was obtained by repeated digestion of the dried flax in a dilute solution of potash, (one-half an ounce of caustic potash to three pints of water;) and, after the careful removal of all traces of potash by washing in distilled water, the exhausted fibre was incinerated, and the amount of ash left deducted. The following were the results:-

Courtrai flax steeped and dressed.-100 parts contained water $8 \cdot 40$, and, dried at $212^{\circ}$, gave of wax and oil 2.30 per cent., and on combustion with soda-lime afforded 1.04 per cent. of nitrogen. Treated, as described, with dilute solution of caustic potash, there remained after the subtraction of the ash obtained by the incineration of the residue, 82.56 per cent. of pure fibre. A sample of the flax dried at $212^{\circ}$ left, when burned, 1.05 per cent of ash; if, therefore, we may assume the amount of nitrogen present as representing the proportion of the so-called proteine compounds contained in the flax, the following statement of the composition of the sample may be giren:-

Flax dried at $212^{\circ}$

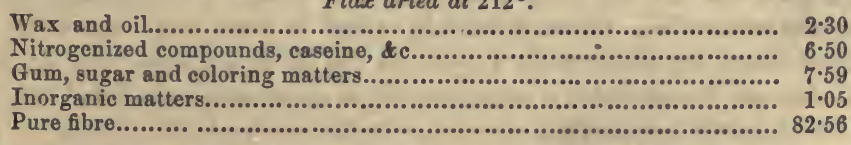

The foregoing analyses therefore show, contrary to what has been frequently asserted, that the fibre of flax in the condition in which it is purchased by the spinner, after it has been steeped and dressed, contains a considerable amount, not merely of the earthy and saline ingredients which the plant has taken from the soil, but of the various compounds, such as wax and caseine, which belong to the unsteeped straw, and upon the presence of which in the fibre it is probable much of its spinning qualities depend. An examination 
of the plant, as pulled from the field in the usual state of maturity, when the seeds contained in the capsules begin to assume a brown color, shows that it contains starch, which can be readily extracted by placing the stems, cut in pieces, in a powerful lever press, and moistening them with a small quantity of water. By allowing the expressed liquid to remain at rest, the starch subsides, and assumes a purple tinge on the addition of a watery solution of iodine. When, however, the flax straw is examined after it has remained exposed to the air for several days in the shock, the liquid obtained by subjecting it to pressure and washing with water was found to afford no indication of the presence of starch. In the dressed flax no trace of starch could be detected, and the discovery of the existence of a considerable amount of grape-sugar is exceedingly interesting, as corroborative of the statement of experienced dressers, that, by storing up the steeped flax, as imperfectly dried by exposure to the air for some weeks before proceeding to remove the adherent woody matters by scutching, the separation of fibre is greatly facilitated and its qualities improved.

\section{On the Deodorizing Properties of Charcoal.}

Iv a recent communication to the Royal Agricultural Society, England, on the above subject, by Prof. Way, he remarked, that, independently of the noxious gases resulting from the putrefaction of animal matter generally, and which consisted principally of sulphuretted hydrogen and sulphuret of ammonia, each particular animal substance, excretion or otherwise, had its peculiar odor, which-although abundantly perceptible by the senses, and in many cases, as in musk, almost inexhaustible-was inappreciable in weight; therefore, by deodorizing a large amount of odor, it was to be inferred that a large amount of manuring matter was thereby secured. He then enumerated the various single and double deodorizers that had been employed. He referred to Sir William Burnett's excellent application of chloride of zinc, and to the ordinary chloride of lime; to gypsum, (sulphate of lime, ) and its conversion, in ammoniacal atmosphere, into sulphate of ammonia and carbonate of lime; to the agreeable odor of pure ammonia, and its power of giving intensity to odors of a disagreeable character, which intensity was lost when the ammonia was withdrawn; to sulphate of iron, (green copperas,) which, when powdered and thrown into tanks, turned black, on account of the sulphuret of iron formed on the decomposition of the sulphuretted hydrogen present. He then proceeded to the consideration of charcoal as a deodorizer. He gave an interesting statement of the peculiar action of charcoals in general, arising, he believed, from the great amount of surface their spherical interstices presented, and of the peculiar action and superior value of animal charcoal over all others. He explained that in charcoals it was not the amount of carbon they contained that constituted their value, but the mode in which the carbon was distributed; that animal charcoal contained only 10 per cent. of real carbon, while wood charcoal contained 90 per cent. He referred to the large amount of water (50 or 60 per cent.) which peat charcoal took up, and to the fallacious dry state of the manures with which this water-carrier was mixed. He feared this mode of introducing water in a latent state into manures, in many cases, gave a turn in the scale more in favor of the manufacturer than of the farmer. He doubted whether the peat charcoal could be used economically for the purpose of soaking up tank-water; if not, he feared it would prove of no advantage, in other respects, as a remunerative agent to the farmer. It had been long before the public, but had not progressed in market value, as it would have done had its application been successful. He considered it to lead to much error in practice that the exact nature of the action of charcoal on ammonia was not better understood by the public. Fresh-burnt charcoal would absorb a large quantity of ammoniacal gas, but it was a mistake to suppose that it would consequently abstract ammonia from a liquid impregnated with it; on the contrary, water had the power of displacing from charcoal the whole of the ammonia it had received in a gaseous state within its pores. Peat charcoal did not either take manure or separate it from sewage; it simply rendered manure portable. He exhibited a striking experiment, showing the power of dry peat charcoal to arrest odors. Two open tumblers were half-filled with the most offensive sewage matter Professor Way could obtain, and the surface of each mass covered with a film of thin paper, and a thin bed of powdered peat 
charcoal resting upon it. .These tumblers were in this state handed round to the members, who ascertained the perfect manner in which the sewage matter was thus rendered no longer offensive to the smell.

Dr. J. Stenhouse, of England, has recently published, in the Journal of the Society of Arts, the following interesting information respecting the properties of charcoal. He says: "Mr. Turnbull, a well-known chemical manufacturer of Scotland, about nine months ago, placed the bodies of two dogs in a wooden box, on a layer of charcoal powder a few inches in depth, and covered them over with a quantity of the same material. Though the box was quite open, and kept in his laboratory, no effluvium was ever perceptible; and on examining the bodies of the animals, at the end of six months, scarcely any thing remained of them except the bones. Mr. Turnbull sent me a portion of the charcoal powder which had been most closely in contact with the bodies of the dogs. I submitted it for examination to one of my pupils, Mr. Turner, who found it contained comparatively little ammonia, not a trace of sulphuretted hydrogen, but very appreciable quantities of nitric, sulphuric acids, with acid phosphate of lime.

"Mr. Turner subsequently, about three months ago, buried two rats in about two inches of charcoal powder, and a few days afterwards the body of a full-grown cat was similarly treated. Though the bodies of these animals are now in a highly putrid state, not the slightest odor is perceptible in the laboratory.

"From this short statement of facts, the utility of charcoal powder as a means of preventing noxious effluvia from church-yards, and from dead bodies in other situations, such as on board a ship, is sufficiently evident. Covering a ehurch-yard, to the depth of from two to three inches, with coarsely-powdered charconl, would prevent any putrid exhalations ever finding their way into the atmosphere. Charcoal powder also greatly farors the rapid decomposition of the dead bodies with which it is in contact, so that in the course of sir or eight months little is left except the bones.

"In all the modern systems of chemistry, such, for instance, as the last edition of Turner's Elements, charcoal is described as possessing antiseptic properties, while the very reverse is the fact. Common salt, nitre, corrosive sublimate, arsenious acid, alcohol, camphor, creosote, and most essential oils, are certainly antiseptic substances, and therefore retard the decay of animal and regetable matters. Charcoal, on the contrary, as we have just seen, greatly facilitates the oxidation, and consequently the decomposition, of any organic substances with which it is in contact. It is, therefore, the very opposite of an antiseptic."

\section{Does Sea Water kill Seeds?}

A QUESTION which has an important bearing upon the actual or possible dispersion of many species over the large geographical area which they are found to occupy, and therefore upon the problem whether the same organic being was created at one point, or at several, or many widely-separated points, on the face of the globe. It - commonly believed and stated that seeds-those of maritime plants excepted-will not ge nate after exposure to salt water; and so general is the belief, that no one, so far as we $k$, has made the experiment until now, when the distinguished naturalist, Mr. Darwin, h hown that seeds of various kinds will germinate promptly after prolonged immersion in sea water. The account of his simple but well-devised experiments is given in the London Gardeners' Chronicle for 1855, as follows :-

"As I had no idea when I began, whether or not a single week's immersion would kill all the seeds, I at first took only a few, selecting them almost by chance from the different great natural families; but I am now trying a set chosen on philosophical principles. The sea water has been made artificially with salt. The seeds were placed out of doors in the shade, in bottles holding from two to four ounces each : the mean temperature being from $44^{\circ}$ to $48^{\circ} \mathrm{F}$. Most of the seeds swelled in the water, and some of them slightly colored it, and each kind gave to it its own peculiar odor. The water which contained the cabbage and radish seeds became putrid, and smelt quite offensively; and it is surprising that seeds, as was the case with the radish, could have resisted so contaminating an influence; and as the water became putrid before I had thought of this contingency, it was not renewed. I also placed seeds in 
a quart bottle in a tank filled with snow and water, to ascertain whether the seeds kept at the temperature of $32^{\circ}$ would better resist the salt water; this water became turbid and smelt offensively. In the following list, where the cases are specified, the seeds have endured their full time:-

"(1) Seeds of common cress (Lepidium sativum) have germinated well after forty-two days' immersion; they give out a surprising quantity of slime, so as to cohere in a mass. (2) Radishes have not germinated as well after the same period. : (3) Cabbage-seed : after fourteen days' immersion only one seed out of many came up; this is rather strange, as the cabbage is a sea-side plant; in the ice-cold salt water, however, several came up after thirty days' immersion. (4) Lettuce-seed grew well after forty-two days; (5) Onion-seed : but few germinated after the' same period; (6) Carrot and (7) Celery-seed grew well after the forty-two days; (8) Borago officinalis, (9) Capsicum, (10) and Cucurbita ovifera, germinate well after twenty-eight days' immersion; the last two, rather tender kinds, were also tried in ice-cold water, and germinated after thirty days' immersion. (11) Savory, or Satureja, did not grow as well after twenty-eight days. (12) Linum usitatissimum: only one seed out of a mass of seeds (which gave out much slime) came up after the twenty-eight days, and the same thing happened after fourteen days; and only three seeds came up after the first seven days' immersion, yet the seed was very good. (13) Rhubarb, (14) Beet, (15) Orach, or Atriplex, (16) Oats, (17) Barley, (18) and Phalaris Canariensis, all germinate well after twenty-eight days; likewise the last-named six, after thirty days in ice-cold water. (19) Beans, and (20) Furze, or Ulex: of these a few survived with difficulty fourteen days; the beans were all killed by the ice-cold water in thirty days. (21) Peas germinated after seven days, but died after fourteen days' immersion out of doors, and likewise after thirty days in the ice-cold water. (22) Trifolium incarnatum is the only plant of which every seed has been killed by seven days' immersion; nor did it withstand thirty days in ice-cold salt water. (23) Kidney-beans have been tried only in the latter water, and all were dead after thirty days.

"As out of these twenty-three kinds of seed, the five Leguminosa alone have as yet been killed, (except the cabbage-seed, and these have survived in the ice-cold water, ) one is tempted to infer. that the seeds of this family must generally withstand salt water much worse than the seeds of the other great natural families; yet, from remarks in botanical works, I had expected that these would have survived longest. It has been curious to observe how uniform, even to a day, the germination has been in almost every kind of seed, when taken week after week out of the salt water, and likewise when compared with the same seeds not salted-all, of course, having been grown under the same circumstances. The germination of the rhubarb and celery alone has been in a marked degree altered, having been accelerated.

"To return to the subject of transportal: it is stated in 'Johnston's Physical Atlas' that the rates of ten distinct currents in the Atlantic (excluding drift currents) are given, and their average is thirty-three nautical miles per diem; hence in forty-two days, which length of immersion seven out of the eight kinds of seed as yet tested have already stood, a seed might be readily carried between thirteen hundred and fourteen hundred miles.

"I will conclude by observing that all the forty to fifty seeds which I have tried sink in sea water: this seems at first a fatal obstacle to the dissemination of plants by sea currents; but it may be doubted whether most seeds, (with the exception of the winged kinds,) when once shed, are so likely to get washed into the sea as are whole or nearly whole plants with their fruit, by being carried down rivers during floods, by water-spouts, whirlwinds, \&c. It should be borne in mind how beautifully pods, capsules, \&c., and even the fully-expanded heads of the Compositce, close when wetted, as if for the very purpose of carrying the seed safe to land. When landed high up by the tides and waves, and perhaps driven a little inland by the first inshore gale, the pods, \&c. will dry, and opening will shed their seed; and these will then be ready for all the many means of disposal by which Nature sows her broad fields, and which have excited the admiration of every observer. But when the seed is sown in its new home, then comes the ordeal; will the old occupants in the great struggle for life allow the new and solitary immigrant room and sustenance?"-Silliman's Journal. 


\section{Alarming Deterioration of the Soil.}

THE constant deterioration of the soils in New England, and throughout most of the agricultural districts of the United States, is a fact of portentous and alarming significance, though it has not yet arrested very extensively the notice of the public. Probably there is no one fact in our agricultural economy of more pregnant interest than this in its bearings upon our future prosperity. Some statistics, illustrating this downward tendency in our ability to produce the fruits of the earth, will now be given; and they will, I think, conclusively prove that a more prudent, skilful, and scientific mode of cultivating the soil is absolutely indispensable.

Between 1840 and 1850 three hundred thousand acres of land were added to those previously under improvement in Massachusetts. Ninety thousand acres were added to our mowing lauds, and yet there was a relative depreciation of the hay crop during that decade of years of twelve per cent. Our tillage lands during the same term were increased forty thousand acres, and yet there was an absolute depreciation in our grain crop of six thousand bushels. The pasturage lands were increased more than one hundred thousand acres, with scarcely any increase of neat cattle, and a reduction of one hundred and sixty thousand sheep and seventeen thousand swine.

The same law of deterioration is also observable in the richer regions of the South and West, showing that, with our present unskilful modes of farming, we are taking much more from the productive ability of our soils than we are returning to them, and that our agricultural prosperity is really and constantly on the wane. This downward tendency is partially hidden from public observation by the vast products which are raised upon the new and almost limitless regions which are every year put under cultivation at the West; but the fact itself is still indubitable.

In the State of New York, between the years 1845 and 1850, 671,692 acres were added to those previously under improvement, and of course there ought to have been at least a corresponding increase in the agricultural products of the State. But what was the fact?

The number of horses decreased is 58,141 .

Milch cows decreased, 63,066.

Other cattle, the decrease was 127,525 .

Sheep, the decrease was $2,990,622$.

Swine, the decrease was 556,002 .

Of potatoes, the decrease was $7,255,066$ bushels.

Of peas and beans, there was a decrease of $1,132,054$ bushels.

Flax, the decrease was $1,956,485$ pounds.

Wool, the decrease was $3,793,527$ pounds.

Wheat, the decrease was 270,724 bushels.

Buckwheat, the decrease was 450,724 bushels.

There was an increase in the amount of corn, rye, oats, barley, hay, butter, and cheese raised in that State, but no greater than would have been expected from the increase of the population, which was 494,323 during those five years.

In Tennessee, the number of cattle raised was-

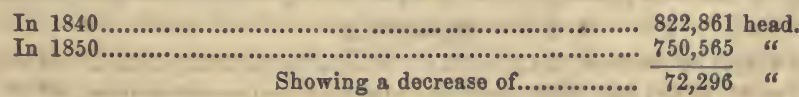

In Kentucky, more than nine-tenths of the entire area of the State is covered with farms. The number of neat cattle raised was-

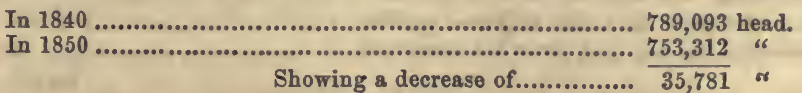

Horses and mules raised in Kentucky-

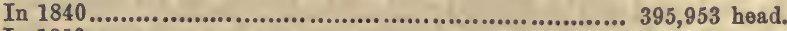

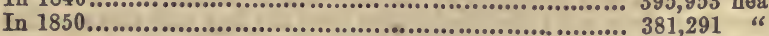

• Decrease.......................... $\frac{14}{14,662}$ " 
It is estımated by intelligent farmers in Indiana that their river-bottoms, which used to produce an average crop of sixty bushels of corn to the acre, now produce only forty. In Wisconsin, which is younger still, it is estimated that only one-half the number of bushels of wheat are now raised on the acre which were raised twelve years ago.

These estimates are based on the returns made to the Patent Office, and are as reliable as any now before the public. What, then, is the conclusion of the whole matter? It is this, that the soils of New England, after all the admonitions we have received upon the subject, are annually growing poorer, and that even the virgin lands of the Great West are rapidly becoming exhausted of their fertility. Other and better modes of cultivation must therefore be introduced and practised, or our country-now the granary of the world-may at no very distant day become dependent on other lands for its daily bread. Within fifty years our population will undoubtedly reach the enormous number of one hundred millions; but the grave question is, How are these myriads to be fed, and clothed, and educated, if our present impoverishing agricultural processes are to be continued? We have territory enough, and it is naturally rich enough to support a population of one thousand millionsa number to which we may yet attain; but how can they be sustained, unless some method is devised to keep up the productive capabilities of our country, and to return to our liberally discounting soils as much, at least, as we abstract from them? This is a problem which many thoughtful and far-seeing men are beginning to ponder, and which requires but little wisdom to solve. - New England Farmer.

\section{Experiments in Feeding.}

THE following account of trials in feeding stock, instituted by John Brooks, Esq., of Princeton, Massachusetts, is communicated to the Journal of the United States Agricultural Society, 1854. The points for determination were the influence of different kinds of food in the production of milk, and the proportion of solid manure to the hay consumed:-

December 17, 1851, commenced feeding two cows about 7 months after calving; the cows were gravid, and expected to calve about March next; live weight, $1600 \mathrm{lbs.}$; one of them 44 and the other 31 months old. Each trial continued 5 days.

First 5 days fed on 2 per cent. of live weight of hay, cut daily..... 32 lbs.

$2 \mathrm{lbs}$. of Indian meal, hay value ........................................ 8 "s

Hay value of daily food..................................................... 40 "6

Hay value of 5 days' food.................................................. 200 6s

Cost of 5 days' food, hay at $\frac{1}{2}$ cent per 1 b...............................\$1.00

Milk in 5 days.............................................................61.875 lbs.

Cost of milk, (hay at $\frac{1}{2}$ cent. a lb., ) 1.6 cents to the lb., or 3.2 cents the wine quart.

Second Trial.

Fed 5 days on $2 \frac{1}{2}$ per cent. of live weight of cut hay.

Cut hay daily............................................................ $40 \mathrm{lbs}$.

Cut hay in 5 days ....................................................... 200 "6

Cost of 5 days' food, hay at $\frac{1}{2}$ cent per lb. ............................ $\$ 1.00$

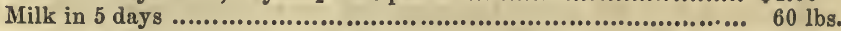

Cost of milk, (hay at $\frac{1}{2}$ cent per lb.,) $1 \cdot 6$ cents the lb., or $3 \cdot 3$ cents the wine quart.

These trials show that $2 \mathrm{lbs}$. of Indian meal are very nearly equal to $\frac{1}{2}$ per cent. of live weight of hay, or that one pound of meal is equal nearly to 4 lbs. of good English hay.

Third Trial.

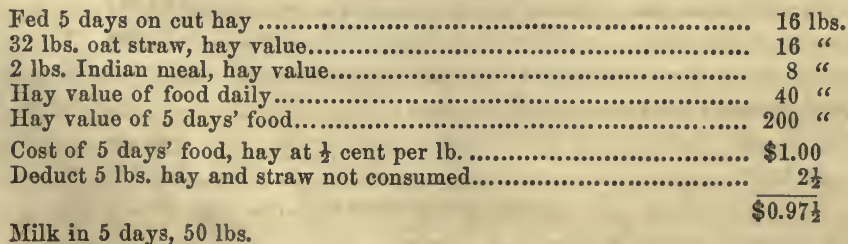

Cost of milk, (hay at $\frac{1}{2}$ cent a pound,) 1.99 cents the $1 b$., or 3.9 cents the wine quart. The hay and straw cut given wet; the meal sifted over the hay and straw. This trial seems to show that $2 \mathrm{lbs}$. of oat straw are not equal for milk to $1 \mathrm{lb}$. of hay. 
Fourth Trial.

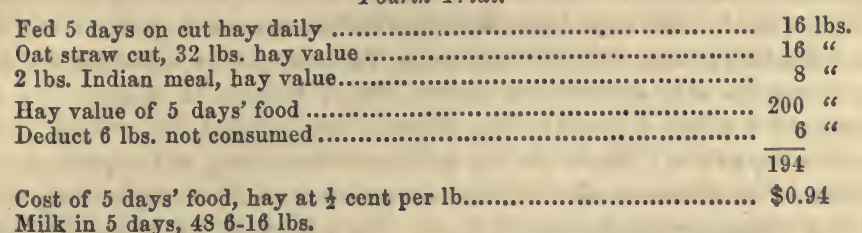

Cost of milk, (hay at $\frac{1}{2}$ cent per lb.,) 1.9 cents per lb., or 3.9 cents the wine quart. The hay, straw, and meal were given dry. The trial shows that hay, straw, and meal dry are not so good for milk as when wet.

February 3, 1852, commenced feeding two cows; one, 33 months old, 14 days after calving, live weight $1000 \mathrm{lbs}$; the other, 31 months old, 7 months after calving, not now in calf, live weight $690 \mathrm{lbs}$. These cows were fed 5 days on $42 \mathrm{lbs}$, or $2 \frac{1}{2}$ per cent. of their live weight of uncut hay, and $50 \mathrm{lbs}$. of flat turnips daily.

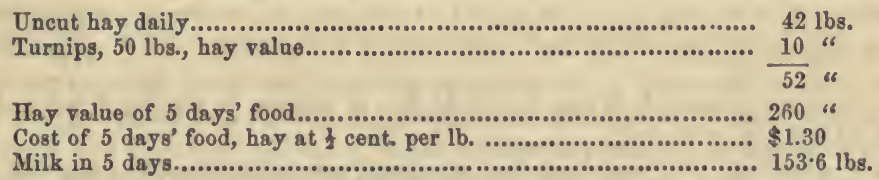

Cost of milk, (hay at $\frac{1}{2}$ cent per lb.,) 0.846 of a cent per lb., or 1.6 cents the wine quart.

Fed five days on cut hay.

Cut hay daily................................................................ 42 lbs.

Turnips 50 lbs., hay value................................................ $\frac{10}{52}$ "

Hay value of 5 days' food............................................... 260

Deduct 5 lbs, not consumed ............................................. 5 of

Cost of 5 days' food, hay at $\frac{1}{2}$ cent per lb.............................. $\$ 1.27 \cdot 5$

Milk in 5 days............................................................. 152.2 lbs.

Cost of milk, 0.837 of a cent per lb., or 1.6 cents the wine quart.

The cows did not eat the hay quite so well as the long hay on the first trial, so that the whole experiment shows a small difference in favor of cut hay.

\section{Third Trial.}

Fed same as second trial, except. gave $3 \mathrm{lbs}$ of Indian meal instead of $50 \mathrm{lbs}$. of turnips.

Cut hay daily ............................................................ 42 lbs.

3 lbs. Indian meal daily, hay value ...................................... 12 "6

Hay value, 5 days' food............................................... 270 "

Deduct $10 \mathrm{lbs}$. hay not consumed...................................... 10 "6

Co

Cost of 5 days' food, hay at $\frac{1}{2}$ cent per lb............................ \$1.30

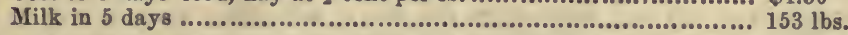

Cost of milk, (hay at $\frac{1}{2}$ cent per lb.,) 0.849 of a cent per lb., or 1.6 cents the wine quart. This trial seems to prove that $3 \mathrm{lbs}$. of Indian meal are equal to 12 lbs. of English hay, or 50 lbs. of flat turnips, for milk.

\section{Fourth Trial.}

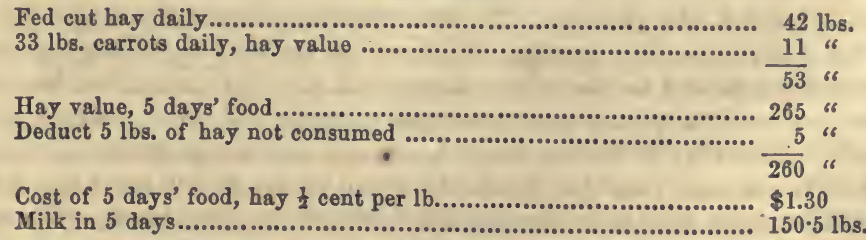

Cost of milk, (hay at $\frac{1}{2}$ cent per lb.,) 0.863 of a cent per lb., or 1.7 cents the wine quart. 
This trial shows that $33 \mathrm{lbs}$. of carrots are not quite equal for milk to $50 \mathrm{lbs}$. flat turnips, or $3 \mathrm{lbs}$. of Indian meal. The cows in all the trials had free access to water.

December 10, 1851, commenced feeding 1 cow, 72 months old; one ditto, 96 months old; one ditto, 48 months old; 5 heifers, 32 months old; 7 heifers, 22 months old; 4 calves, 9 months old; and 4 calves, 8 months old. These cattle weighed, live weight, 14,567 lbs., and were fed 5 days on $277 \mathrm{lbs}$. of cut hay daily, and drank daily $887 \mathrm{lbs}$. of water; dropped daily, $668 \mathrm{lbs}$. of solid manure, or $2.41 \mathrm{lbs}$. of manure for $1 \mathrm{lb}$. of hay consumed.

Second trial commenced December 16, 1851. Fed same cattle five days on $352 \mathrm{lbs}$. hay daily; solid manure dropped daily, $860 \mathrm{lbs}$, or $2.44 \mathrm{lbs}$. for one lb. of hay consumed; drank daily, $868 \mathrm{lbs}$. of water.

February 28, commenced feeding one cow, 72 months old; one ditto, 96 months old; and one 48 months old; 3 heifers, 32 months old; and 6 heifers, 22 months old. The live weight of these cattle was $9472 \mathrm{lbs}$; they were fed 5 days, $240 \mathrm{lbs}$. cut hay daily; solid manure dropped daily, $594 \mathrm{lbs}$, or $2.47 \mathrm{lbs}$. of manure for one lb. of hay consumed. Drank daily 542 lbs. water.

Hay consumed in the three trials.............................................. 869 lbs.
Manure dropped

The proportion of manure to hay is as $2.44 \mathrm{lbs}$. of manure to one $\mathrm{lb}$. of hay; the manure weighed $50 \mathrm{lbs}$. the cubic foot.

Manure, after remaining under my barn one year, weighed $44 \mathrm{lbs}$. the cubic foot-a loss of $6 \mathrm{lbs}$. in one year, or 12 per cent. of its weight when recently dropped.

\section{Experiments in Reclaiming Swamps.}

THE following detail of experiments in the reclamation of swamp-lands has been communicated to the Journal of the United States Agricultural Society by J. W. Procter, Esq., of Danvers, Massachusetts :-

\section{Experiment No. 1-by S. Blaney, of Salem.}

The locus in quo of this operation is situated among the sienite hills in the western part of the city. It contains one and a half acres, extending forty rods in length, and varying from five to ten rods in breadth; the borders irregular, with here and there a ledge of rocks obtruding. Eight years ago it was so densely covered with a growth of alders and blueberries, as to be almost impenetrable to man or beast; especially at those seasons of the year when the water was on. At that time the bushes were cut, and it remained without culture or product until 1852. Mr. B., then becoming the owner, set about bringing it into use.

His first operation was to cut a ditch through the centre, down to the hard pan; the mud from which was taken to the upland for the purpose of compost. Subsequently five or six cords of refuse animal matter, collected from his wool-shop and a neighboring glue-factory, were mingled with this mud, making a heap of about twenty cords. The roots of the bushes and the stumps of the early growth of yellow birch were effectually removed. About two hundred cart-loads of gravelly loam, from the shores adjoining, were carted on to fill the holes and gullies. Then the sod was inverted by the plow to the depth of ten inches. The surface was then pulverized and evened as far as practicable, and the heap of compost applied. About the first of September, 1852, it was sown with grass-seed, herds-grass, and red-top. The whole expense thus far (all the labor having been hired by Mr. B.) is estimated not to exceed $\$ 50$ per acre. No other fertilizing material was applied. In July, 1853 , at the first cutting, four tons one thousand one hundred and seventy pounds of hay were obtained, which sold on the ground for $\$ 18$ per ton. At a second cutting, three tons more were obtained of a quality equally valuable-making the entire produce, within thirteen months of the time of seeding down, seven tons and one thousand one hundred and seventy pounds; or more than five tons to the acre; paying for all the labor and material applied, and leaving a surplus of $\$ 30$ per acre. Mr. B. considers his land worth $\$ 300$ an acre, because it will sell for this amount. The surface presented now is as handsome 
ground for mowing as is anywhere to be seen-all the surplus water being effectually drained off by the centre ditch, with a few covered side-cuts.

It is rare that an experiment is witnessed paying so well in so short a time.

\section{Experiment No. 2-by Adino Page, Danvers.}

This was on the Danvers Town Farm, on a lot containing between three and four acres. Operations commenced in 1850. Previously, it had been a sunken, offensive morass, yielding no valuable growth.

A main ditch was cut through the centre, and shore ditches on either side, and cross ditches about fifty feet apart. Many of these were covered, so as not to appear on the surface. In some places, the mud was eight feet or more deep; in others, from three to fire feet deep. From the shores and knolls adjoining gravel and loam was carried on, so as to give firmness sufficient to sustain the plow. When the water was drained eighteen inches below the surface, where the soil could not be well stirred by the plow, it was effectually done by the use of a meadow-hoe constructed for the purpose. Most of the labor was done by the paupers at the alms-house, (chiefly foreigners,) and no pains was spared to have it thoroughly done. Very little fertilizing material was applied, it being thought rich enough to support any crop that could be started upon it. It was sown to grass in 1851. Very little grass in 1852 ; but between twelve and thirteen tons of the best hay on the farm was cut on this meadow the present season. It is so situated that the surplus liquids from the pig-yard and the sink can be conducted in any quantity and diffused over the land. With such an application, there is good reason to believe four tons to the acre of valuable fodder will be grown annually on this meadow. It is now an appendage to the farm of the value of $\$ 800$ at least; whereas four years ago it was of no value, but rather an eyesore and an offence, breeding miasmata and death. The exact expense of the experiment Mr. P. is not able to estimate. The work has been done at "odd jobs," when other labors did not press, and by those who would have done little else if this work had not been done.

Experiment No. 3-by T. E. Payson, of Rowley.

This was commenced about three years ago, on a part of an extensive meadow of fifty acres or more. The water having been drained away by a main ditch and a sufficient number of cross ditches, Mr. Payson commenced by cutting very narrow ditches, about five feet apart, and throwing the contents of these ditches upon the surface.

The beds thus formed were planted with potatoes. In 1852, the crop of potatoes paid for all the labor and manure that had been applied to the part thus treated. The potato-vines were thrown into the narrow ditches, and the entire surface smoothed and sowed with grass-seed. The crop of good English hay in 1854 exceeded three tons to the acre. Several other acres were planted with potatoes, in like manner, the last season; but, in consequence of the failure of the crops by reason of the rot, the labor has been, in a measure, lost. Until the rot came on, Mr. P. felt encouraged to hope that he should soon have an extended field of English mowing, producing three tons or more to the acre, without any expenditure of capital in bringing it about, except the moderate price of about $\$ 20$ an acre paid for the land.

\section{Experiment No. 4-by Horace Ware, of Marblehead.}

This was on about three acres of swamp, situated adjoining a pond of about five acres. Mr. W.'s first operation was to cut a ditch through upland of half a mile in extent to the shore of the sea, so as to reduce the height of the water in the pond four feet. This caused the surface of the swamp to settle about two feet, leaving it still about two feet above the pond. Then all bushes and other obstructions were cleared from the surface, and a coating of gravel and night-soil mixed, to the depth of about three inches, was applied. The crop of potatoes grown on this land the first year paid for all that had been done to it, and it has since yielded annually three or more tons of good English hay to the acre. 
Mr. W. considers this reclaimed meadow as valuable now as any land appurtenant to his farm.

I might specify other experiments that I have witnessed, some of which did not succeed; probably bccause the work was not thoroughly done, and the fertilizers applied were not of the right character.

\section{Interesting Facts in Grafting.}

Is September, 1853, Dr. Maclean grafted a young plant of the white Silesian beet upon a root of red beet, and vice versâ. At the time of the experiment, the plants were each about as thick as a straw. A complete junction was effccted. There was a slight contraction at the line of junction, much like that formed by "chocking" a rocket-case; above the line of contraction the plant was absolutely white; below it was absolutely red. Not a trace of blending the two colors could be discovered. By similar experiments on other vegetables and plants, Dr. Maclean had so far assured himself of the perfect independence of scion and stock as to acquire the belief that neither the coloring nor any specific characters of one or the other would or could be altered by their union. The result of the trial wholly confirmed that view, and demonstrated that the white beet adhered to the red beet by mere junction of cellular matter; that of the scion and stock holding together in the first instance, and each afterwards produced its own coloring matter in its own new cells as they formed superficially, the red cells adhering to the white cells while in the nascent state, but retaining each the peculiarity belonging to it, without any interchange of contents through the sides of the cells in contact.

This is entirely consistent with all that has been discovered by the modern physiologists who have applied themselves to a study of the nature of the individual cells of which plants consist: They have clearly shown that each cell has its own special powers of secretion; as, indeed, may be seen by any one who examines thin sections of variegated leaves or other parts. It will then be seen that some cells are filled with a red coloring matter; others, with yellow; others, with green. In other words, one cell has the power of secreting red matter; another, yellow; and so on. The colors do not run together, but are contained each within the cell that produces it. Why this is so, no one knows; all that we are acquainted with is the fact that in the cells of the red beet resides a power of forming red matter, and in those of the white Silesian beet that of forming-yellow; and this peculiarity is not affected by the one growing to the other. Red-forming cells produce their like, and yellow-forming, theirs. Thus the limit between the scion and its stock is unmistakably traceable, and, notwithstanding the combination of the two sorts in one, each perseveringly retains that which is natural to it. What is true of beets is also true of all other plants. -Dr. Lindley, Gardeners' Chronicle.

Improved Method of Graftiny.-Mr. L. B. Langworthy, in a communication to the Horticulturist, alludes to a new process whereby a scion of any kind may be cut from the tree after the buds are fully expanded, but not opened, and grafted the same minute, and which almost invariably succeeds if properly executed. In this process, I prefer the terminal point of a limb for the scion, or any part may be used by cutting the wood close to the upper bud, and dipping it twice, with two or three minutes' interval, into a vial containing a small quantity of collodion, or artificial cuticle, which can be procured of any apothecary. It instantly forms an air-tight coating, both flexible and elastic, and protects it from drying and losing its vitality. There is no time of year after the new buds are sufficiently formed, and the stock in a growing state, but what grafting by this process may be performed, in which case have but one bud on the scion, and dip the whole wood, except the wedge, in the collodion, to protect it from the drying sun and heat of summer. It sometimes happens that one has a single choice exotic, difficult to procure, that it is important not to fail in grafting, and this method almost infallibly insures success. This process is particularly applicable to the grafting $_{b}$ of plums and cherries. 


\section{Altctrurnlugy.}

\section{Meteorology for Farmers.}

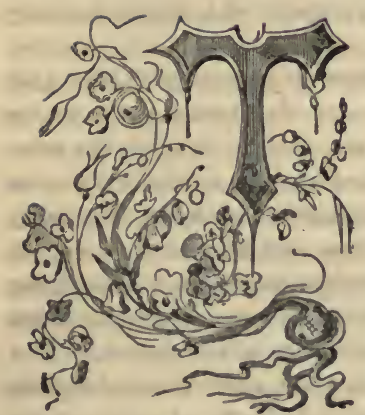

HE following is an extract from a communication made by Lieut. Maury to the Ameriean Farmer, Baltimore, on the importance of organizing a system of national meteorologieal observations, with a view of promoting thereby the great interests of agriculture. Lieut. M. says-

"You ask for the plan of co-operation. It is very simple, and calls on the farmers for little more than good will. I first want authority to take the preliminary steps, and to confer with other meteorologists and men of science at home and abroad, with the view of establishing a uniform system of meteorological observations for the land, as we have done for the sea. If any offeer of the government were authorized to say to the farmers, as I have to the sailors, 'Here is the form of a meteorological journal; it shows you the observations that are wanted, the hours at which they are to be made; tells what instruments are required, and how they are to be used: take it, furnish the government with the observations, and in return the government will diseuss them, and give you a eopy of the results when published'-he would have at once and without cost a volunteer corps of observers that would furnish him with all the data requisite for a complete study of both agricultural and sanitary meteorology. Such an offer to the sailors has enlisted a eorps of observers for the sea, by whose eo-operation results the most important and valuable, and as unexpeeted as valuable, have been obtained. Could not at least one farmer be found on the average for every county in every State that would gladly undertake the observations? I don't think there would be any difficulty on that seore. Sailors have been found to do as much for every part of the sea: on the average, ten observers for a State would be sufficient. Now if we could get the English government, and the French government, and the Russian government, and the other Christian states both of the Old World and the New, to do the same by their farmers, we shall have the whole surface of our planet covered with meteorologieal observers acting in concert, and elieiting from nature, under all varieties of climate and circumstanees, answers to the same questions; and that too at no other expense than what each government should choose to incur for the discussion and publication of the observations that are made by its own citizens or subjects.

"What is wanted in a system of observations like this is uniformity. Hence, co-operation-. an agreement to observe the same things at the same times-is essential to any thing like suecess. We want not only corresponding observations as to the time, but we want them made with instruments that are alike, or that ean be eompared; and then we may expect to find out something eertain and valuable eoneerning the movements of this grand and beautiful machine ealled the atmosphere. Suppose a pretentious fly should place itself upon a steam-engine, and from its own little, narrow, contracted field of observation, attempt to expound the structure of the entire machine. If it had the intelligence both to observe and to reason, it would not find itself more bewildered than any one does and must, who, from an isolated series of meteorological observations, attempts to learn the laws which govern the atmosphere and regulate climates. If you ask me to state beforehand what particular discoveries or special results of value I expect to make, I answer: If I could tell, I would not 
ask your assistance to make them. The fields meteorological are large; there are many of them, and all that I do know about them is, that there is in them mighty harvests of many sorts. Some years ago I commenced such a system for the sea as I am now advocating - and as I now both see and feel the necessity of-for the land. After we had been at work a littlo while and begun to gather in a harvest of useful results by discovering new truths and facts, Congress authorized the Secretary of the Navy to employ three small vessels of the navy to assist me in perfecting these discoveries and pushing forward investigations.

"Now you would have said, What two things can be more remote than maps to show which way the winds blow, and a submarine telegraph across the Atlantic? Yet it seems that they are closely connected, for researches undertaken for the one are found to bear directly upon the other. Among the early fruits gathered by pushing our discoveries, even with the slender means afforded by Congress-for the secretary was authorized to let me have these three small vessels only in case they should cost nothing-there is a promise of a submarine telegraph across the Atlantic.

"One of the results of getting the wires across will be to place the farmers with their provision-markets and produce exactly half the distance in time-and time now seems to be the only true measure of distance-from Europe that they now are. Let us illustrate the value in one respect only of this telegraph to the farmers. A demand springs up in England for breadstuffs, for instance. The news must now wait for the steamer to sail before it is ready to come, and by the time she reaches our shores, and the produce can be sent forward, the chief granaries of Europe have been ransacked, and the American dealer finds himself too late in the market. But when that telegraphic plateau, which we have discovered in the Atlantic, shall be threaded with the magnetic cable, the intelligence will be known in New York, Cincinnati, St. Louis, and New Orleans as soon as it is in Liverpool. Straightway the produce is put in motion, and instead of coming in 'the day after the fair,' as is now too often the case, it will arrive with the young of the flood that comes rolling in from the East to meet the demand. By this achievement, or by the achievements which these investigations at sea have already accomplished in the shortening of voyages and saving of time, who have been the greater gainers, the farmers or the merchants?

"Storms on land have a beginning and an end; that is, they commence at one place, and frequently after several days' travel end at some other; at least, so it is held. What would it be worth to the farmer, or the merchant, or to anybody, if he could know, with something like certainty, the kind of weather he might always expect one, two, three, or more days ahead?

"I think it not at all unlikely that such, to some extent at least, would be among the first fruits of this system of observations that I am proposing.

"Certain of the observers scattered over all parts of the country would probably be required to make daily reports to the central office in Washington as to the weather, each for his own station-say at $9 \mathrm{A.M}$. This would soon enable us to determine the laws of progress as well as the march of the various states of weather, such as gales, rains, snow-storms, and the like; so that by knowing in what part of the country a storm had arisen, we shouldlearning through the telegraph the direction it might take-be enabled to calculate its rate of travel, and to predict within a few hours the time it would arrive at different places on its line of march; and knowing these, the telegraphic agency which the newspaper press of the country has established here, would, without more ado or further cost, make the announcement the next morning in all the papers of the land.

"I allude to this as an exemplification only of some of the first fruits of the plan. I do not suppose that we should be able to telegraph in advance of every shower of rain; but without doubt the march of the rains that are general can be determined in time to give the people in some portions of the country, at least, warning of their approach.

"Such an office as will be required here in Washington to carry out the details of this plan is already in existence. It was established by Mr. Calhoun when he was Secretary of War and it is under the control of the Surgeon-general of the Army. There the meteorological observations that are made at our military posts are discussed and published; and one of the most valuable and interesting reports concerning the meteorology and climates of the country that has ever appeared, is now in course of publication there. Or such an office might be 
made a branch of the 'agricultural division of the patent office.' In either case the nucleus for it is already in existence; and the only expense necessary would be on account of the addition to the force of the office that would be required to discuss the observations after they are made.

"Hence, you will perceive that what I want is, that the farmers and printers, and all who are interested in the weather, should not only give me their good will, but that they should use their influence in helping to bring about such a system of meteorological co-operation for the land, as we have already established for the sea.

"I make the appeal to the farming interest especially, because that is the great interest to be subserved by the scheme; and if the farmers do not really care enough about it to use their influence with their representatives in Congress to procure the very trifling appropriation that is required to get it under way, I do not see why I should give myself any further trouble in the matter.

"Will you not bring the subject in some tangible shape before the agricultural societies of the country? A simple memorial from them to Congress would not fail to procure all the legislative aid necessary.

"Some of the leading scientific men of Europe are ready to join us in such a plan; and with authority to confer with them officially as to details, I have no doubt that most of the governments of the world would undertake, each for itself and within its own territories, a corresponding series of observations, so that we should then be able to study the movements of this great atmospherical machinery of our planet as a whole, and not, as hitherto, in isolated detached parts.

"N.B.-Series of observations more or less extensive have been undertaken in various parts of the country, and for objects more or less general and useful. Among them may be mentioned those of the Smithsonian Institution, under the direction of Prof. Henry, the immediate object of which is an investigation of the law of storms. Several of the States, and many individuals, are co-operating with him; also those of Louisiana by Dr. Barton, concerning sanitary laws, and those of Prof. Espy and others.

"It is hardly necessary to add that the plan now proposed is not calculated to interfere with any of these; on the contrary, it is in furtherance of them all, and differs from them only in being universal, and in establishing co-operation and concert between the observers at sea and those on land."

\section{Indications of Weather as shown by Animals, Insects, and Plants.}

THE following interesting communication was made to the American Association, Cleveland, by Mr. W. B. Thomas, of Cincinnati, Ohio:-

"The possibility of foretelling weather has occupied the attention of observers of natural facts from the earliest period of our records; the certainty with which any thing is arrived at on this subject, like all other parts of natural science, depends upon the knowdedge acquired of those things with which nature has most intimately connected it.

"Without indulging in any comment, I will state a few particulars in regard to the different indicators with which nature has supplied us.

"When a pair of migratory birds have arrived in the spring, they immediately prepare to build their nest, making a careful reconnoissance of the place, and observing the character of the season that is coming. If it be a windy one, they thatch the straw and leaves on the inside of the nest, between the twigs and the lining; and, if it be very windy, they get pliant twigs and bind the nest firmly to the limb, securing all the small twigs with their saliva. If they fear the approach of a rainy season, they build their nests so as to be sheltered from the weather. But if a pleasant one, they build in the fair open place, without taking any of these extra precautions. In recording these facts, we have kept duly registered the name of the bird; the time of arrival in spring; the commencement of nesting; the materials of nest, and its position; the commencement of laying; number of eggs in each nest; commencement of incubation; appearances of young; departure in autumn.

"But it is our insects and smaller animals which furnish us with the best means of determining the weather. 
"We will now take the snails, and show the various phenomena they present. These animals do not drink, but imbibe moisture in their bodies during a rain. At regular periods after the rain, they exude this moisture from their bodies. We will take, for example, the helix alternata. The first fluid exuded is the pure liquid. When this is exhausted, it then changes to a light red, then deep red, then yellow, and lastly to a dark brown. The helix is very careful not to exude more of its moisture than is necessary. It might exude it all at once, but this is not in conformity to its general character, as this would prove too great an exertion. The helix alternata is never seen abroad, except before a rain, when we find it ascending the bark of trees and getting on the leaves. The helices arborea, indentata, ruderati, and minuta, are also seen ascending the stems of plants two days before a rain. The helices clausaligera, Pennsylvanica, and elevata, generally begin to crawl about two days before the rain will descend. They are seen ascending the stems of plants. If it be a long and hard rain, they get on the sheltered side of the leaf, but if a short one, they get on the outside. The luccinea have also the same habits, but the color of the animals differs, as before the rain it is of a yellow color, while after it is a blue. The helices solitaria, zaleta, albolabris, and thyroideus, not only show signs by means of exuding fluids, but by means of pores and protuberances. Before a rain, the bodies of zaleta and helix thyroideus have large tubercles rising from them.

"These tubercles commence showing themselves ten days previous to the fall of rain they indicate; at the end of each of these tubercles is a pore. At the time of the fall of the rain, these tubercles, with their pores opened, are stretched to their utmost to receive the water. Also, for a few days before a rain, a large and deep indention appears in the helix thyroideus, beginning on the head between the horns, and ending with the jointure at the shell. The helices solitaria and zaleta, a few days before a rain, crawl to the most exposed hillside, where, if they arrive before the rain descends, they seek some crevice in the rocks, and then close the aperture of the shell with glutinous substance, which, when the rain approaches, they dissolve, and are then seen crawling about. In the helix albolabris, the tubercles begin to arise after a rain, while before they grew smaller, and at the time of the rain; the body of the snail is filled with cavities to receive the moisture. The helices zaleta, thyroideus, and albalabris, move along at the rate of a mile in forty-four hours. They inhabit the most dense forests, and we regard it as a sure indication of rain to observe them moving towards an exposed situation. The helices appressa, tridentata, falla, and paliata, indicate the weather not only by exuding fluids, but by the color of the animal. After a rain, the animal has a very dark appearance, but it grows of a brighter color as the water is expended; while just before the rain, it is of a yellowish white color. Also just before a rain, strix are observed to appear from the point of the head to the jointure of the shell. The superior tentacula are striated, and the sides are covered with tubercles. These helices move at the rate of a mile in fourteen days and sixteen hours. If they are observed ascending the cliff, it is a sure indication of a rain. They live in the cavities in the side of cliffs. The helix hirsuta is of a black color after a rain, but before, it is of a brown, tinged with blue around the edges of the animal. The tentacula are marked by a cross striæ, and there is also to be seen, a few days before the rain, an indentation which grows deeper as the rain approaches: this helix also exudes fluids, but not with the changes of color of those before mentioned.

"We can also foretell a change of weather by the wasps and other insects.

"The leaves of trees are even good barometers; most of them, for a short, light rain, will turn up so as to receive their fill of water; but for a long rain, they are so doubled as to conduct the water away.

"The rana, bufo, and hyla are also sure indicators of rain, for, as they do not drink water, but absorb it into their bodies, they are sure to be found out at the time they expect rain.

"The locusta and gryllus are also good indicators of a storm. A few hours before the rain, they are to be found under the leaves of trees and in the hollow trunks. We have many times found them thus, but we have never known the instinct of these little fellows to lead them to unnecessary caution." 


\section{Importance of Meteorology to Farmers.}

THE following remarks on the importance of meteorology to farmers were made by Dr. Anderson, of Scotland, in a recent address before the Highland Agricultural Society:-

The whole success of agricultural experiments depends on the watchful care bestowed on the modifying circumstances which affect them, and I have indicated frequent repetition as a means of aroiding the errors which they may occasion; but there is one great modifying influence, the importance of which is every day brought prominently before us, but the accurate estimation of which has surely received less attention on the part of farmers than it deserves. Indeed, it is somewhat remarkable that more has not been done in the study of meteorology, in an agricultural point of view, for the purpose of ascertaining, with more precision than we at present can, the influence of the weather on the amount of production. The progress of science has shown us that the growth of a plant is dependent on certain chemical changes which take place only under the influence of the sun's rays; and the quantity of produce which can be raised on any given surface, provided the conditions of the soil, manure, and the like, are identical, is the measure of the amount of light and heat which reaches it; and. conversely, given the heat and light, we may predicate the quantity of the crop. The plant, in fact, gathers, as it were, the heat which falls upon it; and preserves in a latent state a magazine of that great prime mover of mundane affairs; and when it is burned under a furnace, or consumed by an animal, it only gives off the heat which it had received from the sun, and which is again expended in producing a certain amount of mechanical force, or in sustaining the temperature and causing the muscular efforts of the animal which eats it.

Now all this we know in a general way, but we are sadly deficient in the application of this knowledge to individual localities, and in precise information regarding the climatic peculiarities of different districts; although, if we had this information to conjoin with our experiments in the field, we should doubtless obtain many valuable conclusions. We should find, for instance, that certain manures produce a more favorable effect in dry, and others in wet seasons; and many similar facts, of which we have now only distant glimmerings, would be made clear. By a well-devised set of meteorological observations, these and many other facts would be established in the course of time. We should do even more than this, for though the weather is proverbially uncertain, we should be able to predict, with some degree of accuracy, the meteorological character of each year; for it is known that there is a cycle of years, at the end of which similar seasons occur; and all that we require is a sufficient number of observations to enable us to fix it. It is manifest, however, that if results of any importance are to be obtained, the principle of association must be carried out on the most extended scale, and so as to embrace observations made at a great number of different stations.

\section{Protection against Hail.}

THe second volume of the works of Arago has called attention to several points in meteorology. In the chapter which he devotes to the subject of hail, he states, that, in 1847 , two small agricultural districts of France had lost, by hail, crops to the value of a million and a half of francs. Certain of the proprietors from the neighborhood went to consult Arago on the means of protecting them from like disasters. Resting on the hypothesis of the electric origin of the hail, he suggested the discharge of the electricity of the clouds by balloons communicating by a metallic wire with the soil. These projects, however, were not carried out; and in view of the doubts as to the electric origin of hail, he proposed to investigate the subject anew. He had not the time to bring out any results; but he persisted in believing in the effectiveness of the method proposed.

\section{Statistics of Lightning.}

THE French Academy of Sciences have received some interesting observations on the effects of the lightning-stroke upon human beings. The following facts are the result of patient observations made by M. Boudin, chief surgeon to the Hôpital du Roule: The number of 
people yearly struck by lightning in France averages 200. The number of people killed ky lightning between the years 1835 and 1852 is no less than 1308; the number struck, but not fatally, is about three to one of the number killed. Of the number struck, there were nearly three men to one woman. The region where the lightning had been most fatal is the central plateau of France, comprising the departments of Cantal, 'Puy-de-Dôme, and other departments which are mountainous or present elevated ground. The months during which people are the least exposed to the fatal effects of lightning are the coldest months of the year-viz. November, December, January, and February. Out of 103 people struck, 4 were struck in March, 6 in April, 8 in May, 22 in June, 13 in July, 19 in August, 14 in September, and 15 in October. One-fourth of the people who have been struck may trace the misfortune to their own imprudence, in taking shelter under trees, which attract the electric fluid. The greatest number of people killed by a single flash of lightning does not exceed eight or nine. M. Boudin called attention to two curious facts in connection with this subject. The first was, that dead men, struck by lightning, had been found in exactly the upright position they held when killed; the second was, that other bodies bore upon them faint impressions of outward objects, probably somewhat resembling photographic shadows. Animals, however, are much more exposed to the influences of lightning than men, and suffer more by its destructive properties. More than once a single flash of lightning has destroyed an entire flock of sheep, and, according to M. D'Abbadie, flocks of 2000 in Ethiopia.

Before the application of lightning-conductors, English ships experienced losses annually by the electric fluid estimated at from $£ 1000$ to $£ 1400$; but since their application, such losses are no longer heard of, although some pretend to deny the efficacy of the lightning-rod.

\section{Effect of Flowers on the Air of Rooms.}

Prof. Grax writes to a correspondent of the "Country Gentleman" the following information relative to the effect of plants on the nature of the air of rooms. Prof. Gray says-

"As to their foliage affecting the air, plants practically neither benefit nor injure the air of rooms-the amount of oxygen they increase in daylight, or that of carbonic acid they increase by night, not being large enough, relatively, to make a sensible difference to an individual in the room. For instance, the amount of carbonic acid a dozen potted shrubs would exhale in a single night would be less than what a child sleeping in the room would exhale in the same time, or a small night-lamp burning would exhale, and this, in the actual open state of our apartments, would be wholly unimportant as affecting health. The real objection to plants in sleeping apartments are owing -

1st. To the dampness they might cause from exhalation or evaporation, as they must be kept moist; and $2 \mathrm{~d}$, and chiefly, from the unpleasant effects of the odors of most blossoms in close rooms. The unpleasant effects here are owing to the volatile oil, etc. in the aroma, and not to the carbonic acid; for though flowers do give out carbonic acid gas, day or night, yet this is not copious enough, by its accumulations for a night, to do the least damage.

Very odorous flowers often prove injurious in a close room on account of their exhalations, which contain volatile oils and other principles. I have known persons made ill by sitting under a flowering Pittosporum, in an ordinary room in the day-time. At night it is generally worse, both on account of the room being closed, and from the fact that some fiowers exhale their odors most abundantly at night.

\section{Epochs of Cold and Warm Seasons.}

Dr. Drew, of England, in a recent work on meteorology, furnishes a diagram and series of tables which seem to show that we shall not experience another winter of equal severity to the last for the next eight or ten years. This conclusion is arrived at by a comparison of the mean annual temperature recorded since the year 1771, and the result when tabled may be expressed in the following manner:-

From the years named in the left-hand column, when the temperature fell to a minimum, it 
regularly advanced till it arrived at a maximum in the year named in the right-hand column, and then it again regularly declined-

$\begin{array}{lll}1771 \text { minimum. } & 1779 \text { maximum. } \\ 1784 \text { " } & 1794 \text { " } \\ 1799 \text { " } & 1806 \\ 1814 \text { " } & 1822 & \text { " } \\ 1829 & 1834 \\ 1838 \text { " " } & 1846 & \text { " } \\ 1854 & \end{array}$

The long-continued observations of Mr. Luke Howard, and the elaborate investigations of Prof. Dore, confirm this movement of the mean annual temperature in certain cycles, the duration of which cannot, however, be said to be as yet exactly determined.

\section{Prognostications of the Weather.}

Nomerous meteorological observations have been undertaken recently with a view of ascertaining whether the popular and generally-received opinions respecting atmospherical phenomena have in reality any foundation. The conclusions are, that little or no dependence can be placed upon any of the popular signs or prophecies, and that, in most cases, fair weather predominates even when the prognostications indicate rain. The following table of numerous registered observations on phenomens which are said to indicate either rain or fair weather, shows how the result stood:-

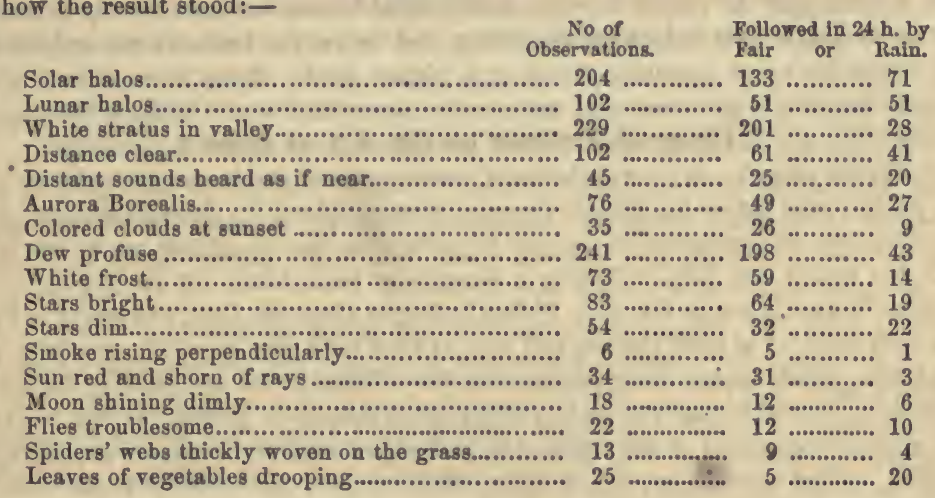

\section{Stable Ventilation.}

IT is very generally supposed, by those who reason on the subject, that catarrhal and other allied diseases in horses are generally due to the unnatural heat of stables. We are fully inclined to admit that much harm may be traced to unduly warm stables, but we must not forget that the horse can endure heat as well as most animals. In the warmest climates he seldom seems to suffer from heat alone, provided he be not confined in stables. Now, so far as mere heat is concerned, we do not suppose that any of our stables are kept at any thing approaching the temperature of those tropical heats, or even summer heats in this country, which a horse can bear with impunity. A horse, in fact, so far as experience teaches, can bear a high temperature alone, and as such; but can he endure a high temperature and an impure atmosphere? He cannot, without becoming diseased. Now, the coexistence of unnatural heat and bad ventilation are just what we find in very many stables at all seasons of the year. When the season, however, is cold, there is somewhat less danger to be apprekended from bad ventilation than when the weather is hot; and yet we find that stablemen do not, as a general rule, make these corresponding differences in their ventilating arrangements which summer and winter respectively require. We have often, it is true, seen the windows of stables and certain upper air-holes left open. But it is a well-known fact, that cool air enters best and most effectively at the ground-level, and hot air escapes easily from 
the top of a room. So that unless there be apertures below, we do not insure a proper circulation of air by merely having open windows. In a paper recently communicated to the Highland (Scotch) Agricultural Society by Mr. Barlow, that gentleman recommended each stall to be ventilated separately. He advised a hole or holes facing the head, level with the floor, and another aperture near the stable-ceiling. The pure air would enter below and be inspired; the hot impure air would ascend and pass out above. This plan is not new; it was recommended by the late Professor Coleman of London, and has been found exceerlingly successful when practically applied. The holes can have slides or plugs of wood so arranged as to graduate the amount of admitted air to the utmost nicety. In hot weather, they may be wide open; in cool weather, they may be partially, and perhaps sometimes almost completely, closed. We are convinced of the fact that a due supply of pure air, be it warm or cool, is the great security against diseases of the respiratory organs in stabled horses. Supplying plenty of good air in the stable places horses in-doors as near on an equality as possible with those at pasture, and by doing so lessens the tendency to disease. When stables or other buildings for farm-stock are ventilated only by doors and windows, it frequently happens that the cold wind comes in so freely as to chill the horses standing near. This renders it needful to shut the windows or doors altogether, and the consequence is, a rapidly-poisoned atmosphere, that fruitful cause of coughs, colds, and chest diseases in general. On the other hand, when each stall is as it were separately ventilated, the apertures are individually small, and may be so managed as to prevent all draught. If we are asked, then, to state the best preventive of disease of the respiratory organs in stabled horses, we have merely to advise the admission of cool, proper breathing air before and below the horse's nose, and the exit of heated impure air by an aperture placed at a higher level. Every horse and every man is continually exhaling a poisonous gas, and common sense itself would indicate the importance of getting rid of this in the speediest manner possible.-North British Agriculturist.

The following remarks on the ventilation of cow-houses and stables are derived from a paper on this subject read before the Hexam Farmers' Club, England, by James Ferguson, Esq.:-

A feeding byre or cow-house for one row of cattle when tied up, should not be less in width than 18 feet within the falls, including a passage at their heads for feeding $3 \frac{1}{2}$ feet wide. The side walls should not be less than 10 feet in height above the floor, and ought to be made smooth with one coat of good plaster, and once at least each year should be carefully washed with hot lime, which makes the atmosphere in the building sweet and healthy for the cattle confined in it. A stable ought to be in every respect (except a passage at the head of the horses, which is unusual) of the same size, and above neither cow-house nor stable ought there to be, on any account, any loft or ceiling whatever, but open entirely to the roof, which should be slated on sarking-boards, and of the usual pitch. The walks, of course, of the stables ought also to have one coat of plaster, and be carefully lime-washed at least once, if not twice, each year.

Now, in order that such houses may be properly ventilated, that stock may be kept in them in a perfectly healthy state, ventilators, which may be made three feet long by two feet wide, should be placed on the apex or highest part of the roof, for the reason that impure or vitiated air in the building, being heated and consequently lighter than the cold air, always rises upwards and vertically, (provided fresh air in sufficient quantity is admitted below,) and flies off by any aperture in a line above it which may facilitate its escape, and therefore out of reach of respiration. But in thus affording means for the escape of the foul air at the proper place, we must not lose sight of the absolute necessity of obtaining fresh supplies of pure air, which should always be admitted into a building at a low level, for the very purpose of lifting or pressing upwards the impure air which will not ascend otherwise; for exactly in proportion as the cold air is admitted below, the vitiated air which has been rendered useless by frequent respiration will be expelled or forced upwards; and it therefore follows that an opening in the highest part of the roof should be made to allow its egress, and that that opening should be formed in such a manner that direct currents of cold air may not obstruct its upward tendency. I must not omit, however, to notice, that if the dung and urine of cattle are not carefully removed every morning, and the channels behind them well flushed out with water, as before observed, in vain may the farmer look for healthy stock, however suitable 
his houses may be; for, depend upon it, ventilation will not cure disease, although it will go a long way to prevent it, if assisted by order and cleanliness on the part of careful servants. And here I may observe that, at all times, servants ought to be allowed by their masters proper time for this part of their duty, for assuredly no part of their employment will in the end remunerate the farmer better than when their stock is carefully and faithfully attended to. In respect to cattle-boxes, where perhaps two cattle are loose and fed together, the dung there, if the cattle are littered every day, may, without fear of doing injury by any offensire emanations, be allowed to lie for a month or six weeks, because, as the dung is firmly trodden down by the cattle going loose, the ammonia cannot escape, and hence no injury can arise. When the dung is removed, a little gypsum thrown over the floor (if water cannot be had) will completely absorb the ammonia and moisture, and the atmosphere again become healthy.

It is a very common method to admit fresh air into a building for farm-stock by latticed windows, but as these allow a direct current of cold air at an improper place, the plan is certrinly objectionable, at any rate, for stables, which ought to be kept at a temperature of about $55^{\circ}$ in winter, and from $60^{\circ}$ to $65^{\circ}$ in summer. Cow-byres, however, should be kept much cooler, and therefore ought to have more air-holes or ventiducts than stables, which would allow a temperature ranging from $55^{\circ}$ to $60^{\circ}$. In order, however, that a good supply of air may at all times be admitted, air-holes or ventiducts should be made through the wall behind the cattle, at say every ten or twelre feet on each side of the entrance or outside door. Into these openings, which may be made through the wall two feet above the floor, tubes of wood or iron should be inserted four or five inches in diameter, or they may be made square, with a grating on the outside end to prevent the ingress of rats or mice. The outside end of the tube should be made flush with the wall when fixed in it, and its length should be five inches less than the wall's thickness, in order that a groove may be cut of that depth and width from its mouth downwards to within six inches of the floor. On this groove a thin flag or board of two inches in thickness should be fixed flush with the wall inside, and the air is admitted indirectly into the building below the end or bottom of the flag, and about six inches from the floor, by an aperture which will be five inches wide and three deep.

\section{Grapes Ripening Earlier than Usual.}

THE editor of the American Agriculturist states that in a recent conversation with an eminent fruit-grower in the vicinity of New York City, he was informed that the Isabella and Catawba grapes are evidently ripening earlier from year to year. Ten to twelve years since, the earliest bunches of Isabellas were ready for market about the 1st of October. The past season they were equally forward on the 12th of September; this season has, however, been a remarkable one, and some allowance is to be made on that account; but last year, and the year before, the grapes were as mature about the 18 th of September as formerly at the end of that month. The authority referred to thinks the Isabella may be cultivated much farther north than has been generally supposed, by reducing the amount of fruit to the vine, so that there may be a greater flow of sap, and by this means an earlier growth and maturity secured. He thinks much more depends upon the method of manuring, pruning, and the general plan of cultivation than upon climate, since they often ripen poorly even in Virginia and Maryland when improperly managed, and yet, in the same season, ripen well in Massachusetts.

\section{Influence of Locality on the Growth and Ripening of Fruit-Trees.}

Tru Genesee Farmer publishes the following extract from an address by J. A. Matson, Esq., before the Greencastle Horticultural Society, Indiana, which contains some useful hints relative to the location of fruit orchards:-

Another subject on fruit culture, which has always been of great interest, and has become much more so within the last two years, is the destruction of fruits by hard freezing in winter and by the late frosts of spring. Nearly all the orchards planted by the early settlers of the West were located in the valleys, and, wherever practicable, near the margin of some river or stream of water. This was done under the impression that the effects of the frosts 
would be neutralized by the fogs arising from the water and resting over the valleys during the morning, and by the protection afforded by surrounding hills from the cold winds.

Fruit-growers in the West, after witnessing the repeated destruction of their crops in the valleys, while the trees located on the bleak tops of the surkounding hills were bending down with their luscious burdens, have now discarded the theory with which they set out.

Dr. Kirtland, of Cleveland, made some interesting experiments on this subject. Supposing that the severity of the frosts in the valleys, compared with its effects on the high lands adjacent, was caused by a current of warm air rushing from the low to the high grounds as the temperature decreased, he stationed himself with a thermometer, lantern, and watch, on a night when a severe frost was expected, on a hill near Lake Erie where the peach crop had never been killed, while his brother was stationed with a thermometer, lantern, and watcl, in the valley below. Each made and recorded observations every half hour during the night, and the result was as follows: From sundown until nine o'clock, each thermometer indicated the same degree of temperature. At nine o'clock, the mercury in the valley thermometer commenced sinking, while that on the hill, at the same time, began to rise; and the doctor observed a perceptible current of warm air flowing up from the valley. At twelve o'clock, the thermometer in the valley indicated $12^{\circ}$ lower temperature than that on the hill, and about the same difference was observed until daylight in the morning.

\section{Influence of Situation on the Diseases of Plants.}

M. Mennevilue, in the Comptes Rendus, Paris, expresses the opinion, which he says is based on long observation, that the great epidemic in France which affects so many plants, and more especially the vines, is due in great measure to influences of temperature. Thus, continues M. Menneville, it appears to me that all valleys having large streams of water, and so situate as to be exposed during winter to cold northerly winds, are more or less free from the ravages in question. The north slopes of hills are generally free also, and certain elevated tracts of country, whether in the south or middle of France, suffer but little, unless it be in those spots which are sheltered by irregularities in the soil.

\section{Protection of Fruit-Trees against Extreme Temperatures.}

Mr. N. T. True, a correspondent of the New England Farmer, writing from Bethel, Maine, gives the following as his experience in cultivating peach-trees and protecting them against the severe cold of a Northern winter. He says-

"I have peach-trees in their fifth year, which have never suffered in the least from the coldest weather. My place is situated $1^{\circ}$ north of Portland, in the White Mountain region, about 700 feet above tide-water. The prevalent idea that extreme cold alone will kill the peach, I believe, must be abandoned; or, rather, the idea that when the thermometer is $12^{\circ}$ below zero it is fatal; I have contended for several years, that it is not so much the extreme cold as the strong winds, pelting sleet and snow, and sudden changes of temperature, that affect the peach. We have had the thermometer once at $34^{\circ}$, and at several times from $12^{\circ}$ down to that extreme degree of cold, and yet peach-trees that were protected by matting or fir-boughs were not injured at all. My practice is this: Late in the fall, I draw the limbs of the tree together and put round some matting-a single fold will answer-drive a stake down by the side of the tree, and fasten the tree to it. One man can protect from one to two hundred trees in a day; care should be taken not to unwrap them too early in spring, so as to expose the fruit-buds to the late frosts. I also protected a locust-tree in the same way. simply by lashing a few fir-boughs to the north-west side of the tree. It now looks as bright as if it were growing in the latitude of Philadelphia.

"I can see no reason why peaches cannot be raised in any part of Maine simply by protecting them in this way. It may not be known to all that, although so far to the north, the ground is rarely frozen to any extent in winter. The early snows prevent this, so that it is only the tops of such trees that need special protection. It is useless to attempt the cultivation of the peach in Maine without some kind of protection; they may survive one, two, or even three winters, should they be mild, but the fourth may kill them all down." 
the flame, each of which would have deposited its hundreds of eggs in a few days. If this plan were generally adopted and persevered in for a few successive nights at the proper season, its effect would doubtless be, if not entirely to destroy, at least to diminish to a very beneficial extent, these mischievous pests. The first hatching of the caterpillar in the spring could not at first be thus destroyed or their ravages prevented; but the second brood, if it may be so termed, which is generally considered most numerous and destructive, and which furnishes the eggs for the supply of the succeeding year, would be cut off to a great extent. However this suggestion may be received, it is at least as practicable as any of the plans that have been proposed for the same object, some of which have been promulgated through respectable agricultural journals, such as the powdering of the leaves of the plant with finely-pulverized quicklime, or the fumigation of each separate plant with sulphurous vapor, produced by burning brimstone on chafing-dishes, each plant being enclosed, during the process, in a tight canvas hood, ten minutes being considered sufficient for each plant. If this were at all practicable, one hand, with great diligence, might, at this rate, go over one acre in fifteen or twenty days.

The caterpillar, which does not usually appear until the cotton-plant is pretty well matured, feeds chiefly upon the leaf, and the degree of damage done depends upon the period it commences its depredations. If so early that a few bolls are matured, the plant must cease to grow when stripped of its leaves. Instances have occurred, but, it must be confessed, very rarely, when the growth of the plant was too vigorous, and continued too late in the season, in which a partial cropping of the leaves by the worm has had a beneficial effect in arresting the growth, and causing the bolls to mature and open. If their appearance is delayed until a period immediately preceding a killing frost, and during a dry season, they confer a benefit in remoring the leaf, which after a frost stains the cotton and renders it very trashy by crumbling and falling upon it.

"The boll-worm is comparatively small, resembling at first the silk-worm in its early stages ; its attacks are made within the calyx, and about the base of the boll, which it perforates, and when first forming, or tender, it wholly devours, or causes to drop off. (See Plate.)—Wailes's Report on the Geology of Mississippi.

\section{The Diseases of the Cotton-Plant.}

THE diseases of the cotton-plant are the rust, the rot, and the sore-shins.

The first is most probably attributable to the mineral properties of the soil, as it is local and partial in its effects; and on the spots of ground affected by it, the difference of soil is obvious to the eye. The appearance of the plant so diseased suggests the existence of microscopic fungi, which exhaust by their parasitic growth the sap of the leares, and cause them to wither and fall.

The rot, or disease of the boll, has been assigned to various causes. The first external indication of its approach is the appearance of an almost imperceptible puncture on the side, and generally near the base of the boll, surrounded by a slight discoloration, or change of tint, presenting the semblance of a minute spot of grease-a character given it in the common conrersation of planters, in speaking of the disease. (See Plate.) The most received opinion, and that best supported, is, that it is occasioned by the larræo of a small insect which is hatched from the egg deposited in the boll in some unknown manner, at an early stage of its growth, and which, feeding on the succulent and pulpy seeds in their early stage of formation, produces the disease without immediately destroying the boll. This not unfrequently is only partially damaged, and continues to grow nearly to its mature size, becoming in the end externally black and hard; the decayed state of the interior of the boll presenting an analogy to the peach or plum, which, though often presenting even a fair and perfect exterior, is found upon opening to have been long preyed upon by the curculio or peach-worm.

It is certain that the diseased and blackened boll, when broken open, reveals a variety of small insects, sometimes in the different stages or conditions of their metamorphosis. Which of these is the real enemy, can only be determined by the close and continued observation of the practical entomologist. *

* The insect theory in connection with the cause of the rot is sustained by observations made during the last two years. It has been remarked that on lands where the different varieties of cotton had been planted sepa- 
This disease made its appearance as early as 1810, and prevailed more or less, for mors than ten years, throughout the South, and occasionally to such an extent in some districts as almost to cause the abandonment of the cotton culture; a contingency prevented by the introduction of the Tennessee green-seed variety, which was exempt from the disease, or much less affected by it than the naked black-seed variety first cultivated. For many years subsequently the rot was unheard of; its partial and unfrequent occurrence being too inconsiderable to create alarm, or occasion any appreciable injury. Its reappearance in 1852 and the season of 1853-4 has, however, on many plantations, been attended with considerable damage.

The remaining disease, popularly known as the sore-shin, attacks the plant in its early stages. If not wholly destroyed, the bark of the stem becomes diseased and hardened, and the sap vessels dried up or obstructed, at or near the surface of the ground. The disease is prevalent during the occurrence of the cold nights of a wet and backward spring. To this cause it is attributed, and may be owing, in some degree, to the plant-louse, (apis pauceron,) which prevails most in such seasons. The growth of the young plant so affected is languid and slow; and although the damaged epidermis may be repaired and overgrown by a new bark, it is questionable whether the plant ever becomes as vigorous and prolific as those which have not sustained this injury. The cause of this malady - too early planting-suggests the proper remedy.

The casting of the forms or germs of the boll, may also, perhaps, be regarded as a disease attendant on a deranged circulation in the plant, owing to an unequal and irregular supply of moisture. It is manifested most generally upon a sudden transition from a very dry to a very wet season, and is consequently so far without remedy; it is, however, doubtless sometimes occasioned or aggravated by injudicious cultivation.-Wailes's First Report on the Geology of Mississippi.

\section{On the Consumption and Manufacture of Cotton.}

Is 1749, some good people in or near Boston organized a society for the "promotion of industry and economy," the wars preceding that period having introduced a habit of idleness among the people, which the strong religious sentiment of the early settlers determined to discourage and rebuke. On the occasion of their anniversary in 1753, three hundred females of Boston assembled on the Common, with their spinning-wheels, and gave a demonstration of their skill in the art of using them. They were neatly attired in cloth of their own manufacture, and a great crowd of spectators collected to witness the scene. This was the first public exhibition of American manufactures, and probably produced as much good and more excitement than those of later days.

In 1787 , the first cotton-milpin Massachusetts was erected at Beverly, by John Cabot and others; but such were their difficulties, that in three years they were almost compelled to abandon the enterprise. As a last resort, they petitioned the legislature for assistance, and the committee to whom the subject was referred reported in favor of granting them one thousand pounds sterling, to be raised by a lottery!

In 1786, two Scotch brothers, named Robert and Alexander Barr, erected carding and spinning machines for Mr. Orr, at East Bridgewater, Mass., which was considered of such importance that the legislature, to reward their ingenuity and encourage machinists, "made them a grant of $£ 200$, and afterwards added to their bounty by giving them six tickets in the State Land Lottery, in which there were no blanks!"

rately, in alternate rows, for experiment, the most tender and succulent varieties, which would naturally first invite the attacks of insects, were those most damaged, while the more hardy and firmly-wooded remained uninjured. The increase of these maladies may probably be traced in some measure to the extirpation or disappear ance of birds, owing chiefly to the destruction of the forests, leaving them in a degree without protection or shelter.

A beneffcent Providence, in the economy of nature, designed these little winged scavengers for useful purposes. To restrain the exuborance of insect life is their peculiar offlce; and so long as they are preserved and protected, their office is effectuslly performed. If man wantonly, and with mistaken impressions as to the extent and char racter of their depredations, will destroy them, he must make his account in submitting to ravages of a more for midable kind, and which may baflle his ingenuity to prevent. This lesson has been taught with a hesvy cost, nowhere, perhaps more clearly than on the rice plantations of the South, where the planters would now gladly woo back the little denizens of the air, which they have frightened away or destroyed. 
In 1784, the first parcel of American cotton, 3000 pounds, was exported to England. In $1791,19,200$ pounds were exported. The next year the quantity rose to 138,328 pounds. In 1793, Whitney's cotton-gin came into operation, and its immediate effect may be inferred from the fact, that the very next year, in 1794 , the United States exported 1,601,760 pounds, and in $1795,5,276,306$. Previous to the invention of the cotton-gin by Whitney, the importation of cotton into Great Britain did not greatly exceed five millions of pounds per annum, and the value of cotton goods exported was only two hundred thousand pounds sterling. Since then, the amount has steadily increased, and in 1852 Great Britain consumed not far from 800,000,000 pounds of raw cotton, and exported $£ 31,000,000$ of manufactured cotton goods.

In the snme year, $(1805$,$) the total consumption of cotton in all the United States was a$ little more than one thousand bales! Now, the eotton consumed by the mills of Lowell exceeds two million eight hundred and twenty thousand pounds per month.

In 1810, Tench Coxe, of Philadelphia, in accordance with instructions from Albert Gallatin, collected all the information he could, touching the condition of American manufactures at that period. The result of his labors was published in 1812; and according to his report, during the year 1810, Massachusetts manufactured thirty-six thousand yards of cotton cloth, and two hundred pieces of duck, the first valued at $\$ 28,000$, and the second at $\$ 6,000$, which was the extent of her factory operations. In all the States combined, there were only 146,974 jards of cotton cloth manufactured during that year. Now, the Massachusetts Mills of Lowell produce something more than five hundred and thirty-six thousand yards per week, or $25,728,000$ per year. In his ardor to promote domestic manufactures, Mr. Coxe urged families to make their own cloth, and recommended the circulation of official tracts or pamphlets, describing the best machinery for family use; and, by way of inciting the South to increased action, advised them to manufacture, for the use of their slares, a "cap of thick home-made, undyed cotton swan-skin, similar in form to the Highland woollen cap of North Britain." He thought such a cap would preserve the health of the slaves, and therefore financially benefit their masters.

The war of 1812 gave a fresh impetus to American manufactures, insomuch that in 1816 a report to Congress showed that forty millions of dollars were then invested in cotton manufactures, and twelve millions in woollen; and that during the year, ninety thousand bales of cotton had been consumed by our factories, and that the aggregate value of all the goods manufactured was equal to about sixty millions of dollars. In 1850 , according to the late census report, there were in all the States 1094 establishments for the manufacture of cotton, employing a capital of $\$ 74,501,031$, and producing goods annually to the value of $\$ 61,859,184$.

There can be no doubt but the great increase of the consumption of cotton can be traced to the invention of the cotton-gin. Before the invention of the cotton-gin, it took $\Omega$ female one whole day to clean one pound of cotton, and the best machine-the roller-gin with fluted rolls -which was in use in 1788 for cleaning cotton, could only finish about thirty pounds in twelve hours. The great consumption of cotton for manufacturing is attributable to its cheapuess; but it never would have become a cheap fibrous material by the old processes of cleaning, and our country never would have become a great cotton country if the cotton-gin had not been invented.

The first attempts to introduce the manufacture of cotton into Great Britain, in common with all like enterprises, met with a fierce and well-directed opposition. In order to protect woollen manufactures, laws were enacted forbidding the use of cotton garments, under the penalty of fine and imprisonment. The laboring classes, who considered cotton detrimental to their interests, frequently manifested their hostility to it by riot and bloodshed; ragabonds, too lazy to work, pretended that cotton had thrown them out of employment and reduced them to pauperism; and felons occasionally pleaded cotton as an extenuation of their crimes; an amusing instance of which may be found in the following letter, published in the Gentleman's Intelligencer, for May, 1784:

\section{"From Cork, in Ireland.}

"This day, one Michael Carmody was executed here for felony, upon which the journeymen weavers of the city (who labor under great difficulties by reason of the deadness of trade, 
occasioned by the pernicious practice of wearing cottons) assembled in a body, and dressed the criminal, hangman, and the gallows in cottons, in order to discourage the wearing thereof. And at the place of execution the criminal made the following remarkable speech:

" 'Give ear, 0 good people, to the words of a dying sinner: I confess I have been guilty of many crimes that necessity compelled me to commit, which starving condition I was in, I am well assured, was occasioned by the scarcity of money, that has proceeded from the great discouragement of our woollen manufactures. Therefore, good Christians, considen that if you go on to suppress your own goods, by wearing such cottons as I am now clothed in, you will bring your country into misery, which will consequently swarm with such unhappy malefactors as your present object is, and the blood of every miserable felon that will hang, after this warning, from the gallows, will lie at your doors. And, if you have any regard for the prayers of an expiring mortal, I beg that you will not buy of the hangman the cotton garments that now adorn the gallows, because I can't rest quiet in my grave if I should see the very things wore that brought me to misery, thievery, and this untimely end ; all which I pray of the gentry to hinder their children and servants, for their own character's sake, though they have no tenderness for their country, because none will hereafter wear cotton but oysterwomen, criminals, hucksters, and common hangmen." "

What would poor Micky say now, could he rise from his dishonored grave, and learn that, despite his prophecy, almost every man, woman, and child, in the civilized world wore that same hated cotton that brought him to the hemp, and that it dispensed happiness and comfort to millions of the human race, who earned their subsistence by its culture and manufacture?

The following tables, furnished us by J. T. Stewart \& Co., Cotton Brokers, of Now York, exhibit a comparative summary of the cotton crops of the United States, since the year $1823-4$, in bales of 400 pounds:-

\begin{tabular}{|c|c|c|}
\hline Crop of & Crop of & Bales. \\
\hline $1854-55 \ldots$. & $2,030,409$ & $1832-33 .$. \\
\hline .......2,930,027 & $1842-43 \ldots \ldots \ldots \ldots \ldots \ldots 2,378,875$ & 1831-32................. 987,477 \\
\hline ....... 3,262,882 & $\ldots . . .1,683,574$ & .............. 1,038,848 \\
\hline . $3,015,029$ & ... 1,634,945 & ............. 976,845 \\
\hline . $2,355,257$ & ... 2,177,835 & ...... 857,744 \\
\hline $2,096,706$ & . $1,360,532$ & $1827-28$ \\
\hline $2,728,596$ & . $1,801,497$ & $1826-27$ \\
\hline . $2,347,634$ & ....... $1,422,930$ & $1825-26$. \\
\hline $1846-47 \ldots$ & . . $1,360,725$ & ........ 569,249 \\
\hline 2,100,537 & .... 1,254,328 & $1823-24 \ldots \ldots \ldots \ldots \ldots \ldots \ldots . \ldots 509,158$ \\
\hline & & \\
\hline
\end{tabular}

The comparative product of the United States, by decades, since 1824, is as follows:-

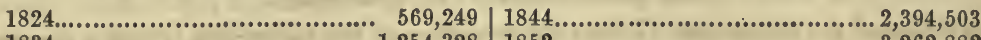

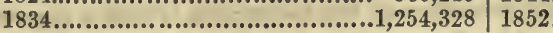
$3,262,882$

The annual quantity of cotton consumed and in the hands of manufacturers, north of Virginia, for the past twenty-six years, is as follows:-

\begin{tabular}{|c|c|c|}
\hline Crop of & Cro & Bales. \\
\hline 593,584 & 389,006 & $1834-35$. \\
\hline 610,571 & 346,744 & 1833 \\
\hline .................. & $1842-43$. & 1832-33. \\
\hline 603,029 & 267,850 & $1831-32$ \\
\hline ................ & $1840-41$. & 1830 \\
\hline ..................... 48 & $1839-40$. & $.126,512$ \\
\hline ................... 5] & $1838-39 . \ldots \ldots \ldots \ldots \ldots$ & $1828-29$. \\
\hline ................. 531,772 & $1837-38 \ldots \ldots \ldots \ldots \ldots$ & $1827-28 \ldots \ldots \ldots \ldots \ldots \ldots \ldots . \ldots 120,593$ \\
\hline 427,967 & $1836-37 \ldots \ldots \ldots \ldots \ldots$ & $1826-27 \ldots \ldots \ldots \ldots \ldots \ldots \ldots . . . . .149,516$ \\
\hline 222,597 & $1836-36$ & \\
\hline
\end{tabular}

The comparative quantity consumed in 1854 and in 1855, south of Virginia, is as follows:-

\begin{tabular}{|c|c|}
\hline .... Bales z & $\begin{array}{l}1855 . \\
18,500\end{array}$ \\
\hline .......... 12,000 & \\
\hline .............................. & 20,500 \\
\hline $1 a \ldots \ldots \ldots \ldots \ldots \ldots \ldots \ldots \ldots \ldots \ldots \ldots$ & 5,500 \\
\hline see................................... & 4,000 \\
\hline & 16,000 \\
\hline Total to September $1 .$. & 85,00 \\
\hline
\end{tabular}


In reference to the consumption of cotton in the country, the past year, both north and south, it will be seen that it has fallen off, although the production has been pretty nearly the same: this may be accounted for, primarily, by the partial failure of the crops of cereals in 1854, the consequent high prices of breadstuffs and provisions, and the general pressure for money felt by all classes in all sections of the country.

The quantity of new cotton received at the shipping ports to the 1st of September, amounted to 34,069 bales; against 1890 last year, 716 in 1852-3, and 5125 the year before. Thus, it will be seen that the quantity of new cotton receired at the ports to the 1st of September this year, is largely in excess of last year; but it is an admitted fact, that at that date, there remained of last year's crop (detained in the interior by low rivers, caused by an unprecedented drought) a very large quantity-say 250,000 bales; some estimates are a little lower, but others even higher; and had the cotton thus detained been brought to market, and added to last year's crop, it would have approximated the great crop of 1852-3; as it is, it will doubtless soon come forward, and materially swell the aggregate for 1855-6, should not a similar state of things exist next season.

The value of American cotton exported in 1854 amounted to $\$ 93,596,220$; of this, $\$ 64,738,391$ was exported to Great Britain, with the exception of a very small quantity to Ireland.

\section{Sea-Island Cotton from Algeria.}

AT the Great Industrial Exhibition at Paris, samples of Sea-Island cotton from Algeria were exhibited, which, in the opinion of good judges from the United States, were equal to any in the world. It has been supposed that this long-stapled cotton would grow nowhere else than on our Southern coast, and vigorous attempts to naturalize it in the Indies have proved failures; yet it grows luxuriantly on certain slopes of Mount Atlas, where the existence of salt springs is supposed to favor its perfection-the underlying mountain being composed in good part of aalt.

\section{Sea-Island Cotton in Texas.}

THR Galveston News states that Sea-Island cotton is successfully cultivated in several parts of the State, and that there is a general disposition at various places, from Gonzales to the Gulf, to go into the cultivation of this description of cotton. Not less than one thousand acres, the News is informed, will this year becultivated with this cotton in Western Texas.

\section{Sea-Island Cotton for Spinning.}

THE following is an extract from a letter of T. Bayley, President of the Manchester Chamber of Commerce, to George M. Sanders, formerly United States Consul at London, respecting the assortment of Sea-Island cotton:

"To the simple question, 'Do the manufacturers of Sea-Island cotton assort it by the lock?' I can give the positive reply that they do not, nor would it, upon an extensive or practical scale, be possible for them to do so. The spinners of the fine Sea-Island cotton, of course, esteem the longest-stapled cotton as the best, and in all their processes they get rid of as much short fibre as they can, and preserve unimpaired all the long fibres. Essentially, the art of the cotton-spinner consists of disentangling the fibres of cotton, in freeing these from all extraneous substances and impurities, in securing the longest fibres, in obtaining them of equal length, and finally placing them parallel, so that they will freely and evenly pass each other into a line of yarn or thread, in the subsequent progress of elongation.

"From my own knowledge, the cotton of Florida is an excellent and desirable quality for the spinner, but it has been sent to market in a 'craply' or knotty condition, which has greatly diminished its value. I have seen Florida cotton cleaned and prepared by the McCarthy gin, and which cotton, I believe, has been increased in value by that preparation to the extent of twenty per cent. That his gin, applied to Florida cotton, would be a great advantage, does not admit of a doubt.

"If the cotton-planter would always recollect that the spinners require only pure, even, and disentangled fibres, I have no doubt he would save himself much trouble, and increase 
the value of the cotton; and if he could classify the fibres according to their length, and pack the cotton in bales with equal and assorted fibres, a further advantage would be the result."

\section{Flax Industry in Russia.}

THE important position which Russia occupies at the present day, as regards the production of flax and hemp, is woll known, but the means of information relative to the production, exportation, or preparation of this article, in common with the statistics of the other sources of agricultural and mineral wealth in this country, are exceedingly limited. All materials for acquiring knowledge relative to these subjects are therefore of especial value.

The flax of Russia differs materially from that produced in either Belgium, Holland, France, Ireland, or the other flax-growing countries of Europe. While the fibre is almost always inferior, the Russian flaxseed has the highest reputation. It is a pertinent subject of inquiry -Why the produce of this seed sown in Russia is not equal to that produced from the seed sown elsewhere? The answer is that, The difference arises from a difference of culture, and also from a difference of soil and climate. It is a fact well known to botanists and fruitgrowers, that a plant or tree yielding fruit, transferred from the north temperate zone to a southern portion of the same zone, generally improves in character and strength, being at the same time more hardy than the cognate plants growing originally in the same latitudes.

Before entering into an account of the method of cultivation followed in Russia, we would briefly direct attention to the geological constitution of the part of Russia where the cultivation of flax is prosecuted to the greatest extent. The soil of a great part of Russia rests upon a sandstone of the secondary series, red or gray in color; this rock, more or less disintegrated, extends throughout the most fertile portions of the country, from $56^{\circ} \mathrm{N}$. lat. to $67^{\circ}$ N. lat., where it terminates. Starting at latitude $56^{\circ} \mathrm{N}$., it extends in level tracts upon the Baltic, touching the district of Riga, stretches along the Gulf of Livonia, embraces a great part of the district of St. Petersburg, extending to Lake Onega, the White Sea, and the Gulf of Archangel ; from thence it bends to the north-east, and finally terminates about $67^{\circ} \mathrm{N}$. lat. The greatest width of this deposit, east and west, is between Windau on the Baltic, and Torapetz to the east. The surface comprehends, first, all the basin of the river Don; second, a great part of the course of the Volga; third, a great part of the course of the Onega, even to its mouth; fourth, most of the basin of the Dwina, even as far as its entrance into the Gulf of Archangel. The climate of this country, as indicated by the mean temperature, is as follows: In the level country along the Baltic, $52^{\circ} 40^{\prime} \mathrm{N}$. lat., the yearly mean of the thermometer is $46^{\circ} \mathrm{Fahr}$. Mean temperature of the winter, $32^{\circ}$; summer, $62^{\circ}$; autumn, $45^{\circ}$. St. Petersburg, situated at $39^{\circ} 56^{\prime}$, has a mean temperature of $38^{\circ}$; in the months of greatest heat the mean temperature is $65^{\circ}$; in the months of greatest cold the mean is $8^{\circ} 6^{\prime}$.

Archangel is situated upon the Dwina, near its entrance into the White Sea. During ten months of the year, from September to July, all access to this place by water is prevented by ice. The Dwina remains frozen until the month of April or May. On the 11th of June the sun remains above the horizon from $1 \mathrm{~h} .27 \mathrm{~m}$. morning, until $10 \mathrm{~h} .37 \mathrm{~m}$. evening. On the 11 th of December it appears only from $10 \mathrm{~h} .9 \mathrm{~m}$. morning, to $1 \mathrm{~h} .51 \mathrm{~m}$. noon. This district is included in that zone where the light continues during an entire month, from the commencement of June to the first week in July. To the constant light and heat of this month the production of flax is due.

Odessa, the centre of another flax-growing district of Russia, is situated upon the Black Sea, lat. $46^{\circ} 59^{\prime} \mathrm{N}$., between the mouths of the Dnieper and Dniester. The soil is of the older tertiary formation, designated by Murchisson as the older Caspian. The climate closely resembles that of the South of France.

Although the flax culture is less advanced in Russia than in other parts of Europe, we have reason to believe that it has been known there for centuries, at least in the vicinity of Odessa, Lithuania, Livonia ; but the provinces of Pleskoff, Novogorod, and Archangel are the districts which at the present day furnish the bulk and better qualities of Russia flax. In Southern Russia they cultivate but comparatively little flax for the fibre, but considerable for 
the seed, the exportation of which to foreign countries is rapidly becoming of great importance. The culture of flax in the north-west and central portions of the empire requires the use of manure, and of thorough plowing and pulverization of the soil; but in the southern portions of Russia, a single plowing, imperfectly performed in the autumn, without the use of manure, is sufficient preparation for obtaining an excellent crop of flax, especially when the season has been moderately moist. In favorable seasons the product of seed is from twenty to twenty-five bushels for one, but the average of the whole country is not more than eight to twelve bushels for every one of seed.

The proprietors who cultivate flax for the seed use the stalks for fuel, not knowing how to turn them to any better account. They also cut or mow the flax, instead of pulling it, which renders it somewhat unsuitable for the production of fibre.

The method of cultivation in that part of Russia where they make but little use of the straw is as follows: They sow on the virgin soil of the steppes, in the ricinity of Odessa, or upon land which has been cultivated with grain or some other crop the preceding year. The crop can be repeated in the same soil for two succeeding years, without any inconvenience. The labor of cultivation is extremely simple. They plow to the depth of about six inches once in the autumn. In the spring they harrow with care, and between the fifteenth of April and the first of May they sow broadeast about three English pecks of seed to two and a half acres. When they design to preserve the fibre, they sow about one-third more flax. The crop is a certain one, if it rain but a very little during the months of May and June. This flaxseed is highly esteemed for exportation, and as it sells for highly remunerative prices, viz., from $\$ 150$ to $\$ 200$ a bushel, the culture rapidly increases in Southern Russia. In 1830, the amount of seed exported was 13,000 bushels: in 1838, it had increased to 300,000 ; in 1839 , to 350,000 , representing a value of $\$ 600,000$. The exportation of flax fibre from this section of country is small, as hand labor is dear, and the population sparse. The small quantity which is prepared is imperfect and low-priced. The rotting is made ordinarily with water, but occasionally dew-rotting is pursued. The subsequent operations, including that of spinning and weaving, are conducted in a manner equally rude and imperfect. The manufacture of cloth is exceedingly restricted, and is wholly of a domestic character, the production not exceeding the local consumption.

In the district known as New Russia, the amount of cloth is not sufficient for the home demand, and the deficit is made up by importations from the northern portions of the empire.

In Lithuania, Couriand, and Livonia, the peasant grows flax once in three years upon the same soil ; in a part of these provinces it is grown principally for seed, but the flax fibre yielded is nevertheless merchantable as "inferior quality," unless the crop is entirely neglected. In those districts where the flax is cultivated for the fibre, the seed is sold under the title of "swingled flaxseed." The most usual method of rotting is by means of stagnant water, and the time required varies from eight to fifteen days.

In $1838-39$, Belgian workmen were employed by the government in various districts, to teach the peasantry the method of rotting flax by the improved processes used in the Low Countries, and the Minister of Finance was authorized to distribute the sum of one thousand silver roubles, in premiums, to the peasants who should most successfully carry out the Belgian improvements.

In quality the flax of Russia ranks after that of Holland, Belgium, France, and Germany. Some attribute this inferiority to difficulties which arise from the nature of the climate. It is said that in Russia "the season proper for vegetation is too short." The flax grows and ripens too quickly-much faster than in France or Belginm, where natnre performs her tasks more slowly and perfectly. Flax in Southern Europe, when sown in March, generally experiences some bad weather, which hinders its first growth, and strengthens the root, and when the warm season afterwards comes on, the vegetation is vigorous and furnishes a flax more delicate than the flax of the Baltic. A difference is noticed even in France, when the sowing is protracted from March until May or June; then here the crops grow more quickly, and the quality of the fibre closely resembles that of the Russian flax.

Two reasons concur to favor the exportation of flax from Russia, viz., the low price, and the division of the flax into classes according to quality. 
The cheapness of flax is owing to the fact that the emperor and the nobles possess all the serfs, and have thus an abundance of cheap hand labor. The land is of little value, and the peasants have little to occupy themselves with in the long winters with the exception of dressing flax.

Flax, in common with all other productions of the country, is classed according to its quality. This is effected as follows: When the flax arrives at Riga or St. Petersburg, it is stored in depôts specially designated for the purpose. Here inspectors, appointed by government, are charged with the duty of classifying it. All marks and designations are first obliterated; the bundles are then opened, and all which is not of the first quality is taken out and placed by itself. This second lot is again examined, and again subdivided according to its quality. A commission appointed by the buyers watch over the inspectors, and no sample of flax is examined unless one or more of the commission is present. When the classification is effected, each parcel receives its distinctive mark. The expense of these regulations, which is inconsiderable, is borne by the proprietors of the flax. This plan offers all satisfactory guarantees to the purchasers, and the owners are prevented taking any unfair advantage.

The export of flax and hemp from Russia has greatly increased witlin the last twenty years, and is progressing. The largest proportion exported finds a market in England. Taking the trade of fourteen years, from 1840 to 1853 inclusive; it appears that during the first seven years of this period, Great Britain was indebted to Russia for 72 per cent. of all her hemp importations; and during the last seven years for about 62 per cent. of flax. About twothirds of all the quantity imported is Russian. From tables of European commerce recently published, it appears that the $28,000,000$ of British people annually export produce to the value of about $£ 90,000,000$ sterling-the $36,000,000$ of France export to the value of about $£ 50,000,000$ - and the $67,000,000$ of European Russia export to the value of about $£ 14,000,000$. Russia exports raw produce exclusively, consisting chiefly of grain, tallow, flax, linseed, hemp, wool, timber, and bristles; the three items first named commonly exceeding in value all the rest.

The following statistics of the flax and hemp exportations of Russia, furnish some idea of the extent of the production of these substances in that country:-

The yearly average importations of flax, hemp, and tow into Great Britain from Russia, for the ten years ending 1851 , was $160,000,000$ pounds. The other countries of Europe import from Russia as follows:-France, in 1838, imported of flax and hemp, 17,000 pounds, in 1846, her imports amounted to over $15,000,000$ pounds, and, in 1849 , to $20,403,466$ pounds. Belgium, which in 1838 imported only 4400 pounds of flax, imported upwards of 4,000,000 pounds in 1846 .

The Russian export of flaxseed averages annually about 9,000,000 English bushels.

At the exhibition of the Industry of all Nations, at the New York Crystal Palace, in 1853, a new variety of flax and flaxseed from Russia was exhibited by Mr. Leon Falkersaborf, member of the Agricultural Societies of St. Petersburg, Moskowa, etc., etc. It was described as a new variety of flax, sown as a winter's crop, and superior to the spring-sown seed. The samples of the flax fibre produced from this seed, which were exhibited in connection with it, were the most perfect as regards strength, lustre, and lifelike appearance, of any on exhibition, and were only surpassed in fineness by one extraordinary premium sample exhibited from Ireland. Samples of this flaxseed were ordered by Mr. Johnson, the Secretary of the New York Agricultural Society, for distribution among American flax growers, and it is to be hoped that its introduction may prove successful and important.

Most of the thread manufactured in Russia is spun by hand. There are, however, two establishments for machine-spinning, the one at Alexandrofsky belonging to government, and introduced as a model; the other, a private establishment of little importance. Both together contain about 50,000 spindles. Notwithstanding, Russia exports a considerable quantity of yarn to America, and supplies in addition, the domestic consumption. The manufacturers in the vicinity of Moscow, Jerosloff, and Archangel furnish the common fabrics consumed in the empire. Fine linens are imported into Russia to a slight extent, the yearly average not exceeding 35,000 pounds in weight. Notwithstanding the low price of the raw material and of hand labor, this branch of national industry is protected by an excessively high tariff of duties, and sailcloth, canvas, and cordage of all descriptions are contraband.-Editor. 


\section{On the Preparation of Vegetable Fibrous Substances.}

As the fibres of Indian plants are now beginning to attract the attention of manufacturers, it may be of some use to publish the results of experiments that have been tried to prepare them for the English market, and to turn them to practical account in India. The demand for fibrous substances as substitutes for flax, hemp, silk, cotton, and hair, is now becoming so great that a market cannot be supplied with a sufficiency of these raw materials to keep our large manufactories in full operation.

As flax and hemp, both substances most urgently called for, and wasted in large quantities iu many parts of India, are hardly ever prepared with sufficient care to make them profitable articles of export, a description of the simplest and most economical methods of cleaning them may prove of interest to the public.

The usual process followed in India for preparing fibres of succulent, fleshy plants consists in culling the plants when in fall vigor, and burying them in wet sand on the banks of a running stream, or in mud at the edge of a tank, and leaving them there to soak and rot for one, two, or three weeks, according to the temperature of the weather. The plant is then taken out and spread in the sun to dry, after which it is stacked or put up in heaps, and covered with a matting of dry leaves to shelter it from wind or rain. It is afterwards beat with heavy sticks upon the dry, hard ground, and well rubbed between the hands to separate chaff and dust. Another method is to take the soaked plant in bundles, and beat out the pulp and impurities on a fiat stone at the edge of a tank or river, in the same way as the washerwomen wash clothes.

The fibres of the Marool or Sansiviera Zeylanica are prepared by scraping and washing in fresh water soon after the plant is cut. The fibres of the Yercum or Calotropie gigantea are separated by exposing to the sun for three days the fresh-cut stalks of the plant, stripped of the leaves. The bark is then peeled off, and the fibres are picked out with the finger and thumb. The two last processes yield fibres of good quality, but in too small quantity to prove remunerative, except as an employment for children.

The system of cleaning fibres by rotting is not suited to warm climates, as putrefaction sets in almost as soon as fermentation; and while one part of a heap of leaves or stalks is beginning to ferment, other parts are brown and stained from putridity, while tho central parts remain fresh and unaltered.

To preserve the color and strength of fibres, all that is necessary is to separato the pulp, bark, or wood, as soon as possible and by the least complicated process. The pulp or juices of plants usually contain mucilage, starch, or gum, which begin to ferment within twentyfour hours after the plant is cut; and if it be left in water during warm weather, fermentation is completed within two or three dars; in cold climates, it takes two or three weeks to run its course. The result of fermentation being completed is that the sap becomes acid and destroys the strength of the fibre. This is followed by putrefaction, which stains the fibre and makes it brownish, brittle, and like chaff.

If the plant be exposed to the sun for a day or two after being cut, the sap dries, and the coloring matter stains the fibre, which cannot then be easily separated from the bark, spiral cells, or woody fibre. In some plants this discoloration is green, in others brownish, or duskyyellow, which cannot be removed by bleaching, as it is a species of natural tanning which occurs in the plant. Such fibres always remain harsh, stiff, and woody, with a tendency to snap on a sudden strain. The plantain fibre is the most liable to this, containing a good deal of tannin, which can only be removed by quickly expressing the juice, and only cutting as much of the plant as can be cleaned in one day.

The general rules for cleaning the fibres of pulpy plants are-first, to bruise or crush the plant, keeping the juice for a coarse kind of vinegar required in another process. The common native sugar-cane mill, with two perpendicular rollers, a long lever handle, and a channel to convey the juice into some convenient vessel, answers this purpose very well; the cost of such a mill is about ten rupees. Those who cannot afford to purchase or erect one, but who can command plenty of labor, will require to provide a few long planks and heavy wooden mallets to beat the plant till all the pulp is loosened. When it is in a pulpy mass, it must be 
taken at both ends and twisted opposite ways to squeeze out the sap. It is then to be well washed in plenty of water, untwisted, and scraped in small handfuls at a time on the board, with an old blunt table-knife or a long piece of hoop-iron fastened into a straight handle. When all impurities are removed, the fibres may be soaked for an hour or two in clear water, and then hung up in the shade to dry. Exposure to the sth at first is apt to discolor them. By this simple process fibres of great strength, of silky appearance, and of a good color, can readily be prepared. The scrapings must be well washed, and set aside in the shade to dry as tow for packing, or as a material for making paper.

The Indian plants, to the cleaning of which this process is applicable, are those of a fleshy or pulpy nature, as the aloe, agave, sansiviera, and plantain genera, of which there are many species. The prices offered in England for Indian fibres thus cleaned varied from $£ 12$ to $£ 18$ per ton, and were said to be only suitable for the manufacture of coarse twine or brown packing-paper. The finest plantain fibre, when carefully cloaned and dressed, was said to be suited for the imitation of silk in carriage-braid and carpet-work. The average value put upon fibres was $£ 50$ per ton, when Russian hemp was selling at $£ 40$ per ton.

On the Cleaning of Plants having Bark and Woody Fibres.-Many of the Indian cordage plants are of this kind, and the native process of cleaning them is very similar to that followed in cleaning fleshy and pulpy plants-riz. by burying in sand or mud at the edge of a tank or in a river, and leaving them to rot. There is this difference, however, that the plants are steeped longer and are never exposed to the sun to dry, or stacked and covered with matting to be cleaned by dry beating. If this were done, the woody fibre would get hard and brittle, and would again adhere to the other fibre, which, being partially rotten, would break in the cleaning. To obviate this, the rotted plant is taken up in large handfuls and beaten on flat stones, first at one end and then at the other; they are next well rubbed and washed, to separate the impurities, and are spread out on the ground to dry. We can hardly wonder that most of the string and rope made from fibres prepared in this rude, coarse way should be dark in color, possessed of no strength and of little value. As a general rule, every day's steeping of a fibre takes from its strength and imparts more or less color. To obriate this, woody plants should be first well beaten with a mallet; then the bark should be separated from the stalk, for it is on the inner part of the bark that the fibres for cordage usually occur. When the bark is brought to a pulpy state, it must be well washed in clean water, to remove as much of the sap as possible, for this is the destructive agent which soon causes putrefaction. The old mode of steeping or rotting flax-plants is quite abandoned in many districts, as the water was found to be poisonous to cattle and fish, and the neighborhood where it was carried on became feverish. The same remark has been made in India, and there are many districts where flax is cultivated on account of the linseed, but the plant is burnt and fibre wasted, lest cattle should be poisoned by eating it. In Flanders, where the greatest care is bestowed on the growth of flax, the preparatory crops are barley and rye, with turnips after them the same year. It is grown the third year of a seven-course rotation, or the fifth year of a ten-course rotation. It is considered an exhausting crop, and the land is richly manured and dressed with liquid manure; the seed is then sown abundantly in the proportion of one hundred and sixty pounds to the acre, a slight harrowing and the passing of a light roller over the ground insuring quick germination.

If the quality of the fibre be the chief object, the seed is sown thickly; the plants come up in a crowded manner, and are tall and of delicate growth. If the seed be the chief object, thin sowing and exposure to the sun is the best, the stalks becoming strong and branched with coarse fibre. The weeding of the flax forms a considerable item in the expense of ats cultivation. This is performed when the plant is a few inches high; it is done by hoeing, or by women and children, who with coarse cloths around their knees creep along on all-fours, which injures the young plant less than walking upon them. The weeders also take care to face the wind, that the tender flax, bent down by their weight, may be assisted in rising again. When weeding is too long delayed, the plant is bruised and injured, and cannot recover its erect position. Some tall and slender varieties are supported by stakes, lines, and cords, about one foot or eighteen inches from the ground, or ropes are tied to stakes lengthwise and crosswise, so as to form a network all over the field. The time of pulling the crop 
depends upon the season and the intention of the grower. If fine fibre be the object, he pulls the flax rather green, but if the quality of the seed be considered, a longer time is given before pulling. The latter object is generally attained when two-thirds of the stalk have turned yellow, and when the seeds have changed from their fluid state, for they ripen sufficiently after the flax is pulled, if not separated from the stalk. Taking up the crop in a wet state is avoided, if possible.

The pulling is carefully done by small handfuls at a time, which are laid regularly across each other to dry, and are afterwards collected in larger bundles, the root-end on the ground and the seed-ends tied lightly together, as sheaves of grain in the harvest-field. The practice of cultivators differs very much as to the after processes. Some disregard the seed, and commence steeping the flax at once; some carry it as soon as it is dry under a shed, and take off the capsules by a process called rippling; others house the flax as soon as it is dry, allowing the seed to remain on, and deferring the processes of rippling and steeping till the following season.

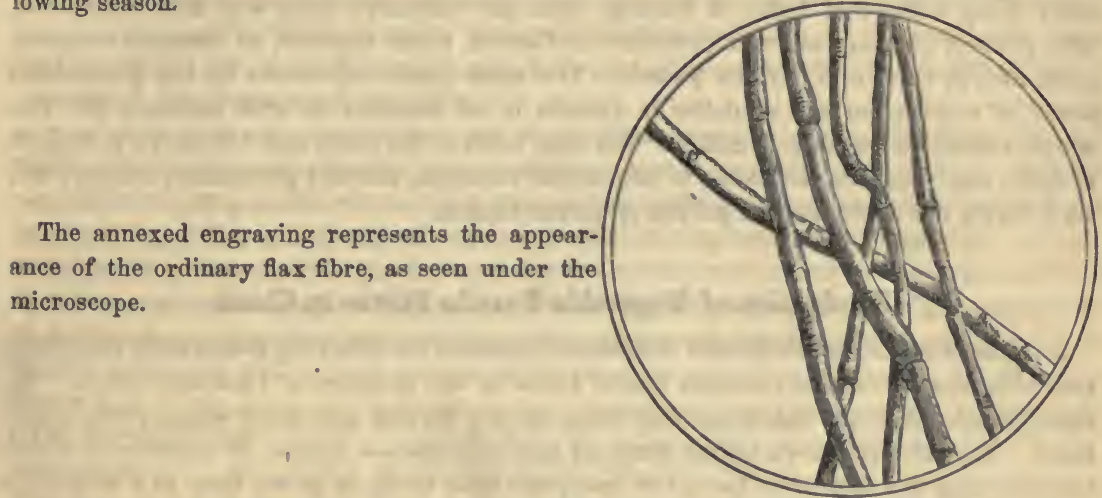

The great obstacle to the growth of flax in England and in the United States is the want of an intermediate interest to buy the straw from the grower, and to prepare the fibre for the spinner. Conducted on the old system, it is only adapted to small occupations, like those of Belgium and Ireland. New processes of preparing the fibre are, moreover, being introduced, which cannot be carried on upon the farm, but require separate establishments, and which appear likely to supersede the old method of steeping.

Two yenrs ago, the most promising of these new processes appeared to be that of Schenck, which consisted in steeping the flax in hot water, and thus effected, in from seventy-two to sixty-nine hours, what under the old system occupied from two to three weeks. In 1852, twenty retteries on this system were established in Ireland, besides several in England.

Since then, two other processes have been patented, which, as far as trials on a small scale have gone, appear to be superior to Schenck's, both as regards the saring of time and expense. One of these is by Watts. It consists in steaming the straw instead of steeping. The other method is Buchanan's, who operates by means of repeated immersions (about ten) in hot water, kept by a very ingenious contrivance from exceeding a certain temperature. The process is conducted by means of cheap and simple machinery, by which labor is saved, the risk of loss from carelessness avoided, and the time required for the preparation of the fibre is reduced to twelve hours. The system is now being tested on a commercial scale in Scotland.

It has been well observed that the chief impediment in the growth of flax consists in the question-"Who is to begin?" The farmer does not grow flax for the want of the rettery, and the rettery is not established for want of the flax. Another difficulty arises out of the continued improvements which are going on in the processes for preparing the fibre, and the perplexity which this occasions among those who are disposed to embark in the undertaking as to which they shall adopt.

The manufacturers are the parties who should make the first move, by establishing retteries, and offering a liberal price to the farmers for their straw. The districts best suited to 
the experiment are those in which the cultivation of flax formerly flourished, and in which the agricultural population are not wholly strangers to its management.

\section{Canadian Hemp. "}

IT may, perhaps, not be generally known that hemp grows spontaneously in Canada, particularly in all the lower or eastern districts of the country. And it is stated, upon respectable authority, that, under good cultivation, the quality is equal to Russian hemp. The soil and climate of Canada are believed to be eminently adapted to the growth both of hemp and flax. Very many years ago, the culture of hemp in Canada was commenced, with all the earnestness and vigor which a well-grounded confidence in the capabilities of the country for such production warranted; but, owing solely, it is believed, to the want of efficient modes of converting the raw produce into a prepared state, and thus securing an immediately profitable market, the culture of hemp in Canada, upon any extensive scale, was then abandoned. The quantity of hemp and flax produced in Canada, taken together, as officially returned, amounted, in 1852 , to $1,917,666$ pounds. The value placed upon this by the government board of registration and statistics in Canada is $3 d$. currency, or $£ 28$ currency per ton, which, reduced to sterling, is $£ 233$ s. The total value of the hemp and flax grown in Canada in 1852 , was, therefore, according to this official valuation, $£ 23,971$ provincial currency; and very nearly the whole was the growth of Lower Canada.

\section{Production of Vegetable Textile Fibres in China.}

A CoRrespondent of the London Athenaum furnishes the following memoranda respecting the cultivation of various vegetable textile fibres in the province of Chekiany, China. He says: Besides rice, the staple summer crops in this district are those which yield textile fibres. A plant well known by the name of jute in India- a species of Corchorus-which has been largely exported to Europe of late years from India, is grown here to a very large extent. In China this fibre is used in the manufacture of sacks and bags for holding rice and other grains. A gigantic species of hemp, (Cannabis,) growing from ten to fifteen feet in height, is also a staple summer crop. This is chiefly used in making ropes and string of various sizes, such articles being in great demand for tracking the boats up rivers, and in the canals of the country. Every one has heard of China grass-cloth-that beautiful fabric made in the Canton province, and largely exported to Europe and America. The plant which is supposed to produce this (Urtica nivea) is also abundantly grown in the western part of this province, and in the adjoining province of Kiangsee. Fabrics of various degrees of fineness are made from this fibre, and sold in these provinces; but I have not seen any so fine as that made about Canton. It is also spun into thread for sewing purposes, and is found to be very strong and durable. The last great crop which I observed was that of a species of Juncus, the stems of which are woven into beautiful mats, used by the natives for sleeping upon, for covering the floors of rooms, and for many other useful purposes. This is cultivated in water, somewhat like the rice-plant, and is therefore always planted in the lowest parts of these valleys. At the time of my visit, in the beginning of July, the harvest of this crop had just commenced, and hundreds of the natives were busily employed in drying it. The river banks, uncultivated land, the dry gravelly bed of the river, and every other available spot, were taken up with this operation. At gray dawn of morning the sheaves or bundles were taken out of temporary sheds erected for the purpose of keeping off the rain and dew, and shaken thinly over the surface of the ground. In the afternoon, before the sun had sunk very low in the horizon, it was gathered up again into sheaves and placed under cover for the night. A watch was then set in each of the sheds; for, however quiet and harmless the people in these parts are, there is no lack of thieves, who are very honest, if they have no opportunity to steal. And so the process of winnowing went on day by day, until the whole of the moisture was dried out of the reeds. They were then bound up firmly in round bundles, and either sold in the markets of the country, or taken to Ningpo and other towns, where the manufacture of mats is carried on on a large scale. It seems to me 
to be very remarkable, that a country like China-rich in textile fibre, oils of many kinds, vegetable tallow, dyes, and no doubt many other articles which have not come under my notice-should afford so few articles for exportation. I have no doubt that as the country gets better known, our merchants will find many things beside silk and tea, which have hitherto formed almost the only articles exported in quantity to Europe and America.

\section{Two new Fibres from Brazil.}

THERE have been reqently imported into England, from Bahia, two varieties of regetable fibre, which are new to commerce. One of them is, commercially spenking, a species of flax, and is proposed to be used in the same way as that material. It is in small hanks, about twelve inches in length: the individual fibres are remarkably fine, and have a peculiar appearance, somewhat resembling a long staple sheep's wool. The color is a pale green. This material was imported experimentally, and was called "tecum." Upon comparing it with a specimen in the "Collection of Liverpool Imports," says Mr. Archer, I am led to imagine that it is the produce of a palm-leaf. The price stated in the foreign invoice is equivalent to eighteenpence per pound.

The other article is a very coarse red fibre, of considerable length, resembling the asta bark in Dr. Royle's collection of Indian vegetable fibres: it is evidently, I think, says Mr. Archer, the fibrous portion of the bark of some tree, probably an acacia. This material was also sent from Bahia, and its application as a substitute for oakum was suggested.

Sir William Hooker, who has examined this last fibre, pronounces it to be the product of a noble tree, the seeds or nuts of which are well known to commerce as the "Brazil-nut." The bark is beaten into oakum, and in this form is much used for caulking ships at Para.

\section{On the Oblique Direction of the Ligneous Fibre, and the Twist of the Trunks of Trees occasioned thereby.}

At a recent meeting of the Academy of Berlin, the following paper, on the above subject, was presented by Prof. Braun:-

The twist of the wood of many trees is a phenomenon well known to wood-cutters, shinglemakers, carpenters, and others, but almost entirely neglected by botanists. The distinguished geologist, the late Leopold von Buch, appears to have first directed the attention of scientific men to it; and De Candolle, in his Organographie, $(1827$,$) was the first botanist who spoke$ of it. Most trees show this obliquity of the woody fibre more or less. In certain species the twist is almost uniformly in the same direction; in others, both directions occur with about equal frequency, while in not a fow no twist is distinctly observable. Sometimes the same direction prevails in the majority of the species of a genus, or even of a whole family; in other cases, opposite directions occur in the same genus or family; and it is curious to remark that in some instances nearly-allied species of Europe and America twist in opposite directions. In a few instances, the fibre of a young tree is twisted in one direction; that of the old tree, in the opposite direction.

In speaking of the direction, it is necessary to come to an understanding, first of all, as to what we mean by right or left, a distinction attended with more difficulty than would appear possible. Prof. Braun follows De Candolle and others in viewing the twist or coil objectively, imagining himself in the centre of the coil. Thus viewed, the bean-vine turns to the left, the hop-vine to the right, \&c. Linnæus and others, however, have adopted the opposite or subjective riew, and regard the bean and other leguminous plants as turning to the right, as they appear to an observer standing before the coil. The twist of the fibre may be discerned in splitting the wood, or in its cracks when the bark is stripped off, or in the course of the fissures made by lightning. Very often the bark itself, at the angles or superficial lines of the trunk, indicate the direction of the wood within very distinctly. We make a few extracts from one hundred and sixty-seven species observed.

No manifest twist has been observed in species of Fagus, Juglans, and Carya, either in Europe or America, nor in Ulmus, Ailanthus, Fraxinus, Acer dasycarpum, Gleditschia, or Robinia, 
though the latter exhibits a very slight twist to the left. The woody fibre twists to the right in Pinus strobus, Ostrya Virginica, the chestnut of Europe, the European and American Salices, Populus pyramidalis, Cornus Florida, Liriodendron, (in Indiana and Illinois, though in cultivated specimens the twist was found to be the other way; but more observations are required,) the peach, plum, and cherry-trees, and in the European Cercis siliquastrum, the only leguminous tree known to twist to the right. The twist to the left hand is the more common: it occurs in most Coniferce, especially in Juniperus Virginiana, Taxodium distichum, Pinus sylvestris, (of which young trees twist, however, in the opposite direction,) Picea excelsa, \&c., Betula and Alnus, Ostrya vulgaris, and Castanea Americana, (both in opposite directions to the nearly-allied species of the Cld World,) Quercus robur, Populus angulata, " Catalpa, AEsculus, Hippocastanum, the pear-tree, and, more than any other, the pomegranate; also most leguminous trees. Most American oaks, the sassafras, Acer nigrum, the appletree, \&c. twist about as often to the right as to the left.

The cause of the apparent twisting is not easily ascertained. It is not occasioned by an actual twisting of the whole stem, but belongs to the growth of the successive annual layers. Prof. Braun connects it with the growth of the wood-cells, the ends of which, at their commencement, are nearly horizontal, but become wedge-shaped as they elongate; and if these wedges assume the same direction in the whole circumference of the stem, as they are apt to do, the wood-cells would assume a certain obliquity; so that this twist of the wood is connected with the intimate nature or disposition of the cells themselves. But this is not sufficient to explain the higher grades of the obliquity, which sometimes reaches an angle of forty-five degrees. It would here be desirable to ascertain whether the cambium cells divide in this oblique direction and high angle. Our common Tupelo, or Pepperidge, or Nyssa, would be a good subject for the investigation, since the obliquity of its wood is generally very considerable, and the layers of a certain number of years incline in the opposite direction from those of the preceding layers.

\section{Observations on the Correspondence between the Leaf-Venation and Rami- fication of the Plant.}

Pror. M'Cosh, in a paper before the British Association, observed that this correspondence might be illustrated under two general heads: 1 . Between the disposition of the branches on their axis, and that of the veins on the midrib, or other veins from which they spring. In trees where the leaf has no leaf-stalk, the tree is feathered from the ground; and, on the other hand, when the leaf has a leaf-stalk, the tree has a bare, unbranched trunk. It had been objected that the beech-leaf has no leaf-stalk; whereas the tree has often an unbranched axis. This objection he had been able to answer to the satisfaction of the gentleman who urged it. It is customary, in planting out beeches, to strip off the lower branches, and cut over the axis, and hence the form which the plant often assumes in lawns; but the beech, when uneaten by cattle, and not drawn up by being planted in the heart of a wood, is feathered or branched from the base. This may be seen from its mode of growth in hedges. He would have it to be understood, however, that this correspondence does not imply that the tree and leaf necessarily assume precisely the same shape. Thus, when the leaf is pinnate, there is no correspondence between the form of the leafage and the form of the tree. $\mathrm{He}$ was inclined to think that when the leaf is pinnate, as in the ash and mountain-ash, the tree is decomposite; that is, instead of sending forth one main axis from top to bottom, it sends $n \mathrm{ff}$, in a scattered way, branch after branch, till the axis is lost. 2. The branch goes off from its axis at much the same angle as the vein goes off from the midrib or lateral vein There was little difficulty in establishing this in plants with woody structure, or in herbaceous plants which have a true branch and not a mere flower-stalk. The only exceptions which he had found in plants with true branches were those with decurrent leaves, such as thistles, where the natural angle seems to be affected by the decurrency of the leaf. But there was a difficulty in establishing the correspondence in herbaceous plants, which either have no branch, or in which it is difficult to say whether we have a branch or merely a peduncle or leaf-stalk; the more so, as botanists had not laid down any rule by which to distinguish 
between branch and peduncle. He had found it necessary, in applying these views to herbaceous plants, to distinguish between what he might be allowed to call the primary and secondary angle, both of venation and ramification; meaning by the primary angle that made by the main branches and the main lateral veins; and by the secondary, that made by the lesser branches or lesser veins proceeding from the others. He had found, in many cases, that the angle at which the peduncle or flower-stalk goes off corresponds not to the primary, but secondary angle of this leaf. (Appended to the paper was a list of 200 species of plants measured by him since 1852.) He remarked, in conclusion, as a proof of the angular structure of plants being a feature of importance, that he had found in corals that there is a definite angle of ramification for every species, and that there is a primary and a secondary angle.

\section{Varieties and Culture of the Basket Willow.}

TnE willow manufacture in the city of New York is already immense, and destined constantly to increase. The amount of imported willow-ware is annually more than three millions of dollars, while the quantity of unmanufactured willow imported amounts to a much larger sum. And this amount of imported ware must also increase largely, unless the manufacture of the ware and the cultivation of the willow should be prosecuted extensively in the United States. The late John Reed, of Staten Island, amassed a little fortune by cultivating less than three acres of apparently worthless swamp, in rearing the osier willow. Others have failed in the attempt, through ignorance of the proper species for this region of the earth, and the proper mode of cultivation. Dr. C. W. Grant, of Newburgh, about five years ago, came to the conclusion that, among his varied objects of enterprise, he would include the cultivation of the willow; for which purpose he purchased a marsh on the Hudson, not far below West Point, connected with an extensive upland farm, which marshy ground he supposed would make a good osier-field. On trial, it was found that only a sinall portion of the ground was adapted for that purpose. Partial failure served only to stimulate him to fresh exertions, and the loss of some capital was followed by the resolve to recover it. He therefore engaged in extensive investigation of the whole subject, and availed himself of all attainable knowledge respecting the culture of the osier in England, Scotland, Continental Europe, and America. Nearly one hundred kinds of willow were imported, and experiments were carefully instituted on different soils, with very satisfactory results. Willow of his production was tested last fall by different basket manufacturers, and found equal in quality to the very best European osier, and far superior to the largest portion of that which is imported. In the course of Dr. Grant's investigations, a new species was found in the county of Suffolk, England, which proves to be a great acquisition not only in the arts, but as an ornamental tree.

To those who have undertaken, or are about to undertake, the cultivation of willow, it will undoubtedly prove very largely remunerative, if conducted with the requisite care and knowledge. No crop will better pay for proper tillage and proper soil-even yielding a profitable return the first year; but in the hands of unskilfulness and neglect it will, of course, prove an entire failure. In Rockland county, a small field of it was planted in the spring, and in the autumn of the same year yielded shoots of the finest quality, avernging at least six feet in length, and some of the tallest more than ten feet. The gross worth of the crop could not be less than $\$ 150$ per acre. Here nothing remarkable was done, but (with a slight exception) every thing was well done. The soil was pretty rich clayey alluvial, and deeply worked, the subsoil plow running to the depth of eighteen or twenty inches, (two feet would have been better.) A very little stable manure and a few bushels of ashes were used as a top dressing. The manure should have been worked in with very light furrow, or with the cultivator, but a henvy rain made it impracticable at the most advantageous season, and in a great measure compensated for the neglect. A small portion of it retained standing water until the middle of June. Some of the cuttings did not, in this wet place, strike at all, and others made little growth. A blind drain was then made through it, when the plants began immediately to thrive, and made a pretty good growth, but not equalling the others by about one-half. The cuttings were of very vigorous one-year old wood, a few of them retaining 
some of the former year's wood. Unless the cuttings have to the heart a high degree of vital energy, the life of the centre fails, and the plant becomes rotten at the heart; and although it does not soon die, it gives but imperfect shoots, whereas the one that is full of vital energy makes a plant in every respect as good as a seedling.

Willow-growing is destined to become a business of impörtance, or rather is now becoming so; and those who early engage in it judiciously will receive the reward. I have just learned that Dr. Grant is so well pleased with it, that he is preparing to plant another field of twenty acres next season. That would generally be thought too much for a new beginner, and in most cases rightly so; but one-tenth of that quantity would be little enough for a beginning, and would be too little, unless you have, of suitable land, (or mean to have,) enough to extend it considerably. Those who make a large business of it will get the best percentage... A few words on the soil suitable for willow. It cannot be profitably grown in a swamp; but a swamp thoroughly drained and cultivated is no longer a swamp. On such, willow will grow most luxuriantly, and so will red clover; but the upheaval of winter frost will throw out the clover and kill it, but will not injure the willow. It must, for its roots, have at least a foot of soil that is not constantly sodden with water-and far better if you get two feet. Then the vigor will be astonishing to those who have not seen it; and to get shoots averaging eight feet is easily practicable, and is quite profitable. I will relate a case that came under my own observation. A field that had been cultivated the previous year (on a portion of it, although the season was very dry, the crop had been lost by too much wetness) was plowed, trenchplowed, and subsoiled; that is, one plow followed another in the same furrow, besides the subsoil plow, making three. It.was commenced early, and found to be very muddy work, and half of it left until after corn-planting, bringing it to the last of May, and some of it was not planted until the early part of June. The cuttings had been provided in the winter, and deeply covered with litter in a cool place; but before the last of planting, some of them had thrown out shoots of considerable length. Drought of unexampled severity followed, (1852.) Apprehension was entertained of entire failure; yet where the ground was deeply worked no failure occurred, but a little not deeply worked was an entire failure. The deep working s? obviated the wetness, that the past wet season caused but little injury. The early-planted are still somewhat the best, but on any part the crop is quite satisfactory.-Correspondence N. Y. Country Gentleman.

\section{New Sources of Vegetable Oils.}

A very large white pea is grown near Shanghae, in China, from which oil is extracted for burning. After the oil is expressed, the refuse is used for manure and for feeding cattle and swine. So extensively is this article used, that from Shanghae alone ten million dollars' worth is yearly distributed over China. This leguminous plant is called Teuss. There is another Chinese production, called tea-oil, said to be produced from the seeds of species of the two genera Thea and Camellia, which oil is nearly unknown in Europe. When fresh, it is quite free of smell, of a pale yellow tint, and devoid of sediment. It resists a cold of $40^{\circ}$ Fahr., and its density is $\cdot 927$. It burns with a remarkably clear white flame. This oil might prove an important article of commerce in the East, because in its properties it is superior to cocoanut-oil and the various other oils used for burning or as oleaginous condiments in Asiatic countries.

From the leaves of the Australian Eucalypti an oil can be procured of equal utility to the cajeput-oil of the East. The sandarac exuding from the calitris or pine-tree, the balsamic resin of the grass-trees, and, moreover, the eucalyptus gum, which could be gathered in boundless quantities in Australia, and which for its astringent qualities might supersede the use of kino or catechu, will, probably, at a future period, form articles of import.-Journal of the Society of Arts.

\section{Vegetable Oils in the Amazon and Rio Negro Districts.}

SPRUCE-remarks that vegetables yielding oils abound in the Rio Negro district. Nearly all the palm-fruits yield oil; but the bright vermilion fruit of Elais melanococca, or Carani 
palm, furnishes it in very large quantity. Various species of Enocarpus, which abound on the Amazon and Rio Negro, are oil-bearing. The oil procured from Einocarpus batana, which forms forests in the Rio Negro, is called batana-oil by the Indians, and resembles much that procured from olives. Raphua toldigera, the Inpati palm, has a very oleaginous fruit, and its leaf-stalks can be used as flambeaux. Andirola-oil is the produce of Carapa guranensis. Bertholletia excelsa, the Castanha or Tuna, is another oil-giving tree of the Amazon district.

\section{Beech-oil.}

Amovg the various kinds of oil used in Northern Germany, especially the kingdom of Hanover, for culinary purposes or as materials of combustion, that extracted from the nuts of the beech (Tagus sylvatica, Linn.) is, on account of its numerous good qualities, deserving of notice. Beech-oil does not play a prominent part in commerce, nor is it likely to do so, owing to the fact that it cannot be procured in large quantities; the country-people who collect the nuts, or who cause them to be collected, use the greater part of the oil extracted from them in their own households, and only dispose of the remaining fraction. This is the reason why it is impossible to give even a rough estimate of the quantity annually produced. About Hanover, the nuts are gathered towards the end of October or the beginning of November; this is done either by picking up by hand those which have fallen to the ground, or by spreading out large sheets under the trees and beating the branches with poles, so as to cause the nuts to separate from them. The latter process appears, at first sight, the least expensive; but as the good nuts have to be separated from the bad (abortive) ones, it is found, on closer examination, to be just the contrary. In 1854, about twenty-five pounds of nuts sold in Hanover for eighteenpence; twenty-five pounds yield about fivo pounds of oil, one pound selling for about serenpence. The oil is of a pale-yellow color, and has an extremely agreeable taste. It is often adulterated with walnut-oil; the latter is even sold as beech-oil, and that may account for the difference of opinion entertained respecting the quality of beech-oil. The towns-people use it chiefly as salad oil; but the peasantry employ it generally as a substitute for butter, \&c., and only when there has been a good harvest of nuts, for burning in their lamps. The husks (epicarpia) are, after the oil has been expressed, made into cakes about nine inches square and an inch and a half thick; these are used for combustibles, and not given, as some people imagine, as food to cattle.Hooker's Journal of Botany.

\section{Rapeseed-oil.}

THE following information respecting the demand for oils, especially that expressed from rapeseed, is derived from the last Report of the Lighthouse Board:-

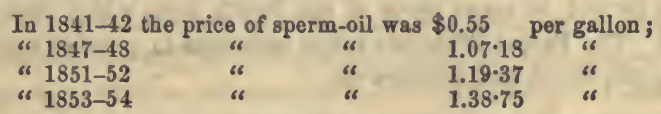

and the last purchase made by public contract for the Lighthouse establishment was at $\$ 1.58$ for full-strained sperm-oil.

The most respectable merchants and ship-owners engaged in the sperm-whale fishery are of opinion that there will be a considerable advance upon the present price ( $\$ 1.60$ per gallon) for winter oil during the present year, and that it will probably be as high as $\$ 2$ per gallon at no distant day.

The rapid advance in the price of this essential article for lighthouse purposes is said to be attributable to the limited and annually diminishing supply, and to the increased demand for it for lubricating and manufacturing purposes in this country and in Great Britain. Numerous experiments have been made to test the practicability of using lard-oil, cottonseed-oil, and some of the various patent oils, both animal and vegetable, in lighthouses; but it is believed that, with the exception of the colza or rapeseed-oil, none of them are suited to purposes of lighthouse illumination. The lighthouses and lightressels on the continent of Europe and in Great Britain, with few exceptions, are now illuminated by the colza or rape- 
seed-oil. It has been found, after careful test and by trial, to be superior in many respects to the best sperm-oil, while its cost is only about one-half the present price of sperm-oil. This valuable agricultural product occupies an important place in the economy of the farmers of France, Belgium, Holland, and many parts of Germany. It is, in fact, the great agricultural staple of many districts, and from which the farmers derive their entire living income. In England, this vegetable is cultivated not so much for the production of oil which it yields, as for grazing and fertilizing purposes. In this country, it is cultivated to some extent for grazing and as a fertilizer of the soil. Among the German population of Texas, the colza is cultivated, and the oil expressed from its seed in sufficient quantities to supply the domestic wants of the cultivators. In Mexico it has been introduced, and it is understood that many villages, towns, and cities, including the city of Mexico, are dependent upon it for oil to light their streets and houses.

There is no doubt that this valuable vegetable could be very successfully cultivated in nearly every portion of the United States; and even at the present European price for the oil, it would prove quite as remunerative as tobacco, wheat, and Indian corn.

The annual diminution in the supply of sperm-oil, and the increasing demand for it for mechanical purposes, would seem to render it indispensable that an article of good quality, and adapted to purposes of illumination, should be found as a substitute for it.

The cultivation of this vegetable on a large scale would prove a great boon to the country, as well as a source of profit to the producers. It would also be the means of rendering us altogether independent of European markets and of their fluctuations for oil for illuminating our lighthouses, in case of a failure of the supply from the sperm-whale fishing-grounds, and also in the event of the interruption of the fisheries and of commerce by war with a powerful maritime State. Should the agriculturists of this country not commence the cultivation of this valuable and remunerative product, and should the supply of sperm-oil continue to diminish in the same ratio it has done for some years past, this government will be reduced to the necessity of importing rapeseed-oil from Europe for the lighthouse service.

\section{A New Oil Plant.}

The small tree (Castigliona lobata) known in Peru under the name of pioncello, and surco, huacho, and sambageque, also growing wild in considerable abundance in those regions, it has been ascertained, yields a valuable oil, well adapted to the purposes of illumination. Its beanlike fruit or seeds, when roasted, have an agreeable flavor, preferable to that of the olive. When eaten raw, the ethereal oil generated between the kernel and the outer skin is a strong cathartic, the effects of which can only be counteracted by drinking cold water. It has been ascertained that the seeds will grow in Baltimore; and, doubtless, plantations of this tree might be formed in many parts of the South, from which vast quantities of oil might be produced. The Patent Office has taken measures to procure some of the seeds of this tree for trial in the South and South-west.

\section{Turpentine Product of the South.}

TuE following is the report of a committee appointed on the part of the turpentine producers of Alabama, in December last:-

The committee to whom was referred the resolution upon the subject of the cultivation of turpentine, \&c., beg leave to make the following report:-That the character of the soil best adapted to the production of the turpentine-pine should be of light and porous nature, with a subsoil of clay capable of retaining moisture. The pine should be of an extended, lowgrowing top, with thick bark and sapwood, the trees not to stand so thickly upon the land as to be too much shaded by the overgrowing foliage. The number of boxes to be cut in a tree should be governed by the size of the same. As a general rule for cutting boxes, the committee recommend the following standard: The box to be thirteen inches in horizontal width, three and a half inches in horizontal depth, and seven inches in perpendicular depth. This will produce a box of the capacity of one and a quarter quarts, which, after a few 
years' use, will be reduced to a box capable of containing.a full quart only, which, from experience, your committee believe to be the most profitable size. Taking a tree capable of sustaining two boxes, they would recommend that the boxes be cut side by side, with a lifestreak of bark of four inches intervening between them, in preference to cutting them opposite to each other, and that one-third or more of the bark should be left for the support of the tree, the boxes to be cut just at the bulge of the tree near the root of the same. The corners of the boxes should be cut out with the inclination of the face of the box, and to extend in a line perpendicular to the outer corners of the same, so as to show a line horizontal with the top of the box, the object of chipping being to expose a new surface of the pores for the exudation of the turpentine. The cut of the hacker should extend a half inch in depth into the tree, and one-fourth in altitude, and the chipping sloould be renewed once a week. The best instrument for the purpose is the hacker with a small bowl, to be kept exceedingly sharp, and the best instrument for sharpening the same is the stone known as the Siam hone or slip.

Your committee have nothing new to suggest or recommend as to the best mode of dipping, or the best instrument for that purpose; but in reference to the scrape or hard turpentine, they would adrise the use of cloths instead of the old-fashioned box for receiving the same. The committee would recommend the light iron axle two-horse wagon as the most expeditious and economical for hauling turpentine. The frame for the barrels should be made of four-by-six-inch scantling, with segments of circles cut therein, one-half across the upper face of the same, to receive the ends of the barrels, with two interior parallel rails, so that when either end of a barrel is removed from the concare which it occupies, it can be rolled from the wagon on a smooth surface. The committee would recommend that when the distiller can avail himself of a hill-side, the simplest plan to elevate turpentine to the still is to extend a railway from the top of the hill to the platform; if upon a level plain, the use of the machine employed by flour mills to elevate their sacks and barrels to the upper stories of the mill, tho said machine being a platform, with four upright posts, with a roller at the end of each, two ropes from the roof of the still-house, passing beneath said rollers, (one on each side,) thence through sheave-blocks and around a cylinder turned by a crank from below. In regard to preparing the turpentine for distillation, we refer you to the explanation made by a member of the committee as to the style best adapted to making the best article of rosin.

The experience of your committee would lead them to decide in favor of a small size still, or with a flat and grently extended surface. The committee would recommend that in distilling, the still should be charged to only two-thirds its capacity, to allow for the expansion of the material during ebullition. The amount of water to be supplied should be equivalent to the amount condensed in the still-worm, and kept in the same ratio as long as the spirit comes over; and should the still have a tendency to boil over, an increased amount of fuel is to be supplied until the excessive ebullition ceases; the heat is then to be diminished, and the still run regularly as before. Your committee deem it nnnecessary to enlarge on this point, as they presume that in all cases of new beginners a practical distiller will be employed.

Your committee recommend, in addition to the usual mode of glueing the spirit casks, that the casks, being partially drained after each glueing, be placed upon a horizontal plane, each head alternately placed apon each plane; and would further recommend the use of the Scotch glue in all cases in which the distiller is unable to manufacture his own glue from good sound hides. The committee would recommend that in making barrels and casks, the staves and heading should be fully dressed, ready for the truss-hoop, and be permitted to remain some time previous to being made into barrels, for the purpose of allowing the staves, \&c. to shrink. By adopting this course the barrels are less liable to leakage. The staves for turpentine barrels should be thirty-two inches in length, the head to be worked in a twenty-inch truss-hoop. The spirit cask should contain forty-five gallons, and in case oak heading cannot be obtained, we would recommend the substitution of poplar instead. 


\section{New American Gum.}

Dúrivg the past year attention has been called to a new gum, known synonymously as Muckeet, Mezqueet, and Musquit, and first described by Dr. S. S. Shumard, U. S. Army. This substance, which bids fair to become of great importance as a substitute for gum Arabic, is the product of a tree flourishing extensively in the high and dry regions of the plains of Western Texas, New Mexico, and the adjacent Indian Territory. It occurs in inexhaustible quantities, and will no doubt in time prove a valuable source of revenue to the inhabitants of Texas and New Mexico, besides affording employment to the different tribes of Indians now roving upon the plains, many of whom would no doubt be glad to gather and deliver it to the different frontier posts for a very small compensation.

In relation to the tree from which this gum is obtained, Dr. Shumard says:-The mezquitetree, from which this gum is obtained, is by far the most abundant tree of the plains, covering thousands of miles of the surface, and always flourishes most luxuriantly in elevated and dry regions. The gum exudes spontaneously in a semifluid state from the bark of the trunk and branches, and soon hardens by exposure to the atmosphere, forming more or less rounded and variously-colored masses, each weighing from a few grains to several ounces. These soon bleach and whiten upon exposure to the light of the sun, finally becoming nearly colorless, semi-transparent, and often filled with minute fissures. Specimens collected from the trunks of the trees were generally found to be less pure and more highly colored than when obtained from the branches.

The gum may be collected during the months of July, August, and September; but the most favorable period for that purpose is in the latter part of August, when it may be obtained in the greatest abundance and with but very little trouble. The quantity yielded by each tree I found to vary from an ounce to three pounds; but incisions in the bark not only greatly facilitated its exudation, but caused the tree to yield a much greater amount. As it is, a good hand will probably be able to collect from ten to twenty pounds in a day. Were incisions resorted to, probably double the amount may be obtained.

The following is a report of the chemical examination of this gum, as made under the direction of Mr. Morffit, of Baltimore. In a communication to Silliman's Journal, Mr. M. says-

It is a spontaneous semifluid exudation, concreting by exposure into tears and lumps of variable size and form. One sample, which was a part of that brought in by Dr. Shumard, and obtained directly from the U. S. Bureau of Indian Affairs, consisted of small, irregular pieces and rounded balls about the size of a hazlenut, semi-transparent, and shading in color from a lemon white to dark amber. When broken, the fracture faces were brilliant; and the gum was easily reduced under the pestle to a dull, white powder. One of the balls was enveloped with an outer pellicle of gum of about one-sixteenth of an inch in thickness.

These proportions approximate very closely to those obtained from gums Senegal and Arabic by Guerin and Mulder. The general appearance, too, of the gum is similar to that of gum Senegal, and the dark inferior qualities of gum Arabic. In chemical properties also it is allied to them, being insoluble in absolute alcohol, partially soluble in common alcohol, and readily forming with hot or cold water a very adhesive mucilage. It is, in fine, a true gum; and promises, in its physical and chemical behavior, much of the adyantage expected by its discoverer as an economical substitute for gum Arabic or Senegal.

The specific gravity of the gum was $1 \cdot 5$, but this determination may possibly admit of correction upon purer samples than were disposable for the experiment.

Its proximate composition was found to be-

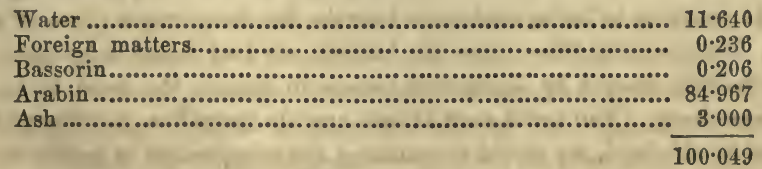

Cerasin was also sought for, but not found. The ash was estimated by burning a given quantity in an atmosphere of oxygen and weighing the residue. 
The ultimate analysis, made also by effecting combustion of the carefully-dried gum in oxygen gas, yielded, in two separate experiments, the following numbers:-

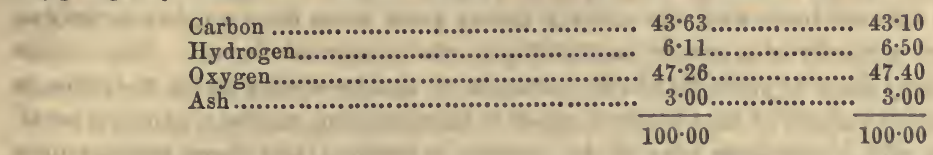

The following additional information respecting this tree is given by the Boston Journal :Kunth notices a Prosopis dulcis which resembles in appearance the tree spoken of by Dr. S., and remarks that it "yields a gum (Mezquitina) which is used instead of gum Arabic," and many have erroneously supposed the two to be identical. The botanical name of the commonly-known mezquite-tree is given by Professor Spencer F. Baird, of the Smithsonian Institute, as Algarabia glandulosce. Dr. Shumard states that it luxuriates only in dry and elevated regions; but all other accounts, including that in the report of Captain Marcy, state that its home is in the "river-bottoms," and its presence is generally considered as evidence of a rich soil. Captain M. states that it is seen standing at such intervals as to present much the appearance of an immense peach-orchard. They are from five to ten inches in diameter, and their stocks about ten feet in length. It is found on the river Gila, and plentifully on the Colorado. The banks of the Rio Grande produce some, as indeed do most of the rivers of the northern part of Texas. It is said to exist in forests of miles in extent in Northern California. Like many of the plants of that latitude, its fruit is seen in blossom and in maturity at the same period. It is first recognised by the Pacific-bound emigrant as a stinted shrub, but as he approaches his destination, it is seen only in a tree of twenty or thirty feet in height.

The gum is, however, not the only valuable product of this tree. Mules devour with avidity the fruit, which is contained in a pod of a twisted appearance, being a berry of the size of a bean, each covered with a mealy pulp. Lieut. A. W. Whipple, of U. S. Corps Topographical Engineers, observing its peculiar effect upon them, was induced to examine it, and found that each berry possessed an intense stringent property. The Indians and Mexicans are in the habit of boiling its chips in water, and with the decoction dyeing articles of apparel, \&c. The tree certainly belongs to the class Mimosa, as does the acacia-tree, from which gum Arabio is obtained; and from the similar properties, not only of the gum but the wood and bark, we may practically regard the two as alike. The gum may be procured during the month of August in large quantities, and brought to market with trivial expenses, and bids fair not only to lessen our importations of gum Arabic, but in a few years to enable us to export with advantage.

\section{Cultivation of Quina in Java.}

Soms time since, under the direction of Professor Miquel, of Amsterdam, the Dutch government undertook the cultivation of the Quina or Peruvian bark-tree in Java. The experiment, by the last accounts, has proved entirely successful. The young plantations established in the mountains thrive extremely well. Lately, M. Karl arrived in Java with a whole shipload full of young plants and seeds from Peru; so that in a few years Java will be able to supply almost as much Quina-bark as is wanted, which is the more a matter of congratulation, as the Quina forests in South America are fast approaching their entire extermination.

\section{On the Cultivation, Uses, and Analyses of Madder.}

Av important communication has recently been published by Mr. Carnes, of Lowell, showing the results of an investigation undertaken with a view of discovering the reason of the superiority of the French or Avignon madders over all others. By the addition of carbonate of lime, the Turkish madders are greatly improved in color; but the French madders, as imported, ground for use, need no such addition. The object of the investigation was to show whether there existed in the French madders a larger amount of carbonate of lime than in the other varieties. 
There are several theories as to the function of the chalk, or carbonate of lime; by some, it is supposed to act by saturating an acid present; by others, it is thought that the combination of two different bases with the coloring matter gives much more solidity to the dye, in consequence probably of a greater insolubility in the compound formed. Experiments made in Germany seem to prove that in all instances of madder-dyeing under the influence of chalk, a certain amount of lime becomes added to the aluminous mordant, and in a subsequent clearing with a soap-bath some of the alumina is removed, and there remains upon the fibre of the cloth the two earths-lime and alumina, in atomic proportions, or nearly so. The madders subjected to analysis were American, Avignon, and Turkey. The American was grown in Montague, Massachusetts, on the farm of Martin H. Clapp, and the roots used were of four years' growth. The land upon which it was grown is the "interval" lying near the Connecticut River; it was treated with twenty loads of strong green manure, and one hundred pounds of plaster to the acre; Indian corn was grown upon it the year previous to planting with madder. The next year the manure and plaster were applied as before, and the madder-roots planted. The crop was cultivated the last three years in the same manner as potatoes, with the addition of one shovelful of well-rotted manure and a little plaster to each hill, late in the autumn of each year. The different samples were burned in a muffle, without regard to the percentage amount of ash which each variety yielded.

The different ashes were found to consist of-

\begin{tabular}{|c|c|c|c|}
\hline & n. & French. & Turkey \\
\hline ................ & $2 \cdot 61 .$. & $3 \cdot 76 \ldots$ & 4. \\
\hline ssa............................. & $7 \cdot 45 \ldots . . . .$. & $4 \cdot 40 \ldots$. & $5 \cdot 50$ \\
\hline Carbonate of soda.. & $39 \cdot 23$ & $9 \cdot 78 \ldots$ & $22 \cdot 71$ \\
\hline Silica.............................. & $8 \cdot 48$ & $25 \cdot 86 \ldots .$. & $27 \cdot 71$ \\
\hline Pho & $12 \cdot 75 \ldots \ldots$ & $19 \cdot 75 \ldots . .$. & 17 \\
\hline $\mathrm{Ca}$ & $23 \cdot 39 \ldots$ & $32 \cdot 76 \ldots \ldots$ & $18 \cdot 35$ \\
\hline esia..... & $6.05 \ldots$ & (?) $\quad \ldots . . . . . . . .$. & $3 \cdot 14$ \\
\hline & $-\ldots$ & $3 \cdot 66 \ldots . . .$. & (?) \\
\hline & $9 \cdot 96$ & $9 \cdot 97$ & 97 \\
\hline
\end{tabular}

The American madder, when treated with from four to six per cent. of chalk, gives colors every way superior to the best French. The "pinks" and "roses" stand the process d'Avisage, furnishing colors which are more "pink" and "rosy" than the French; it also furnishes a purple of a much more desirable shade than that obtained from the French. Used in equal weights, the American gives deeper colors than the French, showing a greater percentage of coloring matter. The ground French madder, as imported, will, if treated with an additional amount of carbonate of lime, furnish colors which are inferior to those produced by the same article without this addition.

The French madder will, if treated with a dilute acid, effervesce strongly. This effervescence will not take place by treating any other of the ground woods or plants used in dyeing in the same way, and seems to indicate the presence of a free carbonate. The Dutch madders have always needed an addition of carbonate of lime to produce brilliant and "fast" colors, but within a few years Dutch madders have been imported, ground on the French process. These do not need any addition of carbonate of lime. The Dutch madders, as formerly imported, will not effervesce when treated with a dilute acid. The new "Dutch roots ground on the French process," when treated in the same manner, show evident signs of the presence of a carbonate.

It would seem as if all that is needed to obtain as good a reputation for the American madders as any in the world, is to have them ground on the French process, which, from the deportment of the different varieties of madder when treated with carbonate of lime, would lead to the supposition that there is a certain amount of carbonate of lime added to the best French roots during the process of grinding.

There seems to be a fair inducement for the farmers and growers of New England to cultivate madder; for although Mr. Clapp labored under many disadvantages, such as building and procuring an entire set of apparatus, drying kilns, \&c., and obtaining but about onethird of a crop from his land as compared with the crops raised in Western New York, still he lost only the interest on the land cultivated. 
Culture of Madder.-Mr. Russel Bronson, of Birmingham, Huron county, Ohio, a successful cultivator of madder, has published a communication upon this subject, which contains the following information:-

"A location facing the south or south-east, is to be preferred. A sandy loam, not over stiff and heavy or light and sandy, or a good brown, deep, rich upland loam, free from foul grass, weeds, stones, or stumps of trees. Where a crop of potatoes, peas, corn, or wheat has been cultivated the past season, plow deep twice, once in Septcmber and once in October, and if rather stiff, let it lie after the plow until spring. When the spring opens, and the ground has become dry and warm, plow again deep, the deeper the better; then harrow well, and strike it into ridges, with a one-horse plow, three feet wide and four feet racant, or making a ridge once in seven feet, raising it, if on rather moist ground, eight or ten inches, and if on dry land, six or eight from the natural level; then, with a light harrow, level and shape the ridges like a well-formed bed of beets, \&c.

We will suppose you intend to plant one acre of ground, and that you have purchased eight bushels of tap-roots in the fall, and buried them like potatoes on your premises; count the ridges on your acre, and take out of the ground one bushel of roots and plant it on one eighth of your ridges; you will then be able to ascertain how to proportion your roots for the remainder.

The following is the manner of planting, cultivating, \&c., when the quantitics of ground do not exceed three or four acres. One person on each side of the ridge to make the holes, (plant four inches below the surface of the bed, or thereabouts, when covered,) one on each side to drop the roots, and one on each side to cover, pressing the hill in the manner of planting corn; or three persons may be placed on one side, as the case may he, whether you have one or more acres to plant. Let the owner be the dropper of roots, and his most thorough assistant behind him. Make the holes from twelve to ten inches apart, and about six inches from the edge of the ridge. As the plants are supposed to have been purchased in the fall, the roots may have thrown out sprouts, and possibly have leaved. In this case, in dropping and covering, you will leave the most prominent sprouts a little out of the ground, as where a plant has leaved, it ought not to be smothered.

When the plant gets up three or four inches, weed with the hoe, and plow with one horse between the ridges or beds, but not on them; this will take place two or three weeks after planting. When up twelve or fiftecn inches, many of the tops will fall; assist them with ten-feet poles crossing the beds, covering with a shovel or garden-rake, throwing the soil from between the ridges. After loosening with the one-horse plow, you will, with a shovel, scatter the earth between the stalks, rather than throw it into heaps; of course we wish to keep the stalks separate, as they are to form new and important roots in the centre of the beds. About the 20th of June you may plow between the beds, and scatter more earth on the fresh tops, (all but the ends,) and when you get through, you may plant potatoes between the beds, if you please. I do not recommend it, if you have plenty of land, although I raised 1,070 bushels of pink-eyes on eight acres the first year, and sixty bushels of corn. If your land is perfectly clear of weeds, you are through with your labor on the madder crop for this year, except in latitudes where there is not much snow and considerable frost; in this case, cover in October, two inches or thereabouts. Second year, some operations in weeding, but no crop between; cover once in June. Third year, weed only. Fourth year, weed in the spring, if a weedy piece of ground.

Begin to plow out the roots in Tennessee (three years old) first of September; Ohio, (four years, ) same time; New York, 15 th or 20 th, after cutting off the tops with a sharp hoe. In plowing out the roots, use a heary span of horses and a large plow. We ought to choose a soil neither too wet nor too dry, too stiff or light. Shake the dirt from the roots, and rinse or wash, as the soil may be stiff or light; dry in a common hop-kiln; grind them in a mill similar to Wilson's patent coffee-mill; this mill weighs from one to two pounds. The madder mill may be from sixty to eighty pounds weight. Grind coarse, and fan in a fanning-mill; then grind again for market. The profit of this crop is immense; the exhaustion of soil trifling, and glutting the market out of the question.

As the tops of the plants spread very much, some advise placing them in hills, somewhat 
like Indian corn, four and even six feet apart each way, and two plants in each hill." - New England Farmer.

\section{On the Cultivation and Production of Sumach.}

A correspondent of the Scientific American furnishes the following information relative to the sumach, several varieties of which grow spontaneously in our own country:- Sicilian sumach is imported largely into this country from Messina and Palermo, antd some of inferior quality is also used, which is grown in Germany and Trieste; if the sumach of this country can supply its place, the object would be worthy of the attention of our agriculturists.

Sumach is extensively used in morocco-tanning, in calico-printing and dyeing. There are three species used in dyeing-the Rhus glabrum, the Rhus corioeria, and the Rhus cotinus. The first two only are used in tanning. The first is the common sumach of North Amcrica, and is much used by our country dyers, and, to a limited extent, by our tanners. The annual shoots or peduncles, with their leaves, are gathered, and in this country are mostly used without grinding.

It is well known that the most astringent vegetables, or those containing the largest portion of gallic acid, are brought from warm climates; and the following facts will prove that the quality of the sumach depends on the warmth of the climate in which it grows. The sumach in Europe is the Rhus coriaria. That which is grown in the north of Europe, and imported from Trieste, is no better than our Northern sumach, excepting a small portion grown in the Tyrol, and even this is not superior to the best American grown in New Jersey; whereas that grown in Sicily, Syria, Spain, and Portugal, where it is cultivated with great care, is found by experience to be vastly superior to that from Trieste, and sells much higher. A similar difference is observable in the sumach grown in this country. That from the southern side of New Jersey is superior to the New York, and that from Virginia to the New Jersey; and there is no doubt that if raised in the Southern States, dried with care, and ground fine, it would be equal to the best imported.

Sumach should be cut or gathered in clear weather, and should be so spread on a floor as to dry rapidly; for, if only a small part should ferment, the whole mass will be seriously injured. It should be finely ground when dry, and packed in bags. No rain or dew should fall on it after cutting, for even the damp from the hold of a ship will greatly injure its quality.

It has been stated that the American sumach will not reproduce from the seed, and if this be true, there would be some difficulty in extending the article to a great extent by field cultivation. Sumach is said to be hybridous, in which case plants from Sicily planted among our glabrum would enable the seed of both to reproduce, and in this way the cultivation might be extended at pleasure.

The Rhus cotinus, or Venice sumach, is also an important article in dyeing. It is known in England as young fustic; the stem and trunk of the shrub, and the root, are extensively used in Europe for dyeing golden and orauge-yellows. The leaves and stalk, when bruised, have an aromatic, but pungent and acid scent. The plant is grown in our nurseries, and sold as an ornamental shrub. It is by some called the fringe-tree, and by others the burning-bush.

The cotinus is cultivated by layers. The stalks sent to market in Europe are from one to two inches in diameter, with the bark taken off. There is considerable white sap outside, and dark-yellow and orange-colored rings inside, the latter being the coloring matter. The leaves from this wood, when cut, are gathered, dried, and ground with the other sumach.

The New York Tribune has the following article upon the production of sumach:-

"I was brought up to the woollen business in Western Massachusetts, a.ad have not only cut and cured, but used tons of sumach as an ingredient for dyeing. The only reason why American sumach is inferior to the imported article is that old growths are used. If it is cut every year and nothing but the new growth saved, it is doubtless equal to that which comes from abroad. Foreigners, who make it an article of commerce, cut, cure, and sell the growth of each year, so that it is full of coloring matter. We used to cut over our growth each year, and thus keeping it down, the sprouts were abundant and of the first quality. Sumach generally grows in rocky, worthless land, and, if managed properly, will yield more value in sumach than it could be made to produce in any other crop with the addition of careful and 
expensive culture. The rocky dells and worthless hillsides of Hampden and Berkshire counties in Massachusetts, yield, or if properly kept down would yield, all the sumach that the entire State would use with all her morocco and cloth manufacture; and could be cut and cured by berry-picking school-boys. I did it before I was old enough to be of any service in working a ship to import it. But nine-tenths of the population, whose children industriously pick blackberries and whortleberries to buy straw hats and school-books, are not aware that sumach is of any earthly use, and would gladly avail themselves of its profit, if informed.

"It should be cut just before frost comes, and cured like corn-stalks, and when dry cut by means of a straw-cutting machine, leaves, sticks, and all, and put into sacks for market; or it might be ground fine in a bark-mill. If cut close to the ground, several sprouts will grow, four feet high, from the stump in a season. This is the sumach of commerce."

\section{The Rice-paper Plant of China.}

THE following description of the celebrated rice-paper plant of China, is derived from a recent article by Mr. Fortune:-

"In April, 1854, the steamer in which I was a passenger dropped her anchor a little way up one of the rivers on the north-east part of Formosa. As this was my first visit to this fine island, and as I knew we had only a short time to stay, I lost no time in going on shore. Before leaving the ressel I had been examining with a spy-glass some large white flowers which grew on the banks and on the hillsides, and I now went in that direction, in order to ascertain what they were. When I reached the spot where they were growing, they proved to be very fine specimens of Lilium japonicum - the largest and most vigorous I had ever seen. As I was admiring these beautiful lilies, which were growing as wild as the primroses in our woods in England, another plant of far more interest caught my eye. This was nothing less than the rice-paper plant-the species which produces the far-fnmed rice-paper of China, named by Sir W. Hooker Aralia papyrifera. It was growing npparently wild; but the site may have been an old plantation, which was now overgrown with weeds and brushwood. The largest specimens which came under my notice were about five or six feet in height, and from six to three inches in circumference at the base, but nearly of an equal thickness all up the stem. The stems, usually bare an the way up, were crowned at the top with a number of noble-looking palmate leaves, on long foot-stalks, which gave to the plant a very ornamental appearance. The under-side of each leaf, its foot-stalk, and the top part of the stem, which was clasped by these stalks, were densely covered with down of a rich brown color, which readily came off upon any substance with which it came in contact. I did not meet with any plant in flower during my ramble, but it is probable the plant flowers at a later period of the year. The proportion of pith in these stems is very great, particularly near the top of vigorous-growing ones, and it is from this pure white substance that the beautiful article erroneously called rice-paper is prepared. The Chinese call this plant the Tung-tsaou. What it was, or to what part of the vegetable kingdom it belonged, was long a mystery to botanists, who were oftentimes sadly misled by imaginary Chinese drawings, as some of those which have been published will clearly show, now that our knowledge has increased.

"The Tung-tsaou is largely cultivated in many parts of the island of Formosa, and with rice and camphor forms one of the chief articles of export. Mr. Bowring, who read a paper upon the rice-paper plant, before the China Branch of the Royal Asiatic Society, informs us that the Canton and Fokien provinces are the chief consumers, and that the town of Foo-chow alone is supposed to take annually not less than $\$ 30,000$ worth of this curions production. The cheapness of this paper in the Chinese market, as Mr. Bowring justly remarks, is evidence of the abundance of the plant in its place of growth, and more especially of the cheapness of labor. 'That one hundred sheets of this material, (each about three inches square,) certainly one of the most beautiful and delicate substances with which we are acquainted, should be procurable for the small sum of $1 \frac{1}{4} d$. or $1 \frac{1}{2} d$., is truly astonishing; and when once the attention of foreigners is directed to it, it will doubtless be in considerable request among workers in artificial flowers in Europe and America, being admirably adapted to their 
wants.' The larger sheets, such as those used by the Canton flower-painters, are sold for about $1 \frac{1}{2} d$. each.

"If the Tung-tsaou proves hardy in England, its fine foliage will render it a favorite among ornamental plants in our gardens."

\section{Healthiness of the Roots of Plants Essential to their Successful Growth}

The following, from the Floricultural Cabinet, is a valuable contribution given upon the authority of the most distinguished physiological botanists, and doubtless represents the truth, at least in part, in regard to the absorbent powers of roots, and the ascent of sap in plants. The objection in regard to mulching would hold good where rich, warm manures are used, such as horse-dung; but not so where straw, leaves, salt-hay, or other rough refuse material are employed.-Ed. Working Farmer.

As the roots of plants are the chief medium through which they receive nourishment, some account of their structure, and of the curious and simple mode by which they effect their object, will, I hope, prove of some utility to the readers hereof.

The root may be defined to be that portion of a plant which grows in an opposite direction to the stem, and differing from the latter in its remarkable downward tendency and from its disposition to shun the light of day. So powerful, indeed, is this disposition to descend, "that no known force is sufficient to overcome it." The chief object of the root appears to be that of fixing the plant firmly in the earth, and of taking up a supply of moisture from the humid medium by which it is surrounded. It usually consists of several ramifications, from the sides and extremities of which, without apparent order or regularity, proceed an indefinite number of delicate fibrils with spongy points. Now these fibrils are the only true roots, and to their soft extremities (spongelets) is consigned the whole office of absorbing fluid; the more woody portion of the root merely serving as canals to convey the fluid thus obtained to the upper part of the plant. The roots generally pierce the soil in a downward or horizontal direction, according to the individual habit, but more especially in that course which offers the least resistance and yields the greatest quantity of soluble food. Hence the propriety of mulching is, by some gardeners, called into question, becuuse the richness of the mulching material, and the warmth produced by its fermentation, has a tendency to attract to the surface the young fibrils. And then, upon the removal of the manure employed in the operation, their extremely succulent and tender tips become exposed to the influence of drought, \&c., than which nothing can be more injurious, as it quickly destroys their absorbing power, and thus deprives the plant of its chief source of nourishment. It has been said that the fibrils are the only true roots, and that the feeding function is chiefly confined to the lax tissue of their extreme points. That this is really the case there can be no reasonable cause to doubt, or why should the success of planting depend so materially upon their preservation? it being a well-known fact that subjects of any size, such as fruittrees, are invariably less prolific the first season after transplantation, than on the previous and ensuing years. Why these little spongelets should possess the power of absorbing moisture with great force, and of transmitting it to every part of the plant, is a curious question, and has given rise to many ingenious conjectures. But it has at length been satisfactorily answered by that clever French author, M. Dutrocet. If a small glass-tube, having its end covered with a piece of bladder, be partially filled with gum-water, and then plunged into simple water, sufficient to wet the outside of the bladder, the latter will be permeated by the water, and the volume within the tube will continue to increase, so long as the density of the fluids on each side of the intervening membrane remains unequal. "But there is also a contrary current to less amount-the interior fluid passing out to mix with the surrounding water." The first and more powerful of these currents is called endosmose, (flow inwards,) and the second and less powerful, exosmose, (flow outwards.) The cause of their motion was by Dutrocet referred to galvanism; but it is now more generally believed to arise from " the attraction exerted between the particles of the different fluids employed, as they meet in the porous membrane." $-D r$. Reid.

"Now the conditions requisite for this action are two fluids of different densities, separated 
by a septem or partition of a porous character. This we find in the roots. The fluid in their interior is rendered denser than the water around by an admixture of the descending sap; and the spongiole (or spongelet) supplies the place of a partition. Thus, then, as long as this difference of density is maintained, the absorption of fluid may continue. But if the rise of the sap is due to the action of endosmose, there ought also to be an exosmose. This is found to take place; for if a plant is grown with its roots in water, the fluid surrounding them is soon found to contain some of the peculiar substances they form, and which are contained in the descending sap. Thus a pea or bean would discharge a gummy matter; a poppy would communicate to the water an opiate impregnation, and a spurge would give it an acrid taste.

"Thus we see how beautifully and how simply this action, extraordinary as it seems, is accounted for, when its whole history is known on principles which operate in other departments of nature."-Dr. Carpenter.

From this it must appear obvious to every one that, to keep plants in a healthy state, the conditions of endosmose and exosmose must be carefully maintained. Thus in the case of bulbs maturing and at rest, and of plants cut down in the autumn, such as Pelargoniums and Fuchsias, the action of the leaves being destroyed, the fluid, rising by the force of endosmose, must gradually subside, and the plants languish into a state of semi-vitality, till such time as genial warmth shall expand the fluid within their latent buds, and cause them to open and put forth new leaves. This is the reason why the application of water to plants thus circumstanced should be carefully avoided, excepting, indeed, a few special subjects, whose succulency is not sufficient to keep them from being shrirelled up.

\section{Tropical Scenery of the Amazon.}

Mr. WaLlace, a recent traveller in South America, gives us the following highly instructive and well-stated estimate of tropical regetation. He says-

"There is grandeur and solemnity in the tropical forest, but little of beauty or brilliancy of color. The huge buttress trees, the fissured trunks, the extraordinary air-roots, the twisted and wrinkled climbers, and the elegant palms are what strike the attention and fill the mind with admiration and surprise and awe. But all is gloomy and solemn, and one feels a relief on again seeing the blue sky and feeling the scorching rays of the sun.

"It is on the roadside and on the rivers' banks that we see all the beauty of the tropical vegetation. There we find a mass of bushes, and shrubs, and trees of every height, rising over one another, all exposed to the bright light and the fresh air, and putting forth, within reach, their flowers and fruit, which, in the forest, only grow far up on the topmost branches. Bright flowers and green foliage combine their charms, and climbers with their flowery festoons cover over the bare and decaying stems. Yet, pick out the loveliest spots, where the most gorgeous flowers of the tropics expand their glowing petals, and for every scene of this kind we may find another at home of equal beauty, and with an equal amount of brilliant color.

"Look at a field of buttercups and daisies, - a hillside covered with gorse and broom, - a mountain rich with purple heather,-or a forest-glade azure with a carpet of wild hyacinths, -and they will bear a comparison with any scene the tropics can produce. I have never seen any thing more glorious than an old crab-tree in full blossom; and the horse-chestnut, lilac, and laburnum will vie with the choicest tropical trees and shrubs. In the tropical waters are no more beautiful plants than our white and yellow water-lilies, our irises, and flowering rush ; for I cannot consider the flower of the Victoria regia more beautiful than that of the Nymphoea alba, though it may be larger; nor is it so abundant an ornament of the tropical waters as the latter is of ours.

"But the question is not to be decided by a comparison of individual plants, or the effects they may produce in the landscape, but on the frequency with which they occur, and the proportion the brilliantly-colored bear to the inconspicuous plants. My friend Mr. R. Spruce, now investigating the botany of the Amazon and Rio Negro, assures me that by far the greater proportion of plants gathered by him have inconspicuous green or white flowers; and, with regard to the frequency of their occurrence, it was not an uncommon thing for me to pass 
days travelling up the rivers without seeing any striking flowering tree or shrub. This is partly owing to the flowers of most tropical trees being so deciduous; they no sooner open than they begin to fall; the Melastomas, in particular, generally burst into flower in the morning, and the next day are withered, and for twelve months that tree bears no more flowers. This will serve to explain why the tropical flowering trees and shrubs do not make so much show as might be expected."

\section{The Ailanthus-tree.}

A CORREspondent of the $\mathrm{N}$. Y. Times furnishes the following statement respecting the distribution and propagation of the ailanthus-tree in the United States. They were imported some fifty years since by a nurseryman in the vicinity of New York, at a time when there was some excitement about manufacturing morocco leather, which previously had been imported. This tree was imported as the one which furnished the material with which the imported morocco leather was tanned. It was soon found that many species of the genus Rhus growing in our country, all of which are more or less poisonous, answered equally as well as the imported ailanthus for making the same leather; hence the demand for the imported plant ceased; but they had been set in one corner of the gentleman's nursery, where they had spread and became as great a nuisance as Canada thistles; the inquiry then was how to get them out of the ground. While the gentleman's son was pondering upon this business, he thought he would try the effect of a puff direct; therefore he set himself to the task, and commenced by calling it "the tree of heaven," and gave a wonderful description of the beauty of the tree-changed the price from twenty-five cents to one dollar for each plant, and told the writer that he sold off the next season five thousand dollars' worth of plants from the same ground that previous to that puff he would have given one hundred dollars to have cleared of them.

The gentleman's success in that one humbug encouraged him to try another with the same plant.

I think it was about the year 1847 or ' 48 that every postmaster in the United States received a package of seeds of the ailanthus, containing one hundred and twenty-five seeds, requesting them to sell one hundred of them at one cent each, and remit to a person named, one dollar, and keep twenty-five seeds to pay them for their trouble; at the same time describing it as one of the most splendid and valuable trees that had ever been discovered.

So far as the writer was informed, about one-half of the postmasters remitted their dollar forthwith, not knowing the tree in question.

\section{Rotation of Forest Trees.}

THERE are millions of acres of pine-forests which present an even surface for tillage, whose improvement for continued and profitable cultivation is a matter of great moment. If their virgin soils do not exhibit an acid reaction, they at least possess too little of alkaline ingredients for high agricultural productiveness. We have been astonished at the benefits that accrued from the application of marl and shell-lime to these virgin earths, in which there was no lack of organic substances. Where the potash came from that existed in such large crops of wheat and corn, appeared a mystery. Lime seemed to bring it out from its before insoluble silicates. Indeed, we can account for the natural fertility in the southern peninsula of Maryland, and those districts of Virginia and Georgia where marl abounds, in ro other way. In an acre of wheat and corn there is five times more potash than lime; while the amount of soluble potash in natural pine-bearing soils is exceedingly small. A pine-tree, when burnt, yields but little ashes, and they are not rich in potash. Pine-leaves, however, yield, pound for pound, twelve times more ashes than pine-wood; and it is mainly the annual fall of leaves on the surface of the ground, giving alkalies drawn from the deep subsoils, as well as organized carbon, oxygen, and hydrogen, that enriches the land. By adding a little lime to this natural source of fruitfulness, the owner of pine-leaves will greatly enhance their value. They can be changed permanently from the production of coniferous plants to that of cereals- 
a difference as wide as that from a loaf of bread made of pine sawdust to one made of wheat flour. The difference in a soil that will yield pine-wood abundantly, but wheat and maize very sparingly, is the proof of plant rotation.

The volatile alkali ammonia which abounds in Peruvian guano works this change in piney wood land for one or two crops, in a remarkable degree. Wood-ashes also produce signal effects on such soils, being far more lasting than guano. Alkalies in some form appear to be necessary to change a pine-growing soil into one adapted for the production of oaks, hickory, and grain. Numerous facts similar in purport to those above stated are well known to every observing farmer; but the reason suggested by Professor Johnston and others, why pine-trees succeed oak forests, and the latter, or beech, or other hard deciduous trees succeed pines, do not appear entirely satisfactory. On the rich lands of the Western States and in Western New York, where beech and maple or oak-bearing soils are left to grow up a second time in forests, they do not, like the comparatively poor land of New Jersey, Delaware, Virginia, North and South Carolina, and Georgia, produce a crop of old field pines, but a second growth of the trees of the primitive forests. Coniferous plants never supercede those of a higher order and more complex development, where the latter can flourish. If pines drive out oaks and poplars, it is because the latter find an uncongenial soil, made not so by nature, but by the labors of man. Nature never rotates her vegetable productions from a higher to a lower order of organism, if her developments are not molested. The deeply-descending tap-root of the pine, its light wind-driven seed, and its abundant foliage, fit it, in an eminent degree, to recuperate impoverished old fields, and prepare the surface of the ground to bear a crop of oaks, corn, or cotton. The growth of pines does not, however, necessarily induce the growth of oaks or beeches; for there is no reason to suppose that the pine forests of North and South Carolina and Georgia have not flourished on the same surface for twenty successive generations of trees. There is no evidence of a natural system of a rotation of plants from pine to oak, and oak to pine, in Southern cultivation.-Am. Cotton-Planter.

\section{The Sesquoia gigantea, or Great Tree of California.}

Tue great tree of California, originally called by the English botanists Wellingtonia gigantea, and supposed to be a new species, has been recently determined by Professor Gray, of Cambridge, to belong to the family Sesquoia, and must hence be known as the Sesquoia gigantea. It inhabits a solitary district in California on the elevated slopes of the Sierra Nevada, near the head-waters of the Stanislaus and St. Antonio rivers, at an elevation of five thousand feet above the level of the sea. From eighty to ninety trees exist, all within the circuit of a mile, with a height varying from two hundred and fifty to three hundred and twenty feet, and from ten to fifteen feet in diameter. Their manner of growth is much like the Taxodium sempervirens: some are solitary, some are in pairs; while some, and not unfrequently, stand three and four together. A tree recently felled measured about three hundred feet in length, with a diameter, including bark, of twenty-nine feet two inches at five feet from the ground; at eighteen feet from the ground it was fourteen feet six inches through; at one hundred feet from the ground, fourteen feet; and at two hundred from the ground, five feet five inches. The bark is of a pale cinnamon-brown, and from twelve to fifteen inches in thickness. The branchlets are round, somerhat pendant, resembling a cypress or juniper. The leaves are pale grass-green. Those of the young trees are spreading, with a sharp, accuminate point. The cones are about two and a half inches long and two inches across at the thickest part. The trunk of the tree in question was perfectly solid from the sap-wood to the centre; and, judging from the number of concentric rings, its age has been estimated at three thousand years. The wood is light, soft, and of a reddish color, like redwood or Taxodium sempervirens. Of this regetable monster, twenty-one feet of the bark, from the lower part of the trunk, have been put in the natural form in San Francisco for exhibition; it there forms a spacious carpeted room, and contains a piano, with seats for forty persons. Op one occasion, one hundred and forty children were admitted without inconvenience.

A piece of the wood, recently examined by Professor Gray, of Cambridge, was found to 
contain, on an average, forty-eight annual layers to the inch. The semi-diameter of the tree, at the point where the specimen examined was taken from, being five feet two inches, (viz. at twenty-five feet from the ground,) supposing the tree increased in diameter at the same rate during its whole life, there would be nearly three thousand annual layers ; but Dr. Gray, in consideration of the greater thickness of the layers of a young tree, and from comparison of sections of the so-called cypress of the Southern States, (Taxodium distichum, assigns about two thousand years as its highest probable age.

Dr. C. F. Winslow, formerly of Boston, furnishes to the California Farmer the following description of a risit to the localities of these gigantic trees; he says: "The road was more or less shaded all the way by pines so gigantic as to awaken in me, who had nerer before seen the native and lofty forest scenery of the north temperate zone, the strongest feelings of wonder and admiration. I had never before conceived of the capacity of the various species of conifera to attain such enormous dimensions. They were often six feet through, and from one hundred and thirty to three hundred feet high, and so symmetrical and perfect in form as to impress me with new and more commanding ideas respecting the force and operation of the vital principle presiding over the nourishment and growth of organized bodies.

"The height of the locality is about five thousand feet above the sea, and two thousand four hundred feet above 'Murphy's Camp,' on the Stanislaus. So far as known, the regetable growth, to which the name of 'Big Tree' has been attached, grows in no other region of the Sierra Nevada, nor on any other mountain range of the earth. It exists here only; and all the individuals of its kind, so far as I can learn, are localized to this vicinity. They are embraced within a range of two hundred acres, and are enclosed in a basin of coarse, siliceous material, surrounded by a sloping ridge of sienitic rock, which in some places projects above the soil. The basin is reeking with moisture, and in the lowest places the water is standing, and some of the largest trees dip their roots into the pools or water-runs. The trees of very large dimensions number considerably more than one hundred. Mr. Blake measured one ninety-four feet in circumference at the root, the side of which had been partly burned by contact with another tree, the head of which had fallen against it. The latter can be measured four hundred and fifty feet from its head to its root. A large portion of this fallen monster is still to be seen and examined; and by the measurement of Mr. Lapham, the proprietor of the place, it is said to be ten feet in diameter at three hundred and fifty feet from its uptorn root. In falling, it had prostrated another large tree in its course, and pressed out the earth beneath itself so as to be imbedded a number of feet into the ground. Its diameter across its root is forty feet. A man is nothing in comparison of dimensions while walking on it or standing near its side. This, to me, was the greatest wonder of the forest. The tree which it prostrated in falling has been burned hollow, and is so large, a gentleman who accompanied us from Murphy's informed us that, when he first visited the place two years ago, he rode through it on horseback for two hundred feet without stooping but at one spot as he entered at the root. We all walked many scores of feet through it; but a large piece of its side has fallen in near the head. But there are many standing whose magnitude absolutely oppresses the mind with awe. In one place, three of these gigantic objects grow side by side, as if planted with special reference to their present appearance. Another, so monstrous as absolutely to compel you to walk around it, and even linger, is divided at from fifty to one hundred feet from the ground into three of these straight mammoth trunks, towering over three hundred fect into the sky. There are others whose proportions are as delicate, symmetrical, clean, and straight as small spruces, that rise three hundred and fifty feet from the ground. In one spot a huge knot of some ancient prostrate giant is visible above the soil, where it fell ages ago, and the earth has accumulated so as nearly to obliterate all traces of its former existence. The wood of this tree, I am told by Mr. Lapham, is remarkable for its slow decay. When first cut down, its fibre is white; but it soon becomes reddish, and long exposure makes it as dark as mahogany; it is soft, and resembles, in some respects, pine and cedar. Its bark, however, is much unlike these trees; nearest the ground it is prodigiously thick, fibrous, and, when pressed on, has a peculiar feeling of elasticity. In some places it is eighteen inches thick, and resembles a mass of cocoanut-husks thickly matted and pressed together, only the fibrous material is exceedingly fine, and altogether 
unlike the husk of the cocoanut. This bark is fissured irregularly with numerous indentations, which give it the appearance of great inequality and roughness. A hundred and fifty feet from the ground it is only about two inches thick on a living tree, which is now being stripped of its bark for transportation from the country.

"The cone of this tree is small and compact, and nearly regularly oval; and, although the tree itself is the largest of the coniferm, its fruit is as small as that of the dwarfish pines of North Carolina and Cape Cod. Its foliage is not, as a general thing, altogether agreeable to the eye, as the head of the tree is small in proportion to the size and height of the trunk. But the boughs, when examined more closely, are bright-green, rather complicated and delicate in structure, and pleasing to the mind by contrast with the rough and gigantic stem and branch from which they spring."

Dr. Torrey, of New York, has recently had an opportuntity of counting the circles in a complete radius of the trunk of the famous Sesquoia exhibited at New York, and he finds that they are one thousand one hundred and twenty in number. From the data furnished by Dr. Torrey, we find that on the radius examined-

Inches.

Inches.

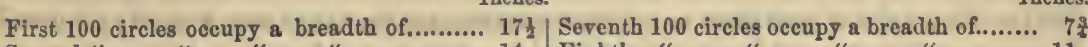

Second " " "...... 14 Eighth " " " "

Third " " " " $" . . . . . .121$ Ninth " 12 " "

Fourth " " " " $"$ "....... "13 13 Tenth " "

Fifth " " " " $"$ "....... 161 Eleventh " 161 " "

Sixth " " " " "....... 8 The remaining 20 layers........................ 1

There are one thousand one hundred and twenty circles in a semidiameter of one hundred and thirty-five inches, or eleven feet and three inches. The facts show that the tree lacks about three centuries of being half as old as it was said to be. Its enormous size is owing rather to its continued rapid growth.

\section{Grafted Chestnut-trees.}

Tux Cincinnati Gazette publishes an interesting letter from Mr. Sheldon I. Kellogg to the Wine-Growers' Association, dated Bordeaux, France, on the cultivation of the chestnut. He says-

"I have been much surprised in seeing the great dependence the poorer classes make upon the large chestnut for their daily food. It is cultivated in this neighborhood in great abundance for this purpose. All classes use them more or less; the rich having them daily brought upon their tables as dessert, either boiled or roasted. It is often made into a soup, which is highly esteemed. They are cooked in a multitude of ways, and I know of nothing of a farinaceous nature which is so very delicate and nourishing.

"The marron, or large chestnut, is the produce of the wild chestnut after being engrafted. The wild tree, at three or four years of age, is cut square off, say four or five feet from the ground. The stump is then split twice. These splits intersect at right angles at the centre of the stump. There is then inserted one good-sized branch of the same tree in every section of the splits, making four branches in each stump. Care is always taken to make the bark of the branches and the bark of the stump join each other as closely as possible. The graft is then surrounded with clay and moss, to prevent the outflow of the sap, and it scarcely ever fails of success. The period selected in this climate for this operation is the month of February. The produce of this graft is usually a fine, large, beautifully-colored marron, about the size of our buckeyes. They are much more delicate in texture and flavor than our own wild chestnut. They are never eaten without being cooked. The tree is a very beautiful one, being, though not so high as ours, much more dense in foliage, and shading a larger space of ground."

\section{Durability of, and Season for Cutting, Ship-Timber.}

TuE New York Nautical Magazine furnishes the following detail of an interesting series of experiments instituted by James Jarvis, Esq., Inspector of Timber for the United States 
Government, at Norfolk. The experiments were made under the direction of the Navy Department, with a view of determining the proper time for cutting timber, and the best mode of curing it or securing it from dry-rot. These are confined to the three principal kinds of ship-timber, viz., live oak, white oak, and yellow pine, and will be of incalculable benefit to the naval and mechanical interests of the United States. When we remember that there is no table of specific gravity that is at all reliable for any meridian in North America, and that our mechanics have been making their calculations from tables of specific gravity found in European works, we shall begin to approximate a conception of its value. A location in the timber districts of this wooded country for practical purposes will satisfy the most incrodulous that little is known about the productions of the American forest.

The following is the order of the experiments followed by Mr. Jarvis: On the 13th of September he received, in twelve-feet lengths, the butts of ten trees of live oak, and an equal number of white oak and yellow pine; five of each kind were worked square at the place where cut, and the remaining five were brought round with the bark on. After their arrival, they were subdivided into three-feet lengths; the square pieces were from twelve to fifteen inches square; the round pieces in bark from twelve to fifteen inches in diameter. The specific gravity of each piece was at once obtained, and then they were located as follows: Four pieces of the squared live oak, and four pieces of the round live oak in bark, were placed in tanks under cover, where were solutions of corrosive sublimate, alum, copperas, and coal tar, and the same number of white oak and yellow pine, amounting in all to twenty-four pieces of the varieties of ship-timber; one-half of which were square pieces, the other half round and in bark. These live oak, white oak, and yellow pine pieces were kept in the tank, submerged one month, at the expiration of which time they were distributed as follows-under cover in open air, planted as posts, and laid as railroad sills. There is a suitable number of the pieces which have not been prepared, also under cover in open air, planted as posts, and laid as railroad sills. A proportion of the pieces are square, and some round, and waterseasoned for six months. After being removed from the water, two pieces are made of one, and one kept under cover, the other in open air. The pieces which have not been in the solution are the test-pieces; and among these pieces Mr. Jarvis has fitted some together, wood and wood, except having between them tarred paper coated with charcoal-dust. A few years will prove, by ocular demonstration, which of the solutions, substances, or water, will make timber most durable. The pieces which have had no preparation on them, and are kept under cover, are weighed each month, to observe the amount of juices or moisture lost by evaporation in one month and in one year. The object in weighing or obtaining the specific gravity each month in the year is that he may be able to determine the best time for cutting ship-timber, or whether it is of any material consequence; and, by testing the weight of the same kinds of timber, in connection with its durability, thus set this matter at rest. The timber used for these experiments is thus described: the live and white oak are of excellent quality, and felled purposely, with a few exceptions, for these experiments. The yellow pine is not as good as is used in the navy; its specific gravity will not prove the fact. The very best of yellow pine is not of the greatest density. Pitch-pine is not as good for decks or deck-frames as other fine-grained pines from the South. The very best yellow pine timber is that in which the even fineness of the grain is continued to the centre or pith of the tree. By careful observation, much information that is valuable may be obtained from the table of specific gravity: notwithstanding the thickness of the bark of the yellow pine, and its lightness, (the specific gravity differing not materially from that of cork,) we find that the pine timber in bark weighs much more than the square timber. This, to the casual observer, would hardly seem possible; the man unacquainted with the nature of yellow pine sap-wood would be likely to doubt the correctness of the table. But such is the nature of the exterior coating immediately under the bark of yellow pine, that we cannot find a more analogous substance than that of sponge; its retentive properties are very similar, and the turpentine with which this sap-wood is saturated is the cause of its increased specific gravity above that of the squared timber, when covered with bark. The thinner the sap-wood, the less the specific gravity. There is an error in the prevailing opinion in relation to the durability of yellow pine timber. Our government has become a heavy stockholder in this pre- 
vailing error, by acting on the supposition that yellow pine timber required a great amount of seasoning. The consequence has been, that large timber-houses have been erected and filled with yellow pine timber, and kept for many years, and when in a state of decay have been used both for new vessels and those undergoing repairs. This is a great mistake; an equal number of months would have answered a better purpose than as many years, as it regards the shrinkage of yellow pine. When in pieces of any considerable size, it shrinks but little when the vessel is in active service; and when used as deck-plank, should be made narrow. The convictions of our judgment lead us to this conclusion, that yellow pine requires no seasoning to make it durable. The ebb and flow of the turpentine is through the sap, as the specific gravity will show; hence we say that the capillary tubes of the heart would have no more of the resinous property, if cut at the proper senson, than is required for strength and to render it durable. There is another error in that of preparing yellow pine timber in the woods, both for private and for naval purposes; it being absolutely necessary that the sap should be excluded. The timber should be eight instead of four-square, thus in effect only taking off the sap, on account of the very best of the timber being next to the sap; this would enable the builder to work out water-ways and all similar pieces without cutting in as far as the pith on the exposed side of the piece. The present manner of cutting yellow pine timber is a reckless waste, the very best parts of the tree being left in the woods.

Inspectors measure square logs clear of sap, and the consequence is, that a very small three-cornered strip or vane of sap is left on the corners; whereas, if at the centre of the length of the $\log$ the sap were removed, and the $\log$ were measured as in other girth measurements, the most valuable parts would be brought as timber into the private and public yards; and although it would be somewhat awkward at first to receive timber in this manner, being accustomed to the square log, yet the price per cubic foot would actually be less, and the timber-getter would save in labor what he paid in extra hauling and freight; and not only so, but he would get paid for all the timber he bought. The government would save thousands of dollars, besides having better pine timber, were the Navy Department to have yellow pine forests at their command rather than timber-sheds stored with pine timber, besides retaining the life of the timber by not having the turpentine drawn from the tree before it is worked into timber, as we have already remarked. The most dense timber is not the best or most durable, because of the amount of turpentine it contains; it is often rendered so near the butt, in consequence of the tree having been tapped while standing, in order to draw off the turpentine. We would prefer the quality of pine we have alluded to in its pristine state, without seasoning, for durability, provided it were properly ventilated when in the ship. With regard to the density of white oak, it may with strong propriety be assumed that the quality is in the same ratio as the density; but we shall discover that the tables of specific gravity do not furnish an index for determining the best quality, inasmuch as they show the squared white oak timber, cut in December and May, to be the heaviest when cut, while at the same time that which was cut in January and July was of the best or better quality. In order to detect this supposed discrepancy, let us follow the subject farther: the timber in bark will show that our first conclusions were correct, inasmuch as the timber cut in July is of the greatest density, and that cut in January differs but a trifle from that cut in December; hence, we are inevitably brought to the threshold of this conclusion, that no table of specific gravity for white oak timber is reliable for determining the quality, unless its weight can be shown in the bark. The reason of this discrepancy between round and square timber in its density is found in the fact that the texture of the grain of some trees is better adapted for receiving the juices than others throughout the entire transverse section, while others receive the supply chiefly through the sap. This latter kind is the best quality, and, as a consequence, is likely to prove the most durable, as well as being the strongest. There may, however, be exceptions even to this as a general rule. With regard to the specific gravity of the live oak, as shown by the tables, we clearly discover that the sap-wood is lighter than the heart, inasmuch as the bark being thin, could scarcely reduce the weight as much as shown by the tables. The tables will not warrant this conclusion of white oak, inasmuch as we find that which was cut in March was heavier in bark than when 
growing plant to famish, or at best attain but a stinted growth, is least in importance with him. It is mainly in their effect in fattening cattle that his trees have become so obnoxious in his eyes, and are falling at the hands of the axe-man.

$\mathrm{Mr}$. D. has two fields, of 30 acres each, as nearly alike in the amount and quality of pasture they furnish as two lots well can be, where he alleges he has by repeated and varied experiments tested the damaging effect of shade. His mode has been to select a sufficient number of cattle of as nearly equal quality as possible for each lot, and in the fall, when he came to draw for the market, he has invariably found that while the open lot furnished a goodly number in suitable condition for the first draft, it was not till the second or third drawing that any could be found in the requisite condition as to flesh in the shaded. He has also, by actual weighing, found a difference of 15 pounds per head increase a month in favor of open fields; and avers that, other things being equal, a lot of steers will gain as much in an open field in four months of summer as they will in five months in a field where they have access to shade. The cattle in the first instance feed at all hours of the day upon dry and fattening grass, instead of standing under the trees, as in the second instance, until driven out by hunger, and filling themselves only in the morning and evening with wet and flashy food. And therefore it is that he cannot afford to keep his trees, and is hewing them down.

\section{Watering Transplanted Trees.}

THE following suggestions respecting the watering of transplanted trees, are communicated to the Horticulturist by Thomas Meehan, of Germantown, Pa. :-

That a plant must have a certain amount of moisture to enable it to live, is well known to every one; and that this moisture must be absorbed through the instrumentality of the fibres or small rootlets, is a no less widely-disseminated fact. When a tree is "well established"that is, has been growing for some time in a given situation-the rootlets pierce the soil, so that they are in a manner encased by it. In this situation, how easy it is for them to draw in their required supplies of moisture! The communication between them and the soil is unbroken, and moisture passes from one to the other by a process nearly akin to capillary attraction. How important, then, that soil thrown in round roots at transplanting should be finely pulverized, and that every means should be taken to induce it to enter every "hole and corner!" But with the greatest possible care, this can never be done to a perfect degree. The soil will still have an opportunity to sink, - that is, will be filled with large air spaces,and whatever roots may be in these cavities or air spaces will either get dried up or injured. It is a good plan, and one which, in critical cases, I have often employed to advantage, to fill up the hole intended for the tree with water, throwing in soil enough to make it of the consistency of thin mortar, into which the tree is put, and the remaining soil drawn in without tramping or pressure of any kind. A tree 80 planted will never require watering afterwards; but it will require other treatment, which will be yet noticed before the end of this chapter.

Surface-water should never be applied to a transplanted tree in the manner usually given, for the following reasons: Every one knows that there are certain substances which do not absorb heat readily, and which are termed good non-conductors; and others which are soon heated, or conductors. Wood is a tolerably good non-conductor, because it will not become as readily heated as iron; while brick is a better conductor of heat than clay or other soil, because it sooner becomes warmed through. A large clod of earth also becomes heated through in much quicker time than the same bulk of soil would have done in a well-pulverized state. This absorption of heat would not, perhaps, be of so much consequence to the plant were it not for the increased impetus it gives to evaporation. A large clod of soil not only soon heats through, but soon dries through; it is a better conductor than pulverized soil. It is obvious, then, that a soil is in a good condition to retain moisture about the roots of newly-transplanted trees when it is as far removed from a clotty condition as possible. But water, when frequently and forcibly applied to the surface, tends to harden it, and renders it liable to "bake" by a very little sun; therefore, surface-watering should, if possible, be avoided, as, indeed, should every thing liable to produce this effect on soils.

The question now occurs, That if a tree has not been watered at transplanting in the man- 
ner above described, and if it is evidently suffering, or likely to suffer, for want of moisture, how is it to be applied, except through the surface? The modé is this: Draw away the soil from around the stem of the tree with a spade or hoe until the roots are nearly reached, and in such manner as to form a basin around it; fill in water to the brim. An hour or so afterwards, when the water has soaked thoroughly away, draw back the dry soil forming the brim of the basin to its former position, as lightly and without pressure as possible. It is all the water it will require that season, if properly performed. And now that we have seen our trees well planted, and those that need it afterwards well watered, how shall we proceed to aid the soil in retaining the moisture supplied to it? Simply by keeping the surface well pulverized, and in the best condition of a non-conductor that we can bring it into; but it is necessary not to mistake what pulverization means. Stirring or "loosening up" a soil is not pulverizing it, though often supposed to be. It is, however, the first step towards it. In farming, the plow stirs up the soil; the roller, or harrow, pulverizes. The hoe and the spade are the gardener's plow; his feet form his roller, or clod-crusher. The operations of plowing and rolling, and of loosening and pressing, in gardening should always go together; and, in relation to tree-planting, whenever a soil is getting hard, or in a "cakey" condition, it should not only be hoed or stirred up, but, as soon as the loosened soil has become a little dry, it should be pressed with the feet and crushed to atoms.

This is the whole secret of the business. Get the soil once well encased round the rootsonce well watered-and all that is necessary afterwards is to keep the surface soil well pulverized; that is, its little atoms well divided, in perfect dust, if you will; and there will seldom be a failure, if the tree be healthy otherwise.

\section{The Tamarind-tree in Virginia.}

William M. Singleton, Esq., of Winchester, communicates the following to the Commissioner of Patents :-

"Of all the ornamental trees propagated among us, either foreign or native, there is none, in my judgment, more desirable than the tamarind. Its growth is rapid, its form symmetrical, its foliage beautifully delicate, and it is altogether highly ornamental; besides, it is perfectly free from blight, as well as from the depredations of insects. If cultivated on our Western prairies, it would doubtless form a valuable acquisition.

"From the growth of some tamarind-seeds which I obtained at a confectioner's shop some eight years since, I have a tree standing in my yard eighteen inches in circumference. The past season it perfected its fruit, which in quality was equally as good as that imported. The seed may be sown in drills, about four inches apart, and covered from two to three inches deep with light, rich soil. They may be sown either in the fall or spring. If in the latter, they should be exposed to the weather during the winter previous, in order that they may be acted on by the frost. When grown to a height of three or four feet, the young trees may be transplanted to the sites where they are permanently to remain."

\section{On the Tapping of the Sugar-Maple.}

Is the spring of 1850 , the following experiments were made under the direction of the $\Lambda$ gricultural Society of Bratleboro', Vermont:-

A committee, consisting of three persons, was appointed to ascertain by actual experiment the proper size and depth of the bore in tapping the sugar-maple. They accordingly proceeded to test this question in the most thorough manner, using all sizes of bits, from half an inch to an inch and a half in diameter, each making his experiment independently of the others; and the result of all was that no difference could be perceived, the half-inch giving as much sap as any other. Each one also tapped several trees, setting two buckets to a tree, with a single spile to each, but bored to different depths, from one to three and a half inches; and the results in this case were, in every instance when the weather was sufficiently warm to thaw the tree through, that the flow of sap was in proportion to the depth of bore; 
and to make the matter more certain, on deepening the shallow bores subsequently, they immediately overtook the others in quantity. These experiments were repeated in 1851 by a different committee, with the same general results.

It thus appears that an aperture half an inch in diameter is almost equally as effective as one of double its size; but, in the one case, the wound readily heals over by the growth of the same season; in the other, the growth of several seasons will hardly close the wound, endangering the vigor and health of the tree.

\section{On the Planting of Trees.}

THE following suggestions, relative to the planting of trees, and the most appropriate time for effecting the same, are communicated to the Germantown Telegraph by Thomas Meehan:-

Our readers will not, doubtless, consider the assertion as very original, that of the numerous trees annually planted, great numbers die; but I am not so sure that they would not attribute the deaths to very opposite causes. Yet the facts of the "millions of cases" lie in a nutshell. I will explain. At the outset, let it not be forgotten, that to the roots of plants small rootlets or fibres are attached, and that all fluids for the support of the plant have to be chiefly received through these fibres. When a tree is transplanted, many of the fibres are broken off or damaged, and, if it has never been transplanted before, most of the fibres being at the ends of the principal roots, far away from the base of the tree, will be left in the ground, and very few come away with it. If the operation is performed late in the spring, the buds burst and the leaves unfold: they ask for moisture, and if the trees have an abundance of fibres, they get a fair supply; if they have few or none, they wither and wilt, and no matter how carefully planted, no matter how carefully pruned, mulched, or watered afterwards, nothing but very extraordinary skill indeed can save them.

This is speaking of trees generally. Some trees have very spongy wood, in which moisture is stored or accumulated; on this moisture they can subsist till the tree has had time to form new fibres. To this class belong the ailanthus, paulownia, catalpa, some poplars, and willows. Others have half-fleshy roots, and can draw a small amount of moisture from these for a time. The horse-chestnut, ash, lindens, many maples, and some evergreens are of this kind. These do not suffer so certainly from the want of fibres as the majority of trees, comprising the numerous varieties of oak, hickory, birch, beech, chestnut, \&c. Now, as the roots of a tree are continually forming fibres, except when actually enveloped in frozen soil, it directly follows that the longer time we give a tree before the bursting of its buds, in which to establish itself after transplanting, the better able will it be to meet the demands of the foliage for moisture when the warm weather comes; and this brings me at once to the pith of the subject-the advantage of autumn planting. A tree planted as soon after the fall of the leaf as possible will begin to form fibres at once, and continue to do so till spring calls the foliage into action, when the roots will be able to meet any ordinary demand made on them; at any rate, it has a better chance than the same tree would have if planted in the spring.

I do not deny that spring planting has many favorable points of view. In my recent work on trees, I have freely granted this; and I would here even go so far with its advocates as to admit that, in some cases and in skilful hands, trees can be made to do better when planted early in spring than in the fall; but, as a general rule and in general hands, and for the reasons I have given, autumn is the safest, and, in many cases, the only safe time in which to remove trees.

\section{Notes on the Grasses.}

Bx Rev. Johy Bachyan, D.D., of Charleston, South Carolina.

So much confusion has been produced by applying the same common names to grasses of different species, that the agriculturist, in sending for seeds designated by the common name, has often introduced either those that were of no value, or were already found growing in 
his own fields or in the immediate neighborhood. To botanists the scientific name is an infallible guide, and it would be well if the farmer could apply the English name, where we have one, to the grasses for which the name was intended, and to render himself familiar with the different species, in order to be guarded against imposition or error.

The following are the specific names of grasses in usual cultivation in America, as also of some of those which may be cultivated with some prospect of success, but which require to be better tested by future culture:-

1. Medicago sativa: the Lucerne.-A native of Europe. This is a deep-rooted perennial plant, sending up numerous tall, clover-like shoots. In the lower country of Carolina it succeeds better than the red clover, being better adapted on account of its tap-root to survive the effects of drought. The objections to it are, that it requires an additional season to bring it to maturity, and frequently dies out in spots. In Europe, a field of Lucerne may be annually mowed or pastured for eight or ten years.

2. Medicago maculata: Spotted Medick.-This is the species cultivated in this country as yellow clover. It is not valued in Europe as a grass worthy of cultivation, but seems to succeed better in our Southern country.

3. Medicago falcata: Yellow Lucerne; Swiss Lucerne.-This species is a coarser and more hardy plant than either of the species mentioned above. I observed it producing a good yield in some of the sandy soils of Switzerland.

4. Trifolium pratense: Common Red Clover.-In all clay soils, more especially in lands containing calcareous matter, clover can be easily raised. The application of gypsum seems essential to its successful culture. For pasturage and resuscitation of poor lands, this is among the most valuable of all our grasses. It should be remarked that some varieties of red clover, of the same species, are perennial; others are biennial, or, at farthest, last only three or four years.

5. Trifolium repens: White or Dutch Clover.-This is a much smaller species, and is not used as hay, but in good soils forms a valuable pasture. There are fifty-nine species of clover described by botanists; a very small number of these are cultivated, the rest are regarded as unproductive.

6. Phleum pratense: Timothy Grass; Herds Grass; Cat's tail Grass, \&c.-This is a most valuable perennial grass, requiring moist ground.

7. Alopecurus pratensis: Foxtail Grass.-Sometimes mistaken for timothy grass, which it much resembles. A large portion of the hay-grass of the Middle States is of this species, which, although having smaller heads than the timothy, is nearly of equal value.

8. Poa pratensis: Smooth-stalked Meadow Grass.-In Kentucky, it is called Kentucky blue grass. It is a valuable grass, and succeeds far better in Kentucky, the valleys in the Virginian mountains, and in New York and Pennsylvania, than it does in any part of Europe, where it is a native.

9. Poa compressa: Compressed-stalked Meadow Grass; Blue Grass of England.-It is far inferior to the other, the Poa pratensis.

10. Dactylis glomerata: Orchard Grass of America; Cocksfoot of England.-This is a valuable grass, and produces an abundant yield. It's habit of growth is tufty, and it spreads very little in the ground. It is better adapted to the Middle States than to our Southern. country. It is a native of Europe.

11. Holcus lanatus: Meadow Soft Grass; Woolly Soft Grass; Yorkshire Fog.-This is the species that has on several occasions been sent from the West, and cultivated at the South, under the name of muskeet grass. This and a kindred species, Holcus mollis, are both natives of Europe. The latter species is possessed of no property to recommend it for cultivation. The former species yields more abundantly, but on account of its woolly, soft, and spongy nature, is not much relisher by cattle, and is not generally made into hay.

12. Agrostis vulgaris.-Red Top.

13. Agrostis stotonifera: White Top Bonnet Grass.

These two species afford to the agriculturist in Europe and the Northern States of America some of the most important objects of cultivation, both for pasturage and meadows.

14. Digitaria sanguinalis: Crab Grass. 
15. Eleusine Indica: Crowfoot Grass.

The seeds of these two species of annual grasses were originally imported from India, but have become naturalized, and succeed very well in our climate. The former comes earlier than the crowfoot. The latter is more succulent, and requires a rich and moist soil. Both are good grasses, and make excellent hay. The ground, however, requires to be annually plowed and manured.

16. Elymus Virginicus: Lime Grass; Wild Rye.-This, as well as two other native species, is perennial, and is a winter grass, but does not make a permianent pasture.

17. Pennisetum typhoideum: Egyptian Millet.-This is one of the most productive of all our grasses, and can be cut three or four times in the season, if proper care be used to cut it above the joints. In the vicinity of Charleston, S. C., it is extensively cultivated as green fodder.

18. Sorghum halapense: Panicled Millet; Means Grass.-A native of Nubia, Syria, and Greece. It possesses many properties of a good grass, is deep-rooted, grows rapidly, is relished by cattle in its green state, and ean be made into good hay.

19. Lolium perenne: Rye Grass; Lolium Italicum: Italian Rye Grass.-These two species are cultivated in Europe, the latter in the South of France and Italy with great success. It is perennial, and especially adapted to a dry, sandy soil. It is sown in the autumn, at the rate of $16 \mathrm{lbs}$. to the acre, the seed harrowed in.

20. Leersia oryzoides: Rice Grass. - This is a most productive grass, and is found in all the swampy places where there are running streams in our Southern country. It can be cut several times during the summer, and its hay is equal to timothy. It will, however, only flourish in swampy places, partly inundated.

21. Spartina glabra: Salt Marsh Grass.-The salt marsh is cut in its green state as food for horses and neat-cattle, and may be converted into hay. Its saline properties render it a favorite food for horses. It grows only in muddy places overflowed by salt water.

22. Holcus polygamum: Guines Grass. - This produces an abundant crop of green food. It is extensively used in Cuba, Jamaica, and other West India Islands. It produces seeds in the vicinity of Charleston, S. C., but the roots are usually killed in winter.

23. Ceratochloa breviaristata: Horn Grass; Fescue Grass.-I have not seen this grass cultivated. It is a native of a soil and climate somewhat similar to our own, and merits our attention from the high encomiums bestowed upon it.

24. Stipa spata: Lewis Grass; Musquit Grass.-The term musquit or muskeet is applied both to trees and grasses in Texas. Several shrubby, dwarfish species of Acacia and Mimosa are called muskeet-trees. Their tufts of rich grasses are called muskeet grass. A friend sent to me the seeds of what he supposed muskeet grass, gathered in several localities, which, when planted, proved to be three distinct species of grass, one of which was Holcus lanatus. At the recent meeting at Columbia of agriculturists of the South, I was favored, through the secretary, with specimens of what he supposed to be the productive Western grass called muskeet. I can scarcely doubt but the true species has at last been discovered. It has been cultivated in Florida and Mississippi with the most favorable results. It proves to be a Stipa, and differing widely from any of the seeds originally sent as those of the muskeet grass.

Specimens of this grass were found in the herbarium of the celebrated traveller Lewis, who, in the expedition with Clark, obtained them on the banks of the Missouri, and were described by Pursh under the name of Stipa juncea. It was subsequently found and described by Nuttall, who obtained it on the prairies of the West. Both botanists had mistaken it for the Stipa juncea of Europe. The latter, moreover, adds, "Not a single species of this genus is useful in agriculture." I have a sanguine hope that the very species he was describing may yet prove a valuable aćquisition to the agriculture of the South. The species being different from that of $S$. juncea, with which I have carefully compared it, required a specific name, and I had given it the name of $S$. Lewissii, when I was informed by the eminent botanist, Mr. Gray, that it had been named by Trinius as Stipa spata, which it must retain. As we have so often been perplexed by the name muskeet, I propose, as its English name, that of Lewis's Grass. 
25. Tripsacum dactyloides: Gama Grass.-This is a very productive, but a rather coarse grass. It requires to be cut when its leaves are young and tender.

26. Digitaria dactylon: Bermuda Grass.-This species produces, short grass, not fit for mowing, but it affords good pasturage for cattle and sheep, and is a somewhat inferior substitute for the blue grass.

27. The Minnesota Rice: Zizania aquatica.-This species has no affinity with the truo rice, which belongs to a genus widely removed, notwithstanding its common name. It is nore nearly allied to the oat, although it differs even widely from that. It is not only found in Minnesota, but abounds on all the shores of the Northern and Western lakes and rivers, and also grows in all the Atlantic States. It ripens irregularly, and drops its seed at the slightest touch. The grain is small, and the hull very adhesive. It is doubtful whether it can ever be brought into successful cultivation.-Southern Agriculturalist.

\section{Grasses for Lawns.}

Tre extreme beauty, evenness, and velvety softness of English lawns have been the theme of admiration of all travellers through the United Kingdom. In our landscape gardening these lawns are the models we strive to equal, no arrangement of trees and shrubbery, and otherwise picturesque location of buildings, producing the proper effect without a well-set, compact, and even sod of green grass. It is but seldom, in this country, a lawn or grassplot, either large or small, is to be seen what it ought to be and what it may be. The difference in this particular between here and England is partially owing to her more moist and humid climate; but more to other causes we shall now advert to, and first and most especially the determination in this country to do every thing fast. We do not take the time, and will not incur the expense, in our agricultural and horticultural operations, as well as in other branches of business, to do things well, but only wish to do them soon. In England, the formation of a good lawn, intended to be permanently laid down to grass, is considered an expensive operation, and one requiring the greatest skill. The subsoil is first, if it requires it, thoroughly drained, and the surface made entirely level. Subsoil, or trench-plowing, is of course adopted, to guard against the effect of drought, and the greatest care taken during the process of levelling and preparing to give it a uniform foundation at a uniform depth; particularly to make the upper six inches everywhere the same, and of a uniform structure of good garden soil. In this way they avoid the uneven spots, hills, and hollows which so disfigure our own lawns, and make a variety of tints in different parts.

A mistake is often made here, in having the soil too poor to produce a constant and luxuriant growth of grass, levelling being often done with the earth out of the cellar of the building just erected. We would recommend, after plowing to the depth of ten to twelve inches, if the soil is thin, it should be covered with a plentiful coat of good barn-yard manure, to be plowed down to the depth of five inches, and the surface afterwards covered with good surface soil at least a couple of inches, to serve as a recipient seed-bed for the young grassseeds.

Much of the outlay may be reduced, where circumstances admit of taking off, previously to laying down the lawn, a crop of potatoes or other roots, which have the effect of making the soil mellow and friable. Previous to seeding, all stones must of course be picked off, and the harrow passed over repeatedly, to pulverize all lumps and reduce all inequalities.

The fall of the year is decidedly preferable for forming a lawn, and it is a great advantage to sow, at the same time with the grass-seed, a small quantity of rye, wheat, or oats, for protection during the winter and succeeding spring, but which must be mowed off when six or eight inches high, to avoid any interference with the growth of the grasses.

The quantity of grass-seed used to the acre for lawn purposes is much greater in England than many persons seem willing to incur the expense of here. Out of six different mixtures of lawn grass-seed recommended for an acre by some English authorities, we find not one to contain less than forty pounds. As there is no use in more than enough, we would say if the ground is properly prepared, and the above precautions attended to, twenty to twenty-five lbs. of seed are sufficient for an acre. 
The kind of grass-seed for an American lawn or park we have a very decided opinion about, and can speak from some experience. We would discard entirely all the crested "dogstail avenas and fescue grasses" of England, as entirely unnecessary and useless here. The very best quality of compact sod can be obtained by sowing equal parts by weight of Poa pratensis, (green or blue grass,) Trifolium repens, (white clover,) and Lolium perenne, (rye grass.) We prefer this to any mixture of other grasses. After being once well set, it should be remembered that a lawn can only be kept beautiful by repeated mowing, and occasional top-dressing, and cleaning with an English lawn rake, which are made expressly for this purpose. In England they are also regularly swept with a broom at stated periods.

For good mowing, an English riveted-back lawn scythe is also indispensable.-Penn. Farm Journal.

\section{Preparation of Grass Lands.}

Frow a report on "grass crops," submitted to the Farmers' Club of Concord, Mass., we make the following extract respecting the reclamation of lands intended for grass: We would also say that it has been our experience in reclaiming meadows and swamps, that to produce a large crop of good grass it is necessary that the land be well and thoroughly drained, and have a good dressing of sand or gravel, or a large portion of the same in the compost manure applied before and after seeding. Otherwise, however well-manured, there will be a weakness of the straw, which will cause it to fall and rot before it has time to grow to be a full crop.

We have also examined the crops of grass grown on meadows reclaimed in various ways, and in our opinion the too-common practice of burning the entire top soil is a bad one. Although the first crop will probably be good, the land and after-crop will be much larger and better without the burning than with it: burning leaving a tendency to moss and wild grass.

There are acres of this burnt land in our own town, that, after one or two seasons, have run back to wild grass, and which it will require nearly twice as much manure to keep in good condition than it would if it had been reclaimed in a different manner.

\section{On the Cultivation of Clovers and Grasses at the South.}

We copy the following memoranda relative to the cultivation of the clovers and grasses at the South, from the address of Col. Isaac Croom, of Alabama, before the Agricultural Association of the slaveholding States: The opinion which has long and extensively prevailed, that clovers and the artificial grasses are incompatible with a Southern climate, exerts a blighting influence on the industrial hopes of the South; and no labor can be more usefully bestowed than in showing its fallacy-none more grateful to the aspirations of the Southern planter. The important question to be decided, then, is, Whether the cultivation of clovers and the artificial grasses is practicable in a Southern climate? If this question shall be affirmatively established, observation and experience will indicate the most suitable varieties; and besides, it will assure a basis for future improvement and prosperity without limit or end. From the result of numerous and varied experiments made in different sections, we have no doubt that red clover will flourish at the South as well as at the North, by the use of carbonate and sulphate of lime, and other proper means, in a soil naturally or artificially good; that this plant is not so much dependent, in fact, upon climate as upon a suitable soil and proper food.

Twenty-five years ago the same erroneous opinion we are combatting farther South prevailed in Virginia, that clover would not grow in the light, sandy, acid soils of the tide-water districts of that State. This error has long since been exploded, and by the use of marl and gypsum red clover is now extensively and profitably grown there. The consequence has been an entire revolution in their agriculture. Coming farther South, it has, during the same period, been found both practicable and profitable, where the proper means have been used, to grow clover on the alluvial soils of North Carolina similar in their texture and composition to those of Virginia, just described. 
It is known to have been the opinion of the late Mr. Poinsett, that if the rice-lands of South Carolina were sufficiently drained and protected from the influence of salt water, many of the artificial grasses would grow well on them, and enable the rice-planter not only to secure an abundant supply of the best bay, but to adopt a rotation of crops, as in Italy, by which his lands would be ameliorated and his crops of rice increased.' In South Carolina, Mr. Calhoun, of Pendleton, Mr. Saxon, of the Abbeville district, and Mr. Sumner, of the Newberry district, have all grown clover with great and uniform success. Going farther South, Mr. Croom states that he has for the last ten years cultivated clover in the canebrake or lime land of Marengo county, Alabama, a few minutes north of 32 degrees, with every success which could be reasonably desired.

Col. C. further states, that it has afforded an abundant supply of grazing for stock of every kind, fattening hogs, sheep, mares and colts, horses not at work, beef-cattle, calves, and goats, from March to November, and a good deal of grazing during the other months. Hay could be made if desired. It is grazed regularly from February to November, and irregularly at other times. During the period of regular grazing, stock of every kind will keep fat without any other food, and nothing is given to them except a little corn to the hogs, to keep them gentle and obedient to the call of the herdsman. The land as yet has shown no disposition to clover-sickness, nor was the crop ever much finer than during the past summer, although there was no rain on it from the 1st April to the 1st July, except, perhaps, one or two very slight showers. Although it cannot be doubted that moist summers are most favorable to its perfect development, yet when it has become well rooted in a deep, rich subsoil, it is less affected by the influence of sun and air than many other of our most valuable plants. It has often attained to the height of four feet.

We have often expressed the opinion, and still maintain it, that when clover is successfully grown, it is a far more valuable crop at the South than at the North. The reasons are, that being a biennial plant, it requires renewing every third year. This renewing is often, if not always, necessary in a Northern climate, but never at the South, so far as our experience goes. The volunteer plants preserve a good stand. Again: during some six months of the year the Northern soils are frozen up or covered with snow, while at the South, during much the largest portion of this time, clover grows finely. We know of other planters in the same county who have engaged in the clover culture, and who are pleased with their success and prospects.

More might be said in its behalf, and more proof adduced, but we believe that sufficient proof has been presented to show not only the inappreciable value of clover to Southern husbandry, but, besides, its adaption to a Southern climate; and that its growth, in truth, is not so much dependent on climate as on the mechanical and chemical characters of the soil.

In the Southern States there is a large quantity of sandy, acid lands, resting upon deep subsoils of the same character. These cannot be recommended for the cultivation of clover. We do not wish, however, to disparage these lands, for they are easily cultivated, and well adapted to some of our most valuable crops, and may be rapidly improved by the field-pea, which has aptly been called "Southern clover." The grasses are not deep-rooted like the clovers, and cannot, therefore, bear so well the influence of a hot sun; but when sown on good soils, with the necessary shade, they flourish in the central districts of the cotton-growing region, and will probably do so in the southern portion of it. Blue, orchard, herds, and timothy grasses, are cultivated extensively in the more elevated belts of the Southern States, and to some extent in the middle districts. In the more southern and eastern portions, also, experiments sufficient to test the practicability of their successful growth have already been made.

The South, however, possesses treasures in her native grasses which she has not yet learned to appreciate. If proper attention were bestowed on these, the value realized would astonish us. As an illustration, a gentleman of Autauga county, Ala., told us, a few weeks ago, that from 20 acres of creek-bottom land he had the present year saved 10 tons of sound, sweet crab-grass hay, which would serve his purposes as well as the Northern hay, for which last he had to pay $\$ 35$ to $\$ 10$ per ton by the time it reached his stable door. 
I have in some instances used this grass for hay; but my principal objection to it is the difficulty with which it is cured for mowing away or stacking, as the case may be.

It should be added, that the soil best adapted for this grass is a rich clayey loam resting on limestone. On thin soils, especially on hard-pan clays, it will not thrive.-Eds. Ohio Cult.

Italian Rye Grass.-At a late meeting of the London or Central Farmers' Club, the subject of discussion was "The Cultivation of Italien Rye Grass." From the report of the remarks made on this subject we select the following items of information, as those most likely to prove of some value or interest to American farmers:-

Italian rye grass has been known to British agriculture for nearly a quarter of a century, the first importation of seed having taken place in 1831, or twenty-four years ago. In that year, one hundred and seventy bushels of it were shipped from Hamburg, and sold in England at two guineas $(\$ 10)$ per bushel. The imports bave increased year by year, reaching to about thirty-five thousand bushels in 1854 , by one firm, and the price is now about $\$ 1.50$ per bushel. Other traders have also imported largely, and thus it appears certain that the cultivation of this grass is increasing, very rapidly. . A seedsman, who sold only twenty-five bushels in 1840 , sold this last year seven hundred bushels. The use of the seed is not now confined to a few of the more enterprising cultivators: "it is general, and everybody sows it." The plant has fully established its claims in the opinion of all who have tried it.

Italian rye grass prefers the adhesive class of soils-loams and clays; but it does well even on sandy soils. When sown by itself, from three to four bushels of seed are used to an acre; when sown with a mixture of permanent grass, eight or ten pounds per acre is an ample share. Italian rye grass and Alsike clover make together a very heavy crop. The seed imported from Lombardy is better than that of British growth. Any one proposing to try it, should use every precaution to secure the best seed. Those who water this plant industriously, usually get three good cuttings in a year. It gives early spring feed, and lasts till quite late in autumn. As watering seems so essential to the growth of this variety of grass, it might be tried in this country with most hope of success on meadows or lands which could be flooded, by damming up the ditches or otherwise after each cutting. Taking the testimony of those who have not used liquid manures, it seems indisputable that this description of grass is admirably adapted for dairy purposes and for growing stock of every kind. For hay, it is not unusual to sow it with red clover.-New Fork Country Gentleman.

The above is one anthority respecting the value of this grass. Other agricultural journals express very different opinions; and by some the Italian rye grass is described as exceedingly injurious to grass-lands.

The late Judge Buel, in treating of the several varieties of this kind of grass, thus writes"The Italian variety gives the largest produce, and were it hardy enough to withstand the cold of our winters, would no doubt become a valuable acquisition to our husbandry."

It is, we believe, generally agreed that thus far in the United States the attempt to cultivate this species of grass has been attended with indifferent success. Much of this may perhaps be attributed to errors in treatment. Its reputation in England is extensive and wellestablished, and the best seed may be imported into this country for less than $\$ 2$ per bushel.-Editor of Year-Book.

"The only person," says the "American Agriculturalist," "we are acquainted with who has grown the rye grass in the United States, and has expressed his approbation of it, is Mr. Alsop, of Middletown, Connecticut. From all we can hear of it, however, it is little superior, for early spring pasture, to the common rye of America, or beardless wheat.

"Ray grass is entirely distinct from rye grass. The former is a perennial, comes forward early in the spring, grows rapidly till July, and yields an abundant aftermath. It requires a rich soil and deep tilth. North of forty degrees of latitude, it should be sown in the spring, and like any other grass-seed. It may occupy the ground entirely alone, or be sown with -other grass-seeds or clover. If sown alone, it requires two bushels of seed per acre; but to get a first-rate stand and thickly cover the ground, three bushels would be better. The cost in New York is $\$ 3$ per bushel for pure, well cleaned imported seed. 


\section{Trifolium incarnatum, or Crimson Clover.}

A ReCent number of the "Transactions of the Highland Agricultural Society of Scotland" contains a prize essay (for which a gold medal was awarded) by James Fulton, respecting this new clover. From his several trials with it during three or four years, it seems to possess some extraordinary properties, which will make it exceedingly valuable. His series of experiments commenced in 1852, and were nine in number, extending down to quite a recent period. From them he establishes the fact that the crimson clover flowers over a long period of its growth; that its rapid and luxuriant vegetation is hardly equalled by any other plant, coming forward to the scythe in ten or twelve weeks after being sown; that its product to the acre is very large, and it answers capitally to precede a crop of wheat, both by its mechanical effect on the soil, and from its alleged power of collecting nitrogen. In one of the experiments, the wheat after the crimson clover was one-third heavier than after turnips, other circumstances being similar; and it is thought it will be quite possible to grow it in England as an intermediate or stolen crop between a wheat and turnip crop, provided it can be got into the ground by the middle or before the end of August. In the first experiment, the seed was sown on the 12th of May; and on the 17th, the blade began to appear above ground; and on the $23 \mathrm{~d}$, the leaves were fully developed. On the 21st of August, (same season,) one square was cut from three separate parts of the field, the average weight of which (green from the scythe) gave eighteen and a half tons to the imperial acre-some of the plants measuring four feet three and a half inches in height. The flowering commenced by the end of June, when the height of the plants was from eleven to thirteen inches, and it matured seeds by the 1st of September. When in full bloom, the field was an object of striking beauty, presenting to the eye an unbroken sheet of scarlet. It appeared to be an especial favorite with bees; on looking at it on a fine day in July, it was difficult to fix on a single plant that had nơt many of them upon it.

In the third experiment, the crimson clover was sown on the 17 th of July, after a crop of potatoes had been taken off. It came up on the third day, and grew so rapidly as to cover the ground in an incredibly short time. The weight of the crop was taken on the 17 th of October, three months after the date of sowing, and was found to weigh twenty-one and a half tons to the imperial acre.

Among other phenomena in the third experiment was noticed its extraordinary power of resisting frost, free radiation, and a remarkable succulent condition, which may account for the surprising weight of the crop. Its radiating powers, to which its immunity from the effects of the frost were probably due, were very conspicuous in dewy and frosty mornings. In the former, the clover was bent down by the deposit of dew, which was much heavier than on other plants, and in the latter it was so densely covered with hoar as to appear like a fall of snow.

\section{Grasses and Grass Cultivation.}

Value of Orchard Grass at the West.-A correspondent of the "Ohio Cultivator" gives the following memoranda respecting the value of the "orchard grass." He says-In 1820, I purchased a peck of this grass-seed in New York, and carried it from thence to Wheeling in my saddlebags. In the following spring, I sowed it in various places on my farm, but mostly on steep banks and woodlands, where the underbrush had been taken out. In every place where it was sown at that time it still retains its primitive luxuriance. It starts to grow very early in the spring, and grows faster than any other grass, and sustains itself better in drought than any, with the exception of clover; and I can further add to these excellencies the fact that it bears the action of the frost better than all other grasses, with the exception of the English spear grass. My woodland pastures are turfed over equal to a timothy meadow, and at the same time it is shaded to an extent that would preclude all other grasses from making the attempt to grow. There are bordering on the Ohio River thousands and even hundreds of thousands of acres of land so steep that ordinary grasses will not grow, and if sown will not sustain themselves; whereas the orchard grass-seed would thrive luxuriantly, and sustain its hold an indefinite time. 
"Ray grass makes a superior lawn; but it must be cut often, otherwise it grows up too coarse. Frequently cut, it becomes fine, and makes a softer, thicker, and more velvety turf than any other grass we have yet seen cultivated in the United States."

For hay, neither ray nor rye grass is equal to timothy or red-top; they grow too coarse, and become too dry and woody.

\section{Beach Grasses.}

Two varieties of grasses, adapted to prevent encroachment of the sea upon the coasts, have been distributed, during the past year, by the Patent Office-the sea-reed, (Arundo arenaria,) which affords a large amount of saccharine matter, compared with the produce of other grasses; and the upright sealyme grass, (Elymus arenarius,) named from its upright, close spike, also affording a remarkable quantity of saccharine matter, averaging one-third of its weight. The latter has hence acquired the name of the "British sugar-cane," and must render hay very nutritious, particularly when cut into chaff and mixed with grain and common hay. Experiments have, however, proved that the sea-reed is unworthy of cultivation as food for cattle out of the influence of the salt spray; and the same remark is about equally true in respect to the upright sealyme grass. But where the two grasses are sown together in their natural place of growth, they prove of great utility, raising a barrier against the encroachments of the ocean the most effectual and durable. The arundo arenaria is applied likewise to several economical purposes, such as the making of hats, mats, ropes, \&c.

These grasses should be planted on such parts of our coasts as may be threatened or be suffering from encroachments of the sea, and upon sandbanks liable to changes and abrasion.

\section{On the Production of Gutta Percha.}

Mr. JAmes MoteEx, who is now travelling in Sumatra and the adjacent islands, communicates to Hooker's Journal of Botany the following information respecting the production of Gutta percha. He says: Of the original article very small quantities are now brought to Singapore; it has become a manufactured substance. A vast variety of gum, at various prices, from three to thirty dollars a picul, is brought in by the natires. Some of these are deep red, some quite white, and many of them are hardly coherent, breaking and crumbling between the fingers. These are cut and broken up, and cleared from scraps of bark and wood which are generally found among them; they are then boiled in an iron pan with cocoanut-oil, and stirred until thoroughly amalgamated; this mixture is allowed to cool again, when it is broken up and reboiled with more oil, sometimes as often as four times, or until the mass acquires a certain tenacity. The good Gutta percha, sliced into thin shavings, is then added in greater or less proportion, according to the quality of the basis, and the whole well mixed. The Chinese who do this are very skilful, and manage to produce from a great variety of gums a very uniform article,- wonderfully so, when it is considered that the gum is bought by the merchants in very small quantities at a time, as the natives bring it in.

There seems to be a great mystery about the Gutta percha trees; I was in the heart of their country, and yet could get nobody to show me a single tree. I think the fact is, that they have all been long ago cut down within any reasonable distance of the settlements. I saw large quantities of the gum, though none of the best quality on the Indragiri. I think I can distinguish at least five sorts, which are probably the produce of different trees, or rather five classes of gums, for perhaps the species are many more, and yet, though I offered great inducements, I could not get even a leaf.

Gum Benjamin.-The Gum Benjamin, another great staple here, I saw collected; the trees are about eighteen inches in diameter, with small, low buttresses to the roots; these are notched with a chopper, and produce the ordinary quality of the drug; the best, of a light buff-color and dense substance, is procured from wounds in the uncovered large roots, and the common wr Foot Benjamin, is procured from the trunk of the tree: the oil of the seeds is valued as an application to boils; it is probably of little use.

Twenty-two different plants are now registered as yielding Gutta percha. These are under 
examination. All the fig tribe yield a kind of Gutta percha. Euphorbia cattamudus and another species-common in India-give a gum like it. The sap of the Muddar-tree is firm and white, and equal in all things to Gutta percha. The inspissated sap or juice of the cultivated Artocarpus (bread-fruit) and the Lola-tree of Ceylon, give substitutes for Caoutchouc or Gutta percha. The Gutta thoor can be made to rival Gutta percha. Asclepia gigantea of the West Indies gives a sort of Gutta percha, and the tree abounds there.

\section{On the Germination of Seeds.}

THE following practical observations on the germination of seeds is communicated to the Horticulturalist, by Thomas Meehan, of Philadelphia:-

There are probably few branches of horticulture so ill understood as the management of seeds. A package of seeds may be placed in the hands of two men, divided between each, and sown by each in his peculiar way; and while one succeeds in raising plants, the other fails. Sometimes the individual who succeeds in raising some particular seed one season, will himself fail in another, though to all appearances the seed was gathered, preserved, and treated exactly in the same manner. There is one class of seeds which preserve their vitality to irregular periods without any extraordinary intervention. The seeds of the cucumber and melon will keep fresh so long, that gardeners say the longer they are kept, the better they are; which, if true, would render them of remarkable value by "the end of the world." Nevertheless, they certainly will keep fresh a great many years. The turnip, the balsam, or ladyslipper, and the parsley are instances of easy vitality, though of a few years less than the gourd tribe; while the onion, spinach, or lettuce will seldom germinate over one year. In all these cases, their preservation is owing to their not being in a position to admit of the mechanical action of heat and moisture in preparing their integuments, or outer coverings, for the chemical action of the elements conducive to germination.

It will be sufficient here to remark that the vitality of seeds is entirely dependent on his relative position of heat and moisture. Some seeds require more moisture than others to tempt them to germinate; others must be indulged with more heat than water, in comparison: but every kind of seed requires its own due proportion of each. Seeds of many plants, as the water-lilies, will only grow in water; and of these, some, as the Victoria, must have an accompanying degree of heat of over $70^{\circ}$, while our yellow pond-lily will germinate at $55^{\circ}$. Other plants, as the balsam, thunbergia, globe amaranthus, \&c., will readily grow in comparatively dry soil.

An examination of the principles concerned in germination teaches us that in preserving the vitality of seeds, or in accelerating their germination, a great part of our attention has to be directed to their outer coverings. Seeds can not lose their vitality while these remain perfect, while they will be in a condition to vegetate whenever this covering is prepared to admit moisture. The different results in the experience of different parties in the time required by certain seeds to grow, is entirely dependent on this. If A. preserve his seed during the winter so that the husk becomes hard and bony, while B. guards his from such a contingency, the latter will arrive at much more speedy results than the former. Let us take an example: the sugar-maple will do. A. gathers his at the fall of the leaf, preserves it in a dry seed-room, sows it in the spring, and it does not come up till twelve months afterwards. But B. gathers it at the same time, puts it in the ground at once, and gets fine plants the next season; or, he gathers his seeds by the end of August, saves them in a cool room till spring, sows them, and then gets plants also "right away," in either case getting ahead of his neighbor. "But where is the difference?" Simply, that B. never allows his seeds to get hard. He places them in the ground to keep their shells soft; or, to the same end, he gathers them, not before their embryos are fully formed, but before their coats have become indurated, and adds to his precaution by keeping them cool till sown. This is a simple experiment, which any one may test for himself.

In successfully raising seed, there is more in this gathering of them before they are what is popularly called quite ripe, than one is at first disposed to admit. I was many years ago struck by this, through accident. On a visit to a friend, he pointed out what he then consi- 
dered extremely rare, a most beautiful double orange African marigold. My friend wished to keep it to himself,-he would give no seed, but he presented me with a flower. When this flower had faded, and was cast aside, seeing the seed looked black and good, I saved them, and at the next spring's sowing I sowed them at the same time with the yellow, which we had. They appeared several days before the others. Simple as this was, it led me to ponder on what we gardeners had always held inexplicable-namely, that on sowing hawthorn-seeds some should come up in one year, while, of the same sowing, some should not appear till the second or third year; and I have since been led to the conclusion, by many similar observations and experiments, that those which came up first were "greener" when gathered than those which took a longer period.

So much for saving seed which we wish to germinate readily. But let it not be forgotten that, if we wish to preserve seed safe and sound to a remote period, the reverse of this must be aimed at; that is, the riper the seed can be obtained, the better. Now, supposing the seed come to hand dry and hard, perhaps from some foreign country,-perhaps old, or perhaps from having been preserved only for a few months in an old coat-pocket, seed-chest, or some other dry, warm place, - how are we to proceed? Still look to the softening of its shell. Suppose, for instance, we have a barrel of peach-stones to sow at once some spring, which, perchance, have been stowed away during the whole winter in the dry store of some dealer. What shall we do ; crack them? Yes, that may do, but it is a tedious operation; can't afford so much time; can do for them in a better way than that. Lay them anywhere aside thinly. To-day, with a water-pot, pour boiling water on them; to-morrow, let them dry; the next day, again pour boiling water on them, as before. Several successive days of this treatment will do. Another way is, to expose them anywhere to a heat of $100^{\circ}$, or thereabout, for a few hours; afterwards pour cold water on them; then dry them again. Repeat the operation a few times, and you may easily have peach-trees the same year from stones sown in the spring. This mode of softening shells is adapted to any kind of hard, bony seed. The heat expands the pores, the moisture enters, and the work of a whole winter's freezing is effected in a few days.

There are many kinds of seeds which have not exactly "shells" for protection, but which nevertheless get pretty hard coverings, if once allowed to get dry. Many of the sterculiaceous and leguminous plants are of this description. I have seen, of the former tribe, seeds of the hand-plant (Cheirostemon platanoides) remain three years perfectly sound in a pot, resisting every attempt of change of heat and moisture to get them to germinate; when a simple soaking in boiling water for a few hours, on their arrival from Mexico, and for a few hours before sowing, would probably have caused them to spring up in as many days. Boiling water is very efficacious poured over such seeds, and left thereon a few hours; or where there is any objection to the use of such hot assistants, though I have never found it to hurt any thing, the seeds may be steeped for two or three days in cold water. I have raised Virgilea luteas from hard and dry seed in this manner in a few days, after being gathered ten months. Alkalies, acids, and various preparations have also been used with various success in softening the integuments of seeds. I do not myself value any of these means much, believing, as I do, that a proper and judicious employment of heat and moisture is abundantly sufficient for every purpose.

\section{Agriculture in Liberia.}

From the recent report made to the Liberian Government, respecting the condition of the model farm and plantation in that colony, we obtain the following information :-

There are now about five thousand coffee-plants in the plantation, the oldest of whichnamely, those planted out in 1850-51-are some of them seven feet high, and the average height of that lot of plants five feet.

The young plants now growing from the seed sown towards the end of the year are so numerous and so promising, that they will probably, at the very lowest estimate, furnish five thousand additional healthy plants, and it is, therefore, fairly presumed, that at the end of - this year the plantation will contain ten thousand flourishing young coffee-trees.

The vines are now increased to twelve hundred plants. Thirty of the most forward plants, three years old, bore a crop in January and February of several hundred bunches. These 
plants were pruned at the latter end of March, and in the following July they were again loaded with about six hundred bunches of grapes, many of which were fine and large. The cinnamon-tree also promises well, and may become valuable here as an article of commerce. From one small plant, introduced in 1850-51, we have now some healthy young plants raised, and many more in process of propagation. The mango also promises well. In 1850-51, a young plant was introduced, about one foot in height. It is now a splendid tree, upwards of twelve feet in height. The olives also grow most luxuriantly. They were about a foot high in 1851 ; and the largest of them are now upwards of ten feet in height. At present, however, they have not produced any blossoms and fruit.

\section{New Mode of Transplanting Trees.}

A MACHINe recently invented in England by Mr. Barrow, and which is highly commended by English authorities, resembles the common tumbrels for the conveyance of large pieces of timber, with the exception that the load is carried in a perpendicular position, and while in motion oscillates in the same manner as the suspended candlesticks in the cabin of a ship, instead of hanging horizontally between the wheels. Four wheels of large diameter support an oblong stage formed of beams of timber strongly knitted together. Two sets of these beams run lengthwise, parallel with each other, there being an interval of about two feet six inches in width between each set. These are firmly bound together at each extremity by another system of beams resting on the axletree of each pair of wheels, so that an opening of a rectangular parallelogram shape is formed in the centre of the stage. When it is proposed to remove a tree, this framework is wheeled up to it, and the transverse bars in front having been temporarily detached, the trunk of the tree is placed within the parallelogram. A square trench, or rather, four trenches of equal length, and at right angles to each other, are then dug, beyond the limit of the roots, and of a depth corresponding to their width. When this is accomplished, the tree is by degrees undermined, and strong planks of deal are, during the progress of that operation, driven from trench to trench, underneath the mass of clay which they enclose. The heads of these planks have chains attached to them, and these again are connected with powerful jacks-screws acting on the same principle of combination as the common patent corkscrew-placed on the stage of the framework, and by the agency of these the whole mass is raised above the level of the earth's surface, when the void occasioned by its removal is filled up, and a way made firm for the passage of the hinder wheels across the chasm. A team of horses is next yoked to the machine, and these transport the tree to the site prepared for its reception, into which it is slowly lowered, and thus the operation is completed.

\section{Experiments on the Effect of Different Methods of Sowing on the Pro- duction of Wheat.}

THE following experimental researches on the effect of different methods of sowing on the production of wheat has been communicated to the American Farmer by Tilghman Goldsborough, Esq., of Ellenboro', Maryland. Four different methods of sowing wheat were adopted:-1. in drills on a level surface; 2 . in drills on a ridged surface, lengthwise the ridges; 3 . broadcast on a level surface; 4 . broadcast in narrow ridges. The field selected for the experiments was of about sixty acres, which in the five-field rotation was that year in clover of one year's growth, succeeding corn. Sixteen breadths, of sixty feet each, and varying in length from six hundred and forty-three to six hundred and eighty-two feet, containing an average of about nine-tenths of an acre, were sown with wheat in each of the above modes alternately. There were, therefore, four examples of each method, thus avoiding as far as possible any errors arising from unequal fertility in the soil. There was no application of manure or any fertilizing matter, for fear of irregularity in the quality or rate of such application. All the land in former years had been dressed with shell-marl, and might be considered good land, but not highly fertile. The wheat was of the variety known as the golden-straw or golden-flint, and was sown in drilling at the rate of one and 
seven-tenths bushels per acre, and at the rate of two bushels to the acre, broadcast. Some time previous to sowing, the ground was harrowed and rolled.

For plot No. 1 there was no additional cultivation previous to the drilling. For No. 2 the ground was ploughed into oval-shaped ridges by a three furrow-plow, one-half being made into ridges, five feet three inches wide, (the width of the drill,) and drilled with all the seven tines or tubes of the drill, and the other half was made into four-feet ridges by the same plow and drilled with five tines, the two outer tines being hooked up and closed. The drills were nine inches apart. No. 3 was sowed by hand, very regularly, upon the ground as left by the last-named harrowing and rolling, and was ploughed in flat by a threefurrow plough, in lands sixty feet wide. For No. 4 the ground, as left by the last-named harrowing and rolling, was marked or laid off into four-feet lands by a small single plow, after which the wheat was sowed by hand and plowed in by throwing the land into four-feet ridges with a three-furrow plow, in which operation the hinder plow was run in the furrows made by the above-mentioned single plow, and therefore the wheat grew well into the furrows subdividing the ridges.

The ground being in fine tilth, the broadcast wheat was not harrowed or rolled after being plowed in. The drilled wheat came up first by some days, and was greatly superior to the broadcast throughout the whole period of growth; so much so, that until the broadcast wheat became high enough to hide the ground, it disfigured the appearance of the field, even when viewed from a considerable distance.

- Throughout the winter and spring that drilled upon a level surface was superior to that drilled upon the ridges; and that drilled on five-feet ridges was superior to that on four-feet ridges; and during the winter and early spring, the drills that were near the tops of the ridges were red, and quite inferior to those on the sides and near the bottoms of the ridges.

In the narrow helt above mentioned, the broadeast wheat was entirely thrown out and destroyed by frost, but the drilled wheat in the same survived the winter.

In order to secure complete accuracy in keeping the different lots separate and distinct, both in the harvesting and threshing, they were not harvested until all the other wheat in the field was cut and shocked; and after the threshing of each lot, the ground around the machine was swept clean, and the whole yield of each lot was put in a separate pile in the barn, where it remained undisturbed until it was fanned, measured, and weighed.

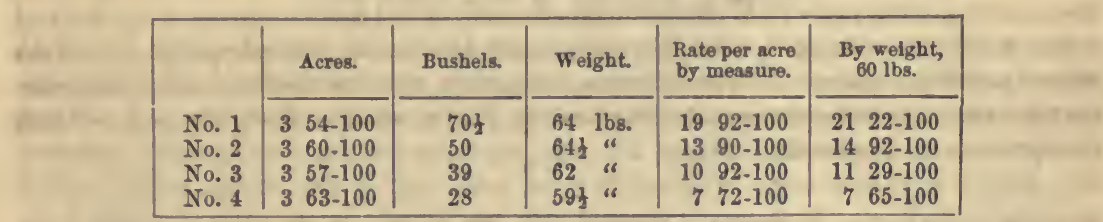

The difference in product between the drilled and broadcast would probably have been less, if the winter weather had not have been so unusually severe, and if a hardier variety of wheat than the Gale had been used, and also if there had been no land inclined to heave out embraced in the ground selected. But the experiments show clearly that drilling as in No. 1 is vastly the most safe and reliable mode; and it is fairly to be inferred from them that in any season and in land of average quality and description, a valuable excess of product may be expected from drilled wheat over broadcast, of which indeed I had been entirely convinced by the experience of the previous six years, in which the white blue-stem wheat was principally observed.

As the publication of these experiments may induce some farmers to purchase wheat drills, I deem it proper to remark that in rather extensive observations I have not seen so great a superiority of drilled wheat over broadcast where the drills were made closer than nine inches. The slopes of such drill furrows are too steep, at least for this latitude, and therefore they fill up so rapidly by the action of rain and frost as to partially smother the wheat; and as they become level, or nearly so, by the end of winter, the wheat loses the benefit of being in a furrow or trench, a position which appears to be of all others the most genial to its growth. 
Seeding Thick or Thin.-The following observations on seeding "thick or thin" are communicated to one of the English Agricultural Journals, by Messrs. Hardy \& Son, seedgrowers, Malden, England:-

"Repeated experiments have proved that the capabilities of grains of corn, whether wheat, barley, or oats, are only to be known by planting early, thinly, and singly, and in order for the full development of each grain, whether on poor or rich soils, it requires to be planted at least three feet apart, square. Although the notion of planting at this extreme distance may be ridiculed and pronounced illogical by thick seeders, yet we contend that by judicious management on good and well-prepared soils, and by planting early in September, each plant of wheat thus treated will invariably not fail to produce four thousand-fold; and half a pint of selected seed is thus sufficient to plant one acre, and, as a natural consequence, it is of course quite possible to obtain a produce of four thousand half-pints-equal to thirty-one bushels and one peck per acre-quite equal to the average yield of the United Kingdom, from the opposite extreme and ordinary practice of sowing two hundred and fifty-six half-pints, or two bushels of seed, and sometimes more, to the acre. Anomalous as this may appear, yet it is certain, and defies irrefragable evidence to prove the contrary, that while four thousand-fold is thus obtainable from a half-pint of seed, not thirty-fold is nor can possibly be obtained from a full crop of two hundred and fifty-six times the quantity, by reason of its extreme thickness; for, were it so, thirty times two bushels would be the average yield, viz., sixty bushels per acre. If our agricultural friends will take the trouble to plant or thin small plots of their wheat to about six inches by twelve apart, or about eighteen plants to the square yard, (the distance we believe proper for obtaining the fullest crops,) their expectations will be fully realized. As the season is now too far advanced to prove the correctness of this statement on wheat crops, we do trust that some unprejudiced farmers will take the trouble to plant, transplant, or thin singly about a rod at least of their barley or oat crops, in the middle of their fields, when it has been up about a fortnight, and afterwards keep it clean by hoeing it deeply with a hack hoe; then all their doubt of the reasonableness of this expostulation will be removed.-Hardy \& Son, Seed-Growers, Malden, England.

\section{Cost of Raising Wheat, Corn, \&c.}

Mr. W. H. Johnson, of Geneva, New York, publishes in the Journal of the New York State Agricultural Society a detailed farm account, from which we gather the following interesting items respecting the cost of different crops the last season. The farm of Mr. J. contains 80 acres of tillable land, divided into nine lots, numbered from one upwards, and accurate account kept with each. The soil is a dry loam, with a clay subsoil, pretty uniform throughout the farm. Each crop is charged with the interest on the value of the land producing it, and with all the labor and material used in its production. Of wheat, six acres were sown, the whole expense was $\$ 122.40$; the product was 126 bushels, or 21 bushels per acre; this makes its cost per bushel a trifle over 97 cents. But deducting the value of the straw, estimated at $\$ 18$, we make the cost of the wheat but 83 cents per bushel. It was sold at $\$ 1.81$, leaving a fair margin for profit at either figure. But at the price of wheat for many years past, the profit would have been little or nothing.

Eight acres of barley cost $\$ 102.20$, and produced 284 bushels, or $35 \frac{1}{2}$ bushels per acre. It cost nearly 37 cents, and sold for $\$ 1.00$ per bushel. This produced a greater per cent. of profit than the wheat, as we believe it generally has for a series of years.

Ten acres of corn on clover sod cost $\$ 153.26$. The product was 410 bushels of corn and $\$ 60$ worth of corn-stalks. Mr. Johnson states the cost of raising the corn at $37 \frac{1}{2}$ cents per bushel; but if we deduct the value of the stalks from the whole expense, it makes the cost of the corn but $22 \frac{3}{4}$ cents per bushel.

Ten cows are kept upon the farm, yielding an average of 210 pounds of butter each. Mr. J. estimates the produce of each cow worth about $\$ 54$, and the cost of keeping $\$ 26.85$. It cost $12 \frac{1}{2}$ cents per pound to make butter on Elmwood Farm, and we think it cannot be sold for less anywhere with much profit. His pork, killed at $9 \frac{1}{2}$ months old, fed on milk and fat- 
tened with corn, cost 5 cents per pound. The balance over expenses on the whole farm for last year was $\$ 953.42$.

Mr. Johnison practices the following system of rotation:-1. Corn, to which is applied all the unfermented manure he can get. The nextspring it is sown with barley, at the rate of $2 \frac{1}{2}$ bushels of seed to the acre; then sown to wheat in the fall, with a top dressing of fine manure of about 6 loads to the acre. The following spring it is sown with 8 quarts of cloverseed and 4 quarts of timothy, with one bushel of plaster per acre, when it is allowed to remain 3 years in grass. The usual product is 55 bushels of corn, 30 of barley, and from 20 to 30 of wheat per acre. The manure is all kept under cover, and a regular system of underdraining is being carried out.-Rural Newo Yorker.

\section{Origin of the Wheat-Plant.}

Some curious botanical facts have been recently laid before the French Academy relative to the transformation of two grasses, Egilops ovata and the AEgilops triaristata. A gardener, M. Esprit Fabre, of Adge, in France, has, without the aid of books, and by simple experiment, brought forward a capital fact showing the mutability of vegetable forms. By experiments, which occupied seven years' time, he proved that the above grasses were capable of being the source of all or the greater part of our species of wheat. He first sowed the seed of the ovata in the fall of 1838 . In 1839 , the plants grew to a height of two feet, and ripened in the middle of July. The ears here and there had one or two grains in them. The crop was five for one, and the straw was brittle and thin. In 1840, the seed of 1839 produced ears more numerous, and generally each contained a couple of grains of an appearance more like wheat. In 1841, the ears were more like wheat, and each had from two to three grains. The figure of the plant was almost like wheat. In 1842, the fourth year of his experiments, the progress was not so sensible as in the previous year. Many of the plants were attacked by rust. The stalks were like Eigilops. The ear gave two or three grains each. In 1843, the stalks grew three feet high. In each ear was two or three well-grown grains, and the straw was stronger. The figure of the plant was like wheat. In 1844, all of the ears were filled. In 1845 , the seventh year, the plants had reached the condition of true wheat. These experiments were made in an enclosure surrounded by high walls. There was no grass inside of it, and no grain raised near the spot. In 1846, he sowed this grain in a field broadcast, and continued it for four years. In 1850 , the straw was full straight, over two feet high, and each ear contained two or three dozen grains of perfect wheat. Thus, a savage plant, subject to cultivation, changed its entire figure and aspects, and gradually assumed a new character.

\section{New Method of Increasing the Produce of the Wheat-Plant.}

Amovg the recent French inventions is one for "increasing the produce of autumn wheat," patented by Mr. D'Urcle. The inventor grounds his discovery upon the fact-positively ascertained "by study and repeated experiments"- that autumn wheat is not an annual, but biennial, like the beet-root and carrot class; and he therefore proceeds to develop the alleged biennial properties by a novel plan of planting and treatment for the increase of the produce. The ground is to be well manured, either before winter or at the beginning of spring, to receire the seed between the 20th of April and the 10th of May, this time being chosen to prevent the chance of blossoming during the year. But the time of sowing may be advanced from year to year; for if it were not for the present degeneracy of the plant, it might occur now in March. Each grain is sown separately, allowing it a large area of ground if the soil is rich, but diminishing according to its sterility. It is deposited in rows in holes at regular distances, from $9 \frac{1}{2}$ to $23 \frac{1}{2}$ inches asunder in each direction, the holes in one row opposite the spaces in the next. Each hole is to contain four or five grains, $2 \frac{1}{2}$ inches asunder. When the plants have attained a height of four inches, all but the finest one in each group are pulled up, and this single one is then left for the harvest of the succeeding year. This curious process is stated to increase the produce very greatly. 


\section{Dioscorea Batatas, or the New Chinese Potato.}

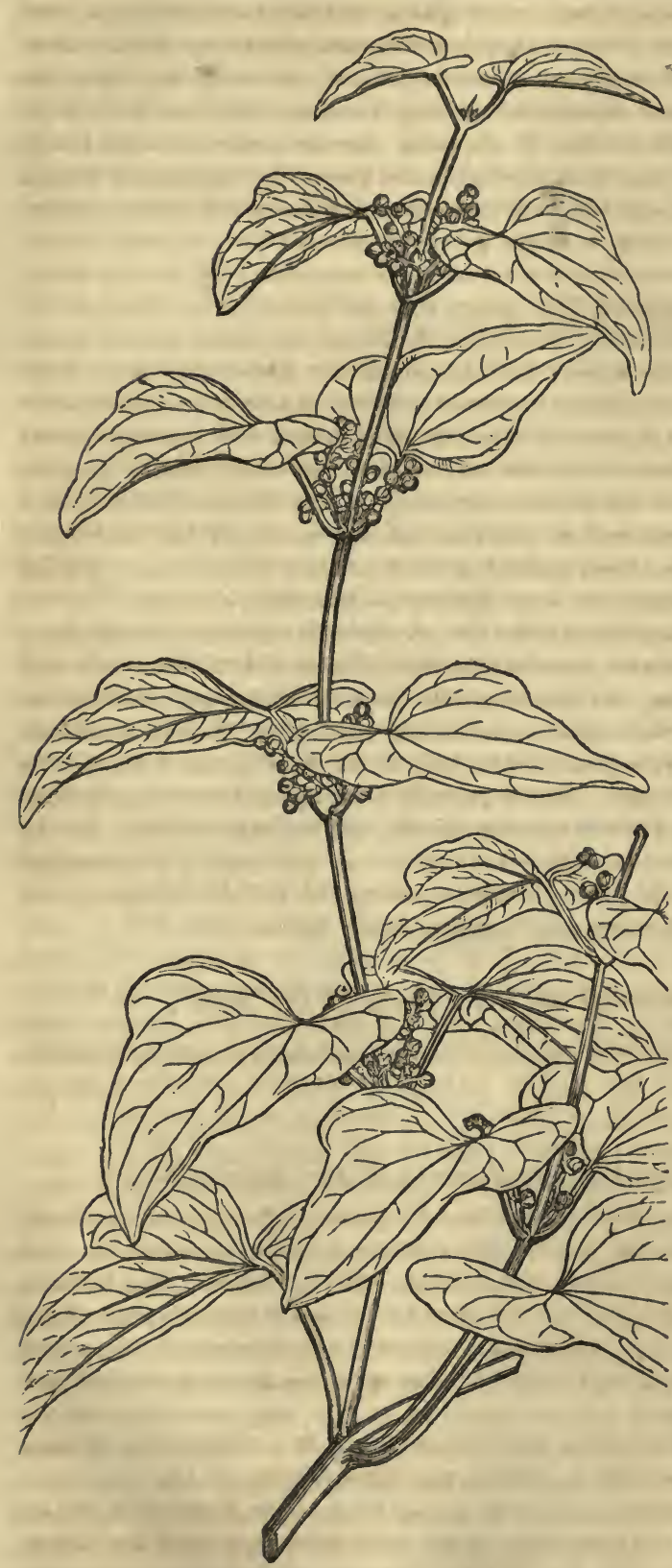

THis new potato was, several years since, transmitted, along with other useful and promising agricultural plants, by M. de Montigny, who is: consul for France at the port of Shanghai, in Northern China. The name which he bestowed upon it was that of Dioscorea japonica; but it has been considered that Dioscorea batatas would not only be a more popular and familiar, but a more appropriate name; seeing that although the plant may in its origin be Japanese, of its cultivation in that dark interior we know literally nothing; while its culture in the northern parts of China, and in latitudes assimilated to our own in point of climate, being a fact quite accessible in all its details, ought not to be submerged under the name that associates it with the very exclusive territory of Japan. The plant, or rather tuber, is doubtless a dioscorea or yam; and yams in general are tropical productions. The various speciesD. alata, sativa, and aculcatayield tubers, which in warm countries are substituted for the potato; and the order is accused of combining with the farinaceous matter existing in its tubers a prevalent acridity, which is sometimes even purgative. Still a few genera are found in temperate climates. Yet all this is nothing. The Solanum tuberosum, our cultivated potato itself, is, it is well known, quite a poisonous plant in a state of nature. Culture may readily ameliorate all this acridity ; and, if we can credit all that has been said in favor of the new importation, has far more than done so. Certain it is, that it holds the same place in the north of China, and is found to comprise the same nutritive properties, as the potato in this country. M. de Montigny has stated that the Chinese at taking up the crop set aside all the smaller roots for seed. It is well known that this is a practice now preferred by our market-gardeners to cutting large potatoes into sets, simply becauso they like a juicy set, 
and find the immature tuber most favorable for their purpose. This is so far fortunate in the case of the new potato, admitting, as we shall presently learn, of its rapid and unlimited propagation; for the Chinese place these tubers first in pits or trenches for preservation, (and they are said to keep far better than potatoes all the winter, covered with straw and a coating of earth, never losing weight or developing exhaustive shoots,) and in spring, being laid out horizontally in beds of prepared mould, they speedily germinate and send forth long, trailing stems, like those of the kidney bean. In six weeks' time the stems attain six feet in length, and are planted out afresh and layered-that is, the plant is laid lengthwise along a slight furrow on the top of a ridge, and all except its leaves covered over with earth. Immediately after rain it begins to take root, or in dry weather is watered until it grows; and in fifteen or twenty days it produces tubers, throwing out at the same time long, trailing stems, which are, however, carefully prevented from taking root and producing a second set of tubers to the prejudice of the main crop. Sometimes the shoots are simply pegged down, without removal of the plant, over the sides of the ridge on which it grows, at intervals of six or eight inches, and there striking root, throw out tubers. By this means it is stated that immense quantities of roots, of the size of our early kidney potatoes of the garden frame, are raised on comparatively small pieces of land. To obtain large-sized tubers, small ones, or portions of large, are planted in ridges at from ten to twelve inches apart; and the plants being allowed to grow freely in autumn, the tubers thus attain an average weight of one pound and upwards. This is the plan which has been pursued at the Museum of France, the only place in Europe where the new plant has hitherto been cultivated.-Mark Lane Express.

This plant, says the writer of a paper sent to the French Central Agricultural Society, may, by its size, weight, and hardy character, become exceedingly valuable in France, as it will serve as a substitute for the potato. Its tubercles, like those of the Jerusalem artichoke, resist in the open air the severest winter without sustaining any injury. Several specimens of these roots of very large size were presented in 1852 to the Society, one of which, of a cylindrical form, was three feet in length; another tubercle, presented in 1853 , weighed three pounds, the former having been in the earth twenty months, and the latter sixteen. During the past season, the French Imperial Society for Acclimation has distributed a large number of these tubercles, with directions for their cultivation, among the various departments of France, as well as Algeria, England, Germany, Piedmont, Sicily, Sardinia, \&c.

\section{Experimental Researches on the Culture of the Potato.}

In consequence of the premiums offered by the New York State Agricultural Society, Mr. H. H. Eastman, of Marshall, Oneida county, New York, has made some interesting experiments in potato culture, the full details of which will be found in the Transactions of the Society for 1852 , page 342 , and in the volume for 1853 , recently issued, page 297.

In the first year's experiments, 1852 , some of the most noteworthy results were as follows: Ashes, lime, sulphur, and saltpetre, (nitrate of potash,) diminished rather than increased the yield. A tablespoonful of gypsum, applied when the potatoes were up, increased the crop from one hundred and thirty to one hundred and fifty-six bushels per acre. Hog-manure, half a shovelful in each hill, gave the largest crop-two hundred and seventy-one bushels per acre. Fowl-manure, a large handful in each hill, gave the next best yield-two hundred and twenty-nine bushels per acre. The plot without any manure at all gave one hundred and sixty-six bushels per acre.

The soil was a gravelly loam, greensward, plowed nine inches deep early in the spring; potatoes planted 18th May, and hoed twice ; variety, red "Irish lunkers."

To test the question of early, medium, and late planting, one plot was planted the 18th of May, and gave one hundred and forty-two bushels per acre; another, planted the 23d of May, gave one hundred and thirty-one bushels; and another, under similar conditions, planted June 8, gave only one hundred bushels per acre.

The experiments in 1853 were with three different varieties : the Mercer or Philadelphia, the red Irish lunker, and the Carter. The ground was a greensward, plowed early in the spring, eight inches deep. Soil mucky; planted May 7; the hills were three feet apart each 
way; seed planted whole. Hoed twice; last time slightly hilled. We have made selections from the principal results, and embodied them in the following table, which shows the produce of the three varieties without any manure, and the effect of the various fertilizers applied in the hill at the time of planting.

\begin{tabular}{|c|c|c|c|c|c|c|c|c|c|}
\hline \multirow{2}{*}{$\begin{array}{l}\text { Description of the manures, and the quantity } \\
\text { applied in each hill. }\end{array}$} & \multicolumn{3}{|c|}{$\begin{array}{l}\text { Total number of } \\
\text { bushels per acre, }\end{array}$} & \multicolumn{3}{|c|}{$\begin{array}{c}\text { Increase per acre } \\
\text { from manure, in } \\
\text { bushels. }\end{array}$} & \multicolumn{3}{|c|}{$\begin{array}{l}\text { Quantity of un- } \\
\text { sound potatoes per } \\
\text { acro, in bushels. }\end{array}$} \\
\hline & 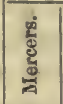 & 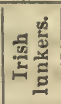 & 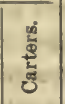 & 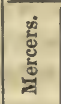 & 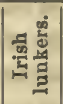 & $\frac{2}{\frac{2}{2}}$ & & $\frac{a}{\frac{x}{b}}$ & 离 \\
\hline & & & & & & & & 1 & 2 \\
\hline 2. & $130 \frac{2}{3}$ & 255 & 28 & 58 & 138 & 147 & $15 \frac{2}{3}$ & $26 \frac{1}{2}$ & 21 \\
\hline " long, unfer & $104_{3}^{2}$ & $154 \frac{1}{2}$ & $179 \frac{2}{3}$ & 32 & $37 \frac{1}{2}$ & 45 & $8 \frac{1}{3}$ & 20 & 4 \\
\hline compost... & $89 \frac{1}{2}$ & $183 \frac{\pi}{2}$ & $152 \frac{1}{2}$ & 17 & $66 \frac{1}{2}$ & 18 & $4 \frac{2}{3}$ & $17 \frac{1}{2}$ & 8 \\
\hline 5. - Tablespoonful of $\mathrm{gu}$ & 87 & 172 & 13 & $14 \frac{1}{2}$ & 55 & 00 & $1 \frac{2}{3}$ & 6 & 3 \\
\hline superpho & $96 \frac{2}{3}$ & $169 \frac{1}{2}$ & 138 & 24 & $52 \frac{1}{2}$ & 4 & $4 \frac{2}{3}$ & 3 & \\
\hline gypsum or plaster. & ...... & $106 \frac{1}{2}$ & $\ldots$ & $\ldots .$. & $10 \frac{1}{2}$ & 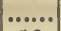 & & $3 \frac{1}{2}$ & \\
\hline 8. $-\frac{1}{2}$ handful of $p$ & $89 \frac{1}{2}$ & 16 & 14 & 17 & 46 & & 31 & & 38 \\
\hline dful of whe & $96 \frac{1}{2}$ & $148 \frac{1}{2}$ & 150 & 24 & $31 \frac{1}{2}$ & 16 & $5 \frac{1}{2}$ & & \\
\hline 10.- & $75 \frac{2}{3}$ & & .... & 3 & $23 \frac{1}{3}$ & ..... & $5 \frac{1}{2}$ & ...... & $\cdots$ \\
\hline 11. $-\frac{1}{2}$ handf & 85 & $143 \frac{1}{2}$ & & $12 \frac{1}{2}$ & $26 \frac{1}{2}$ & & 1 & & \\
\hline 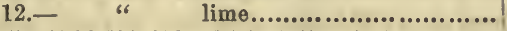 & & & & & & & & & \\
\hline
\end{tabular}

There is a striking difference in the yield of the three varieties-the Mercer, in every case, producing less than the Irish lunkers and the Carters. They have, however, as a general thing, fewer unsound potatoes. The Carters appear to be exceedingly liable to disease. In one instance, No. 4, with compost, more than half, or eighty-three and a half bushels out of one hundred and fifty-two and a half, were unsound.

The hog-manure in the second, as in the first experiments, gives the greatest increase with each variety. The Carters, with this manure, gave two hundred and eighty-two bushels in the aggregate, or two hundred and sixty bushels of sound potatoes, per acre. In these days of potato degeneracy, this is a good crop. Long, unfermented manure gives a comparatively poor crop with all the varieties. Poudrette, wheat-bran, hen-manure, and ashes have but a slight beneficial effect. Lime gave no increase, and gypsum would seem to have done more harm than good, since, with the Irish lunkers, the plot receiving a tablespoonful of plaster in the hill actually yields ten and a half bushels per acre less than that with no manure. This confirms the common opinion that plaster has little or no effect on low, moist soil; while on dry upland it usually proves beneficial. In the first year's experiments, on "gravelly loam," plaster applied when the potatoes were up gave an increase of twenty-six bushels per acre, and, applied in the hill at the time of planting, an increase of thirty-two bushels per acre.

The comparative value of superphosphate of lime and guano for potatoes is a matter of discussion just now, and we were in hopes that these experiments would have thrown some light on the subject. Unfortunately, however, the guano was applied in the hill with the potato, and, of course, the "seed was injured" and the crop lessened. Under these circumstances, it is hardly surprising that the guano, except in one instance, gives a less increase than the superphosphate. Our own experiments and observations on this point lead us to the conclusion that good Peruvian guano is a far superior manure for potatoes than superphosphate of lime. And, indeed, Mr. E. found, in another experiment with Irish lunkers, that guano, applied on the top of the hill at the time of planting, produces a better crop than superphosphate of lime similarly applied. Thus the unmanured plot gave per acre seventy-eight and a half bushels; the superphosphate, one hundred and ten and twothirds bushels; and the guano, one hundred and fifty-six bushels. It is said, too, that in this case also the seed was injured, though doubtless less so than where the guano was in actual contact with the tubers. It is seen that the guano doubles the crop, and gives forty-fire bushels per acre more than the superphosphate of lime. A tablespoonful of saltpetre (nitrate of potash) applied in the hill gave seventy-five and two-thirds bushels per acre, or three bushels less than where nothing was applied. This is in accordance with the previous year's 
experiments, where saltpetre lessened the crop four bushels per acre. A teaspoonful of sulphur gave an increase of six bushels; of gypsum, an increase of eight bushels; and a handful of charcoal, an increase of twenty-six bushels per acre. The experiment of early, medium, and late planting was again tried in 1853, and resulted, as before, in favor of early planting. Variety, Irish lunkers; whole tubers, planted in hills three feet apart. Those planted May 9 th gave one hundred and four bushels; May 30th, seventy bushels; and June 18th, only forty-five bushels, per acre.-Country Gentleman.

On the manures best suited for the potato.-Repeated experiments have confirmed the correctness of the common opinion that nothing equals hog-manure for potatoes. The cold nature of this manure has, perhaps, something to do with this; but we apprehend that it is due principally to the fact that, hogs eating much grain, the manure is especially rich in ammonia. At all events, it is pretty well ascertained that ammonia is largely required by the potato crop. Hence, for the production of a large crop, rich nitrogenous manures and Peruvian guano are the best.

Potatoes generally command a higher relative price than most other crops. Peruvian guano is an admirable manure for wheat; but at ordinary prices, say $\$ 1$ per bushel, it is questionable whether its application pays. On potatoes, at average prices, Peruvian guano is a highly profitable fertilizer. In 1853, H. C. Ives, Esq., of Rochester, planted four acres of potatoes: two without manure, and two dressed broadcast with six hundred pounds of Peruvian guano. The former produced two hundred and thirty-eight bushels; the latter, four hundred and ten bushels; that is to say, for three hundred pounds of guano an increase of eighty-six bushels per acre was obtained.

The experiments on potatoes on the State Farm of Massachusetts last year resulted as follows:

Barn-yard manure $86 \frac{1}{2}$ bushels per acre.

Mapes's superphospate......................................................... $84 \frac{\text { s }}{4}$

De Burg's "6

Guano...

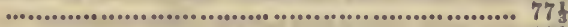
$92 \frac{1}{2}$

" " "

Twelve dollars' worth of manure was used in each case. It is to be regretted that the yield of the land without manure was not ascertained. The crop, owing to the drought, was small. The guanoed acre yields the best, though it is well known that dry weather is more hurtful to the action of gusno than to that of superphosphate. In another case on this farm, on land that had not been manured for four years, having been mown three years, and the last year cultivated with corn cut for fodder, "four hundred pounds of guano gave one hundred and eighty-nine and a half bushels of superior potatoes per acre."

From what we have seen of the effects of good Peruvian guano on potatoes, we feel great confidence in recommending it as a profitable fertilizer for this crop. We would sow from three hundred to four hundred pounds per acre broadcast, and thoronghly incorporate it with the soil before planting the potatoes. A somewhat better effect would be obtained by applying the guano in the hill, covering it with two inches or so of soil, and planting the potato on the top of it. Unless great care is used, however, there is danger of the plant being injured by coming in contact with the guano. It should be scattered over at least a square foot.-Albany Cultivator.

\section{Potato-Seed.}

A curroos fact, not generally known, connected with the production of potatoes from seedballs, is, that no two stems will possess precisely the same qualities, yet many of the tubers will appear so much alike that, when mixed together, they cannot be distinguished by the eye, though it may happen that one variety will be four times as prolific as the other, or may be much better in other respects. The tubers raised from the seeds of the same ball are also prodigiously diversified in regard to color, being pink, black, red, white, green, yellow, \&c.; and, as to shape, are round, nobbed, and varied in all proportions; as to size, some of them being no larger the first year than peas, while others exceed the size of a pullet's egg; as to "earliness," some of them completing their growth in July, while others will not put forth their blossoms until October; as to productiveness, some yield more than two hundred 
to one, while others will give only three or four-fold; as to spreading under the ground, some running out to a great distance, others growing quite near to the stem-some descending deep into the earth, while others will rise to the surface; as to quality, some will be tough and watery, some dry and mealy, some very pleasing to the taste, while others will not be palatable; as to the stems, some will carry a single rod, others an immense profusion of them, some being very luxurious, while others will be dwarfish. In short, as is very remarkable, no sort of connection will be found to exist between any of the peculiarities of the two specimens.

Charles Sears, of the Phalanx Farm, in New Jersey, has communicated to the Working Farmer a detailed statement of the result of sundry experiments he has tried in planting potatoes, with a view of determining whether it is most profitable to plant whole seed or small cuttings. The general conclusions are thus stated:-It will be perceived that the ratio of product to seed is greatest from the smallest-cut seed, as might be inferred would be the case; but deducting the quantity of seed in each case, the net produce per acre is uniformly in favor of planting whole seed, and also as clearly in favor of planting large-sized whole seed, when the cost of seed does not exceed a dollar a bushel, and the crop sells for fifty cents or more; the ratio of product per acre of marketable potatoes from whole seed being relatively as $100,90,73$, and from smallest-cut seed as $62,44,34$. Taking only the first or largest-sized potatoes, the ratio of product per acre from whole seed is as 100,73 , 67. I have also estimated a money valuation of the crop, and the extreme difference at the prices named between the product of the large-sized whole seed and that of the smallest-cut seed is as $\$ 86, \$ 76$, and $\$ 40$, the latter figure being 46 per cent. of the former.

In the foregoing estimation of net results $I$ have not taken account of the cost of culture and marketing, so as to show the actual profit of the crop, because the cost and product differ so greatly in different sections of the country.

Mr. E. C. Roberts, in the New York Country Gentleman, gives the following directions, based on his experience, for cultivating the potato. He says-

"To get seed-roots, select one-fourth acre of arable land, (on which water will not stand,) on an eastern slope, (new land is the best for this use,) fit early in the spring, furrow four or five inches deep, and two feet apart. Select seed-roots that are about the size of a hen's egg, that have touched the ground during the previous winter. Do not cut them; drop one every six or eight inches apart in the furrows, cover them by filling the furrows, and then put a top dressing of two inches of straw or forest-leaves on each row. When the tops are two inches high, pass between the rows with a shovel-plow; follow with a hoe destroying the weeds, and levelling the ground; do not hill. You have nothing more to do until fall, when the ground begins to freeze; then cover with half-rotten straw, chaff, or forest-leaves, three or four inches deep. Your potatoes will now have a chance to ripen and rest during the winter.

"I shall now direct you in planting for culinary use next season. The spring following, before your potatoes sprout, you will plant another seed-patch, as above directed. You will now take the residue, and plant a field crop for culinary use. Plant in drills, four or five inches deep, and three feet apart; drop a potato every eight or ten inches, cover by filling the furrows; cultivate or hoe twice. In this way you will get the greatest yield and best quality. Continue a similar practice from year to year, and, from my own experience, I believe you will find your potatoes yearly increasing in yield and quality.

"The third year you may increase your field crop by plowing in fine manure. All who follow my directions will, the second year, see many seed-balls on the vines in their seedpatch. These may be planted in the fall as I have done, and cultivated carefully, and good will undoubtedly result from it, if pursued in nature's own way. The potato will grow wild in our forests, if planted in them, and thus save those the trouble (who wish to get the wild root) of resorting to their native forests in South America. Finally, we may apply nature's laws profitably to most other products. Seed of every variety should be fully matured, i.e. not harvested until fully ripe. That which approaches the nearest to perfection should be selected for seed, and all roots for seed purposes should remain in the ground where they grew until they bear seed." 


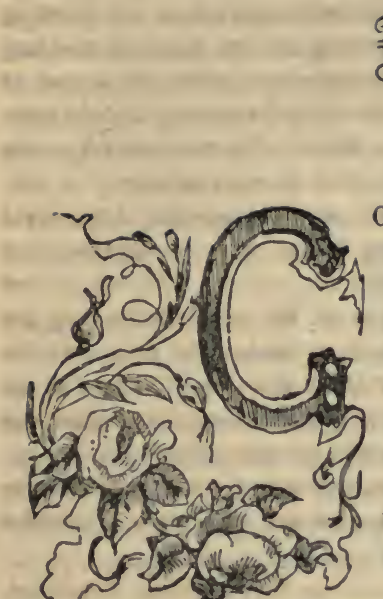

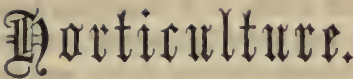

\section{Ancient Gardening.}

OSSIP on Ancient Gardening" is the title of a German work recently translated and published in England by Herr Wüstemann. The three principal topics discussed are-the practice of grafting among the ancients, the cultivation of the papyrus, and the cultivation and use of the rose. In addition, the book contains much additional information, in the form of notes, respecting the agricultural, horticultural, and botanical notions of the ancients, the subjectmatter having been originally prepared in the form of lectures for the Society for the Promotion of Horticulture, at Gotha, Germany.

In respect to the cultivation and appreciation of the rose among the ancients, M. Wüstemann gives us the following information:-

The love of the ancients for roses was something fanatical. We do not so much refer to the poets, for probably the modern and the antique bards may vie with each other in the use of the rose as a commonplace of poetical illustration; but we allude to a strong passion for the visible, tangible, scent-giving rose, as something to be enjoyed by all the five senses, scarcely excluding that of hearing, for a rustle of many roses must have attended some of the more extraordinary manifestations of the idolatry. A time without roses was a contingency to be avoided at any cost; and the Romans, though the mildness of their climate allowed the adored flower to grow at an unusually late season, could not submit to the privations of a winter. Not only were whole ship-loads of roses brought from Alexandria in the inclement season, but various means were devised for $p$ sserving the gathered flowers throughout the year with as much freshness as was attainable. The wreath of roses of which one reads and writes about so often, without any other image than of a curved twig with a tolerably rich supply of floral ornaments, was capable of a high degree of elaboration, for the Roman florists looked upon an enlacement of whole flowers as an exceedingly meagre affair. For a grand work of art, they took the rose-leaves separately, laid them over each other like scales, and thus produced a sort of fragrant sausage.

This refinement in the construction of wreaths is sufficient to show that the luxurious ancients not only insisted on the constant presence of roses, but rere determined to have them in as huge a quantity as possible. The anecdotes that illustrate this :orm of the floral passion could scarcely be surpassed in wonder by the wildest imagination.

To enjoy the scent of roses at meals, (says Herr Wüstemann, ) an abundance of rose-leaves was shaken out upon the table, so that the dishes were completely surrounded. By an artificial contrivance, roses, during meals, descended on the guests from above. Heliogabalus in his folly caused violets and roses to be showered down upon his guests in such quantities that a number of them, being unable to extricate themselves, were suffocated in flowers. During meal-times they reclined upon cushions stuffed with rose-leaves, or made a couch of the leaves themselves. The floor, too, was strewed with roses, and in this custom great luxury was displayed. Cleopatra, at an enormous expense, procured roses for a feast which 
she gave to Antony, had them laid two cubits thick on the floor of the banquet-room, and then caused nets to be spread over the flowers in order to render the footing elastic. Heliogabalus caused not only the banquet-rooms, but also the colonnades that led to them, to be covered with roses, interspersed with lilies, violets, hyacinths, and narcissi, and walked about upon this flowery platform.

As a source of artificial perfumes, the rose was employed by the ancients in other ways than in those oils and waters that are familiar to modern life. When the leaves had been pressed out for higher uses, they were dried and reduced into a powder, called "diapasma," which was laid on the skin after a bath, and then washed off with cold water. The object of this process was to impart a fragrance to the skin. As a medicine, quinces preserved in honey were introduced into a decoction of rose-leaves, and the preparation was deemed good for complaints of the stomach. In the culinary art, roses had likewise their place of honor, and were put into many dishes for the sake of their pleasant flavor. For this end they were sometimes preserved-a delicate process, as they were very apt to become mouldy.

But the connection between the rose and the kitchen takes its most imposing form in the rose-pudding, for which we give Herr Wüstemann's receipt, based upon the authority of Apicius:

Take cleaned rose-leaves, carefully cut off the white part at the lower extremity, put them into a mortar, and pound them, continually sprinkling them meanwhile with a "sauce piquante." Afterwards, add about a glass and a half of the same sauce, and pass the whole through a sieve. Next, take the brains from five calves' heads, remove the skin, and sprinkle over them a drachm of fine pepper. Beat all this in a mortar, still pouring in the sauce as before. Then take the yolks of eight eggs, stir them up with a glass and a half of wine and a glass of sack, and add a little oil. Lastly, anoint the form, into which the whole is put, with oil, and so bake it that it may be equally heated at the top and at the bottom. The pudding is then served up hot.

\section{Influence of Poetry on the Cultivation and Appreciation of Flowers.}

"Every one," says Ruskin, "who is about to lay out a limited extent of garden, in which he wishes to introduce many flowers, should read and attentively study, first Shelley, and next Shakspeare. The latter, indeed, induces the most beautiful connections between thought and flower that can be found in the whole range of European literature; but he very often uses the symbolical effect of the flower, which it can only have in the educated mind, instead of the natural and true effect of the flower, which it must have more or less upon every mind. Thus, when Ophelia, presenting her wild flowers, says, 'There's rosemary, that's for remembrance, pray you, love, remember; and there's pansies, that's for thoughts'-the infinite beauty of the passage depends upon the arbitrary meaning attached to the flowers. But when Shelley speaks of

\footnotetext{
'The lily of the vale, Whom youth makes so fair, and passion so pale, That the light of her tremulous bells is seen Through their parilions of tender green'-
}

he is etherealizing an impression which the mind naturally receives from the flower. Consequently, as it is only by their natural influence that flowers can address the mind through the eye, we must read Shelley to learn how to use flowers, and Shakspeare to love them. In both writers we find the wild flower possessing soul as well as life, and mingling its influence most intimately, like an untaught melody, with the deepest and most secret streams of human emotion."

\section{New Roses.}

Mr. C. G. Wrukinson, of Ealing, England, furnishes to the Horticulturalist the following memoranda of the recent new varieties introduced into England:-

For the last season or two there has been no paucity of novelties among roses, many of which may fairly claim, not only distinctness of color, but decided improvement in form. Of 
those which have been introduced, and naturalized sufficiently to enable them to be spoken of with something like confidence as to their various habits, \&c., those here particularized may safely be added to collections without fear of disappointment. Starting with the gems of the season, (1853-4,) "Prince Leon" and "Paul Dupuy" fairly claim that title-the first a clear cherry-crimson, not very double, but with petals of a substance which give its autumnal bloom quite a non-fading character, retaining its form and color four days in perfection, besides which, it is a model of the cup-shape, with a robust habit; the other, a rich shaded crimson, with a full centre, its guard-petals giving it the cup-shape also, but shallower; they are both sweetly though differently scented. Of clear pink varieties there are several good ones. "Baron de Heckheren" and "Louis Peronny" are our choice; both are nicely formedthe habit of the latter is, however, the stoutest. "Baron de Kermont" is also a good variety in the same style, but rather vase than cup-shaped. Of "rose colors," deep, bright, rich, \&c. \&c., we have received a host; the cream of them, however, may be considered to be included in the following:- "Joseph Descaine," "James Veitch," "Comte de Bourmont," "Inermis," "Dr. Julliard," and "Eugene Sue,"-all being of the old-fashioned color, with nicely-formed flowers; the last is a fine rose, but rather a "hard opener." "Duchesse d'Orleans" must not be forgotten in the rose colors, being of a shade tinged with lilac, and is a fine, bold, and perfectly-formed flower.

The various shades of carmine are so generally admired, that good varieties of that color are sure to be acceptable. "Alexandrine Bachmetiff" and "Souvenir de Levison Gower" are both nicely formed and richly colored. "General Castellaine" is, however, rather darker, and of model form, but not of over robust habit, and "Charles Boissiere," of a reddish tinge, is large, and very double, and an excellent pot-rose.

In crimsons we have certainly a glorious flower in "Le General Jacqueminot," a rich velvety petal, not quite so bright as "Geant des Batailles," nor quite so double, but larger, with very much better form. "Souvenir de Reine des Belges" is a nice flower, in the way of "Prince Albert" H. P., but brighter, and somewhat like "Rivers." “L'Enfunt du Mont Carmel," a light crimson, is desirable where large, robust-growing varieties are essential. Of really dark Hybrid Perpetuals there has been long a want, and in "Triomphe de Paris" we have a variety many shades darker than any of its predecessors, its color being as near an approach to the crimson Boursault as possible; it has also the shallow cup-form to perfection.

The new white Damask Perpetual, "Celina Dubos," with very pale blush centre, though believed to be a sport from "Rose du Roi," is very constant, and is the nearest approach to pure white among the perpetuals; the raising a Hybrid Perpetual of that color (?) having yet to be accomplished. The two brightest H. P.'s that may be depended on are "Mrs. Rivers," a beautifully-shaped and scented rose-a counterpart in color and shape to Alba "Le Seduisant;" the other, "Rosine Margottin," is also well formed, but the petals are not so deep as the former, and may be described as "Duchesse de Montpensier" much improved.

To the Bourbons we have several additions, the best of which is undoubtedly "Vorace," a rich, beautifully-formed crimson, shaded with purple. "Prince Albert," (Paul's,) a bright deep-cherry color, is good; as is "Souvenir de l'Arquebuse;" and the peculiar crimson, shaded with purple, of "Reveil" is novel, besides which, "Lonis Odier," a bright rose color, of strong habit and good shape, is a useful variety.

In Tea Roses the greatest recent novelty is "Gloire de Dijon," and certainly the color, an ochreous yellow, the size, as large as "Jaune Desprez," and the tea-scent, make it a great acquisition. "Madame Willermouz," in the way of, but hardly so stout as, "Devoniensis," has a nankeen centre, is a nice rose; and "Canary," the name of which well conveys the color, is very pure, but it is rather delicate, and not very double.

In this list $I$ have purposely confined myself to those which have earned the characters here given of them in an exposed situation and a cold, stiff soil. There are, I am aware, several which I might, perhaps, have included with safety, but I would much rather delay those here omitted, that I may include them with equal confidence in a list that I trust I shall be spared to prepare. 


\section{Plants for Hanging Vases.}

As a means of floral ornament about our houses, we are not confined to climbing vines and flowers trained to the posts, pillars, or connecting lattice-yyork, but over our heads and around us the most interesting effects may be produced by growing flowers in suspended vases or baskets. Nature has kindly provided us with the means of enjoyment, under even apparently the most unpropitious circumstances, and here she affords us a large list of plants, which not only grow well in the shade, but from their drooping or pendulous habit seem to have been as expressly designed by her for this very mode of culture, as a watch from its works seems designed to measure time. As she has provided the plants, we cannot do less than supply the baskets; and accompanying this article, we give sketches of very pretty pat-

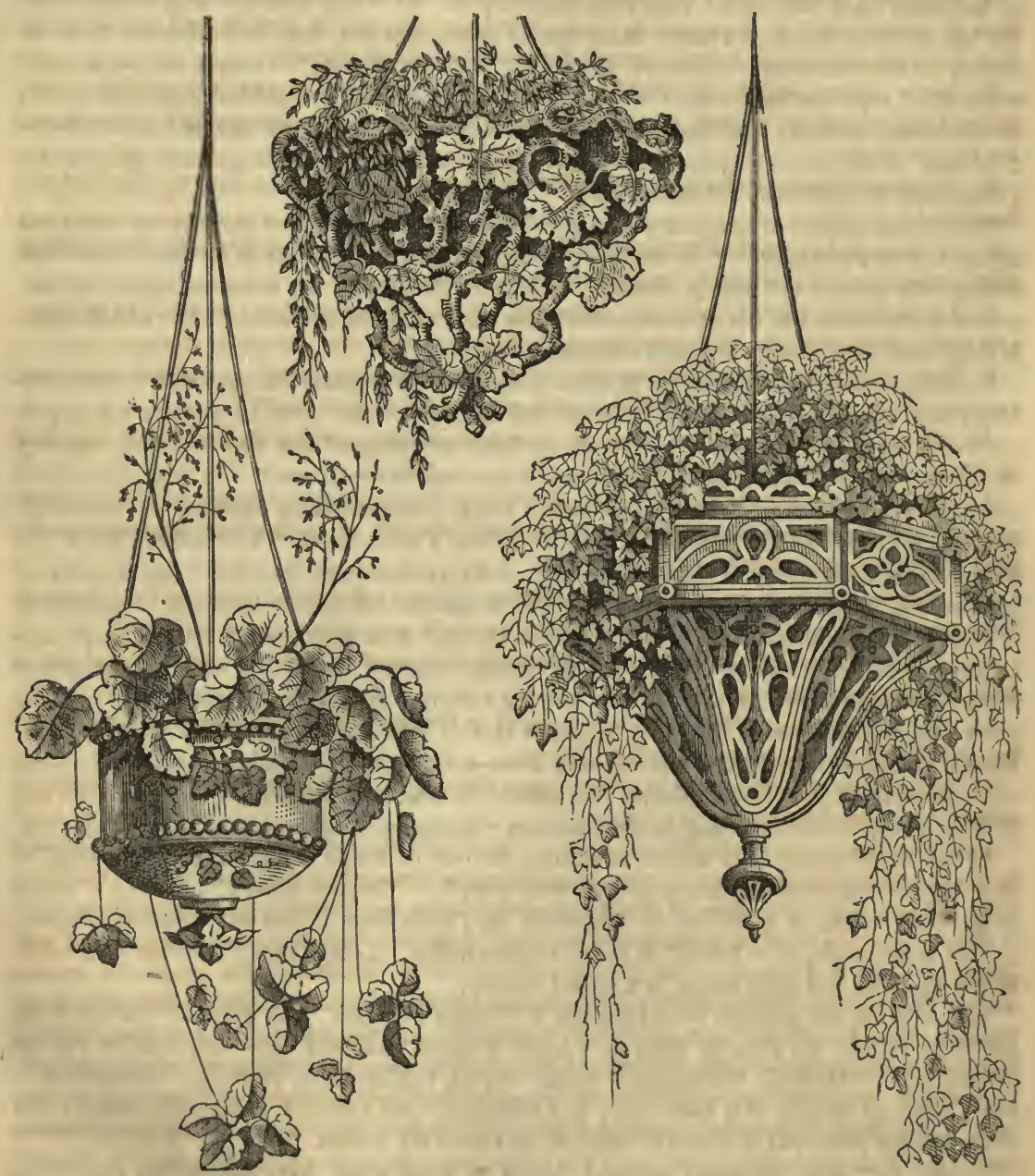

terns made of pottery-ware, which, or similar, may be had of the principal horticultural stores in the large cities. Some very handsome articles may also be made for the same purposes out of branches of trees-oak, cedar, or of some durable wood. Common boards may even be nailed together, and taste and ingenuity exercised in covering it with bark or the scales of pine-cones.

In these vases, and in the partial shade afforded, the following plants will thrive well, re- 
quiring but little water or other attention; and at the approaeh of winter may be taken down, and hung in the parlor, hall, or entry, to add an additional eharm to domestie pleasures for the rest of the year.

1. Linaria cymbalaria: Iry-leaved Snapdragon.-Well known to European travellers from its frequency on the walls of shaded ruins. It is a delieate and graceful grower, bearing a profusion of small purple flowers the whole season.

2. Lysimachia numularia: Yellow Creeping Loosestrife-Has a very pretty habit of growth in its slender stems and small opposite leaves, bearing as it grows in their axils yellow flowers about the size of gold dollars.

¿. Saxifraga sarmenlosa: Creeping Saxifrage.-Its foliage is very prettily veined and marbled, and the spikes of white flowers it throws up are eurious as well as handsome.

4. Fragraria Indica: Mock Strawberry.-Its fruit, though as insipid and tasteless as the food of ghosts might be supposed to be, is so very pretty, and it does so well in the shade, that there are few things I would sooner reeommend for our purpose.

5. Vinca major: Large Periwinkle.-An evergreen with leaves one and a half to two inehes long by one broad, and large blue flowers opening only in the spring; best adapted for large baskets.

6. V.minor: Lesser Periwinkle.-Smaller every way than the last; yet very distinet and handsome.

7. V. perenne : Creeping Periwinkle.-A very distinct species, with long, slender ereeping stems, small leaves, and small, very early blue flowers.

8. Cereus flagelliformis: Catstail or Creeping Cereus-Grows well in the shade in summer, and when removed to the parlor in winter, flowers well near the light of a window.

9. Sedum Sieboldii: Siebold's Stone Crop-With pale purple flowers and glaucous leaves; requires little water or pot-room, and is well adapted for a small vase.

10. Sedum acre: Yellow Stone Crop, or "Love Entangle"-Doing well in either sunshine or shade, and a most abundant bloomer.

11. Viola odorata arborea: Tree Violet-Which, with strong eentral stalks, sends out numerous slender branehlets, hanging over the sides of the pot or basket, and bearing a profusion of very sweet double blue flowers.

12. Calystegia pubescens: Double Convolvulus. A pretty flowering plant, and not likely to be so mueh objected to on aeeount of its ereeping roots here, as in the open ground.

13. Epigea repens: Ground Laurel.-A hardy evergreen with delieiously-seented waxy white flowers, very pretty.

14. Milchella repens: Partridge-berry.-Another evergreen with sweet-scented white flowers, sueeeded by numerous holly-like berries.

15. Polemonium reptans : Creeping Valerian.-Erect spikes of blue flowers, from branehlets which hang over the sides of the basket.

I have eonfined myself to hardy or very nearly hardy plants, and which will thrive and do well in the shade; any of the above may be depended on.-Thomas Meehan : Phila. Horticulturist.

To the above list the editor of the Hortieulturist adds the following additional plants:-

Cobcea scandens as a basket-suspending plant does well, but requires a largish pot and plenty of spaee to droop in. The Lophospermums.-Every species of this genus will answer well. Mraurandia.-All the speeies and varieties. Nierembergia.-All will do well in baskets. Roses trained downward, particularly the Viscomtesse des Cases, will grow and flower well in baskets in green-houses. The Ivy-leaved Geranium in suspended pots quite eovers and eoneeals them. The Verbena, and even the grateful Strawberry, might be cultivated in this way, under glass, and would yield to few other plants for beauty in bloom and fruit, besides yielding a dish now and then of one of the most health-giving fruits we possess.

\section{Green-house Plants for Winter Bouquets.}

Mr. Thomas Meenan, in the Horticulturist, communieates the following article on the selection and charaeter of a stock of winter-blooming green-house plants, suitable for forming baskets and bouquets. I will suppose, says Mr. M., that we have nothing to commence 
with, and have to order a stock to form the nucleus of a permanent collection. I should select the following:-

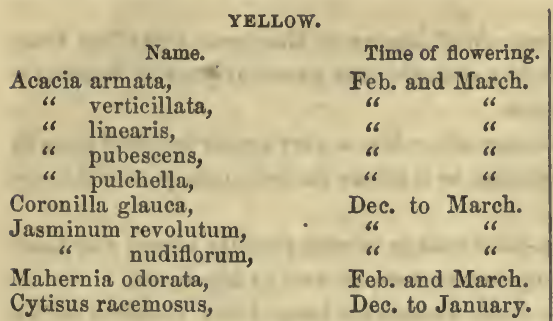

ORANGE-COLORED.

*Abutilon striatum, Cheiranthus Marshallii, Chorizenia varium, " cordata, * Cestrum aurantiacum, - Mannettia bicolor,

* Lantana cracea,

Tropæolum Lobbianum,

\section{WHITE.}

Alaysia citriadora, Cyclamen Persicum, Daphne indica album, Epacris paludasa, " nivalis,

Eupatorium canescens, Fabiana imbricata, Jasminum grandiflorum,

*Jasminum azoricum, Primula sinenis, double Solanum jasminoides, Stevia serrata, Viburnum tinus, Gardenia florida, * Gardenia radicans, Spiræa prunifolia, Deutzia gracilis, " scabra,

Eupatorium elegans, Sparmannia Africana,
Oct. to April.

Dec. to Feb. Nov. to March. Jan. to March. Oct. to February. Oet. to March. "6 "6

Nov. to February. Nov, to March. Feb. and March. Feb. and March. Jan. and Feb. Nov. to January. Feb. and March. Sept. to Dec.

Sept. to March.

Oct. to January.
Oct. to March.
"
Feb. and March.
"6 "

Dec. and Jan. Dec. to Feb.
PINK AND PURPLISH.

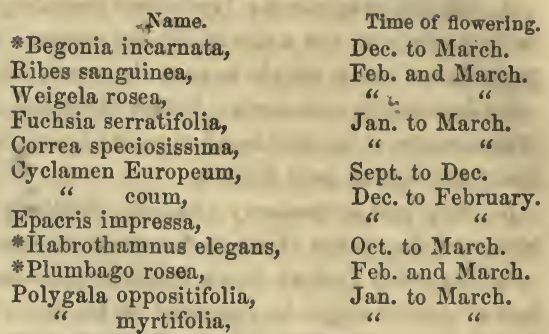

Primula sinensis, double purple, Sept. to Dec. BLUE AND LILAC.

*Heliotropium Voltairaneum, Sept. to April. Salvia patens, Scpt. to Dec.

Viola arborea, $\quad$ Oct. to February. "Neapolitana,

* Pentas carnea, Ageratum coelestinum, Ceanothus rigidus, Neirembergia gracilis, Plumbago capensis, Tropæolum azureum, Veronica Andersonii, Dec. to February. Sept. to April. Oct. to February. March and April. Jan. to April. Sept. to April. Nov. to Feb. Sept. to Dec.

\section{SCARLET AND RED.}

*Euphorbia jacquinæflora, Nov. to March. * Poinsetta pulcherrima, Cuphea platycentra, Bouvardia triphylla, Sept. to Nov.

*Epacris grandiflora,

Hoitzia coccinea,

*Ruellia formosa,

Salvia splendens,

* Aphelandra Ghiesbrechtii,

* Geissomeria elegans,

*Hibiscus rosa sjensis,

Russelia juncea,

Tropæolum tricolorum,
Sept. to March.

Sept. to April.

March and April.

Feb. to April.

Nov. to April.

Oct. to Feb.

Dec. and Feb.

Sept. to Feb.

Sept. to Nov.

Jan. to April.

All of these will do perfectly well in a green-house. Those marked* do best kept a little warmer than the others. They are all of the easiest possible culture, and come into flower between the periods named-different modes and circumstances making a slight difference. Having procured these plants early in the spring, we next proceed to their culture for our proposed object. The tuberous-rooted section, comprising Tropceolums and Cyclamens, will be nearly or quite out of flower; they will require but an occasional supply of water, say once or twice a week, till the leaves are decayed, when the pots containing the plants should be set on a shelf, where they can be kept nearly dry till the end of August, when they may be taken out and replaced with fresh sandy loam in the same pots as before, watered sparingly until they have an abundance of foliage, then to receive an abundant supply. Another class, comprising Acacia, Cytisus, Chorzemia, Daphne, Correa, and Polygala,-if the pots are full of roots, as they often are on being received from a nursery, - should be shifted into pots a size larger, in a soil consisting for the most part of turfy loam, with a small quantity of turfy peat or half-rotten sticks added to it. They will, of course, receive regular watering through the summer, and during the hot season be placed where, for six hours or so, during midday, they can be protected from the sun.

The whole of the other plants may be turned out into a half-shaded border, which has previously been deep dug and lightly manured, till the end of August, when all but Spircea, Deutzia, Weigela, Ribes, and, in short, all but deciduous shrubs, should be prepared for lifting 
into pots. This preparation consists in giving them a thorough soaking with water a few hours previous to taking them up, without which they will suffer materially under the operation. Put them in as small pots as possible, place them in a situation where they will get only the morning sun for some days, and during that time sprinkle them every few hours with water through a fine-rosed waterpot or syringe, and place them gradually in the full light as they seem able to bear it. They will "miss the change" but very slightly, and, besides the requisite labor attending plants kept in pots the whole season, will be much better plants. The exceptions to the above (deciduous shrubs) are best left in the ground till their leares are ready to fall, say about the end of September, as, if they are lifted before the wood is ripe, they seldom flower freely. The plants should be all housed before the weather becomes even "white frosty," and at the return of spring, or, in this latitude, early in May, set out of doors a few days, then cut down as is usual with geraniums, and afterwards planted out to grow, as in the previous season. When the plants turned out of doors have begun to grow, a few young shoots of each kind should be taken off and struck. Young plants thus raised will come into flower a few weeks after the old ones are gone out, and will, besides, come in useful to retain wherever the old ones grow too large. Besides the plants I have above noted as permanent green-house plants, there are many special things that cannot be dispensed with. The Camellias Double While, Candidissima myrtifolia, and Lady Hume's Blush are essential in a collection of bouquet flowers; nor can Azaleas Indica alba, Phonicia, and Smithii be omitted. These can be grown with the other plants, by giving them an open, turfy soil, well drained, and an abundance of water while growing; little when comparatively at rest and partially shaded in summer-time. The Horse-shoe or Scarlet Geraniums, Geranium Comptonianum, the Oak-leaved, and Rose-scented are essential ingredients in my idens of a winter bouquet; and in the spring of the year, the lighter-colored Cinerarias and white and scarlet Verbenas. Cuttings of all these should be put in expressly for this purpose early in the summer, and grown for a few months in the fall. Mignonelle and Phlox Drummondii should also be sown in pots with these, for the same object.

The Rose must not be forgotten. For a small green-house, I would select the following kinds as blooming very freely under very common treatment: Cels, white; Devoniensis, pale lemon; Ludame Bosanquel, creamy white; Souvenir de Mlalmaison, rosy white; Caroline, salmon white; Lyonnais, salmon; Common Daily or Monthly China, pink; Hermosa, rose ; Carmin Bean, purplish rose; Agrippini and Louis Philippe, crimson. Roses for blooming early in winter should, in all cases, be turned out of their pots, and lifted in August, in the same manner as already described for a class of plants. When they are repotted, a good proportion-say one-third-of coarse stable-manure, with the turfy loam employed, will be of great service.

There are many other plants, and tribes of plants, which are indispensable to make a green-house gay in the fall, winter, and spring, as Chrysanthemums, Cactuses, Hyacinths, Lechenaultia, Pimelia, \&c. But I have thought it best to confine myself to plants which will serve at once to adorn the green-house and to cut for the centre-table.

\section{Directions for Making Bouquets.}

THE following directions for making bouquets are derived from a communication published in the Horticulturist :-

Hand-bouquets should not exceed eight inches in diameter, and if for an ordinary occasion, the flowers may be gathered without regard to color; but for a bridal bouquet white flowers should predominate, although violets, mignonette, and heliotropes may be added for perfume. For an ordinary bouquet, six or more large flowers are requisite, giving the preference to camellias and roses. The camellias should be cut off close to the calyx of the flower, and an artificial stem provided for it, either by a wire bent, as shown in fig. 1, which is thrust down through the centre of the flower, between the petals, so as to be entirely concealed, or else by passing the wire laterally through the upper part of the calyx and the lower part of the petals, as in fig. 2. In the latter case, the two ends of the wire should be bent down and twined together. The camellia is also sometimes cut off with a small portion of the stem, and 
tied to a small stick or twig. Be very careful in handling the camellias, as the slightest bruise will impair their beauty. The roses can either be cut with long stems, or tied to supports.

Fig. 1.

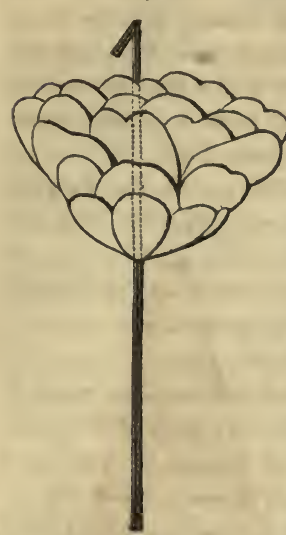

The smaller flowers should be arranged in very small bunches, or singly, and also tied to twigs or whisk. If the bouquet is of the pyramidal form, it should be made on a strong stick, as in fig. 4 , commencing at the top witis the smaller flowers, and gradually widening at the base with the larger, taking care to assort the colors so as to make as much contrast as possible, and also to fill in the interstices between the larger flowers with the smaller.

If the bouquet is flat, as shown in fig. 3 , it is not absolutely necessary to have a strong stick in the centre, but I would recommend it on account of its advantages in preserving a symmetrical form. Begin with a ca-

Fig. 3.

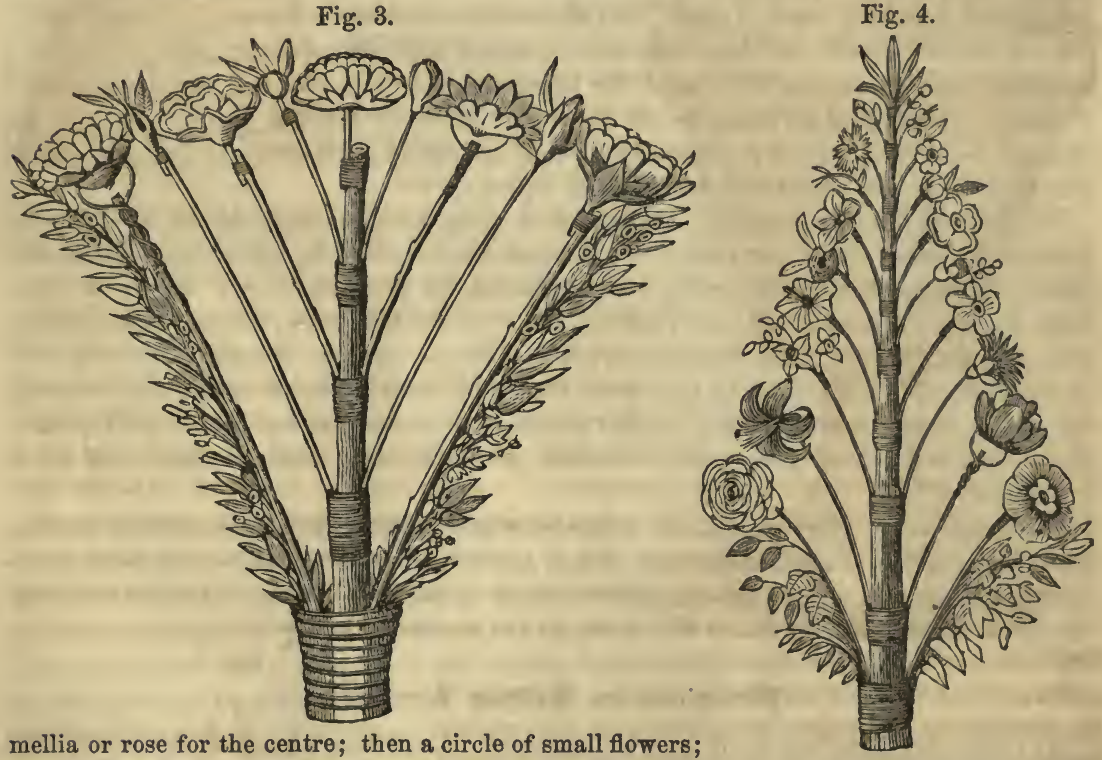

mellia or rose for the centre; then a circle of small flowers;

then say four or more roses or camellias disposed around the centre, and then another circle of small flowers; and then, if the bouquet is not large enough, another row of camellias or roses, and a few more small flowers, finishing with a circle of rose or oak-leaf geraniumleaves tied singly to whisk straws, and some arbor-vitæ, cedar, or other evergreen, below all. To preserve a flat or oval surface to a bouquet, be careful not to tie the stems or twigs too high up on the centre stick, for in that case the flowers would face outwards, as in a pyramidal bouquet, instead of upwards. If you wish a bouquet to be kept for a long time, the interstices between the twigs or stems should be filled with moss, evergreen, or any thing that will retain moisture. It will add much to the grace and beauty of the bouquet to introduce skilfully some handsome green foliage to break the monotonous effect; and some of the smallest and choicest flowers should be allowed to project beyond the surface of the bouquet. 
Large bouquets, or pyramids, for table ornaments, are generally made on a framework of evergreen. For this purpose, take a number of branches of cedar, hemlock, or other everFig. 5.

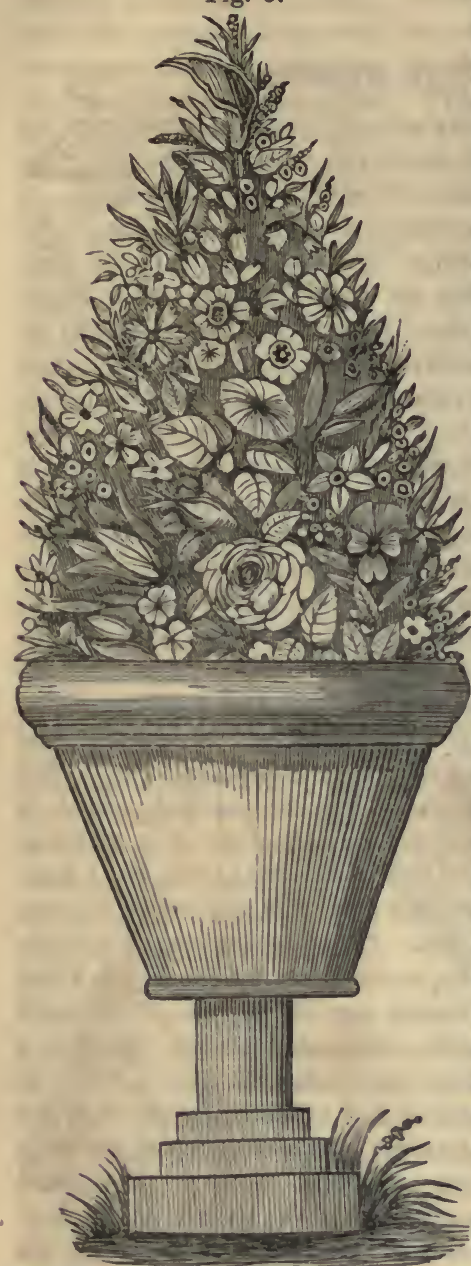
green, and bind them in a kind of sheaf, with strong twine, commencing at the top. After it is properly secured, trim off the stems at the base with a knife, so as to be perfectly even, and with a pair of scissors or shears clip the top so as to form a perfect cone. The flowers are to be inserted into this.

Fig. 6 represents a very complete apparatus for preserving flowers in water, and at the same time arranging them into the proper form for a table ornament. It is composed of a number of circular tin vessels, one over another, and diminishing in size from the base up, forming a cone. These vessels are filled with water, and the stems of the flowers inserted into them. Fig. 7 is a graceful design for a wire basket, to be lined with moss. It is of the shape called by ladies "gipsy," and the Fig. 6.

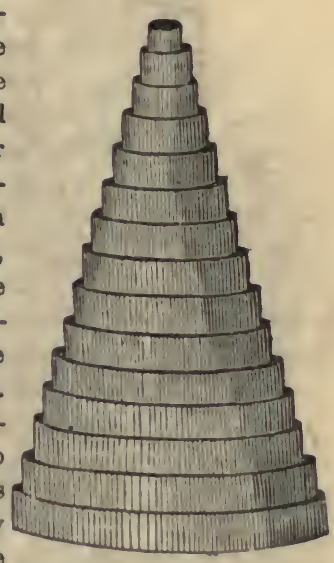
effect of it when filled with flowers is far more graceful than those of a more formal and rigid pattern. A wire basket for moss should hare a wooden base, and after the sides are lined with moss, the basket should be filled with wet or damp sand, which should be covered neatly with moss, taking care that the surface is oval, so as to display the flowers to advantage. The stems of the flowers should be inserted in holes made with a sharp stick in the sand. The choicest and smallest flowers should be used to cover the handle.

Fig. 5 represents a table ornament of simple construction, but of graceful design. Take a large-sized flower-pot, of say from fourteen to eighteen inches diameter, and cover its sides with sheets of moss, secured by passing strong black linen thread around it. This should be mounted on a wooden base, formed of two square blocks of wood, one smaller than the other, surmounted by a circular or cylindrical piece of wood. In the upper end of the latter should be a wooden or iron peg or bolt, which should pass up through the circular hole in the bottom of the flower-pot, to keep it in its proper place. On the upper edge of the flower-pot place a rim formed of a band of hay two or three inches in diameter, either twisted or tied around with twine. This and the wooden Fig. 7.

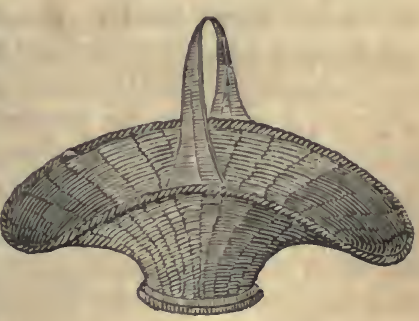
base should also be covered with moss. The pyramid of flowers may be made on a framework of evergreen, as just directed, or the apparatus fig. 6 may be used. Festoons on the sides would add greatly to the beauty of this design, and should be formed on pieces of hoop or wire. They should be large in the middle, and gradually diminish at both ends. 
I have thus endeavored, hurriedly, and briefly as possible, to describe, for the benefit of my amateur friends, the process of making bouquets and floral designs, and hope that $I$ have succeeded at least in affording them some assistance.

\section{The California Nutmeg-Torreya myristica.}

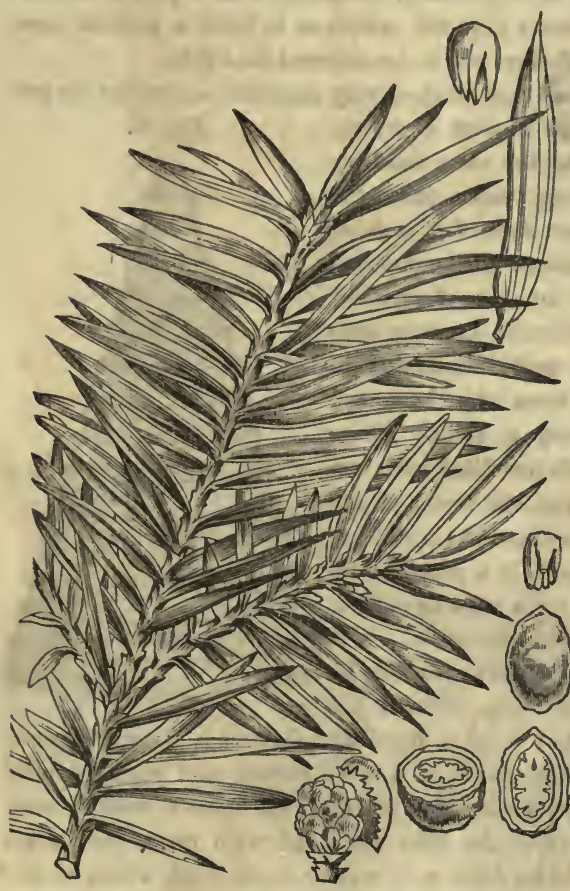

THE annexed engraving represents the tree which has of late years been often alluded to as the California nutmeg. It is a beautiful evergreen, growing to the height of thirty or forty feet, and inhabiting the elevated regions of the Sierra Madre. The fruit and kernel strongly resemble the common nutmeg. The slightest glance, however, at the internal structure of the fruit, at once identifies this tree with the Torreya of the Southern United States, found only in the Ashalaga and Apalachicola country of Middle Florida. The foliage has the form and deep rich green of the Florida species, or $T$. taxifolia, as well as of the yew; but the leaves are much larger, being from one and a half to two and a quarter inches long. They spread out on two sides, and are tipped with a sharp, rigid point. The fruit, as it may be popularly called, is about the size and form of a greengage plum, and in the dried state has a paleolive color; but this may not be its natural tint. The outer covering is a thick, fleshy, nearly-closed urceole, or dish, which completely invests the seed, and closely adheres to it, except near the summit. It is smooth and even, and soft to the touch. The seed is usually oblong, and greatly resembles a large pecan-nut, but frequently it is more ovate. The shell is smooth, thin, and fragile. The kernel is conformed to the shell, and has the external and internal appearance of the nutmeg. When cut transversely, the resemblance is perfect. The seed, however, is wholly destitute of the delicate aromatic odor of the Oriental spice, for it has the strong terebinthine character of the coniferæ. Neither is the fleshy covering of any known use. It is more probable that, like the fleshy cup-a-berry of the yew, it is of a poisonous nature. Still, the discovery of this tree is interesting to the botanist and to the horticulturist. But two other species are known besides. One of them (T. nucifera Sieb. and Zuce) is a native of Japan, and the other has only been found hitherto in Middle Florida, in very confined stations. As an ornamental tree, the California nutmeg deserves to be extensively cultivated. It must be hardy, as it grows on the mountains, where the winter is very severe. The enterprising Messrs. Parsons \& Co., of Flushing, sent out a person to California for the express purpose of collecting the ornamental and useful plants of that country; and among other varieties, he obtained, last year, some ripe and fresh seeds of the California nutmeg. These have since germinated freely.

\section{New Plants.}

Rheum nobile.-The annexed figure represents one of the most striking of the new plants brought by Dr. Hooker from the Himalayas. This plant, which is a true rhubarb, and has received the name Rheum nobile $2_{2}$ is about three feet in height, and forms conical towers of the most delicate straw-colored, shining, semi-transparent, concave, imbricating bracts, the 
upper of which have pink edges, the large, bright, glossy, shining, green radical leaves, with red petioles and nerves, forming a broad base for the whole. On turning up the bracts, the beautiful, membraneous, fragile, pink stipules are seen like red silver paper, and within these again the short, branched panicles of insignificant green flowers. The root is very long-often many feet-and winds amongst the rocks; it is as thick as the arm, and bright yellow inside. After flowering, the stem lengthens, the bracts separate from one another, become coarse red-brown, withered, atrd torn; finally, as the fruit ripens, they fall away, leaving a rugged-looking stem, covered with panicles of deep-brown pendulous fruit. In winter theso naked black stems, projecting from the beetling cliffs at an elevation of 14,000 feet above the sea-level, or towering above the snow, are in dismal keeping with the surrounding desolation of the season.

Such is Dr. Hooker's ac-

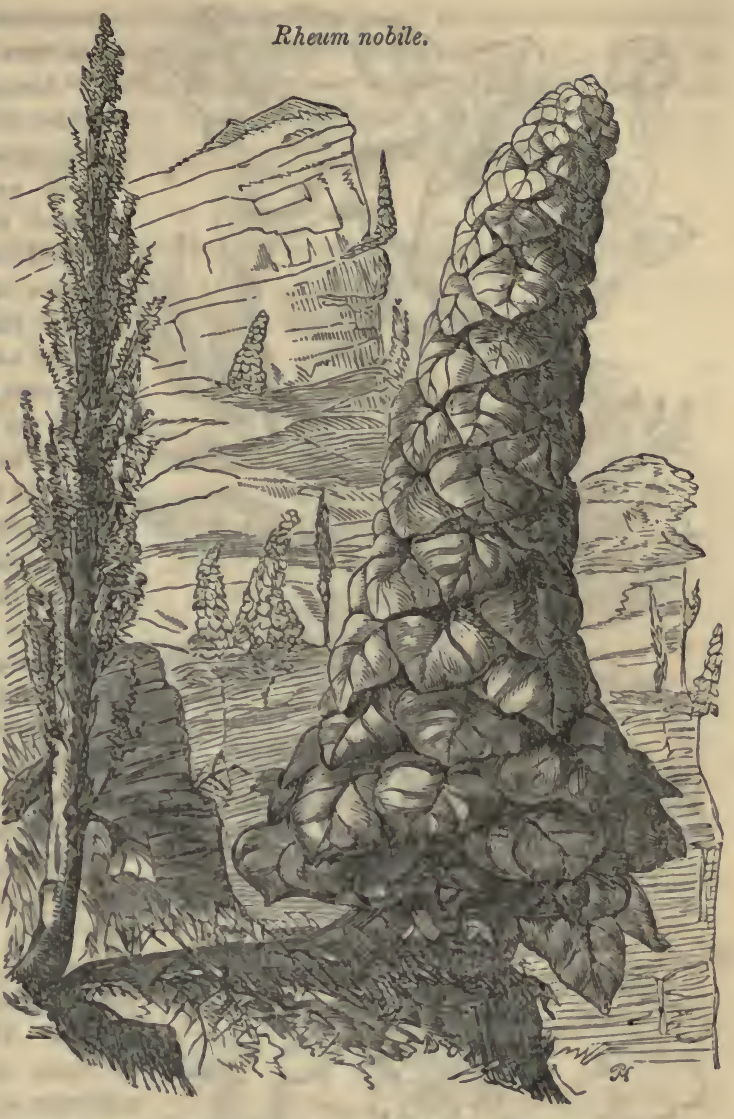
count of this curious plant. Some of the seeds sent to Kew Gardens grew, and the seedlings lived two years; but we regret to learn that they have now been lost.

Saxe-Gothara conspicua.- This remarkable plant, which will probably rank among the most highly valued of our hardy evergreen trees, is a native of the mountains of Patagonia, where it was found by $\mathrm{Mr}$. Lobb, forming a beautiful tree 30 feet high. In the nursery of Messrs. Veitch, of Exeter, England, it has lived in the open air four years without shelter, and has all the appearance of being well adapted to the climate of England. The country in which it grows is, indeed, more stormy and cold than any part of Great Britain. Its native habitat is described as the most desolate and sterile of any part of the western coast of Patagonia. One variety grows to an enormous size, particularly in the vicinity of the snow-line. Trees have been seen by Mr. Lobb upwards of 100 feet in height, and more than eight feet in diameter. Saxe-Gothæa may be described as a genus with the male flowers of a podocarp, the females of a dammar, the fruit of a juniper, the seed of a dacrydium, and the habit of a yew. The leaves of this plant have altogether the size and general appearance of the English yew, (Taxus baccata;) but they are glaucous underneath, except the midrib and two narrow stripes within the edges, which are a pale green. The male flowers consist of spikes appearing at the ends of the branches, in a raceme more or less elongated. The female flowers form a small, roundish, pedunculated, terminal, scaly, imbricated cone.

Mysore hexacentre, (Hexacentris Mysorensis.)-This charming stone-climber, from India, is well worthy the attention of amateur or professional growers of new and rare plants. It was shown first in England, in May, 1852, before the London Horticultural Society, and was pronounced the most attractive among all the new and fine plants exhibited. This is saying a 


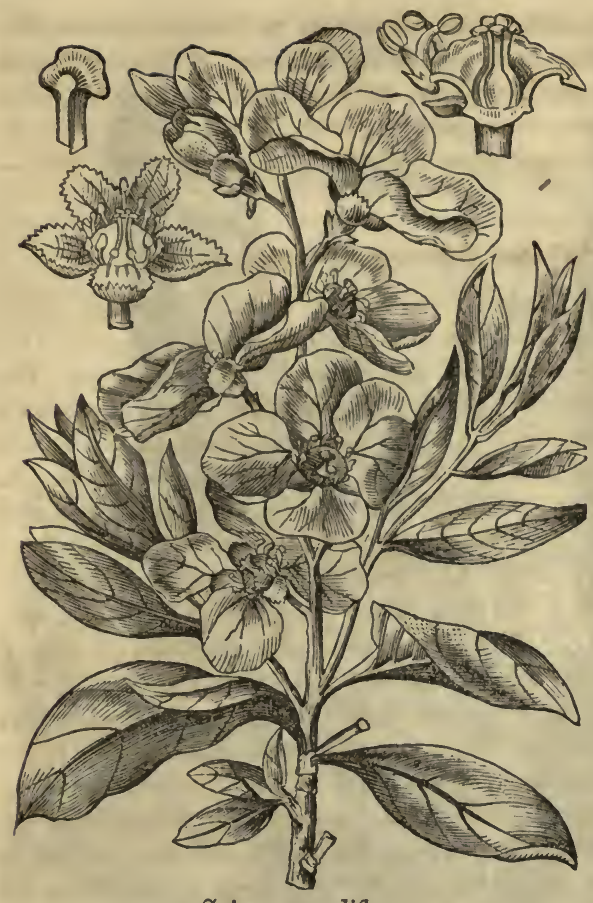

Spirea grandiflora.

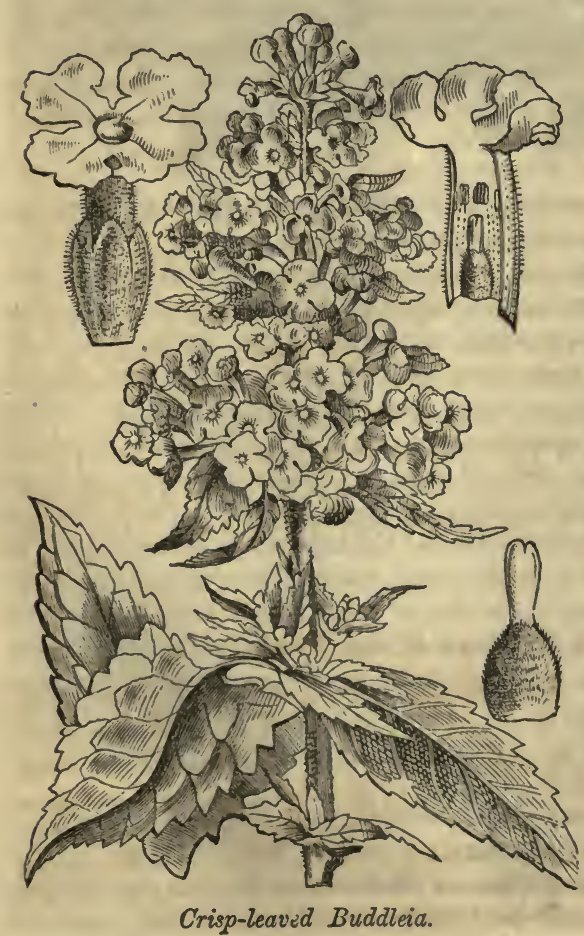

great deal. We copy the following description from "Paxton's Flower Garden:"-

"Among all the plants exhibited in the garden of the Horticultural Society last May, "none excited such universal interest as that now represented. It formed a small umbrella-like creeper trained over trellis, the whole circumference of which was loaded with pendulous racemes of most beautiful large yellow and crimson flowers. The plant was sent to Messrs. Veitch, of Exeter, from the Mysore country, which it inhabits, as its name indicates. No doubt it is the best hot-house climber that has been introduced for many years. It is added, that before the plant is out of bloom, the pendulous flower-stalks are from two to two and a half feet long.

Spirea grandiflora-Large-flowered Spirea. Nat. order Rosacea. (See Figure.) -This remarkable plant was sent by $\mathrm{Mr}$. Fortune, under the name of Amelanchier racemosa, from the north of China; and it is certain that its conspicuous, large flowers cannot fail to recommend it as a very desirable, ornamental, and shrubbery plant. The habit and foliage are that of an Amelancheir; but the structure of the flowers point to the genus Spiræa. The calyx-tube is remarkable in form, much contracted below, then suddenly at the narrow faux expanded and recurved, and the whole lined with a fleshy disc, at the end of which the fifteen stamens are inserted in threes. The species is extremely different from any hitherto described.-Curtis's Botanical Magazine.

Buddleia crispa, "Crisp-leaved Buddleia," from Western Himalaya, at an elevati ,n of from five thousand five hundred to seven thousand five $\theta^{\prime}$ hundred feet above the level of the sea, and a very desirable shrub for "English" gardens, where it requires the protection of a wall-flowering from the beginning of February until May, and scenting the air around with its fragrance. Description.-A shrub from twelve to fourteen feet high; branches opposite obtusely tetragonal, the younger ones densely covered with tawny or ferruginous down. Leaves on woolly petioles, one quarter of an inch long, ovate or oblong, the lower ones cordate at the base, upper ones 
cuneate, thick, tomentose, densely so beneath, with ferruginous or cinerous tormentum, the margin toothed and crisped, rarely entire, except in the upper leaves. Flowers arranged in capitula, constituting spikes or racemes, and these, from the many short flowering branches, forming panicles. Stamens, four; filaments, short; anthers, short, oblong; pistil, quite included; ovary, ovate, downy except at the base; style, very short; stigma, clubbed, bifid.Phil. Horticulturist.

\section{Propagation and Winter Forcing of Roses.}

AT a conversational meeting of the New York Horticultural Society, as reported by the "American Agriculturist," Mr. A. Bridgeman read the following remarks on roses:-

"My practice does not, I presume, differ much from that pursued by other growers. For compost, I prefer a proportion of two bushels of regetable mould or rotted leaves, two bushels of chopped sod passed through a coarse sieve wide enough to allow moderate-sized lumps to pass through, one bushel of hotbed manure, and one of sand. The sod I use is clayey. In propagating by cuttings, I find that wood of one month old will strike in many cases very readily, and when put in during the latter part of February, will be rooted in March. I use cutting-pans about three inches deep, and a compost of two-thirds of sand to one of loam, and apply bottom heat. I have a bed heated by a flue passing through it, which I find very useful for this purpose. When well rooted, I pot them off into small-sized pots, and plant them out in May. In the fall, I repot them in the compost already mentioned, and keep them in a cool house, without fire-heat, till January, unless the frost is too great, when I protect them slightly, but use no fire-heat till the last of January or February. These plants flower well. The tea, Bourbon, and China are treated in this way; the hybrid perpetuals or moss roses are not included, as neither these nor the noisettes are adapted for winter flowering. I do not prune very closely in the fall; but in May, prune thoroughly and sink the pots in the soil, and lift them in September for winter flowering, repotting them if necessary, and pruning out all dead wood. At this season care must be taken not to break the ball much. The temperature should be kept moderate. A dry atmosphere is very injurious, and is the chief cause of failure in keeping plants in rooms. The water should always be applied at the top; where saucers are used, it is only for cleanliness. Planting out secures strong plants, but is not admissible for winter blooming. I have found hybrid perpetuals to succeed best on their own roots. Teas and Bourbons will do well from layers. In England and the north of France budding is generally practised, and succeeds well; but here it is quite different. I have known many failures in budding, and in some cases not more than twentyfive out of a thousand have succeeded; two out of a dozen is often the proportion in our climate.* Budded plants are liable to produce suckers, which have been sometimes mistaken for young, vigorous shoots. Tea roses require lighter soil, and flower more freely than Bengal or Bourbons; they will also bear more heat, and should be placed in the warmest part of the house. Roses for forcing should have as much sun and air as possible, with a moist atmosphere. I have found roses in green-houses, planted in the border, with bottom heat, produce more flowers with $50^{\circ}$ of heat than in other cases with $70^{\circ}$, and have had better flowers when the temperature did not exceed $50^{\circ}$ than at $65^{\circ} ; 55^{\circ}$ is a good temperature for forcing. In reply to the question, 'Is manure-water good?' I say, 'Yes, if applied judiciously in small portions in March.'”

\section{Roses Propagated by Cuttings of the Roots.}

A writer in the "Horticultural Cabinet" says: Haring been advised to try the experiment of raising rose-trees by taking cuttings of the roots, I did so, and found it to succeed admirably. The mode was as follows: The first week in March, I took some of the long, thick, fleshy-looking roots of my English, French, moss, and perpetual roses, and cut them

* This is greatly at variance with our experience. They may be seen budded in the nurseries in Philadelphia, as successfully as peach or apple-trees, by the thousand; and many varieties bloom more freely, and produce larger flowers, when budded, than on thir own roots. $-E$ E. Horticulturist. 
into pieces about three inches long. I then smoothed the surface of a border in front of a peach wall; upon this I laid the roots flat, at about six inches apart; when the roots were placed, I covered them with fine sifted earth, half an inch deep, gently beaten into the cuttings; I then laid four inches more of loamy soil, well enriched, giving the whole a good watering, and when dry, smoothed the surface over with the back of the spade. By the middle of May, every cutting had sent one, and some two strong shoots; and on examination, I found the soil I had covered the cuttings with to be filled with a mass of fine roots. I have anxiously watered the bed, as, being in a sunning situation, I found it got more dry, more especially so from the bed being raised from the old surface of the border; it would have been better to have sunk it, so as finally to have it even with the surroundings.

\section{On the Cultivation of the Rynchospermum jasminoides.}

Turs beautiful climbing plant was introduced into England from Shanghai in the year 1844. It is rarely to be met with; but no doubt when its beauty and adaptibility for growing in green-houses become known, it will be more common. At a little distance this flower resembles the jasmine, and possesses a delicious odor. The plant is evergreen, and, like the iry, sends out rootlets up the stems whenever they come in contact with the soil; hence it is easily propagated by taking a shoot near the soil, or by cuttings of half-ripened wood. The branches of this plant are moderately stout, and require but little support.

This plant requires but little cultivation beyond what is required for green-house plants of this description. It usually commences flowering in April, and if placed in the greenhouse, will continue to bloom for six weeks or two months. It thrives best in a soil of onehalf turfy loam, one-fourth peat or leaf-mould, and the same of white sand, all well incorporated together.-The Florist and Horticultural Journal.

\section{New Fact noticed respecting Bulbous Roots.}

THE "Magazine of Horticulture" says: What is in common language termed a bulbous root, is by Linnæus termed the hybernacle or winter lodge of a young plant. The bulbs in every respect resemble buds, except in being produced underground, and include the leaves and flower in miniature, which are to be expanded in the ensuing spring. By cautiously cutting (in the early spring) through the concentric coats of a tulip-root longitudinally from the top to the base, and taking them off successively, the whole flower of the next summer's tulip is beautifully seen by the naked eye, with its petals, pistil, and stamen. The flower exists in other bulbs in the same manner; but the individual flowers of others being less, they are not so easily detected, or so conspicuous to the naked eye. In the buds of the Daphne mezereon, and in those of the Hepatica, and at the base of the Osmunda lunaria, a perfect plant of the future year may be found, complete in all its parts.

\section{Materials for a Cutting Pot.}

Provide either broken potsherds, pebbles, or chips of stones from a mason's yard, and place them in the bottom of the pot. Over these put rough, fibrous peat or turf: this will act as drainage, which is most essential ; then prepare peat, loam, and silver sand in equal parts, with the addition of a little powdered charcoal: let these be well incorporated together and passed through a fine sieve; put this compost on the top of the above-mentioned drainage and press it well down. This must be in sufficient quantity to reach within $1 \frac{1}{2}$ inch of the top of the pot. Finish with pure silver sand, and let the whole be well watered, to settle all down before the cuttings are put in. Then, having bell-glasses at hand, and the pots ready, dibble the cuttings into the sand, which will induce the emission of roots, and these will strike down into the compost, which, prepared as directed, will suit any plant. After the cuttings are inserted, let them be watered with a fine-rosed pot to settle the sand round them. Cover with the bell-glasses, and shade until they have become rooted. Cuttings must not be put in too closely together, otherwise they will damp off. Wipe the condensed moisture from 
glasses once a day, but keep them close for the first fortnight or three weeks; afterwards admit air by degrees, by placing a little wedge under the glasses. When the cuttings are rooted, remove the latter altogether. Sprinkle occasionally with water from a fine-rosed watering-pot. By attending to these minutiæ, success will certainly be attained. A slight hot-bed is the best place for cuttings.-Gardener's Chronicle.

\section{New Garden Pot.}

THE following account of a new kind of garden pot appears in the Revue Horticole:-An English amateur, Mr. Keir, residing in Paris, has contrived a method by which the branches of trees can be more conveniently layered than heretofore. Pots with a slit on one side have been long in use; but difficulty has been found in their use out of doors, on account of the want of any good means of securing them in a fixed position or at any desired height. Mr. Keir proposes to make such pots with a tubular projection on one side $(a b)$ through which a staff may pass, and, being driven into the ground, hold the pot perfectly steady.

The adjoining cut explains at a glance the nature of the invention. In forming such a pot, it is said that the potter must take care that the slit $c$ is 80 small as to just allow the branch $d$ to pass in, without leaving room for the earth to slip out. But this precaution seems needless; for it would be easy to prevent the earth slipping by means of pebbles or crocks applied to the slit after the branch is inserted, and as the pot is being filled with earth.-Horticulturist.

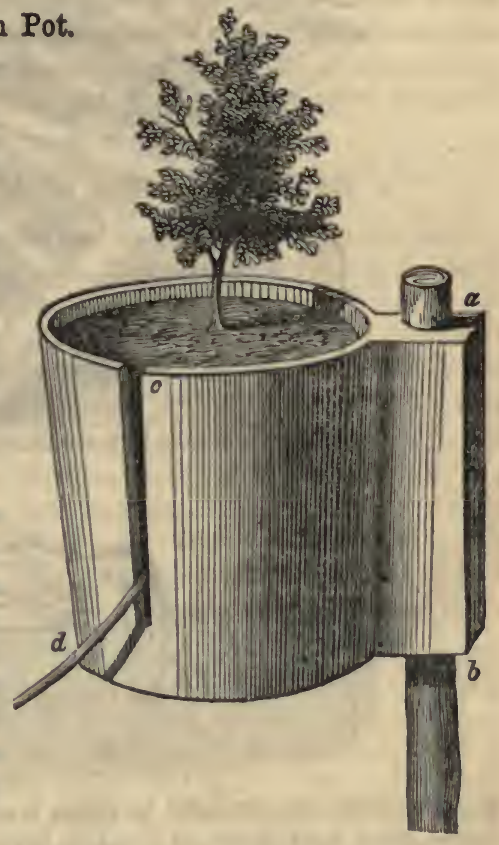

\section{Improvement in the Frames of Grape-Vines.}

THs annexed figures represent an improvement in the frame of grape-vines, recently invented and patented by S. Oscar Cross, of Sandy Hill, Washington county, New York:-

Fig. 1 is a perspective view, and fig. 2 is a vertical section, showing how the frame can be bent down so as to expose the grapes in a horizontal position. The nature of the invention consists in an adjustable elevating and depressing grape-frame for the better cultivation of the grape. The grape-frame is constructed of wall-strips, two by four inches, cut to any desirable length, say ten or twelve feet; and slats or cross-pieces of about an inch in thickness and three in width, and six or seven feet long, are fastened about two feet apart to one edge of the wall-strips. The vine is now placed upon the frame and slats fastened to the other side, thus securing the vine within the frame, as represented in figure $1, \mathrm{~A}$. The frame can be supported in any position by the legs attached to it, and can be fastened there by driving pins or stakes through holes in the foot-pieces, or it can be fastened in various ways; the vine itself will secure the foot of the frame. The advantages of the invention are stated to be as follows-riz. the fruit is more easily gathered, as it can be brought to a convenient altitude, and the vine conveniently lowered to the ground, when it can be covered with straw or otherwise to protect it from winter-killing. The size of the fruit is increased by allowing the frame to lie on or near the ground, which secures to the vine a greater amount of heat, as it receives warmth from the earth as well as from the sun, and is not exposed to cold winds as much as those on elevated frames; the quantity is also increased, as it sets abundantly and grows larger on or near the ground. The grape-beetles and insects are not as destructive to buds and foliage on or near the ground as on elevated frames. Care should be had not to expose the fruit to too much sun during the early stages of ripening, but the 
Fig. 1.

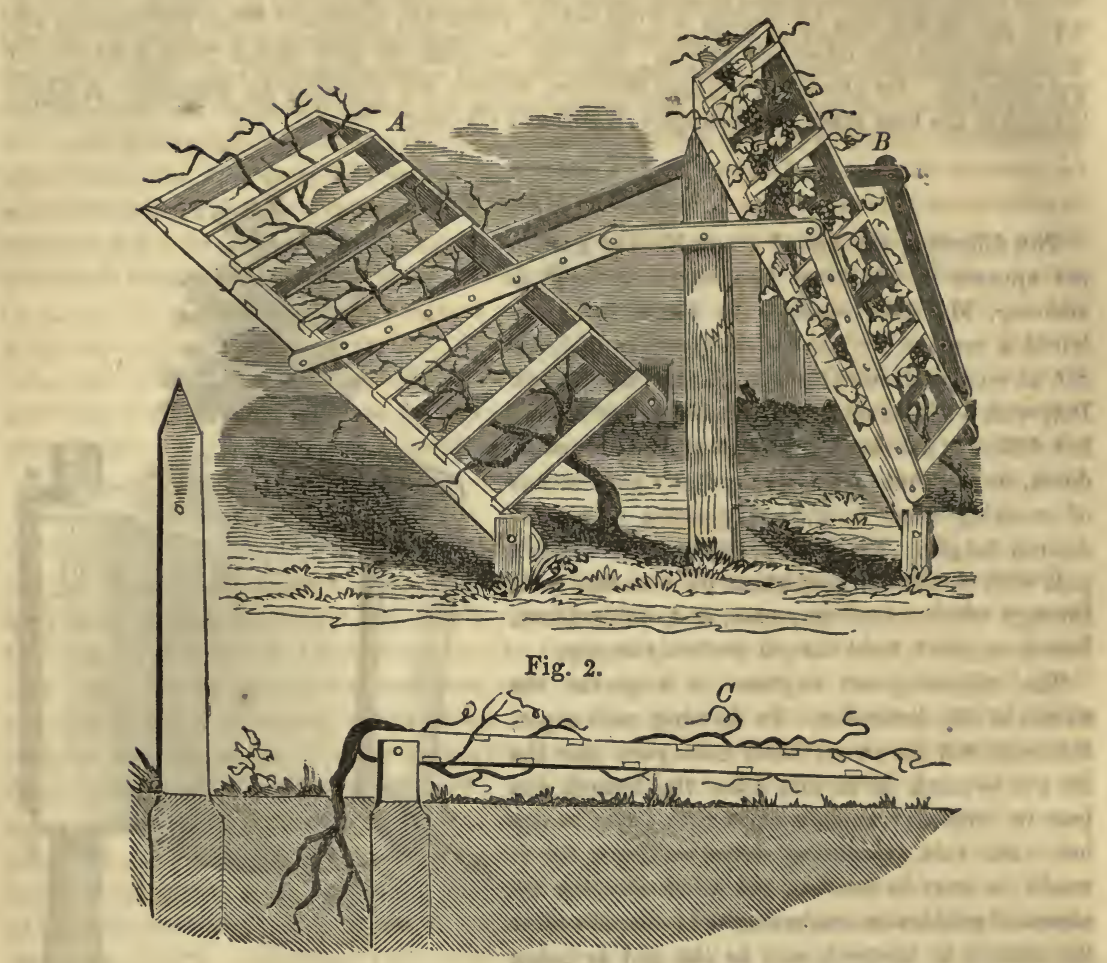

process should be completed by giving it a full exposure, as frame B; the fruit is readily protected from light frosts, as it can be lowered to the ground, where it is less exposed, as in fig. 2, and if necessary can be easily covered; or, if the ground had been sown with corn or oats as soon as the fruit was sufficiently advanced to admit of elevating the frame, it would form a mat in which the fruit would be imbedded, so as to protect it from light frosts, and would be of service to protect the vine from winter-killing. Thus, by this adjustable frame and method of managing it, tender and choice varieties can be raised and ripened in northern latitudes with less trouble and a better prospect of success. The invention is adapted to a variety of forms, and can be used in several ways: a frame can be so constructed as to turn back against buildings, fences, etc., and dispense with legs and foot-pieces attached, proplegs (fig. 2) being used instead; or a row of posts set north and south will support two rows of frames, one on each side, made so as to turn back like a trap-door, as in fig. 1, being held in any position by means of supporters attached to the frame on the upper side, the other end being held to the posts by pins passing through both; the frame can be elevated or depressed by a series of holes in the supporters.

The claim is for an Adjustable Elevating and Depressing Grape-Frame, with or without supporters attached, and made of any known material. It therefore embraces a variety of modifications not represented in the annexed figures.

In relation to the advantage experienced from the horizontal training of grape-vines, the London Gardener's Chronicle states that it has received ample evidence from a well-known English horticulturist in respect to the benefit derived from this method. On vines which has been trained horizontally, some twenty in number, the mildew has never appeared, while the produce has been singularly good. In an adjoining house, however, in which the more ordinary mode of training was adopted, the vines have been severely attacked, and when the first evil had been subdned, the disease broke out a second time with equal virulence.

It is not difficult to explain the increased fruitfulness arising from this method of training, 
which delays the descent of returning sap, to the presence of which, in an unusually concentrated form, the production of fruit is principally due, as is proved by the process of ringing; while the liability of plums and apricots to gum, whose branches are trained in a perfectly horizontal direction, depends upon the same abnormal accumulation of sap. This, however, has no necessary connection with the production of the fungi, which, on the contrary, are generally the more prevalent in exact proportion to the luxuriant appearance of a crop. If, for instance, the leaves of a potato crop present a peculiarly rich green tint, it is almost sure to suffer from mildew, and an attentive search will most probably detect unequivocal signs of the evil, while a crop with a yellowish and apparently sickly appearance will entirely escape. It does not, however, follow that the habits of every parasite should be the same; and inasmuch as it does really appear that vines in which the branches are horizontal do not suffer, or at least do not suffer so much from mildew, the horizontal method, though it would be unwise to expect any complete exemption from the practice, is well worth the cultivator's consideration, especially when it is considered that on the continent the vines which are kept low, without any attempt at horizontal training, suffer far less than those which grow on trellises.

\section{Varieties of American Grapes.}

How many kinds of grapes are native to the United States it is impossible to say; Dr. Rafinesque catalogues forty species and one hundred varieties in a little hand-book of vines, published in 1830 , which he offers "as the result of his observations during many years, and many thousand miles of travel." Since this was published, much new territory has been added to our great Republic, in some portions of which native grapes in great variety and profusion are found. Travellers in Texas and California, especially, agree as to the wonderful profusion of vines noticed in both these States. Upon the Pacific, wine is already manufactured, not in abundance, but still with results so satisfactory, that it will be but few years before it is an established source of revenue to the State. We hear of one farmer there raising ninety thousand pounds of grapes annually; of premiums given for the best wines; of bunches weighing from one to eleven pounds each. Their grapes also are represented to be larger than ours- "large as plums," and superior in color and flavor. The berries, too, are very tender, and the skins thin. The vines are pruned down to two or two and a half feet from the ground, and the large, indolent masses of fruit rest upon the lap of the common mother.

The grapes of California are called "Catawba," by some "Sweetwater." The berries are oblong, egg-shaped, of a light reddish-brown color; in flavor delicious; they are destitute of pulp, and so tender as to be difficult to handle. Like all the rest of our native grapes of any value, they are claimed to be "of foreign origin." History is thus falsified, and our vines robbed of their birthright. Major Adlum discovered a fine grape in the gardens of Mr. Johnson, near Fredericktown, Maryland, and another in the gardens of Mrs. Scholl, of Clarksburg. He says, "A German priest, who saw Mrs. Scholl's vine in full bearing and when ripe, pronounced it the true Tokay, and says he saw the same kind growing in Tokay, in Hungary!" The Schuylkill Muscadel was christened "The Cape grape," as Mr. Longworth says, "to give it reputation;" and to this day, many believe it to be a native of Africa, although its wild brethren are found in plenty all over Pennsylvania. The Isabella, formerly called the Laspeyre grape, is a native of North Carolina.

To return, however, to the grapes of California. There are no vineyards in the immediate vicinity of San Francisco, but vines are cultivated in the valleys, especially to the southward of the State; and a strong red wine, resembling claret, is drank by the country-people from their own grapes. At Los Angelos, they make a very excellent white wine, something like the Catawba in flavor.

The "Mustang" and the El Paso are the peculiar grapes of Texas. The former, which is scarcely accredited as a wine grape, is known only at present as a wild vine, indigenous to the soil which produces it. The El Paso has, however, been successfully cultivated. The following, from De Bow's "Industrial Resources of the South and West," gives us some account of the region which is said to produce the best wine in the world:- 
The settlement of El Paso extends from the Falls of the Rio Grande on the north to the Presidio on the south, a distance of twenty-two miles, and is one continuous orchard and garden, embracing within its area an industrious and peaceable population of at least eight thousand. This spacious valley is about midway between Santa Fé and Chihuahua, and is isolated from the other Mexican settlements by the mountains which rise on the east and west, and close into the river on the north and south. The breadth of the valley is about. ten miles. The most important production of this district is grapes, from which are annually manufactured not less than two hundred thousand gallons of perhaps the best and richest wine in the world. This wine is worth two dollars per gallon, and constitutes the principal source of revenue to the country. Great quantities of grapes are also dried in clusters and preserved for use during the winter. In this state they are considered superior to the best raisins that are imported from Europe.

The great Mustang grape of Texas is also said to be a wine grape of superior quality. It grows in the greatest profusion, without cultivation, in every part of Texas, and upon all varieties of soil. The wine produced from it is said to resemble port. Not alone in California and Texas, but throughout the entire South, do native grapes flourish in wonderful luxuriance. The sea-islands that fringe the coasts from Norfolk to the Florida reefs are embroidered with wild vines, laden with clusters, as well as the margins of rivers that intersect the mainland. Florida abounds in this delicious fruit; in Alabama, grape-culture is already exciting much attention, and the native grapes produce not only wines of most excellent quality, but also a very great variety of wines. Their cultivation is very easy, and the vines are abundant bearers. A gentleman, in a letter to the "Alabama Planter," says: "A vineyard at maturity, say the fourth year, would be good for from five hundred to seven hundred and fifty gallons; the seventh, for one thousand gallons; the Scuppernong much more, to the acre. Among other properties possessed by our native grape, the quantity of vinous matter they possess is most remarkable. A bushel of bunches, as pulled from the vine, will give three gallons of wine, and after undergoing a second operation, about one gallon more of a lighter but most agreeable wine. It would take a third pressure to produce the meagre drink with which, in part, they feed the peasantry in France who tend the vintage."

The woods of Louisiana, Mississippi, and Arkansas abound in varieties of wild vines that yield masses of fruitage, renowned as raccoon, bear, bull, chicken, and fox grapes. As yet, we have had no specimens of wines of these celebrated brands. One of these wild vines has been successfully cultivated already, under the name of "Bland's Madeira," and doubtless there are many species which, by the skill of the vine-dresser, may be made to yield an agreeable variety of wines; in fact, our chief dependence must be upon our indigenous grapes, that are already acclimated by nature's unerring training. It is well to observe that a grape may produce a superior wine in one district, and yet be of little value in another; so that although one species may disappoint the cultivator in Arkansas, that is no reason why it should be rejected by his brother in Tennessee or Louisiana, or vice versá.

In Georgia, the luscious Muscadines gathered in the wild state produce a wine of considerable merit; as yet no attempt has been made to give them a formal training, except here and there upon a small scale. This is also the case in South Carolina.

North Carolina is the natal soil of the Catawba, the Herbemont, and the Scuppernong; the first two of these unquestionably owe their reputation to the skill of the cultivators of Ohio and New York, and have only a limited growth in their native State; but Scuppernong vineyards are found from Currituck, on the extreme north, to the southern counties on the Cape Fear River, and extend inland almost to the foot of the Blue Ridge Mountains; while so various are the qualities of wine produced, that some kinds command three or four dollars per gallon, and some kinds can be purchased for five or six dollars a barrel! There are two species of this grape-the best having a white, silvery skin, with a rich metallic lustre, while the inferior kind bears a small, black berry. Mr. Longworth says, "The black Scuppernong bears from one to four berries on a bunch, and would, in times of war, if lead be scarce, be as valuable, even when fully ripe, as the Fox grape, for bullets. The white Scuppernong, also, has a very small bunch, and is a better grape than the black. But the skin 
is thick, and the pulp hard; it will never be valuable as a wine grape, unless to give to other must aroma and flavor.

If for no other purpose than this-namely, to mix with the must of less flavored grapes, to give character to the wine when made-this Scuppernong will prove to be most valuable to this country. The "Traminer" of the Rheingan, a small-berried grape, abounding in saccharum, and full of aroma and strength, is so used to mix with the "Riesling," the favorite grape of the Rhine, in the production of the first-class German wines. And that the generality of European wines owe their excellence to the judicious mixture of various growths and vintages is so well known as scarcely to need repeating here.

But the value of the Scuppernong as a wine grape has not yet become fairly tried; at least not in North Carolina. Of all the samples we have tasted, not one was the pure and original fermented juice of the grape, but, in every case, more or less sophisticated with sugar or honey, and not unfrequently with whiskey or brandy. It is usual to add three pounds of sugar to one gallon of the must, and then a little distilled spirits of some kind is poured into every barrel of wine "to make it keep." Subjected to this treatment, the fluid degenerates into a sort of vinous grog, and its peculiar character as a wine is almost entirely lost. Still, in spite of this, it has an aroma which is somewhat grateful.

That species of the Muscadine called the Scuppernong is a very sweet grape, but sweet grapes are often wanting in saccharine matter. For a familiar instance, take the Catawba and Isabella grapes. To the taste the latter is by far the sweetest fruit; nevertheless, in making a sparkling wine, the Isabella needs a liberal allowance of sugar, while the Catawba wine requires little or none. McCulloch, in his treatise on wine-making, makes a very accurate distinction between the "sweet principle" and that which constitutes the "sugar" in fruit. The latter, the saccharine principle, is the element which by the process of fermentation is transmuted into alcohol or spiril of wine, a certain percentage of which is necessary in all vinous fluids. This spirit of the wine is derived directly from the sugar of the grape. Now, the difference between the sweet element and the saccharine element is very clearly shown by McCulloch, who illustrates the subject by comparing molasses with refined sugar, the first being much the sweetest of the two to the taste, and yet not comparable to the latter in its proportion of pure saccharum. And if we may venture upon a theory, we should say " that the reason why sweet grapes makes a wine less sweet than those not so dulcet to the taste, lies in this: that in the sweet grape the whole quantity of saccharum is absorbed in the production of alcohol, while in those more abounding in sugar a portion only is transmuted into alcohol; the superflux of sugar remaining in undisturbed solution, and sweetening the wine, less or more, as may be."

Now the Scuppernong grape produces a wine naturally hard and dry, with little to recommend it but its peculiar aroma and flavor; and, in consequence, the must is artificially sweetened to make it a marketable or salable commodity. So long as this method of treatment is practised, neither it nor any other American wine so used can rank with any wines of Europe, except with the spurious productions of Cette, Lisbon, and Marseilles. The difficulty lies in this: our vine-growers are afraid of a hard, dry wine, because popular taste so far (especially in the rural districts) has been corrupted by the sweetened, sophisticated, poorest class of imported wines, the sweet malagas and pure-juice ports that are current in every country town. Pure, wholesome wines never are, and never should be, sweet; a glass of syrup is no refreshment for a laborer, and, as a daily beverage for anybody, actually repulsive; and as we are looking forward to the period when our wine shall be used as the common drink for all classes of people, we should define now and here that by "wiNes" we mean the pure, fermented juice of the grape, without the admixture of any thing else whatsoever.

That the Scuppernong is a hard, dry wine, when made without sugar, is doubtless true; but the question is, "What character will this very wine assume when mellowed by age?" The Sercial, the king of Madeiras, is as harsh, anstere, and repulsive, for the first few years, as a blue-nosed Presbyterian elder fresh from the synod, nor is it drinkable until age has corrected the acerbity of its temper; but what then? Then it becomes one of the most exquisite fluids in the world, and commands a price superior, in some instances, to any known 
wine, with the exception of Imperial Tokay. The real merits of the native wine of North Carolina, then, still need development; age and proper treatment must, in time, produce something; for the Scuppernong is not destitute of delicate aroma-an important quality, indeed. The mode of culture is peculiar: the vines (layers, not cuttings) are planted one hundred feet apart; the main branches have space to run fifty feet each way, at right angles from the centre, before meeting. Each vine may be represented thus, + , the laterals interlacing over head and forming a canopy. The branches are never pruned, as it is said "the vine would bleed to death." Like the vines in Lombardy, these are high-trained, (haut tige,) the lowest branches being eight feet above, and parallel with, the ground. The yield is most abundant, a single vine often bearing thousands of bunches; the berries small, and but few to the bunch. Instances have been cited of single vines yielding enough grapes to make several barrels of wine, and covering two and a half acres of ground.

We have seen specimens of native vines of Virginia of excellent quality. The Catawba there is an abundant bearer, and the wine made from it essentially different from that of Ohio. The climate of this State would seem to be peculiarly adapted for the purpose, and the wild and waste land might be turned to profitable account in the production of vines. To Virginia we are indebted for many species already popular, among which we may instance "Norton's Seedling," the "Woodson," and "Cunningham." Here, too, the Bland grape grows abundantly, under the name of the Virginia Muscadel. In Maryland and Delaware, also, a variety of native grapes are cultivated, some of extraordinary productiveness. One vine raised by Mr. Willis, (near Baltimore,) in 1832, yielded twenty-five thousand bunches; and in the following year, Messrs. C. M. Bromwell and R. Monkland certify "that they counted upon it fifty-four thousand four hundred and ninety bunches, omitting small and young ones, which would have added at least three thousand more."

That part of the United States between the thirty-eighth and forty-fourth parallels of latitude, so far, is entitled to the supremacy in grape-culture. Already the wines of Ohio and Missouri begin to supplant the imported Rhine and Champagne wines here, even at the same prices. Terraces rise above terraces on the hillsides of the Ohio River, and the red bluffs begin to disappear benenth masses of vine foliage and purple clusters of fruit. In Pennsylvania, at the end of the last century, an association was formed for the purpose of cultivating the grape for wine, and vineyards were established at Spring Mill, under the superintendence of Mr. Peter Legoux. This was a failure: foreign vines were tried and abandoned, and finally the wild grape called Schuylkill Muscadel met with temporary success.

In New Jersey the vine has been cultivated for many years, especially in the neighborhood of Burlington. The soil of some parts of this State is peculiarly adapted for this purpose, and we may hope hereafter for better wines than those she now furnishes under a variety of foreign brands. Still further West, we find that Indiana, Illinois, and Michigan are improving the hint given by Ohio; in fact, Indiana must be recognised as one of the pioneers; for, in the beginning of this century, the most considerable quantity of native wine made in the United States was from the Cape or Schuylkill grape of Vevay, Switzerland county, Indiana.

Missouri already ventures to contest the palm with Ohio. In 1852 , the vineyards at Hermann embraced some forty or fifty acres only, and this year we are informed that no less than five hundred are under cultivation there, besides many other vineyards in the interior of this thriving State. At the Crystal Palace Exhibition in Now York, six prizes were awarded to vine-growers of Missouri for samples of superior native wines, both Isabella and Catawba, still and sparkling. The last grape is the favorite there, as it is also in Kentucky and Tennessee. In St. Louis, the native wines are rapidly supplanting the foreign, especially the sparkling kinds; at the hotels there, the majority of wines on the tables are of home production.

The two principal wine grapes of Ohio are the Catawba and the Isabella; the first, however, in the proportion of twenty to one. Both are natives of North Carolina. The first was found and noticed merely as a wild grape, in the year 1802, by Colonel Murray and others, in Buncombe county, North Carolina. There it reposed for upwards of twenty years 
without attracting attention, and so would have remained probably until now, had not its merits been discovered by Major John Adlum, of Georgetown, North Carolina, in or about the year 1826. Major Adlum, an officer of the Revolution, formerly Surveyor-General of Pennsylvania, was a great cultivator of the grape, and devoted the last years of his life to that purpose. In the course of his experiments with native vines, he found this one in the garden of a German at Georgetown, and, after a fair trial, was so convinced of its value as a wine grape, that he sent some of the slips to Mr. Longworth, with a letter, saying, "I have done my country a greater service by introducing this grape to public notice than I would have done if I had paid the national debt." Adlum paid the debt of nature soon after, but the slips fell into good hands. For nearly thirty years, with patient perseverance, these grapes were nurtured by Mr. Longworth, until the hour has arrired when the prophecy of Major Adlum seems certain of fulfilment. Thirty years of patient labor; thirty years of unfaltering faith; thirty years of man's life; what a span it is! stretching from hopeful youth to hoary age; a long while, my good friend, to look forward to-a long way to look back. In the thirty years to come we may have occasion to thank these pioneers-we may see greater results than either of them dreamed of.

The Isabella grape was first introduced to notice by Mr. George Gibbs, of Brooklyn, Long Island. The slips were brought from North Carolina by Mrs. Gibbs, his wife, and the rine, in compliment to her, was named the "Isabella." Originally, it was called the "Laspeyre grape," Mr. Bernard Laspeyre, who resided near Wilmington, North Carolina, having the parent vine from whence these slips were derived. By him it was supposed to be a foreign grape; but all scientific writers on vines in this country assert that the species in a wild state is quite common, and is unquestionably an indigenous production of the United States. Of these two grapes, the best wines are made in Ohio. We may also mention that the "Herbemont," another variety of the "natives," produces an extraordinary fine wine, the flavor being like the purest Amontillado, and essentially different from the other two.

In comparing the American wines with those of Europe, we must bear in mind that they are distinct in flavor from any or all of them. Sparkling Catawba is not Champagne, nor can Isabella be compared with any other wines known in the world. It is a peculiarity of these wines that no spurious compound can be made to imitate them, and in purity and delicacy there is no known wine to equal them.

The most expensive wine in Europe, the "Tokay," contains the least amount of alcohol, 9.85 per cent.; but the "Still Catawba" shows a percentage of 9.50 only, being, in fact, the lowest percentage of spirit to be found in any wine in the world.

One more fact, in passing. By the Patent-Office Report for the year 1853, it is stated that the value of American wines exceeds that of the tobacco crop:

Value of wines grown in the United States.....................\$2,000,000

But not alone for the production of wine are grapes valuable. The seeds of grapes are eaten by birds; and a fine fixed oil, similar to olive-oil, is made from them in Parma, Lombardy, and other parts of Italy, suitable either for cooking or burning in lamps. The cuttings of the vines are always salable to propagate new vineyards; the leaves can be used to feed cattle, and they are fond of them. The finest printer's ink is made from the carbon of the charred stalks of old vines. And from the lees of wine we get cream of tartar, which no family should be without. And then the raisins! Whether it be from the enormous crop of children raised annually in our States, or from some other unknown reason, we import more raisins than all the rest of the world put together! So much for the vine as a source of national prosperity.-Putnam's Magazine.

\section{Profits of the Cold Grapery.}

Is a recent number of the Horticulturist, Mr. William Charlton furnishes a statement of the produce and expenses of a cold grapery, planted in March, 1850. Mr. C. premises that there is nothing extraordinary in the amount of fruit raised by him, more than what others 
are obtaining by skill, care, and attention. The average weight of the respective crops given, if taken collectively, would be one pound per bunch, all of which would have readily sold at from fifty to seventy-five cents per pound; the lowest price, however, is only calculated. The following number of bunches of good quality have been cut in the respective years: 1851, 262 bunches; 1852, 618 bunches; 1853, 918 bunches; 1854, 1147 bunches; making a total of 2495 bunches.

The following calculation shows the balance side of the question:-

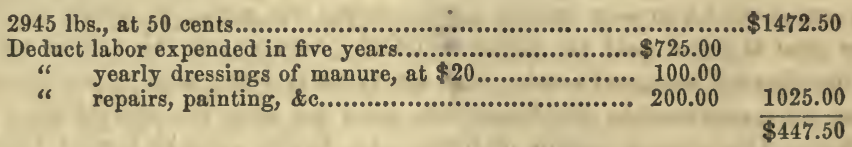

By the above example it will be seen that there is $\$ 447$ above the lowest wholesale market price; and as the house, border, \&c. cost about $\$ 2000$, it leaves a surplus profit of $4 \frac{1}{2}$ per cent. per annum upon invested capital, which in the present position looks somewhat low; but it must be understood that in this case profit was not the object; every thing was done, regardless of expense, to make a good and handsome structure. The best French glass was used, and all labor paid by the day; besides which, in the first year, there is no return profit, and the last season is the only one in which a full crop has been allowed. Take into consideration, also, that the labor account for management is reckoned at $\$ 2$ per day, and it will be readily seen that a good and suitable house may be built and tended so as to give a large return profit. A house of equal dimensions, and well furnished, can be erected at $\$ 12$ per lineal foot, with the exception of cistern, force-pump, hose, and tank; and if we make an estimate of all incidental expenses on a house equal to the above, and fifty feet long, it will stand thus: house, 50 feet long, furnished with two coats of paint, at $\$ 12, \$ 600$; brick cistern cemented, 10 feet square, $\$ 70$; tank, force-pump, and hose, $\$ 90 ; 25$ tons of manure for borders, at $\$ 2, \$ 50$; materials for drainage, $\$ 20 ; 90$ bushels of bones, at 50 cents, $\$ 45$; 100 bushels of charcoal, $\$ 15$; labor, making borders, etc., $\$ 20$; 48 vines, at 50 cents, $\$ 24$; total, $\$ 934.00$.

$\mathrm{As}$, in the first example, the house is 74 feet long, and, in the latter, 50 feet, the comparative weight of fruit that may be taken will be about two-thirds, or $1954 \mathrm{lbs}$., at the same prices, making the total value for the five years, $\$ 982$; and, making the same comparison in labor, expenses, \&c. in both cases, we may put down $\$ 298$ gain upon a capital of $\$ 934$, which shows a profit of about six per cent. per annum, and this too at the commencement. If we were to calculate upon seven years, the percentage would amount to nine per cent.; and continued further, it would be still greater, as the vines will continue each season to produce a full crop.

From these illustrations it will be readily seen that, with good management, there is no loss in having a cold grapery, even though partial failure may occur.

\section{Green-houses and their Management.}

THE following memoranda on the above subject are derived from the pages of the Horticulturist:-

In the first place, care must be taken that your house is well built, so that it will exclude the outer air. Second, it must not be too large for the heating apparatus; a small house well heated will produce more flowers than a large one poorly heated. Third, have your furnace and stock-hole entirely within the house-say under the centre stage. This, I am aware, is objected to by some; but if the flues draw well, which they will be sure to do if there is a regular ascent in them from the furnace to the chimney, and coke or charcoal is used in kindling the fires, you will never be incommoded with smoke or gas, while the additional heat obtained will be at least a fourth. Be careful not to let the earth come in contact with either flues or furnace. Fourth, provide a good supply of outer shutters, to use at night. Fifth, do not build your house too high, or all the heated air will ascend, and leave the lower part of the house too cold. And this brings us to the most important matter of all-namely, the 
requisite degrees of heat and moisture to promote health and bloom. Many amateurs are greatly misled by the directions given in works on gardening, particularly in those published in England, as to the temperature and ventilation. In most of these works the minimum temperature of a green-house is set down at $40^{\circ}$; and consequently the young beginner thinks that so long as he keeps his plants from freezing, he is perfectly safe. This temperature will answer for what are considered strictly green-house plants-such as Camelias, Rhododendrons, Azaleas, Laurustinus, Pittosporums, and other hard-wooded plants; but in a mixed greenhouse, where there is a large proportion of soft-wooded and herbaceous plants, a much higher temperature must be maintained, in order to have them bloom well. For this purpose the mercury in ordinary winter weather should not fall below $60^{\circ}$, or $55^{\circ}$ in very severe weather, and do not be alarmed if it rises to $70^{\circ}$ or $75^{\circ}$ on a fine, bright day. The directions given in English works, and too often followed by English gardeners, in regard to ventilation; are not at all suited to the climate of the Northern and Middle States of the Union. Our atmosphere is so much drier, and our winters so much colder, that much less ventilation will answer. The difficulty we frequently have to contend with is, that in cold windy weather we have too much ventilation; and I am satisfied that if some of my amateur friends would expend a trifle more in cotton, (for filling crevices,) coal and shutters, and less in buying the latest novelties, we should have fewer complaints of the want of bouquets during the winter months. While insisting strongly on a high temperature, let me not neglect to enjoin on my readers the importance of supplying the plants with plenty of moisture. The whole matter can be comprehended in a nutshell-keep your fires and syringe going. With a good heat, you can syringe the house almost every bright, sunny morning; whereas, if your house is kept at a low temperature, and you give much moisture, you will find that the foliage will turn yellow and fall.

My readers will understand that the above directions are given for the management of a mixed collection of plants; but I would recommend, in all cases where it cau be done, to divide your house into two compartments; and in that case you can keep the green-house at $40^{\circ}$ or $45^{\circ}$, and the hot-house at $65^{\circ}$, minimum.

- Another very important matter-and one without which all your other trouble will be of no avail-is the selection of the proper kinds of plants, and also the proper proportion of each kind, as some kinds are much more used in making bouquets than others. I subjoin a list of plants which are almost indispensable for winter bloom, and are yet so easily propagated, and at so little cost, that they come within the reach of almost every one. By getting a plant or two, or a package of seeds, of each kind, in the spring, you can by fall propagate a sufficient number to fill your house :-

\section{A LIST OF PLANTS 8UITABLE FOR WINTER BOUQUETS, WITH THE PROPORTIONS OF EACH KIVD.}

25 Eupatorium elegans,

25 " salicifolium,

25 Stevia serrata,

25 " paniculata,

25 Sweet Alyssum,

25 White Candytuft,

25 Heliotropes,

25 Mignonette,

25 Chinese Primroses,

25 Verbenas, of sorts

25 Neapolitan Violets,

25 Bouvardia leianthus,

25 Poinsettia pulcherrima,

25 Euphorbia jacquinætlora,

25 Roses,

10 Wall Flowers,

10 Stock Gillies,

10 Scarlet Geraniums,

10 Cinerarias,

10 Fuchsias,

10 Habrothamnus,

10 Oak-leaf Geraniums,

10 Epiphyllum truneata,
From cuttings. "s

“

s6

From seed. "6

From cuttings. From seed. "6

From cuttings.

From offsets.

From cuttings. " "

“

Cuttings and seed.

From cuttings.

Seeds and offsets.

From cuttings. "6

“

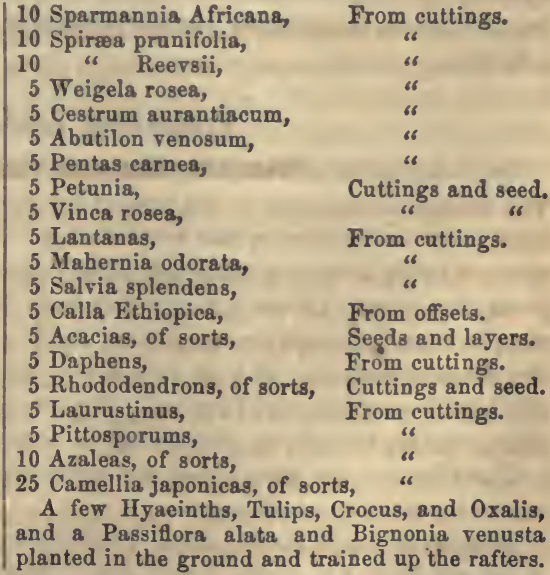

The eleven varieties first mentioned in the above list are indispensable for forming the ground-work or filling up of a bouquet, and consequently a larger quantity of them are re- 
quired. The Spircea prunifolia and Reevsii, and Weigela rosea, should be kept out of doors, and two or three brought in to force every two or three weeks. The former can be forced into bloom in three weeks. The Rhododendrons, Laurustinus, Pittosporums, Azaleas, and Camellias, should be planted in the coolest and shadiest part of the house. In the above list every plant is excluded that is either difficult of cultivation, very expensive, or that continues in bloom but a short time and furnishes but few flowers.

\section{Grafted Plants.}

IT is, we think, incontestable, that although two plants of different species may be made to form a mutual adhesion by the process of grafting, yet that such adhesions are seldom if ever permament, or even advantageous to the vigor of the scion. It is only when varieties of the same species are worked on each other that a perfectly sound and durable union is effected; and not always even then, as we see when a fast-growing apple-tree is grafted upon a diminutive variety, such as the Paradise. If the union is to be perfect, and the double or grafted plant to be in all respects as healthy as either of its parents, the two must grow at the same rate, must have their sap in action at the same instant of time, and the quality of their secretions, be they what they may, must be identical. This happens when pear-trees grow on pear-trees, or apples on apples, of similar habits. It does not happen in the same degree when pears are grafted on quinces, or peaches are budded on the varieties of plum; for, although we employ such stock, and with advantage, it is expressly because there is so much difference in the constitution of the scion and stock as to diminish the rate of growth of the former; and although the peach will live for many years on the plum, yet all gardeners know how great is their tendency to separate. In fact, if an old peach-tree worked on a plum stock be allowed to dry, and is then so placed horizontally that the point (of graft and stock) rests without support between two upright posts, and then receive a violent blow, the stock and scion will come asunder, as if no organic union had ever been effected. Had the peach been worked on the peach under equally favorable conditions, no such fracture would be practicable.

Wherever we look yre are met with evidence of this fact. A man may graft a cherry on a common laurel, a cedar of Lebanon on a larch, or a China upon a dog-rose, and we all know that salable plants are thus manufactured. But it will soon cease to be worth while for the trade to form such plants, seeing that buyers now generally learn that they are merely ephemeral curiosities. If any one doubt this, let him inquire how many of the thousands of worked coniferæ which have come into market within the last twenty years are still alive. It would turn out, we have little doubt, that the only healthy specimens now discoverable are those of varieties of the same species or closely-allied species, worked on each other, as the yellowberried yew on the common yew, or the deodar on the cedar of Lebanon.-From Gard. Chron. (Florist.)

\section{Preserving Tender Flower-Roots.}

QUITE a number of beautiful summer flowers may be preserved by the most simple means. The dahlia may be taken as the type of the class we have reference to. Many, no doubt, lose their roots during winter, and wonder why. They should be cut off close to the ground after the first sharp frost has destroyed their beauty, taken out of the soil without breaking the roots, and placed in the sun till they have become perfectly dry. In winter, they simply require to be just kept free from frost, and in a naturally dry cellar or place where fires do not dry the atmosphere. If kept in a damp place, they will rot, and if in a place where much fire-heat is used, they will dry up. If placed in a box, with some perfectly dry sand among them, and kept as above, success will be certain.

The following are plants that are easily kept this way, the first two doing better than if raised by seed the usual way:-

Four-o'clocks, (Mirabilis jalapa ;) Scarlet-flowering Bean, (Phaseolus multiflorus ;) Dahlias; Jacobean Lily, (Amaryllis fomosissima;) Tiger Flower, (Ferraria pavonia and conchiflora;) Corn Flag, (Gladiolus gandavensis and floribunda;) Tuberose, (Polyanthus tuberosa ;) some of the iris and lilies that are tender, and the Madeira vine.-Country Gentleman. 


\section{On the Vitality of Seeds.}

A RECENT number of the Rêvue Horticole contains some interesting facts relative to the vitality of seeds:-

In 1817 , M. Serrail, in the department of the Aude, made a garden bordering on the river Fresquel. The ground being sloping, he arranged it in terraces. The lowest bed, which ran parallel with the river, and nearly at its level, was frequently submerged by its freshets. Not knowing how to occupy the space, he sowed some persicaria, (Polygonem persicaria,) and thought no more about it.

The following year, (in 1818, ) he thought he could make better use of this portion of his garden by planting in it Provence reeds, (Arundo donas.) The strong-growing grass made rapid development, and in less than three years formed a continual barrier, in the thickness of which the river during its overflows deposited a large quantity of mud, which gradually raised the level of the bed. The reeds, each year deeper buried by these deposits, followed the ascent of the soil, by prolonging, little by little, their rhizome by the upper part. In the month of February last, M. Serrail had this plantation destroyed; the rhizome of the Arundo, which then formed three superposed beds, the lowest being nearly reduced to mould, were dug out of the soil, and the underlying earth transferred for compost to the bed immediately above. What was his astonishment when, two or three months afterwards, he saw this bed, as well as the excavation whence the earth had been taken, cover itself with an abundant crop of persicarias! He then recollected the seed which he had sown thirty-five years before, and he could not doubt but that these plants came from the seeds sown by him at that time, and which were preserved unhurt under the thick bed of mud which the reeds had stopped in the way, and which had solidified in the network of their root-stocks. It is doubtless to their burial in the soil at such a depth that the atmospheric influence could not reach them, that the seeds owed the preservation of their germinative power during so long a period of years. The result would have been very different if, in place of being covered, they had been kept in an apartment, as seeds which we destine for sowing generally are; bccause then the alternatives of heat and cold, of dryness and humidity, and especially the prolonged contact with the air, would have developed in them a fermentation incompatible with their vitality. This is a fact of daily experience, and one which gardeners have but too much occasion to observe; every one knows that seeds have less chance to grow the older they are; there is, however, a marked difference in this respect in different species.

The other observation of which we have to speak, and which is due to M. Micheli, is a new proof of the rapidity with which seeds not sheltered from atmospheric influences are deprived of life. He conceived the idea of experimenting on old seeds whose age he knew exactly, and of a great number of species. He made a sowing in the open ground during last spring, but a very few plants came up; these were Cynoglossum linifolium, Chrysanthemum carinatum, Coreotsis diversifolia, Escholgia Californica, of which the seeds were gathered in 1816; Convolvulus tricolor, Hibiscus trionum, and Ipomœe purpurea, which were two years older; in the case of a single species, (the Malapi grandiflora, the data went back to 1840 ; that is, they were twelve years old.

These results conform entirely to those which have been obtained in England. The British Association for the Advancement of Science some years since appointed a commission to study specially this interesting question of the longevity of seeds. In one of its latest sittings, it received from Dr. Lankester, the chairman of this committee, the report of the twelfth experiment on this subject. This experiment was tried with seed gathered in 1844, a part of which was sown in 1850 and 1851. The result has been the rapid diminution of the number of germinating seeds as they became older-a result which must be expected after all that we know on the subject; the question, therefore, can be considered as settled, at least in a general manner.

At this same meeting there was again mention made of those famous seeds of raspberries found in a Celtic sarcophagus, which have been sown with success. In England, as in France, this extraordinary fact has found many disbelievers; but new investigations have been made with much care during last year, and they have tended to confirm it. Among 
other witnesses still living, we may mention Dr. Royle, the celebrated botanist. He has asserted that he was present when the brown matter containing the seeds, and which had been collected in the remains of the skeleton, was presented to Dr. Lindley; and he further declared that he had no doubt of the truth of what has been said of the germination of seeds preserved under the ground for ages.

The deep burial of seeds, therefore, we repeat, is the true and probably the only means of preserving their vitality for an indefinite length of time. We should have been happy at this time, if our ancestors of some centuries ago had thought of keeping in reserve for us, in this manner, some seeds on which we could experiment. They did not do it, nor could they, because the minds of that day were not turned towards that kind of observation. But why do not we, whom scientific questions interest to so high a degree, prepare this experiment for our descendants? This will be an act of foresight for which they will thank us, andwho knows ?-perhaps which will be a means of transmitting our names to the most distant generations. - Florist.

\section{Culture of the Peach, and the Yellows.}

For the last few years the culture of the peach has declined. The "yellows," "blight," peach-worm, and curculio have been singularly destructive. Old orchards are dying out, and comparatively few new ones formed to replace them ; confidence in their successful culture is yearly growing weaker, till in almost every region we travel we are told, "Peaches will not grow with us any more."

To grow peaches successfully, the aspect of the site of the orchard is of the first importance. Contrary to the general idea in favor of a southern exposure, a north-western or western is preferable. Those in a southern aspect seldom bear well over five years, or live over ten; in any other, there seems to be no limit to their age. Rarely do we meet with a peach-tree on a northern slope stricken with the "yellows," while aged, healthy trees are invariably found there in perfection.

Theory confirms this view of the proper site for peach-trees, as well as observation: not being a native of this country, it is, like most exotics, not perfectly adapted to our climate. The sap-vessels of the wood are large, and there is a large amount of moisture stored up in them in the winter season. When these vessels are frozen through, they become particles of ice, and any sudden thaw is apt to burst the cell tissues, if the expansion by freezing has not done it; so that trees in situations where they are not apt to be suddenly thawed in winter are more liable to escape injury. In the respect of soil, the peach is not so fastidious as it is often supposed to be. Any kind of loam will suit it as well as "Jersey sand ;" and the whole subject may be summed up in the observation, that the peach will do well in any soils except heavy clays or soils retentive of moisture.

In preparing the ground, if it be of a nature to get very dry in summer-time, it should be trenched eighteen inches in depth, or subsoiled, if the culture is to be carried on to a large extent. Sandy soils will not require the operation. All strong manures are superfluous, if not injurious; wood-ashes, and in some cases lime in small quantities, have been found beneficial.

The after-management of the peach is a very simple affair. It consists, in chief, of " letting them alone." If they do not seem vigorous, prune back, or shorten in a little, some of the young shoots; the maxim is sound, If you want wood, prune and "mine out;" if fruit, cut as little as you can. Keep the ground around and about the trees constantly tilled, cultirated, and clean.

The writer holds the immediate cause of the "yellows" to be the rapid and constantly varying action of severe frosts and warm suns on the moisture in the tree during winter; and the predisposing cause, any thing that causes a large supply of moisture to be laid up.

The circumstance that first caused this train of reasoning was a very simple one: Some five years ago, after a severe winter, a fine specimen of Evonymus japonicus, which for the few seasons before grew very vigorously, pushed forth in a very weak manner. Next year, the leaves were ccmpletely yellow, as much so as any peach-tree. The head was then cut away, when the wood was found to be entirely dead, with the exception of two very thin 
circles of wood on the outside. Two years previously, the frost or winter had been sufficient to kill the wood, but not the bark, or perhaps portions of the wood contiguous to the bark, and through this channel just enough sap had been drawn barely to support existence and to send down two weak courses of wood. The conclusion was, that the bark of plants possesses sometimes a greater power of resisting the effects of frost than their wood. The short supply of sap produced by these circumstances caused the yellowness in the leaves.

Repeated examinations of a peach-tree under the "yellows," since the case above stated, show that the peach also will carry its bark safely through a winter severe enough to destroy the wood which it encloses, and that the same reduced supply of sap produces the same identical "yellows" as in the Evonymus.

Supposing this view sound, what cure would it point out for the "yellows?" None. It is incurable; the wood is diseased-dead-cannot be renovated; but preventives are very apparent. Always plant in warm soil, and if the atmosphere of the locality is any way humid, choose an aspect not freely exposed to the winter's sun; or if there be any causes leading to late growths or succulency that cannot be removed by aspect, much might be done towards the early ripening of the wood by divesting them only of their foliage. The two main preventives are-first, early ripening of the wood; second, by guarding against bursts of hot sun on thoroughly frozen wood, the chief cause of much injury frost has to account for.-Melocoton, (Philadelphia Florist.)

\section{Strawberry Culture.}

A Correspondent of the Gardener's Chronicle (England) calls attention to the following new facts connected with the cultivation of the strawberry; he says-

The first year's produce of strawberry-plants from runners of the preceding senson is generally considered of little account; but, with attention to certain points of treatment, I have reason to believe that it may be made nearly equal to the average produce of the second year. I observed lately, in the grounds of a market-gardener, a bed of Keen's seedlings, which, he informed me, were from runners of last year planted out at the end of summer. They were bearing plentifully, though perhaps not carrying so heavy a crop as a neighboring bed two years old; nor were the plants, of course, so large and stocky. I have myself some plants of another kind, from runners of last year, which have six and eight fruit-stems or trusses; and the aggregate amount of fruit borne on these plants is quite equal to that on any of the plants from which they were made, now two years old. The course I adopted in making these plants was this: In June, last year, I laid down such runners as I wished to make fresh plants from, removing all others as they were thrown out, whether from the parent plants or from the rooted runners. In September, the now rooted plants were detached from the old ones, and removed with a ball of earth to the place where they have since remained. The removal might, I presume, be as advantageously made at a later period - say in October or Norember-if the ground they are intended to be placed in should happen to be occupied at an earlier time with other crops. By paying attention to laying down a limited number of runners early, and concentrating the energies of the parent plant in causing them to form their roots, I consider that the constitutional maturity and bearing power of the new plants are materially forwarded, so as to enable them to produce a fair crop the next season, instead of having the ground almost uselessly occupied for a whole year with immature and imperfectly-bearing plants, as must necessarily be the case when the beds are made in spring.

\section{Strawberries of 1855 .}

M. P. Barry, of Rochester, New York, communicates to the Horticulturist the following results of his experience with some of the more recent varieties of strawberries during the past season:-

Scott's seedling, of which we had but a very small bed, and consequently a trial not quite satisfactory, has not come fully up to its Boston reputation. It is large and handsome, and 
very distinctly characterized by its long, conical form; crop moderate, and flavor rather indifferent.

Longworth's Prolific and McAvoy's Superior, of which we had good beds, in fine order for a fair trial, have both turned out poorly; the crop has been light, and the berrics of both imperfectly filled out. This, by-the-by, is a general failtng of all the Cincinnati varieties. While I still rank these two varieties as good, I decidedly prefer, for our section, Burr's nero Pine and Walker's seedling. The latter variety is of undoubted excellence and value as a staminate.

Moyamensing improves by acquaintance, and is really a productive and excellent fruit. Iowa-"Iowa male," as some call it, and "Washington," as many of the Cincinnati growers have it-is a prodigious bearer, (staminate,) of a pale-red color and rather indifferent flavor, very hardy and valuable for market. Jenny's seedling, when fairly treated, is an abundant bearer and a good berry, hardy and vigorous. Genesee has been pretty extensively tested, and proves to be a great favorite. It is a staminate uncommonly hardy and vigorous; the berry large, roundish oblong, with a long neck; color, light shining red, very beautiful; flavor, medium. Monroe Scarlet continues to prove, whenever tested, an immense bearer, of good size and fair quality. The "Orange Prolific" is a prodigious bearer, bright color, firm, and quite late. Hooker's seedling, raised by H. E. Hooker, of Rochester, a large conical, darkcrimson bearer, like Black Prince, evidently a seedling from it; very productive; of good quality; will rank among the best new sorts; a good match for Walker's, which is also from Black Prince, no doubt. Two years ago, I received from some one in Steuben county, New York, a few plants called "Steuben's seedling." This season they have borne well; fruit, dark-red, firm, and of good flavor; plant, very hardy, vigorous, and productive. I think well of it; but.it now requires more than ordinary merit to entitle a new sort to attention. We have tested many new foreign sorts so fully as to warrant an opinion on their value here.

Bicton Pine I still think well of; indeed, I think more of it than ever. It is like most other foreigis sorts, not so hardy as our native varieties, which have mostly the scarlets for their type; but, with a trifling protection, it may be wintered safely anywhere, and bear a good crop of large, handsome, flesh-colored berries, having an agreeable musky aroma. Cremont Perpetual, which created a sensation some years ago around Paris, proves to be not a perpetual, as the famous "Crescent seedling ;" but we have gathered from it this season a crop of magnificent berries. Belle Blanche, from France, proves to be identical with Bicton Pine. Triomph de Gand, from Belgium, is a large, handsome, light-crimson fruit, of rather indifferent flavor, and bears well. Duc de Brabant, from Belgium, rather large, long conical, bright shining red; flavor, musky and agreeable. Very early; well worthy of trial. Cobi Prolific (English) shows a wonderful profusion of bloom, and sets a fair crop of berries; roundish, slightly flattened, dark-red; flavor, medium. Trollope's Victoria promises better than any other English variety ever received here. The plant is hardy, vigorous, and bears a large crop of magnificent fruit, rivalling the British Queen in its best condition; roundish ovate, light shining red; flavor would rank as good. Among fifty sorts, this has borne away the palm in appearance. Ingram's Prince of Wales, from England, Honneur de Belgique and Compte de Flanders, from Belgium, all give sufficient promise to warrant more extensive trial.

I may state here that the season was remarkably favorable for the production of large crops of strawberries and large fruits. Rainy, cool weather, more English than American; flavor was not so good as usual. I have been told by a gentleman, whose word I cannot doubt, that, from an acre of land under Large Early Scarlet, over one hundred and twenty bushels of fruit were gathered, and sold at an average to the dealers at about ten cents per quart.

\section{Raising New Varieties of Pear from the Seed.}

THE following communication on the above subject is communicated to the Philadelphia IIorticulturist, by Thomas Rivers, of England:-

For some twenty years or more, I have occasionally raised pears from seeds, and must confess that my success has been nothing to boast of ; but latterly I have, in a measure, 
changed my mode of operations, so as to make the raising of seedling pears far more interesting than merely sowing the pips of a good pear, without name, grafting the young shoots from the seedlings, and waiting till they bear fruit. My method is, I flatter myself, adapted to your climate, and is as follows:

As soon as the pear-eating season commences, I have some two or three dozen nine-inch pots filled with a compost of loam and rotten manure-say two-thirds of the former to onethird of the latter. Some sand added will improve it. These pots are then placed on bricks or tiles, to keep out the worms, in some convenient situation near the house, and in each pot is a smooth slip of lath painted ready to be written on. I will assume it to be October : I am eating a fine specimen of the Louise Bonne pear; the pips are plump and brown; I take them from the core, go to one of the pots of earth, and with my finger and thumb carefully press in the pips, one at a time, to about an inch deep, and level the surface with my hand; I then write on the label, say, "Louise Bonne pear, October, 1855." A piece of slate or tile is then placed on the pot 80 as to completely cover it, and prevent the ingress of mice. A few days after this I may be again eating a Louise Bonne pear; I reserve the pips, remove the covering from the pots, and plant them with the others; and so repeat this till some fifteen pips are planted, which will raise quite enough trees from one variety. The same process may be repeated at other times and seasons with other species. I omitted to say that, at the end of November, all the pots should be covered with mulch one foot deep. The young plants from the pips sown in the autumn will make their appearance early in April, if the weather be mild; the pips $80 \mathrm{wn}$ in February or March will not regetate till April or May; the pips sown in May will probably remain dormant till the following April.

There are two methods of managing young pear seedlings. The most simple, and one well adapted for those whose hands are full of gardening matters, is merely to let the pots stand on the bricks or tiles, removing them to a shady place, all the summer giving them abundance of water. Each young tree will, or ought to be, twelve to eighteen inches in height by the end of summer, and its stem as thick as a quill, and well ripened. About the end of October, these seedlings may be planted out in the garden, in rows three feet apart, and eighteen inches apart in the rows, with labels to each sort; and in the following April, if there is a wish to bring them rapidly into bearing, each young seedling tree may be cut down to within two inches of its base, and one or two scions made from it, (one ought to be enough, and that made from the lower part of the shoot.) These should be grafted upon some stout stocks, or upon branches of a bearing tree. An excellent plan is to buy at a nursery old dwarf pear-trees at a cheap rate, without names, to plant them out one year, and then to graft them with seedlings, cutting them to a stump nine or ten inches in height. They will soon make nice pyramidal trees, and, by being removed biennially, will come into bearing quickly, and not occupy much room. Every sort should be labelled with its origin in this way: "From Marie Louise, Nov. 1854," and 80 on. This gires much interest to the culture of seedling pears; for, while waiting some six or seven years till they bear fruit, their habits will be found very interesting. In most instances, a strong family likeness to their parent may be distinguished in the leaves and shoots of the young trees, varied by now and then a puny, weakly young one, which will canker and die in three or four years; and then by some one or two trees in ten showing a wide departure from the parental stock, making vigorous, thorny shoots, and growing as much in one year as other members of the family in three. Contrary to the views of "masters" in general, it is these renegades that give the liveliest hopes to the raiser of pears. I have at this moment several rows of seedling pears, five years from the graft. They were grafted on old dwarf pear-trees, and have been lifted and replanted twice. This has checked them, so that they are now in a bearing state. They are all labelled with their origin. Thus far, I have given the most simple method of raising seedlings by sowing in pots and not transplanting till autumn. Another method is to place the pots in a gentle forcing-house, either in January or February. The young plants soon make their appearance, and, when they have made four leaves in addition to the seed-leaves, they should be raised carefully with all their fibres, and potted into three-inch pots. As soon as these are full of roots, they should be shifted into larger pots, and kept growing under glass 
till the beginning of June. They may then be planted out in light, rich soil; and the probability is they will be three feet high by autumn.

We have October and November pears without end; their names are legion, and serve to create distaste rather than a wish for a collection of pears. To raise new and fine late pears, a word or two as to the selection of proper kinds as parênts may not be amiss. That fine, large, late pear, Leon le Clerc de Laval, reckoned a baking pear, but which in May and June becomes soft and agreeable, should be crossed with the Winter Nelis, the most delicious of all our winter pears. The Eastern Beurré may be crossed with Beurré d'Aremberg, always vinous' and racy; the Triomphe de Jodoigne may be crossed with the Josephine de Malines; and so on. There are two methods by which fertilization may be brought about, in one of which chance is in a certain extent trusted to. This is by training the bearing branches of two pear-trees on a wall so that the blossoms are mingled, or planting two pyramids of the two kinds of pears selected in a situation far removed from any others. The certain method is to select $\Omega$ blossoming spur, or rather say a bunch of blossoms, and a day or two before they expand remove all the anthers, cover the blossoms with a fine piece of muslin, and the following day fertilize the flowers with the pollen of the variety fixed upon to cross with. This is done simply by finding some flowers in full bloom, with the pollen perfect, and placing them on the blossoms under the muslin cover, closing it immediately, and tying it securely, so as to prevent the ingress of bees. To those who have inclination or leisure, this occupation will be found of much interest; and to those who have not, the chance method will be equally so.

The theory and practice of the late Van Mons, which for so many years has made such a noise on the Continent, has been given in American works on fruits; but I may, I trust, be allowed to repeat it in as few words as possible. He commenced by sowing the seeds of some hardy, inferior pear, and, as soon as the trees bore fruit, he sowed the pips from them, waiting again till the second generation bore fruit, from the pips of which he raised trees, and so on for several generations. He gave out to the world that by this method he raised all his best pears, and that those of the last generations were nearly all good. This seems to be in unison with the well-known fact that cultivation brings on amelioration; but his assertion that by thus raising successive generations his last seedlings became so fruitful as to bear some years earlier than the first, or those raised in the ordinary way, was a delusion, brought on, I suppose, by enthusiasm. That some out of his many thousands of seedling pears would bear fruit some years before others, I have no doubt; but that it resulted from the system, was an error.

I am also inclined to think that his system of amelioration by successive generations, although on paper attractive and interesting, was slow and uncertain, for the following reason: Some few years since, I was travelling in Belgium, and paid a visit to the garden of the late Major Esperen. I learned that he had no system of raising pears, but that he sowed seed according to his fancy, and trusted to chance. I was surprised to find that he had raised, in $\approx$ comparatively small garden, and out of a small number of seedlings, such pears as Josephine de Malines, Bergamotte d'Esperen, Fondante de Noel, Fondante de Malines, and some others. I afterwards saw the vast collection of Van Mons's thousands of large trees raised from seed after his system, and among them all it may be safely said that there was not one variety to surpass, or even equal, the two first-named varieties raised by chance. To chance also, and not to this much vaunted-of system, we owe such pears as Marie Louise, Glout Morceau, Beurré Rance, Beurré d'Aremberg, and, above all, Winter Nelis; so that we may console ourselves with the idea that chance is very liberal, and the system of Van Mons not so; for, after a whole lifetime devoted to it, it failed to give him five pears to surpass the above, or one to equal the last-named. I remember feeling assured, when first I heard Van Mons talk of his theory, that it was not tenable; for, if amelioration was progressive in seedlings raised in successive generations without crossing, and if in like manner fertility was increased by it, the peachorchards in America would give fruit all perfect in quality, and of wonderful fertility, - for the peaches in some of the States are raised, generation after generation, from the stones. What wonders the fortieth generation of peach-trees ought to be! They should bear fruit even the first year from seed. Among the hundreds of varieties of pears with the name of Van Mons attached to them, there are some very good, although by far too many are sorts 
ripening in October and November; but by raising pears from the seed in America, you will have sorts better adapted to your climate, and of equal, or even perhaps of better quality than the too numerous varieties from Belgium.

\section{Prof. Kirtland on the Pear.}

THE experience and observation of fifty years, directed to a practical subject, can scarcely fail to arrive at conclusions worthy of attentive consideration; and such we deem those of Prof. J. P. Kirtland, of Cuyahoga county, Ohio, on the cultivation of the pear.

Pear-trees of great age are found in some parts of the country; notable instances are those on Detroit River, planted near two hundred years ago, and still productive and healthy, while recent plantations-made within the last thirty years-have disappeared. This suggests, first, the query: Why was the first stock of pear-trees, reared in Connecticut, Ohio, and Michigan, thus thrifty and healthy? Two causes operated mainly in producing such an effect: 1 . The trees were raised from the seed; and 2 . The superficial virgin soil was rich in vegetable matters, the accumulations of thousands of years. As to the second cause, aftcr stating that analysis shows a large percentage of phosphate of lime and potash in the pear-tree, Mr. K. adds-

Vegetables require their food as much as animals. If it be afforded in too restricted quantities, they both will be stinted in their growth and predisposed to disease. Each must also have food of appropriate qualities. An absence of any one of the elements shown to exist in the ash of the pcar will render the tree unhealthy, and probably soon occasion its death. In almost every virgin soil the nccessary food for the pear exists sufficient to insure a rapid and healthy growth of one generation of trees. Cultivation of other crops, as well as the demand of the pear-tree itself, soon takes up most of those elements existing in the superficial soils, especially the phosphate of lime.

The second query is the opposite and explanation of the first- "Why have more recent attempts at rearing this tree been less successful than the first?" Two causes are assigned, as follows:-

1. Suckers have been too commonly substituted for seeds in propagating this specics of fruit; since the earliest generation of trees was produced in those several States, seedlings are generally hcalthy-suckers never for any length of time. The circumstances of their springing from the roots is an evidence of pre-existing disease. That disease is sure to be inherited by every sucker. Their growth may be rapid for a time, but is akin to the malignant developments which sometimcs occur in the animal frame, and is sure to end in prcmature disease and death.

2. The exhaustion or deficiency of the necessary inorganic elements in the soil has a more extensive influence. In ordinary soils the pear-tree cannot be reared successfully, any more than it can "imbibe a solution of phosphates and potash from a soil made up exclusively of insoluble flint and clay." The professor adds: In localities where those requisite elements are furnished, but in too limited amount, this tree will exert its efforts mainly in producing blossoms or fruit-buds in excess, which of course will prove abortive the season ensuing from a want of food, and very little new wood will be formed.

On the other hand, if most of those elcments abound, but the main one-the phosphate of lime-be absent, or in a restricted amount, the tree will of ten make a vigorous effort at forming new wood, the leaves will be luxuriantly developed early in the season, and the shoots will rapidly elongate with a spongy texture, till the period arrives for making a draft on the soil to furnish the necessary amount of phosphates, in order to mature the young and tender growths. This draft usually occurs in the hot and sultry weather of June or July, and is not duly honored. The result is, the delicate tissues immediately die, a rapid chemical change occurs in them, and it is said the tree died of the "fire-blight."

The "fire-blight" is the blight of innutrition, and specifically distinct from the frozen sap-blight, the canker-blight, often occurring in the insect-blight, which also attacks apple, quince, and mountain ash-trecs, occasionally. A third query still occurs: "Why, in certain localities, has the pear-tree continued healthy, and endured to such extreme age?" To this it is replied, 
That some localities abound in the necessary food. The tertiary formations in New Jersey, and the trap dykes in Connecticut, are rich in all necessary elements, and, without doubt, the clays of the Detroit River banks contain more than the usual amount of phosphates. And it is suggested, that-

In some instances this tree is sustained for a long period of time by the accidental supply of food. The dead carcass of some large animal may have been deposited near its location, a pile of bones, leached ashes, decaying vegetable matter, the refuse of a slaughter-house, or night-soil. Perhaps flocks of ducks, geese, hens, or turkeys make their roosts on or under its boughs for days and months in succession. From these and similar sources, phosphate of lime may be furnished. Other collateral influences have favored these bicenturians in certain localities. The pear-tree requires a rather moist and tenacious soil; not, however, wet and saturated with stagnant water. If placed on a loamy or clayey soil, abounding in the requisite inorganic elements, with pure water percolating beneath at a depth at which it can merely be reached by the extreme roots, this tree will be as hardy, strong-growing, and durable as the oak. Climate also exerts an influence on its health and prolificness.

The deficiencies which occur in most soils may be, to some extent, artificially supplied. Animal bones, urine, the sweepings of the poultry-house and yard, and guano are the principal sources from whence the supplies must be furnished. My own trees have been greatly improved, both in their vigor, and productiveness, by burying about their roots large quantities of unground bones: time and weather break them down as rapidly as the trees call for supplies. The surface of the ground has been dressed with ashes and refuse lime. Under this course of treatment I never had a pear-tree attacked with any species of blight. This may have been accidental. In conclusion, I would say that, in common localities, no one should set out one pear-tree more than he can annually cultivate with care, and can constantly supply, in some form, with the requisite food. A starved fruit-tree is of no more profit than a starved animal.-Rural New Yorker.

\section{Time when Pears should be Gathered.}

The following article, on the gathering and ripening of the pear, by M. De Jonghe, of Brussels, is taken from the London Gardener's Chronicle:-

Formerly, when the varieties of pears in cultivation were comparatively few, there was little difficulty in knowing the time when each sort ought to be gathered; but now, when the number of good varieties is so much increased, the proper time for gathering the respective sorts cannot be known without a certain experience acquired during a period of from three to five years, in order that a mean may be obtained; for the maturity of the fruit on the tree depends-

1. On the individual constitution of the tree and its liability to change. 2. On the soil in which the tree is planted. 3. On the influence of the stock. 4. On the temperature of the season, whether more or less favorable for accelerating the maturity of the fruit. In order to know exactly the mean period of maturity on the tree of any particular variety of fruit, it is necessary to observe several trees of such variety, planted in different soils and situations. With regard to the varieties of pears which ripen at the end of summer or early in autumn, it is not difficult to fix the date when they should be gathered; for, in the same situation, this, in different years, does not vary more than ten days. The influence of soil, of stocks, and of temperature more or less warm and dry, is not so great on early fruits as on the late autumn, winter, and spring varieties. With regard to the summer and early autumn kinds, they cannot always be left to ripen completely on the tree, grown as a pyramid or standard; and it is needless to add that these sorts of fruits do not, in our climate, merit a wall, where, in fact, they are never so good as in the open ground. When a considerable number of fruits is observed to have reached the point of maturity, and when, with a slight pressure of the thumb, the stalk is readily detached, without twisting, at its junction with the spur, a portion of the fruit should then be gathered, and allowed to acquire their full maturity in the fruit-room. This first gathering will ease the tree, and the whole of the nutritive sap will be 
directed towards the remaining fruits, which, in consequence, become much finer; and these are gathered in the same manner, and successionally. The opcration of successional gathering, called, in Frcnch gardening terms, l'entrecueillement, may be very advantageously followed up, because all the fruits on a tree never ripen simultaneously; and that they may acquire full perfection, it is important that they should be left on the tree to attain the necessary degree of maturity, known to the practised eye by certain signs, which it would be difficult to point out without entering into tedious details.

With regard to the late autumn, winter, and spring pears, the same proceeding is adopted; it is only by successional gathering, l'entrecueillement, that we can hit upon the proper time, and know the happy medium between gathering too early or too late. When some fruits, neither bruised nor pierced by insects, of a late variety of pear begin to drop, although not affected by strong winds, nor by the continued drought which we sometimes experience in our climate towards the end of September, and when the leaves begin to turn yellow and fall from the tree, an attentive and experienced person will pcrceive that the pcriod of gathering is close at hand. As above statcd, the period of the maturity of the fruit on the tree, and likewise in the fruit-room, depends in a great measure on the soil in which the trce is planted; and the most delicious qualities of certain varieties of pears are owing to the peculiar nature of the soil. The lighter, warmer, and drier the soil, the sooner the flow of sap cnds, and the earlier the fruit indicates the necessity of partial gathering. But in case of a stiff, cold soil, it is the reverse.

It cannot be denied, and all practical men agree, that the stock has great influence, not only as regards the period of gathering the fruit, but also with respect to that of its ripening in the fruit-room. I knew a cultivator who raised stocks for budding with summer and autumn fruits, others for winter and spring varieties. With regard to the summer and autumn kinds, the nature of the stock is of little importance; but when long-keeping sorts are worked on wild-pear stocks, which stocks, if allowed to fruit, would produce summer pears, it is certain that the period of ripcning of late pears worked on thcse stocks would be affected. I have seen some seedlings, planted in proper soil, produce fruit of which the medium time of ripening on their own roots had been fixed between December and Februnry; but when grafted on summer or early-ripening wild pears, the ripening of the above varicties, grown in similar soil, was accelerated more than a month. Such irregularities do not result from propagations on the quince stocks, because these are identically reproduced from layers. The importance of avoiding the unsuitable union of winter and summer fruits will be readily admitted; that is, the grafting of late-ripening varieties of pear-trees on early-ripening wildpear stocks.

I am aware it will be objected that the purchaser would not take precautions on this point into consideration; that he only sces to the young trees having been once or twice properly cut or pruned; and that a certain number of such-and-such varieties required for his plantation is obtained. I understand these objections, because they do in reality exist. However, there are some intelligent amateurs who wish to obtain good articles on which they can depend, and are willing to pay a good price for them as a just remuneration to the producer.

Warm and early seasons accelerate the maturity of the fruit on the trec, but not in the fruit-room. After a good summer and warm autumn, pears keep better, are always longer in becoming fit for use, than when the scason is otherwise, especially as regards the late sorts. In conclusion, from what has bcen stated, it results that the same kind of fruit cannot be gathered uniformly at the same date, owing to various circumstances which influence the ripening; that by successional gatherings, or at intervals, the proper time for different localities is best ascertained; "and that, in general, all the varieties ought to be gathered before their perfect maturity, which should be obtained in the fruit-room.

\section{Catawissa Raspberry.}

The Catawissa raspberry originated in the graveyard of a little Quaker meeting-house in the village of Catawissa, Columbia county, Pennsylvania. The fruit is of medium size, inferior to many of the new popular varieties, but is sufficiently large for all economical pur- 
poses. Its color is dark-red purple when ripe, and is of a very high flavor. It bears most abundantly after the young wood, on which it produces its best fruit; attains a height of four or five feet; usually begins to ripen early in August, and even sooner. The fruit is produced on branches continually pushing out from all parts, successively appearing in various stages of growth, from the blossom to perfect maturity; and often there may be counted more than fifty berries on a branch. As the fruit of each branch successively ripens, the later ones gradually diminish in size; but there is no suspension of blooming or fruiting before the plant is checked by frost. If protected in-doors, it mdoubtedly would produce during the winter months. One great advantage of this over other varieties of the raspberry is, that if the stocks should be accidentally broken or cut off, or should be killed by winter frost, it is all the better for the crop. Another advantage is, that from the small space of $a$ few yards well cultivated, a daily dessert for a small family would be at hand for from three to four months of the year.-Horticulturist.

\section{The Ground Cherry.}

Under this name, Mr. P. S. Beers, of Southville, Connecticut, describes in the Horticulturist a fruit of a species of Solanum. It is about the size and shape of a cherry, of a cream color, and enveloped in a dry, paper-like calyx. It is much more agreeable to the taste, when eaten raw, than any tomato. The stalk of a full-grown specimen is nearly an inch in diameter at the ground, and about three feet high; its habits of growth are similar to the tomato. It bears transplanting well, and comes to maturity early in the season. If sown from the seed, care must be taken that the young plants are not mistaken for weeds, and rooted up. Mr. Beers states that this fruit is excellent for pies and preserves, and also for eating in a raw state.

\section{On the Cultivation and Propagation of the Cranberry.}

Mr. Sulurvar Bates, of Bellingham, Massachusetts, who has given much time and attention to the cultivation of the cranberry, furnishes the following information respecting the culture of this valuable and profitable fruit. In regard to the selection of soils and varieties of the plant, Mr. Bates says-

Select a situation for your cranberry-field on a clay soil, on such as is not liable to bake, or on a dark loam soil, or on all moist soils where there is a mixture of sand; reclaimed lands, such as can be made moderately dry, are well adapted to grow the cranberry. Persons commencing the cultivation would do well to distribute their plants in different locations, as by so doing the best soils may be ascertained. As far as ascertained, there are three varieties of the cranberry susceptible of cultivation in the United States-the barberry, the cherry, and the bell. The last-mentioned seems to be the only variety that can be made to flourish in a dry soil. In its wild and cultivated state, it is much larger than either of the others, and is frequently found on the borders of bogs, extending towards the uplands. .Those engaging in the cultivation of the cranberry should select the bell variety; and'by commencing with those that have been cultivated and naturalized to a dry soil, they will much sooner accomplish their object, and with much less trouble and expense, as the plants multiply and increase abundantly. Persons commencing with one or two thousand, will be able to obtain plants of their own raising sufficient to transplant acres in two or three years. In extensive field-culture no great degree of moisture is necessary, but a uniformity is to be desired. Soils adapted for the strawberry are suited to the cranberry, but no animal or vegetable manure should be applied. The vines propagate by runners like the strawberry. Where the land is rich, and liable to grass and weeds, we prepare the ground by removing the top soil at a sufficient depth to prevent their growth. This may be easily done by plowing the sod, and removing the top soil in carts or otherwise. The object in doing this, is to make the soil so poor that nothing will grow to obstruct the growth of the cranberry.

If the land is poor, so that grass and weeds will not vegetate, then it may be plowed and harrowed without other preparation - the greatest object in cultivation being to have the plants 
placed in a poor soil, or to render it so by remoring the top soil by filling up or by any other process. If these rules are followed, there is no difficulty whatever in their cultivation.

In setting out a cranberry plantation, the soil is prepared the same as for sowing grain, by plowing, harrowing, and making your soil even; then mark it out in drills 18 or 20 inches apart, putting the plants in the drills 5 or 6 inches apart; hoe them slightly at first, till the roots become clinched, and afterwards no other cultivation is needed. The plants may be expected to run together and cover the whole soil in two or three years. The cranberry grown by cultivation usually yields from 150 to 400 bushels per acre; its fruit is two or three times as large as the wild fruit, and of a beautiful flavor; it readily keeps sound from the harrest-time of it to the time of harrest again. The fruit is generally gathered in September; it is gathered with wire-teeth rakes made for the purpose; one man will generally gather from 30 to 40 bushels per day, with the aid of a boy to pick up the scattering fruit.

Persons having a garden of moderate size, and wishing to raise their own cranberries of a superior quality, can do so by obtaining a few plants; and with a small amount of labor at the commencement, will find their cultivation both easy and profitable. The proper time for fall transplanting is October and November; for spring, from the opening of the same till about the 25th of May.

The bell cranberry may also be grown in pots and boxes, and in these situations is an exceedingly ornamental plant, as the fruit when protected will remain upon the vines until they again blossom, the blossoms starting each year from the new growth. The exceeding beautiful appearance of this slender vine, standing erect, and clothed in the most luxuriant green, bearing its delicate blossoms, and laden with rich clusters of crimson-colored fruit, renders it, as an ornament for the window, garden, or green-house, entirely unrivalled. As the cranberry naturally grows in a very wet soil, it is generally supposed it will not thrive in a dry soil; but this idea is erroneous. Mr. Bates has cultivated the cranberry on a dry soil for several years with the utmost success, having produced 300 bushels to the acre on several acres, and his fruit double the usual size.

The method of cultivation followed by Mr. Hall, a well-known cultivator in Massachusetts, is to spread on his swampy ground a quantity of sand: this is to kill the grass; but where sand is not at hand, gravel will answer the same purpose. He then digs holes four feet apart each way, and puts in the holes sods of cranberry-plants about one foot square.

In Massachusetts, the cranberry crop is once in a few years cut off by the late spring frosts. This may be prevented where a meadow is so situated as to be flowed. The water should not be over one or two inches deep on the cranberries, nor left on later than the last of May in this climate. If kept on till it becomes warm, it will kill the vines. Sometimes, in the Eastern States, the cranberries are destroyed by a frost in September; where water is convenient and plenty, the meadow could be flowed on cold nights, at this season, as well as in the spring.

Previous to shipping cranberries, they should be run over a platform slightly inclined. The rotten and bruised fruit will not run off, but stick going down the platform, and are scraped off and thrown away. The perfect fruit is then put into tight barrels, which are headed up, filled with water, and in this manner they arrive in Europe in perfect order, and have frequently sold in foreign ports at $\$ 20$ per barrel.

Rakes are now made for the express purpose of gathering cranberries, and although these rakes tear the vines somewhat, yet the crop is not diminished by raking; on the contrary, it has been increased. Some years ago, a gentleman in Nassachusetts commenced raking his little patch of one-fourth of an acre. The first year it produced 12 bushels, the next 18, the third 25, and so on till his last harvest, when the crop amounted to 65 bushels. This increase is easily accounted for by the method of gathering with rakes-the pulling up a few of the vines loosens the ground; and although not intended, yet in fact the raking acts as a partial cultivation. In order to promote the cultivation of this fruit, we understand that arrangements have been made by the American Institute for supplying horticulturists with cranberryplants early in the spring. Plants are also supplied by Mr. Bates, of Bellingham, Massachusetts. The usual price charged for the bell cranberry is from seven to eight dollars per thousand plants. 


\section{On the Cultivation and Improvement of the Water-Melon.}

THE following suggestions respecting the cultivation of the water-melon are communicated to the Horticulturist by Edward Decker, of New Brighton, N. Y. :-

Having made selection of a spot for your melon-patch, you will greatly benefit your ground and forward yourself by manuring in the fall instead of stopping till the busy spring-time commences, and you find you have a dozen things want attending to at once.s. After giving your ground a middling coat of manure, dig it well two spits in depth, throwing it up in ridges to enable it to receive the benefit of a guod sharp frost, which will mellow and sweeten the soil, besides destroying millions of insects in the embryo state.

The last week in April or the first in May is the most desirable time to sow your seed. Having levelled and forked over the ground that was manured in the fall, commence by marking off your plot into squares nine feet apart each way; dig out the soil two feet square, spreading it equally all round; then fill up the holes with good rotten manure; the top spit from an old pasture, in equal quantities, well mixed and broken with the spade, is the best, but any good, light, moderately rich soil will do; fill the holes six inches higher than the surrounding ground; over these place your melon-boxes, and sow from eight to ten seeds in each. If you have not the convenience of boxes, four bricks laid edgeways so as to form a square, and covered with a sheet of glass, is a good substitute. As soon as you have sown your seeds, place the sashes on the boxes, and let them remain on till the seed is fairly up; then commence giving air on all favorable opportunities, not forgetting to pull the sashes off in warm showers, and increasing as the plants progress in strength; thin them out to four plants in each hill so soon as they have made two rough leaves; keep them free from weeds, and draw the soil about the stems, so as to strengthen them against the winds. When they have made four or six rough leaves, stop the end of each shoot, to make them branch out. As soon as the weather becomes settled, remove the sashes, but let the boxes remain, as they prevent in a great measure the plants from being attacked by a black and yellow-striped bug, and can easily be taken away when they become filled with vines. The best remedy we have found for the destruction of this pest is a slight sprinkle from the rose of a watering-pot of whale-oil soap, diluted in water-half a pound of soap to six gallons of water-every other day from the time the plants make their appearance until they begin to grow freely. As every foot of ground is valuable in small gardens, it is advisable to sow a row of early bush beans, turnip-rooted beets, etc. between the hills, and they will be off the ground before the melons occupy the whole; attending to hoeing and keeping clear of weeds is all the further assistance they require.

\section{Removal of Bark from Apple-trees.}

THE practice of taking off the old bark from apple-trees has been in use nearly two centuries. The old, cracked, and dead bark on the stem and thick branches affords soil and shelter for mosses and lichens, and also forms a fit receptacle for numerous larvæ, which in time devour the tender leaves and buds as they shoot forth. Besides, by removing the old bark the living bark is brought in contact with the air, and myriads of insects prejudicial to the trees are destroyed. In performing this operation, great care must be taken not to injure the live bark and lay bare the alburnum. As the dead bark is more easily detached when it is moist, the best time to perform the operation is immediately after a heary rain, with an instrument having a dull edge, such as a spade or Dutch hoe, lest the live bark should be injured. After this, and especially if the trees have been too closely scraped, a wash of soft mud from the bottom of puddles may be applied with a paint-brush or soft broom. As soon as the trees have been scraped, all the bark, moss, etc. should be collected and burnt; for unless that is immediately done, the larræ will not be long in taking shelter in the ground or in the grass around the bottom of the tree._-Gardener's Chronicle.

\section{Caladium esculentum.}

A WRITER in the Philadelphia Florist states that this esculent root, which is extensively cultivated in Georgia and South Carolina, has recently been imported into Texas from the 
Sandwich Islands. It seems remarkable that any one inhabiting the Southern country should be so ignorant of this common vegetable as to be at the trouble of importing it some thousands of miles when it could be procured close at hand. The plant is known as the Tanyer, the Eddo, and the Jabavi. As for its value as an esculent, the most that can be said of it is, that it is a very poor substitute for the potato. There is, however, considerable difference in the quality of the roots, some being very dry and mealy, others of a finer texture are very mucilaginous; of the first, the white ones are far preferable to the purple. The young shoots, or rather buds - that is to say, the portion of involuted and blanched leares that can be procured from them shortly after they first sprout from the earth-when dressed like asparagus, form probably the most delicious vegetable that can be eaten. The French formerly cultirated it for this purpose in Hayti, under the name of Chou caraibe, or Carribean cabbage. The writer in the Florist says he knows of no plant which will produce more to the acre than this, particularly if left in the ground for two years, when the whole soil appears to become one solid mass of roots.

\section{The Ammabroma, or Sand-Food of Sonora.}

THIs new plant has recently been brought to notice by Mr. H. B. Gray, who was attached to one of the recent explorations across the continent for the purpose of ascertaining the practicability of constructing a railway to the Pacific. It is a parasitic plant, with a large and fleshy root: a parasite which Professor Torrey, of New York, to whom Mr. Gray submitted it for examination, finds to constitute "a new genus of the small group or family represented by the little-known anomalous Corallophyllum of Kunth, and the Pholisma of Nuttall; in the floral structure and the scales more like the latter, from which it is distinguished by its woolly, plumose calyx, and its singular cyathiform inflorescence." It was found in abundance through a range of naked sand-hills skirting "Adair Bay," near the Gulf of California, furnishing an isolated band of Papigo Indians with an important article of food. The fresh plant is cooked by roasting upon hot coals, and resembles the sweet-potato in taste, having much saccharine matter about it. It is likewise dried and mixed with less palatable kinds of food, such as musquit, beans, \&c. It is represented to be a very delicious vegetable; and could it be transplanted, Mr. Gray believes that it would constitute an important acquisition to the table, probably not second in demand to the sweet-potato or asparagus. In the opinion of Professor Torrey it cannot be grown elsewhere, unless the root of the shrub, which is entirely under ground, \&c., to which it attaches itself, can be transplanted. The name given to this root is the Ammabroma Sonora, which signifies the sand-food of Sonora.

\section{The Lawton Blackberry.}

Aт a recent meeting of the New York Farmers' Club, Mr. Field said he had been experimenting with the common bramble to see whether the improvements effected in the blackberry by Secore, and carried into extensive operation by Lawton, were the result of change in the soil and cultivation, or whether it could be traced to a peculiar variety of the bramble. He took a plant from the woods, where it had grown in fine soil, and planted it in poor soil, and yet it produced berries as large as Lawton's, although only a small crop. Several bemies measured four inches each in circumference. From his experiments he was convinced that there were distinct varieties of the bramble, some of which were more favorable than others to produce the fine fruit now grown by Lawton, and that it is to the variety, rather than to either the soil or the cultivation, that the superiority is to be attributed.

\section{New Varieties of Currants.}

La Versaillaise, La Hative, and La Fertile, three varieties comparatively new, are well worthy of cultivation. The first is the largest currant known-larger even than the Cherry currant; its bunches are very long. The second and third are well named, for La Hative is as early as Knight's Early Red, but with berries much larger; and La Fertile is a most prodigious bearer, so that its leaves are hidden by its fruit. 
Transparent White proves a most excellent sort. Its fruit is more amber-colored than any other white currant.-Rivers's Catalogue of Fruits, late Supplement.

London Currants. - A writer in the Horticulturist speaks of the fine currants of the marketgardens near London, which are grown in the following manner: They are planted in rows, twenty or thirty feet apart, and three or four feet apart in the rows; the ground, which is naturally good, is highly manured, and cropped between with vegetables. When the plants commence bearing, they are pruned very hard; the greater part of the young wood is thinned out, and what is allowed to remain is shortened back to two or three inches. By this means the trees are always kept short, never attaining a greater height than two or three feet. These strong-manured and well-pruned trees produce magnificent fruit, and in great abundance, well remunerating the market-gardener for his trouble.

\section{New Plan for Raising Hops.}

Ar the recent State Agricultural Fair of New York, a plan of raising hops upon a frame was exhibited, which is worthy attention from all hop-growers. A wire stretched between posts holds strings upon which the vines climb. The hops, when ripe, are to be protected by tin caps to shed off the rain.

\section{Japan Pea.}

THIs new and rare article is found to be adapted to our soil and climate, and yields bountifully. The writer has counted on an average 300 pods to each plant-pods containing from two to three peas. They are small, round, of a cream color, and very hard. Should think they might be ground. They are very nutritious. The plant attains the height of about thirty inches; it is stiff and woody; unlike all other peas, it stands independent of all surrounding objects, and upright, like a shrub or small tree. Experience will prove the best manner of cultivating and harvesting.

They should be planted or sown about the usual time of planting corn, not earlier, as frost is fatal to the young plants.-J. W. Briggs, Genesee Farmer.

\section{Mexican Frijoles.}

There are two varieties of frijoles cultivated in Mexico; the one, small, of a black color, growing on the coast and in the hot climate, (tierra caliente;) the other, of a brown color and a larger size, in the high lands, under the temperate and cold climate of that republic. They grow in small bushes, and yield abundantly. The time of planting them is in the months of April and May. The frijoles are the principal food of the Mexican population. When ripe and dry, they are generally soaked in soft water three or four hours, and then cooked in water with chopped onions and pork or lard, without salt.

The culture of frijoles has been tried for the last few years in Prussia with great success, where they have been recommended to the farmers as a substitute for potatoes. They are a substantial, healthy, and most palatable food. Like the potatoes in Europe, they are always met with at the tables of the rich and poor.

For a delicate dish, the following direction is used: Soak the frijoles in soft water for three hours, and boil them with chopped onions and lard, without salt, in the evening, until they are nearly done. The next day, take sufficient lard, put chopped onions in it, and when very hot, add the frijoles with their gravy to it, and let them boil quickly for a quarter of an hour, seasoning with pepper and salt. Care must be taken not to let the gravy boil all away, as when dry they are not so savory.-Hunt's Merchant's Magazine.

\section{The-Sorgho, a new Sugar-Plant.}

THE scarcity of corn in France during the past year has drawn attention to a new plant, recently introduced from China, which promises to supersede, to a certain extent, the use of beet-root in the manufacture of sugar and the distillation of alcohol. The agricultural 
committee of Toulon has recently addressed a report to the Minister of War with respect to the use of the plant in question. It is called the Sorgho, or Holeus saccharatus, and was first introduced into France in 1851, by M. de Montigny, the French consul in China, who sent some grains of the seed to the government. Since then the culture of the plant has been commenced with success in Provence, and promises to be of great advantage to Algeria. The sorgho has been called the "sugar-cane of the north of China;" and numerous experiments have recently been tried with a view to ascertaining if it possesses the properties necessary for producing a crystallizable syrup, so as to become a rival to sugar-cane and beet-root. According to the report of the Toulon Agricultural Association, it would appear to have those properties. The fact has been ascertained by a series of experiments made in the department of the Var. It also appears to be richer in the saccharine principle than any known plant, except the vine. Beet-root contains from eight to ten per cent. of sugar; the sorgho produces from sixteen to twenty per cent., from which eight or ten per cent. of pure alcohol, fit for all industrial and domestic purposes, can be produced. The refuse is excellent food for cattle, who are very fond of it. The plant grows with great rapidity, and does not require irrigation. The sorgho is not a new discovery, as it has been used from time immemorial by the inhabitants of the North of China, by whom large quantities of sugar are extracted from it. But this is the first time it has been produced on any thing like an extensive scale in Europe.

M. Vilmorin has succeeded in making cider of the sorgho. In one experiment, with 200 kilogrammes of stalks, the product in juice was 55 per cent. of the weight of the stalks. This quantity would give 6000 gallons to each hectare of land, ( $2 \cdot 47$ acres.)

This plant, or a variety of it, has also been found in South Africa, where it has received the name "Imfe," or "Imfy." Mr. Wray, an English planter from Natal, states that fifteen varieties of it may be found upon the south-west coast of Caffraria. In rich soil, it grows to the height of six to nine feet, stalks erect, with flexible reclining leaves. Its habits are very similar to that of Indian corn, but more elegant. It forms generally a tuft, composed of six or seven stalks, terminated by a conical or rather serrate panicle, green at first, then passing by violet shades into the deep purple of ripeness. Mr. Wray further states that the imfy will grow wherever Indian corn will ripen, though it likes a hot, bright summer; that two crops a-year may be harvested in our cotton States, and one in any part of our country south of $45^{\circ}$; that it does not require replanting oftener than the hop, (say four times in a century;) and that it will yield three to four thousand pounds of choice sugar to the acre at each harrest.

Mr. Wilder, a missionary of the American Board to South Africa, in a communication to the New York Journal of Commerce, confirms the statements of Mr. Wray, and, in addition, says: "While growing, the imfy resembles broom-corn, and prodnces its seed after the same manner. The natives of Natal plant it with Indian corn, and cultivate it in the same manner, and it comes to perfection in about the same time, say from three to four and a half months. They cultivate it wholly for its saccharine juice, of which, under but slight pressure, it yields a much larger quantity than does the common sugar-eane, but not of so rich a quality. I should say that the same bulk of juice contained from one-half to three-fourths as much sugar as the juice of common cane. The adrantages it has over common cane are, that it grows well wherever Indian corn does, it is raised from the seed in four months ready to be made into sugar, it grows on high lands as well as on low, and the abundance of seed it produces may be used for provender for horses."

Notwithstanding the flattering notices which have been given, and the high expectations which seem to have been formed respecting these plants, a writer in the Philadelphia Florist maintains that the sorgho or imfy is merely a variety of the ordinary broom-corn, "turned up in a foreign land."

\section{Pumpkins and Squashes.}

We know of no vegetable genus in which there is so much confusion of names and characters among cultivators as the pumpkin and squash tribe, or Cucurbita of botanists. Their common names have so multiplied, that a farmer, wishing to grow some for his stock or his 
table, can hardly tell what to ask for at the seed-stores, or what will be the character of his crops when obtained.

The following communication from Dr. T. W. Harris, of Cambridge, Massachusetts, to the Pennsylvania Farm Journal, furnishes much desirable information respecting the origin, qualities, and uses of the several varieties of these vegetables:-

In September, 1834, Mr. John M. Ives, of Salem, Massachusetts, exhibited in Faneuil Hall, Boston, a new squash, to which he subsequently gave the name of the "Autumnal Marrow Squash." This fruit, thus introduced and brought into notice, soon became a great favorite, and has ever since been extensively cultivated for table use, as a sauce and for pies, in the vicinity of Boston. So popular has it become in the market of Boston, that it may well be called "the Boston Squash," though I never heard that name applied to it. Mr. Ires, in his description of it, called it a variety of Cucurbita melopepo, which is an error. If not a mere variety of Commodore Porter's Valparaiso squash, it doubtless descended from the same stock as the latter. It must not be confounded with the kind cultivated in England under the name of "Vegetable Marrow"-a very poor vegetable, as I am assured by friends who have eaten it in London-and apparently one of the sorts which in New England would be called summer squashes. The "Autumnal Marrow" is eaten only when fully ripe; the "Vegetable Marrow," like "Cymlings," is eaten only in an unripe state. The former comes into eating in September, but may be kept with care till March. When pure or unmixed by crossing with other kinds, it is considered as the very best autumnal and winter squash in New England. Many cultivators have allowed it to degenerate or become mixed with the larger and grosser Valparaiso, so that we do not often find it in entire purity in our markets. It generally has only three double rows of seeds.

I am not sure what is the fruit denominated Connecticut Field pumpkin, and the cheese pumpkin is unknown to me except by its name in catalogues.

The Valparaiso squashes, of which there seem to be several varieties, known to cultivators by many different names, some of them merely local in their application, belong to a peculiar group of the genus Cucurbita, the distinguishing characters of which have not been fully described by botanists. The word squash, as applied to these fruits, is a misnomer, as may be shown hereafter; it would be well to drop it entirely, and to call the fruits of this group pompions, pumpkins, or potirons. It is my belief that they were originally indigenous to the tropical and subtropical parts of the western coast of America; they are extensively cultivated from Chili to California, and also in the West Indies, whence enormous specimens are sometimes brought to the Atlantic States. How much soever these Valparaiso pumpkins may differ in form, size, color, and quality, they all agree in certain peculiarities that are found in no other species or varieties of Cucurbita. Their leaves are never deeply lobed like those of other pumpkins and squashes, but are more or less five-angled, or almost rounded, and heart-shaped at base; they are also softer than those of other pumpkins and squashes. The summit or blossom-end of the fruit has a nipple-like projection upon it, consisting of the permanent fleshy stile. The fruit-stalk is short, nearly cylindrical, never deeply five-furrowed, but merely longitudinally striated or wrinkled, and never clavated or enlarged with projecting angles next to the fruit. With few exceptions, they contain four or five double rows of seeds. To this group belong Mr. Ives' autumnal marrow squash (or pumpkin) before named, Com. Porter's Valparaiso squash, (pumpkin,) the so-called mammoth pumpkin or Cucurbita maxima of the botanists, the turban squash or acorn squash, Cucurbita piliformis of Duchesne, the Cashew pumpkin, Cole's Connecticut pie-squash, Stetson's Cuba squash, and his hybrid called the Wilder squash, with various others.

The variety introduced from Valparaiso by Com. Porter became known to me about the year 1830, since which time it has been more or less cultivated in New England, both for the table and for stock. It is of an oblong, oval shape, of a pale reddish-yellow color externally when ripe, nearly smooth, and very slightly furrowed, and often grows to a large size. It readily mixes with the autumnal marrow, but is inferior to it in quality. It may prove better and more valuable in the Middle and Southern States than in New England.

The turban, sometimes called the acorn squash, because when the fruit is small it 
resembles somewhat an acorn in its cup, seems to be the Cucurbita piliformis of Duchesne. It sometimes grows to a large size, measuring fourteen or fifteen inches in transverse diameter, and looks like an immense Turkish turban in shape. Specimens raised in my garden in 1851, were little more than ten inches in diameter, and weighed ten pounds or more, having very thick and firm flesh, but a small cavity within. They proved excellent for table use, equal in quality to the best autumnal marrows. They keep quite as well as the latter.

The earliest account of the Cashew pumpkin that has fallen under our notice is contained in the English translation of Du Pratz's History of Louisiana, (vol. ii. p. 8,) where it is called Cushaw. In the original French work, the name given to it is Giromon. Du Pratz described two varieties: one round, and the other curved, or of the shape of a hunter's horn. The latter was considered the best. The cushaw or cashew pumpkin is not cultivated or much known in New England. I raised some specimens of the crook-necked variety (which has only three double rows of seeds) a few years ago, from seeds received from New Jersey. They did not ripen well, and many of them rotted before half ripe. They are evidently too tender for a New England climate. From the account given of them by $\mathrm{Du}$ Pratz, they seem well suited to Louisiana, where they are much esteemed.

The genuine mammoth pumpkin, or true Potiron, (Cucurbita maxima,) may be considered as the typical species of this group, having rather soft, roundish heart-shaped, and entire leaves, a short, cylindrical fruit-stem, a permanent fleshy stile, and five carpels or double rows of seeds. The form of the fruit is an oblate spheroid, depressed at the blossom and stem ends, and marked with ten or more wide meridianal furrows. It sometimes grows to an immense size, two feet or more in diameter, and sixty pounds or more in weight, being light in proportion to its size, on account of the large hollow within. It is known to vary much in color and size, and somewhat in form. In some of its variations, it may have lost its original characteristio form so far as to be no longer recognised. If this be true, Cole's Connecticut pie-squash, the round Valparaiso squashes, and several others may be merely varieties of the mammoth pumpkin. To some of the varieties of this fruit, the name Giromon or Giromont, otherwise written Giraumon and Giraumont, signifying a rolling mountain, seems originally to have been applied, in allnsion to the form and size. French writers subsequently transferred this name to certain varieties of the Cucurbita pepo.

The plants of the foregoing Valparaiso, or Potiron group, are more tender and less hardy than those of the common pumpkin, or Pepo group; they are also much more subject to the attacks of worms or borers (AEgeria cucurbitoe) at the roots. Their fruits, compared with common pumpkins and winter squashes, have a thinner and more tender rind, and finer-grained, sweeter, and less strongly-flavored flesh, on which accounts they are preferred by most persons for table use.

The second group contains the common New England field pumpkin, bell-shaped and crook-necked winter squashes, the early Canada winter squash, the custard squash, and various others, all of which (whether rightly or not cannot now be determined) have been generally referred by botanists to the Cucurbita pepo of Linnæous. This group is readily to be distinguished from the first one by the following characters: The leaves are rough, and more or less deeply and acutely five-lobed. The fruit has only three carpels or double rows of seeds, and the stile drops off with the blossom. The fruit-stem is long, and clavated or enlarged next the fruit, where it spreads out into five claw-like projections, and is five-angled and deeply five-furrowed. The fruit is eaten only when fully ripe, and it may be kept with care throughout the winter. The rind, though sometimes quite hard, never becomes a woody shell, and the flesh remains juicy and succulent till it rots, never drying up into a spongy or fibrous substance, in which respects these fruits differ from what are called summer squashes. The seeds are not so broad, thick, or plump, and white as those of the potiron group, but are smaller, thinner, and of a grayish color.

The common field pumpkin of New England, which formerly was extensively raised for stock, and is still used for the same purpose, and of which our pumpkin-pies and pumpkinsauce were made till the winter crook-neck and autumnal marrow came to be substituted therefor, has a form somewhat resembling that of the mammoth pumpkin, but its longitudinal 
often exceeds its transverse diameter; its color is of a deeper yellow or orange, the furrows on its surface not so deep or broad, and its rind much thicker, and in some varieties quite hard. Its flesh is rather coarse, of a deep orange-yellow color, and of a peculiar strong odor. Baked pumpkin and milk, pumpkin-sauce, and dried pumpkin for winter use have had their day, and gone out of fashion; and pumpkin-pies are now mostly made of the autumnal marrow and crook-necked winter squashes, except by some of the old folks, who still prefer the pumpkin baked in a milk-pan, and without any pastry.

The New England "crook-neck squash," as it is commonly but incorrectly called, is a kind of pumpkin, perhaps a genuine species, for it has preserved its identity, to our certain knowledge, ever since the year 1686, when it was described by Ray. It has the form and color of the Cashew, but is easily distinguished therefrom by the want of a persistent stile, and by its clavated and furrowed fruit-stem. Before the introduction of the autumnal marrow, it was raised in large quantities for table use during the winter, in preference to pumpkins, which it almost entirely superseded. Many farmers now use it instead of pumpkins for cattle, the vine being more productive, and the fruit containing much more nutriment in proportion to its size. It varies considerably in form and color. The best kinds are those which are very much curved, nearly as large at the stem as at the blossom end, and of a rich cream color. Some are green, variegated with cream-colored stripes and spots. Some are bell-shaped, or with a very short and straight neck, and are less esteemed than the others; for the neck, being solid and of fine texture, is the best part of the fruit. These crook-necks can be kept all winter, if not exposed to frost, and I have eaten of them when a year old. On account of its hardiness, its fruitfulness, and its keeping qualities, this is perhaps the most valuable variety to the New England farmer. It is said to degenerate in the Middle and Southern States, where, probably, Porter's Valparaiso or some kindred variety may be better adapted to the climate.

The early Canada squash seems to be a precocious and dwarfed variety of the common crook-neck. It is smaller, with a short and often straight neck, and is of a dark and dirty buff color externally. It comes into eating early, quite as soon as the autumnal marrow, and was, indeed still is, much esteemed as a table vegetable.

The custard squash or pumpkin is an oblong, deeply-furrowed, and prominently ten-ribbed fruit, with a pale buff and very hard (but not woody) rind, and fine, light-yellow flesh, much esteemed in the making of pies and puddings. From seeds received from Paris, under the name of Patagonian squash, I raised a fruit exactly like the custard squash in form and size, but of a dark-green color externally, and entirely worthless as an article of food. Nevertheless, I infer that the custard squash is merely an improved variety from the same original stock.

The fruits belonging to this second group probably originated in the eastern and central parts of the two Americas. They were cultivated by the Indians, and were found here in their gardens and fields by Europeans on the first settlement of the country. Pumpkins, or bell-shaped squashes, (as New Englanders would now call them,) were found as far north as Saco, by Champlain, in 1605 and 1606. A similar variety was cultivated by the Iroquois Indians, and still bears their name in France. Pumpkins were found by Raleigh's colony among the Indians in North Carolina, and by early voyagers in the West Indies. There are indigenous kinds in Brazil, and we have seen that even Patagonia has added another to the common stock. Cultivation has, doubtless, improved their qualities, and has caused them to sport in numerous varieties, so that it is now difficult, if not impossible, to determine which of the known kinds are typical species and which are mere varieties.

A third group remains to be described. The representatives of it are the Cucurbita melopepo, verrucosa, and ovifera, of Linnæus. It includes all those kinds called in New England summer squashes, because they are eaten only during the summer while they are soft and tender, and in an unripe state. These are the only two squashes, if regard be had to the origin of the name, derived from the language of the Massachusetts Indians, by whom, according to Roger Williams, this kind of fruit was called "Askutasquash, which the English from them call Squashes." From the same authority, and from other sources, we learn that the Indians of New England cultivated this kind of fruit or vegetable, and used it for food; 
that some of their squashes were "of the bigness of apples, of several colors," while others are represented by Champlain as being considerably larger, turbinated, and more or less puckered on the margin, and of the same form as that which in France is called Bonnet de prêtre, probably the prototype of our scalloped squash, or Cucurbita melopepo. Bartram found a squash-vine growing wild in the interior of East Florida, climbing to the tops of the trees, and bearing little yellow squashes of the form and size of an orange. Mr. Nuttall informs us that the warted squash, Cucurbita verrucosa, was "cultivated by the Indians of the Missouri to its sources." It has generally been supposed, on the authority of Linnæus, that the egg-squash, Cucurbita ovifera, was a native of Artrachan in Tartary. On turning to the account of it given by Dr. Lorche, from whom Linnæus received his specimens, I find it included in a list of plants not natives of the vicinity of Astrachan, but cultirated only in gardens, where it is associated with such exotics as Indian corn or maize, with which it was probably introduced directly or indirectly from America. We also learn from Lorche that this species varied in form, being sometimes pear-shaped; that it was sometimes variegated in color with green and white; and that the shell served instead of little boxes. Here we have plainly indicated the little gourd-like, hard-shelled, and variegated squashes that are often cultivated as ornamental plants. From these and similar authorities, we conclude that summer squashes were originally natives of America, where 80 many of them were found in use by the Indians, when the country began to be settled by Europeans.

The summer squashes, like the plants belonging to the second group, have acutely fivelobed, rough leaves, and large yellow flowers, a clavated five-angled and five-furrowed fruitstem, and a deciduous stile. Their seeds also resemble those of common pumpkins and winter squashes, but are smaller and thinner; some of them are runners and climbers, other's have a dwarf erect habit, and hence are sometimes called "bush squashes." They differ from all the foregoing kinds in having, when ripe, a hard and woody rind or shell to the fruit, with a slimy and fibrous pulp, which, when dry, become a mere stringy and spongy mass. Hence these fruits are only eaten while they still remain tender and succulent, and never in a ripe state. On account of their woody shells, they are sometimes mistaken for and miscalled gourds, from which they are not only distinguished by their oval and thin seeds, but by the largeness and yellow color of their flowers, - those of gourds being smaller and white, - and by their deeply-lobed and rough leaves, those of gourds being entire, or at most only slightly angular and downy.

Under the name of Cucurbita melopepo is to be included what in New England is called scalloped squash, and in the Middle and Southern States, cymlings; perhaps the patty-pan squash is another synonym for the same. This melopepo is a very broad and thin or compressed fruit, with scallop edges, and more or less warted surface; it measures often ten or eleven inches in transverse diameter, and three to four from stem to blossom. It varies in form, being sometimes much thicker, and more or less turbinated or top-shaped, when it takes the name of Bonnet de prêtre, or priest's cap; perhaps this is really its original form. Other varieties, nearly round, are sometimes seen.

The Cucurbita verrucosa is the cucumber-shaped warted squash, generally with a slightlycurved neck. In the West Indies there is a much larger, oblong, ovoid squash, with a somewhat warted surface, which is also referred to the Cucurbita verrucosa. Intermediate between these, there is another, which may be described as pestle-shaped, measuring ten inches or more in length, and quite smooth on the surface. These two kinds, namely the Cucurbita melopepo and $C$. verrucosa, with all their varieties, are generally of a dwarf habit, with erect stems.

Cucurbita ovifera, with its varieties auriantiaca, the orange or apple squash, and the pyriformis, or pear-shaped and variegated squashes, has a running or climbing stem. Some of the orange squashes are the very best of the summer squashes for table use, far superior either to the scalloped or warted squashes.

The vegetable marrow, as it is called in England, has been considered by botanists as a variety of the Cucurbita ovifera of Linnæus; if this be correct, cultivation has forced it to a most unnatural size, and has greatly changed its original form. 


\section{Propagation of the Olive in the United States.}

Durivg the past season, the Patent Olfice has distributed in the Southern States bordering on the Atlantia and Gulf of Mexico, choice cuttings of the olive, selected in the South of France. It is already well known that this product has been cultivated in some parts of Florida and California for many years; and, doubtless, there are other sections of country uniting the conditions necessary for the growth and perfection of its roots. It may be stated that, while the Floridas were held by the English in 1769, one Dr. Turnbull, a famous adventurer of that nation, brought over from Smyrna a colony of fifteen hundred Greeks and Minorcas, and founded the settlement of New Smyrna on the Mosquito River. One of the principal treasures which they brought from their native land was the olive. Bartram, who visited this colony in $\mathbf{1 7 7 5}$, describes that place as a flourishing town. Its prosperity, however, was of momentary duration. Driven to despair by hardship, oppression, and disease, a part of these unhappy exiles died, while others conceived the hardy enterprise of embarking for Havana in an open boat, and in three years their number was reduced to five hundred. The rest removed to St. Augustine, when the Spaniards resumed possession of the country, and in 1783 a few decaying huts and several large olive-trees were the only remains to be seen of their wearied industry. Numerous attempts, at different times, have been made to propagate the olive from seeds, in various parts of the South, which have proved unsuccessful. This want of success may be attributed, in part, to the tendency of the olive to sprout into inferior varieties when propagated from seeds; but after the experiment has been fairly tested by cuttings of choice and well-proved varieties, it is hoped that this "first among trees" will sooner or later become celebrated in the regions of the South.

Mr. R. Chisholm, in a recent communication to the Charleston (South Carolina) Mercury, states that he has cultivated two kinds of the olive for ten years, and that its fruit ripens fully in the low countries of the South. He has now three hundred trees under cultivation, but he believes that it cannot be cultivated at present for the sake of its oil, as cotton is a more profitable crop.

Olives in California.-At a meeting of the California Academy of Natural Sciences, held February 5, 1855, drawings and specimens of the California olive were exhibited by Dr. Kellogg. The specimens in question were brought by Col. D. Ransom, of the United States Survey, from San Fernando. It is well acclimated in California at all the old mission stations. This tree, as stated by Dr. Kellogg, is thrifty on the sea-coast, declivities, and valleys, when the soil is free from stagnant moisture, and when the debris is fat gravel. It grows to the height of twenty feet, with a trunk of eight or ten inches diameter, and forms a picturesque ornament to avenues and plantations. Its branches are graceful; its foliage evergreen; its wood excellent; it lives to a great age, and can be propagated by cuttings.

\section{Culture of Horse-Radish.}

Mr. B. F. Cutter, of Pelham, New Hampshire, in a communication to the New England Farmer, recommends the following plan for the cultivation of horse-radish :-

Take any good rich land with a deep soil that is suitable for a garden, root crops generally, or a well drained bog-meadow that is in a good state of cultivation, and ridge by turning two furrows together three feet apart; make smooth by raking if necessary, and plant the seed fifteen inches instead of two feet apart: some cultivators put it nearer both ways. The after cultivation consists in keeping the ground light and clear from weeds in any way that best suits the cultivator. I prepare my seed early in the spring, by taking roots one-quarter of an inch in diameter, and cutting in pieces one inch long; wash clean and rub off all fibrous roots, and then cover them up in the ground until the sprouts are an inch long, and previous to planting, rub off all but the best one. The reason for this operation is, that you will have less small roots; consequently, more large ones. For the cultivation of horse-radish generally, dig, late in the fall, all that is wanted for winter use, and let the rest remain in the ground for spring, as it is not easy to keep it well in dry cellars. 


\section{Celery.}

When celery-plants commence to be bushy, I find they do best to be cut down, and I repeat that process some three or four times, and each time I give them soluble manure. This plan renders them so strong, that when I plant them out in rows they do not require shading with leaves even, as is usual. It is wrong to plant celery in low, damp places, where the land is not drained. But if the land be drained so as to let off the water, you will do well to keep up a constant stream all day. It is a good plan to have a trough made with two boards a V-shape, and place it across the highest part of the celery rows. Have a plughole over each row, so as to allow the water to run into any row required to be irrigated; the stream should always be kept up until the water has reached the extremity of the trench. It will pay well to keep a man pumping all day, if the land be such as to get rid of the water, and not allow it to become stagnant. Celery cultivated in this way will grow six feet long.-Prof. Mapes, Proc. New York Farmers' Club.

\section{Sprouted Wheat good for Seed.}

A correspondent of the Rural New Yorker, W. Garbut, Wheatland, New York, states that sprouted wheat is about as good for seed as that which is uninjured by wet weather. Mr. Garbut says-

The excessive wet weather in harvest sprouted so much of the wheat in this section, that many of the farmers are very anxious to procure sound wheat for seed. I can assure them that they need not be solicitous on that account, for wheat that has been sprouted will germinate as freely a second time as it did the first, and with equal vigor. To test the fact, on the 17 th of this month I took some of the worst sprouted wheat that I had; every kernel of it had grown, and it was so thoroughly dry that the sprouts all rubbed off. I put it into rich soil of suitable moisture. On the fifth day much of it made its appearance, and now, on the eighth day, many of the spears are three inches long, and as strong and as vigorous as I ever saw young shoots of wheat. Every kernel of it has grown.

\section{New Use for the Sweet-Potato Vines.}

Mr. P. A. Strober communicates the following information to the Georgia Telegraph :-It may not be generally known that the sweet-potato vine may be saved during the winter, and used the following spring, in propagating a new crop. I have tried the experiment during this year to my entire satisfaction, and therefore feel it my duty to communicate the result for the benefit of the public. In the fall, (any time before frost,) the vines may be cut in any convenient length, and placed in layers, on the surface of the earth, to the depth of twelve or eighteen inches; cover the vines, while damp, with partially-rotted straw (either pine or wheat will answer) to the depth of 'six inches, and cover the whole with a light soil about four inches deep. In this way the vines will keep during the winter, and in the spring they will put out sprouts as abundantly as the potato itself when bedded. The draws or sprouts can be planted first, and the vine itself can be subsequently cut and used, as we generally plant slips. This experiment is worthy the consideration of farmers, as it will save a great many seed-potatoes, (particularly on large plantations,) which can be used for feeding.

\section{Cultivation of Root Crops.}

No subject connected with agricultural improvement is more frequently discussed than that of root culture. Each root, from carrots to common turnips, and from ruta bagas to radishes, has its advocates. Yet, with a few exceptions, even our best writers seem to have confused ideas as to the object and effect of an extensive cultivation of root crops, and their consumption on the farm by animals. Most writers advocate the cultivation of root crops because more nutritious food can be obtained from an acre of land in this way than in any other. This is a one-sided view of the matter, and leads to numerous errors in opinion and 
practice. The principal reason for the extensive culture of root crops, the effect their growth has on the soil, and the amount of fertilizing matter which their consumption furnishes for the higher order of plants, is overlooked. Nearly, if not quite, as much nutritious matter can be obtained from an acre cultivated with Indian corn as from the same acre cultivated with turnips. In this respect, therefore, there is little adviantage in growing turnips. But take another view of the subject: suppose that one acre is planted with Indian corn, and another, alongside, with turnips, and that the crops from the two acres are constrmed by animals, and the manures made from them returned respectively to each acre, and both are sown to wheat: the wheat on the turnip acre would be a better crop than on the corn acre. Wo think there can hardly be the shadow of a doubt on this point. The value of roots, therefore, is partly, if not principally, due to their fertilizing effect on the soil; and in deciding which root to cultivate, we must by all means bear this in mind.-New York Country Gentleman.

\section{Beets Vs. Turnips for Feeding Stock.}

TuRnips are raised to a greater extent, both in Great Britain and this country, than any other kind of roots, except, perhaps, potatoes. But water enters very largely into their composition, so as to detract from nutritive qualities. According to Dr. Anderson, the chemist to the Highland Agricultural Society of Scotland, the beet is much more profitable for feeding than the turnip. He states that he has analyzed a crop of mangel-wurzel, amounting to thirty-four tons per acre, and ascertained by that analysis that the nutritive matter produced exceeded two and a half times that of a good, and three and a half times that of an average, crop of turnips.

Mr. A. Y. Moore, President of the State Agricultural Society of Michigan, states that the kind of root which has produced the greatest quantity of milk with him, is the sugar-beet.

Others have found the sugar-beets of superior value, so much so, that one farmer within our knowledge has raised them as a field crop for a great many years. He says they yield as abundantly as any other root, and are at the same time more nutritive than others, with the exception of carrots. He, too, thinks they are superior, for milch cows, to any other root or vegetable whatever. He informs us that butter made in winter from cows fed on this root, in addition to their dry feed of hay, is nearly as great in quantity as in the fall, and of nearly, if not quite, as rich a color and quality.

\section{On the Art of Cultivating Fruit-Trees.}

THE absolute necessity of proper preparation and deep and thorough cultivation of the soil, especially for certain fruits, is now generally admitted, though regard must always be had to the natural activity in the sap of the species, and to the degree of fertility of the soil. Surely it would be unwise to apply the same cultivation to the peach and the cherry as to the apple and the pear, or to treat any of these on new and fertile grounds as in old and exhausted lands. The influence of soils is remarkable. But by these we do not mean the identical spot, the artificial bed in which the tree stands; for, in time, the roots take a wide range in search of food. Some fruits are good in nearly all places; others, only in their original locality : some succeed best on light, loamy, or sandy soils; others, in stiff, clayey soils. In the latter, many pears-for instance, the Beurre bose and Napoleon-are astringent; while in the former they are entirely free from this quality. The Beurre rance, in England and in some parts of France, is the best late pear. So it is also in some parts of the soils in Belgium; while with others, and with us, it is generally inferior. The flavor of fruit is much influenced not only by soil, but also by climate and meteorological agents. Thus, in a cold, wet, and undrained soil, disease commences in the root, and, as a natural consequence, the juices of the tree are imperfectly elaborated, and unable to supply the exigency of the fruit. Even injurious substances are taken up. A plum-tree has been known to absorb oxide of iron, so as not only to color the foliage, but also to exude and form incrustations on the bark, and finally to kill the tree. As an instance of climatic 
agency, it is sufficient to report the fact, that out of fifty varieties of American peaches grown in the gardens at Chiswick, England, only two were adapted to the climate.

In relation to appropriate fertilizers for fruit-trees, a diversity of opinion prevails. All agree that certain substances exist in plants and trees, and that these must be contained in the soil to produce growth, elaboration, and perfection. To supply these, some advocate the use of what are termed special manures; others ridicule the idea. We submit whether this is not a difference in language rather than in principle; for by special fertilizers, the first mean simply those which correspond with the constituents of the crop. But are not the second careful to select and apply manures which contain those elements? And do they not, in practice, affix the seal of their approbation to the theory which they oppose? Explode this doctrine, and do you not destroy the principle of manuring and the necessity of a rotation of crops? Trees exhaust the soil of certain ingredients, and, like animals, must have their appropriate food. All know how difficult it is to make a fruit-tree flourish on the spot from which an old tree of the same species has been removed.

The great practical question now agitating the community is, How shall we ascertain what fertilizing elements are appropriate to a particular species of regetation? To this, two replies are rendered: some say, analyze the crop; others, the soil. Each, we think, maintains a truth, and, both together, nearly the whole truth. We need the analysis of the crop to teach us its ingredients, and that of the soil to ascertain whether it contains these ingredients, and, if it does not, what fertilizers must be applied to supply them. Thus, by analysis, we learn that nearly one-quarter part of the constituents of the pear, the grape, and the strawberry consists of potash. This abounds in new soils, and peculiarly adapts them to the production of these fruits; but having been extracted from soils long under cultivation, it is supplied by wood-ashes or potash, the value of which has of late greatly increased in the estimation of cultivator8.-Annnal Address before the Pomological Convention, by Marshall P. Wilder.

\section{Improvements in Raising Fruit-Trees.}

A BomeMrav arboriculturist has successfully introduced a new mode of planting. Instead of using the process of grafting, he takes an offshoot of any fruit-tree-an apple-tree, for instance-and plants it in a potato, both being carefully placed in the soil, so that five or six inches of the shoot shall be above the ground. This latter takes root, grows with rapidity, and produces the finest of fruit. - Maine Farmer.

\section{On the Gathering and Preservation of Fraits.}

NEXT in importance to the ability to grow any given crop successfully, is a knowledge of the means and appliances that are best adapted to preserve it in its best condition for future use and sale. It is not the mark of a prudent farmer to suffer his grain to be damaged for want of storage; neither is it wise for any one who has fruit to gather and assort for market, to permit ill-judged haste to bruise the tender cells or mar the external appearance and form. Much has been said on the imperative necessity of not allowing apples, or any fruits designed for long keeping, to receive even the slightest bruise or indentation. Why this necessity for preserving the delicate cellular tissue intact, will be evident if we consider for a moment the reasons therefor. The juices of all fruits are contained in cells; and it is by the growth and aggregation of these cells, protected by their external covering, that fruit attains its ultimate size. When fruits have attained their full growth and development-or become ripe, as we say-the laws of vitality are suspended, except as relates to the preservation of the seed ; and the ever-active agencies of chemical decomposition are ready to commence their work, and thus continue the ceaseless round of production and decay.

So long as the temperature is kept below the germinating point, or below the degree at which decomposition commences, and the natural moisture inherent in itself is not permitted to escape, many fruits may be kept in all their freshness for a long time; but in how many instances are all these conditions a perfect blank! Go into our orchards, and observe care- 
fully the general method of procedure. Instead of feet properly shod stepping carefully among the branches and delicate twigs, how often does the iron-shod heel bruise or tear off the bark, and leave ragged wounds to be healed by the abused tree! Instead of picking off the fruit one by one, and placing it gently and with care in the basket, the long pole to whip the branches is brought into requisition; and though it may be sport to the lads to see the apples fly through the air and fall heavily upon the earth, pierced, very likely, by the stubble of the wheat, oat, or barley crop, (taken off that the use of the land be not:lost,) yet when gathered, how few will you find in a fit state for keeping!

Now, all this wholesale process of bruising and waste may be remedied, by the exercise of a little forethought in providing means of access to the branches of the trees. Had we a crop of nice fruit to gather, in anticipation of the friendly fireside chat during the long winter evenings, we should not deem it time lost to spend a few days in providing stepladders, folding-ladders, and canvas sheets with rings at the corners, by which they could be extended under the trees if necessary, in order to gather the fruit difficult of access. When collected in our basket, we would not pour them heavily upon the floor of our fruitroom or into the barrel; neither would we convey them homeward or to market in a springless conveyance. When about to place them in winter quarters, we should reject every unsound or bruised one, remembering that the old proverb holds true in this as in every case"Evil communications corrupt good manners;" which, paraphrased, would read, "Every unsound or decaying specimen of fruit will invariably depreciate the value of the rest, and dispose them to rot."

In regard to the winter-keeping of fruit, the Hon. M. P. Wilder, of Boston, in the "Horticulturist," states that his experiment of keeping fruits was suggested by the difficulty of avoiding the bad effects of moisture and warmth in his old fruit-cellars under his dwellinghouse; and the same difficulty exists on the ground-floor of buildings. "I therefore resorted," he says, "to the other extreme-a cool and dry chamber on the north end of my barn, the location of which being over the carriage-room. I am now quite satisfied that we have at last attained the proper location for a fruit-room-namely, a cool upper apartment with lined non-conducting walls."

But we apprehend the great difficulty to be found in the want of care and attention to these points is this-Will it pay? To such we do not know that we can give a better reply than by giving the experience of a noted fruit-grower, who is satisfied that it does pay. Mr. Pell, of Pelham, New York, in some remarks before the American Institute, thus explains his process :-

* * * "To do this reasonably, they should be picked from the tree by hand with great care, so as not to break the skin or bruise the fruit in the slightest degree, as the parts injured immediately decay, and ruin all the fruit coming in contact. Apples shaken from the tree become more or less injured, and totally unfit to be kept through the winter, or even shipped to the nearest ports. My pippin fruit is all picked by hand, by men from ladders, into half-bushel baskets, from them into bushel-and-a-half baskets, in which they are carried in spring wagons, twelve at a time, to storerooms covered with straw, where they are carefully piled, three feet thick, to sweat and discharge by fermentation some 30 per cent. of water, when they are ready for barrelling for shipment to Europe or elsewhere. If they reach their port of destination before the second process of sweating comes on, they will keep perfectly four months. I have kept them sound two years, and exhibited them at the end of that time at the Institute Fair, Castle Garden. They have been sent to Europe and China from my farm, packed in various ways-namely, in wheat chaff, buckwheat chaff, oats, rye, mahogany sawdust, corkdust, wrapped separately in paper, and in ice. By the mode I now adopt, I can warrant them to bear shipment superior to any other, except ice."Genesee Farmer.

\section{On the Ripening of Fruit.}

We make the following extract, on the ripening of fruit, from the address of Hon. Marshall P. Wilder, before the U. S. Pomological Society :-

Much progress has been made in this art within a few years, and important results have 
been attained. The principle has been settled that the ripening process can be controlled. Autumnal fruits have been kept and exhibited the succeeding spring. We have seen the Seckel, Bartlett, and Louise Bonne de Jersey pears in perfection in January, and even later. The maturity of fruits depends on saccharine fermentation. This is followed by other fermentations, as the vinous and acetous. To prevent these, and preserve fruit in all its beauty, freshness, and flavor, the temperature must be uniform, and kept below the degree at which the fermentation or the ripening process commences. Our remarks, like our experience, have special regard to the apple and the pear, though the principle is doubtless susceptible of a more extensive application. Fruits designed to be kept for a considerable time, should be gathered with great care some days before the ripening process commences, especially summer pears. A summer pear ripened on the tree is generally inferior. In respect to the latter, Mr. Barry, editor of the Horticulturist, has so aptly expressed my own sentiments, that I use his language: "The process of ripening on the tree, which is the natural one, seems to act upon the fruit for the benefit of the seed, as it tends to the formation of woody fibre and farina. When the fruit is removed from the tree at the very commencement of ripening, and placed in a still atmosphere, the natural process seems to be counteracted, and sugar and juice are elaborated instead of fibre and farina. Thus, pears which become mealy and rot at the core when left on the tree to ripen, become juicy, melting, and delicious when ripened in the house." Various fruit-houses have been built, both in this country and in Europe; and experience shows that their object can be attained only by a perfect control of the temperature, moisture, and light. Hence, they must be cool, with non-conducting walls, or with exterior and interior walls, or a room within a room. Thus the external atmosphere, which either starts the saccharine fermentation or conveys the agents which produce it, can be admitted or excluded at pleasure. It is possible, however, to preserve the temperature at so low a degree and for so long a time, as to destroy, especially with some varieties of the pear, the vitality, and therefore all power ever to resume the ripening process. Experience proves that for the common varieties of the apple and pear, about forty degrees of Fahrenheit is the temperature best suited to hold this process in equilibrium. The proper maturing of fruit thus preserved demands skill and science. Different varieties require different degrees of moisture and heat, according to the firmness of the skin, the texture of the flesh, and the natural activity of the juices. Thus, some varieties of the pear will ripen at a low temperature and in a comparatively dry atmosphere, while others, as the Eastern Beurré, are improved by a warm and humid air.

Some varieties of the pear ripening with difficulty, and formerly esteemed only second rate, are now pronounced of excellent quality, because the art of maturing them is better understood.

But so many experiments have been tried or are in progress, and so much has been written on this branch of our subject, that I need not enlarge, except to say that the art of preserving and ripening fruit in perfection involres so much scientific knowledge, as to require great attention and care; and, until its laws are more fully developed, must be attended with considerable difficulty.

\section{On the best Method of Storing and Preserving Potatoes.}

Aт a recent meeting of the Farmers' Club of Whitby, England, some interesting statements were made relative to the best methods of storing and preserving potatoes. The general opinion expressed was, that the potatoes when first gathered should not be housed or packed a way immediately, but be spread out thinly for ten days or two weeks under shelter, in order that they may be allowed "to sweat." If room in out-houses is not abundant, they may be put in small heaps in the field, and carefully covered with straw; here they should be allowed to remain for about a fortnight. It was also particularly recommended that the potatoes should be sorted, as soon as gathered, into three sorts-the marketable, for seed, and the bad and small ones. 


\section{The Oidium Tuckeri, or Grape Malady of Europe.}

Frом a paper read before the Royal Institution of Great Britain, by M. Brockedon, we obtain the following information respecting the singular disease which has of late years proved so destructive to grapes of France and other parts of Europe :-

It appears to have been first observed in England by an observant gardener of Margate, whose name has been given to the fungus producing the disease-viz. Oidium: Tuckeri. It is an egg-shaped fungus, one of an immense family of this class of destroyers, but one not before known or recognised; and though it bears a close resemblance to those which are found upon the potatoe, peach, cucumber, \&c., yet it is distinguished from all others by a microscopic observer, and has never yet been found upon any other plant, and, when found upon the grape, has always been destructive. Its first appearance is like a whitish mildew, showing itself principally upon the young grape when about the size of a pea. When the spore of this fungus has settled on the young berry, it enlarges and radiates irregularly in fine filaments, which often cover the whole surface, extending with great rapidity. These fix themselves by imperceptible attachments, which do not appear to penetrate the cuticle; numerous branches from the mycelium are unfruitful; others are jointed, and rise vertically like the pile of velvet; the upper joint enlarges, rounds itself into an elliptical form, ripens, separates, and is carried off with the slightest motion of the air, to find another grape upon which it can be developed. Warmth and moisture favor its rapid fructification; a succession of spores rise from the same branch, and often two, three, or four ripen and disperse almost at the same time. Its effect upon the grape is to exhaust the juices of the cuticle, which ceases to expand with the pulp of the fruit; it then bursts, dries up, and is utterly destroyed. This fatal disease has returned with increased virulence in each succeeding year. In 1847 the spores of this Oidium reached France, and was found in the forcing-houses of Versailles and other places near Paris; but the disease soon reached the trellised vines, and destroyed the grapes out of doors in the neighborhood, and continued to extend from place to place; but until 1850 it was chiefly observed in vineries, which lost from this cause, season after season, the whole of their crops. Unhappily, in 1851, it was found to have extended to the south and south-east of France and Italy, and the grapes were so affected that they either decayed, or the wine made from them was detestable. In 1852, the Oidium Tuckeri reappeared in France with increased and fatal energy; it crossed the Mediterranean to Algeria, has shown itself in Syria and Asia Minor, attacked the Muscat grapes at Malaga, injured the vines in the Balearic Islands, utterly destroyed the vintage in Madeira, greatly injured it in the Greek Islands, and destroyed the currants in Zante and Cephalonia, rendering them almost unfit for use; and so diminished the supply, that five hundred gatherers did the ordinary work of eight thousand! But it is in France that its frightful ravages are chiefly to be regarded as a national calamity, where the produce of the soil in wine is said to exceed five hundred millions of hectolitres; two-fifths of the usual quantity of wine made there has been destroyed, and what has been made is bad. It has not touched with equal severity all the departments.

M. Möhl has most carefully examined whether the Oidium of the grape lives on other plants besides the vine, but he is decidedly of opinion that it does not. Some persons have supposed that it was caused by insects, because occasionally they have been found on diseased vines; but the idea is now utterly rejected, for not the slightest appearance of disease precedes the fungus, which creeps over the epidermis, but does not enter its tissues. It envelops the grape, absorbs the juices of the superficial cells, and stops the growth of the cuticle. The pulp expands within the fruit, bursts longitudinally, its juices are lost, and it dries up. In an early stage of the disease the fungus may be wiped off, and the fruit will come to maturity. The Oidium never matures on decayed vegetable substances; it lives and fructifies only on living tissues. By many it is asked, Is the Oidium the cause, or the consequence of the disease of the vine. The vine, one party says, is over-cultivated and liable to affections which the wild healthy plant resists, and it should be treated as in a state of plethora: tap it, lessen its sap, and it will invigorate so as to resist the poison of the Oidium. This has been tried and has failed. If this were the cause, also, it could not have so suddenly and widely extended itself. 


\title{
Agricultural Znothogy,
}

\author{
IXCLUDIXE
}

THE INTRODUCTION OF NEW BREEDS OR SPECIES OF ANIMALS, NOTICES OF IMPROVEMENTS IN THE TREATMENT AND GROWTH OF STOCK, THE PRODUCTION OF ANIMAL FIBROUS SUBSTANCES, DISTRIBUTION OF ANIMALS, ETC.

\section{On the Introduction of Foreign Domestic Animals into South Carolina.}

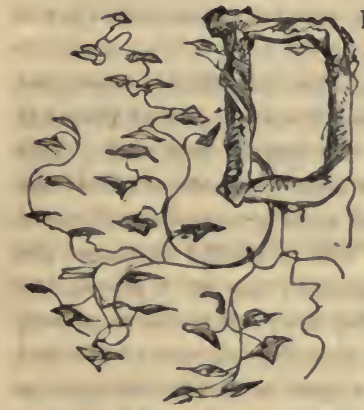

R. DAVIS, of Columbia, S. C., furnishes to the Patent Offiee the following communieation respecting the introduction of various breeds of foreign domestie animals into the Southern States, especially South Carolina :-

The want of ealcareousness in nearly all of the soils of the Southern States, together with the heat of the sun, renders them unfit for perennial grasses for grazing; henee they are more suitable for browsing, as both tend to originate shrubbery and weeds. In 1836, having had some experience in the importation of short-horned, Devon, and Ayrshire eattle into the South, I then summarily advaneed an opinion, "that all cattle brought from a Northern to our Southern elimate must neeessarily degenerate to the peculiarities of our location, and that it would be easier to improve eattle already acclimated, or import animals from a still warmer region." In my late sojourn in Asia and the East, I had reference to this observation in importing Cashmere, Scinde, and Malta milking-goats, as well as the Brahmin ox, or Nagore, of India, the Asiatic buffalo, or water-ox, and other animals.

The Cashmere, Persian, Angora, and Circassian goats are one and the same animal, changed in some respeets by altitude, though but little by latitude. They abound in all this inaceessible territory, and are the eating, milking, eheese and butter-making and elothes-making animal of the whole country. They are finely developed for the table, mueh disposed to fatten, very white and beautiful, with long fine wool or curly hair, yielding about four to four and a half pounds to the fleeee. They ean be easily proeured by an energetic man, acquainted with the peeuliarities of the population, and at a cost of $\$ 4$ to $\$ 6$ eaeh on the spot. I brought to the United States, in 1849 , seven females and two males. They have kids only every spring, usually two at a birth. The full breeds have inereased only to about thirty, from the aecidental eireumstance that in nearly every instance the issue has been males.

In locating these animals in different seetions of South Carolina, I can see no difference between those reared here and the imported, with the exception that those reared in this State are finer and heavier fleeed than those imported.

On my arrival, I immediately procured a number of our little diminutive native female goats, and erossed them upon a Cashmere buek. Their progeny had hair very fine, but little longer than that of the does. I again erossed the females of this progeny upon the other Cashmere buck, and it was difficult to distinguish these from the pure breed; and the subsequent eross eannot be detected. In the spring, I contemplate effecting still another cross. I eonsider this a most valuable and useful experiment, as I made an arrangement with amateurs to sell pure bueks at $\$ 100$, and to exchange annually, so as to furnish them with the 
advantages of different crosses. In ten days all the pure breeds were taken, with a demand for many more. Even the mixed kids have been readily taken by those deternined to infuso their blood with their stock. In these arrangements, however, I have located them from the top of the mountains to the seaboard, both in Carolina and Georgia. Apart from their manifest practical aptitude in all these particulars, there is this ultimate value to be considered : a Cashmere shawl is worth from $\$ 700$ to $\$ 1500$. Why is this difference, except in their intrinsic value from durability as wearing apparel $?^{i} \mathrm{I}$ have socks which I have worn for six years, and are yet perfectly sound.

No naturalist has yet been able to assign a systematic law regulating the acclimation of animals. The Merino sheep, whenever it has been removed, has generally changed, and in most cases for the worse. Even when crossed upon the best Saxony sheep, it was a deterioration; but when crossed upon a coarse-wooled animal, it improved the fleece; and the cross fixed both the character of the wool and the carcass. This fact is observed in many other instances, demonstrating that the constitution of animals must be connected with location to fix the character of the wool or the carcass. In fact, the same temperature, but modified by altitude instead of latitude, does not produce the same results. On all the table mountain and valley plains between Persia and Turkey in Asia, all the animals have fine, long, silken hair, as the Angora cat, grayhound, and rabbit's, and I have seen the same in some specimens of the Koordistan horse. To a considerable extent this is the fact on the western part of South America.

In connection with this part of the subject, I will now mention the Thibet shawl-goat, belonging to the coldest regions. I accidentally came in possession of a pair of these animals, but lost the male. I have a considerable increase from the female, bred with a Cashmere buck. The Thibet goat has, under a long, coarse hair, a coat of beautiful white wool, which, when combed, makes about a pound to a fleece. I had these specimens with me at the Zoological Gardens in London; and, in comparing them with a stuffed specimen of a Rocky Mountain goat, I could not discover the slightest difference; nor do I yet see any change of the fresh cross of the Cashmere buck upon my Thibet doe; but in the third cross upon the Cashmere, we may expect a valuable experiment by changing the fine under-wool, or down, into a conjoint and uniform covering of wool. In regard to the Scinde goat, so called from the province at the mouth of the Indus, he is a gigantic animal, with pendulent ears twenty-two inches long, is used for the table and dairy, and is very similar to the Syrian goat. The Malta milking-goat is also for the dairy, giving about a gallon of milk in a day. It may not be uninteresting for me to state a fact observed by me in the malarious sections of the United States and Mexico. In all the similar sections of Asia and the East, they regard cow's milk as being an exciting cause to bilious fevers, as well as to liver complaints, and hence use only goat's milk. The modus agendi, I see, has been a matter under discussion by the faculty of Paris.

Having given thus much on the subject of goats, I now hasten to the cattle. In referring to the Nagore or Brahmin cattle of India, in Youatt's work on British cattle, it will be perceived that they are organized to undergo the fatigues of the hottest climates known, and will carry a soldier six miles an hour for six consecutive hours. I brought but one pair to the United States, and, as far as I can learn, my crosses of them upon other cattle are the first known in this country. I crossed this bull upon Ayrshire, Devon, and Durham breeds, as well as upon our common cattle. The offspring is considered, by all who have seen them, far the handsomest animal of the cow kind. They are symmetrical and active, and can keep fat when any other cow would starve. I had this half-breed crossed again upon our cattle, but am not yet sufficiently experienced to report of their milking qualities. As evidence, however, that our agriculturists confide in the appearances, my half-breeds readily sell for $\$ 1000$ a pair, and the second cross, or half-Brahmin, at from $\$ 100$ to $\$ 300$ each. Preferring the mixed breeds to the pure, I sold to Mr. Edes, of Kentucky, the original pair for $\$ 4000$, as that State would prove a better place to hreed and disseminate the stock. As Kentucky is the dependence of the South for beeres, they needed an animal that could come to us in the hot months of summer, and remain healthy and sound. They hare from this animal a progeny that will travel thirty miles a day in August; and the further South they 
go, the better adapted are they-the great desideratum to the Northern breeder and the Southern consumer.

The Asiatic buffalo, or water-ox, is a large, ugly, hardy animal. The cows are good milkers, making fat and good-flarored beef, though coarse-grained, and precisely suited to sea-coast marshes, where no other animal can venture, as well as to lands subject to inundation.

\section{Introduction of the Chinese Yak into Europe.}

THE Garden of Plants, at Paris, has recently received, for the purpose of acclimation and propagation in France, a number of yaks from China-ar animal which Buffon says "is more precious than all the gold of the New World." In Thibet and China this animal serves as a horse, an ass, a cow, and a sheep ; it bears heavy burdens, draws large loads, supplies milk, has flesh which is excellent, and hair which can be wrought into warm cloths. To naturalize them, therefore, in Europe would be an immense service to mankind; and, as they bear cold bravely, the French naturalists have every hope that they will be able to do so. Some Chinese have been brought over to attend the yaks, and they will teach the French the way of treating them and of curing them in sickness. The yaks are of lowish stature, are singularly shaggy, and have tails more bushy than those of horses.

It is to be hoped that the people of the United States will take their share in endeavoring to accustom Asiatic and African animals to our climates. It is not very creditable to our boasted nineteenth century that in this respect it is far behind the old Romans. Out of the many thousand species of which the animal creation consists, only between forty and fifty are, in fact, domesticated.

\section{Acclimatization of the Cashmere Goat in the United States.}

AT the Annual State Fair of New York for 1854, three Cashmere goats were exhibited by Dr. Davis, of South Carolina. It is the aninial of which the Cashmere shawls are made, the value of which does not depend, as many suppose, upon their rarity, but upon the fact that the material surpasses every other like article in its capacity for wear. The Cashmere goat was introduced into South Carolina several years ago, by Dr. Davis, from the interior of Asia Minor, and the breed has since been carried into the adjoining States of North Carolina, Georgia, Alabama, Tennessee, and Florida, and mixed with the native goat. The hair of the animal, which is pure white, is most beautiful. It somewhat resembles in appearance the finest portion of the fleece of the Chinese sheep, a few of which were on exhibition. It is curly, soft in texture, and brilliant in appearance. The animal is extremely delicate in shape, though hardy. A sock made from the hair was shown with the goats. We learn that the meat is white and delicate, and is preferred, in the parts of South Carolina where they are reared, to mutton. A herd will protect itself against dogs, which constitutes a great advantage over sheep in localities where dogs are troublesome. Throughout South Carolina, the ordinary animal has risen largely, in price, from the facility with which the breed is improved by this cross.

A letter from Dr. Davis, June, 1855, to the Greensborough (S. C.) Beacon, states, that " the fourth crop of the Cashmere upon our native goat is fully equal to the pure Cashmere." This animal, the doctor says, is destined to make a great revolution in the agriculture of the whole South. Beautiful cloth is now made by negro weavers, with ordinary plantation looms, from the second cross. All the native goats in South Carolina, he states, are now appropriated to crossing with the Cashmere breeds, and Georgia and Virginia are also breeding these animals extensively.

\section{Introduction of Camels into the United States.}

AT the last session of Congress, in accordance with a recommendation from the Secretary of War, an appropriation was granted for the purpose of importing and introducing the camel into the United States, to be used for transportation on the prairies and deserts of the West. 
For the purpose of carrying out the plan and procuring a sufficient number of these animals, an expedition, under the charge of Lieutenant Porter, U.S.N., and Major Wayne, of the Army, sailed from New York, in June last, for Egypt and the Mediterranean.

It is the intention of the latter officer to visit Egypt, Nubia, Arabia, and such other countries of the East as produce the camel, where he will examine the different varieties, study their habits, and select such as, in his opinion, are best adapted to the climate and food of the district where it is proposed to introduce them. The camel is as greatly improved by careful raising, and by the selection of good varieties, as the horse is; hence it may not be in the countries originally indigenous to these animals that those best suited to our wants will be found.

The camel of Egypt, used to a hot, dry, and little-varying climate, would not be adapted to the changeable climate and cutting northers of Texas. Yet it might answer well for the region on the Pacific slope of the Rocky Mountain range bordering on Mexico, where the arid deserts occur. The Persian or Bactrian camel, which is used on the steppes of Siberia and the plateaux of Central Asia, will doubtless be found the best adapted for our prairies and the Rocky Mountains. The experiment is a most important one, and, if successful, will revolutionize the present mode of travelling across the prairies; but more particularly the desert regions, where water and grass are scarce.

\section{Tartar or Shanghaî Sheep.}

Mr. E. Emerson, of Philadelphia, communicates to the Progressive Farmer the following. information relative to the Tartar or Shanghai sheep, recently introduced into this country:-

They are of good size, with ears drooping forward, prominent noses, agreeably expressive faces, covered with a short and very fine glossy silken hair. The fleece is light and best adapted for blankets and similar woollen textures. The value of this breed does not, therefore, consist in the fleece; but must be sought for in the remarkable facility it offers to increase the supply of this kind of animal food almost at pleasure, for the ewes have lambs twice a year, generally from three to four at a birth, and not unfrequently five at a time. I have a ewe which brought three lambs last February, all of which were raised to maturity. About the middle of November, she had two more, and at the same time her two February ewe lambs each brought a lamb, making her progeny in nine months no less than seven, all living and thriving, save one accidentally killed.

The quality of the mutton is of the highest order. When in China, several years ago, I was not a little surprised to find the eagerness exhibited by every one for mutton; and never did I see a leg brought upon the table of which any thing was left but the bone. I attributed this partiality, in a great degree, to the high price of the meat, the cost of which to foreigners was something like fifty cents per pound. But I have since been convinced that while rarity contributed something to the flavor, there was still more due to the intrinsic qualities of the meat, which is entirely free from any woolly or other disagreeable taste, and has a delicacy resembling venison. This characteristic of the mutton of the Tartar sheep, with the capacity they afford of furnishing lambs at any time of the year, must make them of great value to those whose chief object is to breed for the shambles.

I have crossed the breed with a good stock of country sheep, and have about twenty-five half-bloods, pronounced remarkably fine sheep by all who have seen them, being rather larger than the full-bloods, with much better fleeces. How they are to turn out in the excellence of their mutton and prolific qualities remains to be tested. Probably they will exceed common sheep in the average number of their lambs, but not equal the full-bloods in their astonishing prolific qualities, and this to many persons may constitute an improvement.

\section{On the Artificial Propagation of Fish in American Waters.}

THE subject of the production and propagation of fish by the artificial methods discovered in France some years ago, and since successfully introduced into that country and Great Britain, has especial claims upon the attention of all interested in the increase and development of our national resources. "We understand," says a writer in Putnam's Magazine, 
" that the Natural History Society of New Jersey are prepared to make, to the three States of New York, New Jersey, and Pennsylvania, an offer to restock the Iludson, Passaic, Raritan, and Delaware rivers, with salmon fry; provided the legislatures will jointly, or severally, pass such laws for the preservation of the fish, until they shall become fully established in those waters, and forever during spawning season, including the removal of all obstacles to their free ingression and retrogression to and from the salt water, as shall be deemed sufficient; the society asking no privilege, or remuneration, beyond the actual expenses of providing and transporting the fry."

There are two ways in which fish may be propagated artificially in any quantities. The one is by taking the breeding fishes alive, male and female, previous to their depositing their spawn, in the gravel shoals of their native beds, and compelling the female fish, first, by a gentle pressure of the hands upon her sides, to deposit her ova on a layer of gravel, in a box suitably prepared for the purpose, covered with a wire grating, and provided with suitable apertures, similarly guarded at one extremity to admit the influx and afflux of spring water from a source of proper temperature, without which the ova cannot be matured. This done, the male fish is, by a similar treatment, forced to emit his milt over the female ova on the gravel, which are thus impregnated, when the box is placed so as to receive a constant current of aerated running water, subjected to which the eggs are hatched, and the young fish excluded in a space of

114 days, when the temperature of the water is ........................................3 $6^{\circ}$

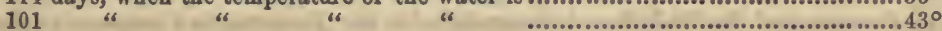

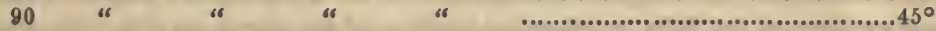

The experiments by which these facts were arrived at were performed in the open air, in natural streams, liable to the ordinary influences of the atmosphere and weather.

The second method is the mixing in the same manner of the milt of the male with the ova of the female fish, taken out of the bodies of fish recently dead. It is proved, indubitably, that the eggs thus prepared, and similarly subjected to the flow of aerated spring water, will produce living fish. This method has been largely put into practice in France, where extensive waters have been stocked with both fresh and salt-water species, although it is certain that sea-fishes, if excluded from salt water, lose much of the characteristic excellence of their flesh; while it is doubtful, at least, whether they have the power, under those eircumstances, of reproducing their species.

Both these methods, however, presuppose the possibility of having either the live fish taken on the spot, when in condition for the immediate deposition of its ova, or the dead fish, in the same condition, immediately, or within a fow hours, after the capture-since it cannot be expected that the vitality of the ova would long survive the death of the parent animal. These conditions, therefore, render it indispensable that the experiments should be performed, and the system of breeding carried on, where the living fish or the dead fish immediately out of the water can be readily procured; that is to say, in the immediate vicinity of salmon rivers. This would, of course, render it necessary to form breeding establishments at a distance from this section of the country, and to provide for their subsequent transportation. Fortunately, however, this difficulty is obviated by another peculiarity of the young salmon, which the Natural History Society of New Jersey propose to turn to account in their scheme of restocking the rivers named above. On first emerging from the membrane in which it was enclosed, or being hatched, the young fry has the yolk of the egg attached to the anterior part of the abdomen, immediately behind the gills, and for the first twenty-seven days of its existence takes no manner of food externally, being supported wholly by its absorption of this nutritious substance. At the end of this period, it has attained the length of about three-quarters of an inch, and is enabled to forage for itself and live on the prey which it captures, which is identical with that of the trout. During the first twenty-seven days of its life, therefore, the young salmon may be enclosed in bottles, casks, or any other utensils of the like nature filled with water, which it is not necessary to change during that period, and may be transported any distance which can be compassed by steam within that time. If then turned out into rapidly running, aerated streams with gravel bottoms, suited for the nutriment of trout, it will remain in those waters until the middle of the May of the year 
next ensuing, or the second after the deposition of the ova which produced it in the month of October or November. In the autumn of that year they will return, grilse, as they are now termed, varying in weight from two to eight pounds. In the succeeding, or third year, having deposited their ova in the streams wherein they were themselves hatched, they will redescend to the sea, not increased in weight or size; but will make their reappearance in the same autumn, ascending to reproduce their species, full-grown fish, weighing, it is confidently alleged, from twenty to forty pounds in weight.

It is on this quality of the young fry of the salmon, as we understand, that the Natural History Society rely for the accomplishment of the scheme.

They calculate with certainty on procuring, at small cost, the young fry, just excluded, with the yolk yet adherent-from correspondents in the British provinces-enclosed in hogsheads of spring water, which can readily be transmitted by marine steamers to New York, and thence by rail to the localities where they should be emancipated.

The feeding streams of the Passaic, Raritan, Delaware, and Hudson hare, we are informed, been carefully explored and investigated by several gentlemen; and waters have been found, abounding in trout, communicating with these rivers, without the interruption of any impassable natural falls, admirably calculated for fish nurseries, and requiring only a modification of the dams to enable them at once to become the spawning-places and abodes of countless myriads of fry. Into these streams, being the Second and Third rivers, as they are termed, for the Passaic, the Black River for the Raritan, the Request and Muscanetcong for the Delaware, and the Walkill and Esopuskill for the Hudson, they propose to turn out sufficient numbers of fry, fully to insure the stocking of the rivers, provided the States will farnish the actual cost of the purchase and transportation of the fish-making no demands for their own time, labor, and travel-and grant the protection which they conceive to be necessary, and without the concession of which, it is understood, that they will not stir in the business.

With regard to the feasibility of this scheme, according to the premises, there cannot be a question. It has been proved, in other countries, that waters can be as easily stocked with fish as parks with game, or pastures with cattle; and, in view of the fact that these rivere did once, beyond denial, abound in salmon, there can be no doubt, in any unprejudiced mind, that they can be made to produce them again, in undiminished numbers. Nor is it to be disputed, that the method proposed by these gentlemen is simple, reasonable, and well calculated to produce the desired end; while it is presumed that the character and qualifications of the persons engaged in the project may be taken as a sufficient guarantee for the plan being well carried out in its details.

There remain to be considered, the conditions on which they offer to restock the rivers, and the practicability and propriety of the according of those conditions by the legislatures of the States concerned.

The conditions, we learn, are as follow :

1. An absolute prohibition to kill or take salmon in any of the rivers named, or in the bays, estuaries, channels, or sea-ways into which they flow, for the space of fire years, under the penalty of $\$ 100$ for each and every such offence, the whole to go to the informer.

The term of five years is selected, as giving an opportunity to the fish to breed three times previous to the capture of any.

The large amount of the penalty, and its disposition, are assumed to be necessary, in order to induce neighbors and fishermen to inform one against the other; the ordinary small fine, exacted in the usual game-laws, having been found utterly inoperative to procure the rendition of informations.

2. The prohibition, under the same penalties, of taking trout in the same waters and their tributaries, for the same terms of years.

This clause is adopted on account of the difficulty of distinguishing between trout and the young salmon fry, which, unless thus protected, would be liable to destruction, as their congeners the brook trout.

3. The prohibition, under the same penalties, forever, of taking salmon between the months of October and April, in any of the waters named or their tributaries, or on their spawning- 
beds, or on, or within half a mile of, above or below, any fish-weir, dam, or run-way, over which the fish may pass at any season of the year.

4. The prohibition, under the same penalties, of the erections of any stake-weirs or permanent nets, extending from either shore, above one-third of the width of the stream, or intercepting the main channel or current of the river.

5. The absence of any clause, providing that persons shall not be held answerable in penalties for violating the said prohibitions-on their own ground. Such exception having been found invariably and totally to prevent and nullify the operation of all protective laws, and to preclude all benefit arising from them.

6th, and lastly, a statute compelling all mill-owners, proprietors of dams, weirs, or the like, to erect, within a certain number of months after the passage of the act, to every fall, weir, or mill-dam, exceeding four feet in height, a slope or apron, extending on the lower side of the fall, from a point one foot below the head of water maintained, to the bottom of the river at $\Sigma n$ angle of not exceeding forty-five degrees to the horizon; such aprons not to be less than twenty feet in width, or the whole width of the stream in the smallest brooks; and in rivers of two hundred yards and upwards in width, not less than one hundred yards in width, and as nearly as possible in the main current or tide-way of the stream or river.

These are the conditions-easy conditions, it seems to us-on which it is offered to make an attempt, which, there is little doubt, would prove fully successful. That they are strictly practicable, as far as constitutionality is concerned, cannot be doubted. They trespass on the rights of no man; would entail but a small expense on a small class of property holders, which no man of ordinary patriotic feelings could hesitate a moment to incur for the carrying out of the great aims in view.

Further than this, we believe the protection asked would be adequate to the carrying out of the plan, and that no degree of protection, short of that which is asked, would be adequate.

That the object aimed at is worthy of a trial, is not to be denied or doubted; and that, if attainable, it would be productive of great national benefit, is as certain-it being no less than the creation, or, at least, the regeneration, of a new, or quasi new, branch of national industry, which would necessarily employ and produce a large capital, which would give work and wages to several thousands, probably, of hands, and, what is of yet more consequence, would furnish, in these times of high prices, scarcity of provisions, and increasing demand for food, a cheap and abundant article of nutriment for the masses.

Again, the necessary outlay for restoring these waters is rated at so mere a trifle, that it is unworthy of a thought-the estimated expense of stocking the rivers named, in the first instance, not exceeding a thousand or two of dollars, added to the individual outlay of a few mill-owners, in remodelling their dams in a manner which would permit of the ingress and regress of the fish, without, in any wise, affecting the height of the head of water or the supply maintained by the present system.

\section{Artificial Propagation of Fish in Ohio.}

At the Ohio State Agricultural Fair for 1854, specimens of trout, artificially propagated, were exhibited by Messrs. Ackley and Garlick, and attracted much attention as the successful result of one of the earliest efforts made in this direction in the United States. In the Olrio Farmer, for September, 1855, we find the following account of Messrs. Ackley and Garlick's proceedings, furnished by the last-named gentleman. Mr. G. says:-

Early in the spring of last year, Prof. H. A. Ackley and myself determined to make the experiment of artificially breeding fishes. After some deliberation, we concluded to select the speckled trout (Salmo fontinalis) for our first experiment. Accordingly, in the month of August last, I started for the Sault Ste. Marie, with the purpose of obtaining the parent fishes, while Prof. Ackley was preparing a suitable place for their reception, by building a dam across a very fine large spring of water on his farm, some two miles from Cleveland. There was no difficulty in capturing as many as I desired; but it was quite another kind of sport to transport them alive a distance of near six hundred miles. After various vexations, 
among which was the loss of the first shipment, we succeeded in getting down three lots, in all about one hundred and fifty, in fine condition, and lodged them safely in their new home, where they seemed as happy and as sportive as they were in the beautiful blue waters of Lake Superior. In the month of September, I made a trip to Port Stanley, Canada, for another lot, and succeeded in getting home about forty môre specimens, constituting, certainly, a very fair beginning to our enterprise. We did not, however, expect to rear any young fishes this season, for we supposed the transportation, \&c. would prevent them from depositing their eggs; but in this we were most agreeably disappointed, for, on the 15 th of November, we discovered unmistakable evidences that they were about to engage in this interesting process. Several male trout had proceeded up the stream, and commenced preparing the beds in which the eggs were to be deposited. This was done by removing all the sediment and sand from certain gravelly locations. These beds were about one foot in diameter, consisting of coarse and fine pebbles, the spaces or interstices between which were to be the future depository for the eggs. This peculiar construction of their beds, or nests, is highly essential to their preservation, as it protects them from being washed away by freshets, also from being devoured by small fishes, which are always prowling about seeking them for food. The male trout at this time was very beautiful, being decked out in the most gaudy colors imaginable, and his actions showed clearly enough that he was quite vain of his personal appearance. In the course of five days, the females made their appearance. They were not near so gaudy in their dress; but had a most staid and matronly look. The next step was choosing their mates. After the usual amount of flattering attentions to the females, with which they seemed highly delighted, and some battles among the males, this important matter was settled, apparently to the satisfaction of all parties. Our trout were from four to six weeks later than their usual time in depositing their eggs, owing, no doubt, to the vicissitudes incident to transportation, change of water, \&c.

On the 20th of November they had fairly commenced operations, one pair of fish occupying each bed-the male manifesting the utmost jealousy, and, if any suspicious interloper approached, he was instantaneously attacked and driven off. On the 21 st, I captured a pair by means of a landing-net, and placed them in a bucket of water, and, being provided with an earthen vessel, I made my first attempt at artificially spawning and impregnating the eggs. This was accomplished as follows: I partially filled the earthen vessel with water, and, taking the female in my left hand, and making gentle pressure on her abdomen with my right, the eggs were forced into the earthen vessel containing the water; the male was treated in precisely the same manner, forcing the spermatic fluid into the same vessel; the appearance of the eggs was almost immediately changed from their bright golden-orange color to a pale transparent yellow; they were then placed in running water with the vessel containing them. On the 9 th of January, one of the eggs was placed under a microscope. The egg, which at first had been a simple cell, was now multiplied into a countless number of cells, of different sizes, with traces of blood-vessels; the eyes also being perceptible. On the 22d of January, we examined them again, and to our joy we found a young fish, which had just left its narrow place of confinement to try its new mode of existence; it was very lively in its motions, but could not be considered an expert swimmer, owing to an appendage to its abdomen, of nearly the size of the egg, which in fact it was, containing the material for the further development of the yet very imperfect fish; this sack was filled with a multitude of minute cells, whose absorption keeps pace with the development of the fish. When the young fish leaves its egg, it measures about half an inch in length; neither the mouth, gills, nor any of the abdominal viscera are visible, all of which would be plainly discerned with the microscope, if they existed, owing to its almost perfect transparency. The heart, with the principal blood-vessels, and even the corpuscles of blood, are beautifully shown with a microscope of moderate power. Their external appearance is remarkable. The eyes, are large and quite well developed; the pectoral fins are also in an advanced stage of development, and in constant and rapid motion, which, I think, in the more advanced stage of the fish, has something to do with its respiration, as they are placed near the opening of the gill-covers. The other portions of the fish are quite rudimentary, no other fins being perceptible; but in their place is an attenuated margin, or finlike substance, as on the tail of the tadpole, commencing 
where the dorsal fin should be, and continuing uninterruptedly around the caudal, and terminating with the anal fin, or rather where it should be.

This finlike substance undergoes a constant change as the fish grows older. At fourteen days, the dorsal, adipose, caudal, and anal fins are plainly seen; but as yet none of them have rays, except the caudal, in which they are very distinct. The rays of the caudal fin are first apparent at the centre, although the general form of the rudimentary tail is very unsymmetrical, the superior lobe being the larger, and the outline not unlike that of the tails of many heterocercal fishes. At this age the fish has more than doubled its former length; the mouth, gills, and abdominal viscera are visible; and it manifests a desire to take food by nibbling at the unhatched eggs, and pieces of meat placed in the ressel containing them. Its color is now materially changed, being of darkish gray on its back and upper portions of its side. The sack suspended from the abdomen at this time becomes smaller and less globular in form, being more contracted anteriorly and posteriorly. The habits of the little creature are also much changed, as it now swims smartly, and endeavors to hide itself whenever disturbed.

Owing to imperfections in our arrangements where we placed the eggs for hatching, accumulations of sediment buried them up, destroying them by hundreds; this aceumulation was much more fatal when the embryo fish was nearly ready to make its exit from the egg. To avoid their further destruction, on the 26 th of January we brought the remaining eggs to our office, and placed them in a glass jar, and supplied them and the young fish with fresh water daily. In this situation they have remained until the present time, the young fish making their appearance from day to day, the last one rupturing its oval envelope on the 10th day of February. I have seen as many as six make their appearance in as many minutes. The temperature of the water at the spring was $42^{\circ}$ Fahrenheit. Since they were brought to the office, the water in which they have been kept has varied from $42^{\circ}$ to $50^{\circ}$.

This experiment has afforded us one of the finest opportunities to be desired for the study of embryology ; but professional duties have prevented us from making as minute observations as we could have wished. We have, however, repeatedly and distinctly seen the blood-corpuscles in the returning veins enter the auricle of the heart and then pass into the ventricles, and from thence into the aorta. Altogether, it has afforded us one of the most pleasing anil instructive lessons in the early stages of animal existence that we have ever had. Another fact, in which all are interested, has been clearly demonstrated: Every one who may be so fortunate as to possess a spring of water of moderate size can rear this charming fish in great numbers, and the streams that have been depopulated by the untiring zeal of the angler can be replenished with a little trouble and at a small expense.

After the eggs have been obtained from the female fish and impregnated, it is necessary to remove them to a suitable place for incubation. Messrs. Ackley and Garlick adopted the following plan:-At the head of a spring we built a house eight feet in width by twelve feet in length. We placed a tank-made of two-inch plank-four feet wide by eight feet long, and two feet deep, in the end of the building nearest the bank. The water from the spring enters the tank through a hole near the top, and escapes through a similar hole at the other end, from whence it is received into a series of ten successive boxes. These boxes are eighteen inches long, eight inches wide, and six inches deep, and are so arranged that the first box is much higher in the series than the last one. They must be filled with clean sand and gravel to the depth of about two inches, the sand being placed at the bottom. The impregnated eggs are to be scattered over and among the gravel, care being taken not to have them in piles or masses. The boxes should be carefully examined every few days, after the eggs have been deposited in them, and all tho eggs which have lost their vitality should at once be removed. This may be effected with a pair of forceps made of wire, the jaws of which should be flattened a little, in order to seize the egg with greater facility. The eggs which have lost their vitality may very readily be distinguished from the others by their whiteness.

It is very desirable that pure, clear water should be used, in order to aroid a deposition of sediment, which is very destructive to the eggs, particularly towards the close of the term of incubation. When sediment is found to be accumulating, the water should be agitated 
with a goose-quill or soft brush, moving the quill or brush briskly about in the water, and then suffer it to run off. Repeat this process until the water is free from sediment, and runs off clear; or the eggs may be removed into a vessel filled with clean water, with a skimmer, there to remain while the boxes are being cleansed. The hatching-boxes should be grated, on that side from which the water escapes, with wire cloth, the meshes of which should be sufficiently fine to prevent the eggs, or the young fish, when they make their appearance, from passing out. A very neat and convenient hatching apparatus is the flat wicker-basket, the interstices of which are fine enough to prevent the eggs from passing through. These baskets are to be placed in running water. Care, however, must be taken, as well as with all other apparatus for the same purpose, that a place be selected where the current of the water is not so rapid as to wash or pile the eggs up in the end opposite to where the water enters. Whenever the baskets become foul by sediment or vegetable matter, the eggs can be transferred to a clean one, and the basket cleansed. A conduit or flume must be constructed, of plank or boards, to contain a sufficient depth of water, in which the baskets are to be placed. The utmost cleanliness is absolutely necessary during the whole time of incubation; it is one of the essentials to insure success.

The method adopted by Gehen and Remy was to place the eggs in zinc boxes of about one foot diameter, with a lid or cover on them, and the sides of each box being pierced full of small holes, care being taken to have the edges of the holes very smooth. These boxes, then, were partly filled with sand and gravel, and then placed in running water. They partially buried the boxes in the gravelly bottom of the streams, and there examined them from time to time. The plan adopted by M. Costa, at the College of France, is to arrange several parallel boxes, in the form of steps, on each side of the principal one, which is placed at the top of the series, from which all the others are supplied with water, the top one being supplied from a fountain, and the supply of water being regulated by a stop-cock. In this case the eggs are placed on willow hurdles instead of gravel.

Whatever plan may be adopted, great care and watchfulness are essentially necessary to insure success. A regetable parasite, termed by naturalists Byssus, frequently attaches itself to the eggs, and destroys them. The best way to remedy this evil is, to remove very carefully all the eggs that are free from the parasite, and throw those away which have been attacked, and at the same time thoroughly cleanse the boxes or baskets.

\section{Fish-breeding in France.}

IN a recent visit to the fish-hatching establishment of M. Coste, in Paris, the French Minister of Agriculture reports that he found there two hundred and fifty thousand newlyhatched fish, one hundred and fifty thousand of which had only just been brought up from the establishment at Huniguen. All this large number were conveyed to Paris at the same time, and without a perceptible loss. The fish comprised common trout, trout from the lakes, salmon from the Rhine, and trout from the Swiss lakes.

\section{Growth of Fish.}

While Pisciculture is gaining ground in every country in modern Europe, it may be amusing to our readers to publish certain facts within our own knowledge relative to the increase in size of fish in particular waters in Belgium. The growth of the salmon, as proved by the marked fish in the Scotch fisheries, is notorious, and has already been fully noticed. In four months' time, it has been proved that the young fry, between the period of their leaving their native rivers for the sea and their return, have increased in weight varying from three to seven pounds. Without the positive proof of identity by marking, this would have been considered wholly chimerical. We have now to notice the increase, in the waters at Boitsfort, near Brussels, of the jack, the only species of fresh-water fish which has as yet been put to the test in regard to its growth. In these waters, in October, in 1852, about two thousand were left as stock, none exceeding two pounds in weight, the fish thus put in being indigenous to the water; these fish have been caught the present month 
with rod and line as high as six pounds each, showing an excess in weight of four pounds in sixteen months-a rate only known in the first rivers in England. But the most extraordinary increase has been in the fish not indigenous. In the month of March of last year, a fresh supply of jack was put in as stock from a neighboring water, the largest being three pounds in weight; these fish were marked by cutting off a portion of their tail fin. Two of the fish thus marked were caught last week, one weighing eight and a half pounds, another seven and a half pounds, thus showing a positive increase as to one of fire and a half pounds, in a period of eleren months, taking it even upon the assumption that the fish so caught were those weighing the excess of weight of three pounds when put in, and of which weight there were but few. We have been informed that in these waters the other description of fish, such as carp, tench, perch, and eels, increase, as to the two former, after the rate of two pounds per annum; but this will form the subject of future experiment by marking, which has not been hitherto done. It is generally known that change of water from that in which they have been bred is most productive of profit to fresh-water fish; but it would be incredible, without the proof, that $\mathrm{a}$ fish of three pounds could add five and a half pounds to its weight within the period of a year. For the information of amateurs in the gentle art, the lake in which these jack are is of about ten acres, supplied with three continuous streams of water running through it. No fish breed in it but roach, jack, perch, and eels, the coldness of the contributory water stopping all breeding of carp and tench; the supply of the latter being through store-fish of from three ounces to half a pound, which, from observations made, increase in the ratio before mentioned.-Brussels Herald.

\section{Transporting Eggs of Fishes.}

Is the last sitting of the French Societe Zoologique d'Acclimation, M. Millet detriled a series of experiments he had lately made in conveying fecundated eggs. The result was, he said, that the eggs, when wrapped up in wot cloths and placed in boxes with moss, to prevent them from becoming dry and being jolted, may safely be conveyed not only during twenty or thirty, but for even more than sixty days, either by water, railway, or diligence. He added that he had now in his possession eggs about to be hatched, which have been brought from the most distant parts of Scotland and Germany, and even from America. MI. Millet stated a fact which was much more curious-namely, that fecundated eggs of different descriptions of salmon and trout do not perish, even when the cloths and moss in which they are wrapped become frozen. "He had even been able," he said, "to observe, by means of a microscope, that a fish just issuing from the egg, and of which the heart was seen to beat, was not inconvenienced by being completely frozen up. This he explained by the fact that the animal heat of the fish, even in the embryo state, is sufficient to preserve around it a certain quantity of moisture."

\section{Effects of Legislative Enactments in Re-creating Fisheries.}

THE following extract, from a recent report of the "Inspectors of Irish Fisheries," shows conclusively the good effect of judicious protective enactments in re-creating fisheries in rivers where they are rapidly dying out:-In illustration of the benefits of a steady persererance in a proper system, we may allude to the Foyle- a noble river in the North of Ireland, washing the walls of Londonderry - "where the produce has been raised from an arerage of forty-three tons previous to 1823 , to a steady produce of nearly two hundred tons, including the stake-weirs in the estuary, and very nearly to three hundred tons, as we believe, in the year 1842." The inspectors also mention the effects of protection in the case of the small river of Newport, county Mayo. In three years, after the parliamentary regulations were introduced and enforced, the produce of this river was raised from half a ton, or, at the utmost, a ton every senson, to eight tons of salmon and three tons of white trout, for the season ending the third year, with every prospect of further increase. Another fact, bearing upon this point in our own country, is, that by the enactment of certain prohibitory laws as to the taking of the fish at undue seasons, and the erection of insuperable obstacles to the ingress 
of the breeding fish and the regress of the smelts, as the young fry are technically termed on their descent to the sea, the supervisors of the county of Oswego, in New York, have succeeded in re-establishing fisheries in the waters of the Salmon River and its tributaries, to the great advantage of the circumjacent regions. From these facts it is clear that, by the extension of similar provisions to any waters wherein salmon have formerly existed, but are now extinct, coupled with measures considerately undertaken for repeopling the breeding streams about their head waters with young fry, all and every one of our ebstern Atlantic rivers might be rendered equally prolific with those noble salmon rivers, the St. John, the Miramichi, the Restigonche, the Nepisiquit, and others flowing into the bays of Chaleurs and Gaspé, and more so than the Foyle, the Tay, the Clyde, the Forth, and other Scottish and Irish rivers, even in their improved condition.

\section{On the Sterility of many of the Varieties of the Domestic Fowl, and other Hybrid Species.}

Trin following is a paper recently read before the Boston Society of Natural History, by Dr. Kneeland, of Boston :-

The strange mania which has of late years manifested itself for unnatural crosses in birds and quadrupeds, might, if properly investigated, and with an eye to science rather than to gain, lead to many interesting facts bearing upon hybridity. I do not refer to the impositions passed upon a public always ready to be cheated, but to the real, bona fide crossings of allied and remote species. There was a time when most naturalists believed that all our varieties of domestic stock, as of cattle, sheep, goats, dogs, fowls, \&c., were derived, each genus respectively, from a single wild original; and that man's care, or rather his abuse, had obtained from this the numerous existing varieties. In the present state of our knowledge, we think we are justified in saying that the varieties of cattle, of the dog, \&c., have been produced by the crossing, natural and forced, of several more or less nearly-allied species; for instance, who shall dare to decide between the Asiatic buffalo, the European aurochs, and Cuvier's extinct species, as the undoubted wild original of the varieties of our cattle? Whence the necessity of reducing all varieties to a single stock, endowed with great powers of variation, especially when there are several wild species, each equally entitled to be considered the original? It seems to me that the simplest view of the case is the bestviz. that these varieties are the result of the mingling of many species, guided by the wants or caprices of man. In other words, I believe that no one wild original can lay claim to the origination of the varieties of our cattle, of our sheep, of our goats, of our dogs, of our barn-yard fowls; and, to carry the opinion to the legitimate consequences, that no one species of man can lay claim to the paternity of all the human varieties.

The reasons for this opinion have been often stated, and need not be repeated here; some new observations will only be added in confirmation. Arid yet, with this belief in the diversity of origin of our domesticated animals and the human races, it seems to me that hybridity is a true test of specific difference. It is an axiom with some, that different species will not produce fertile offspring; and hence, to them, the fact of the production of such off spring proves that the parents belong to the same species. On the contrary, Dr. Morton makes different degrees of hybridity, the offspring being more prolific according to the nearness of the species; thus making hybridity no test of specific difference. Of these two opposite opinions, I prefer the first. By a hybrid race, I do not understand an offspring prolific for a few generations, and then gradually dying out, or feebly supported by crossing with the original stocks; but a race capable of propagating itself, without deterioration, or without any assistance from either of the parent stocks. Such a race, I maintain, the world has never seen, and never will see, under the present laws of animated nature. You may take any part of the animal scale, from a barn-yard monster to a mulatto, and the fact is the same; they cannot hold their own; they must and do return to one or the other of the primitive stocks, or must die out, unless crossed by the pure originating blood.

The subject which suggested these remarks is the sterility and deterioration of some of the bighly-bred varieties of our domestic fowls. It has become quite a general source of com- 
plaint by many farmers in this section of the country, who, in times past, had plenty of eggs, and to spare, from a small number of common fowls, that, since the origin of the mania which has happily been called the "Hen Fever," they have found themselves, with their improved gigantic breeds, unable to procure any thing like their usual supply of eggs from the same number of birds; and that they have not only raised the birds at the expense of several dollars a pound, but have been obliged to buy eggs for family use. This has become such a source of annoyance and pecuniary loss, that it deserves to be considered. It is a natural consequence of forcing birds from different countries and of different origins to propagate a hybrid offspring, for this very reason prone to degeneration, which is increased by the impossibility of crossing the hybrids by the supposed pure originals. The size of the birds seems to be obtained in this case at the expense of the reproductive powers. The admixture of different original species, and breeding "in and in," have been carried beyond the limits fixed by nature, and deterioration is the result.

To ascend from birds to man, what we have seen in our domestic fowls, we find occurring again in the mulatto and other hybrid human races. The mulatto is often triumphantly appealed to as a proof that hybrid races are prolific without end. Every physician who has seen much practice among the mulattoes knows that, in the first place, they are far less prolific than the blacks or whites; the statistics of New York State and City confirm this fact of daily observation; and in the second place, when they are prolific, the progeny is frail, diseased, short-lived, rarely arriving at robust manhood or maturity. Physicians need not be told of the comparatively enormous amount of scrofulous and deteriorated constitutions found among these hybrids.

The Colonization Journal furnishes some statistics with regard to the colored population of New York City, which must prove painfully interesting to all reflecting people. The late census showed that, while other classes of our population in all parts of the country were increasing in an enormous ratio, the colored were decreasing. In the State of New York, in 1840, there were fifty thousand; in 1850, only forty-seven thousand. In New York City, in 1840 , there were eighteen thousand; in 1850, seventeen thousand. According to the New York City Inspector's report for the four months ending with October, 1853-

1. The whites present marriages............................................................. 2,230

" colored " "

2. The whites " births ...................................................................6,780

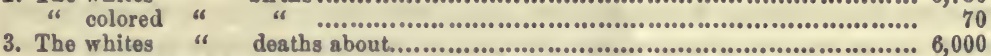

(exclusive of 2,152 among 116,000 newly-arrived emigrants, and others unacclimated.)

" colored exhibit deaths

160

giving a ratio of deaths among acclimated whites to colored persons of thirty-seven to one; while the births are ninety-seven whites to one colored. The ratio of whites to colored is as follows :-

Marriages, 140 to 1; births, 97 to 1; deaths, 37 to 1.

According to the ratio of the population, the marriages among the whites, during this time, are three times greater than among the colored; the number of births among whites is twice as great. In deaths, the colored exceed the whites not only according to ratio of population, but show one hundred and sixty-five deaths to seventy-six births, or seren deaths to three births -more than two to one. The same is true of Boston, so far as the census returns will enable us to judge. In Shattuck's census of 1845 , it appears that in that year there were one hundred and forty-six less colored persons in Boston than in 1840, the total number being 1842. From the same work, the deaths are giren for a period of fifty years, from 1725 to 1775 , showing the mortality among the blacks to have been twice that among the whites. Of late years, Boston, probably, does not differ from itself in former times, nor from New York at present. In the Compendium of the United States Census for 1850, p. 64, it is said that the "declining ratio of the increase of the free colored in every section is notable. In New England, the increase is now almost nothing ;" in the South-west and the Southern States, the increase is much reduced; it is only in the North-west that there is any increase, "indicating a large emigration to that quarter." 
What must become of the black population at this rate in a few years? What are the causes of this decay? They do not disregard the laws of social and physical well-being any more than, if they do as much as, the whites. It seems to me one of the necessary consequences of attempts to mix races; the hybrids cease to be prolific; the race must die out as mulatto; it must either keep black unmixed, or become extinct. Nobody doubts that a mixed offspring may be produced by intermarriage of different races-the Griquas, the Papuas, the Cafusos of Brazil, so elaborately enumerated by Prichard, sufficiently prove this. The question is, whether they would be perpetuated if strictly confined to intermarriages among themselves; from the facts in the case of mulattoes, we say unquestionably not. The same is true, as far as has been observed, of the mixture of the white and red races, in Mexico, Central and South America. The well-known infrequency of mixed offspring between the European and Australian races, led the colonial government to official inquiries, and to the result that, in thirty-one districts, numbering fifteen thousand inhabitants, the half-breeds did not exceed two hundred, though the connection of the two races was very intimate.

If any one wishes to be convinced of the inferiority and tendency to disease in the mulatto race, even with the assistance of the pure blood of the black and white races, he need only witness what I did recently-viz. the disembarkation, from a steamboat, of a colored pic-nic party, of both sexes, of all ages, from the infant in arms to the aged, and of all hues, from the darkest black to a color' approaching white. There was no old mulatto, though there were several old negroes; many fine-looking mulattoes, of both sexes, evidently the first offspring from the pure races; then came the youths and children, and here could be read the sad truth at a glance. The little blacks were agile and healthylooking; the little mulattoes, youths and young ladies, further removed from the pure stocks, were sickly, feeble, thin, with frightful scars and skin-diseases, and scrofula stamped on every feature and every visible part of the body. Here was hybridity of human races, under the most favorable circumstances of worldly condition and social position.

\section{Alpaca, or Peruvian Sheep.}

THE following is an abstract of a paper by Capt. James Pedersen, read before the United States Agricultural Society, Washington, February, 1854, on the alpaca, or Peruvian sheep:It is well known that for several years past various attempts have been made by those interested in the advancement and improvement of the races of domestic animals, to introduce the llama, alpaca and vecuna, of South America into England and the continent of Europe. Owing to the extreme care of the Peruvian government at all times against allowing those animals to be exported, most of the attempts made have been unavailing. A few specimens have, however, been introduced from time to time, and in almost every case have been found to thrive and adapt themselves to the changes in climate. This is especially the case, so far as regards their introduction into England. It is therefore reasonable to draw the inference that if the removal of these animals from their native mountains to the comparatively moist and humid climate of England has not proved injurious to them, they certainly cannot fail to be indifferent to a change to the Middle, Western, and Northern States of America.

The character and habits of these animals is very similar to that of our own sheep, or perhaps an amalgamation of them and of those of the domestic goat. They are gregarious, excessively gentle, and timid to a degree. One valuable quality they possess, that deserves especial attention, is, that they require neither keeper nor fence, or at most one of the slightest description; for wherever they are driven, there will they remain for hours, or for days even, without wandering more than a few yards from the spot.

To those who are not aware of the extreme difficulty that there always has been to obtain these animals, owing to the jealousy of the Peruvians to their being exported, it may appear extraordinary that efforts on a large scale have not been long since made to introduce them. From time immemorial the llama has borne an inestimable value in the eyes of the inhabitants of the southern Pacific coasts. They have found in them combined the beast of burden for the transit of ore from the mines of Andes to the seaboard, the raw material for 
clothing in their wool, and wholesome nourishment in their flesh. As in the case of the Egyptians of old, the value of the animal clothed it centuries ago with the character of sanctity. And thence arose and have been perpetuated prejudices which superstition has nurtured into fixed principles. "So that in the present day the Peruvian associates the idea of personal misfortune, if not sacrilege, with the separation of his favorite llama from his native home. The mild temper and perfect domestication of these animals have led to the establishment of an attachment between the Peruvian and his flock of sheep analogous to that existing between the Arabian and his horse. But the difficulties in procuring the animals are not dependent upon national prejudice only. The laws of the country preclude the export of them, and so stringently are they enforced that $I$ have ascertained upon undoubted authority that repeated but unsuccessful attempts have been made by the resident ministers from European courts at Lima, in their official character, to obtain them. And the same result attended an application made some time since by our minister, Mr. J. Randolph Clay, who was directed, at the instance of the Now York Agricultural Society, officially to apply for permission to obtain them.

An incident has been discovered, also, which deserves mention, as evincing the strong prejudice alluded to above, which is this-namely, that in several instances in which these animals have been purchased by individuals for export in some indirect way, it has been afterwards ascertained that the llamas had been in some way injured so as to insure their early death after leaving the country. And I regret to say that in my own attempt recently made, I have found that one of my animals had been thus treated. As an evidence of the high esteem in which these alpacas are regarded as an addition to the domesticated animals, I may mention that in my searches in Peru to obtain them, I met with an individual who is at this very time stationed upon a rancho on the border, but without the boundary of the country, where he is rearing them for the purpose of their export to Australia. And I found from him that he has made arrangements with the government in Australia for the sale of all the alpacas that he sends there at the rate of $£ 60$ a head, without, however, being restricted from finding a better market for them if he can do so; the sole object of the government being to procure the introduction of the animals into the country.

These animals are found in all parts of South America upon the Pacific coast, from the equator to about the twenty-fifth degree of south latitude, inhabiting principally the mountainous ranges, frequently at the height of twelve to fourteen thousand feet above the level of the sea, and in the region of continual mist and snow. It is not, however, in these intemperate regions alone that they find a congenial abode; on the contrary, they are found to prosper equally on the middle elevations of the Andes, where in the summer the clouds accumulated from the evaporations of the sea are blown over and burst in torrents of which we can form but a faint idea. No change of temperature appears, however, to affect these interesting animals; and when to these considerations is added the circumstance that in temper and docility they combine the intelligent vivacity of the deer tribe with the meek and confiding innocence of our own sheep, it appears impossible to conceive an animal better adapted, in every point of view, to form a valuable addition to our farms and homesteads. Such an animal would live and thrive where sheep would starve.

It is of course as a wool-producing animal that the alpaca is esteemed in Europe, and in which its value would consist, if introduced into this country. And there are large tracts of unprofitable mountainous country in the Western States that are admirably adapted to its habits.

The following comments on the character of the alpaca wool, and the hardiness of the animal, are taken from a recent publication by Mr. Walton, of Scotland. He says:

"There are instances of alpaca wool measuring thirty inches long; frequently it is seen twenty inches, and it averages from eight to twelve. In the samples there appeared to be no under wool-no closer and intermediate covering. There is, in the mass, what is technically called a trueness; that is, an equal growth, and an exemption from shaggy portions, accompanied by a soundness, by which is meant the general strength of the fibre-properties, certainly of the first import to the manufacturer. In consequence of this characteristic disposition, alpaca wool breaks less in the act of combing, is freer from shreds, spins easily, and, 
not being so harsh or so stubborn, does not injure the machinery so much. The thread spun with it is also finer and truer. In the manufacture of fine goods, it is agreed that the pile cannot be too soft or too silky, provided the strength of the fibre is not impaired. As well as I could, I have compared the strength of a filament of alpaca with those of other wools, and found it the strongest; and as it is devoid of that irregularity of surface, (the knots and joints which some persons liken to those of a bamboo cane,) the cloth made from it must consequently be less harsh to the touch. Another advantage consists in the greater weight of the fleece, for it ranges from ten to twelve pounds; whereas that of our full-grown sheep seldom exceeds eight pounds, and in the small breeds from four pounds, downwards. From the larger size of the animals, and the increased surface consequently covered, the alpaca necessarily yields most wool; and it has already been ascertained that on British pasture the weight improves. At the Royal English Agricultural Show, held at Liverpool in July, 1844, a sample of black wool was exhibited, taken from an alpaca belonging to the Earl of Derby's flock, the staple of which appeared to be about a foot long, when his lordship's farm-agent expressed his conviction that the same animal had then seventeen pounds upon its back.

"Another material question is, Could the alpaca live in our country? Although delicate in appearance, the alpaca is perhaps one of the hardiest animals of the creation. Nature has provided him with a thick skin and a warm fleece, and as he never perspires, like the ordinary sheep, he is not so susceptible of cold.

"Another great advantage in the alpaca is, that he is not liable to the many diseases incidental to common sheep, and which have so often raged like a pestilence among the tenants of the Scotch hills. In Peru, where the circumstances are as near as possible alike, the llama and alpaca are not hurt by changes of diet incidental to the seasons."

\section{Best Sheep for New England.}

THe follawing article, the result of carefully-conducted experiments, is communicated to the Albany Cultivator by Lawrence Smith, of Middlefield, Mass. :-

It is the general opinion among farmers that large animals will consume as much more food than small ones as their comparative weights differ. Should this argument prove true with two animals of the same species, (which I think is very doubtful,) it would be a still greater absurdity to suppose that the consuming powers could be determined by the weight of so different species as the New Oxford and Merino. These two breeds have been trained for different purposes-one, for its thick coat of fine wool, without regarding its fattening propensities; the other, for a heary carcass, without so much attention to the quality of its wool. I think, however, that according to food consumed, there is no breed of sheep which will produce more worth of wool than the New Oxford. A good flock will average 8 pounds easily, and will readily sell for 30 cents per pound.

The experiments between these two breeds have been very carefully and accurately conducted, in the following manner: Selected ten Merino ewes, four years of age, in perfect health; also, at the same time, selected eight New Oxford ewes about the same age: had them placed in comfortable quarters, and well watered. Commenced with each lot at the same time; weighed an equal amount of hay for each from the same place in the mow, and continued the experiment for seven successive days, giving them hay enough so as to have them leave a little every day. That which was left was weighed and credited to each flock. The following result has been obtained:-

10 Merino ewes, weighing 769 pounds, consumed in seven days................ 160 pounds hay.

8 New $0 x$ ford ewes, weighing 1068 pounds, consumed in the same time...... 140 " "

From this experiment we learn that 9 New Oxford ewes, with an aggregate weight of 1201 pounds, consume no more food than 10 Merino ewes, weighing 769 pounds. The relative profits of these two breeds may be set down as follows:-

For the ten Merino ewes, 50 pounds wool, at 40 cents per pound.................. $\$ 20.00$

$8 \mathrm{lambs}$, at $\$ 1.50$ each.................................................................... 12.00 
9 New $0 x$ ford ewes will shear 63 pounds wool, at 30 cents per pound.

14 lambs, at $\$ 3$ each.

In this statement $I$ have given the highest figures we have been able to realize from Merino ewes that have-been carefully bred for a long course of years. Few sheep in this country will come up to it.

In figuring up the profits from the $0 x$ ford ewes and lambs, I have endeavored to set the amount low enough to insure equal results to any farmer who possesses a soil of medium quality. In the richest grazing districts, the profits would greatly exceed the sum I have set. There are many instances of these lambs attaining to over one hundred pounds' weight on nothing but the milk which the dam afforded and common grass pasture. The largest lamb in our flock last season (which was very dry) weighed 104 pounds at 7 months of age.

The scarcity of these sheep in this country, and the high prices at which they are held, prevents the possibility of stocking our farms very plentifully with them at present. The best way for a general introduction of this blood, at a cheap rate, is to cross them on to our Merino ewes. This cross produces lambs but very little larger than the Merino. The experiment with farmers in this section has proved very satisfactory. The lambs are extremely hardy. They will thrive on less milk, are more quiet in their habits, the size is greatly increased, and the mutton is superior in quality.

These half-blood ewe lambs should all be saved, and when old enough, coupred again with a full-blood buck, having no relationship; and by repeating this process, always breeding towards the thorough-bred 0xford, - a beautiful flock of sheep can be obtained at a moderate cost.

These sheep possess qualities and attractions which entitle them to the highest rank among our domestic animals. They are just suited to farms of moderate extent. The owner can realize from a few of them a very handsome income, nearly all ewes of good size bearing twins. Their great square forms and snow-white fleeces form a pleasing contrast with the green pastures on which they feed.

They are orderly to a fault, never having caused me the least trouble. They are always found in the pasture, if the fence is passable. They can be managed by any young child, being fond of society and the caresses of the master. I had supposed, before I commenced breeding these sheep, that they were rather dainty in their feeding habits, and would require the best of keeping in order to make them thrive. This, however, is not the case. They rather choose the coarser weeds and brakes, a part of the time, to the best of hay.

\section{Introduction of the Angora Goat into England.}

Is 1852, Mr. Salt, the eminent English manufacturer, imported into England a number of Angora goats, with the intention of naturalizing the same in that country. The experiment has been highly successful, and at the present time Mr. Salt has a numerous flock of angoras, which have been bred in the vicinity of Bradford. The animals only require to be kept from wet, and cold does not seem to injure them. The hair is of a beautiful quality, and thus far has not degenerated. It is known in commerce as the "mohair."

\section{Mules.}

Mr. R. Cookrell, an extensive planter in Tennessee, in a communication to the Nashville Banner, gives the following information respecting the mule:-

"The mule is the great field-laborer in the commanding staples of the South-cotton, sugar, and rice; and as he is one of the annual exports of Tennessee, and as he will continue to be so, he is destined to hold even a higher position than heretofore among the live-stock of the State. The large, heavy-boned mule, produced from overgrown jacks of excessive heavy bone or improper tampering, are generally lazy, or soon become so by labor, and become very slow; their driver may force them on, but in a few steps they take their slow, natural gait again. Such mules are therefore almost worthless, and should not be bred if it can be 
avoided. The most perfect mules are not to be expected from the excessively large, coarseboned jacks, or excessive high feeding, but from the laws of nature carried out to the greatest perfection by skilful breeding and feeding.

"An error has existed for many years, and still exists, concerning the size of mules. Size has been made a measure of value in the mule, almost regardless of form and spirit, and so it has been in their sire, the jack.

"I have been employing a mule team for twenty-five years in the cultivation of cotton in Mississippi, and my team now numbers one hundred. In this time I have used every variety of the mule (except the most inferior kind) that has ever been grown. At the commencement of planting operations, I adopted the prevalent error that size was the measure of value, and pursued it for many years, much to my prejudice. By long trials, and by comparing the relative performances and lastingness of the large team which $I$ have used, aided by observation and reflection, I am fully' satisfied that the medium-sized mules, full of spirit and action, with a neat, firm leg, and a round body, with his levers set right for easy motion, his head and ears up, ready to move at the word, is the animal of most value of his kind."

\section{Improved Cattle for the Dairy.}

THE following is an abstract of a communication addressed to the Secretary of the Ohio State Board of Agriculture, by'George Vail, Esq., of Troy, New. York, and published in the Ohio Farmer, on the most approved cattle for dairy purposes. Mr. V. is well known as one of the earliest importers and most careful breeders in the United States:-For a number of years he imported and bred Shorthorns exclusively; but as his farm was not well adapted to grazing, and after fully proving what might be done with that class of cattle, he sold his herd in 1852. Being partial to improved stock, he has, since his sale, been getting by importation, and selection in this country, a small and excellent herd of Devons. He says : "This breed of cattle is my choice next to Durhams. So far as I have tried them, I am of the opinion that when placed in localities where pasture is abundant, they may prove profitable to the breeder. The sprightly action, uniform color, and fine symmetry of the Devons, added to their intrinsic value, will render them popular when they become known."

Mr. V., in his communication, says:- "You ask if for the small farmer either of the improved breeds of cattle will meet the public expectation, when we breed for milk and fattening qualities in the same animal, or whether a cross with the Holderness, or other breeds, would improve their qualities for all uses? In answering this question, I will premise by saying I am aware that many Durhams have been bred with special reference to their aptitude to take on flesh, without much regard to their milking qualities; consequently, many of these are unfitted for the dairy. There are, however, families or tribes of Durhams possessing superior dairy qualities, and when no longer useful as milkers, on account of age or other eauses, may be turned off, and will then take on flesh about as rapidly as those which are bred exclusively for the butcher. If I am correct in this opinion, then I am prepared to hazard the assertion, that no useful result can be arrived at by crossing the Shorthorn cow with any other breed, with the prospect of improving upon the dairy qualities of the best milking families or tribes of Shorthorns which may be procured in this country. That there are tribes of such Shorthorns, that are not inferior to the best native dairy-stock in the country, I think there cannot be a doubt. If so, then it is obvious that it would be a waste of time to attempt to rear a new breed of cattle for dairy purposes: as such experiments would occupy many years to test their utility, it is believed that no practical breeder would attempt it.

"I now proceed to show that there are specimens among Shorthorns of this country which are superior to most if not all of the breeds of this country for dairy purposes. In 1844, the New York State Agricultural Society offered a premium for the largest quantity of butter, to be the product of six cows, of any breed, in thirty consecutive days, the cows to be kept upon grass pasture or green fodder, and not to be allowed slops or other feed for thirty days previous to and during the trial. In order to test the dairy qualities of the Shorthorns, compared with other breeds, and thus give the great dairy interests of the country an oppor- 
tunity to form a judgment of the relative merits of the different breeds of cattle for dairy purposes, I put six Shorthorns on trial, and kept them on grass alone, and the result was, they produced, in thirty days, $262 \mathrm{lbs}$. and $9 \mathrm{oz}$. of butter, it being an average of $43 \mathrm{lbs} .12$ oz. to each cow. To ascertain the quantity of milk the six cows gave, I carefully weighed and measured the milk drawn from them in one day, and the result was a weight of 265 lbs. $10 \mathrm{oz}$., and measured 134 quarts, wine measure, averaging $22 \frac{1}{3}$ quarts per day. It is proper to state that I had twelve cows, from which I took the six for trial. This statement may be found recorded in full in the Transactions of the New York State Agricultural Society, 1844, page 215. I had one cow, 'Young Willey,' that produced in seven days $13 \frac{1}{2}$ lbs. of butter. I sold a two-year old heifer, called 'Ruby,' daughter of the above, to S. P. Chapman, of Madison county, N. Y. He put his heifer on trial, when five or six years old, to compete for a premium offered by the Society above named, for the largest quantity of butter made from one cow in ten days in June, and ten days in August, 1850, to be fed on grass pasture only. She produced a fraction over forty pounds of butter in these twenty days, and was awarded the first premium. Another cow I called 'Eunice 1st.' I had her milk, the produce of one day, measured, and the result was thirty-two quarts, wine measure. Eunice $2 d$ produced in one day thirty-four and a half quarts of milk, and there had previously been made from her milk nineteen and a half pounds of butter in seven days. Beside the tribes of which the above were members, I had others of superior milking qualities, which I could refer to; and I doubt not there could be selected from the numerous herd of Shorthorns in this country equally good milkers with those referred to.

"I do not desire to mislead any one in this matter, and therefore it is proper to say, that although it is a generally received maxim in cattle-breeding that 'like begets like,' yet there may, and probably will be, individual exceptions to this rule, relative to the milking qualities of the progeny of every animal bred from such cows. My experience is, that it is rare that a failure will occur, when uniform good milkers are bred to a male descended from an equally good milking stock. Hence it will be seen that the selection of the male is all-important when milking qualities' are sought. I entertain the opinion that cows, heifers, or steers, reared from cows possessing fine milking qualities, will, when needed for the shambles, put on flesh as fast, and with as little expense, as those not in possession of good capacities for milk. The milking and fattening qualities of the Shorthorns (and those two qualities constitute the value of this or any other breed) are to be found in great perfection in most of the herds of the country, in separate animals. By commingling these, there could be presented to the country a breed of animals of great value.

"In conclusion, I remark, that it seems to me that there is another good reason for not attempting to improve by crossing, as the Shorthorns are a well-established breed, perfected by a long course of scientific breeding, with pedigrees for many generations recorded in the herd-book, which will always prove a great convenience to such as may keep and breed the Shorthorn for dairy purposes."

\section{Management of Dairy Stock.}

Ar the request of the Council of the Royal Agricultural Society, Mr. Horsfall, a gentleman of great celebrity and success as a dairy farmer, furnished, in May last, a paper respecting the methods pursued by him for the feeding and management of cows for dairy purposes. The following abstract of this valuable paper, prepared for the N. Y. Country Gentleman from the publications of the Society, gives the essential features of Mr. Horsfall's plans and operations:-Mr. H. commences his report of his mode of management with his dairy stock, by saying that he had found it stated on good authority that store cattle of a fair size maintain their weight and condition for a length of time when supplied daily with $120 \mathrm{lbs}$. of Swedish turnips and a small portion of straw, and that the experience of a district in Yorkshire, where meadow hay is the staple food during winter, shows that such cattle maintain their condition on 33 lbs. of such hay each, per day. These respective quantities of turnips and of hay correspond very closely in their nutritive properties, containing a very similar amount of albuminous matter, starch, sugar, and phosphoric acid. 
These same quantities of food, or their equivalents, if supplied to cows in milk, and of the same size, will be found insufficient, as the cows will lose perceptibly in condition. This is easily explained when we find their milk rich in substances which serve for their support when in store condition, but going to the formation of milk when kept for dairy purposes. Even the accumulated stores of flesh and fat on a milch cow seem to be drawn upon, and converted into components of milk, caseine, or butter. Dairymen near large towns, where fodder is higher than in rural districts, 'and where the dairy produce is disposed of in-new milk, take advantage of the fact just stated. They prefer altogether cows in high condition when they purchase them, finding that their stores of flesh and fat will serve to be converted into milk at a cheaper rate than by purchasing fodder. They supply their cows with sloppy food, more adapted to induce quantity than quality; and when the cow has lost greatly in condition, and is no longer profitable, she is sold to purchasers in farming districts, where food is cheaper, to be fattened again for dairy purposes or for the butcher.

But when cows are kept mainly for the production of butter, for which poor milk is not adapted, the food of such cows must be that which is best adapted for an abundant supply of the product wanted. With a view to determine the kind of fogd best adapted for the production of the best quality of butter, Mr. H. was led to give attention to the chemical composition of milk. From several analyses, he has come to the conclusion that, taking a full yield of milk, four gallons a day, which will weigh upwards of $40 \mathrm{lbs}$, there will be, on an average, of dry or solid material, $5 \cdot 20$ lbs., consisting of

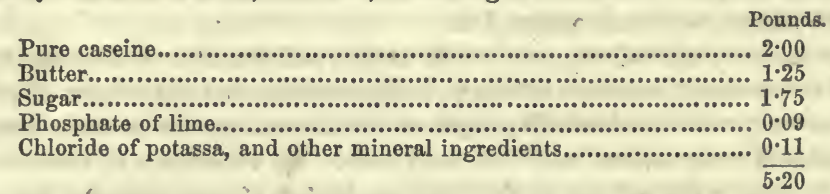

In endeavoring to supply abundant material for these, by furnishing their elements in the food, Mr. H. found that turnips are objectionable on account of their flavor, which has led him to use them but very little for his dairy stock, and to use, in moderate quantities, instead of them, cabbage, kohl rabi, and mangel-wurzel. If hay alone were to be used to supply the constituents of a full yield of milk, it would require an addition to the quantity needed for bare maintenance so large that no cow could be induced to consume it.

Finding that he could not use hay and turnips in such a way as to keep his dairy cows in good condition, and also to furnish them with an ample supply of the elements of milk for the production of butter, Mr. H. sought the aid of such substances as are rich in albumen, oil, and phosphate of lime, paying regard to their comparative cost with a view to profit. He thinks that nitrogenous and other substances have a higher value for special than for general purposes, and that this adaption of materials, characterized by peculiar properties, has not yet gained the attention to which it is entitled. After repeated trials to ascertain the kind of food best adapted to produce a full supply of milk rich in butter, in addition to keeping his cows in good condition, Mr. H. has adopted the plan which follows, and which we give in his own words:-

"My food for milch cows, after having undergone various modifications, has for two seasons consisted of bean straw, oat straw, and shells of oats, in equal proportion, rape-cake, 5 . lbs., and bran, 2 lbs. per day, for each cow. These materials are blended together, moistened, and well, steamed. They are supplied three times, ad libitum, per day, in a warm state. The attendant is allowed $1 \mathrm{lb}$. to $1 \frac{1}{2} \mathrm{lb}$. per cow, according to circumstances, of bean meal, which he is charged to give to each cow in proportion to the yield of milk; those in full milk getting 2 lbs. each per day, others but little. It is mixed with the steamed food on its being dealt out, separately; when this is eaten up, green food, consisting of cabbages from October to December, kohl rabi till February, and mangel till grass-time. With a view to nicety of flavor, I limit the supply of green food to from 30 to $35 \mathrm{lbs}$. per day each. After each feed, $4 \mathrm{lbs}$. of meadow hay, or 12 lbs. per.day, are given to each cow. They are allowed water twice per day to the extent they will drink."

As some of the materials used by Mr. H. are not in common use as food, he annexes some 
remarks on what he regards as their distinctive properties:-Bean straw, uncooked, is dry and unpalatable, but by the process of steaming it becomes soft and pulpy, emitting an agreeable odor, and imparting flavor and relish to the mess. - It should be cut on the short side of ripeness, which it may be without interfering with the plumpness of the bean. In albuminous matter, which is especially valuable for milch cows, bean straw has nearly double the proportion contained in meadow hay. Bran also undergoes a great improvement in its flavor by steaming, and it is probably improved in its capacity of being readily converted into nutriment. Bran contains about 14 per cent. of albumen, and is peculiarly rich in phosphoric acid, nearly two per cent. of its whole substance being of this material. The properties of rape-cake are such as will cause it to be more highly valued than it has ever hitherto been for dairy purposes, if the opinion of Mr. H. in regard to it be not altogether too high. It contains nearly 30 per cent. of albumen, and is rich in phosphates, and also in oil. The objection made by some to it on account of its flavor, Mr. H. has overcome by his mode of preparing it by steaming, \&c. The cattle do not refuse it, and the flavor is not at all perceptible in the milk or butter. During the month of May, Mr. H. turns out his cows on a rich pasture, housing them at night, and supplying them with a mess of the steamed mixture and a-little hay, morning and evening. . From June to October mown grass is given instead of hay, in addition to what they get in the pasture; and also two feeds of the steamed mixture. This is continued till October, when the cows are again wholly housed. With such treatment, Mr. H.'s cows usually give from 12 to 16 quarts (imperiaf) of milk per day, and keep in good condition at the same time for about 8 months after calving. Then they usually fall below 12 quarts, and gain several pounds every week in fat and flesh. Another advantage or element of profit is the richness of his manure from cows 80 fed. His pasture lands are yearly improved, and not impoverished. The average amount of butter from every. 16 quarts of milk is 25 ounces.

\section{On the Fattening of Cattle.}

Tre following is the substance of a prize essay on the fattening of cattle, by George Dobits, published in the Journal of the Royal Agricultural Society:-

"The first point," he says, "is to have a good sort of bullock to begin upon. I do not recommend any particular breed to the depreciation of all others, because different localities require different descriptions of animals; but caution breeders that it is right to select the characteristic marks of the breed they intend purchasing, and warn them particularly never to purchase a coarse, ill-made, bad-bred animal, because they may fancy it is cheap. A man has never got so bad a bargain as when he has, as the saying is, 'got too much for money.'

"The first criterion for judging of the disposition of the beast to fatten quickly, in my opinion, is that peculiar, soft, supple feel of the skin which is commonly called handling well. This is generally accompanied by hair of a soft, fine quality, in great plenty. The eye should be full and clear, and the head well formed; the shoulders not upright, but lying well back; the chest full; the ribs deep, and well arched out; the flanks well down; the hips nearly level with backbone, and in proportion to the rest of the carcass as to width; the rumps wide, und not too low down, appearing as if, when fat, the tail ends would be level, (but this the butchers in my neighborhood are in the habit of calling the fool's point;) the purse should be of full size and soft to the touch, (this I consider a material point;) the twist good; and the legs short and small in proportion to the carcass, as the offal will be light in proportion to the leg-bone.

"Next observe the temper of the animal; in selecting from a considerable drove, you will often find beasts possessing many of these good points, yet in a lower condition than some of the animals of worse appearance. Consider well whether this may not arise from the masterful disposition of the ill-made one, and whether, when put to fatten where every beast may eat his share of food without disturbance, the good-bred one will not soon surpass his more masterful neighbor. If you observe a beast that is constantly watching an opportunity of goring any other that comes in his way, leave him behind, even if he is much heavier than 
those you select; he may be a great trouble to you; and although the jobber may think you have selected them badly, he will sell them according to what they are worth at the time, and the present weight is the great point with him. For this reason, always select the animals before purchasing, rather than agree to give a certain price per head to pick where you like from the drove.

"I think the quality of an animal is of more consequence than his form for common fattening purposes, but have both good if you can. But if you are thinking of fattening an animal to show for a prize, be sure to have his form as perfect as possible, for all the flesh you may lay on him will not hide any great defect in his form; also ascertain, if possible, how the animal is descended: ten to one, but the progeny becomes similar to the progenitor. But this is generally a most unprofitable affair, and I strongly recommend all young farmers to leave it in the hands of those gentry who can afford the loss, many of whom there are in the country, and they deserve our best thanks for their patriotism, for it certainly shows the capabilities of different breeds, and thereby enables the observing farmer to profit by the experience of others. Never buy any animals that are excessively poor; they will consume a great deal of food before they are got into health enough to fatten; for, depend upon it, unless your animals are well-bought, fatting cattle will never pay enough to leave the manure clear profit, which it ought to do, although I fear with the majority of farmers it is far otherwise.

"Summer Grazing.-I shall say but little with respect to summer grazing, as the wording of the Society's advertisement appears to apply more particularly to winter fattening; merely remarking that the fences should always be kept thoroughly good, a weak place being strengthened before it becomes a gap-prevention, in this case, like many others, being better than cure; that the bullocks should be well supplied with water, and have plenty of shade; never allow them to be frightened by dogs, etc.; treat them kindly, and they will soon cease to fear your presence; do not let a day pass, if you can help it, without seeing them. There is an old saying which ought to be impressed on every farmer's memory-it has been of great service to me in the course of my life; it is: 'The master's eye grazeth the ox.' A friend of mine has lately adopted a plan, which under the same, circumstances I should strongly recommend; it is that of giving a small quantity of oil-cake to animals grazing, for the sake of improving an ordinary pasture, and its effects are astonishing. The pastures I allude to are small, and one or two bullocks more than they are calculated to carry are put into each; the lot are then allowed four pounds of cake per day per head; this, at a cost of about two shillings per head per week, which I believe the stock well paid for, has entirely altered the face of pastures from what they were three years ago, when the plan was first adopted by him, and I believe without any loss to himself.

"Winter Feeding. - I now come to the point of winter feeding. First, as to the places in which they are kept, I unhesitatingly give my opinion in favor of stall-feeding, for all the common purposes of grazing, but not for young beasts that are to be summered again, or for prize oxen; the former should have small well-sheltered yards, with good sheds; if the fences are so high that they cannot see over, it is much the better; and the latter, loose boxes, with plenty of room for them to walk about, because they have to be kept up for such a long period, that, if no exercise were taken, the health might suffer. It is the abuse of stallfeeding that has got it into disrepute with some people, and the not treading down straw enough with others. This last I hold to be an advantage, instead of a disadvantage; for, depend upon it, it is not the size of the dunghill, but the quality of the manure, that causes the farmer's stack-yard to be well filled. If managed well, I contend that there is no plan so good as stall-feeding. The fattening-house may be of any size or shape, but it is necessary that there should be underground drains, with gratings, to carry off the urine into the liquidmanure tank; shutters behind the bullocks, to regulate the heat, and a wide passage at their heads to feed them and clean their mangers. The advantages I conceive to be, the quantity of litter required being smaller, therefore the muck being made better, the temperature being more easily regulated, and every bullock being allowed to eat his share in peace. , The disadvantage of the animal not being able to rub himself as well, I consider fully done away with by the rough brush which I recommend.using; and although theorists may fancy the health of the animal likely to suffer, $I$ have never found it so in practice. 
"Now with respect to their food, so much does this vary, I shall simply give the plan I recommend, leaving my readers to follow it if they like, and improve upon it whenever they can.

"I think in many instances stall-feeding is not commenced early enough in the autumn. As soon as the weather becomes damp, and the days shorten much, say some time in October, the grass in my neighborhood loses its feeding' properties, and then the sooner your bullocks are put up the better. For this purpose, I recommend having some of the large forward descriptions of turnips provided; perhaps the 'red tankard,' although watery, and soon becoming of little value, are at this very early season the best of any, from their early maturity; these are sown in April, at the rate of an acre to every eight bullocks, which will last them three or four weeks, according. to the crop, and leave a light fold to begin the sheep upon; at the end of which time the forward Swedes are ready to begin. During this period I give them little or no oil-cake, if they are only in moderate condition; but they have half a stone of bran a day, mixed with an equal quantity of hay or straw chaff. Some persons may fancy this food is of too loosening a nature, but I can assure them, from several years' experience, that although bran is loosening itself, yet it has the effect of preventing the watery white turnip from purging too much. Although the bullocks do not gain much in weight during this time, yet I am satisfied they go on faster afterwards; the reason of which is, I suspect, that their bodies are more prepared for the artificial state they have to live in for the next few months. Early in November the food must be changed to Swedes, cake, etc.-the quantities of each must vary according to circumstances; the following I consider a good allowance where Swedes are not scarce; if they are, more oil-cake must be giren instead of a part of them, or if very plentiful, they may be allowed even more: the morning's bait, one bushel of Swedes, well cleaned from dirt and cut small, given a few at a time; then, the refuse pieces being well cleaned out, a dry bait consisting of two pounds of oil-cake, three pounds of bran, and a little hay chaff. While they are feeding, the manure and wet litter must be well oleared away, and any which may be on the bullocks taken off, the floor swept clean, and plenty of fresh litter put in; then have every bullock well brushed with what is called a dandy-brush, being a brush made of whalebone, for taking the rough dirt off of horses. (Let no slovenly farmer fancy this to be a whim of mine; depend upon it, the ballocks are kept in much better health and greater comfort for it.) They must now be left quiet; they will soon lie down and rest, and chew the cud till after dinner, when another bushel of Swedes is given as before, in small quantities, followed by a similar dry bait of cake, bran, and hay chaff, but with the addition of three pounds of bean meal; this is left with them at night. Be careful that the shutters are opened or closed according to the weather, so as to maintain an even, warm temperature, but not hot enough to make them perspire, if it can be avoided. Be also careful that the mangers are well cleaned out between every bait. I have mine cleaned at the commencement of the season, and as often afterwards as I think necessary, with scalding-water and the scrubbing-brush.

"After a month or so the cake may be increased, and, if it is thought more convenient, the Swedes may be changed for mangel-wurzel. Many persons object to using mangel until the spring; they certainly are more valuable than Swedes in the spring, and therefore should always be used last. Never change from mangel-wurzel to Swedes, after you have once began them, or the bullocks will not go on so fast; but if, from having a bad crop of Swedes, or from any other cause, you want to begin mangel early, you have only to lay them exposed to the air for a week or two to wither, and they may be used as early in the season as is required.

"It will be observed that cleanliness, warmth, and quiet are the great points I insist. upon, of course coupled with good feeding; but very many tons of oil-cake are annually wasted, because the comfort of the animals is not more attended to.

"Before I conclude, I wish to give these recommendations respecting selling the bullocks when fat: Do not determine upon parting with them exactly at a given time; but if a butcher wants to buy a part of them a few weeks before you think they are ready, calculate how they are paying for what they have eaten; and, if you feel satisfied on that head, do not run the hazard of getting a bad sale by refusing a good offer, or perchance the opportunity may 
not return. Sell them to butchers -at home, if you can. - Always estimate the weight and value of your bullocks the day before any one is coming to buy them; and, after letting the butcher handle and examine them well, let them out into a yard for him to see; they will always show better than when tied op."

\section{Improving Stock.}

There is one circumstance relative to the introduction of new breeds which must not be passed over in silence, because no farmer can neglect it without a certain loss. Every kind of pasture is fitted to raise animals to a particular size; when beasts of a larger size are brought in than the quality of the food is calculated to support, these animals, whether cows, horses, sheep, or any other kind, will degenerate apace, and never prove useful until they come down to that standard or size adapted to their situation and suited to their food. On the other hand, when a smaller breed than ordinary is brought in, they continue to increase in bulk until they come up to the pitch which is suited to their nourishment. But there is this remarkable difference between the two progressions in respect to profit-that in the retrograde process, where animals are brought from rich pastures and a comfortable situation to the reverse, they are in every instance worse than the indigenous breed; whereas, the animals which are brought from worse to better, continue to improve until they arrive at that perfection which the change in their situation is calculated to produce. These causes may not immediately have their full "effect, but in a few years they certainly and evidently will. He makes, for this reason, a much safer experiment who brings cattle from worse to better, than he who brings them from better to worse.-Agricultural. Report, Perth Society, England.

\section{Judging Animals.}

A CORREspondent of the "Mark Lane Express" (England) makes the following remarks on the method of judging and estimating the value of animals. He says-The difficulties which are often experienced by the most competent judges in deciding between two really first-rate animals of a first-rate sort, are greater than the majority of people who have never acted in the capacity of judge have any idea of.

I will take an instance of two first-rate Shorthorn bulls, neither of them having a faulty point. Judge A. says-"What a superb back No. 1, has!" B. says-"But look at the depth of carcass in No. 2." "But the length of the quarter in No. 1!" continues A.; and in return B. draws attention to the silky texture of the skin of No.2. The question, is here put to Judge C., who should decide the case; but he has to balance in his mind whether a superior back is more to be considered than an extraordinary depth of carcass; and, again, is a firstrate quality of hide equivalent to an unusual length of quarter? And thus points, without having some definite value attached to them, might be compared one against another ad, infinitum, without ever coming to a satisfactory conclusion.

Now, what I wish to see is, a definite value affixed to every point in the perfect animal, and when such cases of nicety as I allude to do occur, let the judges take point by point, and compare value in numbers, and then the animal commanding the highest amount would be the one selected. If the perfect animal were 50 , the component parts might be something as follows:

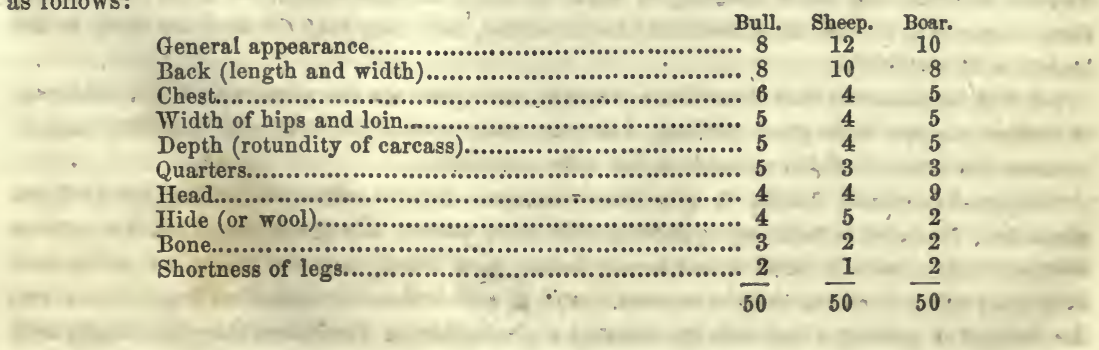




\section{Blanketing Cows.}

A correspondent of the Rural Intelligencer, who has been travelling through Holland, says that "great care is there taken of their cows, both in winter and in summer. In a lowery, wet day, you will see the cows in the field covered with blankets; aye, even more commonly than a horse is blanketed here in the winter. This care is well repaid by a greater flow of milk and a less consumption of forage."

\section{Hereditary Diseases of Cattle.}

Mr. Fivlar Dus, in a recent prize essay on this subject, in the Journal of the Royal Agricultural Society of England, mentions as the most important hereditary diseases of cattlediarrhœa, rheumatism, scrofula, consumption, dysentery, malignant tumors, and the affections depending on the plethoric state of the body. The characters which cattle should possess in order to perpetuate in their offspring a healthy and vigorous constitution, he givesamong others the following:-

"The head small; muzzle fine and tapering; nostrils large and open; the eyes full and lustrous; ears small, and not too thick; the head well set on the neck; the distance between the ears and the angle of the jaw short, but the width behind the ears considerable, (no dairy cow should have a short, thick neck;) the chest wide and deep; the girth, taken immediately behind the shoulder, should closely correspond with the length from behind the ears to the rise of the tail ; the carcass of a barrel shape, for a thin, flat-ribbed animal eats largely, thrives badly, and is usually liable to diarrhoea; there should be little space between the prominence of the hip and the last rib; the quarter large; the measurement from the prominence of the haunch backwards to the rise of the tail, and downwards to the hock, as great as possible; the lower part of the haunch thick and broad; the hide thick and pliant; smallness of bone is a sure indication of early maturity and aptitude for fattening. These, among other characters and qualities enumerated by Mr. Dun, indicate the possession of a vigorous and healthy constitution and freedom from all inherent disease."

\section{New Food for Sheep.}

A Foreigr correspondent of the Agricultural Gazette furnishes the following information respecting the use of the horse-chestnut as a suitable food for sheep. He says: While I was at Geneva, I observed every one collecting carefully the fruit of the horse-chestnut, and on inquiry I learnt that the butchers and holders of grazing-stock bought it readily at a certain price per bushel. I inquired of my butcher, and he told me it was given to those sheep in particular that were fattening. The horse-chestnuts were well crushed-something in the way, so I understood, that apples are previous to cider being made. They are crushed or cut up in a machine kept solely in Switzerland for that purpose; then about two pounds' weight is given to each sheep, morning and evening. It must be portioned out to sheep, as tơo much would disagree with them, being of a very heating nature. The butcher told me that it gave an excellent, rich flavor to the meat. The Geneva mutton is noted for being as highly flavored as any in England or Wales.

\section{Corn and Cob Meal.}

THe grinding of corn and cobs' together, which we have heard ridiculed very much by some formerly, has now become an everyday occurrence, farmers being convinced that the cob contains too much nutriment to be thrown away.

Our experience heretofore in regard to its use is this: For those animals that chew the cud it is a most excellent provender; but for those that do not, it is not so valuable. Thus, for oxen, cows, and sheep, it is a capital feed. These animals, after what they swallow in the warm vat, called the first stomach or paunch, have the faculty of throwing it up again in small portions called cud, and chewing it over in a leisurely manner until it is ground very fine; and then after being thus thoroughly mingled with the saliva, swallowing it again into 
another stomach, where all its nutritive matter is extracted by the proper organs created for that purpose. The horse and the hog, having no such or'gans to re-chew, do not derive so much' benefit from the ground cob as the animals above named. Hens derive more benefit from corn and cob meal than they do from corn meal alone. In fowls of this class there is an apparatus analagous to animals that chew- the cud. First, they take dry food into their crops; here it becomes soaked as. if it were in a warm vat; . from this it passes into the gizzard, which, furnished with gravel-stones, acts the part of grinding fine, by aid of the strong muscles of that organ, whatever passes into it. Here the particles of the cob meal, thoroughly pulverized, and mingled with the gastric juices, become dissolved, and form nutrition for the body.

We do not mean to say that corn and cob meal is not good provender for horses and hogs, but that they do not derive so much benefit from pound for pound, or bushel for bushel, as oxen, cows, etc. do.-Maine Farmer.

\section{Period of Human Life.}

M. Flourens, the distinguished French physiologist, has recently published a book, in which he announces that the normal period of the life of man is one hundred years. The grounds on which he comes to this new philosophic conclusion may be briefly stated: It is, we believe, a fact in natural history that the length of each animal's life is in exact proportion to the period he is in growing. Buffon was aware of this truth, and his observations led him to conclude that the life in different species of animals is six or seven times as long as the perriod of growth.'. M. Flourens, from his own observations and those of his predecessors, is of opinion'that it may be more safely taken at five times. When Buffon wrote; the precise period at which animals leave off growing, or, to speak more correctly, the precise circumstance which indicates that the growth has ceased, was not known.' M. Flourens has ascertained that period, and thereon lies his present theory." "It consists," says he," "in the union of the bones to their epiphyses. As long as the bones are not united to their epiphyses, the animal grows; as soon as the bones are united to the epiphyses, the animal ceases to grow." Now, in man the union of the bones and the epiphyses takes place, according to M. Flourens, at the age of twenty; and, consequently, he proclaims that the natural duration of life is five times twenty years. "It is now fifteen years ago," he sayș, "since I commenced researches into the physiological law of the duration of life, both in man and in some of our domestic animals, and I have arrived at the result that the normal duration of man's life is one century. Yes, a century's life is what Providence meant to give us." Applied to domestic animals, M. Flourens's theory has, he tells us, been proved correct. "The union of the bones with the epiphyses," he says, "takes place in the camel at eight years of age, and he lives forty years; in the horse at five years, and he lives twenty-five years; in the ox at four years, and he lives from fifteen to twenty years; in the dog at two years, and he lives from ten to twelve years; and in the lion at four years, and he lives twenty." As a necessary consequence of the prolongation of life to which M, Flourens assures man he is entitled, he modifies very considerably his different ages. "I prolong the duration of infancy," he says, "up to ten years, because it is from nine to ten that the second dentition is terminated. I prolong adolescence up to twenty years, because it is at that age that the development of the bones ceases, and consequently the increase of the body in length. I prolong youth up to the age of forty, because it is only at that age that the increase of the body in bulk terminates. After forty the body does not grow, properly speaking; the augmentation of its volume, which then takes place, is not a veritable organic development, but a simple accumulation of fat. After the growth, or more exactly speaking, the development in length and bulk has terminated, man enters into what I call the period of invigorationthat is, when all our parts become more complete and firmer, our functions more assured, and the whole organism more perfect. This period lasts to sixty-five or seventy years; and then begins old age, which lasts for thirty years." But though M. Flourens thus lengthens man's days, he warns him, more than once, that the prolongation of them can only be obtained on one rigorous condition - " that of good conduct, of existence always occupied-of labor, of 
study, of moderation, of sobriety in all things." To those who may be disposed to ask why it is that of men destined to live a hundred years, so few do so, M. Flourens answers triumphantly - "With our manners, our passions, our torments, man does not die, he kills himself!" And he speaks at great, length of Cornaro, of Lessius, and mentions Parr and others to show that by prudence; and above all, sobriety, life can easily be extended to a century or more.

\section{On Horse-flesh for Food.}

M.'St. Hrtarre, the President of the Society for Acclimation of Foreign Animals in France, has recently published a communication demonstrating the advantages of horseflesh for food. After speaking of the predilection of the ancient Germans for horse-flesh, he has inquired into the aversion now so general. Both the Scandinavians and Germans kept in a sacred pasture a race of white horses for sacrifices to Odin, and after the sacrifice they boiled them for a feast. This is no doubt the origin of the hippophagy, which continued among these people until driven out as a part of paganism by the spread of Christianity. Yet in spite of the efforts of Pope Gregory III. and his successors, the use of horse-flesh continued for a long time in Scandinavia. The race of white horses is still found pure in the stables of Fredericksberg, belonging to the king of Denmark.

The nomadic tribes of Asia still retain their relish for horse-flesh, although they have an abundance of cattle and sheep. . Among the people of Europe, who have anew taken up the use of horse-flesh, the Danes were the first. During the siege at Copenhagen, in 1807, it was authorized by the government, and since then it has continued to be eaten. In the capital of Denmark, there is a butcher's stall for selling horse-flegsh alone, licensed by the government. At times it has been introduced into Paris. During the scarcity at the time of the Revolution, the greater part of the meat eaten for six months was from slaughtered horses, and no inconvenience resulted from it. Along the Rhine, in Catalonia, and in the Maritime Alps, the celebrated Larrey many times had recourse to this article of food for his wounded soldiers. He depended on it mainly at the siege of Alexandria, and owed to it, in a great degree, the cure of the sick. From these facts, and a multitude of others he enumerates, M. J. Geoffroy St. Hilaire concludes that horses may be used as wholesome, economical, and nutritious food.

\section{The Successful Features of Bee-Culture.}

Trr essential features of successful bee-cnlture are the following:-1. bees should be placed in a good hive-one which will bear exposure to the weather; 2 . the keeper should be able at any time to inspect their condition; 3 . they should be allowed to swarm; 4. they should be protected from the encroachments of the bee-moth; 5 . the hive should be sufficiently ventilated, especially in winter; 6 . no bees should ever be destroyed; 7 . the keeper should be able to avail himself of all the labor which they can perform; 8 . he should ascertain and note their weight of stock in autumn and spring; 9 . bees which occupy a good hive (and they should be put into no other) should rarely be dislodged. These are by no means all the important features of a good system of bee-culture. But these I regard as indispensable; others are cómparatively of minor importance or incidental. Without each of these, any system which may be adopted must present glaring defects, and must prove unprofitable in proportion as such defects are found to exist.-Dr. Henry Epdy, (Journal of the United States Agricultural Society.)

\section{The New Silk-Worm, Bombyx Cynthia.}

DURiva the past year, considerable attention has been given in Europe to a new variety of silk-worm recently introduced from the East Indies, and known as the Bombyx cynthia. Various attempts had been made to introduce this worm into Piedmont, Italy, from Calcutta ; but in every case the eggs failed to arrive in a living state. It was then thought that the 
chances of success in propagation were best at Malta, where the plant known as Palma Christi is abundant, and where it would be a great acquisition to the poor but industrious population of that island, in which expensive attempts to introduce the mulberry have wholly failed on account of the poverty of the soil. In carrying out the new plan proposed, Sir William Reed, the governor of Malta, lent his aid, and, after a series of trials and failures continued for more than two years, a successful result was attained. - From Malta, eggs have since been sent to Piedmont and Southern Italy, Egypt, and most parts of the Mediterranean.

Mr. G. W. Kendall, in writing to the New Orleans Picayune, from Paris; gives the following additional information respecting this new silk-worm. He says: It appears this new species of silk-worm (which is a native of China) can live in Europe, and can thrive not only on the leaves of the Palma Christi, but on lettuce. and weeping willow, and even wild endive, and reproduces itself several times in the course of the year. The name' given to this new species of the silk-worm is the Bombyx cynthia. Everybody is familiar enough with the silkworm (thanks to the morus-multicaulis fever!) to know that the silk in which the worm entombs himself is composed of an uninterrupted thread, which, in turn, consists of twin tubes laid parallel by the worm in the act of spinning, and glued together by a kind of varnish

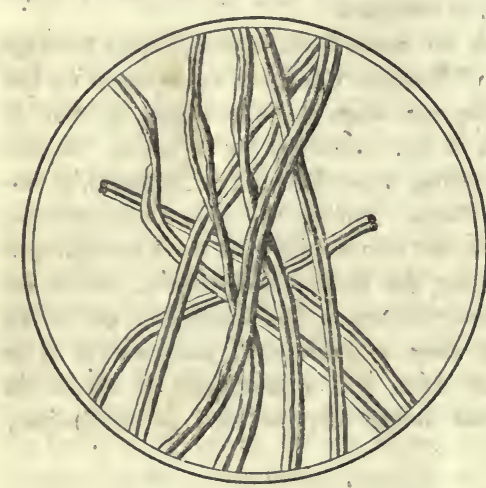
which covers their whole surface. (This appearance of a silk-thread, as seen under a microscope, is well exhibited in the annexed engraving.) The numerous windings of the cocoon-threads are also connected with a gum which is easily dissolved, allowing the silk to be readily wound upon reels, provided the worm is not allowed to pass through its chrysalis state, (which is prevented by exposing the chrysalis to a high degree of temperature.) The chrysalis pierces the cocoon, the silk cannot be wound, and it is used as floss, and is carded (as cotton, which, from the shortness of its fibres, cannot be spun until it has been carded) before it is employed.

The cocoon of the Bombyx cynthia is not entirely closed, and the chrysalis, after becoming a butterfly, may escape from its prison without injuring the value of the silk; consequently, if the cocoon of the Bombyx cynthia can be wound, the silk-grower will not be forced to sacrifice the grub to save the cocoon. This reserved aperture is defended against dangerous curiosity in a very singular manner. On the side of the grub, and through which it must come out, the cocoon is terminated in a sort of point, which is formed by the convergence of a crown of stiff, continuous threads running in such a manner as to prolong the side of the cocoon, which renders this passage impassable from the outside; while it is easily traversed by the imprisoned grub, which, as soon as he is transformed, is engaged in a sort of a hopper, (like a mill-hopper,) the sides of which are stretched wider as it moves farther on, at the same time that the "hopper" exerts, by its elasticity, a pressure favorable to development of the butterfly's newly-acquired and large wings. The stiff threads which constitute the point of the cocoon are doubled, glued, and folded on each other, so as to remain unbroken, in such a way that the cocoon remains in its integrity after the hatching and the flight of the butterfly. It is not yet known whether the cocoon can be wound; it is certain that Alcan's process (boiling) is ineffectual to dissolve the gum which unites the thread; but experiments made with an alkali and water appear to succeed. I think the cultivation of this worm may be pursued with the greatest advantage in all our sea-board Southern States.

\section{Silk in California.}

At a meeting of the California Academy of Natural Sciences, April 30, 1855, Dr. Behr exhibited a specimen of native silk, the product of the Gaturnia ceanotha, which he con- 
sidered would be equal to any of the cultivated species of the silk-worm, should proper attention be devoted to it. "He had found the caterpillar principally on the ceanothus; hence he had applied to it this specific name. The Chinese produce their silk from the Gaturnia atlas, to which species this is doubtlessly superior. Dr. Behr presented drawings of the worm in three different stages of its growth.

\section{On the Orange Insects.}

Aт a recent meeting of the Boston Society of Natural History, the following paper on the insect so destructive of late years to the orange-trees of Florida, compiled from the notes of the late Dr. Burnett, was read by Dr. A. A. fould:-

Dr. Gould observed, that during the winter' of 1853-4, the last which Dr. Burnett spent in Florida, he undertook, among other researches, to investigate the structure and natural history of the orange insect. This is a minute insect of the Coccus tribe, which, within a few years, has so invaded the orange-groves as almost totally to destroy them. The essay commenced by him was left in a very imperfect state; and it is conjectured that he had prepared other materials, so as to illustrate his paper with delineations in detail, but which are either in other hands or have been lost.

For the execution of his purpose, Dr. Burnett visited a place called Mandarin, formerly of considerable wealth, where, it is said, twenty vessels might at once be sometimes seen loading, but now in ruins. In 1837-8, Mr. Robertson carried to that place from New York two small orange-trees, about two feet in height, bearing fruit about the size of an egg, with the insect upon them. The first year it was not known what they were, but in three years they had spread over the whole point. The annual yield at this time was about $1,500,000$ oranges, worth about $\$ 10$ a thousand. The orange-growers reported that the orange insect would spread during July and August to the prickly ash. Dr. Burnett did not observe this, but noticed the same insect on the lemon.

The insect has eight segments, besides the triangular head-piece. The females are from 2'sth to $\frac{\text { d }}{2}$ th of an inch in length.. They usually contain from eight to fifteen eggs, the development of which continues all winter. The males are from $\frac{1}{35}$ th to $\frac{1}{30}$ th of an inch in length, and are winged. The wings lie, over each other horizontally on the back when at rest. They are two only, but.behind/them are halteres, consisting of a single joint, with a process curved like a shepherd's crook. The wings consist, as usual, of flattened cells. The. legs have the middle pair shortest; tarsus, one-jointed; abdomen, rounded, (eightjointed,) with a teat-like process at the end, from which extends a long stile, composed of two semi-canals. The mouth and oral apparatus is rudimentary, though the antennæo are ten-jointed and highly developed. The internal organs of nutrition are deficient or rudimentary in this respect, corresponding with the oral parts. The eyes are four, two on each side; the eye proper is oval, situated laterally, and consisting of a solid body, $1 \frac{1}{\delta 0} \delta$ th of an inch in diameter, perfectly structureless, imbedded in a dark-red pigment, and covered with a thin cornea. The accessory eyes are anterior and lateral from the others, and of the same structure. The young, when excluded, are not fully formed, but remain under the shield of the mother until developed and able to crawl away; but as she may move along during oviposition, the embryos may be found behind or around her. The fact, that one side of a leaf is frequently found covered with the scales of males almost exclusively, would seem to favor the idea that they are produced as a distinct brood; and another fact, also, that among a hundred specimens, old and young, examined during the winter, almost all were females, and only, by chance, was one male found to be near.

\section{On the Protection of the Plum-Tree.}

A CoRrespondent of the Country Gentleman, writing from Western Massachusetts, gives the following details of his successful experience in cultivating the plum. He says: I attribute my success mainly to an hereditary strain of Yankee principle, producing a strong 
propensity to use a jackknife. My trees are mostly grafted on to, suckers of the native or wild plum, near or at the surface of the ground. The scions take well in such stocks, and grow strong, frequently from four to seven feet in a season. In the spring of the first year, I cut back to two or two and a-half feet, and each spring following from one-third to seveneighths of the last year's growth. This causes them to grow stocky, with low, bushy heads, and to set thickly with fruit-spurs. I have trees in different varieties of soil: some in cultivated, some in grass land. All do well. I manure with what is most convênient, without regard to kind or quantity.

The great enemy of the plum-tree is the black knot. Now comes the grand questionBlack knot, what is it? Is it a disease or the work of an insect? I will endeavor to answer these questions according to my observations. I consider it to be the work of an insect, with which $I$ have no personal acquaintance except in the maggot state.

From frequent observation, combined with practice, I find that June is the time to look for the enemy. There are no black knots then of this year's growth, but simply swellings upon the branches. Now use your jackknife, and you are sure of your foe. When these swellings first commence, so as easily to be found, the insect is the exact color of the excrescence, and so small as usually'to escape detection. Nevertheless he is there. From the middle of June to the 1st of July they are easily found, generally two in a knot, varying from one-twentieth to three-eighths of an inch in length-the largest; in the mean time, are leaving their cells. I have found them near by, sheltered by the rough bark, covering themselves with a thin silk-like web. To all who wish to raise plums, I would say, here lies the secret. Cut green knots instead of black ones. By following this practice, I have succeeded in raising very fine trees-not a black knot is ever seen on them. A swelling is occasionally found, but it is taken in time to secure the maggot. By this means the insects are reduced to that degree that my trees never, suffer thereby. I have trees from four to six years from the graft, from eight to ten feet high, with large, spreading heads, bearing the first season from one to more than two bushels per tree of most splendid fruit.

In regard to the curculio, the following is my experience: Among all the remedies heretofore published, only one has secured the design intended. I do not say that most or any of them are "humbugs," but that the curculio is a "hum-bug" in spite of them. I have tested, and I think fairly, lime, ashes, plaster, sulphur, cotton-all without avail. I do not doubt the sincerity of those giving the above remedies; but think they must have been deceived; that the curculio was not there at all, or in numbers so small as not seriously to effect damage. It requires but little. observation to convince any one that insects of all descriptions migrate from place to place, overrunning one vicinity, and vacating another in close proximity, or even one or more trees of a garden, while others are not infested at all. I know not what any one has, or what else may be, discovered, but so far with me jarring is the only remedy that has had the desired effect. Either the curculio here is not so sensitive or not so well behaved as in other places, for he seems determined to yield to nothing but death. Therefore I would advise those who wish to be sure of their plums, to commence as soon as they are fairly set, jarring on to sheets, and killing, once a day (at noon) for two weeks. This has with me secured a bountiful crop.

At a recent meeting of the New York Farmers' Club, Prof. Mapes stated that he practised this year jarring off the plums in the early part of the season that were bitten, all of which were burned; and thus he so far destroyed the curculio that he has had large quantities of the finest plums.

Dr., Underhill stated, that he planted his plum-trees in such a manner that they hang over water, and was not troubled with curculio in the slightest degree. "Upon 150 trees thus planted, I have never found a single curculio. The trees are 'set in the bank of an artificial pond, at an angle of $45^{\circ} . "$

Dr. Underhill further stated, that his plan to get rid of the trouble of caterpillars " is to cut down every wild cherry-tree about my place. Some preserve these trees for the worms to breed upon. It is an error. They are the great breeding places of all caterpillars that are destructive to fruit. My opinion is, that every wild cherry-tree should be exterminated."

Mr. Henry Croft, of the Toronto Horticultural Society, recommends the use of sulphu- 
retted hydrogen, as evolved from the hydrosulphide of ammonium, as a preventative against the attacks of the curculio. So far as it has been tried, it appears to act as a complete remedy. It is applied as follows: A few ounce phials, with open mouths, suspended from the limbs of the tree, are filled with the liquid hydrosulphide diluted with water; in a very few days, as the strength of the solution diminishes by exhalation, add an additional quantity of liquid. Hydrosulphide of ammonium, it is scarcely necessary to add, is exceedingly cheap. A solution of hydrosulphuric acid, which is still cheaper, would undoubtedly answer the same purpose.-Editor.

A correspondent of the Horticulturist states that the plan of covering the ground beneath the trees with fresh horse-manure when the fruit is beginning to form, has successfully prevented the attacks of the curculio. I have been told of others, he says, who have succeeded in saving their plums, by hanging bottles of pyroligneous a cid, creosote, chloride of lime, etc. in the trees. From this we are led to infer that strong, pungent odors are not agreeable to the apparently sensitive olfactories of the insect. The only difficulty that appears here is, that preparations of this character are very volatile in their nature, and soon become exhausted, and it is troublesome and expensive to renew them often. This objection, however, I think is obviated in the following plan, which has proved eminently successful the past season. It is this: As soon as the fruit is as large as peas, take a common paintbrush or any other brush, or a woollen rag, and some fish-oil, and cover all of the principal branches and trunk of the tree with the oil.

The Horticulturist also states, that Mr. John Brush, of Brooklyn, has saved the plums on a number of trees, the present season, by binding bunches of tansy upon the limbs in several places. The fruit upon the trees thus treated ripened to perfection, while that near by, not thus protected, was entirely destroyed by the insects.

At a recent pomological meeting at Cincinnati, Mr. Kelly stated that several fruit-growers in that vicinity had tried the following recipe for preventing the destruction of plums by the curculio, with great success. - It is also an effectual remedy for mildew on grapes:

Put half a pound of sulphur and onẹ pound of fresh lime into a tight barrel; then fill up with boiling water, and cover closely for ten or twelve days, when it will be fit for use. This forms hydrosulphite of lime, and has an unpleasant odor which is offensive to insects, but the liquid is not injurious to vegetation. It is used by sprinkling the trees or vines with a garden-engine or syringe, repeating the application every three or four days, or oftener if showers occur to wash off the material.-Ohio Cultivator.

Description of the Curculio. - We make the following extract from the report of Mr. Townsend Glover on the curculio, which will be published in the forthcoming agricultural report of the Patent Office:

"The plum-weevil, or curculio, (Rhynchanus nenuphar,) is one of the most destructive insects that the horticulturist has to fear, not to plums alone, but to cherries, nectarines, and apples, which are indiscriminately attacked; and in the more Southern States peaches also suffer much from the larvæ of a weevil of this kind, of similar habits and shape, if not identically the same. The perfect curculio is about two-tenths of an inch in length, of a dark brown color, with a spot of yellowish white on the hind part of each wing-case. The head is furnished with a long curved snout or bill, with which it is enabled to bore into the unripe fruit by means of jaws placed at the end of this bill. The wing-cases, which are ridged, uneven, and humped, cover two transparent wings, by which the perfect weevil is enabled to fly from tree to tree; but when these wing-cases are closed, the back appears without any suture or division, which has led to the very erroneous idea among farmers that the insect cannot fly. When disturbed or shaken from the tree, it is so similar in appearance to a dried bud that it can scarcely be distinguished, especially when feigning death, which it always does when alarmed. As soon as the plums are of the size of peas, the weevil commences the work of destruction by making a semicircular cut through the skin with her long, curved snout, in the apex of which curve she deposits a single egg. She then goes to another plum, which is treated in a similar manner, until she has exhausted her whole stock of eggs. The grubs, which are hatched by the heat of the sun, immediately eat their way to the stone in an oblique direction, where they remain gnawing the interior until the fruit is 
weakened and diseased, and by this treatment falls from the tree. The grub, which is a small, yellowish, footless, white maggot, then leaves the fallen fruit, enters the earth, changes into a pupa, and in the first brood comes to the surface again, in about three weeks, as a perfect weevil, to propagate its species and destroy more fruit. It has not yet been decicied whether the latest generation of the weevil remains in the ground all winter in the grub, or in the pupa state. 'Dr. E. Sanborn, of Andover, Massachusetts, asserts, however, that the grubs, after having entered the earth, return to the surface in about six weeks as perfect weevils, which must remain hidden in crevices until spring. The most popular opinion is that they remain in the larva or pupa state. The worm or grub is often found in the knots or excrescences which disfigure and destroy plum-trees,' and has been wrongfully accused of being the cause of these swellings; but it is highly probable that the weevil, finding in the young knots an acid somewhat similar to that of the unripe fruit, merely deposits its eggs therein as the nearest substitute for the real plum.

"Some of the remedies recommended for preventing the ravages of these insects are absurd, such 'as tying cotton round the trees in order to prevent them from ascending, when it is known that they are furnished with wings, and fly from tree to tree with the greatest ease. Among the remedies at present in use, one is to cover the fruit with a coating of whitewash, mixed with a little glue, applied by means of a syringe; another is to spread a sheet upon the ground under the tree, and then jar the principal branches suddenly with a mallet covered with cloth, so as not to bruise the bark, when the perfect insects will fall into the sheet and feign death, and may be gathered and destroyed. Hogs are sometimes turned into plum-orchards, where, by eating the fallen and diseased fruit, they materially lessen the evil. Coops of chickens are placed under the trees, and the branches often shaken; the insects fall, and are eagerly seized and devoured. All fallen fruit should be gathered up several times in the course of the season and burned, or given to hogs, or destroyed in some other way. By so doing, thousands of the grubs which have not yet left the plums are destroyed; but, as yet, no thoroughly practical remedy has been made public, and the above are merely mentioned as being useful in small gardens containing only a few trees."

\section{Camphor vs. Pea-Bags.}

A correspondent of the "Horticulturist" says:

"Four years ago, last spring, my seed-peas were more than half destroyed by bugs, the largest and best varieties being most injured. The summer following, I had boxes made, one for each variety, with a cover; and when the peas were gathered, I put into each box with two quarts of peas, from six to eight bits of gum-camphor the size of a large pea, and mixed them together, and closed the box. The next spring there was not a pea injured. I have pursued the same course every year since, and have not had one pea affected by bugs."

\section{The Wheat-Weevil.}

AT a recent meeting of the N. Y. State Agricultural Society, the following remarks relative to the wheat-weevil, were made by Dr. Fitch, of N. Y.:-

It appears that this insect, has long been known in England, but is not found in France. It appears strange that they should have found their way across the Atlantic, and not across the Channel. They were found in Vermont in 1820. ' It has since extended, with the strides of a giant, over the country. Lașt year it reached Indiana, and did great damage to the wheat crop. It is estimated that the injury done the wheat crop in New York State the past year, at $\$ 2.18$ per bushel, exceeds fifteen million dolląrs.

No doubt when we know the habits, etc. of the wheat-weevil, we shall be able to destroy it. The insect deposits its eggs the last of May. Just before harrest some of the insects leave the ears of wheat and descend into the ground. The others remain in the grain and may be easily destroyed. If we could discover some means of destroying those which are in the ground, we might hope soon to stay the ravages of this insect. In Great Britain the wheatweevil is kept in check by a parasitic insect. This parasite is not found in this country. We 
have imported the weeril, but not its destroyer. Can we not bring this parasite across the Atlantic? This certainly appears to be the most feasible plan of destroying the weevil. The lecturer then expressed his intention of endeavoring to obtain this parasitic insect. "We trust he may succeed.

\section{How to clean Animals and Plants of Vermin.}

M. RAsparr, the eminent French chemist, gives an account of a plan for destroying vermin on animals, and also on trees and plants. The process he recommends is tó make a solution of aloes, (one gramme of that gum to a litre of water,) and by means of a long.brush to wash over the trunks and branches of trees with this solution, which will speedily, he says, destroy all the vermin on them, and effectually prevent others from approaching. In order to clean sheep or animals with long hair, they must either be bathed with this solution, or be well washed with it. The writer mentions several trials which he made of the solution with the most complete success, and very strongly recommends it to general use.

Mr. E. S. Mygott, in the "Germantown Telegraph," recommends an infusion of quassia, applied cold, as a means of freeing plants and trees of lice and other.insects.

\section{The Apple-Borer.}

THe impression has been prevalent, especially at the West, that little need be feared from the apple-borer. And for this reason among others, this apparently insignificant insect has been stealing a march on us which has resulted in great-damage. We learn from different quarters that its ravages have been terrible. If these things are so, our readers will permit us-to make a few remarks on the natural history of the borer, and on some other matters which may throw light on the best mode of resisting its attacks:-

What is the berer?-The borer is the larva or grub which is hatched from the egg of a beetle, belonging to the family of Buprestidø or Buprestians. The beetle itself is about half an inch long, with brown and white stripes, and flies at night.

When does it lay its eggs? - In the latter part of May, and first part of July, it pierces the bark of the tree with its spear, and deposits its eggs under the bark. This it does near the root of the tree, in perhaps the greater number of cases, especially in small trees. Indeed, some writers, whose observations seem to have been confined to one or two classes of operations performed by the beetle, state that it deposits its eggs only at the root of the tree. This is a mistake. We have dug them within the last few weeks from all parts of the trunk, from the ground to the branches; they seem to have a special liking for those parts of the tree which are decayed. On the south-west side of the tree, where the sun has scorched the bark or the wood beneath, also where the bark has been bruised by cattle or in any other way, also where the tree is naturally weak and shows signs of early withering and death-wherever any or all of these inducements are offered, the beetle seems quite ready to accept the invitation and make its investment. Let no one imagine, therefore, that his trees are free from the borer, because he finds none about the roots; let him examine all parts of the trunk carefully, and especially the weak, wounded, or decayed parts. He may find them in any of these portions of the tree.

Appearance of the grub, and way of doing its work. -The egg seems to be hatched by the natural warmth of the season. The appearance of the grub is the following: It is whitish in color, with large head and body, whose diameter is about half that of the head, and whose length is about four times that of the head; its general shape resembles that of a tadpole. We have seen. them of different sizes, from half an inch to more than an inch long. Their ravages are committed in getting their food, which is the inner bark of the tree and the tender wood. Sometimes they feed on the solid wood, especially in small trees. They are furnished with a strong pair of jaws, with which they eat their way along, leaving behind them a thin track of powder, like sawdust; they may be easily followed by these signs when they confine their operations to the surface-wood. They may remain in the tree several years before they emerge in the form of the beetle; for it is in the tree that they get their entire 
growth. In small trees they often penetrate to the very heart of the trunk, and seem to burrow there for the winter.

How have they found their way to our orchards? - They seem to follow the progress of improvement, and to keep pace with the planting of trees and shrubbery of all kinds. They appear to go from the older portions of the country to the more newly-improved regibns, making a few miles' progress every year; we are inclined to think that they can spreas quite rapidly by the transportation of young trees from distant nurseries. It behooves us to look well to the trees we buy; we do not know certainly 'that nurserymen can detect the presence of the grub in all cases, but we think it can be ascertained whether the tree has been stung.

How shall we resist the borer? - In all ways; no one thing will do the whole work; under the head of prevention, we would suggest several things:

1. Buy none but sound trees; sound, we mean, in every sense; trees of vigorous growth, of fine roots, of unbroken bark, and that never have been stung by the beetle.

2. After setting the trees out carefully, protect them from the attacks of the beetle by washing them with the following preparation: To two quarts of soft-soap add half a pound of sulphur, and dilute the mass till it is as thin as paint, by pouring in strong tobacco-water. The tobacco-water may be prepared by breaking up fine two ounces of strong tobacco, and pouring on two or three quarts of soft warm water, and letting. it stand two or three days before the wash is made; apply the wash with an old broom freely to the trunk and lower branches, after the rough bark has been scraped off. Make one application about the middle of May, and another about the first of June. It is said the beetle will not.touch a tree that has thus been treated.

3. Before the weather becomes very hot, we think the trees should be well whitewashed with lime; or protected from the sun by a board or by wrapping a wisp of straw or hay round the portions most exposed to the heat. White does not absorb heat as darker colors do. If the trees are whitewashed, or one of the other covers for the young trees are used, very few; we think, will be injured; always supposing that the preventives mentioned first are faithfully employed.

4. A little circle of ashes should be placed at the root of the tree close around the collar, This, it is believed, will prevent the beetle from disturbing the tree at that point, if it be done early enough in the season.

How shall we destroy the borers we have? - In the case of trees that have been seriously injured, we can say nothing better than that they should be pulled up, root and branch, and the part that contains the grubs destroyed. If they have been but little hurt, the grubs should be carefully extracted and killed, and the wounds covered with grafting-wax or shell-lac, and the tree washed as above suggested. - If young trees have been much punctured, we believe they had better be destroyed at once. It will be of little use to try to save them; and if they do live, they would be weak and nearly worthless. We repeat that the trees already infested should be treated with the wash mentioned above, after the grubs have been taken out. This would, it is hoped, prevent their return.-Ohio Farmer.

\section{Prevention of the Weevil.}

THe following plan for the prevention of the weevil is said to be adopted with success by farmers in Vermont: The season after it makes its appearance, they go through their wheatfields about the time the wheat is heading, immediately after a shower, or while the dew is on it, and scatter newly-slaked lime broadcast, so that it will adhere to the heads and stems of the grain. They use about a bushel to the acre. Good lime should be secured, and slaked by sprinkling a little water over it, so as to retain all its strength. A paddle may be used in scattering it. The remedy has, it is said, been so effectually tried, as to leave no doubt of its sućcess. The "Akron Beacon" (Ohio) also states that the plan has proved an efficient remedy, during the past season, in the county of Muskingum, Ohio. 


\section{Anrioultural statistict.}

\section{The Agricultural Productions of the United States for the year 1855.}

Is preparing the following estimates of the various agricultural productions of the United States for the year 1855, the information given has been obtained from many different sources. While the estimates of those best qualified to judge concerning the specific quantities produced differ to a wide extent, all authorities agree that the harvest, taken as a whole, has been one of unparalleled abundance in all sections of our country.

Statistics of the Wheat Crop for 1855. - The lowest estimate published of the wheat crop of 1855 is that of the Cincinnati Price Current, which computes the aggregate of the fourteen leading wheat-growing States at one hundred and fourteen millions five hundred thousand bushels. The next important estimate, published in the New York Herald, computes the aggregate of the whole country at one hundred and sixty-eight millions five hundred and seventy-two thousand bushels; and is less than that of the New York Courier and Enquirer, which estimates a maximum of one hundred and seventy-five millions. The estimates, however, which seem to us as most reliable, are those published in the New York Times, by Charles Cist, Esq., well known for his statistical information and correct judgment. Mr. Cist, after the most careful study and examination of the subject, gives as his opinion that the wheat crop of 1855 , in the United States, will reach, at the very least, the enormous amount of one hundred and eighty-five millions of bushels. The wheat crop of 1839-censu's of 1840 - was an ordinary crop, and a product of eighty-four millions eight hundred and twenty-three thousand two hundred and serenty-two bushels. That of 1849 -census of 1850 $\rightarrow$ deficient crop, yielded one hundred millions four hundred and eighty-five thousand nine hundred and forty-four bushels. How great that deficiency was in one State (Ohio) may be judged by the fact that, under a greatly-increased breadth of cultivation, the crop of 1849 fell short of that of 1839 more than two millions of bushels.

The following table exhibits the returns of the wheat crop in the fourteen leading wheatgrowing States, as given by the census of 1850 , and the comparative estimates of the Cincinnati Price Current, the New York Herald, and Mr. Cist in the New York Times :-

\begin{tabular}{|c|c|c|c|c|}
\hline & $\begin{array}{c}\text { Census Reports } \\
1850 .\end{array}$ & $\begin{array}{l}\text { Cincinati } \\
\text { Price'Current. } \\
1855 .\end{array}$ & $\begin{array}{l}\text { Herald. } \\
1855 \text {. }\end{array}$ & $\begin{array}{l}\text { Cist. } \\
1855 .\end{array}$ \\
\hline Ohio. & ...14,487,000.. & (16,000,000 ... & $25,000,000$ & $40,000,000$ \\
\hline Pennsyl & vania...................... & & & \\
\hline Virginis & $\ldots \ldots \ldots \ldots \ldots \ldots \ldots \ldots \ldots \ldots \ldots \ldots \ldots \ldots \ldots \ldots \ldots \ldots \ldots \ldots, 212,000 \ldots \ldots$ & $\ldots 12,000,000 \ldots$ & - & . \\
\hline New Yo & 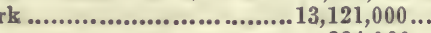 & $\ldots 15,000,000 \ldots$ & $.16,000,000$ & $\ldots 15,000,000$ \\
\hline Alabam: & 294,000 & $\ldots \quad 500,000 \ldots$ & 700,000 & ... 1,500,000 \\
\hline Illinois. & . & - & - $23,000,000$ & -...20,000,000 \\
\hline Indiana & . & . $10,000,000$ & $.19,000,000$ & ....15,000, \\
\hline Iowa.... & . & .• $2,500,000$ & .. $3,000,000$ & ... 5,000,000 \\
\hline Kentu & $y \ldots \ldots \ldots \ldots \ldots \ldots \ldots \ldots \ldots \ldots \ldots \ldots \ldots, 2,142,000$ & . $3,000,000$ & .. $3,500,000$ & ... 6,000 \\
\hline Marylar & d............................... 4,494,000 & $4,000,000$ & $\begin{array}{l}.0 \\
5,000,000\end{array}$ & .. 5,50 \\
\hline Michiga & 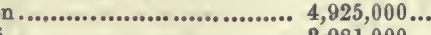 & ... 6,000,000. & .. $7,000,000$ & ...99,000 \\
\hline Missour & .................. 2,981,000. & ... 4,000,000 & .. $5,500,000$ & ... 6,00 \\
\hline Tenne & ................... 1,619, & ... 3, & 0,00 & 6,00 \\
\hline & (n) & • $\cdot, 000,000$ & $9,000,000$ & $. .11,000,000$ \\
\hline & Total ..........................92,086,000 & $114,500,000$ & $\begin{array}{r}156,700,000 \\
11,872,000\end{array}$ & $\begin{array}{r}171,000,000 \\
14,000,000\end{array}$ \\
\hline & Total.............................100,468,000 & & $168,572,000$ & $185,000,000$ \\
\hline
\end{tabular}


The following table gives the production of wheat in the other States and Territories, according to the census of 1850 , and according to the estimates of the Herald for 1855 :-

\begin{tabular}{|c|c|c|}
\hline \multirow{3}{*}{\multicolumn{2}{|c|}{ rkansas }} & shels of Wheat. \\
\hline & & . 1855 . \\
\hline rkansas & & 300,000 \\
\hline ....................... & 17,000 & $\begin{array}{r}20,000 \\
20,000\end{array}$ \\
\hline .................. & 41,000 & 50,000 \\
\hline , & & \\
\hline$\ldots \ldots \ldots \ldots \ldots \ldots \ldots$ & 1,000 & 2,000 \\
\hline 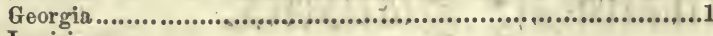 & & . $1,200,000$ \\
\hline$\ldots$ & - & ......... \\
\hline & & \\
\hline & & .......... \\
\hline .............. & 137,000 & ........ 200 \\
\hline Non. & & \\
\hline & & \\
\hline ......... & & . \\
\hline .............. & & \\
\hline & & \\
\hline & 41,000 & \\
\hline & 535,000 & \\
\hline ........ & 1,000 & ......... \\
\hline & 196,000 & \\
\hline & & \\
\hline & 107,000 & .......... \\
\hline & - & ........ 20 \\
\hline 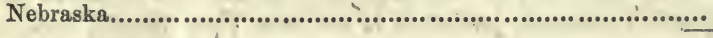 & - & - \\
\hline 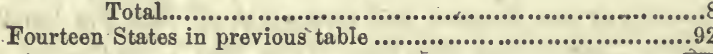 & 2,000 & 200 \\
\hline & & \\
\hline
\end{tabular}

In comparing the estimates as given by Mr. Cist with those of the New York Herald, and also with those of the New York Courier and Enquirer, (leaving out of consideration those of the Cincinnati Price Current, as far below the truth,) it will be seen that the principal element of difference consists in the estimate placed upon the crop of Ohio. Making this the same for each estimate, and the aggregates differ but little. In regard to the estimate of Mr. Cist, he says: I consider Kentucky, Alabama, and Tennessee entitled to the estimate given by me, not less on account of the favorable season, but because, in 1839, they yielded respectively four millions eight hundred and three thousand one hundred and fifty-two, eight hundred and thirty-eight thousand and fifty-two, and four millions five hundred and sixty-nine thousand six hundred and ninety-two. For the old States of Maryland, Virginia, New York, and Pennsylvania, which have formerly been the principal sources of supply for wheat, my estimate is not greatly above that of the Price Current, and is less than that of the Herald. It is in the great wheat-growing States of 'Ohio, Illinois, Indiana, Iowa, Michigan, Wisconsin, and Missouri, which, great as is their aggregate, has far from developed their productive capacity, that the great difference between my estimate and that of most others consists. And my estimates of those States differ little in the aggregate, except as relates to Ohio, from those of the Herald. Our difference upon Ohio, and his short allowance for California and Texas, would about make up the difference of our 'general aggregate. And now for Ohio. My estimate of its wheat crop, for 1855, of forty millions, will, doubtless, startle many persons, and discredit my judgment with yet more. Why I should exceed by 150 per cent. on this point the figures of other business men in our City and State, is well calculated to inspire suspicion, surprise, and distrust. The wheat crop of Ohio was, in

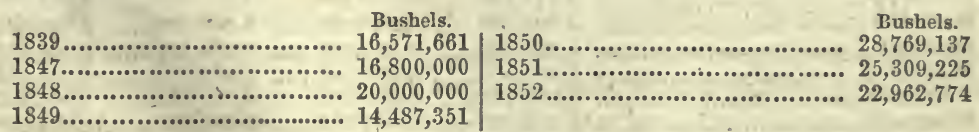

The figures for 1839 and 1849 are taken from the United States Census of 1840 and 1850. Those for 1847 and 1848 will be found in the Patent Office Agricultural Reports for those years. The figures for the three later years are taken from the official returns in the office of the auditor of the State of Ohio. The exhibit of 1850, although the largest on the list, is 
short fourteen counties, which neglected their return. These counties, calculating on the basis of their product of 1851 , produced in $1850,2,978,116$ bushels, making the true aggregate of that year $31,747,255$. With our increase in ground opened and sowed in wheat for the past five years, the stimulus of high prices in prospect under foreign demand, and the great productiveness of the season itself, I am persuaded that I do not put the increase of the present crop too high at $8,252,745$ bushels-which would give the aggregate I claim for Ohio, of forty millions.

The truth is, that all the important facts as regards the quantity of wheat this year, lie in a narrow compass. The seven States I have referred to furnish largely more than half the entire wheat crop of the country, while their surplus is nearly the entire surplus of the United States-the residue of the States affording little more than the home supply throughout themselves. Hence, if we know the increased crop of these States, we substantially know what the aggregate increase of the whole crop is. Upon the question "What will be the surplus of the wheat crop in the United States for 1855?"' Mr. Cist adds the following remarks, which will be found to contain important and valuable information:- " This question is not one of ready solution, because that surplus is as elastic as India-rubber. It depends entirely on circumstances. If Europe wants wheat or flour from us, and is obliged to pay, as lately, high prices, it is difficult-to limit our surplus." Unless her harvests fail to an extraordinary degree, we have enough to supply all her wants. Paradoxical as it appears, the more she wants the more we have to spare, and the less she wants the less we shall have for export. If she wants none, we shall have none for export. The surplus will, in that case, be used freely at home, and beyond that use, what is not required for seed will be stored away for the next season's sale for home or foreign consumption. If, on the other hand, high prices rule, less wheat will be used at home. Indian corn, potatoes, \&c. will take its place exten'sively, and the shipments of wheat and flour to Europe of this year's crop surpass for quantity all precedent. For the purpose of illustrating my views, I submit a table of our annual product of wheat since 1839, together with our exports of the article from same date:-

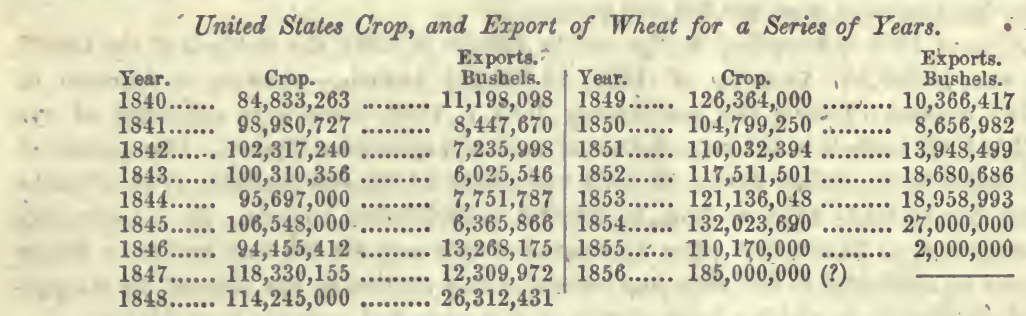

"The years given above are taken of the export, not of the growth, being of course one year later-the fiscal year of the United States ending June 30 . Thus, for example: the crop of $110,170,000$ bushels, set down against 1855 , refers to that harvested in 1854 ; and the $2,000,000$ bushels exported in 1855 , or up to June, 1855 , is from the crop harrested in 1854.

"The export figures for 1854 and 1855 are obviously approximations merely; and although I would not hold myself responsible for the absolute accuracy of the export returns, I doubt not that they are substantially correct. They prove two or three important facts. It is obvious by this table that the quantity of wheat exported from the United States is entirely independent of the amount of the existing crop. Thus, the exports of 1848 and 1854 are in quantity double those of 1847 and 1849 , although the product of the first-named years did not exceed those of the last two. The exports of 1840 and 1846 also doubled those of 1843 and 1845, although their crop was not as abundant by fifteen per cent. The exports of 1852 and 1853 , on a crop of less than $239,000,000$ bushels for both years, were more than $37,500,000$ bushels, while the exports of 1842 and 1844 , on a crop of nearly $200,000,000$ bushels, hardly reached fifteen millions. In all those years it was the foreign demand, stimulating high prices here, which enhanced the export, as it was the absence of that cause which diminished the exports of others. If the foreign demand did not enlarge the export of 1855 , 
it was not because the wheat crop had failed to any great extent, but because the drought of 1854 had so cut short the supply of corn, potatoes, \&c., as to compel a larger use of wheat than would otherwise have taken place."

Accepting the estimate of Mr. Cist as the correct one, wiwe have as the value of the wheat crop of 1855, at a dollar and a quarter per bushel, an aggregate of more than two hundred and thirty-one millions of dollars.

Statistics of the Crop of Indian Corn for 1855,-Abundant as has been the crop of wheat in the United States for 1855 , it is but one iten of our agricultural productions, and not the largest. The great staple crop of the United States is Indian corn, which, during the past season, has furnished the largest crop ever gathered. The amount, according to Mr. Cist, cannot be less than $1,000,000,000$ of bushels, and may exceed these figures by 20 per cent. By the census returns, the corn crop of 1839 was $377,531,875$ bushels; that of 1849 , $592,071,104$, showing an actual increase in ten years of $214,539,229$ bushels, or 58 per cent.

From returns made to the auditor's office of Ohio, we have the following statistics of the corn crop in that State for 1851, '52, and '53:-

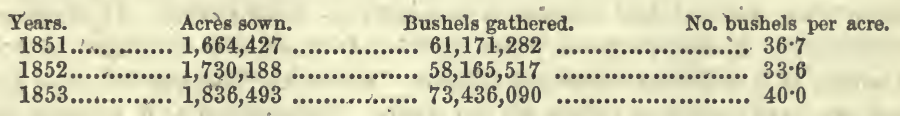

The exports of corn from this country, including corn meal, at different periods, have been as follows:-

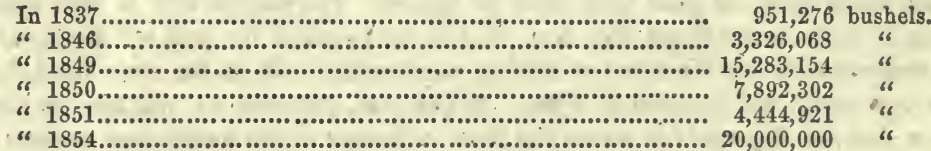

The value of the corn crop of 1855 may be safely estimated at $\$ 400,000,000$.

Oat Crop of 1855.-The estimate of the oat crop of the United States for 1855 has been given by Mr. Cist as at least 400,000,000 bushels.

Rye.Crop of 1855.-According to the census returns of 1840, the product of the United States was $18,645,567$ bushels; of $1850,14,188,813$ bushels,-showing a decrease of $4,456,744$ bushels. During the year ending June 1,1850 , there, were consumed of rye about $2,144,000$ bushels in the manufacture of malt and spirituous liquors. The amount of rye cultivated in the United States in 1853 was about $14,000,000$ bushels. The estimate for 1855 may be safely fixed at from $16,000,000$ to $18,000,000$ bushels. Some authorities estimate as high as $20,000,000$. The diminution of this crop for the last twelve or fifteen years may be attributed in the main to a corresponding decline in the demand for the purposes of distillation, to which a large portion of this grain had annually been applied.

Rice Crop of 1855 . - The rice crop of 1840 was returned by the census at $80,841,422 \mathrm{lbs}$;; of $1850,215,313,497 \mathrm{lbs}$. The crop of 1855 cannot be less than that of 1853 , which was estimated at 250,000,000, and in all probability exceeds it.

Barley Crop of 1855. - The annual production of this grain, according to the census of 1840 , was $4,161,504$ bushels; in $1850,5,167,015$ bushels; estimate for $1853,6,590,000$; for $1855,7,500,000$ bushels.

Potato Crop for 1855. - The potato crop of the United States, according to the census of 1840 , was $108,298,060$ bushels; of $1850,104,056,044$ bushels, of which $38,268,148$ bushels were sweet-showing a decrease of $4,232,016$ bushels. This deficiency in the crop of 1849 , as compared with that of 1839 , is attributed to the discouragement caused by the disease. The crop of 1853 has been estimated at $106,000,000$ bushels. The season of 1855 has been mare favorable for the potato than that of any previous year for a considerable period, and the quantity planted during the past year has also been unusually large. We estimate the crop as at least $115,000,000$ bushels.

Peas and Beans for 1855. - The amount of peas and beans produced in the United States, according to the census of 1850 , was $9,219,901$ bushels. The amount raised in 1853 , exclusive of the production of market-gardeners, was estimated at $9,300,000$ bushels. Our estimate for 1855 is $9,400,000$ bushel's. 
Production of Sugar in 1855.-According to the census returns of 1840, the amount of cane-sugar produced in the United States was 119,995,104 lbs.; of 1850, 247,577,000 lbs., showing an increase of $127,581,896 \mathrm{lbs}$, , besides $12,700,896$ gallons of molasses. It was estimated that, in 1815, the cane-sugar made on the banks of the Mississippi alone amounted to $10,000,000 \mathrm{lbs}$; in 1850 , it had reached the enormous quantity of $226,000,000 \mathrm{lbs}$., besides upwards of $12,000,000$ gallons of molasses. The amount of cane and maple-sugar made in the United States in 1853-54 was estimated at 545,000,000 lbs., besides $14,000,000$ gallons of molasses and syrup. The sugar crop of 1855-56 will not exceed that of 1853-54. The production of maple-sugar in the United States for 1855 was not far from 27,000,000 lbs. The total consumption of sugar in the United States for 1854, cane and maple, has been estimated at 732,000,000 lbs.

Hemp Crop of 1855. - The crop of hemp in the United States for the past season has been below the average. The production of 1854 was 22,000 tons, while that of 1855 will not, it is said, exceed 16,000 tons. One reason for the diminished crop is to be found in the scarcity of seed. Early in the present season, an agent of the hemp-growers of the West procured in Europe several thousand bushels of choice seed, which will tend to improve the character of our domestic hemp-possibly diminish the risk of future failures of the crop.

Concerning the flax crop, no reliable data can be obtained. There is reason to believe, however, that the production is increasing yearly. The importations of Manilla hemp for the last few years have been as follows: $1851,71,566$ bales; $1852,110,258 ; 1853,102,292$. The imports for the first six months of 1855 were 27,142 bales.

Cotton Crop of 1855 . - The cotton crop of $1855-56$ is variously estimated at from $3,200,000$ to $3,500,000$ bales. The crop grown last year (1854) was a small one, amounting to $2,847,339$ bales against $2,930,027$ in 1853 , and $3,262,582$ bales in 1852.* An unusually early frost in the cotton districts, on the 7 th, 8 th, and 9 th of October, in South Carolina, will undoubtedly diminish the crop to some extent, but more cotton than usual has been planted during the last season, and the weather has also been generally favorable. It has been found that the magnitude of the crop has generally corresponded with the date at which the plants produce their first blooms in spring and the advent of frost in autumn. It is clear that the blooms or blossoms might appear in Louisiana and Florida several weeks before their appearance in Carolina or the upper sections of the cotton region. By close observation, it has been ascertained that, taking the average period at which blooms usually appear, it extends from the last week in May to the 15th of June; hence, the nearer tho blooming approaches the one or the other of these periods, in connection with early or late frost, will be the yield of the crop. Early blooms and late frosts produce large crops. Late blooms and early frost, on the contrary, produce short crops, or such is the theory. The growth of one year's crop is included in the statistics up to the 1st of September of the following year. Hence an early frost in 1852 would appear in the statistics of 1853 . In examining a table extending over a period of nineteen years, we find the earliest notice of a killing frost on the 7 th of October, 1838, when the crop was only $1,350,100$ bales. The latest date at which it appeared was on the 10th of December, 1848, when the crop was $2,000,000$ to $2,100,000$. In 1851 , no frost occurred until after the full maturity of the plant to injure it, when the crop was 2,355,000. For the nineteen years, we find an average occurrence of frost to be during the last week in October and the first few days of November.

Wine Production of 1855. - The estimated production of wine for 1855 varies from 600,000 to 750,000 gallons. $\dagger$

Hay and Grass Crop of 1855. -According to the census of 1840; the hay crop of the United States was $10,248,108$ tons; in $1850,13,888,642$ tons. The crop of 1855 has been estimated at $15,000,000$, which, at $\$ 10$ per ton, would amount to $\$ 150,000,000$.

The above estimate does not include the value of the grass crop appropriated for pasturage, which equals at least in value the hay crop, giving an aggregate value for the entire grass crop of $\$ 300,000,000$. 


\section{Pork Trade of the West, 1854--55.}

Twe Cincinnati Price Current furnishes the following 'estimate of the pork trade of the West for 1854-55:-The following table shows the number of hogs packed in the principal pork-raising districts during the packing season of $1853-54$, and $1854-55$ :

\begin{tabular}{|c|c|c|c|c|}
\hline 718,650 & 571,165 & Illinois.. & $\begin{array}{l}1853-54 \\
344,047\end{array}$ & .... 41 \\
\hline sssee........... 50,880 & 6,000 & Missouri..... & 130,025 & ..... 128,261 \\
\hline Indiana.............. 601,820 & ....... 505,830 & Wisconsin............. & 59,900 & 39,272 \\
\hline Kentucky........... 502,925 & ........ 337,799 & Detroit, Mich......... & 7,500 & 5,000 \\
\hline Iotra.................. 48,060 & ........ 102,131 & Buffalo, N. Y........ & 8,000 & 15,000 \\
\hline
\end{tabular}

Showing a deficiency in 1854-55 of 463,066 hogs.

The average weight of the hogs packed in Ohio, Kentucky, Indiana, and 'Tennessee, in 1853-54, was 208 lbs. ; in 1854-55, 1921 lbs. In other States, the average in the same years was $218 \mathrm{lbs}$. Taking these figures as the average; the crop, reduced to pounds, compares as follows:-

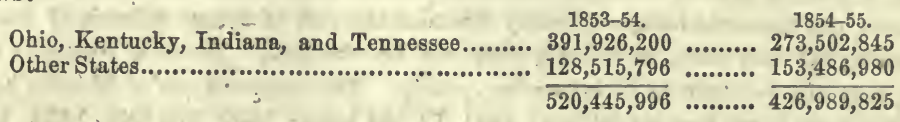

Showing a deficiency of $103,457,171 \mathrm{lbs}$, , being a trifle over 20 per cent. The increase in pounds last year over the preceding year's crop was $22 \frac{1}{2}$ per cent. The product of this season is, therefore, 20 per cent. less than that of $1853-54$, and $2 \frac{1}{2}$ per cent. greater than that of 1852-53.

According to the census returns of 1840 , there were in the United States 26,301,293 swine; of 1850 , there were $30,354,213$; showing an increase of $4,052,920$. The present number may be estimated at $32,000,000$, which, at $\$ 5$ each, would be worth $\$ 160,000,000$.

The average annual production of lard in the United States is estimated at ninety-six millions of pounds. Of this amount, twenty millions are-shipped-from Cincinnati. England and Cuba take more lard of us than all the rest of the world. Each of these countries buy over eight millions of pounds.

\section{Commerce in Animals, and Consumption of Animal Food.}

HeRETofore we have known very nearly the number of animals raised in the United States, but we have not known the number and weight of animals actually consumed in the country. But this fact is very desirable, and will prove very useful. ' It is well known that the cattle, as well as the hog trade, furnishes a very large portion of the exchanges of the country, and hence the question of how much, where, and when animal food is consumed, has a direct relation to the financial as well as commercial concerns of the country. The progress of statistics, however, gradually furnishes the materials to show this and all similar problems. The great difficulty is to find a unit of measurement for the consumption of cattle and hogs. In the cattle trade, we know that the great cities of the country are the main purchasers of cattle, insomuch that what enters into general commerce is a very small amount of what is consumed in the large towns. With hogs it is something different, for an immense amount of pork and lard enter into general commerce for exportation, especially to southern latitudes, and for the navies and armies of the world.

At present we shall confine ourselves to the supply and consumption of cattle and sheep as food; in other words, beef and mutton. For the consumption of beef we want a unit. It might have been furnished by the statistics of Smithfield Market, London, but we are not aware that they have been kept and recorded. The New York market, however, is a still better test, for the whole of our population are meat-eaters. "The aggregate number of cattle, sheep, and calves consumed in New York City, including Brooklyn, is as follows: cattle, 154,000; sheep and lambs, 470,000. We know very nearly the average weight of these animals, and the population by whom they are consumed. The average weight of the 
cattle may be taken at 750 pounds, and of the sheep and calves, 80 pounds. The population of New York and suburbs in 1854 was about 750,000. Here, then, we have the elements for the solution of the general problem. Three-fourths of the cattle, \&c. consumed in New York came from the West, beginning with the, Valley of the Alleghany in New York and Pennsylvania. Averaging the value of cattle at $\$ 70$ each, and the sheep and calves at $\$ 5.50$, at the place where first sold, we have as their aggregate value the sum of $\$ 13,365,000$.

But in respect to the general consumption of cattle in this country, the consumption of New York shows that each 1000 persons in civic population consume 205 cattle and 533 sheep per annum. This gives us the consumption of the population of the principal large towns and cities in the United States; amounting to $3,938,656$, as eight hundred thousand beeves, and two and a half millions of sheep and lambs. At an average of $\$ 50$ each for the beeves, and $\$ 3$ each for the sheep, which is not too much, we have the following result:-

Value of 800,000 beeres................................................ \$40,000,000

Value of $2,500,000$ sheep and lambs...................................... $\quad \$ 7,500,000$

Let us now add to this the hogs of commerce$3,000,000$ at $\$ 8$

Total

$24,000,000$

If, now, we add to this aggregate the pickled beef, the salt, barrels, and labor used in packing pork, and, finally, the value of wool sold from sheep, we find the commerce in animals amounting in value to full one hundred millions of dollars, - an amount greater than the entire cotton crop. Two-thirds of this entire product comes from the States in the Valley of the Ohio ; and we shall not be beyond the mark in saying that the States of Ohio and Kentucky create an exchange on the Atlantic States equal to twenty millions of dollars per annum, derived from the commerce in animals.

In reference to the avernge weight consumed, if the above number of beeves, sheep, and hogs be reduced to their aggregate weight, and then divided by four-millions, (the aggregate of town or city population,) the result will be about 15 ounces to each individual per diem. Now, the daily ration of solid meat allowed in the British navy is 12 ounces, which may be taken as the average for adults. The excess of quantity found in the above calculation will be fully accounted for by exportation to other conntries, and by the consumption of towns of less than 5000 inhabitants. The general accuracy of the above calculation is; therefore, sufficiently proved, and the magnitude of the result furnishes another illustration of the value of internal commerce.-Condensed from the Cincinnati Price Current. 


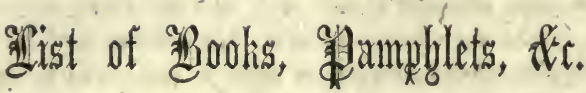

ON MATTERS PERTAINING TO AGRICULTURE, PUBLISHED, IN THE UNITED STATES DURING THE YEAR 1854-55.*

Aluen, John Frske. Victoria Regia, or the Great Water-Lily of America, with a Brief Account of its Discovery and Introduction into Cultivation; with Illustrations by WILLLAM Sharp, from Specimens grown at Salem, Massachusetts. Boston: Dutton'\& Wentworth.

Alinn, Lewis F. The American Herd-Book; containing Pedigrees of Shorthorn Cattle, with Introductory Notes. Buffalo: Thomas \& Lathrops. This work, of 650 pages, contains two thousand seven hundred full pedigrees, besides the produce of cows which are registered, and upwards of fifty portraits of living animals. Price to subscribers, $\$ 5$; to non-subscribers, $\$ 6$.

Annual Register for 1856, Illustrated. Price, 25 cents, paper; 50 cents, bound. Luther Tucker \& Sons, Albany; New York.

Bement, C. N. The Rabbit Fancier : a Treatise upon the Breeding, Rearing, Feeding, and General Management of Rabbits: 1 vol. 12mo, pp. 102. Saxton \& Co., New York:

Chandere, J. N. Scientific Exposition of the Cause and Cure of the Potato Rot.

Charlton, William. The Cold Grapery. 12mo, pp: 95. Saxton \& Co., New York.

Coxiadon, J. W. Analytical Class-Book of Botany, illustrated by a Compendious Flora of the Northern States. Pp. 228. Appleton \& Co., New York.

Cotton is King; or, The Culture of Cotton. Moore, Wilstach, Keys \& Co., Cincinnati, Ohio. Dana, Samuel L. Muck Manual. New and enlarged edition. Saxton \& Co., New York.

Darby, Professor Johv. Botany of the Southern States. In Two Parts. Part I. Structural and Physiological Botany and Vegetable Products. Part II. Description of Southern Plants, arranged on the Natural System. Preceded by a Linnæan and a Dichotomous Analysis. A. S. Barnes \& Co., New York.

Degran, J. W. Address before the Brooklyn (New York) Horticultural Society.

Downing's Landscape Gardening. New edition. Saxton \& Co., New York. Price, $\$ 3.50$.

Emmons, E., M.D. Agriculture of New York. Vol. V. 4to. State publication.

Fuint, Charles L. The Agriculture of Massachusetts, as shown in the returns of the Agricultural Societies for 1854 .

Fox, Charles. The American Text-Book of Practical and Scientific Agriculture. Elwood \& Co., Detroit.

Fruit, Flower, and Kitchen-Gardener's Companion. By Patrick Neil, F.R.S.E. Adapted to the United States, from the fourth edition, revised and improved by the Author. Edited by G. Emerson, M.D. With Notes and Additions by R. G. PArdee, Author of "Manual of the Strawberry Culture." With Illustrations. Price, \$1. Saxton \& Co., New York.

Fryatr, H. N. Agriculture: its Essentials and Non-Essentials. 8vo, pp. 60. Magagnos \& Co., New York.

Harves, B. and C. S. Catalogue of Pure Red Shorthorns, owned by;-Elizabethtown, New Jersey.

Hulls, Joriv S. The Necessity, Effects, Practice, and Profits of Land Drainage. Circular. Wilmington, Delaware. 
Horses and Mules. Saxton \& Co., New York.

Journal of the United States Agricultural Society. By William S. King, Secretary. Boston, Massachusetts.

KERN, G. M. Practical Landscape Gardening, with reference to the Improvement of Rural Residences. Cincinnati : Moore, Wilstach, Keys \& Co.

Liebig, Justus. The Relations of Chemistry to Agriculture, and the Agricultural Experiments of J. B. Lawes. Translated by S. W. Johssov, Albany, New York. Luther Tucker \& Co. Price, 25 cents.

Locke, JoHn, Dr. An Address on Agricultural Chemistry. Warren County (Ohio) Agricultural Society.

Manures: how to Make, Preserve, and Use. G. A. Tuttle \& Co., Rutland, Vermont.

Minutes of the Philadelphia Society for the Promotion of Agriculture, from its institution in February, 1785, to March, 1810.

Munv, B. The Practical Land-Drainer. 12mo. C. M. Saxton, New York.

NAsB, J. A. Progressive Farmer: a Scientific Treatise on Agricultural Chemistry, the Geology of Agriculture, on Plants and Animals, Manures and Soils applied to Practical Agriculture; with a Catechism of Scientific and Practical Agriculture. Price, 60 cents. Saxton \& Co., New York.

National Pomological Society: Proceedings of the Fifth Meeting, Boston.

Ohio Pomological Society: Transactions of the Sixth Session, Colúmbus, Ohio.

PardeE, R. C. On Strawberry Culture. Price, 75 cents. Saxton \& Co., New York.

Patent Office Report: Agricultural Department, 1854.

Remeerin, Cunrres. On the Vine. Saxton \& Co., New York.

Rurfis, Edmend. Essays and Notes on Agriculture. 12mo. J. W. Randolph, Richmond, Virginia.

SAxtox's Rural Hand-Books. Third Series. Saxton \& Co., New York.

Schexck's Gardener's Text-Book. J. P. Jewell \& Co., New York.

Thanz's Agriculture. New edition. Price, \$2. Saxton \& Co., New York.

Tromas, Johs. Old Farmer's Almanac. Hickling, Swan \& Co., Boston.

Tномаs, Joнn J. Farm Implements, and the Principles of their Construction and Use: an Elementary and Familiar Treatise on Mechanics, and on Natural Philosophy generally, as applied to the ordinary practice of Agriculture. With two hundred engraved Illustrations. Harper \& Co., New York.

Trowbridge, F. Cranberry Culture. .New Haven, Connecticut.

Wailes, Professor B. C. L. Report on the Agriculture and Geology of Mississippi.

Waring, Grorge E. Elements of Agrioulture: a Book for Young Farmers. Appleton \& Co., New York.

Weeks, John M. Manual on Bees; or an Easy Method of Managing Bees in the most profitable manner to their owner; with infallible Rules to prevent their destruction by the Moth. With an Appendix by Wooster A. Flanders. Price, 50 cents. Saxton \& Co., New York.

Wells, David A. Annual of Scientific Discovery; or Year-Book of Facts in Science and Art, for 1855. Boston: Gould \& Lincoln; Philadelphia: David A. Wells \& Co., 124 Arch Street.

Wells, David A. The Year-Book of Agriculture; or Annual of Agricultural Progress and Discovery, for 1855-56. Childs \& Peterson, Philadelphia. Price, \$1.50, Illustrated.

WetherinL, C. M. Chemical Examination of the Bakers' Bread of Philadelphia.

Wherler, Gervase. Homes for the People in Suburb and Country, adapted to American Climates and Wants; with Examples, showing how to Alter and Remodel Old Buildings. Scribner, New York.

Youatt and Martin, on the Hog. Edited by Ambrose Stevens. Mlustrated. Price, 50 cents. Saxton \& Co., New York. 


\section{Table of fruits,}

\section{RECOMMENDED BY POMOLOGICAL SOCIETIES FOR CULTIVATION IN DIFFERENT SEC- TIONS OF THE UNITED STATES}

In the following valuable table, derived from the Horticulturist, the Editor has catalogued the most popular varieties of fruits recommended by various pomological societies of the United States, for general cultivation. To each variety is affixed the several States in which they have been recommended by fruit committees, those only being enumerated which have been recommended by at least three States, the object being to exhibit a list of such as have proved successful over a wide area. As a table of reference, the Editor of the Horticulturist remarks: "It will be found valuable to all engaged in fruit-culture, or who are collecting information on the subject."

\section{APPLES.}

Baldwin-New York, Del., N. J., Vermont, New Hampshire, Maine, Ohio, Missouri, Ill. Roxbury Russet-New York, N. J., Vermont, Maine, Mich., Ohio, Missouri, Indiana, Ill. Northern Spy-New York, New Jersey, Vermont, Maine.

Rhode Island Greening-N. Y., Penn., N. J., Vt., Maine, Mich., Iowa, Ohio, Ind., Ill. Swaar-New York, Michigan, Ohio, Illinois.

Esopus Spitzenbury-New York, Pennsylvania, Vermont, N. H., Mich., Ohio, Mo., Il.

Early Harvest-New York, Pennsylvania, New Jersey, Vermont, New Hampshire, Virginia, Ohio, Missouri, Indiana, Mlinois, Delaware, Michigan, Iowa.

Sweet Bough-New York, Pennsylvania, Vermont, Maine, Illinois, Delaware, New Jersey, Virginia, Missouri, Indiana, New Hampshirè, Ohio.

Summer Rose-New York, Pennsylvania, Delaware, New Jersey, Ohio, Missouri, Illinois. Fall Pippin-New York, Penn., Del., New Jersey, Mich., Virginia, Ohio, Missouri, ml. Belmont-New York, Michigán, Ohio.

Hubbardson Nonsuch-New York, New Jersey, Vermont, Massachusetts, Maine.

Golden Sweet-New York, Maine, Missouri.

Red Astracan-New York, Vermont, New Hampshre, Maine, Iowa, Ohio, Missouri, $\mathrm{nl}$. Jonathan-New York, Ohio, Missouri.

Early Strawberry-New York, Pennsylvania, Ohio.

Danver's Winter Sweet-New York, Delaware, Vermont, Massachusetts, Maine, Ohio.

William's Favorite-New York, New Hampshire, Maine.

American Summer Pearmain-New York, Delaware, Illinois.

Summer Queen-New York, Pennsylvania, Michigan, Ohio, Missouri, Indiana, Tlinois.

Maiden's Blush-New York, Delaware, New Jersey, Ohio, Missouri, Indiana, Illinois.

Porter-New York, Vermont, New Hampshire, Massachusetts, Maine, Ohio, Missouri.

Gravenstein-New York, New Jersey, Vermont, New Hampshire, Maine, Ohio

Vandervere-New York, Maine, Missouri, Indiana, Illinois.

Yellow Bellflower-New York, Penn., Del., N. J., Vt., Mich., Iowa, Va., Ohio, Mo., Ia., Ill. Fameuse-New York, New Jersey, Vermont, Massachusetts; Maine, Mlinois.

Newtown Pippin-New York, Delaware, N. J., Mich., Iowa, Va., Ohio, Missouri, Ind., Ill. Rambo-New York, Penn., Delaware, Mich., Iowa, Ohio, Missouri, Indiana, Illinois.

Smokehouse-Pennsylvania, Delaware, Virginia, Indiana.

Fallenwalden-Pennsylvania, Delaware, Ohio.

Golden Russet-Pennsylvania, New Hampshire, Ohio, nlinois.

Winesap-Pennsylvania, Delaware, New Jersey, Ohio, Illinois.

White Bellflower-Pennsylvania, Missouri, Illinois.

Holland Pippin-Michigan, Missouri, Indiana.

Rawle's Janet-Iowa, Virginia, Illinois.

Lady Apple-Delaware, Ohio, Missouri. 
PEARS.

Bloodgood-Conn., Vermont, New Jersey, Delaware, Penn., Georgia, Ohio, Mississippi.

Doyenné d’ Eté-Conn., New Jersey, New York, Maine, Mass., Ohio, Indiana, Mississippi. Tyson-Conn., New Jersey, Penn., New York, Maine, Massachusetts, Ohió, Mississippi.

Dearborn's Seedling-Conn., Vermont, N. J., Delaware, Penn., N. Y., Maine, Georgia, Ohio. Julienne-Conn., Dęlaware, Penn., South Carolina, Ohio, Indiana, Mississippi.

Bartlett-Conn., Vermont, N. J., Del., Penn., N. Y., Maine, Georgia, Iowa, Ohio, Mo., Ind. Beurre Bosc-Conn., Vermont, New Jersey, New York, Maine, Indiana, Mississippi.

Beurre Diel-Conn., New Jersey, New York, Georgia, Ohio, Missouri, Mississippi.

Golden Beurré of Bilboa-Connecticut, New Jersey, Maine, Georgía, Mississippi.

Flemish Beauty-Conn., Vermont, New Jersey, New'York, Maine, Georgia, Ohio, Miss.

Louise Bonne de Jersey-Conn., Vt., N. J., Del., Pa., N. Y., Me., Mass., Geo., O., Ia., Miss.

Fondante d'A Automne-Conn., New Jersey, Penn., New York, Mass., Georgia, Indiana, Miss.

Seckel-Conn., Vermont, N. J., Del., Penn., N. Y., S. C., Georgia, Ohio, Mo., Indiana, Miss.

Van Mons Leon le Clerc-Connecticut, New York, Georgia.

Duchesse d'Angoulême-Conn.; New Jersey, Delaware, New York, Maine; South Carolina, Georgia,' Ohio, Missouri, Indiana, Mississippi.

Beurré d'Aremberg-Conn., Vermont, New Jersey, Delaware, New York, Maine, Ohio.

Vicar of Wakefield-Conn., Vermont, New Jersey, Delaware, Mass., Maine, Indiana.

Winter Nelis-Conn., Vermont, N. J., Del., Penn., N. Y., Maine, Georgia, Ohio, Ind., Miss.

Madeleine-Conn., N. J., Delaware, Penn., N. Y., Georgia, Ohio, Missouri, Indiana, Miss.

Andrewos-Connecticut, Vermont, New Jersey, New York, Massachusetts, Georgia.

Beurre Brown-Connecticut, New York, Georgia, Indiana.

Elizabeth-Connecticut, New Jersey, Massachusetts.

Heathcot-Connecticut, Vermont, Maine, Ohio.

Beurre Goubault-Connecticut, New Jersey, Mississippi.

Beurré d'A malis-Connecticut, Delaware, Maine, Georgia, Mississippi.

Onondaga-Connecticut, New York, Ohio.

Marie Louise-Connecticut, New Jersey, New York, Maine, Georgia, Ohio, Mississippi.

Duchesse d'Orlean's-Connecticut, Deląware, Massachusetts.

Napoleon-Connecticut, New York, Maine', Ohio, Missouri.

St. Ghislain-Connecticut, New Jersey, Pennsylvania, Maine, Georgia, Ohio.

Frederick of Wirtemburg-Connecticut, New York, Maine, Georgia; Ohio.

Urbaniste-Connecticut, New Jersey, New York, Maine, Massachusetts, Missouri.

Easter Beurre-Connecticut, New Jersey, Delaware, New York, Georgia, Ohio, Indiana.

Beurré Giffard-Connecticut, New Jersey, Pennsylvania, Maine, Indiana, Mississippi.

Doyenne Boussock-Connecticut, Delaware, Massachusetts.

Dix-Connecticut, New York, Georgia, Ohio, Mississippi.

Paradise d' Automne-Connecticut, New York, Massachusetts.

White Doyenne-Conn., Vermont, N.Y., Maine, S. C., Geo., Ohio, Mo., Miss., Penn., IIl.

Glout Morceau-Conn., Vermont, N. J., Del., N. Y., Maine, Georgia, Indiana, Mississippi.

Passe Colmar-Conn., New York, Maine, Georgia, Mississippi.

Rostiezer-Vermont, New Jersey, New York, Maine, Massachusetts, Indiana, Mississippi.

Beurré d' Anjou-New Jersey, Delaware, Massachusetts, Mississippi.

Lawrence-New Jersey, Massachusetts, Ohio.

Washington-New Jersey, Delaware, Pennsylvania, Ohio.

Brandywine-Delaware, Pennsylvania, Massachusetts, Mississippi.

Doyenne Gris-Pennsylvania, Georgia, Mississippi.

Steven's Genesea-New York, Georgia, Ohio.

Fulton-New York, Maine, Massachusetts, South Carolina.

Buffum-New York, Maine, Massachusetts.

PEACHES, RECOMMENDED BY AT LEAST TWO STATES.

Yellow Alberge-Ohio, New York.

Early Tillotson-Ohio, Georgia, New York, New Jersey. 
Morris's Rare Red Ripe-Ohio, Missouri.

Early York-Ohio, Missouri, Georgia, Pennsylvania, New Jersey, New York.

Malta-Ohio, Georgia.

Early Ann-Ohio, New York.

Red Rare Ripe-Ohio, Georgia, New Jersey, New York.

Yellow Rare Ripe-Ohio, Pennsylvania, New Jersey.

George IV.-Ohio, Georgia, New Jersey, New York.

Grosse Mignonne-Ohio, Missouri, Georgia, New York.

Late Heath Cling-Ohio, New Jersey, Kentucky, Missouri, Georgia.

Coolidge's Favorite-Ohio, New York, Massachusetts.

Late Admirable-Ohio, Georgia, Missouri.

Craùford's Early-Ohio, Missouri, Georgia, Pennsylvania, New Jersey, New York.

Crawford's Late-Ohio, Georgia, Pennsylvania, New Jersey, New York.

Morris's White-Ohio, Missouri, Georgia, Pennsylvania, New Jersey, New York.

New Yonk Rare Ripe-Ohio, New Jersey.

Troth's Early-Missouri, New Jersey.

Early Newington-Missouri, New Jersey.

Lemon Cling-Missouri, Georgia, New York.

Old Mixon Free-Georgia, New Jersey, New York, Ohio.

Royal George-Georgia, New York.

Tippecanoe-Georgia, New Jersey.

Large Early York-New Jersey, New York.

Red Cheek Melocoton-New Jersey, Néw York.

\section{PLUMS, RECOMMENDED BY AT LEAST TWO STATES.}

Green Gage-New York, Conn., New Jersey, Delaware, Penn., Maine, Georgia, Ohio.

Jefferson-New York, Connecticut, Maine, Georgia, Ohio.

Lawrence's Favorite-New York, Pennsylvania, Maine, Georgia.

Purple Gage-New York, Maine.

Bleecker's Gage-New York, Connecticut, Maine, Ohio.

Coe's Golden Drop-New York, New Jersey, Georgia, Ohio.

Columbia-New York, Maine.

Drap d'Or-New York, New Jersey, Maine, Ohio,

Huling's Superb-New York, Georgia, Ohio.

Imperial Gage-New York, Connecticut, Maine, Georgia.

Smith's Orleans-New York, Conn., New Hampshire, New Jersey, Maine, Georgia, Ohio.

Washington-New York, Conn., New Hampshire, New Jersey, Maine, Georgia, Ohio.

Frost Gage-New York, Connecticut, Maine, Georgia.

Emerald Drop-New York, Connecticut."

Reine Claude de Bavay-New York, Maine.

Yellow Magnum Bonum-New York, New Hampshire, Connecticut, Maine.

Yellow Gage-New York, Connecticut, New Jersey, Ohio.

Lombard-Connecticut, New-Hampshire, Maine.

Bingham-New Hampshire, Georgia.

Duane's Purple-New York, Ohio.

\section{CHERRIES, RECOMMENDED BY AT LEAST THREE STATES.}

Belle de Choisy-New York, Conn., New Jersey, Maine, Ohio, Indiana, Massachusetts.

Black Eagle-New York, Conn., New Hampshire, Penn., Maine, Michigan, Ohio, Missouri.

Black Tartarian-New York, Conn., N. J., Delaware, C. W., Mich., Ohio, Mo., Ind.,-Miss.

Bigarreau (Yellow Spanish) - N. Y., N. J., Del., Ohio, Missouri, Ind., N. H., Mich., Miss.

Downer's Late-New York, New Hampshire, New Jersey, Maine, Ohio, Mississippi.

Elton-New York, Conn., New Jersey, Delaware, Penn., Maine, C. W., Mich., Ohio, Mo.

Knight's Early. Black-New York, New Jersey, Ohio.

Napoleon Bigarreau-New York, Connecticut, Michigan, Ohio, Missouri, Mississippi.

Belle Magnifique-New York, Pennsylrania, Canada West. 
May Duke-New York, Conn., N. H., N. J., Del., Maine, Mich, Georgia, Ohio, Ind., Miss. White Bigarreau-New York, Conn., New Hampshire, Delaware, Mich., Ohio, Mississippi.

Black Heart-New York, Delaware, Michigan, Ohio, Missouri.

Early Purple Guigne-New York, Mississippi, New Jersey, Canada West.

English Morello-New York, New Jersey, Delaware, Georgia, Missouri.

Kentish Morello-Connecticut, Maine, New Jersey, Georgia, Indiana.

Honey Heart-Connecticut, Maine, Massachusetts.

Coe's Transparent-Connecticut, New Jersey, Massachusetts.

Gov. Wood-Massachusetts, Ohio, New York.

American Amber-Michigan, Ohio, Missouri.

\section{APRICOTS.}

Peach-Ohio, Mississippi, Georgia, New Jersey.

Moorpark-Ohio, Mississippi, Georgia, New Jersey, New York.

Breda-Ohio, Mississippi, Georgia, New Jersey, New York.

Large Early-Ohio, Mississippi, New York.

\section{NECTARINES.}

Elruge-Ohio, New Jersey, Massachusetts, New York.

Early Violet-Ohio, New Jersey, Massachusetts, New York.

\section{QUINCES.}

Orange Apple-Ohio, New Jersey, New York.

Portugal-Ohio, New Jersey.

\section{HARDY GRAPES, FOR OUT-DOOR CULTURE.}

Catarba-Ohio, Missouri, Iowa, Georgia, C. W., Mass:, Delaware, New Jersey, Conn.

Isabella-Ohio, Mo., Iowa, Georgia, Michigan, C. W., Mass., Del., N. J., Vermont, Conn. Clinton-Michigan, Canada West.

Elsinboro'-Delaware, New Jersey.

\section{CURRANTS.}

Red Dutch-Nèw York, Delaware, Massachusetts, Canada West, Missouri, Ohio.

Knight's Sweet Red-New York, New Jersey.

White Dutch-New York, New Jersey, Delaware, Mass., Canada West, Missouri, Ohio.

White Grape-New York, Canada West.

Black Naples-New Jersey, Massachusetts, Canada West.

May's Victoria-Massachusetts, New York, Canada West.

\section{RASPBERRIES.}

Red Antwerp-New York, Connecticut, New Jersey, Canada West, Mississippi, Ohio.

White (or -Yellow) Antwerp-New York, Canada West, New Jersey, Massachusetts.

Fastolf-New York, Connecticut, New Jersey, Maine, Massachusetts, Mississippi, Ohio.

Franconia-New York, Connecticut, Vermont, New Jersey, Maine, Massachusetts.

Knevett's Giant-New York, Connecticut, Maine, Massachusetts, Ohio.

\section{STRAWBERRIES.}

Hovey's Seedling-Ohio, Miss., Ind., Mo., C. W., Mass.; Maine, Del., N. J., Conn., N. Y. Iowa-Ohio, Missouri.

McAvoy's Superior-Ohio, Indiana.

Hudson-Ohio, Canada West, New York.

Jenney's Seedling-Ohio, Maine, Connecticut, New. York.

Burr's New Pine-Ohio, Missouri, Canada West, New York.

Black Prince-Mississippi, Canada West, New York.

Large Early Scarlet-Mississippi, Missouri, C. W., N. Y., Mass., Maine, Delaware.

Boston Pine-Indiana, Maine, Connecticut, New York. 


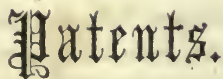

PATENTS, DESIGNS, RE-ISSUES, AND ADDITIONAL IMPROVEMENTS, ISSUED BY THE PATENT-OFFICE OF THE UNITED STATES, FROM JULY 1sT, 1854, TO JULY 1sT, 1855, INCLUSIVE.

Patents. 1934

DESIGNS.

52

RE-IsSUES

44

AdDITIONAL IMPROVEMENTS.

13

ToraL.

\section{TABLE}

SHOWING THE WHOLE NUMBER OF PATENTED INVENTIONS RELATING TO AGRICULTURE, FROM JULY 1st, 1854, TO JULY 1st, 1855, INCLUSIVE; NATURE OF THE INVENTIONS, WITH NAMES AND RESIDENCES OF THE PATENTEES.

Whole Number of Agricultural Patents.

\section{PLOWS.}

T. F. Chapin

John Lyon, (Ditching Plow).

J. S. Hall

Joshua Gibbs

D. \& S. Swartz, (Fastenings of Plows).

0. G. Ewings

W. Price, (Plow for planting potatoes)

H. F. Baker.

J. Hibbs.

C. A. Robbins, (Ditching Plow)

Arnton Smith.

Alfred Doe.

George Esterly

J. W. Haggard \& G. Bull, (Rotary Plow)

J. Reynolds.

D. Russell, (Spade Plow)

T. J. Hall.

N. Warlich

T. J. Hall, (Gang Plow)

E. C. Travenner \& O. Nesmith

L. G. Evans.

C. H. Dana

G. Lichtenthaler. 388
Walpole, N. H.........Patent issued July 25, 1854.

Harrisburg, Iowa..... " " " "

Manchester, Pa....... " " August 1, “

Canton, Ohio.......... " " 15 , "

.Tonis Brook, Va..... " " " 22 , "

Heart Prairie, Wis.... " " " 29 , "

Goldsborough, N. C.. " " " " "

Centreville, Ind...... " " Oct. 24, "

Tullytown, Pa........ " Nov. 14, "

Iowa City, Iowa..... - " . " " "

Scottville, Ind......... " J Jan. 16, 1855.

.Concord, N. H........ " " " 30 , "

Heart Prairie, Wis... " "Feb. 13, "

Bloomington, Ill..... " " " " " "

Republic, Ohio........ " " " " " "

Drewersburg, Ind.... " " "

Tawakana Hills, Tex. " April 4, "

La Fayette, Ala......

Tawakana Hills, Tex.

Hamilton, Va.

Springhill, Ala........

West Lebanon, N. H.

Limestoneville, Pa...

.




\section{CULTIVATORS.}

C. K. Farr

Auburn, Miss.

Patent issued Aug. 1, 1854.

D. W. Shares.

Hamden, Conn.

"6 ". "6

W. T. Bazemore.

Bibb Co. Ga.

" 29, "6

Whiteford, Ohio.

Nov. 14, "6

Job Brown

Lawn Ridge, Ill.......

John Imel.

Liberty, Ind.

6 66 66

Ypsilanti, Mich.......

J. Stockdale, (Cultivator Teeth).

Poplin, N. H.

Jan. 2, 1855

" 30 , "

Feb. 20, "

N. B. Chase \& C. W. Saunders, (Hand Cultivator)....Wilkinsonville,Mass.

S. A. Knox.

Worcester, Mass......

G. W. N. Yost.

Port Gibson, Miss....

II. D. Ganse

Freehold, N. J.........

R. P. Vanhorn.

Jackson Town, Ohio.

W. P. Zane, (Cultivators for sweet potatoes).

Woolwich, N. J.

F. L. Smithson, (Cultivators for tobaceo)

Mecklenburg Co. Va.

A. H. Morrel

Marlen, Texas.

J. Stryker.

Six-Mile Run, N. J.

March 7, "

" 14, "

"6 21 , "6

" 28, 6

"6 "6

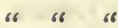

April 4, "

"11, "6

" 18 , "

\section{SEED PLANTERS.}

Samuel Ide.

C. A. Wakefield

C. Randall, (Re-issue).

W. Bullock.

J. T. \& L. P. Wait.

S. M. Hockman.

J. H. - King, Jr. .

Wm. Redick.

C. H. Dana.

Louis Dascr.

A. B. Earle

G. W. Lee.

M. Waterbury

D. W. Shares, (Seed Planters and Cultivators).

J. Andrews.

A. Anderson

Jarvis Case.

E. Morgan.

S. L. Stockstill \& P. H. Humes.

J.Williams \& J.W. Bausman, (Cotton-seed Planters)Alleghany Co. Pa....

John Blackwood.

Job Brown.

R. Romaine.

A. J. Barnhart.

H. Ludington \& S. R. Lupton.

E. Morse

D. H. Phillips.

B. M. Snell.

Iliram Moore...

M. Ward

C. B. \& B. S. Borden \& A. R. MeLean.

J. W. McGaffey...

J. W. Corey.

P. Raines, (Corn Planters)

G. W. Brown

A. H. Morrel, (Cotton-seed Planters)

L. W. Colver.
East Shelby, N. Ya...Patent issued July 4, 1854.

Plainfield, Mass......

Palmyra, Ga.

Red Falls, N. Y.......

Waterloo, S. C.

Tonis Brook, Va.......

Georgetown, D. C....

Uniontown, Pa........

West Lebanon, N. H.

Washington, D. C....

Franklin, N. Y

Ereildown, Pa.........

Cuba, N. Y.

Hamden, Conn........ Winchester, Mass.....

Markham, Canada...

Springfield, Ohio......

Morgantown, Va......

Brandt, Ohio.

Franklin Co. Ohio....

Lawn Ridge, Ill.......

Montreal, Canada....

Schooleraft, Mich.....

Addison, $\mathbf{P a ́}$.

Walpole, N. H.........

Greenville, IIl.

Hancock, Md.

Clímax, Mich...........

Owego, N. Y.

West Dresden, N. Y.

Syracuse, N. Y.

Craw fordsville, Ind...

London, Ohio...

Galesburg, IIl..........

Marlin, Texas.

Louisville, $\mathbf{K y}$
" 25, "6

" 6

Aug. 1, "

" 15, "

" 29 , “

" 6 "

"6 "6 6

Sept. 5,

66 66

Oct. 24, "

Nov. 21, "

" " 6

Dec. 12, "

660

Jan. 2, 1855.

" 16 , 6

" "

640

" 23, "

" 30 , "

"6 "6

Feb. 28, "

6 66 o6

March 14, "6

" 21, "

66 "6

"6 6

" 28, "

" $6 " 6$

April 4, "

"6 "6

"11, "

May 1, "

" 8 , "

" 10 , "

6 17 , "6 
Stevens, Crosby \& Pearson.

T. S. Minniss.

L. A. Butts.

C. H. Dana.

J. Beebe, (Corn Planters)

J. Selby.

M. D. Wells

0. Stoddard, (Hand Corn Planter)
Boston, Mass.

Meadville, $\mathrm{Pa}$

Cuba, N. Y.

West Lebanon, N. H.

Oakland, Mich.......

Lancaster, Ohio.......

Morgantown, Va......

Blisti, N. Y.
Patent issued May 17, 1855.

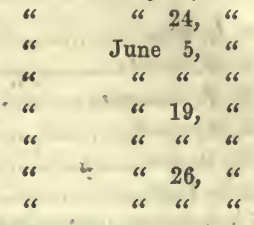

\section{GRAIN AND GRASS HARVESTERS.}

A. Gale, (Mowing Machine)

A. Whitely, (Track Clearers to).

G. A. Bruce, (Maize Harvesters).

J. S. Burnham.

A. Whiteley

J. J. Weeks

J. H. Manny.

J. Swartz.

C. Wheeler, Jr.

J. S. Gage, (Clover Harvesters)

W' F. Ketchum..

J. E. Brown \& S. S. Bartlett..

M. Burnett \& C. Vander Woerd.

John E. Newcomb.

O. B. Judd.

A. Palmer, (Frame of Grass Harvester).

D. Russell, (Harvester Cutters).

E.A. Morrison, (Delivering apparatus of Harvesters).Lawrenceville, Va...

J. H. Maydole \& A. W. Morse.

F. Russell, (Mowing Machine)

C. Wheelér.

R. J. Morrison.

J. H. Manny.

F. Russell, (Mowing Machine)

W. A. Wood.

A. Diets \& J. G. Dunham

Jarvis Case........

E. B. Forbush.

Philo Sylla

R. L. Hawes, (Machine for dressing Lawns).

J. Atkins, (Platforms of Grain Harvesters)..

A. Whitely, (Attaching wheels to Harvesters).. a) 6

T. N. Lupton.

J. H. Manny.

B. N. Nicholson.

J. Haines..

F. Peabody

C. Wilson \& W. Moore, Jr. (Mowing Machine)..

M. G. Hubbard.

A. Diets \& J. G. Dunham.

J. Richardson, (Modification of motion of)

C. Taylor.

S. Hull, (Attaching seat to).

J. H. Manny, (Cutters of).

" " "6 (Guard-fingers of).
Eaton, N. Y.

Boston, Mass...

Springfield, Ohio......

Mechanicsburg, Ill...

West Jefferson, Ohio.

Springfield, Ohio......

Oyster Bay, N. Y....

Rockford, Ill.

Buffalo, N. Y...........

Poplar Ridge, N. Y..

Dowagiac, Mich......

Buffalo, N. Y.........

Woonsocket, R. I....

Boston, Mass..........

Whitehall, N. Y......

Tittle Falls, N. Y....

Brockport, N. Y.

Venice N. Y...

Richmond, Va.........

Rockford, Ill.

Boston, Mass.

Hoosic Falls, N. Y....

Raritan, N. J..........

.Springfield, Ohio......

Buffalo, N. Y.

Elgin, Ill.

Worcester, Mass.......

.Chicago, Ill............

Springfield, Ohio.....

Winchester, Va........

Rockford, Ill...........

Davidsonville, Md....

.Pekin, Ill................

. Salem, Mass............

Yardleyville, Pa.......

New York City.

Raritan, N. J..........

Buckeystown, Md....

McKeesport, Pa.......

Poughkeepsie, N. Y..

Rockford, Ill...........

Poughkeepsie, N. Y..Patent issued July 25, 1854.

Aug. 22, "

" 29 , “ "

Sept 19, "

" " " "

" 26 , "

Oct. 17, "

Nov. 14, " "

Dec. 5, "

“ 19, "

666

Jan. 2, 1855 .

" "6 "

6 9 , 6

"16, "

" 30 , "

" 6

" 64

Feb. 6, "

" 28, "

"6, 6

" 13, "

March 7, "6

"6 21, "6

6 640

" 28, “

April 18, "

" " "

"6 6

April 25, 1855.

"6 "6

ct in a

"6 "

May 8, “

"6 "6

" 10 , "6

" 17 , "6

" 24 , "6

"6 "6

June 5, "

“ " 6

" 19 , "6

" 26 , "

66 66

646

"6 66 
RAKES AND HARROWS.

C. Brown, (Harrester Rakes)

W. Anderson, (Harrows)

D. M. Cummings, (Rakes)

J. Myers, (Harrows).

M. D. Wells, (Horse Rakes)

J. G. MeCauley, (Harrows)

G. A. Brown, (Hay-making Machine)

S. N. \& W. F. Stillman, (Garden Rakes).

D. Haldeman, (Harrows).

A. H. Gaston \& J. Smith, (Rakes and Elevators)...Sunbury, Ohio

W. J. Keeney \& J. R. Tarbox, (“

C. Clareni, (Harrows).

L. Brainard \& L. Newton, (Rotary Harrow).

H. Chatfield, (Rakes).

F. Peabody, (" "
“ ).
Upper Alton, III

Ulysses, N. Y.

Enfield, N. H

Powhattan Point, 0 .

Morgantown, Va......

Stone Bridge, Va.....

Middletown, R. I.....

Leonardville, N. Y...

Morgantown, Va.....

Switzerland, Ind......

New York City

Attica, N. Y.

Waterbury, Conn.....

.Salem, Mass..
Patent issued July 11, 1854.

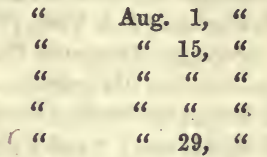

Jan. 23, 1855.

Feb. 13, "

" 20 , "

March 21, “

April 4, “

" " "

"11, "

" 18 , "

April 18, “

\section{STRAW-CUTTERS, ETC.}

A. B. Earle

W. Gale.

J. B. Stockton, (Springs to knives of)

J. A. Pitts.

G. L. Squier.

J. H. Bennett.

W. Lackey.

Ira Rose.

D. Russell.

S. T. Sharp

T. C. Simonton \& L. J. Wicks..

F. Fitzpatrick

H. Peckham .

W. H. Fullerton, (Hackling Corn-husks)

J. Straub, (Corn-cob Cutter).

L. Woods, (Hedge Trimmer).

J. S. Griffith, (Corn and Cob Crusher).

W. D. Wilson, (Corn Grinder and Crusher).

A. \& C. N. Clow, (Corn Shellers)
Franklin, N. Y

Troy, N. Y.

Warren Co. Ky........

Buffalo, N. Y.

Chicopee, Mass........

Bennington, Vt......

Worcester, Mass......

Akron, Ohio............

Drewersburgh, Ind...

Danville, Mo.

Patterson, N. J........

Cincinnati, Ohio.......

King's Ferry, N. Y...

.Louisville, Ky.........

.Cincinnati, Ohio......

Quincy, IIl.

Huntington, Pa......

Richmond, Ind.......

Port Byron, N: Y.....
Patent issued Aug. 22, 1854.

Sept. 12, "

" 26, "

Jan. 16, 1855.

" 30 , "

Feb. 20, "

April 11, "

"6 "6

(6) 16 of

a 60

16 4

May 24, “

June 26, “

July 11, 1854.

“ 25 , of

“ " c

Feb. 6, 1855.

May 24, “

June 26, "

\section{HORSES, CARRIAGES, ETC.}

W. MeCord, (Horse Power).

Sing Sing, N. Y.......Patent issued July 11, 1854.

W. R. Palmer, ( " " improvement)..............Elizabeth City, N. C.

S. Tomlinson, (Holding-docks of Horses)..............Pleasant Valley,N.Y.

A. J. Gibson, (Vehicles)

Clinton, Mass...........

N. B. Livingston, (Coupling for Carriages).............Portland, Ind..........

W. H. Towers, (Horse-shoes).

Philadelphia, Pa......

A. J. Gibson, (Improved attachment of Thills)....... Clinton, Mass.

" " (Whiffletrees " ")............. " " .........

Geo. Souther, (Tires for Carriage-wheels)...

Boston, "

S. Stone, (Dumping Cart)

Kirkersville, Ohio....

T. Mardock \& W. C. Kellar, (Saddle Trees)

W. S. Rabeock, (Dumping Wagon).

J. S. McClelland, (Buggies).

Cincinnati, " "....

Stonington, Conn.....

Jefferson, Ind.

A. Moffit, (Spring-body Carriages).....................Brownsville, Pa........

E. Turner, (Hame Fastenings).

Baltimore, Md.........

C. Darling, (Securing Hubs to Axles)

Utica, N. Y.

R. Spencer, (Saddle Trees).

Southport, Conn......

" (Harness Saddles) New York, N. Y.

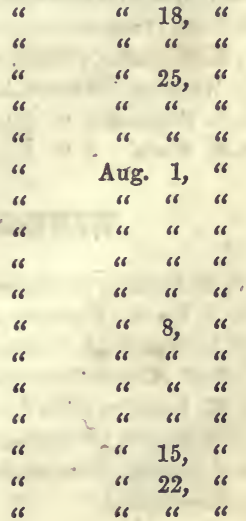


N. Warlick, (Horse-shoeing Apparatus)

Lafayette, Ala.

..Patent issued Aug. 29, 1854.

A. J. Gibson, (Coupling for Carriages)

Clinton, Mass.

Sept 12, “

S. Briggs \& J. G. Talbot, (Neck-yoke)

Sloansville, N. Y.....

T. Hardman \& A. Vose, (Whiffletrees).

Pittsfield, Vt.

C. Jarnagin, (Seats for Wagons)

L. Dederick, (Ox-yokes).

Clinton, Teûn.

" 26 , "

Albany, N. Y.

" 6 " 6

Oct. 31, "6

Jan. 2, 1855.

Z. Butt, (Self-loading Cart).

Lincolnton, N. C...... "

J. Wilkinson, (" and Unloading Carts)..............Hopewell Cot. Wks. P. 0. Pa.

J. A. Sprague, \& B. O’Connor ( " “ )........... Dayton, Ohio.

J. Tucker, (Ox-yokes)...

.Norway, Me............

R. R. Gray, (Blocks for Horse-collars).

Crawfordsville, Ind.

E. H. Penfield, (Dock.holders for Horses).............. Middletown, Conn...

Mar. 14, "

May 1, "

"6 21, "6

May 17, “

June 19, "6

Dec. 12,1854 .

\section{AGRICULTURAL INVENTIONS RELATING TO COTTON, WOOL, FLAX, ETC.}

N. Chapman, (Cotton-press)

D. Warner, Jr., (Dressing Flax).

W. Watt, (Hemp-rotting Process)

Maj. B. Clarke, (Feeding and Cleaning Seed-cotton)Newman, Geo..........

A. P. Keith, (Cotton-gins)

H. Clark, ( " " )

D. W. Hughes, (Hemp Brakes)

G. D. Allen, (Cleaning Sisal Hemp)

" " " (Stripping Seed from Broom-corn)..... " " ".......

J. Walker, (Hulling Cotton-seeds)....

J. B. Mell, (Cotton-gins).

P. Lancaster, (Implement for Shearing Sheep)......Burr Oak, Mich.......

J. How, (Machine for Bundling Wool).

J. Grout, (Self-acting Cotton-press)...

R. A. L. McCurdy, (Cotton-gins).

A. Adams, (Cotton and Hay Presses) South Hadley, Mass.
Dover, England.......

.Riceboro', Ga.

.Mystic River, Conn..Patent issued Aug. 8, 1854.

Bridgewater, Mass...

Newport, Fla............

.New London, Mo.....

Key West, Fla.........

Deer Creek, "

Hocking City, Ohio.

.Sabine Parish, La....

Jerseyville, Ill.........
Sept. 5, "6

Nov. 21, "6

Dec. 19, “

Jan. 2, 1855.

Fob. 13, "

"28, "

Mar. 7, "

"6 6 6

" 28, "6

April 4, "

" 25, "

May 1, "

June 12, "

" 26, "6

Nov. 28, "

\section{DAIRY IMPLEMENTS, ETC.}

J. Gleason, (Milk Strainer).

Geneva, N: $\bar{Y}$.

Patent issued July 4, 1854.

S. W. Ruggles, (Self-acting Cheese-press)..

Fitchburg, Mass......

E. Gore, (Butter-workers).

Bennington, Vt......

E. King, ( " " )

Macklenburgh, N. Y.

P. Wilbor, (Cheese-presses)

Milan, Ohio............

E. Webber, (Churns).

Gardiner, Me.........

H. A. Roe, (Cheese Vats).

West Apdover, Ohio.

E. Gore, (Churns).

Bennington, Vt.......

J. M. Williams, (Butter-workers).

Blanchester, Ohio....

H. Webster, (Churns)

E. B. Clement, ( " ) . Ogdensburg, N. Y....

J. M. Wade,

Barnet, Vt:.............

Clintoń, Mich.

$\begin{array}{ccc}\text { 66 } & 66 & 66 \\ 66 & 25, & 66 \\ 66 & 66\end{array}$

Ang. 22, "

Dec. 5, “

"12, "6

Jan. 2, 1855.

Feb. 6, "6

(6) 6

"13, "

June 26, "6

\section{WINNOWERS, CORN SHELLERS, THRASHERS, ETC.}

W. M. Palmer, (Thrasher)

Palmyra, Me.

Patent issued Aug. 1, 1854.

H. N. Black, (Cleaning and Drying Grain)...

Philadelphia, Pa......

M. H. Mansfield, (Grain and Clover-seed Screens)...Ashland, Ohio........

C. Reif, (Clover Separator)

Hartleton, Pa.

S. W. Ruggles, (Fan Blower)

Fitchburg, Mass......

II. H. Beach, (Winnowers).

Chicago, Ill

A. J. Smith, (Corn Shellers).

Piqua, Ohio.

G. Maynard, ( "

.Greenfield, Mass......

\begin{tabular}{|c|c|c|}
\hline 66 & 6 & "6 \\
\hline 66 & "6 & 66 \\
\hline " & " & 8 \\
\hline " & 6 & 66 \\
\hline "s & "6 & 15 \\
\hline $6^{\circ}$ & " & 29 \\
\hline " & Sept & 12 \\
\hline
\end{tabular}


S. Moore, (Feeding-grain Separators \& Thrashers).Central Bridge, N.Y..Patent issued Oct. 3, 1854. T. B. Woodward, (Smut Machine)......

. Kensington, $\mathrm{Pa}$.......,.

J. Hollingsworth, ( " " re-issue).

Zanesville, Ohio......

A. Bowen, (Straw and Grain Separator).

Wadesville, Va........

S. Gumaer, (Corn Shellers).

Aurora, $\Pi 11 . . . . . . . . . .$. .

J. P. Smith, ( " " ).............................Hummelstown, Pa..

W. Moore, (Grain Winnowers)

Belleville, Ohio........

G. Daniels, (Thrasher and Grain Cleaner).............Philadelphia, Pa......

J. P. Smith, (Corn Sheller).

Hummelstown, Pa....

C. Leavitt, (Portable Grain Mill)...

Quincy, Ill..

G. Leach, (Grain Cleaner)

Owego, N. Y..........

B. J. Trimmer, ( "6" " 6 ).

Parma, N. Y..........

C. Campbell, (Cleaning Wheat),

California.

C. B. Horton, (Iullers of Buckwheat).

Elmira, N. Y............

Rowland, Stephens \& Mason, (Drying Grain)........ Brooklyn, N. Y........

C. Street, (Grain Drills).

Barre Centre, N. Y...

II. D. Reynolds, (Grain Cleaners)

Pendleton, Ind........

B. Bridendolph, (Hominy Mills).

II. Mellish, (Grain

\section{6 ).}

J. Barker, ( W Winnowers)
A. B. Craw ford, (Clover Hullers)...

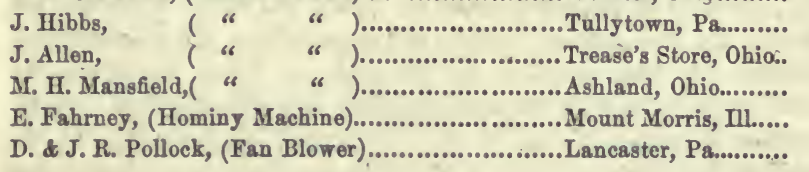

" 10 , "

c 17 , 6

" 24, "6

Nov. 7, “

"6 6

"14, "

Feb. 13, 1855.

"6 28 ,

c6 66

Mar. 14, "

April 4, "

May 1, "s

"17, "

6 60

"24, "

June 19, "

Aug. 22, 1854.

"6 "6

Oct. 31, "

Nov. 28, "

Jan. 30, 1855.

Feb. 13, “

"28; "

May 10, “

June 19, “

\section{MISCELLANEOUS.}

G. J. Bundy, (Potato Diggers)

J. Taggart, (Excavating Earth).

M. Walker, Sr., (Iron Picket Fence).

II. N. \& J. C. Bill, (Securing Axe Helves)

D. Strouder, (Ditching Spade).

D. Zeigler, (Cider Mills).

W. B. Walker, (Manufacture of Brooms)

J. L. Lord, (Grindstone Frame).

E. Marshall, (Manure Spreaders)

R. M. Abbe, (Hog Pens).

J. W. Fawkes, (Manure and Lime Spreader).

A. R. Hurst, (Manure Excavators)...

H. Fry, (Mole Trap, re-issue).

II. Eddy, (Bee Hives).

J. J. Weeks, (Sausage Stuffer).

A. Winter, (Sawing Fire-wood)

E. Ford, (Granaries).

I. W. MeGaffey, (Potato Diggers).

D. Phillips, (Farm Gate)..

G. D. Stillson, (Excavating Machine)

T. C. Ball, (Seythe Fastening).

J. L. Rolland, (Machine for Kneading Dough)...

W. H. Allen, (Meat Chopper)...

T. D. Aylsworth, (Hop Frames).

J. Parker, (Machine for Slaughtering Hogs).

W. D. Titus \& R. W. Fenwick, (Bridle Bits).

J. G. Goshen \& S. M. Eby, (Maize Leaf as a substi-

tute for Tobacco)

C. Crum, (Processes for Making Bread).

R. C. Manck, (Ditching Machine).
Lyndon, Vt.

Roxbury, Mass.......

Philadelphia, Pa.....

Willimantic, Conn....

New Burlington,Ind.

Lewistown, Pa.........

Bennington, N. H....

Chester, Conn.........

Clinton, N. J.

Thompsonville, Con.

Christiana, Pan.......

.Harrisburg, ".........

. Cincinnati, Ohio......

N. Bridgewater,Mass

Buckram, N. Y........

Rondout, " ........

Spring Cottage, Miss.

Philadelphia, Pa......

Shaftsbury, Vt.........

Rochester, N. Y.......

Shelburne Falls,Mas.

Paris, France.

Lowell, Mass...........

.Frankfort, N. Y........

Louisville, Ky........

Brooklyn, N. Y,.....

Shirleysburg, Pa......

Hudson, N. Y.

Harrisburg, Va
Patent issued July 4, 1854.

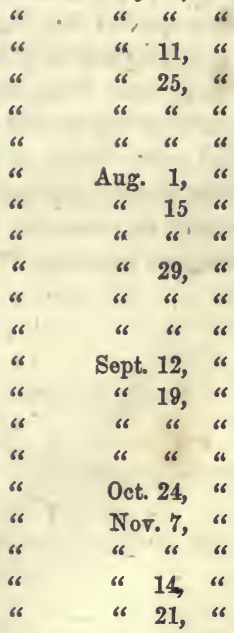

“ Jan. 9, 1855.

" 6 "

6 64

Feb. 30, "

" 6 "

"20, 6

Mar. 7, “

"14, " 
S. N. Maxam, (Apple Parer)

Shelburne, Mass.......Patent issued A pril 11, $185 \hat{j}$.

P. Manny, (Hay Press).................................... Waddam's Grove, Ill.

E. A Tabbs, (Sawing Fire-wood, etc.)...................Hampton, N. H.......

C. L. Harson \& M. R. Brailey, (Farm Gates)..........Norwalk, Ohio.........

S. Ingersoll, (Sawing or Felling Trees)................. Greenwich, Conn.....

H. B. Lumm, (Farm Gates).

Sandusky, Ohio.......

J. B. Reyman, (Fences)

Dubuque, Iowa.........

C. Winegar, (Closing and Opening Gates)

Union Springs, N. Y.

T. J. Kindleberger, (Cider Mills). Springfield, Ohio......

W. P. Greenleaf, (Fastening Scythes to Snaths).....Washington, .N. H...

G. King, (Pressing Tobacco in Plugs)

Farmville, Va..........

C. R. Webb, (Wind Mill).

Philadelphia, $\mathrm{Pa} . . . .$.

S. Gorton \& F. Morris, (Stump Machine).

Crawford county, $\mathrm{Pa}$.

W. D. Parker, (Ice House)

New York, N. Y......

W. Thompson, (Self-operating Circular Gate).

Nashville, Tenn.......

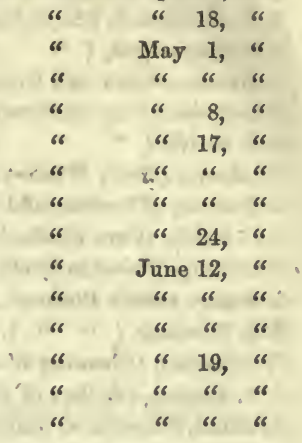

\section{Statistics of Patents.}

Mr. J. S. Brown, of Washington, has recently published a catalogue of all the patents granted by the United States Government up to the commencement of the year 1855. From this we learn that the whole number of patents granted for Grain and Grass Harvesters has been one hundred and eleven; for Plows, three hundred and seventy-two; for Straw-Cutters, one hundred and fifty-three; for Smut machines, one hundred and forty; for Winnowing machines, one hundred and sixty-three; and for Threshing machines, three hundred and seventyeight. The highest numbers in classes belong to the agricultural department, with the exception of Stoves, on which the enormous number of 682 patents have been issued, and 478 for designs, making a total of 1160 patents on Stoves.

On Air Engines, not one of which is in use, no less than twenty-one patents have been granted. No less than 148 patents have been granted on Steam Boilers; and yet, for all this, there are but few engineers who do not entertain the opinion that many improvements have yet to be made on them. The manufacture of India-rubber goods is but of recent date, and yet no less than forty-two patents 'have been obtained on such manufactures. Sewing machines are of still more recent date, the first patent having been obtained in 1846, only nine years since; and yet no less than sixty patents have been granted on such machines. This affords evidence of their popularity and usefulness. The number of Water-Wheel patents is somewhat high, being 327 , but that of Washing machines comes nearly up to it, being no less than 309 . 


\section{N D E X.}

Adriance's improvement, 111.

Abbe, R. M., improved hogpens, 42.

Agricultural chemistry, 135.

and economic botany, 231.

education in U. S., 7.

mechanics, 21.

science, new theories in, 177.

statistics, 375 .

value of gypsum, 171.

zoology, 341 .

Agriculture connected with science, 21.

in Liberia, 281.

its progress in Great Britain, 7. present state of, 21.

Ailanthus-tree, 262.

Alcohol from the Asphodelus ramosus, 207.

Allen's machine, 111.

Allibone, S. Austin, life of Downing, 5.

Alpaca sheep recently introduced into U. S., 16. or Peruvian sheep, 354.

American grapes, varieties of, 307.

Ammabroma, or sand-food of Sonora, 327.

Ammonia, supply of, in ordinary soils, 161.

Amounts of ammonia and nitric acid in rain water, 177.

Amount of manure applied per acre, 161.

Analysis of the ashes of oak and pine-leaves, 165.

Anderson, Alexander, potatoe-planter, 101.

Andrews's broadcast seed-sower, 99.

Angora goat, its introduction into.England, 357.

Animals, judging the value of, 364 .

Apple-borer, 373.

Arnold, Francis, his improvement, 48.

Aroma of A merican wines, 207.

Artesian wells, boring for, 53 .

Ashes of oak and pine-leaves compared with cotton, \&c., 165.

Atkins's reaper, trial of, 110.

Axle-box, Goodman's improved, 41.

BARK, removal from apple-trees, 326.

Barnhart's hand corn-planter, 98.

Basket willow, culture of, \&c., 249.

Beach grasses, 279.

Bean \& Wright, patent of, 120.

Bearing rein, uselessness of, 38.

Bedstead, alarm, 51.

Bee-culture, success of, 367.

Beech's improved grain and seed fan, 119.

Beech-oil, 251.

Bee-hives, drone-trap for, 46.

Bcets v8. turnips for feeding stock, 336 .

Benefit of droughts, 182.

Bennet, J. H., improved straw-cutter, 107.

Bethel, John, his patent, 79.

Bill, H. A. \& J., their improvement, 49.

Bit for refractory horses, 37.

Blatch ford's solidified milk, 62.

Bocage, J. W., illustration of his invention, 24.

Bolting, improrements in, 34.

Bones, new method of using and dissolving, 183.

Book-farming, 22.

Booth, W. S., his experiment, 55 .
Bouquets, directions for making, 297.

green-house plants for winter, 295.

Bowen', A., thrasher and grain separator, 118.

Bowerman, of Detroit, his invention, 22.

Boydell's steam horse, 80.

Bran of wheat, proximate principles of, 196.

Bread, improved manufacture of, 199.

Brick, patent, 53.

Brooks, John, èxperiments in feeding, 206.

Brown, A. D., his improvement, 22.

A. P., his self-regulating windmill, 36 .

Bruce, G. A., patent of, 110.

Buchanan, Mr., 74.

Buckwheat straw, new use of, 208.

Bulbous roots, new fact respecting, 304.

Burke, Hon. Francis, his invention, 26.

Burgess's improved reaper, 110.

Burnham, J. S., patent of, 110 .

Butter making, 60 .

in milk, estimation of, 60 .

method of testing, 59 .

mould, 59.

Caladium esculentum, 326.

California, agriculture in, 15. great tree of, 263.

Calve-8uckler, 45.

Camels, introduction of, into the U. States, 343.

Camphor v8. pea bags, 372 .

Canadian hemp, 246.

Capillary attraction of the soil, 181.

Cart, self-loading, 44 .

Caryl's flax-dressing machine, 25.

Cashmere goat in the United States, 161, 343.

Catawissa raspberry, 323.

Cattle, fattening of, 361 .

for the dairy, 358 .

interest of the Western States, 16.

in Kentucky, 16.

Cellar floors, 51 .

Celery, 335.

Charcoal, deodorizing properties of, 212.

Cheese, preservation of, 200. vat, Roe's improved, 61 .

Chemical investigations of the phenomena of vegetation, 168.

Cherry, ground, 324.

China, vegetable textile fibres produced in, 246.

Chinese economy of manure, 140 . potato, 286.

Churns, improved, 61.

Cider and wine mill, patent, 71 . manufacture of, 68 .

Clay-hall draining, 164.

Cleaning of Sea-island cotton, 22.

Cleveland, Charles, his patent, 49.

Clinton, L., improved straw-cutter, 107.

Clod-crusher, compound-action, 57.

Cloth made from plantain fibre, 26.

Clover, crimson, 277.

Clovers and grapes at the South, 275.

Coffee, use of; among the natives of Sumatra, 204.

Cold and warm seasons, 226. 
Cold grapery, 312.

Collette, C. Hastings, his patent, 76

Composition of salt for dairy purposes, 188.

Corn and cob mill, 123.

and cob meal, 365 .

grinder and crusher, 121.

planter, 104.

planters, improvement in, 99.

sheller and winnower, 120.

shellers, thrashers, \&c., patents for 1855, 392.

stalks, machine for cutting, 22.

stalks, manner of removing, 22.

Cotton-cleaner, 25.

cleansing of Sea-island, 22.

consumption and manufacture of, 236.

fibre, its length, 233.

plant, diseases of, 235 .

its enemies, 234.

and its varieties in the U. S., 231. rafting of, 23.

rope becomes smooth by use, 23 .

rope stronger than manilla, 23.

saw-gins, improvement in, 22.

seed-cake as food for cattle, 197 .

stalks, machine for cutting standing, 24.

Cows, blanketing of, 365 .

Cranberry, cultivation of, 324 .

Cream, proportions of', in milk, 60 .

Crops, those benefited by plaster, 172.

Cultivator, improved, 90.

improved rotary, 88.

rotary, 91.

two-horse, 91.

Cultivators, patents for $1855,389$.

Currants, new varieties of, 327 .

Cutting pot, materials for, 304 .

DAIRY implements, patents for 1855, 392. salt best adapted for, 188 .

stock, management of, 359 .

Dana's hand corn-planter, 98.

Dederick's improved hay-presses, 66.

Deodorizing properties of charcoal, 212.

Dickey's patent butter-mould, 59 .

Dietz \& Dunham's reaper and mower, 109.

Digging machine, Gibson's, 81.

Dioscorea batatus, or new Chinese potato, 286.

Domestic fowl, and other hybrid species, 352.

Downing, biographical notice of, 5 .

Drainage, land, experience in, 163.

Draining of Lake Fucino, 143.

Droughts, benefit of, 182 .

Duplex safety rein, 37 .

Edisto IsLaNd, cotton gin in use there, 22.

Education, agricultural, 7.

Egan, T., improvement in dressing flour, 33.

Egg-hatching, artificial, 47.

Eggs, arrangement for holding, 48.

of fishes, transportation of, 351 .

Elastic horse-shoes, 36.

Ellis \& Gordon, excavating machine, 94.

Ellsworth, H. L., experiments of, 87 .

Excavating machine, 94.

Exhibition of the natural productions of Illinois, 12.

of Royal Agricultural Society, 12, 13.

Experiments with manures, 162.

FACr in manuring, 157.

Farinaceous aliment obtained from straw, 198.

Farmers should give heed to science, 21.

Faucet, improved, 49.

Feeding, experiments in, 216.

Felton, A., improved mill, 120.
Fence, cost of, to fence the country, 126.

Fences, wire, 127.

Fenwick's corn-planter, 101.

Fibres, two new ones from Brazil, 247.

Fibrous vegetable substances, 243 .

Field fence, 128.

Fields, G. B., patent of, 91 .

Fish, artificial propagation of, in Ohio, 347.

breeding in France, 350. growth of, 350 .

propagation in Ohio, 16.

Fisheries, legislative enactments re-creating, 351.

Fiskie's steam plow, 79 .

Flax-breaking and scutching machine, 25. dressing machine, Caryl's, 25. gases evolved in steeping, 210. industry in Russia, 240. recent improvements in its preparation, 25.

Floral fête at the London Crystal Palace, 13.

Flour barrel, ventilating, 32 . bolts, feeding, 34 .

Flour, machines for dressing, 33.

Flouring and bolting, improvements in, 34 . mills, 124.

Flowers, odors of, 207. their effect on the air of rooms, 226.

Food, new articles of, 20. new, for sheep, 365 .

Forbush's machine, 111.

Ford's improved granary, 29.

France, amount of wine consumed there, 72.

French industrial exhibition, 13. agricultural department, 13.

Fresh meat, experiments on the preservation of, 203.

Fruit, cultivation of, in New York, 13. drying of, 133.

preservatory, 46 .

the ripening of, 338 .

Fruit-trees, cultivation of, 336 .

improvements in raising, 337.

influence of locality on, 229.

manuring of, 146.

protection of, 230 .

rotation of, 262.

Fruits, the gathering and preservation of, 337.

GAGE, J. S., clover-gatherer, 108.

Gale, W., improved straw-cutter, 106.

Gang plow, 87.

Garden pot, new, 305.

Gas lime, value of, 147 . and water pipes, improved joints for, 50 .

Gate, self-acting, 129.

Germination, effect of colored light on, 208. of seeds, 280.

Gibbs' \& Mapes's rotary spade; 81.

Gibbs, Griffith \& Co., grain warehouse of, 28. L. H., invention of, 81 .

Gibson's digging machine, 81.

Goodman's improved axle-box, 41.

Gore, Ezekiel, patents and improvements, 58, 61 .

Grafted chestnut-trees, 265. plants, 314.

Grafting, interesting facts in, 220.

Grain and grass harvesters patents, 1855, 390. and grass-seed headers and harvesters, 108.

Grain, method of feeding, to millstones, 122. mills, portable, 122.

should be cut, when, 195.

and seed-cleaners and winnowers, 119. and smut machines, 120.

transported in barrels, economical, 27. transportation of, 26.

Granaries, improvements in, 27. 
Granary, Ford's improved, 29.

Granger's magic eorn and cob mill, 123.

Grapery, cold, 312.

Grape-mildew, 195. vines, improvement in the frames of, 305 .

Grapes ripening earlier than usual, 229. and grass cultivation, 277. varieties of American, 307.

Grass-land, preparation of, 275.

Grasses for lawns, 274. notes on, 271.

Greeley, Horace, his correspondence, 77.

Green-house plants for winter bouquets, 295.

Griffith, G. R., his cotton-raft, 23.

Grinding-mills, 120.

Grittiness of pears, 209.

Ground cherry, 324.

Grano deposits of the Atlantic, 158. and nitrate of soda on a peat-bog, 163. how to use, 158.

mixing common salt with, 160 .

Gum, new American, 254.

Gutta percha, production of, 279.

Gypsum, agricultural value of, 171 . analyzed, 173.

duration of its effect, 173.

effect of, on the quality of plants, 172.

quantity of, and time of application, 173.

HaIL, protection against, 225.

Hallenbeck's machine, 111.

Halliday, Danl., improvement in windmills, 35.

Hall's sille-hill plow, 83 .

Hammon, Heman B., invention of, $\mathbf{4 0}$.

Hand thrashing-machine, 105. seed-planters, 97.

Hanford, W. B., barrow, 95.

Harness-buckle, improved, 39.'

Harrow, flexible, 96. roller and seed-planter 96 .

Harrows, improvements in, 95.

Hats, papier-maché, 53.

Hayes, Dr., on the composition of guanos, 158.

Hay-caps, 65.

knife, improved, 104.

making, 191.

presses, improved, 66.

Helve fastener, improved, 49.

Hemp, Canadian, 246.

and flax-breaker, Hughes's, 25.

flax and wool, patents for 1855, 392.

recent improvements in its preparation, 25. Sugett's improvement in treating, 25.

Hildreth, G. W., invention of, 87.

Hill's combined harrow, roller, and seed-planter, 96.

Hoe, Knox's horse, 89.

Hog killing in Cincinnati, 43. pens, improvement in, 42.

Holwell, W. A., invention of curbing bit, 38 . invention of safety rein, 37 .

Hops, new plan of raising, 328 .

Horne, J. V., patent of, 120.

Horses, carriages, \&c., patents for 1855, 391

Horse-chestnut for food, 20. flesh for food, 367 .

muzzles, 39. neck-yoke, 41.

Horse-radish, culture of, 334 .

Horse-shoe, improved by W. H. Towers, 37. shoeing apparatus, 36. shoes, improvements in, 36 . without nails, 36 .

Horticulture, 291.

Houses, building-stone, 132.
Hot-beds, construction of, 63 . cotton waste in, 65 .

Hughes's hemp and flax-breaker, 25.

Human life, period of, 366 .

Hyde, W. S., invention of, 84.

ICE-CREAM freezer, 61.

Importation of cattle in the United States, 16. Indian-meal sizing, 120.

Indications of weather as shown by animals, \&c., 223:

Influence of soil on the action of plaster, 173.

Insects, use of red camomile destroys them, 205.

Irwin, John $L_{\text {., new invention of, } 41 .}$

JAPAN PEA, 328.

Jennings's process for improving the quality of flax fibres, 25.

Johnson, H. M., invention of, 88.

S. W., on the value of gypsum, 171.

Jones, J. O., his new patent horse-shoe, 37.

KeEch's AND STILLWELL's combination fanning mill, 119.

Ketchum's maehine, 110.

Kind, Mr., improvements in machinery, 53.

King, Mr., invention of, 49 .

Kirtland on the pear, 321.

Knox's horse-hoe, 89.

Kroger, A. E., improved harvester, 109.

LABELS, necessity of correct, 50 .

Lake Fucino, draining of, 143.

Lancaster, P., his patent, 45.

Land drainage, experience in, 163.

Lapham's cultivator, 91 .

Lapham, Wm., patent of, 110.

Leach's grain-cleaner, 119.

Leaf venation, and ramification of the plant, 248 .

Leavitt, Charles, patent of, 122.

Leavitt's, D., barn, 30.

Leary, A., his experiments, 76.

Liberia, agriculture in, 281.

Liebig, his teachings, 21.

on phosphates in turnips, 176.

on the improved manufacture of bread, 199.

Liebig's fifty propositions, 183.

Lightning, statistics of 225 .

Ligneous fibre, and twist of trunks of trees, 247.

Lime, refuse, of the gas-works, 148.

List of agricultural works, 382.

Logs, way to transport, 55 .

Longworth, Mr., of Cincinnati, 73.

Lupton, T. W., improvement in harvesters, 109.

Lyon, John, invention of, 85.

Machine for cutting corn-stalks, 22.

Madder, its cultivation, uses, \&c., 255.

Maize harvesters, improvements in, 110.

Manning's reaper and mower, 109. reaper, trial of, 110 .

Manure, amount of, applied per acre, 161.

Chinese economy of, 140 .

excavators, 125.

experiments with, 162 .

liquid, collection and preservation of, 145 .

preparation of muck for, 152.

sewage, 157.

subterranean application of liquid, 139.

Manures, covered and uncovered, 146.

nascent, 150.

Manuring, a fact in, 157.

fruit-trees, 146.

Mapes's lifting subsoil plow, 84.

Mapes, Prof., on soil analyses, 175. 
Marchand's suggestion, 60.

Maury, Lieut., meteorological observations, 20.

McFarland's corn-planter, 104.

Meat for food, relative value of different kinds, 199.

Mechi, Mr., and Tiptree Hall, 140.

Mell, J. B., his invention, 25.

Meteorology for farmers, 221.

Mexican frijoles, 328.

Mildew, grape, 195.

Milk, solidified, 62 .

Milker's protector, 44 .

Mills, flouring, 124.

Mixing of common salt with guano, 160 .

Mosquito window screen, 55.

Mowing and reaping machines, scale for estimating the value of, 114 .

trials of, 110 .

machines v8. scythes, 108 .

Muck, preparation of, for manure, 152. .

Mules, 357.

NATURAL supply of ammonia in ordinary soils, 161.

Nesmyth, John, patent of, 127.

New method of determining nitrogen, 175 . theories in agricultural scienee, 177.

Nitrogen, absorption by plants, 166 . new method of determining, 175.

Nitrate of soda and guano on a peat-bog, 163. on a peat-bog, 163.

Nixon's potato-planter and seed-drill, 103.

Nordyke \& Hunt, patent for dressing flour, 35 .

Nutmeg of California, 300 .

ODors of flowers; 207.

Oidium Tuckeri, or grape malady, 340 .

Oils, new sources of vegetable, 250.

Oil-plant, new, 252.

Olive, propagation of, in the U. States, 334 .

Orange insects, 369.

Oregon, fruit crop for 1854, 15.

Ox-yokes, 40.

Ogster, C. \& L. B., their improvements, 39.

PARKER's flax-breaking and scutching machine, 25.

Parker, Wm. D., his patent, 46.

Parmentier, Mr., of Long Island, 73.

Pasturage, qualities of, 189.

Patents, agricultural, for 1855,388 .

Patent office reports, character of, 20.

Peach, culture of, 316 . the yellows of, 316 .

Pear, Kirtland on, 321. new varieties from seed, 318 .

Pears, grittiness of, 209. time for gathering, 322 .

Pearsal, Thomas, his improvements, 32.

Peat-bog, nitrate of soda and guano on, 163.

Peckham's cultivator, 91 .

Phosphate of lime-a new test, 175.

Phosphates in turnips, 176.

Pierce, John B., his improvement, 41.

Plantain fibre, cloth made from, 26. new mode of preparing, 26.

Planting plow, 85 .

Plants for hanging vases, 294. influence of situation on diseases of, 230 . new, 300 . under different conditions, 208.

Plaster, crops benefited by, 172. does not exhaust the soil, 174 . effect of climate and weather on, 173 influence of soil on the action of, 173 .
Plow cultivator, 84.

improved ditching, 85 .

improvement wanted in, 82 .

Mapes's lifting subsoil, 84 .

subsoil and trench, 86 .

Plows, improvements in their construction, 86 . patents of, for 1855,388 .

trial of, at Paris Exhibition, 89.

without plowmen, 87.

Plowing, amount of travel, 83.

Poetry, its influence on cultivation of flowers, 292.

Potato, on the culture of, 287.

planter and seed-drill, 103.

seed, 289.

substitutes for, 19.

Potatoes, machine for planting, 101. method of storing, 339 .

Powell, T. M., improved ice-cream freezer, 61 .

Present state of agriculture, 21.

Prindle, D. R., patent of, 128 .

Pumpkins and squashes, 329 .

QuALITIEs of pasturage, 189 .

Quina, cultivation of, in Java, 255.

\section{RAFTing cotton, 23.}

Rain water, ammonia and nitric acid in, 177.

Rakes and harrows, patents for 1855, 391.

Ramsay's flexible harrow, 96.

Rapeseed-oil, 251.

Raspberry, Catawissa, 323.

Reapers and mowers, trial of, at the French Exhibition, 113.

mowers, and harvesters, 108.

Records, uncertainty of preserving, 49.

Redick, Wm., corn-planter, 99.

Review of prospects and progress of agriculture, 7.

Rhynchospermum.jasminoides, 304.

Ricepaper-plant of China, 259.

Riddle, Gen., experiments of, 183 .

Robinson, J. A., cultivator, 90.

Rollers, wooden, of the Sea-Island cotton-gin, 23. Root crops, cultivation of, 335 . superphosphate of lime for, 160.

Roots and plants, their health essential to their growth, 260.

preservation of tender flower, 314.

Roses, new, 292. propagated by cuttings of the roots, 303 . propagation and winter forcing of, 303 .

Rugg's mower and reaper, 110.

Rural economy, 21.

pursuits should be directed by science, 21 .

Russia flax and hemp exportations, 242.

Russel, F., mowing machine, 108.

Russel's machine, 110.

SAlisburx, S. M., M.D., experiments of, 182.

Salt, composition of, for dairy purposes, 188. use of, in boiling vegetables, 204.

Saw-gins, improvement in cotton, 22.

Saws for cutting cotton-stalks, 25.

Scale for combined reapers and mowers, 118. of points in trials of mowers, 117 . of reapers, 115 .

Science is connected with agricalture, 21. Seabrook, Gov., his experiments, 23.

Sea-Island cotton, 232.

from Algeria, 239.

for spinning, 239.

in Texas, 239.

Sea water, does it kill seeds, 213.

Seed-planters, patents for 1855,389 . sower, 98. 
Seeds, germination of, 280. vitality of, 315 .

Sesquoia gigantca, or great tree of California, 263.

Servage manure, 157.

Sewerage products for agricultural purposes, 135 .

Shearman, S., patent of, 122.

Sheep, best for New England, 356. machine for shearing, 45 . Tartar or Shanghai, 344 .

Ship timber, season for cutting, 265.

Side-hill plow, Hall's, 83.

Silk in California, 368.

Silk-worm, new species, 367.

Sizing, Indian meal, 120.

Snell, B. M., patent plow of, 85 .

Soda, nitrate of, as a fertilizer, 162.

Soil analyses, value of, 175 .

capillary attraction of, 181 .

deterioratiun of, 215.

its influence on the action of plaster, 173 .

Solidified milk, 62 .

Sorgho, or new sugar-plant, 328.

Sowing, modes of, on the production of wheat, 282.

Spades and diggers, improvements in, 81.

Shade-trees, too many injurious, 268.'

Sprouted wheat good for seed, 335.

Squire, G. L., straw cutter, 107.

Stable rentilation, 227.

Statistics of barley crop for 1855,378 . of cotton in the United States for 1855, 379. of hay and grass for 1855,379 .

of hemp and Hax for 1855, 379 .

of Indian corn crop for 1855,378 .

of oat crop for 1855,378 .

of patents, 358 .

of peas and beans crop for 1855, 375 .

of potato crop for 1855,378 .

of rice crop for 1855,378 .

of rye crop for 1855,378 .

of wheat crop for 1855,375 .

of wine production in the United States, for $1855,379$.

Steadman, T. S., clover-8ced headcr, 108.

Steam for agricultural purposes, 78 .

Steam-engine, farm, 12, 81 .

Steam-engines, portable, for farming purposes, 11 .

Steam machinery for cultivating land, 79.

plow, Fisker's, 79.

sawing machine, 58 .

Stewart, Dr., David, on manure, 150.

Stock, improving, 364.

Stouffer, Brough, and Barr, their improvements, 34.

Strawberrics of 1855,317 .

Strawberry culture, 317.

Straw-cutters, 106. patents for $1855,391$.

Straw, farinaccous aliment obtained from, 198.

Stump-extractor, improved, 56.

Sugar, improvements in manufacture, 76. maple, tapping of them, 270 .

Sugett's improvement in treating hemp, 25.

Sumach, its cultivation, \&c., 258.

Superphosphate of lime for root crops, 160.

Swamps, experiments in reclaiming, 218.

Sweet-potato vines, new use for, 335 .

TABLE of fruits recommended, 382 .

Taggart, Samuel, his patent, 34 .

Tallow from the tallow-tree, 62.

Tamarind-tree in Virginia, 270.

Tea, Chinese method of scenting, 204.

Teddying machines, 107.

Tennessee cotton, 232.

Terra cotta, manufacture of, 50 .

Thompson, W., putent, 129 .
Thrasher and grain-separator, 118.

Tile-laying machine, 77.

Till, Levi, improved brick, 52 .

Timber, preserving, 202.

Tires on wheèls, new mode of securing, 41.

Titus's and Fenwick's patent bit, 37 .

Top dressings, 154.

Towers's improved horse-shoe, 37.

Traction engine, 80.

Transportation of grain, 26.

Trees, adaptation of, to economic purposes, 134. new mode of transplanting, 282. planting of, 271.

Trifolium incarnatum, or crimson clover, 277.

Tropical scenery of the Amazon, 261.

Turnip and root-cutter, 106 .

Turnips, machine for thinning, 77. phosphates in, 176.

Turpentine, product of the South, 252.

UPLAND cotton, 232.

Use of nitrate of soda as a fertilizer, 162.

VALUE of soil analyses, 175 .

Vegetation, chemical investigation of, 168 .

Vegetable fibrous substances, 243.

oils in the Amazon and Rio Negro districts, 250.

new sources of, 250 .

textile fibres in China, 246.

Vegetables, preservation of, 202.

use of salt in boiling, 204.

Ventilating flour barrel, 32.

Vermin, to clean animals and plants from, 363 .

Vice, T. C., invention of, 35 .

Vine, limits of its cultivation, 72.

Vitality of seeds, 315 .

WAKEFIELD's seed-planter, 97.

Walks, weeds in, 188.

Ware, J. M., his patent, 44.

Warlick, Noah, his horse-shoeing apparatus, 36.

Washing machine, frictionless, 49.

Watering transplanted trees, 269.

Weather, indicated by animals, \&c., 223. prognostications of, 227.

Webster, B. B., improvement in window screens, 55.

Weeds in walks, 188.

Weevil, prevention of, 374 .

Weigle, J., patent of, 121.

Wells's patent grass seed-sower, 98.

Whalen, Seth, improved hay-knife, 104.

Wheat, corn, \&c., cost of raising, 284. methods of sowing, and their effects, 282. plant, its origin, 285. new mode of increasing its produce, 285 .

Wheeler, Clark, improved drone-trap, 46.

Wheeler's machine, 111.

Wick's and Simonton's straw-cutter, 107.

Williams's lever plow, 86 .

Willis, W. W., his stump-extractor, 56 .

Wilkinson, Prof., 30.

Wilson, W. D., patent of, 121.

Rev. Mr., thrashing machine, 105.

Wind, the cheapest power for a farmer, 36 .

Windmills, self-regulating, 35 .

Wine, manufacture of, 71 .

in Georgia, 76.

Wines, aromia of American, 207.

Wire fences, 127.

Wool-growing interest in Tennessee, 15.

Wright's reaper, 110.

$\mathrm{Y}_{\Delta \mathrm{K}}$, introduction of, into Europe, 343. 
n

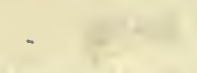

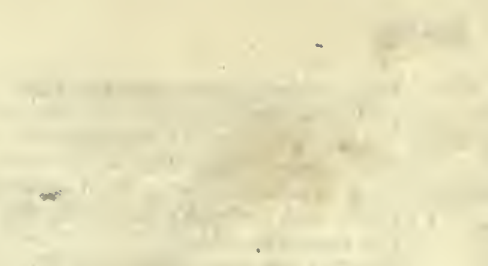

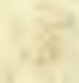

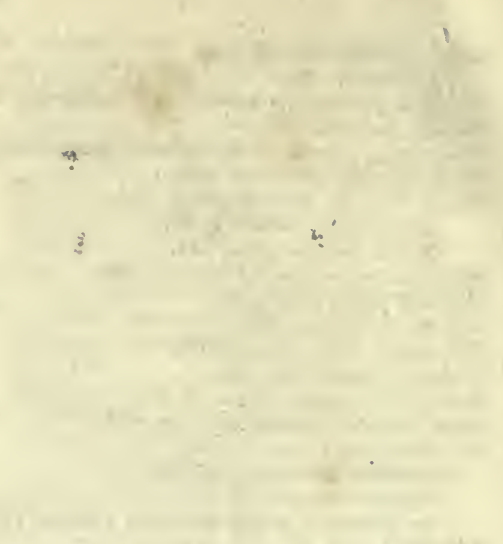

- $4+2+$

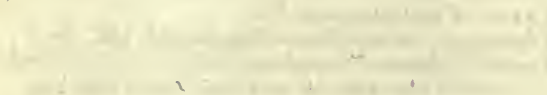

in $\quad$ in

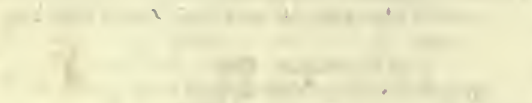

$$
\begin{aligned}
& 45
\end{aligned}
$$

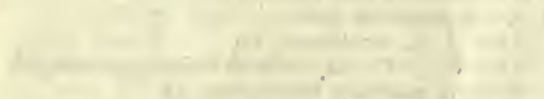

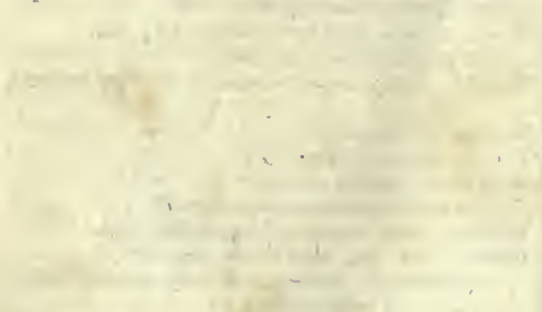

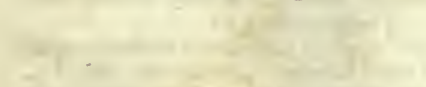

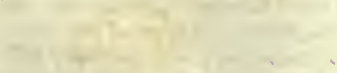

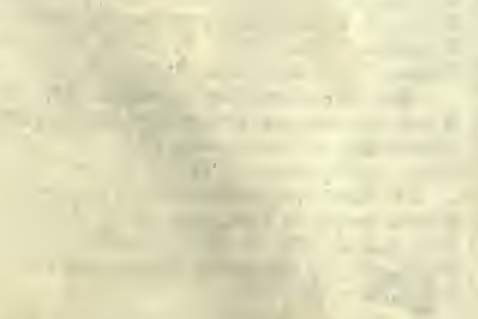$$
\text { nand }
$$

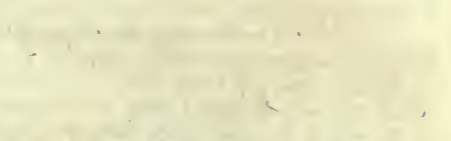

$$
\begin{aligned}
& x^{2}+2= \\
& 3-2-2+2=
\end{aligned}
$$
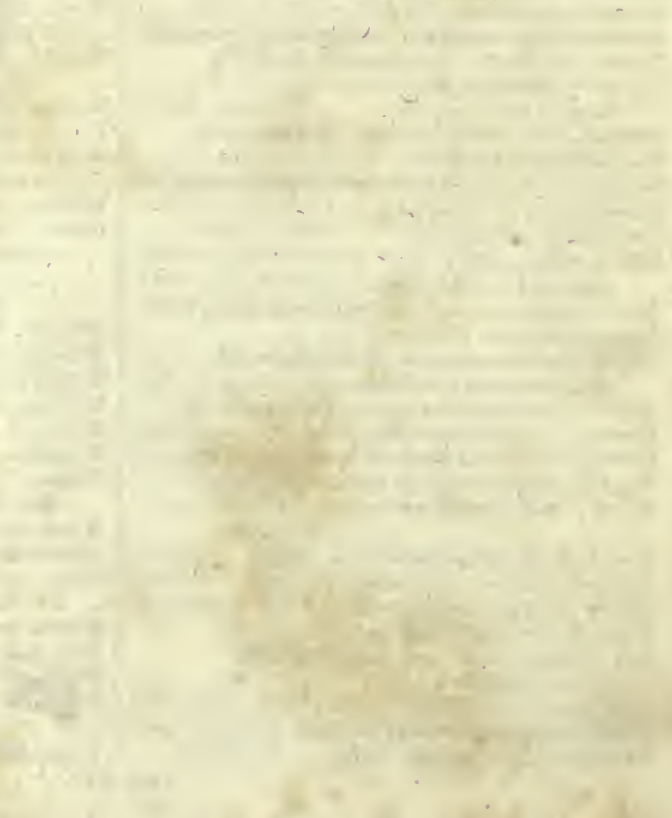





\section{YCC 109335}

\section{Wralle \\ 260274}


y.

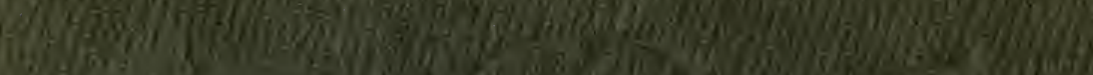

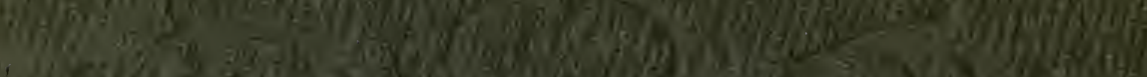

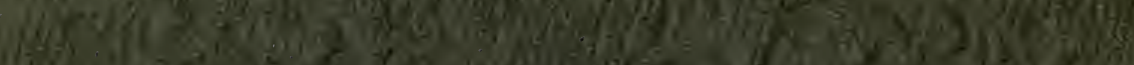

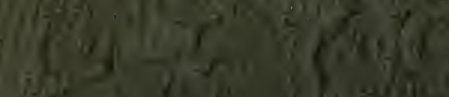

I.

(6)

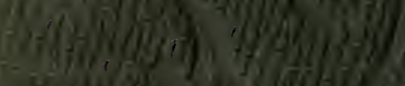

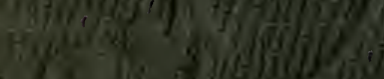

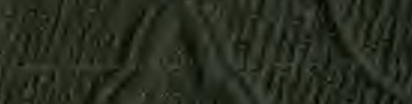

130.18

1.

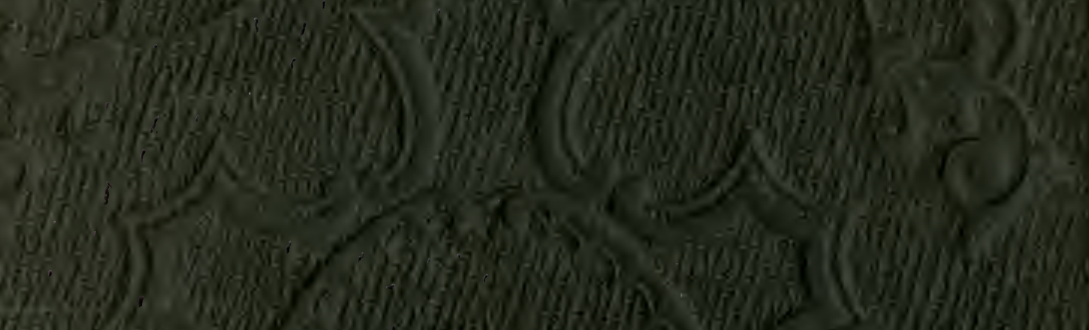

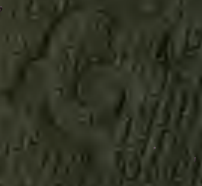

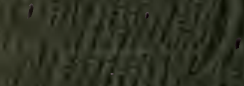

Whif

IIX)

ato

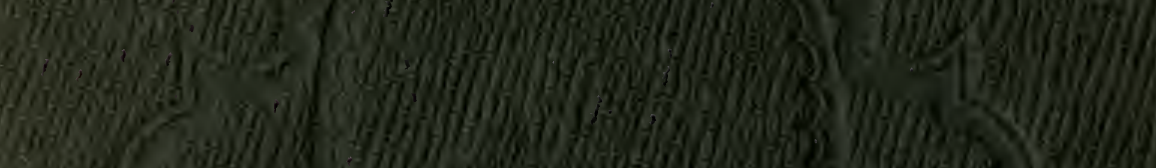

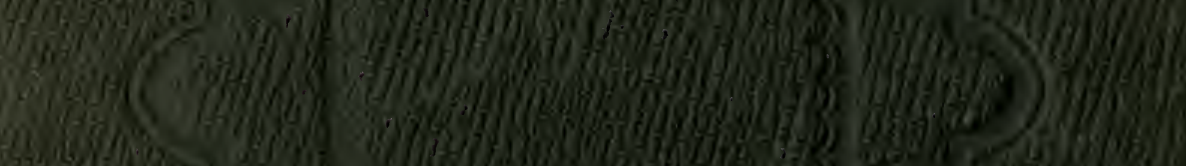

W19. a. (3) A. (19.

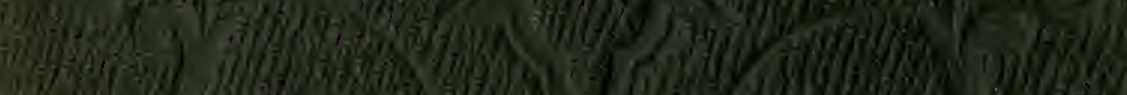
What

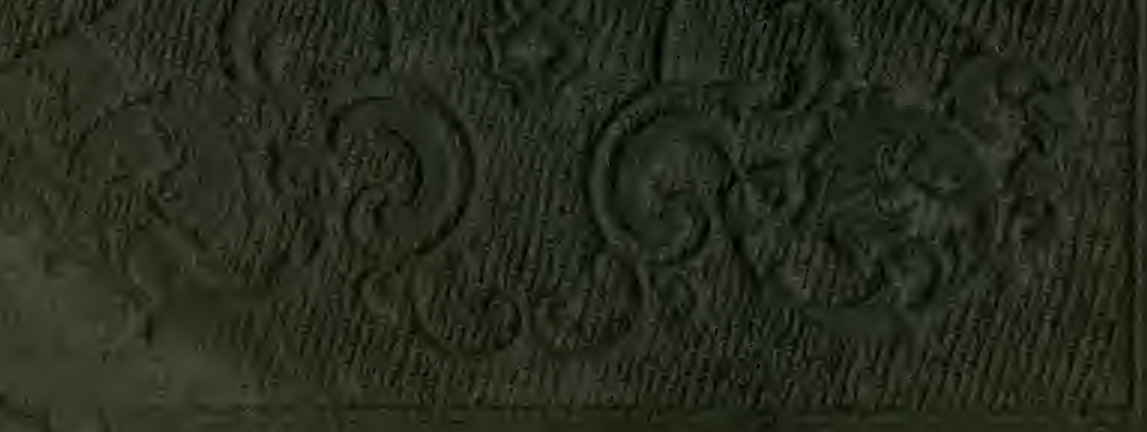

